PAULO CORDEIRO MACHADO

ANÁLISE MULTIESCALA DA ABRASÃO DE AÇOS AUSTENÍTICOS AO MANGANÊS APLICADOS EM BRITADORES DE MINÉRIO 
PAULO CORDEIRO MACHADO

\section{ANÁLISE MULTIESCALA DA ABRASÃO DE AÇOS AUSTENÍTICOS AO MANGANÊS APLICADOS EM BRITADORES DE MINÉRIO}

Tese apresentada à Escola Politécnica da Universidade de São Paulo como requisito para obtenção do título de Doutor em Ciências

Área de Concentração:

Engenharia Mecânica de Projeto e Fabricação

Orientador: Prof. Titular Amilton Sinatora 
Este exemplar foi revisado e corrigido em relaçăo à versăo original, sob responsabilidade única do autor e com a anuência de seu orientador.

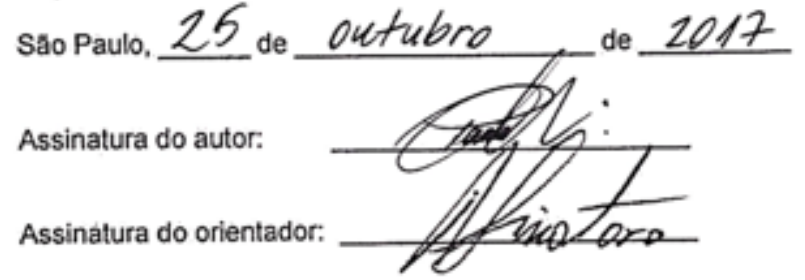

Catalogação-na-publicação

Machado, Paulo Cordeiro

Análise multiescala da abrasăo de aços austeníticos ao manganês aplicados em britadores de minérios / P. C. Machado -- versão corr. -- São Paulo, 2017.

$275 \mathrm{p}$.

Tese (Doutorado) - Escola Politécnica da Universidade de São Paulo. Departamento de Engenharia Mecânica.

1.Desgaste abrasivo 2.Recristalização dinâmica 3.Multiescala 4.Aço austenítico 5.Cristalografia I.Universidade de São Paulo. Escola Politécnica. Departamento de Engenharia Mecânica II.t. 


\section{AGRADECIMENTOS}

\section{Aos professores:}

Amilton Sinatora, orientador, pessoa a ser seguida, me ensinou muitas coisas, a tribologia foi uma delas. Esta pesquisa é o resultado de sua orientação e gestão motivacional.

Deniol Tanaka, foi um verdadeiro Sensei de análise de falha, corrosão e seleção de materiais, será lembrado em cada disciplina ministrada, suas aulas terão mais 30 anos de vida.

Roberto Martins, inúmeras dúvidas solucionadas e boas discussões a respeito de subestruturas, falha de empilhamento e cristalografia.

Izabel Machado, contribuiu para formar uma referência crítica a respeito do comportamento mecânico de materiais.

Hélio Goldenstein, colaborou desde o início deste ciclo, conhecedor de histórias metalúrgicas, bem como desta ciência.

Eduardo Albertin, contribuiu com o seu conhecimento científico-tecnológico, da termodinâmica a cinética de transformação de fase.

Ricardo Fuoco, pelo comprometimento, colaboração e discussões a respeito do processo de fabricação de revestimentos de britadores de minério.

À equipe abrasiva, pelas atividades em conjunto, discussões e expansão da barreira do conhecimento desta nobre área da tribologia.

Luiz Franco, referência deste texto de agradecimentos, é um amigo sábio, descontraído e sempre disposto a colaborar de forma crítica, considerando o seu intervalo de confiança de $100 \%$.

Jimmy Penagos, um abrasivo clássico, parce, sempre ajudando todos, sendo mole ou duro tende a resistir ao desgaste.

Juan Pereira, abrasivo multiphase, lamelar e alinhado ao "eixo da zona" <001>, amigo, juntos tentamos entender o mundo nano.

Gustavo Tressia, amigo austenítico, sempre disposto a contribuir em meio seco ou úmido.

Marcos Ara, um abrasivo centrífugo multilayer, paulistano, durante o TriboPará V.01 impressionou-se com o sabor roots do açaí paraense. 
Renata Ferreira, elasto-abrasiva, obrigado pelas discussões sobre delineamento experimental.

Larissa Lara, apesar de não ser oficialmente uma abrasiva, Ihe considero uma, com visão diferenciada e foco preciso, enxergar a origem da falha é o seu dilema. Obrigado pelo apoio com o software de tratamento de imagem.

À equipe escorregadia responsável por tratar de temas flex teve sua contribuição. Iramar Tertuliano, responsável pelas primeiras boas impressões da equipe do LFS. Nossa conversa na sala da Kratos (LABMEC-UFPA) rendeu bons resultados. Obrigado!

Tiago Cousseau, pronto para qualquer desafio tribológico, seja em regime limítrofe em laboratório ou hidrodinâmico nas ondas do Guarujá, obrigado.

Francisco Profito, simulador do sistema anel-cilindro de motores, sempre aperfeiçoando os algoritmos e disposto a colaborar com a equipe.

Rafael Obara, rugosidade é o seu middle name, pesquisador focado e fractal, cilindros de motores e modelos de desgaste são sua diversão, grato pelas discussões.

Alexander Zuleta, poucos o conhecem como Deisson, o responsável pela sua defesa de tese, desenvolveu uma metodologia de ensaio de válvulas, mais um conhecedor de motores, grato pelo apoio.

Gustavo Siebert, apesar de morarmos em lados opostos do país, mostrou que Palhoça-SC e Belém-PA tem muito em comum, as discussões de recristalização na célula eutética do laboratório renderam.

Juan Sebastian, pollito parce, tem corrido bem em pistas numéricas, apesar de seu preparo experimental, obrigado pela contribuição adesiva.

Pablo Alejandro, parce ou mono, escrevendo a tese a cada batuque, reflexão é o seu forte, o skate nem tanto. Obrigado pela amizade e discussões em francês, inglês ou português.

Roberto Oliveira, ou Bob, obrigado pelas contribuições finais, sempre colaborando com todos do laboratório.

Murilo Garcia, conhecedor do bulletproof coffee, sempre disposto a contribuir, grato pelo apoio organizacional.

André Zuin, químico, responsável por encapar nanopartículas redutoras de desgaste, obrigado pelas discussões triboquímicas. 
Pedro Tayer, novo na área e causando fadiga, mais um para a equipe.

Leonardo Thiodoro, amigo de classe, discutimos o livro do Hutchings (1992) do início ao fim, não esqueci de você.

\section{Aos simuladores, endentadores e sinterizadores:}

Philip von Pritzelwitz, de point load a qualidade de solo, inteligente e eficiente, projetamos dois tribômetros para a UFPA, um deles é mutante (ensaios: pino x disco a seco e lubrificado, abrasão LTM e crushing pin-on-disk), obrigado por tudo.

Vanessa Seriacopi, amiga de estudos estatísticos e de esclerometria, uma verdadeira abrasiva numérica, deu asas às partículas abrasivas.

Ana Júlia Tertuliano, contemporânea paraense, dedicada e batalhadora, sinterizar é com ela.

Newton Fukumasu, doutor em chamas numéricas ("sqn", foi experimental!!), obrigado pelo apoio com os experimentos de microesclerometria.

Cassiano Bernardes, além de fazer parte da dupla sertaneja do LFS (Arnaldo e Cassiano), endentou grãos continentais (001), (111) e (101) de aço Hadfield, muito obrigado.

Arnaldo Lima, primeira voz da dupla, também toca com precisão o instrumento de pontas Hysitron, sempre colaborando.

Cristiano Lagatta, obrigado pela contribuição nos primeiros ensaios de nanodureza.

Guido Boidi, membro italiano da equipe, conversa boa, muitas histórias e aventuras com sua LXL 350.

Luiz Lima, simulador nato, obrigado pela companhia nas antigas bolas de terça.

Felipe Carneiro, mais um jogador - torcedor, sempre disposto a uma boa conversa na copa ou na bola.

Roberto Balarini, capixaba, discípulo do Prof. Cherlio Scandian (UFES), veio aperfeiçoar sua arte no LFS.

Marcionila Santos, de latitude próxima, traz um pouco do nordeste brasileiro à equipe. 
À equipe técnica, sempre presente e prestativa.

Raphael Ferreira, de instruções operacionais do MEV à fabricação de bancada, sua colaboração foi imprescindível.

Fábio do Nascimento, preciso nas atividades experimentais, ajudou bastante.

Rodney Santos, sentinela do laboratório, sempre disposto a ajudar e a organizar.

Rafael Melchior, grato pela ajuda nos ensaios de britador e outras atividades, o rock and roll e a velocidade sempre presentes nas viagens de fusca a Baruerí.

Carlos Ramires, trilha, chácara, churrasco e games, obrigado pelo apoio.

Cássio Silva, mais um membro disposto a colaborar, obrigado.

Silene Carneiro, a administração do laboratório está em suas mãos, eficiente e amiga.

Sidney Carneiro, prestar contas é com ele, obrigado pelo apoio e amizade.

À Família, em especial:

Celeste Machado, minha mãe amada, companheira, alegre, forte, em vida se dedicou para prover a melhor educação aos seus filhos, deixou saudades para muitos.

José Machado, pai querido, incansável, conhecedor de sistemas mecânicos a combustão e a vapor, uma história de vida longa, das margens do Trombetas às do Guamá.

José Machado Neto, irmão para todas as horas, conhecedor de muitos assuntos, iniciou na mecânica bem cedo e atualmente se aventura na medicina.

Cecília Machado Éleres, minha tia ou melhor, segunda mãe, sempre presente para transmitir boas energias, em momentos importantes me norteou.

Camila Machado, amor para a vida, companheira, parceira de muitas atividades indoor ou outdoor, da cozinha as ruas, estradas e praias, obrigado pelo apoio incondicional.

\section{Aos Laboratórios e colaboradores:}

LABMICRO-Poli/USP (Laboratório de Microscopia): Prof. André Tschiptschin e Verissimo Santos, pelas análises de EBSD.

LTP - Poli/USP (Laboratório de Tecnologia de Pavimentação): Profa. Liede Bernucci e Edson de Moura, pelos contatos e ensaios de abrasivos. 
LCT - Poli/USP (Laboratório de Caracterização Tecnológica): Prof. Henrique Kahn, Profa. Carina Ulsen, Juliana Antoniassi, Thais Bortotti, Saulo Silva, Ademar e Alfredo, pelas análises de DRX e de distribuição granulométrica, e pela disponibilização do britador de mandíbula.

Microscopia de Transmissão - IPEN: Prof. Nelson, Profa. Larissa Otubo e Nildemar, pelas análises de microscopia de transmissão, além das discussões de resultados.

Laboratório de Corrosão - IPT: Taeko Yonamine pela colaboração, discussão e acuidade para realizar as análises de FIB, horas passadas em boa companhia, obrigado.

LTF - Poli/USP (Laboratório de Transformações de Fases). Arthur Nishikawa, Luis Varela, Lucas Nishikawa, Ana Chaves e Mohammad Masoumi, pelo apoio, companhia, musica e discussões metalúrgicas.

\section{Às Empresas:}

Vale, pelo apoio para a realização do projeto Avaliação de materiais de desgaste para mineração (TRIBOVALE), período 10/2012 a 05/2015. Ao engenheiro Ronaldo Jabour pela supervisão e críticas durante o desenvolvimento do projeto. Ao apoio do projeto Rede 3M (UFPA/VALE/FAPESPA) para o desenvolvimento da área de tribologia na região norte do país.

Metso, pela fabricação das amostras para o ensaio de britador de mandíbulas e disponibilidade de materiais desgastados em campo para estudo.

Serveng, pela disponibilidade de espaço e de material para a realização do ensaio de britador de mandíbula Ao Sidnei Morais e ao Daniel Araújo, pela colaboração e apoio.

À Universidade Federal do Pará, pela oportunidade concedida.

Professor José M. V. Quaresma, amigo, orientador durante a graduação e mestrado, contribuiu com minha formação na área de engenharia de materiais.

Grupo de pesquisa em engenharia de materiais (GPEMAT), um grupo formado por pessoas comprometidas, vazar ligas de alumínio era a diversão, em breve será a tribologia na mineração. 


\section{RESUMO}

O desgaste abrasivo de dois aços austeníticos ao manganês, materiais com grande utilização na mineração, foi estudado empregando metodologia multiescala (escalas: macro, meso e micro). Na macroescala foram estudados os mecanismos de dano e de desgaste de revestimento de britador utilizado em campo. Na mesoescala foram realizados ensaios de britador de mandíbula e de esclerometria linear. $\mathrm{Na}$ microescala o ensaio de esclerometria linear foi utilizado para avaliar os efeitos da camada encruada em campo e da orientação cristalográfica dos grãos austeníticos dos aços com $12 \% \mathrm{Mn}$ e $20 \% \mathrm{Mn}$. As técnicas de caracterização utilizadas nesta pesquisa foram: macro e microdureza, nanodureza instrumentada, MO, MEV, DRX, EBSD, FIB e MET.

A pesquisa foi dividida em três Capítulos, intitulados: "Desgaste abrasivo dos aços austeníticos com 12 \%Mn e 20 \%Mn via ensaio de britador de mandíbula"; "Efeito do encruamento e da orientação cristalográfica no desgaste por riscamento dos aços austeníticos $12 \% \mathrm{Mn}$ e $20 \% \mathrm{Mn}$ "; e "Microestrutura da subsuperfície do aço austenítico com 12 \%Mn deformado por desgaste abrasivo".

O primeiro Capítulo mostrou, a partir do ensaio de britador de mandíbulas (mesoescala), que o aço com $20 \% \mathrm{Mn}$ tem tendência de maior resistência ao desgaste que o aço com $12 \% \mathrm{Mn}$. Este resultado foi obtido para a mandíbula fixa do britador, na qual a severidade de desgaste foi superior a mandíbula móvel, por apresentar microcorte e microsulcamento como micromecanismos predominantes, enquanto na mandíbula móvel o micromecanismo predominante foi a microendentação.

No segundo Capítulo observou-se que o desgaste por riscamento (mesoescala e microescala) não depende do perfil de encruamento gerado em campo. Entretanto, foi identificado o efeito da orientação cristalográfica, planos (001), (111) e (101), no desgaste por riscamento dos aços com $12 \% \mathrm{Mn}$ e $20 \% \mathrm{Mn}$.

No último Capítulo a análise multiescala mostrou que a microestrutura deformada na subsuperfície sofre alterações semelhantes em diferentes intensidades. Nas três escalas de análise foram observadas uma camada com grãos ultrafinos (nanométricos), na subsuperfície, e uma de transição com maclas de deformação. A formação dos grãos ultrafinos foi associada à recristalização dinâmica por deformação plástica, na qual faz parte do mecanismo de auto reparação superficial. 
Além dos resultados apresentados, o desenvolvimento desta pesquisa de doutorado permitiu a elaboração de duas metodologias: i. análise do efeito da orientação cristalográfica no desgaste por microesclerometria; e ii. análise de microestrutura revelada por ataque iônico - FIB.

Palavras-chave: Análise Multiescala. Desgaste abrasivo. Orientação cristalográfica. Recristalização dinâmica. 


\begin{abstract}
The abrasive wear of two manganese austenitic steels, materials broadly used in mining industry, was studied using multiscale methodology (scales: macro, meso and micro). In the macroscale the mechanisms of damage and wear of in-service crusher liner were studied. In the mesoscale, jaw crusher and linear scratch tests were performed. In the microscale the linear scratch test was used to evaluate the effects of the hardening layer and the crystallographic orientation of the austenitic grains of steels with $12 \% \mathrm{Mn}$ and $20 \% \mathrm{Mn}$. The characterization techniques used in this research were: macro and microhardness, instrumented nanohardness, OM, MEV, DRX, EBSD, FIB and TEM.
\end{abstract}

The research was divided into three chapters, entitled: "Abrasive wear of steels with $12 \% \mathrm{Mn}$ and $20 \% \mathrm{Mn}$ via jaw crusher test"; "The effect of the in-service workhardening and crystallographic orientation on the micro-scratch wear of austenitic steels with $12 \% \mathrm{Mn}$ and $20 \% \mathrm{Mn} "$; and "Subsurface microstructure of the deformed austenitic steel with $12 \% \mathrm{Mn}$ by abrasive wear".

The first chapter showed, from the jaw crusher tests (i.e. mesoscale), that the steel with $20 \% \mathrm{Mn}$ tends to be more wear resistant than the steel with $12 \% \mathrm{Mn}$. This result was obtained to the fixed jaw crusher, in which the wear severity was superior to the movable jaw, since it presents microcutting and microploughing as predominant micromechanisms, whereas in the mobile jaw the predominant micromechanism was microendentation.

In the second chapter, it was observed that scratch wear (i.e. meso and microscale) does not depend on the in-service work-hardening profile. However, it was identified the effect of crystallographic orientation, (001), (111) and (101) planes, on the scratch wear of the steels with $12 \% \mathrm{Mn}$ and $20 \% \mathrm{Mn}$.

In the last chapter, the multiscale analysis showed that the subsurface deformed microstructure changes with different intensities. At the three analysis scales, a layer with ultrafine grains was observed in the subsurface and mechanical twins. The formation of this layer, with nanometric grains, was associated with dynamic recrystallization by plastic deformation, in which it is part of the self healing effect. In addition to the results found, the development of this doctoral research allowed for the elaboration of two methodologies: i. Analysis of the effect of crystallographic 
orientation on the scratch wear; and ii. Microstructure analysis revealed by ion etching - FIB.

Keywords: Multiscale analysis. Abrasive wear. Crystallographic orientation. Dynamic recrystallization. 


\section{LISTA DE FIGURAS}

Figura 1.1. Distribuição do gasto energético em minas de superfície 3

Figura 1.2. Diagrama de resistência à abrasão de aços em função da microestrutura e dureza

Figura 1.3. Diagrama de blocos da análise multiescala

Figura 2.1. Influência da adição do $\mathrm{Mn}$ no diagrama isopleta Fe-C-Mn.

a) $2,5 \% \mathrm{Mn}$. b) $4,5 \% \mathrm{Mn}$. c) $13 \% \mathrm{Mn}$ 13

Figura 2.2. Propriedades mecânicas do aço Hadfield classe A em função do teor de carbono. a) Resistência à tração. b) Tensão de escoamento. c) Alongamento... 16 Figura 2.3. Propriedades mecânicas do aço Hadfield classe A em função do teor de manganês. a) Resistência à tração e tensão de escoamento. b) Alongamento .. 16 Figura 2.4. a) Seção transversal do aço manganês submetida a ensaio de mandíbula. b) Aço Hadfield deformado (30 \%) sob compressão ........................... 18 Figura 2.5. Microestrutura do aço Hadfield. a) Fundido. b) Tratado termicamente... 19 Figura 2.6. Micrografia de aço Hadfield como fundido com carbonetos lamelar e acicular

Figura 2.7. Curvas TTT de precipitação de carbonetos durante resfriamento após solubilização

Figura 2.8. Curva temperatura-tempo-transformação para o aço Hadfield (12\%Mn - $2 \% \mathrm{Mn}$ ) fundido com diferentes teores de carbono

Figura 2.9. Sistemas de deformação plástica em estruturas cristalinas. a) Escorregamento de discordâncias. b) Dobramento. c) Maclação. d) Transformação de fase

Figura 2.10. a) Aproximação da variação de energia livre (CFC $\rightarrow \mathrm{HC}$ ), $\Delta \mathrm{G}^{\mathrm{r} \rightarrow \varepsilon} \mathrm{e}$ EDE $\left(\gamma_{l}\right)$ em relação a variação da concentração de $M n(1,15 \% C)$. b) Dureza (redução fixa) em relação a variação da concentração de $\mathrm{Mn}(1,2$ \%C)

Figura 2.11. Grãos austeníticos com deformação de 0,30 evidenciando maclas de deformação. a) MEV. b) TEM.

Figura 2.12. Imagens de MO mostrando diferentes formações microestruturas em função da deformação sob tração ao longo da direção 111. a) Sistema primário de maclas a $51^{\circ}$. b) Ativação do sistema primário e secundário de maclação com $25 \%$ de deformação

Figura 2.13. Ilustração do efeito Hall-Petch dinâmico. O mecanismo de maclação forma-se devido à baixa EDE 
Figura 2.14. Tribossistemas relacionados ao desgaste abrasivo 26

Figura 2.15. Desgaste abrasivo a dois e a três corpos 26

Figura 2.16. Desgaste abrasivo em função da razão entre a dureza de partículas abrasivas e a dureza de material desgastado.

Figura 2.17. Micromecanismos de desgaste entre partícula abrasiva e superfície do material. 28

Figura 2.18. Micrografias (MEV) da interação de abrasivos minerais com superfícies de aços: (a) microsulcamento, (b) microcorte e (c) microtrinca 29

Figura 2.19. Razão do microcorte e do microsulcamento em função da razão do ângulo de ataque e o ângulo de ataque crítico

Figura 2.20. Resistência à abrasão em função da dureza para vários tipos de materiais submetidos a testes de abrasão de alta tensão

Figura 2.21. Diminuição do ângulo crítico para o aço ferramenta - ensaio de esclerometria linear. a) Revenido a $400{ }^{\circ} \mathrm{C}$ por 30 min (518 HV30). b) Revenido a $300{ }^{\circ} \mathrm{C}$ por 30 min (637 HV30). c) Como recebido (854 HV30)

Figura 2.22. Resistência ao desgaste abrasivo em esclerometria linear e pino $x$ lixa do aço X5 Ni-Cr-Ti deformado

Figura 2.23. a) Modelo de desgaste abrasivo. b) Risco em aço Hadfield com endentador cônico de ponta esférica

Figura 2.24. Perfil transversal de um risco em aço Hadfield indicando a formação de pile-up e do hole

Figura 2.25. Diagramas de micromecanismos de desgaste (a) em função da dureza $(H)$ e (b) em função da resistência cisalhante superficial $(f)$

Figura 2.26. Correlação do coeficiente de atrito e grau de penetração para esclerometria com endentador de pino de aço e disco de aço temperado.

Figura 2.27. Imagens das superfícies dos aços Hadfield (6 - 12 \%Mn) submetidas ao ensaio de desgaste por risco (esclerometria linear) causado pelo deslizamento de um diamante na superfície nas amostras: (a), (c) $\mathrm{Fe}-6 \% \mathrm{Mn}$ (6,3 \%Mn, 0,91 \%C, 1,03 \%Mo) e (b), (d) Fe - 12 \%Mn (11,9\%Mn, 1,44 \%C, $0,49 \% \mathrm{Mo}$ ). Superfícies tratadas antes do ensaio por polimento eletrolítico (a) e (b), e por polimento abrasivo (c) e (d).

Figura 2.28. Difratogramas de aços austeníticos (6 e $12 \% \mathrm{Mn}$ ) com polimento eletrolítico e polimento abrasivo 
Figura 2.29. Relação entre perda de massa relativa e concentração de carbono do aço Hadfield. Ensaio de mandíbula.

Figura 2.30. Efeito do percentual de carboneto contínuo em contorno de grão na resistência ao impacto

Figura 2.31. Morfologia dendrítica de carbonetos reprecipitados em contorno de grão de aço Hadfield evidenciados após ensaio Charpy. E = $10 \mathrm{~J}$. MEV-SE. a) $2.500 x$. b) $1.0000 x$

Figura 2.32. Microestrutura das fraturas de amostras tratadas em isoterma de $750{ }^{\circ} \mathrm{C}$. a) Transversal -1 minuto. b) Topografia -1 minuto. c) Transversal 20 minutos. d) Topografia -20 minutos

Figura 2.33. Desgaste relativo (razão entre a perda de massa do material em análise e a perda de massa do material de referência) por goivadura (gouging wear ratio) em função da resistência ao impacto Charpy ..

Figura 2.34. Detalhe da superfície desgastada de mandíbula (britador). a) risco de abrasão com formação de proa (seta amarela). b) "enrugamento", deformação do material (seta azul) na frente da proa

Figura 2.35. Perfis de dureza (ao longo da seção transversal da superfície deformada) do aço Hadfield deformado em diferentes condições. a) Britador de mandíbula. b) Britador de mandíbula. c) Britador giratório, de mandíbula e por impacto.

Figura 2.36. Imagens de MET de cavaco de alumínio puro (a) e de zinco puro (c), as imagens b e d mostram as respectivas imagens de difração

Figura 2.37. Imagens de MET de superfície desgastada de latão, $\mathrm{Cu}-40 \% \mathrm{Zn}$ (a), e cobre puro (b)

Figura 2.38. a) Micrografia obtida via FIB, corte transversal à superfície desgastada do disco de cobre. b) Imagem de MET - Campo claro da camada subsuperficial e imagem de difração de uma área recíproca da camada de grãos ultrafinos.

Figura 2.39. Modelos de formação de grãos ultrafinos por deformação plástica a frio.

Figura 2.40. Modelo de recristalização dinâmica por rotação. a) Quebra do contorno de subgrão alongados. b) Rotação do contorno de subgrãos em $30^{\circ}$ recristalizando o material e formando grãos equiaxiais 
Figura 2.41. Desgaste por riscamento em $\mathrm{Ti}$ - 8,5 \%Al com polimento eletrolítico. Ponta de aço com $30^{\circ}$ e $0,25 \mathrm{~N}$. a) textura basal. b) textura transversal

Figura 2.42. Risco no aço $(\mathrm{Fe}-38 \% \mathrm{Ni}-6 \% \mathrm{Al})$ produzido no ensaio de esclerometria com $0,25 \mathrm{~N}$

Figura 2.43. a) Imagem de MEV-SE do micropilar deformado na direção [2 110 ].

b) Imagem de campo escuro via MET da seção paralela à (001) transversal do micropilar deformado na direção [2 1110$]$. c) Imagem de MEV-SE do micropilar deformado na direção [19 8 21]. d) Imagem de IPF com as direções cristalográficas de ensaio e suas indicações no tetraedro de Thompson.

Figura 3.1. Diagrama de blocos

Figura 3.2. a) Britador e mandíbulas. b) Desenho das mandíbulas móvel e fixa...... 61 Figura 3.3. Modelo para fundição em molde de areia das mandíbulas fixa e móvel. a) Lado A. b) Lado B

Figura 3.4. Mandíbulas fundidas desmoldadas. a) Bloco da mandíbula fixa.

b) Conjunto fundido. c) Bloco da mandíbula móvel.

Figura 3.5. Mandíbulas fixas e móveis retificadas

Figura 3.6. Desenho da vista lateral do britador de mandíbulas com indicação de parâmetros dimensionais. $L=$ comprimento da câmara; $A A=$ abertura de alimentação; APA = abertura de saída (posição aberta); APF = abertura de saída (posição fechada) e; $\alpha$ = ângulo de esmagamento.

Figura 3.7. Sistema de britagem - ensaio de britador de mandíbula.....

Figura 3.8. Perda de massa das mandíbulas fixa e móvel acumulada em função do peso de abrasivo britado. Ensaio interrompido para levantamento de massa de abrasivo.

Figura 3.9. Resultados da classificação por peneiramento do abrasivo para o ensaio. a) Percentual acumulado de abrasivos retidos. b) Percentual de abrasivos retidos.

Figura 3.10. a) Sistema de britagem em operação. b) Vista superfior da alimentação de abrasivo

Figura 3.11. Difratograma do abrasivo

Figura 3.12. Mandíbula fixa e móvel após ensaio de britador de mandíbula. A caracterização de micromecanismo de desgaste foi realizado na região de saída das mandíbulas 
Figura 3.13. Micrografias das mandíbulas fixa e móvel para os aços $12 \mathrm{Mn}$ e 20Mn. 50X

Figura 3.14. Percentual acumulado de abrasivos retidos em função da abertura da peneira (a) e percentual de abrasivos retidos (b) antes e depois do processo de britagem

Figura 3.15. Resultados do teste de hipótese entre os resultados de perda de massa entre os aços $12 \mathrm{Mn}$ e $20 \mathrm{Mn}$ para (a) MF com $\alpha=0,05$ e (b) MF com $\alpha=0,1$

Figura 3.16. Desgaste relativo das mandíbulas fixa e móvel para os aços $12 \mathrm{Mn}$ e $20 \mathrm{Mn}$

Figura 3.17. Perfil de microdureza para mandíbula fixa e móvel dos materiais $12 \mathrm{Mn}$ e $20 \mathrm{Mn}$

Figura 3.18. Perfil de microdureza de revestimento de britador desgastado em campo para aços Hadfield classe B-1 e classe C .

Figura 3.19. Imagens de estereografia da região de entrada para MF (a) e MM (b), respectivamente. Aço 12Mn. 5X

Figura 3.20. Imagens de estereografia da região central para MF (a) e MM (b), respectivamente. Aço $12 \mathrm{Mn} .5 \mathrm{X}$

Figura 3.21. Imagens de estereografia da região de saída para MF (a) e MM (b), respectivamente. Aço 12Mn. 5X

Figura 3.22. Imagens de estereografia da região de entrada para MF (a) e MM (b), respectivamente. Aço 20Mn. 5X

Figura 3.23. Imagens de estereografia da região central para MF (a) e MM (b), respectivamente. Aço 20Mn. 5X

Figura 3.24. Imagens de estereografia da região de saída para MF (a) e MM (b), respectivamente. Aço $20 \mathrm{Mn} .5 \mathrm{X}$

Figura 3.25. Imagens de MEV-SE da superfície desgastada das MF (a) e MM (b) na região de saída para $12 \mathrm{Mn}$. 50X

Figura 3.26. Imagens de MEV-SE da superfície desgastada da MF (a) e MM (b) na região de saída para $12 \mathrm{Mn}$. a) 100X. b) $200 \mathrm{X}$

Figura 3.27. Imagens de MEV-SE da superfície desgastada da MF (a) e MM (b) na região de saída para $12 \mathrm{Mn}$. a) $300 \mathrm{X}$ com inclinação de $30^{\circ}$. b) Imagens com elétrons secundários e retroespalhados, 500X 
Figura 3.28. Imagens de MEV-SE da superfície desgastada da MF (a) e MM (b) na região de saída para $20 \mathrm{Mn}$. 50X

Figura 3.29. Imagens de MEV-SE da superfície desgastada da MF (a) e MM (b) na região de saída para $20 \mathrm{Mn}$. 100X

Figura 3.30. Imagens de MEV-SE da superfície desgastada da MF (a) e MM (b) na região de saída para $20 \mathrm{Mn}$. a) 1500X. b) 200X

Figura 3.31. Resultados de interferometria para a região central da MF e MM do aço $12 \mathrm{Mn}$

Figura 3.32. Resultados de interferometria para a região central da MF e MM do aço $20 \mathrm{Mn}$

Figura 3.33. Resultados de interferometria para a região de saída da MF e MM do aço $12 \mathrm{Mn}$

Figura 3.34. Resultados de interferometria para a região de saída da MF e MM do aço $20 \mathrm{Mn}$.

Figura 3.35. Imagens de FIB da superfície desgastada do aço 12Mn. a) Local de análise, 5.000X. b) Microestrutura da subsuperfície, 10.000X. c) Ampliação da região próxima à superfície, 20.000X. d) Ampliação da região a $10 \mu \mathrm{m}$ da superfície, 30.000X

Figura 3.36. Imagens de FIB da superfície desgastada do aço $20 \mathrm{Mn}$. a) Local de análise, 5.000X. b) Microestrutura da subsuperfície, 10.000X. c) Ampliação da região próxima à superfície, 20.000X. d) Ampliação da região a $10 \mu \mathrm{m}$ da

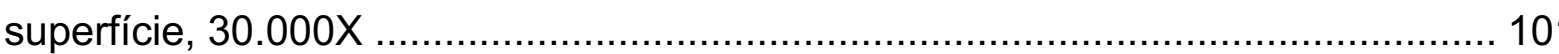

Figura 4.1. Diagrama de blocos ........................................................ 108

Figura 4.2. a) Tribômetro UMT-2 Bruker. b) Câmara de ensaio UMT-2

Figura 4.3. a) Revestimento de britador cônico (liner superior). b) Seção do revestimento de britador. c) Amostra do revestimento do britador (seção transversal) desgastada em campo, modelo da metodologia empregada no ensaio de esclerometria do perfil de encruamento

Figura 4.4. Etapas do método de obtenção de perfil transversal via interferometria óptica 3D

Figura 4.5. Perfil médio de um risco e indicação de parâmetros geométricos

Figura 4.6. Risco em escala micrométrica em aço Hadfield. a) Formação de borda em forma de borda. b) Seção transversal do risco indicado pela seta preta (Figura a) 
Figura 4.7. a) Nanoendentador Hysitron. b) Endentador cônico.

Figura 4.8. Perfil da ponta cônica e modelo de ângulo de ataque.

Figura 4.9. a) Seção do revestimento de britador. b) Amostra do revestimento do britador (seção transversal) desgastada em campo. c) Modelo da metodologia empregada no ensaio de microesclerometria do perfil de encruamento

Figura 4.10. Modelo de distribuição de riscos adotado para os ensaios de microesclerometria

Figura 4.11. Fluxograma da metodologia de microesclerometria em orientações cristalográficas conhecidas

Figura 4.12. Montagem do sistema de microesclerometria com identificação das regiões de imagem de FIB (corte transversal ao risco).

Figura 4.13. Micrografia dos aços $12 \mathrm{Mn}$ deformado (a) e não deformado (b), e $20 \mathrm{Mn}(\mathrm{c})$

Figura 4.14. Perfil de microdureza Vickers do revestimento do britador

Figura 4.15. Micrografias (MEV-SE) do risco. Ampliação de 500X para imagens pontuais e de 50X para a imagem de todo o risco.

Figura 4.16. Resultados de força normal $\left(F_{n}\right)$, força tangencial $\left(F_{t}\right)$ e coeficiente de atrito $(C O F)$ em função do tempo $(s)$ correlacionado à projeção $3 D$ do risco (fator de amplificação de $25 \%$ ).

Figura 4.17. Micrografia e imagem 3D ( $\mathrm{CCl}$ ) do risco. a) Micrografias (MO) sobrepostas, 200X. b) Projeção 3D do risco - vista lateral. c) Perfis transversais do risco.

Figura 4.18. Resultados de resistência ao desgaste em função de $f_{a b}$

Figura 4.19. Coeficiente de desgaste $\left(k_{a b}\right)$ em função do $f_{a b}$ para o aço $12 \mathrm{Mn}$ deformado em campo e não deformado

Figura 4.20. Microesclerometria no perfil de encruamento $(d=1,6 \mathrm{~mm})$ com micrografia e perfil de dureza. MEV-SE. 100X.

Figura 4.21. Coeficiente de atrito em função da distância da superfície desgastada (série i). a) Todas as forças normais. b) $20 \mathrm{mN}$ e $50 \mathrm{mN}$

Figura 4.22. Micrografias dos riscos com carga normal de $100 \mathrm{mN}$ ao longo do perfil de encruamento. MEV-SE. 900X. a) $d=0,1 \mathrm{~mm}$. b) $d=0,6 \mathrm{~mm}$. c) $d=1,1 \mathrm{~mm}$. d) $d=1,6 \mathrm{~mm}$

Figura 4.23. Micrografia dos riscos para a carga de $200 \mathrm{mN}$. MEV-SE. 900X. a) $d=0,1 \mathrm{~mm}$. b) $d=0,6 \mathrm{~mm}$. c) $d=1,1 \mathrm{~mm}$. d) $d=1,6 \mathrm{~mm}$ 
Figura 4.24. Curva de coeficiente de atrito ao longo do risco, com $F_{n}=200 \mathrm{mN} \mathrm{e}$ $d=1,1 \mathrm{~mm}$

Figura 4.25. Coeficiente de atrito em função do grau de penetração (série i)

Figura 4.26. Micrografia dos riscos na camada deformada em campo para cada carga. $d=1,6 \mathrm{~mm}$. MEV-SE. 900X. a) $F_{n}=20 \mathrm{mN}$. b) $F_{n}=50 \mathrm{mN}$. c) $F_{n}=100 \mathrm{mN}$. d) $F_{n}=150 \mathrm{mN}$. e) $F_{n}=200 \mathrm{mN}$. f) $F_{n}=250 \mathrm{mN}$

Figura 4.27. Resultado da análise de EBSD para o aço 12Mn. Imagem de IPF (a) da região indicada na imagem estereográfica (b).

Figura 4.28. a) Gráfico de coeficiente de atrito em função do comprimento dos riscos nos planos (001), (111) e (101) do aço 12Mn. b) Micrografia do risco no plano (001). c) Micrografia do risco no plano (111). d) Micrografia do risco no plano (101). 900X

Figura 4.29. Profundidade dos riscos nos planos (001), (111) e (101) ao longo do perfil longitudinal obtidos durante o evento abrasivo. Aço 12Mn

Figura 4.30. a) Imagem de FIB do perfil transversal do risco no plano (001), 15.000X. b) Aumento do lado direito do risco, 30.000X. c) Aumento do lado esquerdo do risco, 30.000X. Aço 12Mn

Figura 4.31. Imagem da seção transversal (via XTEM) de monocristal de Ge com endentação com força normal de $50 \mathrm{mN}$. a) Imagem com campo claro. b) Imagem com campo escuro e imagem de difração da região com maclas.

Figura 4.32. a) Imagem de FIB do perfil transversal do risco no plano (111), 15.000X. b) Aumento do centro do risco, 30.000X. c) Aumento do lado esquerdo do risco, 30.000X. Aço 12Mn

Figura 4.33. a) Imagem de FIB do perfil transversal do risco no plano (101), 15.000X. b) Aumento do lado esquerdo do risco, 30.000X. c) Aumento do lado direito do risco, 30.000X. Aço 12Mn

Figura 4.34. a) Deformação plástica lateral e proa do risco no plano (001). b) Deformação plástica lateral e cavaco do risco no plano (111). c) Deformação plástica lateral e cavaco do risco no plano (101). Imagens de FEG. Aço 12Mn ..... 150 Figura 4.35. Resultado da análise de EBSD para o aço 20Mn. Imagem de IPF (a) da região indicada na imagem estereográfica (b).

Figura 4.36. a) Gráfico de coeficiente de atrito em função do comprimento dos riscos nos planos (001), (111) e (101) do aço $20 \mathrm{Mn}$. b) Micrografia do risco no 
plano (001). c) Micrografia do risco no plano (111). d) Micrografia do risco no plano (101). 900X

Figura 4.37. Profundidade dos riscos nos planos (001), (111) e (101) ao longo do perfil longitudinal obtidos durante o evento abrasivo. Aço 20Mn

Figura 4.38. a) Imagem de FIB do perfil transversal do risco no plano (001), 15.000X. b) Aumento do lado esquerdo do risco, 30.000X. c) Aumento do lado direito do risco, 30.000X. Aço 20Mn

Figura 4.39. a) Imagem de FIB do perfil transversal do risco no plano (111), 15.000X. b) Aumento do lado esquerdo do risco, 30.000X. c) Aumento do lado direito do risco, 30.000X. Aço 20Mn

Figura 4.40. a) Imagem de FIB do perfil transversal do risco no plano (101), 15.000X. b) Aumento do lado esquerdo do risco, 30.000X. c) Aumento do lado direito do risco, 30.000X. Aço 20Mn

Figura 4.41. a) Deformação plástica lateral e proa do risco no plano (001). b) Deformação plástica lateral e cavaco do risco no plano (111). c) Deformação plástica lateral e cavaco do risco no plano (101). Imagens de FEG. Aço 20Mn..... 161 Figura 4.42. Energia dos riscos nos planos (001), (111) e (101) para os aços

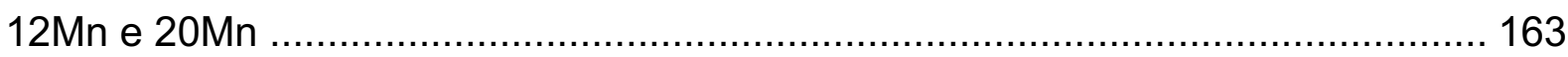

Figura 5.1. Diagrama de blocos na análise multiescala ..................................... 168

Figura 5.2. Modelo metodológico de corte em ângulo (taper section) da superfície desgastada

Figura 5.3. Etapas do procedimento de obtenção de lâmina para MET. a) Formação da cavidade no risco. b) Formação de cavidade simétrica à primeira. c) Fixação da lâmina na ponta Omniprobe com solda de Pt e corte em "U". d) Fixação da lâmina no porta amostra (grade de cobre) com solda de Pt. e) Afinamento e limpeza da lâmina

Figura 5.4. Revelação e aquisição de microestrutura via FIB. a) Superfície polida. b) Ataque iônico com feixe de íons de gálio. c) Aquisição de imagem com feixe de íons de gálio

Figura 5.5. Superfície desgastada do revestimento de britador cônico. a) 200X.

b) $600 \mathrm{X}$. c) $1.000 \mathrm{X} . \mathrm{d}) 1.800 \mathrm{X}$

Figura 5.6. a) Microestrutura da subsuperfície de desgaste (corte em $45^{\circ}$ ), 50X. b) Trinca intergranular, 400X. c) Onda de aço Hadfield formada pelo processo de abrasão, 250X. d) Micrografia da área em destaque na Figura a, 100X 
Figura 5.7. Micrografia abaixo da superfície desgastada (corte transversal) no ensaio pino $\mathrm{x}$ lixa.

Figura 5.8. Microestrutura da subsuperfície deformada de revestimento de moinho SAG. Corte ortogonal. MO. 100X

Figura 5.9. Imagens de MEV-SE (cross section). a) Trincas transgranulares, 100X. b) Local de nucleação da trinca e novos pontos de nucleação de trincas (setas), 1.500X. c) Trifurcação de trinca transgranular, 500X

Figura 5.10. Divisão das camadas 1 e 2 na subsuperfície deformada na escala macro (campo)

Figura 5.11. Micrografias ópticas da seção transversal do aço Hadfield sem deformação (a), com 60 minutos de deformação via USP e (b) com 240 minutos de deformação

Figura 5.12. Superposição de micrografias (SE-MEV) da onda de material deslocado

Figura 5.13. Mapa de elementos da área com a onda de material deslocado

Figura 5.14. Micrografias obtida via FIB de regiões da Figura 5.12. a) Quadro 7.

b) Quadro 8

Figura 5.15. Microestrutura da subsuperfície (quadro 9 na Figura 5.12)

Figura 5.16. a) Nanoendentações na área 10a indicada na Figura 5.12.

b) Gráfico de carregamento e descarregamento dos pontos 1 e 7 da Figura a...... 191

Figura 5.17. a) Nanoendentações na área $10 b$ indicada na Figura 5.12.

b) Gráfico de carregamento e descarregamento dos pontos 1 e 7 da Figura a...... 192

Figura 5.18. Resultado de EBSD-IPF da região deformada a $1 \mathrm{~mm}$ da superfície desgastada em campo (a) e da base da onda (b)

Figura 5.19. Imagens de IPF e gráfico de desorientação dos quadros indicados pelo número 3 (Figura 5.18a). a) Imagem de IPF com eixo de referência. b) Gráfico de desorientação em função da posição do eixo de referência da Figura a. c) Imagem de IPF com eixo de referência. d) Gráfico de desorientação em função da posição do eixo de referência da Figura $c$.

Figura 5.20. Imagens de IPF e gráfico de desorientação do ponto indicado pelo número 2 (Figura 5.18a).

Figura 5.21. Imagens de IPF e gráfico de desorientação do grão maclado, Figura 5.18a... 
Figura 5.22. Imagens de IPF e gráfico de desorientação do grão com macla de recristalização indicado na Figura $5.18 b$.

Figura 5.23. Microestruturas da subsuperfície do revestimento de britador cônico. a) Cavidade na superfície desgastada e decapada (análise 1). b) Microestrutura da subsuperfície. c) Ampliação da área do quadro $c$ na Figura $b$. d) Ampliação da área do quadro d na Figura $b$.

Figura 5.24. Microestruturas da subsuperfície do revestimento de britador cônico. a) Cavidade na superfície desgastada e decapada (análise 2). b) Microestrutura da subsuperfície.

c) Ampliação da área do quadro $c$ na Figura $b$

Figura 5.25. Resultado de DRX - amostra desgastada em campo

Figura 5.26. Imagens de MEV-SE da subsuperfície da mandíbula fixa. Ensaio laboratorial de britador de mandíbula. Corte inclinado com $45^{\circ}$. a) 100X. b) 450X. c) $1.500 X . d) 1.500 X$

Figura 5.27. a) Local de análise, 5.000X. b) Microestrutura da subsuperfície, 10.000X. c) Ampliação da região próxima à superfície, 20.000X. d) Ampliação da região a $10 \mu \mathrm{m}$ da superfície, $30.000 \mathrm{X}$

Figura 5.28. Microestrutura da (a) subsuperfície $(10 \mu \mathrm{m})$ e das regiões nas posições (b) $100 \mu \mathrm{m}$, (c) $150 \mu \mathrm{m}$ e (d) $200 \mu \mathrm{m}$. 20.000X.

Figura 5.29. Imagens de IPF-EBSD da subsuperfície de regiões com distâncias de (a) $10 \mu \mathrm{m}$, (b) $100 \mu \mathrm{m}$ e (c) $200 \mu \mathrm{m}$. 20.000X.

Figura 5.30. Imagens de IPF e gráfico de desorientação da região em destaque da Figura 5.29a

Figura 5.31. Imagens de IPF e gráfico de desorientação da região em destaque da Figura $5.29 c$

Figura 5.32. Resultado de DRX - amostra desgastada em ensaio de britador de mandíbula.

Figura 5.33. Riscos nos planos cristalográficos a) (001), b) (111) e c) (101), $900 X$

Figura 5.34. Microestrutura da subsuperfície do risco no plano (001). 12Mn.

a) $10.000 X$. b) $20.000 X$

Figura 5.35. Microestrutura da subsuperfície do risco no plano (111). $12 \mathrm{Mn}$.

a) $10.000 X$. b) $20.000 X$ 
Figura 5.36. Microestrutura da subsuperfície do risco no plano (101). 12Mn. a) $10.000 \mathrm{X}$. b) $20.000 \mathrm{X}$

Figura 5.37. a) Imagem de MET - campo claro da camada com grãos ultrafinos. b) Ampliação da região indicada na Figura a. c) Ampliação da região indicada na Figura $b$. d) Ampliação da região indicada na Figura c. e) Imagem de difração da área de análise da Figura $d$.

Figura 5.38. Aço Hadfield deformado por high-speed pounding. a) Imagem de MET (campo claro) e SAED da camada subsuperficial. b) Distribuição de tamanho de grão (Raio-X)

Figura 5.39. Aço Hadfield deformado por shot peening. Imagem de MET (campo claro) e SAED da camada subsuperficial. a) Dois minutos de shot peening. b) 30 minutos de shot peening. c) 60 minutos de shot peening. d) Maior aumento da área da Figura $c$

Figura 5.40. Imagem de MET e SAED da subsuperfície do aço inox 316L deformado por ultrasonic shot peening. (a) e (b) $30 \mathrm{~s}$ de tratamento. (c) e (d) $810 \mathrm{~s}$

Figura 5.41. Imagem de MET e SEAD para a subsuperfície de liga de alumínio deformada por high-pressure torsion

Figura 5.42. Imagens de MET - campo claro da região de transição (a) e da região com maclas de deformação (b) .

Figura 5.43. a) Imagem de MET - campo claro da região de transição com quadros indicando áreas de análise de difração, Figuras $b, c, d$ e e

Figura 5.44. Imagem de MET da camada deformada por erosão do aço Hadfield 229 Figura 5.45. a) Imagens de MET de regiões nanocristalina e amorfa de dentro da banda de cisalhamento. b) Imagens de difração da região amorfa. c) Imagem de difração da região de transição (amorfa e nanocristalina). d) Imagem de MET em alta resolução da região amorfa.

Figura 5.46. a) Imagem de MET - campo claro da região com maclas de deformação. b) Imagem de difração de elétrons da área recíproca da Figura a .... 231 Figura 5.47. Diagrama de dissipação de energia.

Figura 5.48. Montagem do modelo de recristalização dinâmica da microestrutura da subsuperfície deformada pelo desgaste abrasivo. Perfil longitudinal do risco ... 234 Figura 5.49. Diagrama de blocos do modelo de dissipação de energia para um evento abrasivo 
Figura A.1. Desgaste relativo $\left(\mathrm{g} / \mathrm{m}^{2}\right)$ das mandíbulas fixa e móvel dos aços 253

Figura A.2. Perfil de dureza para mandíbula fixa e móvel dos materiais $14 \mathrm{Mn}$ (a) e $23 \mathrm{Mn}(\mathrm{b})$ 254

Figura B.1. Análise de correlação - Série i. (a) e (b) 50 mN. (c) e (d) 100 mN. (e) e (f) $200 \mathrm{mN}$

Figura B.2. Análise de correlação - Série ii. (a) e (b) 50 mN. (c) e (d) 100 mN. (e) e (f) $200 \mathrm{mN}$

Figura B.3. Gráficos de coeficiente de atrito para os ensaios nos planos a) (001),

b) (111) e c) (101) para o aço 12Mn

Figura B.4. Gráficos de coeficiente de atrito para os ensaios nos planos a) (001),

b) (111) e c) (101) para o aço $20 \mathrm{Mn}$ 258

Figura B.5. Gráficos de profundidade do risco $(h)$ para os ensaios nos planos a) (001), b) (111) e c) (101) para o aço 12Mn 260

Figura B.6. Gráficos de profundidade do risco $(h)$ para os ensaios nos planos a) (001), b) (111) e c) (101) para o aço $20 \mathrm{Mn}$

Figura B.7 Micrografia (MEV-SE) dos riscos no plano (001) para o aço 12Mn. a) Ensaio 1. b) Ensaio 2. c) Ensaio 3

Figura B.8. Micrografia (MEV-SE) dos riscos no plano (111) para o aço $12 \mathrm{Mn}$. a)

Ensaio 1. b) Ensaio 2. c) Ensaio 3 263

Figura B.9. Micrografia (MEV-SE) dos riscos no plano (101) para o aço 12Mn. a) Ensaio 1. b) Ensaio 2. c) Ensaio 3 264

Figura B.10. Micrografia (MEV-SE) dos riscos no plano (001) para o aço $20 \mathrm{Mn}$.

a) Ensaio 1. b) Ensaio 2. c) Ensaio 3

Figura B.11. Micrografia (MEV-SE) dos riscos no plano (111) para o aço 20Mn.

a) Ensaio 1. b) Ensaio 2. c) Ensaio 3 266

Figura B.12. Micrografia (MEV-SE) dos riscos no plano (101) para o aço 20Mn.

a) Ensaio 1. b) Ensaio 2. c) Ensaio 3 267

Figura C.1. Obtenção de cavacos via aplainamento do aço deformado. 268

Figura C.2. a) Micrografia via MEV de cavaco de aço Hadfield deformado, aumento de 300X. b) Aumento de 1.000X da área em destaque na Figura a ........ 269 Figura C.3. Micrografia via MO de cavaco de aço Hadfield deformado. 1.000X .... 270 Figura C.4. Resultado de EBSD-IPF sem clean up (a) e com clean up (b) da subsuperfície deformada pelo desgaste laboratorial em britador de mandíbula..... 271 Figura D.1. Curvas de distribuição considerando os desvios das amostras 
Figura D.2. Curvas de distribuição considerando as incertezas das médias .......... 271 


\section{LISTA DE TABELAS}

Tabela 2.1. Classes do aço Hadfield.

Tabela 3.1. Composição química dos aços em estudo (\% em peso)

Tabela 3.2. Principais parâmetros de duas versões do ensaio de britador de mandíbula.

Tabela 3.3. Porosidade (\%) dos aços $12 \mathrm{Mn}$ e $20 \mathrm{Mn}$

Tabela 3.4. Desgaste relativo ( $\mathrm{g} / \mathrm{m}^{2}$ para $100 \mathrm{~kg}$ de abrasivo britado) das MF e MM

Tabela 3.5. Isotropia da rugosidade para MF e MM nas regiões central e de saída - aços $12 \mathrm{Mn}$ e $20 \mathrm{Mn}$

Tabela 3.6. $S_{a}$ das superfícies desgastadas na região central e de saída da MF e MM para os aços $12 \mathrm{Mn}$ e $20 \mathrm{Mn}$

Tabela 4.1. Composição química dos aços em estudo (\% em peso) 109

Tabela 4.2. Valores de COF e profundidade dos riscos para as forças normais de $50 \mathrm{mN}, 100 \mathrm{mN}$ e $200 \mathrm{mN}$

Tabela 4.3. Coeficiente de atrito médio, grau de penetração $\left(D_{p}\right)$, ângulo de ataque e profundidade do risco

Tabela 4.4. Profundidade média dos riscos da série i e ii; grau de penetração e ângulo de ataque

Tabela 4.5. Coeficiente de atrito médio dos riscos nos planos cristalográficos (001), (111) e (101) para o aço 12Mn

Tabela 4.6. Coeficiente de atrito para os planos (001), (111) e (101). Aço 20Mn .. 154

Tabela 4.7. Valores de área da camada com grãos ultrafinos, profundidade média do risco, $D_{p}$ e ângulo de ataque dos riscos nos planos (001), (111) e (101) para os aços $12 \mathrm{Mn}$ e $20 \mathrm{Mn}$

Tabela 4.8. Valores de energia gasta no riscamento dos planos (001), (111) e (101)

Tabela 4.9. Módulo de elasticidade combinado dos planos (001), (111) e (101) dos aços $12 \mathrm{Mn}$ e $20 \mathrm{Mn}$ obtido via nanodureza instrumentada.

Tabela 5.1. Alterações microestruturais em função da escala de análise 236

Tabela A.1. Composição química dos aços $14 \mathrm{Mn}$ e $23 \mathrm{Mn}$. 252

Tabela A.2. Desgaste relativo $\left(\mathrm{g} / \mathrm{m}^{2}\right)$ das mandíbulas fixa e móvel dos aços. 252 


\section{LISTA DE ABREVIATURAS}

$\begin{array}{ll}\text { CFC } & \text { Estrutura Cúbica de Face Centrada } \\ \text { COF } & \text { Coeficiente de Atrito } \\ \text { EBSD } & \text { Electrons Backscattering Diffraction } \\ \text { ECAP } & \text { Equal Channel Angular Pressing } \\ \text { EDE } & \text { Energia de Defeito de Empilhamento } \\ \text { EDS } & \text { Energy Dispersive X-Ray Spectroscopy } \\ \text { FEG } & \text { Focused Electron Gun } \\ \text { FIB } & \text { Focused lon Beam } \\ \text { GD } & \text { Grãos Originais Deformados } \\ \text { HPT } & \text { High Pressure Torsion } \\ \text { HSP } & \text { High Speed Pouding } \\ \text { IPEN } & \text { Instituto de Pesquisas Energéticas e Nucleares } \\ \text { IPT } & \text { Instituto de Pesquisas Tecnológicas } \\ \text { PIB } & \text { Produto Interno Bruto }\end{array}$

LABMICRO Laboratório de Microscopia Eletrônica e de Força Atômica

LCT Laboratório de Caracterização Tecnológica

LFS Laboratório de Fenômenos de Superfície

MO Microscopia Óptica

MEV Microscopia Eletrônica de Varredura

MET Microscopia Eletrônica de Transmissão

SAED Selected Area Electron Diffraction

SPD Severe Plastic Deformation

TWINP Twinning Induced Plasticity

TRIP Transformation Induced Plasticity

TTT Temperatura-Tempo-Transformação 
UFG Ultrafine Grains

USP Ultrasonic Shot Peening

XRD X-ray Diffraction 


\section{LISTA DE SÍMBOLOS}
$A_{c m}$
Linha que indica a temperatura de transformação da austenita em $\mathrm{Fe}_{3} \mathrm{C}$
d
Distância entre um ponto a superfície desgastada
$D_{p} \quad$ Grau de penetração
f Tensão de cisalhamento interfacial
$f_{a b} \quad$ Diferença entre a área de material deslocado e removido
$\boldsymbol{F}_{\boldsymbol{t}} \quad$ Força tangencial
$F_{n} \quad$ Força normal
$\boldsymbol{h} \quad$ Profundidade do risco durante o evento de abrasão
HV Dureza Vickers
J Joule
$\boldsymbol{k}_{a b} \quad$ Coeficiente de desgaste abrasivo
$\mathbf{L} \quad$ Comprimento do risco
mm Milímetro
$m \mathbf{m} \quad$ MiliNewton
MPa MegaPascal
nm Nanometro
p Distância entre a origem do risco e um ponto ao longo do comprimento
$R^{2} \quad$ Coeficiente de determinação
S Segundo
$\boldsymbol{t}_{0} \quad$ Valor do teste de hipótese
$\boldsymbol{t}_{c r} \quad$ Valor crítico do teste de hipótese
$\boldsymbol{v} \quad$ Velocidade de riscamento
w Largura do risco
$W_{v / s^{-1}} \quad$ Resistência ao desgaste abrasivo
$Z_{g t} \quad$ Profundidade de transição geométrica do endentador 
$\alpha$

$\alpha_{c r}$

V

$\dot{\varepsilon}$
Ângulo de ataque

Ângulo de ataque crítico

Fase gama (Austenita)

Taxa de deformação 


\section{SUMÁRIO}

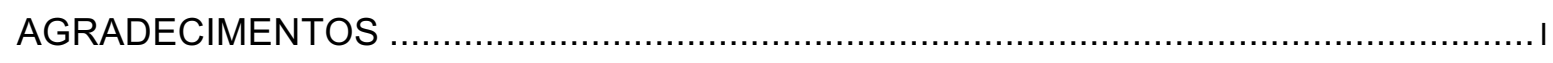

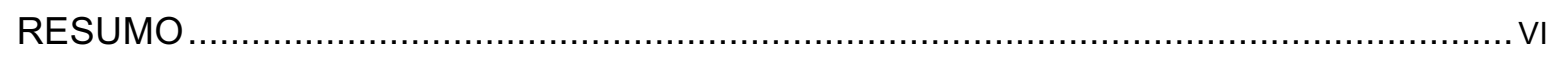

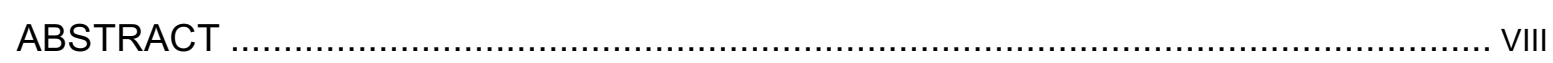

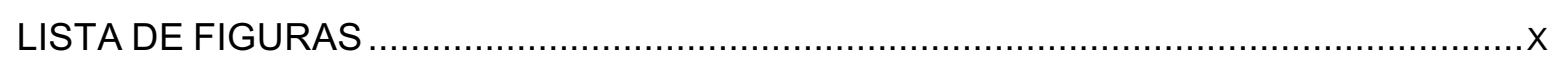

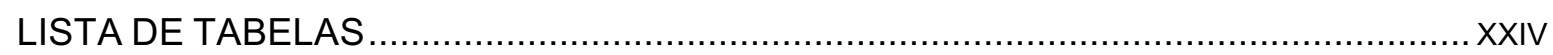

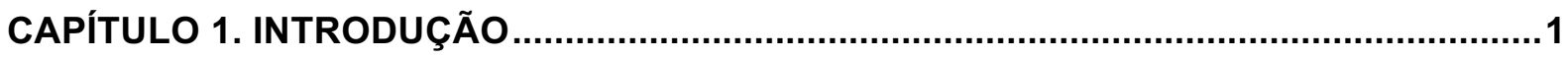

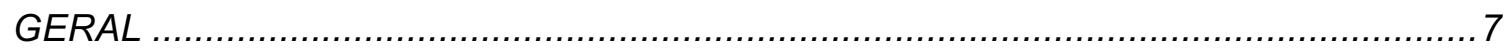

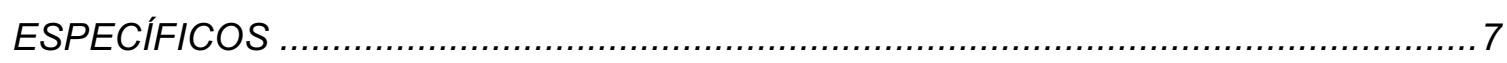

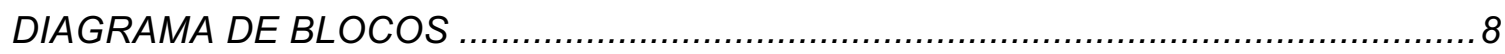

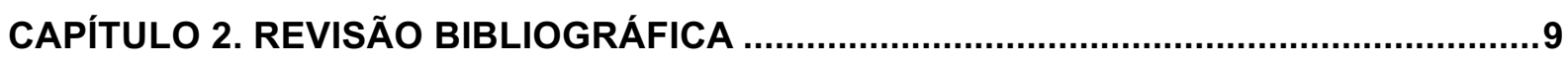

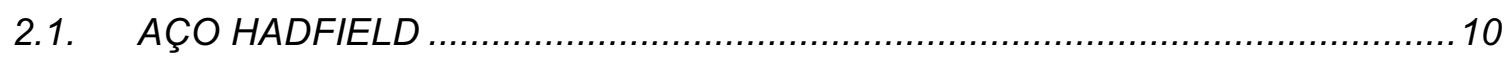

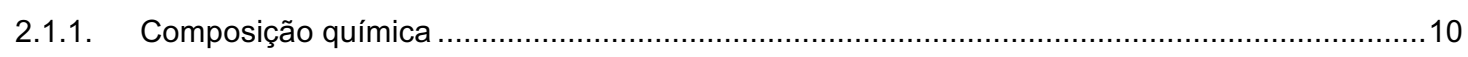

2.1.2. Influência da composição química nas propriedades mecânicas ..............................................15

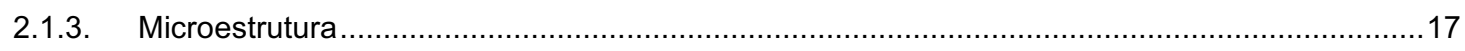

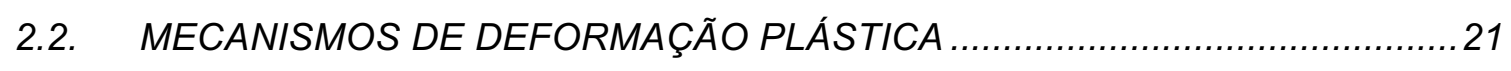

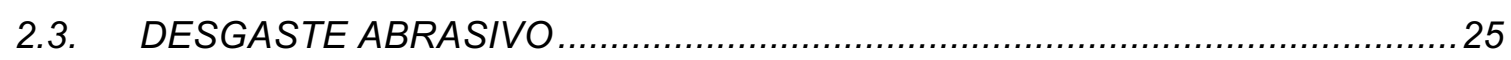

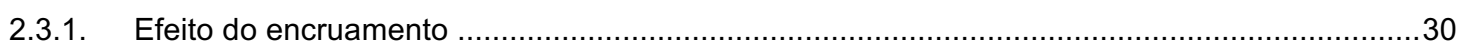

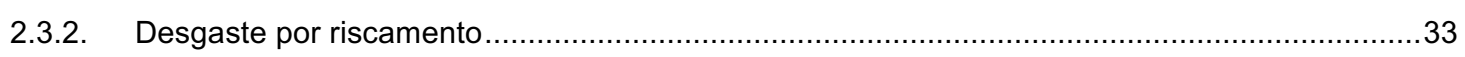

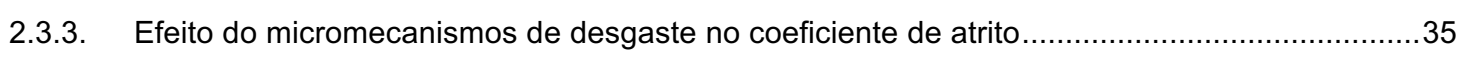

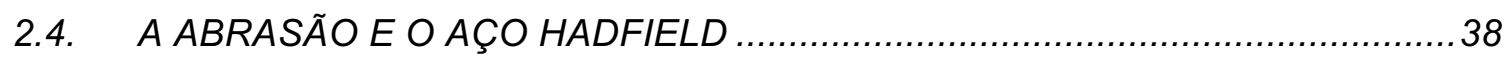

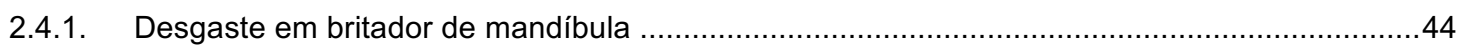

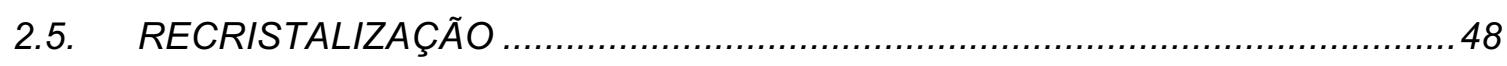

2.6. EFEITO DA ORIENTAÇÃO CRISTALOGRAFICA NA ABRASÃO....................54

CAPÍTULO 3. DESGASTE ABRASIVO DOS AÇOS AUSTENÍTICOS $12 \% \mathrm{MN}$ E $20 \% \mathrm{MN}$ VIA ENSAIO DE BRITADOR DE MANDÍBULA ..........................................................58

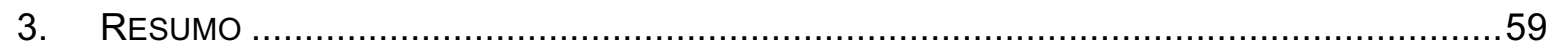

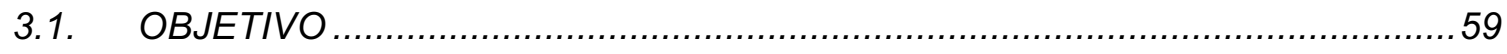

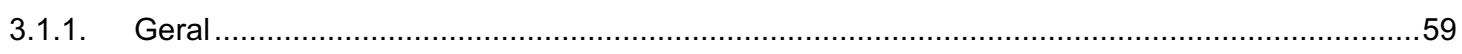

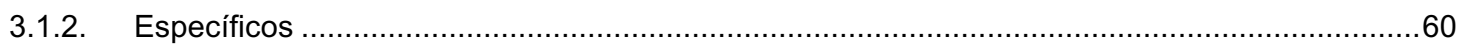

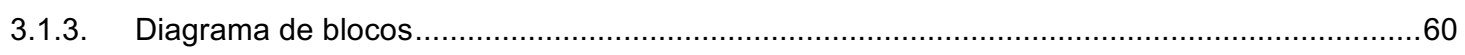

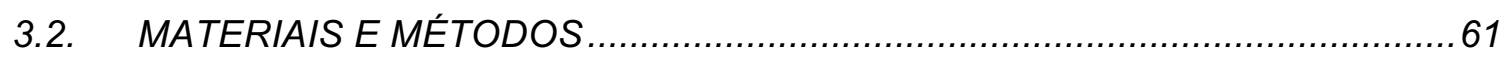

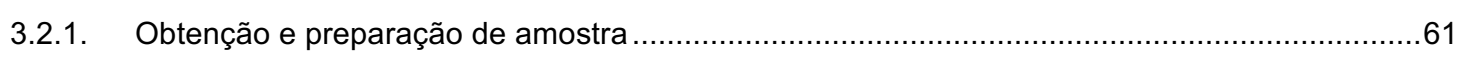

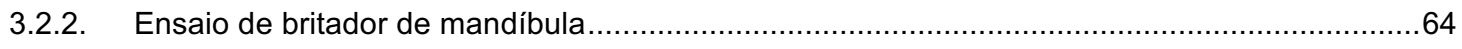

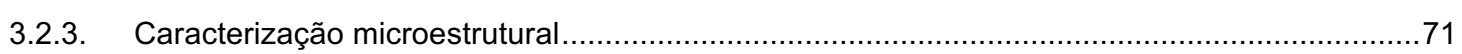

3.2.4. Caracterização do micromecanismos de desgaste ..................................................................

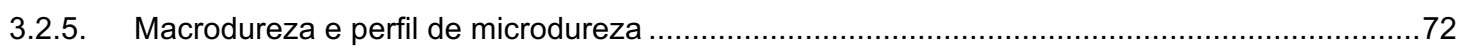

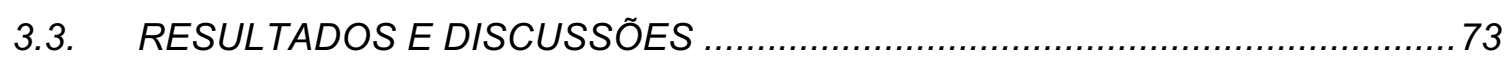




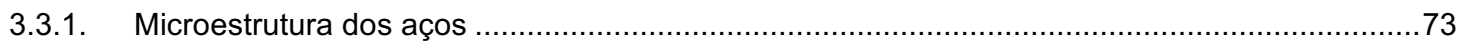

3.3.2. Distribuição granulométrica dos abrasivos britados ...................................................... 74

3.3.3. Desgaste dos revestimentos das mandíbulas ............................................................. 75

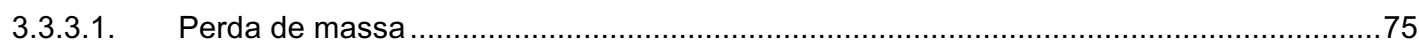

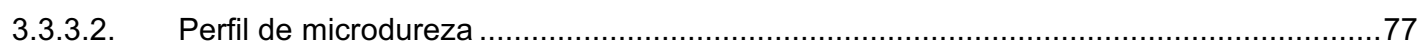

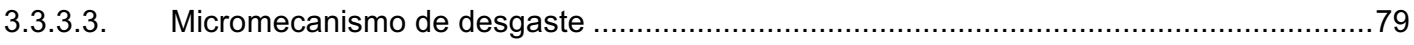

3.3.3.4. Microestrutura da subsuperfície de desgaste .......................................................98

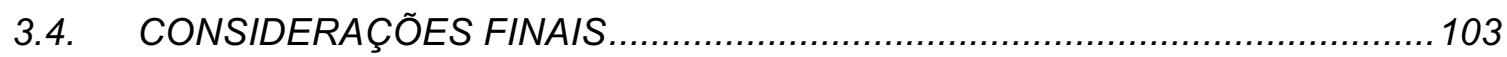

CAPÍTULO 4. EFEITO DO ENCRUAMENTO E DA ORIENTAÇÃO CRISTALOGRÁFICA NO DESGASTE POR RISCAMENTO DOS AÇOS AUSTENÍTICOS 12 \%MN E $20 \%$ MN .105

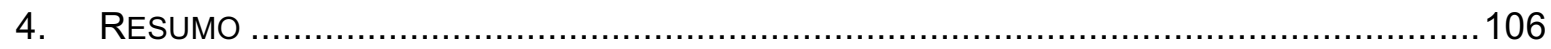

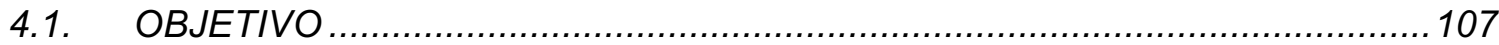

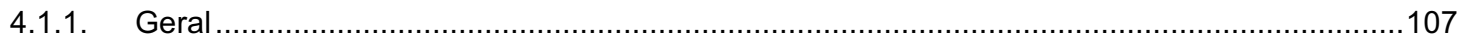

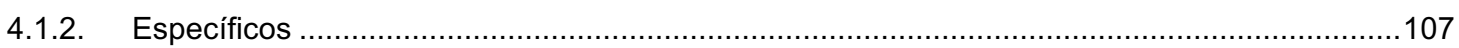

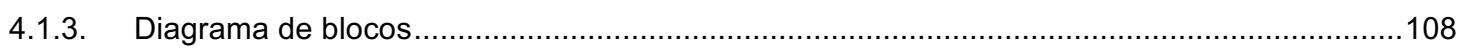

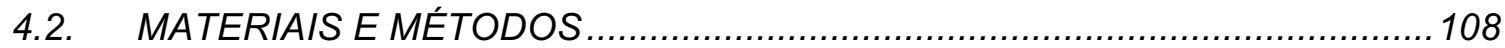

4.2.1. Obtenção e preparação de amostra ............................................................................ 108

4.2.2. Macrodureza e perfil de microdureza .......................................................................... 109

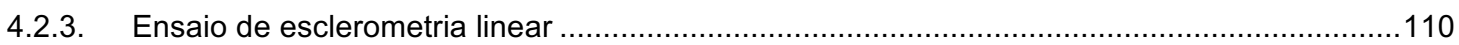

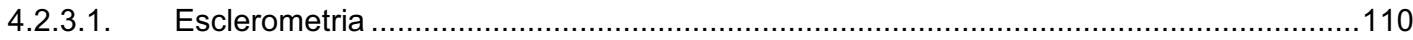

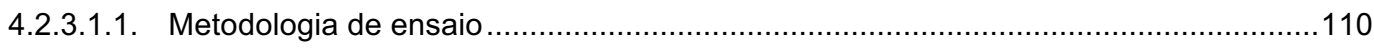

4.2.3.1.2. Caracterização dos riscos......................................................................... 112

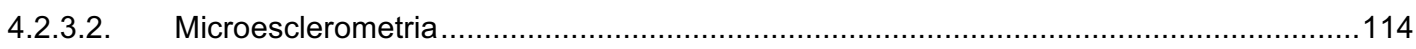

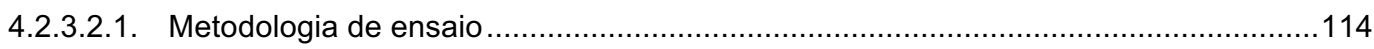

4.2.3.2.2. Efeito do perfil de encruamento .................................................................. 116

4.2.3.2.3. Efeito da orientação cristalográfica ................................................................ 118

4.2.3.2.4. Caracterização da microestrutura da subsuperfície ...............................................120

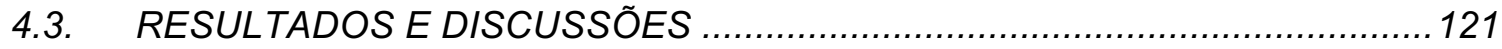

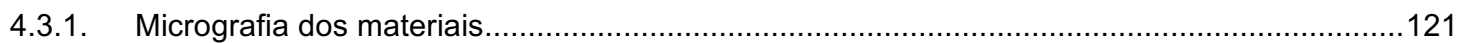

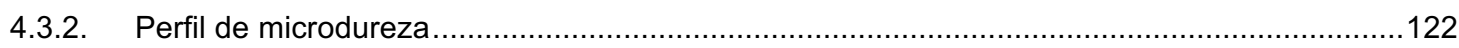

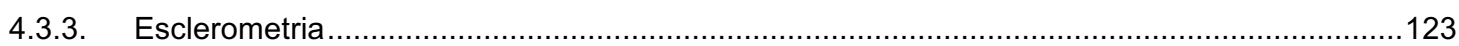

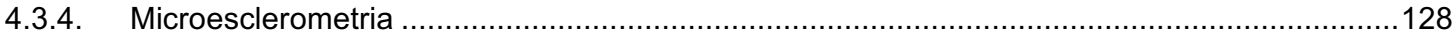

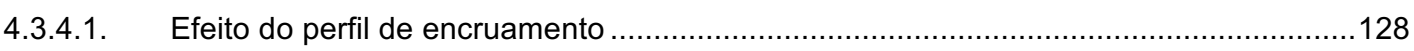

4.3.5. Efeito da orientação cristalográfica ........................................................................... 139

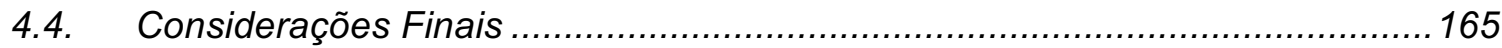

CAPITULO 5. MICROESTRUTURA DA SUBSUPERFÍCIE DO AÇO AUSTENÍTICO COM $12 \%$ MN DEFORMADO POR DESGASTE ABRASIVO .................................................166

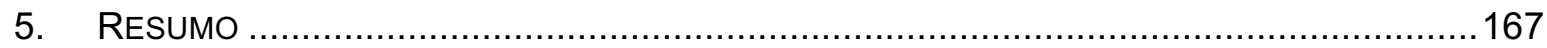

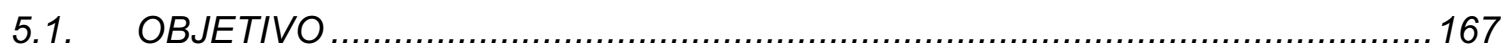

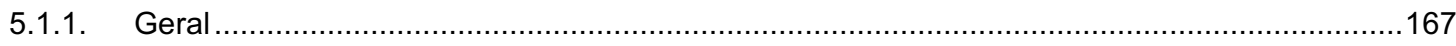

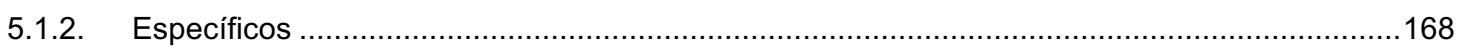




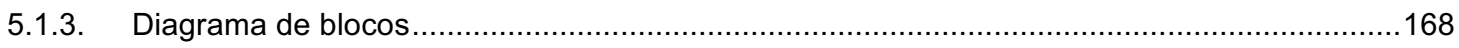

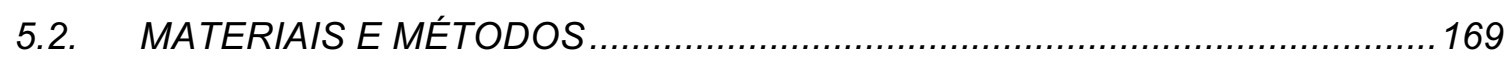

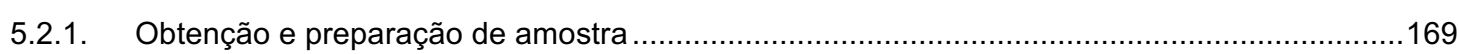

5.2.1.1. Amostra de revestimento de britador cônico ........................................................ 169

5.2.1.2. Amostra de revestimento de britador de mandíbula (ensaio laboratorial) ......................169

5.2.1.3. Amostra de microesclerometria linear (ensaio laboratorial) .........................................169

5.2.2. Corte em ângulo (taper section) .............................................................................. 170

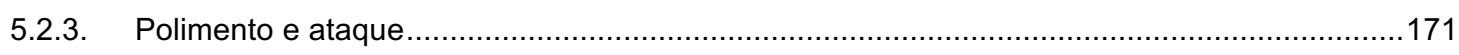

5.2.4. Lâmina para microscopia eletrônica de transmissão (MET) …............................................ 171

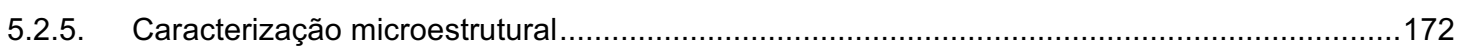

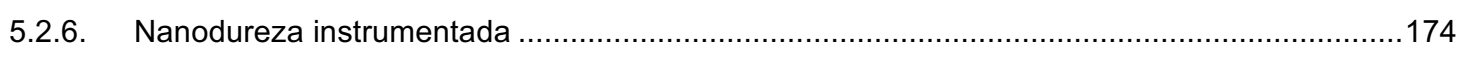

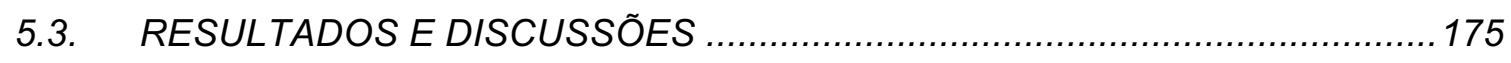

5.3.1. Superfície de desgaste e microestrutura da subsuperfície do revestimento de britador cônico

5.3.2. Microestrutura da subsuperfície do revestimento de britador de mandíbula (ensaio laboratorial)

203

5.3.3. Microestrutura da subsuperfície do risco (ensaio de microesclerometria) ...........................215

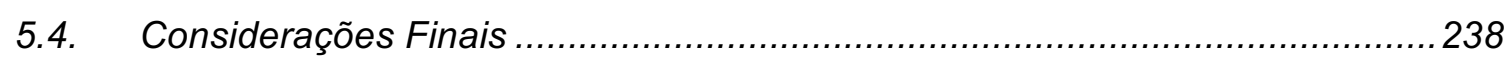

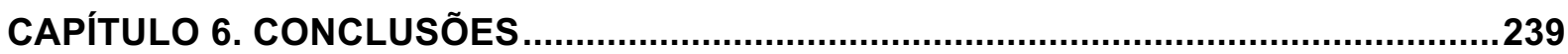

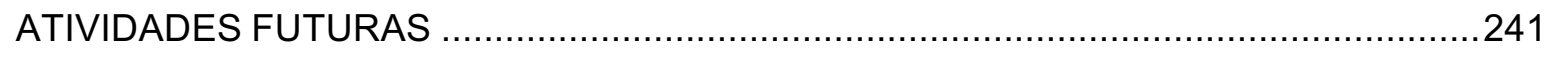

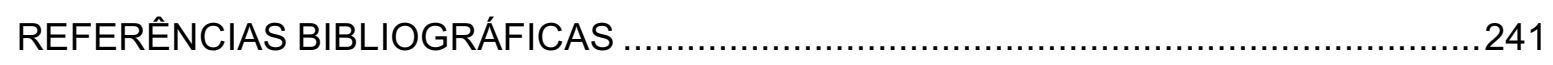

APÊNDICE A - DESGASTE ABRASIVO DOS AÇOS AUSTENÍTICOS 12 \%MN E 20 \%MN

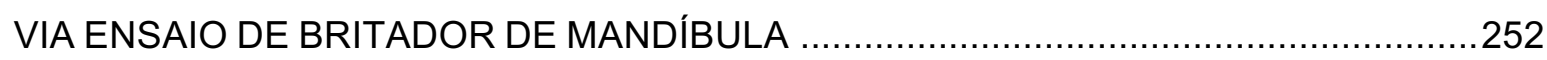

APÊNDICE B - EFEITO DO ENCRUAMENTO E DA ORIENTAÇÃO CRISTALOGRÁFICA NO DESGASTE POR RISCAMENTO DOS AÇOS AUSTENÍTICOS 12 \%MN E 20 \%MN .....255 APÊNDICE C: MICROESTRUTURA DA SUBSUPERFÍCIE DO AÇO AUSTENÍTICO COM

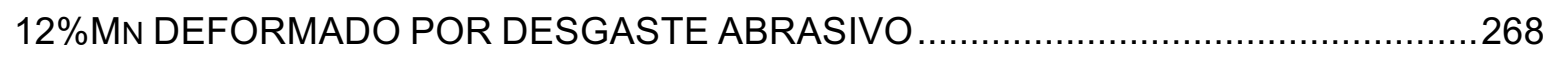

AMOSTRA DE CAVACO

MICROESTRUTURA DO CAVACO OBTIDA POR APLAINAMENTO ..........................26

COMPARAÇÃO ENTRE RESULTADO DE EBSD COM CLEAN UP E SEM CLEAN UP

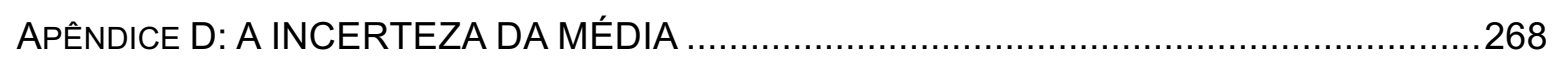


Capítula 1. INTRODUCÃO

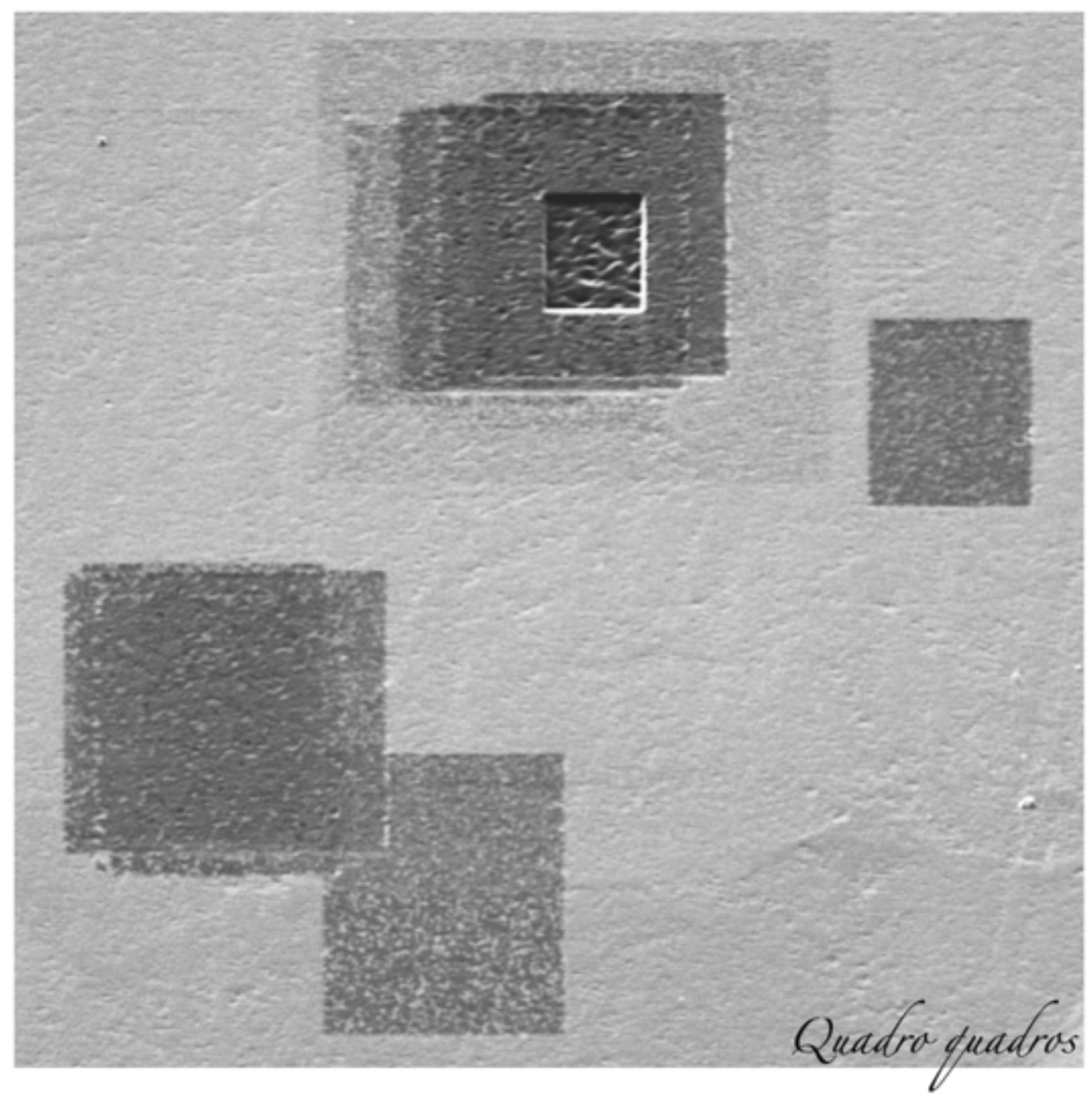


Reduzir perdas econômicas, como as decorrentes de falhas de equipamentos, parada não planejada de produção, reposição de peças desgastadas prematuramente, é o principal objetivo das pesquisas sobre desgaste (EYRE, 1976). A relação entre o desgaste, atrito e custo com o produto interno bruto foi tema de pesquisa do Ministério de Tecnologia da Grã-Bretanha em 1964, o relatório dessa pesquisa é conhecido como "Jost Report". O autor deste relatório, Peter Jost, mostrou que o desgaste é responsável por perdas econômicas equivalentes a $2 \%$ do produto interno bruto (PIB) de países desenvolvidos (JOST, 1990). Após cinco décadas Budinski estima que os custos relacionados ao desgaste podem chegar a $9 \%$ do PIB (BUDINSKI, 2013 apud HÄRKISAARI, 2015). Hutchings estimou que a aplicação dos conhecimentos de tribologia pode contribuir com a redução de: 5 \% do custo relacionado à energia consumida pelo atrito, $2 \%$ do custo de lubrificantes, $45 \%$ do custo de manutenção e reposição de equipamentos; e $22 \%$ do custo de paradas de máquinas (HUTCHINGS, 1992).

O gasto de energia mundial associado ao setor industrial de mineração foi estimado em $5 \%$, sendo que a maior parte desse gasto concentra-se no trabalho mecânico, refrigeração, exaustão, atrito e desgaste (HÄRKISAARI, 2015). As operações de mineração podem ser divididas em extração, processamento mineral, transporte e atividades de apoio. Segundo (HÄRKISAARI, 2015) nas minas de superfície o processamento mineral tem o maior gasto energético, $49 \%$, seguido do transporte (21\%), atividades de apoio (19 \%) e extração (11\%), Figura 1.1. A autora utilizou como base de dados o relatório do Programa Industrial Canadense de Conservação de Energia (Mining Association of Canada, 2005). 
Figura 1.1. Distribuição do gasto energético em minas de superfície

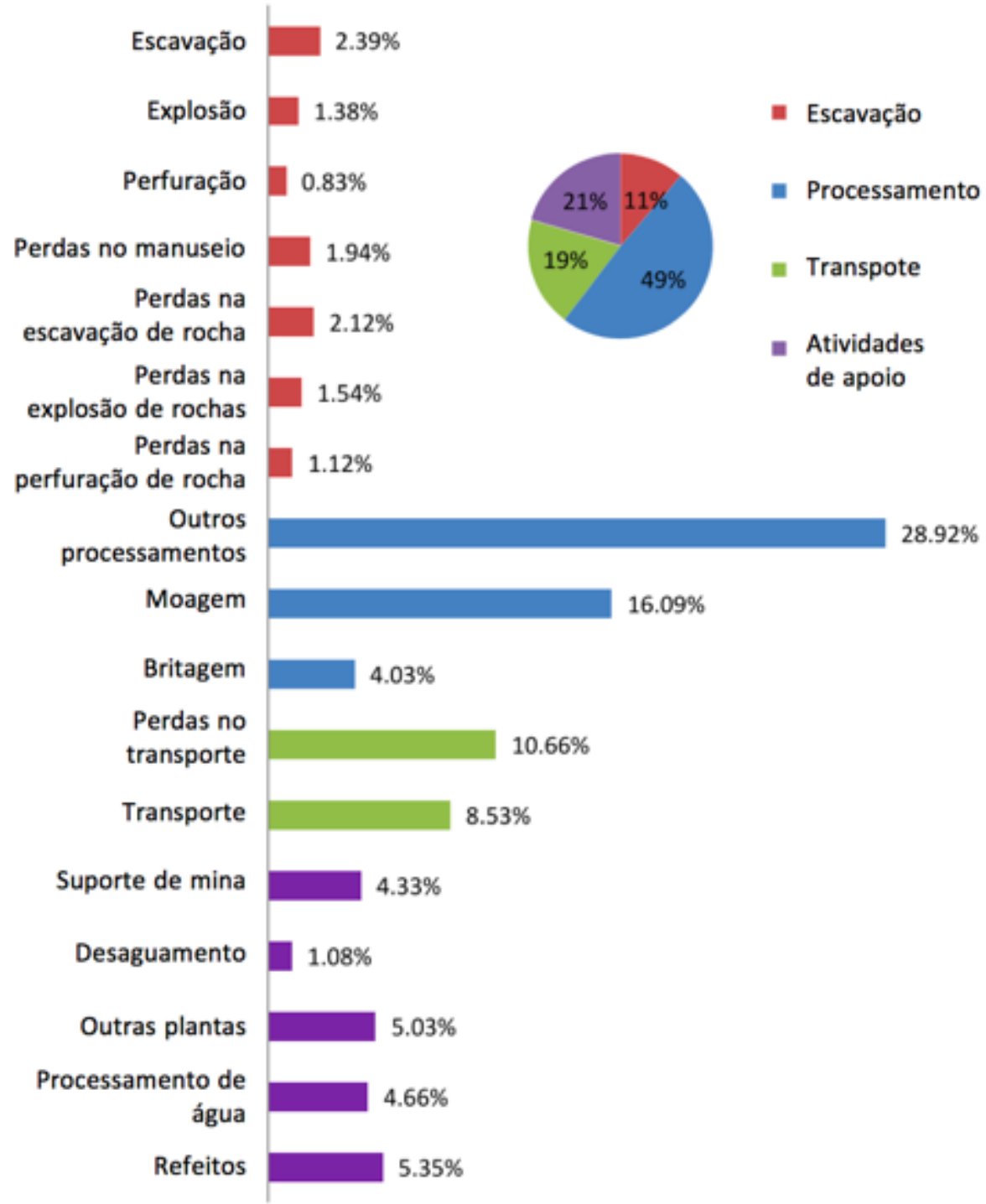

Fonte: Härkisaari, 2015

Neste cenário, em que o processamento mineral concentra $49 \%$ do gasto de energia do processo de mineração, o desgaste abrasivo representa $50 \%$ do desgaste de componente de máquinas industriais (EYRE, 1976). Na mineração a abrasão é o tipo de desgaste predominante devido a interação com partículas sólidas (minério) e a inevitável presença de sílica (partícula dura) que eleva a severidade do desgaste por apresentar valor de dureza superior ou equivalente às fases duras das ligas metálicas utilizadas nos revestimentos de equipamentos de cominuição.

Härkisaari mostrou que o gasto anual com componentes de reposição e manutenção de um britador de mandíbula primário equivale a $13 \%$ do seu valor de compra 
(HÄRKISAARI, 2015). A autora destacou que a diminuição de gasto energético no processamento de minério pode ser obtida a partir da otimização do processo de fragmentação e melhoramento da resistência ao desgaste dos materiais utilizados nos revestimentos.

Segundo Gousseland os materiais metálicos ferrosos como o ferro fundido branco, aços (martensítico e perlíticos) e o aço Hadfield são os mais utilizados em revestimentos de equipamentos de processamento mineral. $O$ aço Hadfield se destaca dos demais materiais ferrosos quando a interação do minério com a superfície dos equipamentos tem altas tensões e impacto (GOUSSELAND, 1974).

O aço Hadfield foi patenteado em 1883 por Robert Abbot Hadfield, com a composição de 1,2 \%C e 12,5\%Mn (GOUSSELAND, 1974), sendo essa a composição clássica. Essa composição química evoluiu cobrindo uma ampla gama de teores de manganês, de 6 \% a 14 \% (ASTM G128, 2012).

A resistência à abrasão do aço Hadfield é associada à sua alta capacidade de deformação plástica e endurecimento por deformação em serviço. Este aço é utilizado principalmente em revestimento de britadores de estágio primário, secundário e terciário de britagem de minérios, além de outros fins, como por exemplo, em sistemas de mudança de linha ferroviária (jacaré ou crossing) (SUBRAMANYAM; SWANSIGER; AVERY, 1990).

Moore apresentou um mapa de desgaste para diferentes microestruturas de aços em função da dureza (Figura 1.2) e não considerou a capacidade real de encruamento dos aços austeníticos, limitando-a em $250 \mathrm{HV}$ (MOORE, 1981), quando, na realidade, ela pode chegar a valores na ordem de 700 HV (AVERY, 1949).

A Figura 1.2 é um exemplo da concepção corrente na literatura que busca explicar a resistência à abrasão em função da dureza e da microestrutura do material. Nesta Figura foi sobreposta uma elipse que mostra uma interpretação alternativa relacionada à dureza, considerando essa variável como dureza após encruamento pelo desgaste, e à orientação cristalográfica. 
Figura 1.2. Diagrama de resistência à abrasão de aços em função da microestrutura e dureza

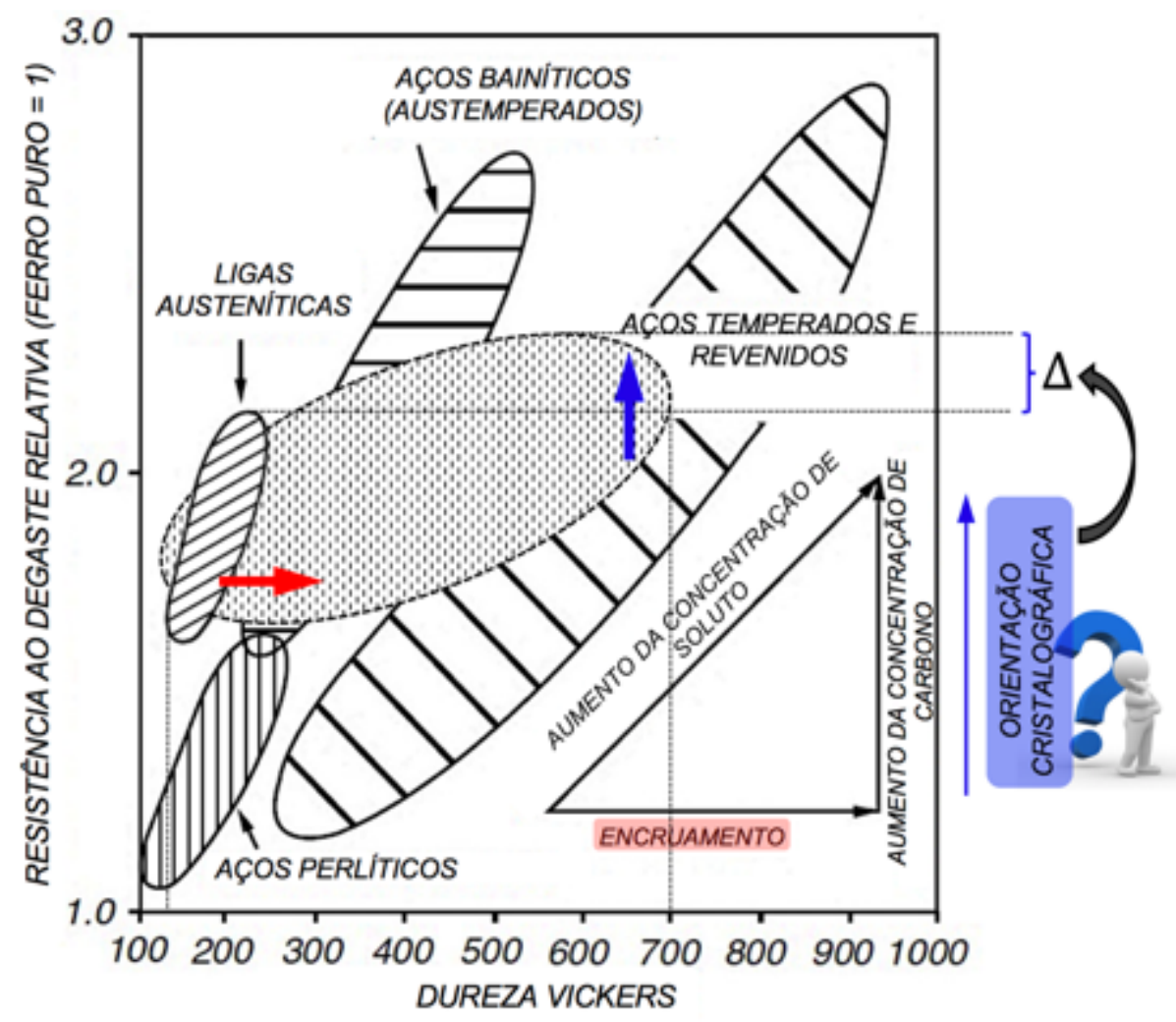

Fonte: Adaptado de Moore, 1981

Nesta pesquisa de doutorado o encruamento e a orientação cristalográfica são investigadas sob a ótica de uma abordagem em multiescala do fenômeno abrasivo, de modo a desenvolver uma visão mais abrangente do fenômeno abrasivo e de seu efeito sobre a microestrutura da subsuperfície de dois aços austeníticos ao manganês (12\%Mn e $20 \% \mathrm{Mn})$. A multiescala foi dividida em macroescala, mesoescala e microescala. A norma ISO 15577-1 de 2002 mostra uma divisão de escalas aplicadas em ensaios de dureza, na qual define que endentações com profundidades maiores que $0,1 \mathrm{~mm}$ são consideradas macroscópicas (macroescala) e endentações com profundidade entre $0,1 \mathrm{~mm}$ e $0,0001 \mathrm{~mm}$ são consideradas microscópicas (microescala). Contudo esta norma foi utilizada como referência para a análise multiescala, na qual, além das escalas macro e micro, tem a escala meso. A mesoescala foi definida como um subnível da macroescala, na qual representa os ensaios laboratoriais de britador de mandíbula e esclerometria linear.

Esta tese foi organizada em diferentes capítulos de materiais e métodos; e resultados e discussões, de modo a atender a metodologia multiescala do fenômeno 
abrasivo. Os Capítulos 1 e 2 tratam-se da Introdução e da Revisão Bibliográfica, respectivamente, enquanto que os Capítulos 3, 4 e 5 referem-se aos estudos intitulados: Desgaste abrasivo dos aços austeníticos $12 \% \mathrm{Mn}$ e $20 \% \mathrm{Mn}$ via ensaio de britador de mandíbula; Efeito do encruamento e da orientação cristalográfica no desgaste por riscamento dos aços austeníticos $12 \% \mathrm{Mn}$ e $20 \% \mathrm{Mn}$; e Microestrutura do aço austenítico com $12 \% \mathrm{Mn}$ deformado por desgaste abrasivo, respectivamente. Estes Capítulos são compostos por resumo; objetivos; materiais e métodos; resultados e discussões; e considerações finais. No final do texto tem-se o Capítulo de conclusões (Capítulo 6). 


\section{OBJETIVOS}

\section{GERAL}

Estudar o fenômeno de abrasão de aços austeníticos ao manganês em uma abordagem multiescala.

\section{ESPECÍFICOS}

- Avaliar o desempenho dos aços com $12 \% \mathrm{Mn}$ e $20 \% \mathrm{Mn}$ em condição de desgaste abrasivo via ensaio de britador de mandíbula;

- Avaliar o efeito do encruamento e o efeito da orientação cristalográfica no desgaste por riscamento dos aços $12 \% \mathrm{Mn}$ e $20 \% \mathrm{Mn}$;

- Caracterizar a microestrutura da subsuperfície do aço com $12 \% \mathrm{Mn}$ após desgaste abrasivo nas escalas macro (revestimento de britador usado em campo), meso (ensaio de laboratório) e micro (ensaio de laboratório). 


\section{DIAGRAMA DE BLOCOS}

O diagrama da Figura 1.3 mostra os níveis da análise multiescala com indicação dos ensaios e métodos de caracterização utilizados, assim como os Capítulos associados aos níveis da multiescala.

Figura 1.3. Diagrama de blocos da análise multiescala

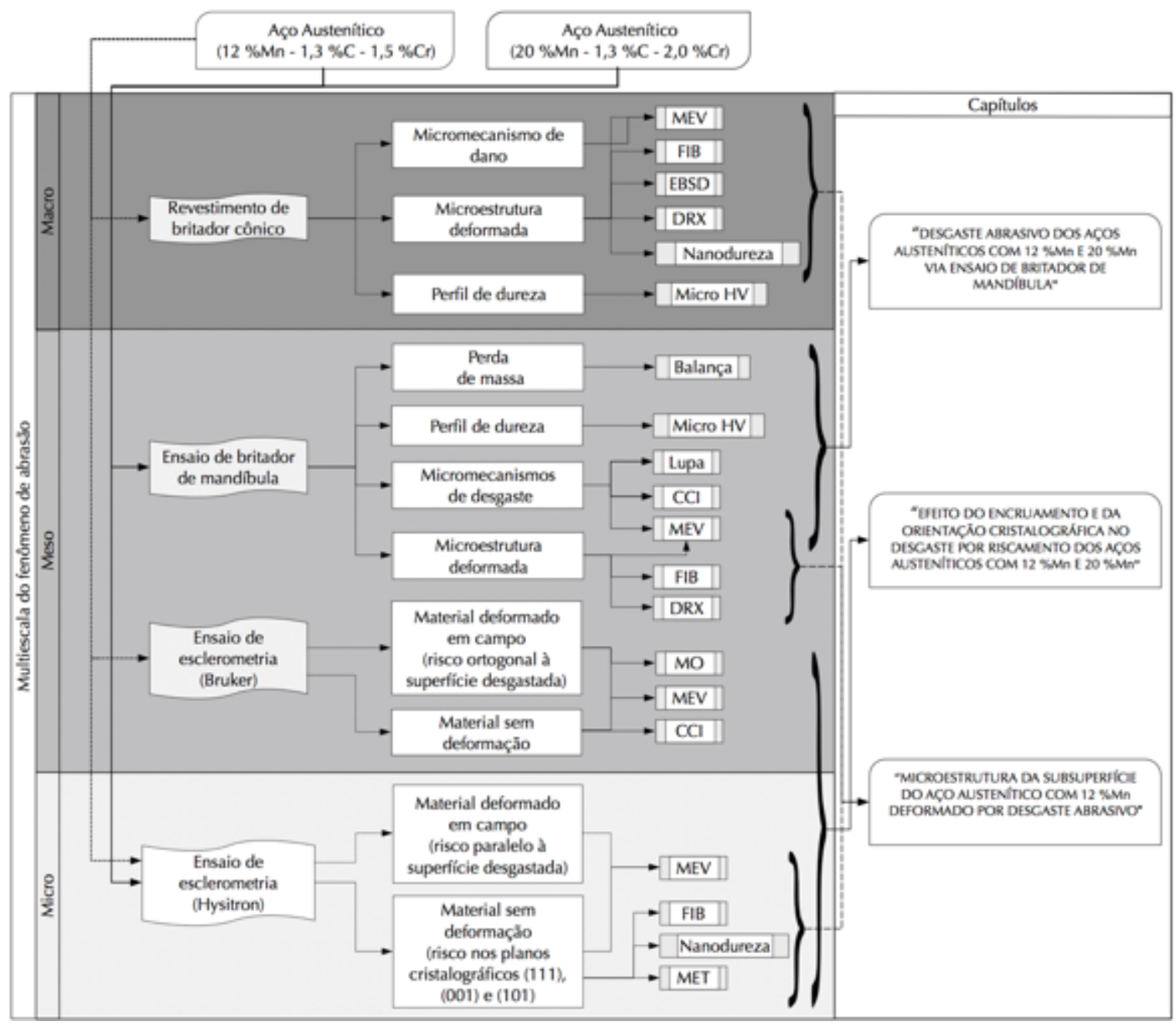


Capitula 2. REVISATO BIBLIOGRÁFICA

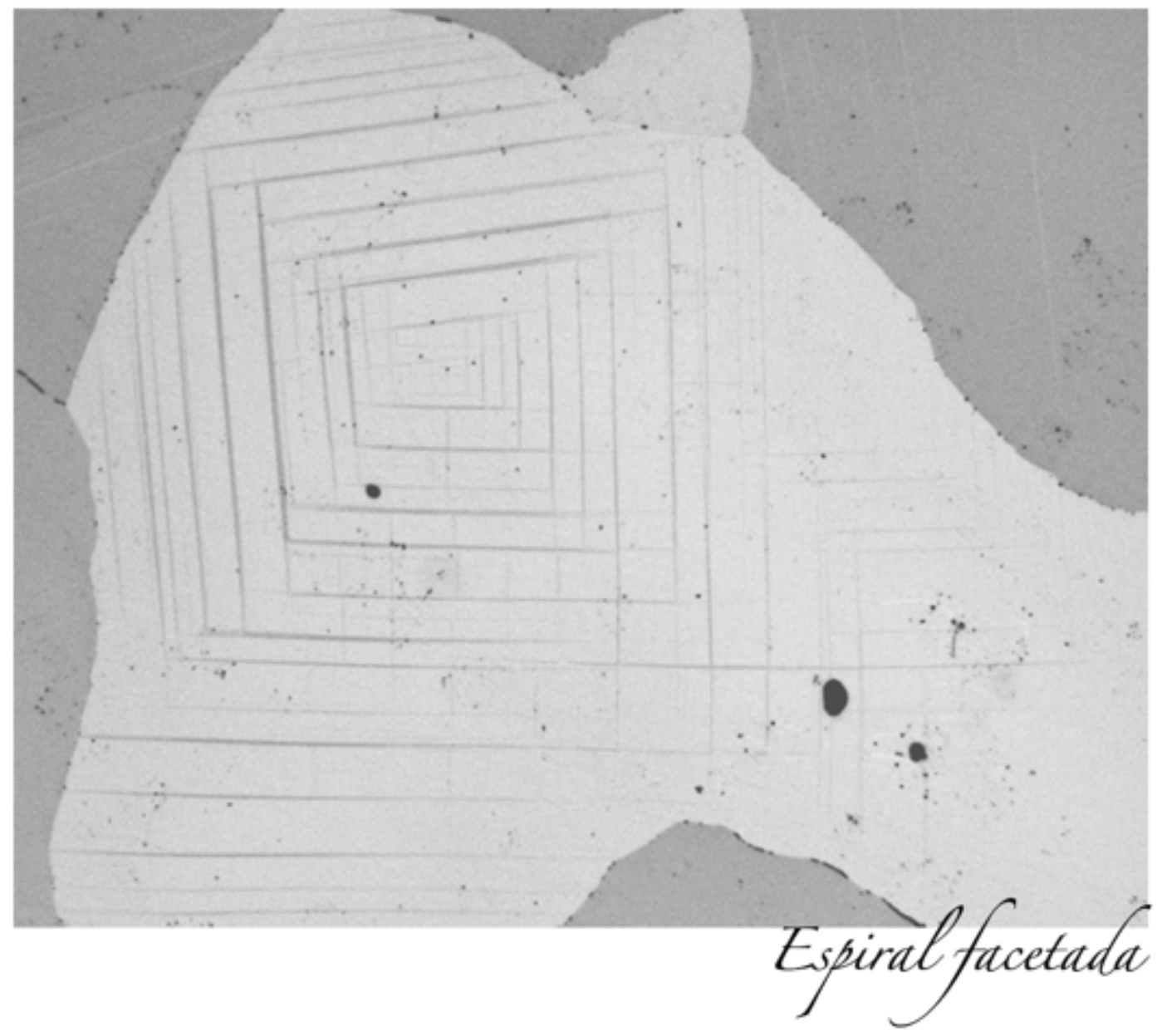




\subsection{AÇO HADFIELD}

O aço austenítico manganês Hadfield apresenta resistência ao impacto Charpy acima de $100 \mathrm{~J}$ (com entalhe), 50 \% de deformação real em carregamento quaseestático (ensaio de tração), tensão de escoamento de 340 a $420 \mathrm{MPa}$ e tensão de ruptura de 550 a $1000 \mathrm{MPa}$ (AVERY, 1949; BAYRAKTAR; LEVAILLANT; ALTINTAŞ, 1994; SUBRAMANYAM; SWANSIGER; AVERY, 1990). Tem grande aplicação em equipamentos de movimentação de terra, fragmentação de rochas (revestimento de britadores de mandíbula, cônicos e giratórios), em linhas ferroviárias nas transições de via (jacaré - frogs, switches and crossings) e em blindagem de equipamentos de guerra (BAYRAKTAR; KHALID; LEVAILLANT, 2004; SUBRAMANYAM; SWANSIGER; AVERY, 1990).

Com grande capacidade de endurecimento por deformação o aço Hadfield apresenta $220 \mathrm{HV}$ na condição de não deformado, quando deformado chega a $580 \mathrm{HV}$ e pode atingir $700 \mathrm{HV}$ em algumas condições de trabalho a frio, por exemplo, no ensaio trepanning (AVERY, 1949). O gradiente de encruamento estabiliza-se em $\sim 6 \mathrm{~mm}$ de profundidade em relação a superfície desgastada (deformada) em revestimentos de britadores (LINDROOS et al., 2015a; TANAKA, 2011). Essa característica do aço Hadfield não é evidente nos aços perlíticos ou martensíticos revenidos, por apresentarem menores elevações de dureza com o encruamento (PEREIRA, 2016; TRESSIA, 2015). Desta forma, o aço Hadfield é um aço especial para aplicações que provoquem deformação plástica necessária para formação da camada encruada de maior dureza (SUBRAMANYAM; SWANSIGER; AVERY, 1990).

\subsubsection{Composição química}

A norma ASTM A128 (ASTM G128, 2012) descreve as nove classes do aço Hadfield, Tabela 2.1. Os dois elementos químicos mais importantes são o carbono e o manganês. Nas ligas mais antigas a relação entre o teor de carbono e o teor de manganês é de um para dez. Outros elementos visam aumentar as janelas de processo de tratamento térmico e alterar propriedades mecânicas e metalúrgicas (SUBRAMANYAM; SWANSIGER; AVERY, 1990). 
Tabela 2.1. Classes do aço Hadfield

\begin{tabular}{|c|c|c|c|c|c|c|c|}
\hline \multirow{2}{*}{ Classe } & \multicolumn{7}{|c|}{ Composição (\% em peso) } \\
\hline & $\mathrm{C}$ & $\mathrm{Mn}$ & $\mathrm{Cr}$ & Mo & $\mathrm{Ni}$ & $\mathrm{Si}$ & $P$ \\
\hline $\bar{A}$ & $1,05-1,35$ & $11,0 \mathrm{~min}$ & - & - & - & $1,00 \max$ & $0,07 \max$ \\
\hline B-1 & $0,9-1,05$ & $11,5-14,0$ & - & - & - & $1,00 \max$ & $0,07 \max$ \\
\hline B-2 & $1,05-1,2$ & $11,5-14,0$ & - & - & - & $1,00 \max$ & $0,07 \max$ \\
\hline B-3 & $1,12-1,28$ & $11,5-14,0$ & - & - & - & $1,00 \max$ & 0,07 max \\
\hline B-4 & $1,2-1,35$ & $11,5-14,0$ & - & - & - & $1,00 \max$ & $0,07 \max$ \\
\hline C & $1,05-1,35$ & $11,5-14,0$ & $1,5-2,5$ & - & - & $1,00 \max$ & $0,07 \max$ \\
\hline $\mathrm{D}$ & $0,7-1,3$ & $11,5-14,0$ & - & - & $3,0-4,0$ & $1,00 \max$ & $0,07 \max$ \\
\hline$E-1$ & $0,7-1,3$ & $11,5-14,0$ & - & $0,9-1,2$ & - & $1,00 \max$ & 0,07 max \\
\hline E-2 & $1,05-1,45$ & $11,5-14,0$ & - & $1,8-2,1$ & - & $1,00 \max$ & 0,07 max \\
\hline $\mathrm{F}$ & $1,05-1,35$ & $6,0-8,0$ & - & $0,9-1,2$ & - & $1,00 \max$ & $0,07 \max$ \\
\hline
\end{tabular}

Fonte: ASTM A128, 2012

A classe A tem composição química padrão do aço Hadfield. Nessa classe o teor de carbono varia de 1,05 até $1,35 \%$ numa amplitude de 0,3 pontos percentuais. A classe $B$ foi dividida em subclasses, cada uma delas compreendendo um intervalo de teor de carbono da ordem de 0,15\%. Nessa classe o teor de carbono se eleva da subclasse B-1 para a subclasse B-2. A especificação das subclasses pode ser um recurso quando se pretenda explorar com consistência os eventuais benefícios dos teores de carbono. As classes C, D e E apresentam faixas de composição para os elementos de liga cromo, níquel e molibdênio, respectivamente. A classe $F$ refere-se ao aço Hadfield com menor concentração de manganês, de 6 a $8 \%$. A literatura associa os teores de manganês da classe $F$ ao endurecimento por transformação martensítica, evidenciada por (BAUSCHKE; HORNBONGEN; ZUM GAHR, 1981; ZUM GAHR, 1987). Como se vê na Tabela 2.1 o teor de manganês é mantido de 11 a $14 \%$ exceto, como se viu, para a classe $F$.

A variação do teor de carbono (C) adicionado no aço Hadfield altera o seu comportamento metalúrgico. $\mathrm{O}$ aumento do teor de carbono desacelera a transformação perlítica e aumenta a taxa de formação de carbonetos pró-eutetóides por aumentar sua temperatura de estabilidade (KUYUCAK; ZAVADIL; NEWCOMBE. P., 2001a). Com isso tem-se a facilidade de precipitação de carbonetos em contorno de grão, principalmente para valores maiores que 1,4 \%C (AVERY, 1949). Valores elevados de carbono prejudicam o processo de tratamento térmico e de fundição (AVERY, 1949). No tratamento térmico de solubilização e resfriamento em água a 
elevação do teor de carbono aumenta a reprecipitação de carbonetos em contorno de grão fragilizando o aço Hadfield (FUOCO et al., 2012).

A concentração de manganês $(\mathrm{Mn})$ do aço Hadfield é responsável pelo efeito de estabilidade da austenita em temperatura ambiente (AVERY, 1949), considerando uma condição fora do equilíbrio termodinâmico (metaestável). Além deste efeito termodinâmico causado pelo manganês em solução no aço, este elemento químico causa efeito na cinética de transformação de fase. Avery apresentou o seguinte exemplo relacionado ao efeito do manganês na cinética de transformação de fase de ligas ferrosas: para um aço com $1,1 \% \mathrm{Mn}$ em tratamento isotérmico a $370{ }^{\circ} \mathrm{C}$ a transformação de fase ocorre em $15 \mathrm{~s}$, no entanto, aumentando a concentração de manganês para $13 \%$, a transformação pode requerer dois dias (AVERY, 1949).

$\mathrm{O}$ aço Hadfield com concentrações menores de manganês (6 a $8 \%$ - classe $F$ ) é susceptível à transformação martensítica quando deformado. Esse fenômeno promove alterações de propriedades mecânicas e físicas do material (BAUSCHKE; HORNBONGEN; ZUM GAHR, 1981; ZUM GAHR, 1987). A Figura 2.1 mostra os diagramas isopleta $\mathrm{Fe}-\mathrm{C}$ - Mn. Com o aumento da concentração do manganês $(2,5 \%$ - Figura 2.1a; 4,5 \% - Figura 2.1b e $13 \%$ - Figura 2.1c), nota-se o deslocamento da transformação eutetóide expandindo a fase $\mathrm{Y}$ e aumentando a região $(\alpha F e)+\gamma+M_{3} C(B R E W E R, L$.; CHANG, 1973). 
Figura 2.1. Influência da adição do Mn no diagrama isopleta Fe-C-Mn. a) 2,5 \%Mn. b) 4,5 \%Mn. c) $13 \% \mathrm{Mn}$
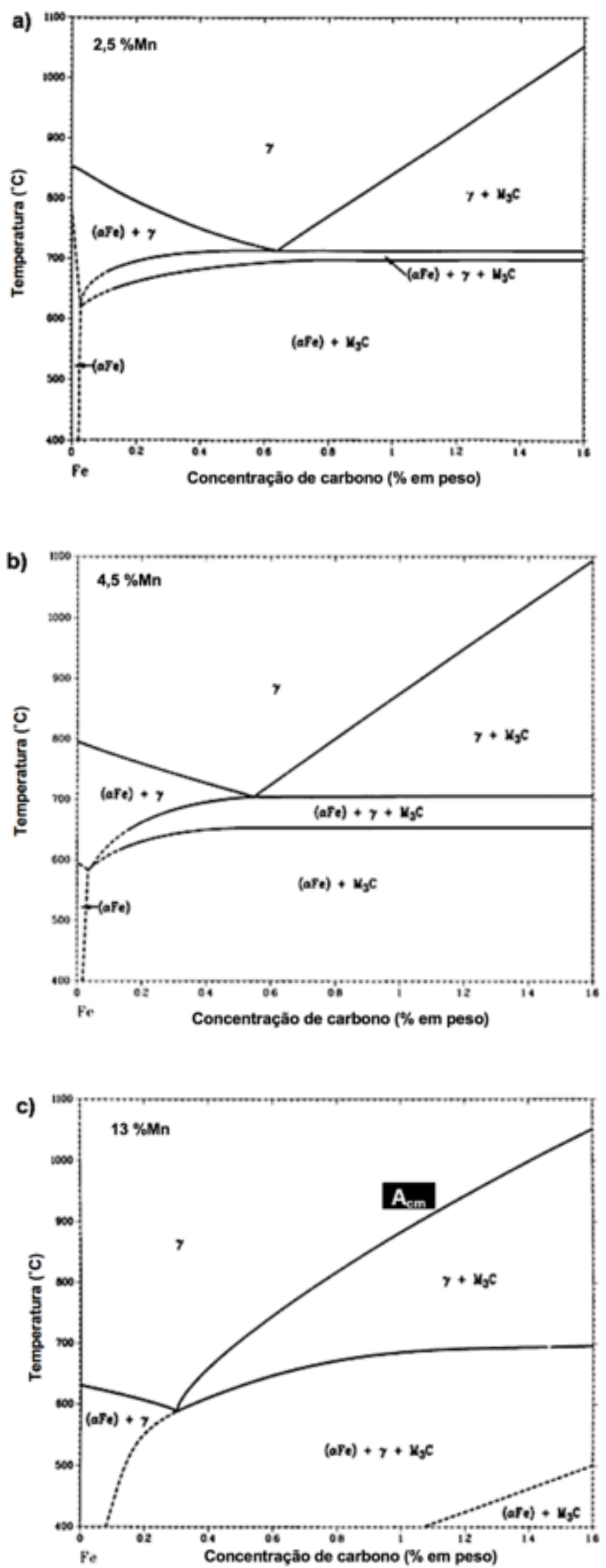

Fonte: Brewer; Chang, 1973 
A adição de cromo $(\mathrm{Cr})$ de até $2 \%$ é usual para o aço Hadfield, por melhorar as propriedades mecânicas e a resistência ao desgaste (SUBRAMANYAM; SWANSIGER; AVERY, 1990). No entanto, aumenta a estabilidade de carbonetos, elevando a temperatura de formação facilitando a reprecipitação durante 0 tratamento térmico após solidificação. Assim, o processo de solubilização necessita de temperaturas mais elevadas para atingir solubilização em matriz austenítica de forma homogênea (KUYUCAK; ZAVADIL; NEWCOMBE. P., 2001a; SUBRAMANYAM; SWANSIGER; AVERY, 1990).

O molibdênio (Mo) é adicionado no aço Hadfield usualmente entre 0,5 a $2 \%$, por apresentar-se em solução na matriz austenítica, evita a formação de carbonetos e fase perlítica em contorno de grão durante o tratamento térmico após solidificação (AVERY, 1949; SUBRAMANYAM; SWANSIGER; AVERY, 1990). E possibilita o aumento da faixa de aplicação de carbono (DIESBURG, D. E.; BORIK, F., 1974). Ele é utilizado principalmente na fundição de peças de grande porte (revestimentos de equipamentos de fragmentação de minério), as quais apresentam menor taxa de extração de calor no núcleo da peça sendo regiões mais propicias à formação de carbonetos. Por ter custo elevado alternativas de processo podem ser aplicadas para minimizar a formação de carbonetos, por exemplo, redução da concentração de carbono ou cromo (SANTOS et al., 2010; SUBRAMANYAM; SWANSIGER; AVERY, 1990).

A adição de níquel ( $\mathrm{Ni}$ ) em concentrações acima de $4 \%$ estabiliza a austenita. Auxilia na manutenção de propriedades não magnéticas do aço, principalmente das camadas descarbonetadas. E aumenta a soldabilidade, conferindo maior estabilidade metalúrgica ao aço Hadfield (AVERY, 1949; SUBRAMANYAM; SWANSIGER; AVERY, 1990).

O silício (Si) é utilizado entre 0,1 a $1 \%$ em função de características metalúrgicas de processo, visando obter a fluidez do metal líquido de acordo com o processo de fundição adotado. Apresenta contribuição no aumento de propriedade mecânica, mas acima de 2,2 \%Si há uma queda acentuada de resistência à tração (AVERY, 1949; SUBRAMANYAM; SWANSIGER; AVERY, 1990).

O fósforo $(\mathrm{P})$ é considerado uma impureza do processo. Acima de 0,06\% $\mathrm{P}$ contribui com a fragilidade a quente (hot shortness) e diminuição do alongamento em temperaturas elevadas. Em peças fundidas ocorre a formação de trincas a quente (hot tears) (AVERY, 1949; SUBRAMANYAM; SWANSIGER; AVERY, 1990). 
$O$ enxofre (S) tem afinidade com o manganês presente no aço Hadfield e forma inclusões arredondadas. Este elemento deve ter concentração baixa $(\leq 0,05 \%)$ para minimizar o número de inclusões, as quais são concentradoras de tensão sendo sítios para nucleação de trincas (AVERY, 1949; SUBRAMANYAM; SWANSIGER; AVERY, 1990).

\subsubsection{Influência da composição química nas propriedades mecânicas}

As Figuras 2.2 e 2.3 mostram resultados de propriedades mecânicas de aços Hadfield classe A (tratados por têmpera em água após solubilização a 1040$1095^{\circ} \mathrm{C}$ ) em função da variação dos teores de carbono e manganês (SUBRAMANYAM; SWANSIGER; AVERY, 1990).

A Figura 2.2a mostra o efeito da variação do teor de carbono na resistência a tração do aço Hadfield. A variação de $0,4 \% \mathrm{C}$ para aproximadamente $1,2 \%$ promove aumento da resistência a tração de $290 \mathrm{MPa}$ para $840 \mathrm{MPa}$ (valor médio). A elevação do teor de carbono de $0,4 \%$ para aproximadamente $1,0 \%$ leva, aparentemente, a uma elevação monotônica da tensão de ruptura.

A relação do teor de carbono com a tensão de escoamento para o aço Hadfield é mostrada na Figura 2.2b. Para uma variação de 0,6 \%C (entre 1,0 e 1,6 \%) tem-se um aumento contínuo na ordem de $100 \mathrm{MPa}$ na tensão de escoamento, apesar de ser mostrado no gráfico uma reta que indica a não variação da tensão de escoamento a partir de $1 \% \mathrm{C}$. A Figura $2.2 \mathrm{c}$ mostra que o aumento do teor de carbono provoca a diminuição do alongamento do aço. Teores de carbono de 0,9 a $1,25 \%$ apresentam um valor médio de $40 \%$. Abaixo de $0,9 \% \mathrm{C}$ e a partir de $1,25 \% \mathrm{C}$ o alongamento apresenta valores inferiores a $40 \%$. 
Figura 2.2. Propriedades mecânicas do aço Hadfield classe $A$ em função do teor de carbono.

a) Resistência à tração. b) Tensão de escoamento. c) Alongamento
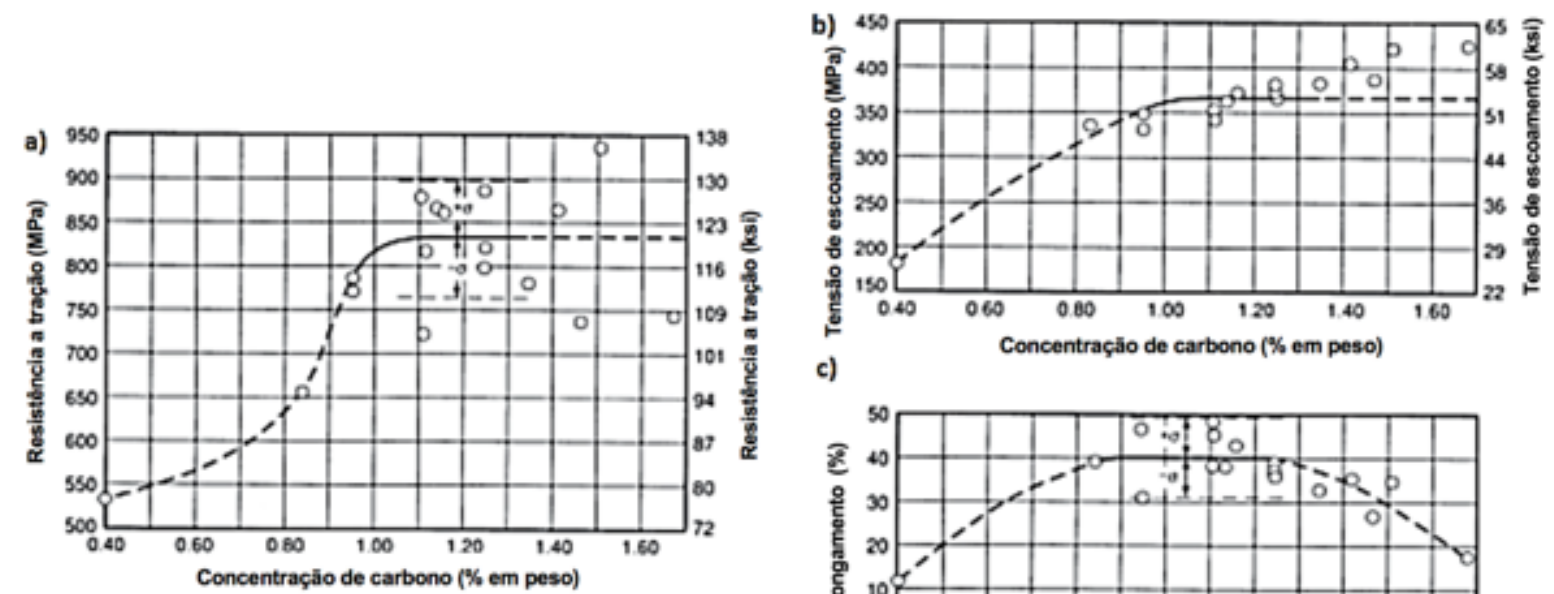

c)

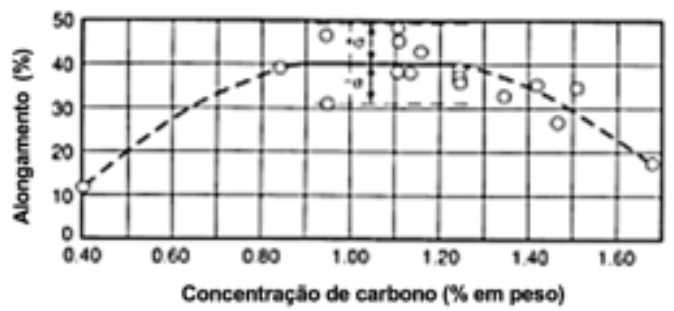

Fonte: Subramanyam et al., 1990

A Figura 2.3 mostra que o aumento do teor manganês no aço Hadfield influencia suas propriedades mecânicas (resistência à tração e alongamento).

Figura 2.3. Propriedades mecânicas do aço Hadfield classe A em função do teor de manganês. a) Resistência à tração e tensão de escoamento. b) Alongamento
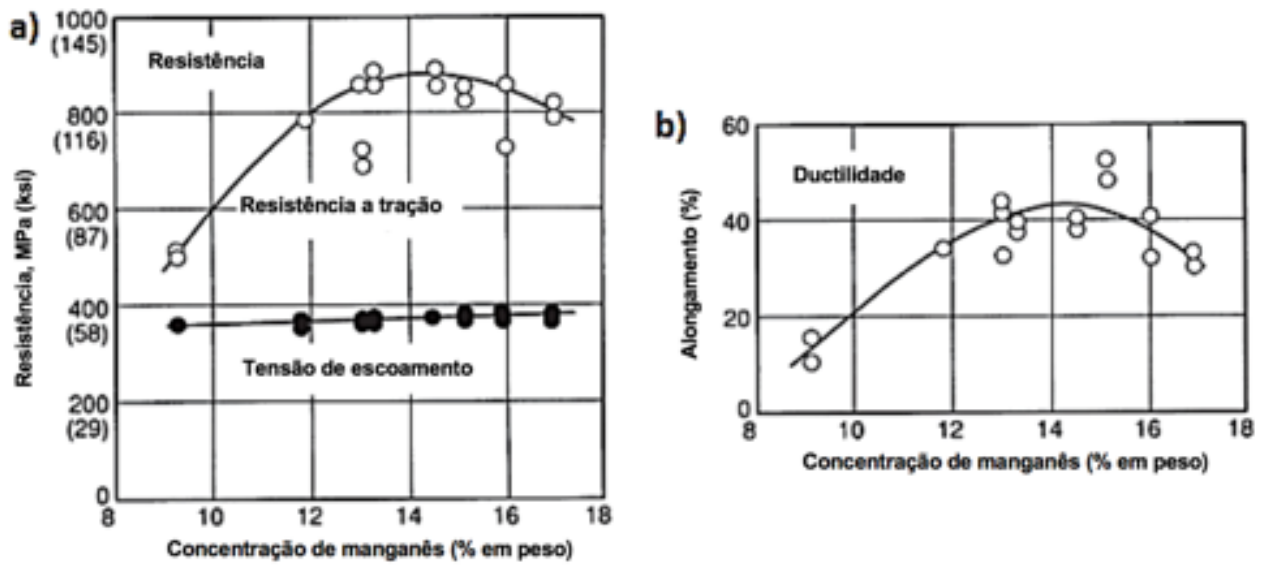

Fonte: Subramanyam et al., 1990

A Figura 2.3a mostra que o aumento do teor de manganês afeta minimamente a tensão de escoamento. No entanto, observa-se significativo aumento na resistência a tração. Com o aumento do teor de $\mathrm{Mn}$ em 5 pontos percentuais os autores obtiveram um aumento de $400 \mathrm{MPa}$ de resistência a tração e para o alongamento um aumento de $35 \%$. Entretanto, de $14 \%$ a $17 \%$ de Mn observa-se a tendência de 
diminuição da resistência a tração e alongamento, atingindo o valor de $800 \mathrm{MPa}$ e $30 \%$, respectivamente (AVERY, 1949; SUBRAMANYAM; SWANSIGER; AVERY, 1990).

Os elementos $\mathrm{Cr}$ e Mo adicionados no aço Hadfield também influenciam suas propriedades mecânicas. A adição de cromo eleva a tensão de escoamento e diminui a resistência à tração e o alongamento. Além disso, na fabricação de peças espessas a adição de cromo pode apresentar aumento de fração volumétrica de carbonetos e diminuição de ductilidade do aço Hadfield (SUBRAMANYAM; SWANSIGER; AVERY, 1990).

A adição de molibdênio no aço Hadfield promove o aumento de tenacidade, resistência à fratura de fundidos, e tensão de escoamento de peças espessas fundidas, solubilizadas e resfriadas em água. No entanto, a partir de 1,8 \%Mo têmse a diminuição do alongamento e da resistência a tração do aço Hadfield (SUBRAMANYAM; SWANSIGER; AVERY, 1990).

\subsubsection{Microestrutura}

O aço Hadfield com composição química padrão, 1,2 \%C e $12 \% \mathrm{Mn}$ (\%C sendo 1/10 da $\% \mathrm{Mn}$ ), tem microestrutura austenítica. Quando deformado plasticamente o aço Hadfield sofre maclação, assim, apresentando comportamento de material TWIP. Vatavuk e Goldenstein (VATAVUK, J.; GOLDENSTEIN, 1986) avaliaram o aço Hadfield sob condições de alta taxa de encruamento e observaram a formação de bandas de deformação na região deformada, as quais são descritas por (ADLER; OLSON; OWEN, 1986), como maclas de deformação, Figura 2.4. 
Figura 2.4. a) Seção transversal do aço manganês submetida a ensaio de mandíbula. b) Aço Hadfield deformado (30 \%) sob compressão
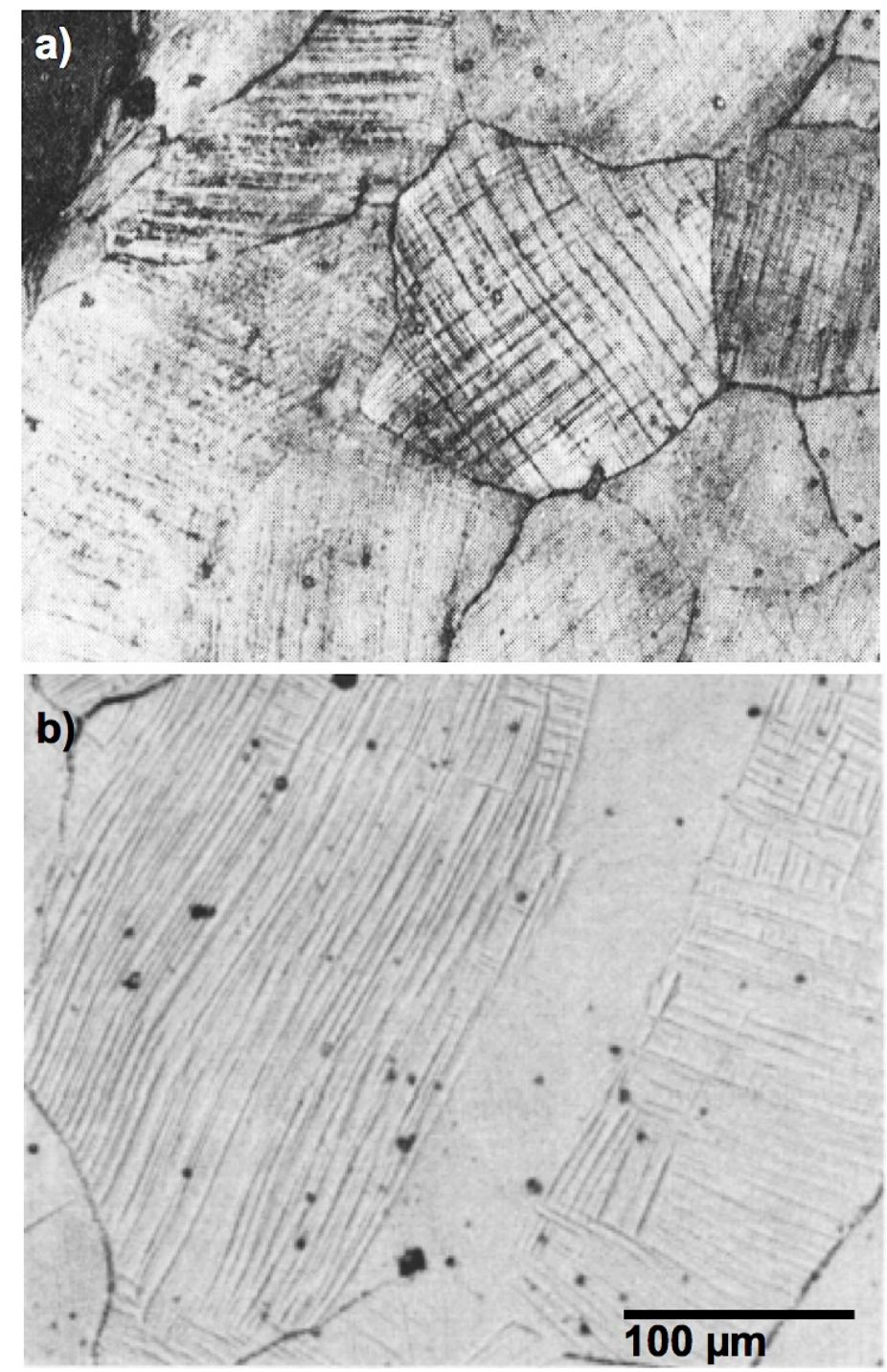

Fonte: a) Vatavuk; Goldenstein, 1987. b) Adler et al.,1986

O aço Hadfield após solidificação apresenta resistência à tração de $400 \mathrm{MPa}$ e alongamento menor que $1 \%$. Esses valores de propriedades são resultado da precipitação de segunda fase em contorno de grão (AVERY, 1949), Figura 2.5a. De acordo com Zavadil e Kuyucak para o aço Hadfield como fundido atingir tenacidade acima de $100 \mathrm{~J}$ deve aplicado um tratamento térmico de solubilização na faixa de 1050 a $1120{ }^{\circ} \mathrm{C}$ atingindo a região acima da linha $A_{c m}$ (ZAVADIL; KUYUCAK, 2002), Figura 2.1c. O tempo de tratamento equivale a $1,5 \mathrm{~h}$ para cada $25 \mathrm{~mm}$ de espessura (Subramanyam et al., 1990). Esse tratamento térmico é aplicado para minimizar ou eliminar as partículas secundárias e/ou segunda fase geradas na estrutura bruta de solidificação. Em seguida aplica-se resfriamento em água agitada para obter uma 
solução sólida supersaturada, ou seja, solutos dissolvidos na matriz, objetivando a ausência de carboneto em contorno de grão (FUOCO et al., 2012; SANTOS et al., 2010; SUBRAMANYAM; SWANSIGER; AVERY, 1990).

A Figura 2.5 mostra os casos extremos para a microestrutura do aço Hadfield. $\mathrm{Na}$ Figura 2.5a o material encontra-se no estado bruto de fundição e tem segunda fase em contorno de grão (carboneto contínuo - CC, perlita - P e carbonetos eutéticos E). E na Figura 2.5b o material tem uma típica microestrutura de aço austenítico manganês com grãos austeníticos sem carbonetos, resultado do tratamento térmico eficiente (SANTOS et al., 2010).

Figura 2.5. Microestrutura do aço Hadfield. a) Bruto de fundição. b) Tratado termicamente

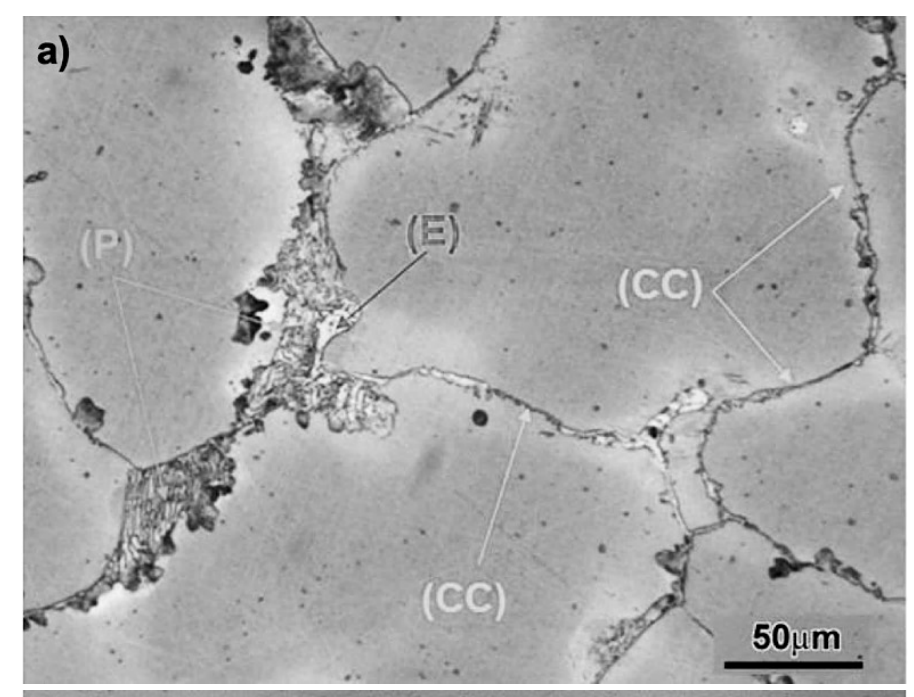

b)

$50 \mu \mathrm{m}$

Fonte: Santos et al., 2010

A Figura 2.6 mostra outra imagem da microestrutura bruta de fundição do aço Hadfield, na qual observam-se carbonetos aciculares e carboneto lamelar no contorno de grão. 
Figura 2.6. Micrografia de aço Hadfield como fundido com carbonetos lamelar e acicular

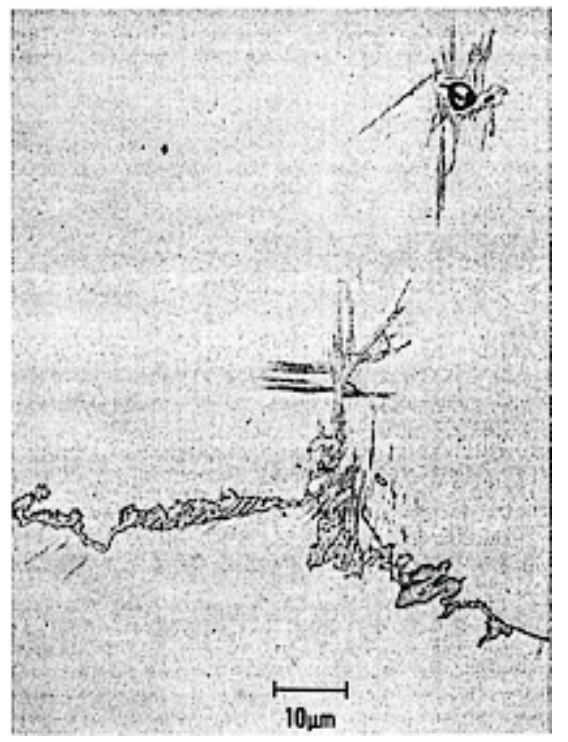

Fonte: Kuyucak; Zavadil; Newcombe, 2001b

A curva temperatura-tempo-transformação (TTT) para o aço Hadfield é importante para a aplicação do tratamento térmico, por mostrar a taxa de resfriamento limite para evitar a reprecipitação de carbonetos em contorno de grão no processo de resfriamento em água, após a solubilização, Figura 2.7.

Figura 2.7. Curvas TTT de precipitação de carbonetos durante resfriamento após solubilização

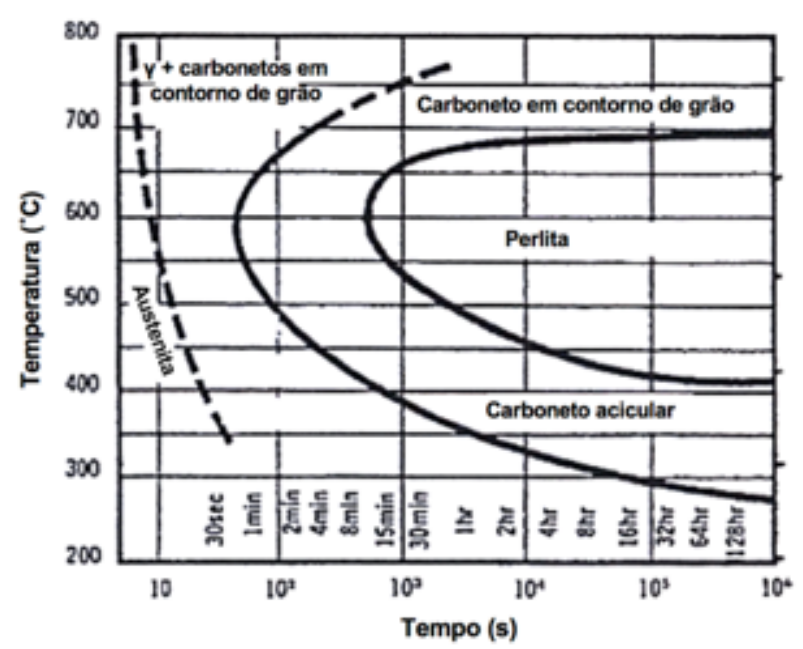

Fonte: Kuyucak et al., 2001

A adição de cromo em aços promove a diminuição da difusividade do carbono, atrasando a transformação perlítica. No entanto, o cromo no aço Hadfield aumenta a estabilidade do carboneto, elevando a sua temperatura de formação. Esse efeito é perceptível na curva de TTT, deslocando a curva para a esquerda diminuindo a 
eficiência do resfriamento após solubilização (KUYUCAK; ZAVADIL; GERTSMAN, 2004).

Segundo Tsujimoto a diminuição do teor de carbono no aço Hadfield minimiza a formação de carboneto contínuo em contorno de grão por deslocar a curva de temperatura-tempo-transformação para a direita, como se observa no gráfico da Figura 2.8 (TSUJIMOTO, 1979).

Figura 2.8. Curva temperatura-tempo-transformação para o aço Hadfield ( $12 \% \mathrm{Mn}-2 \% \mathrm{Mn}$ ) fundido com diferentes teores de carbono

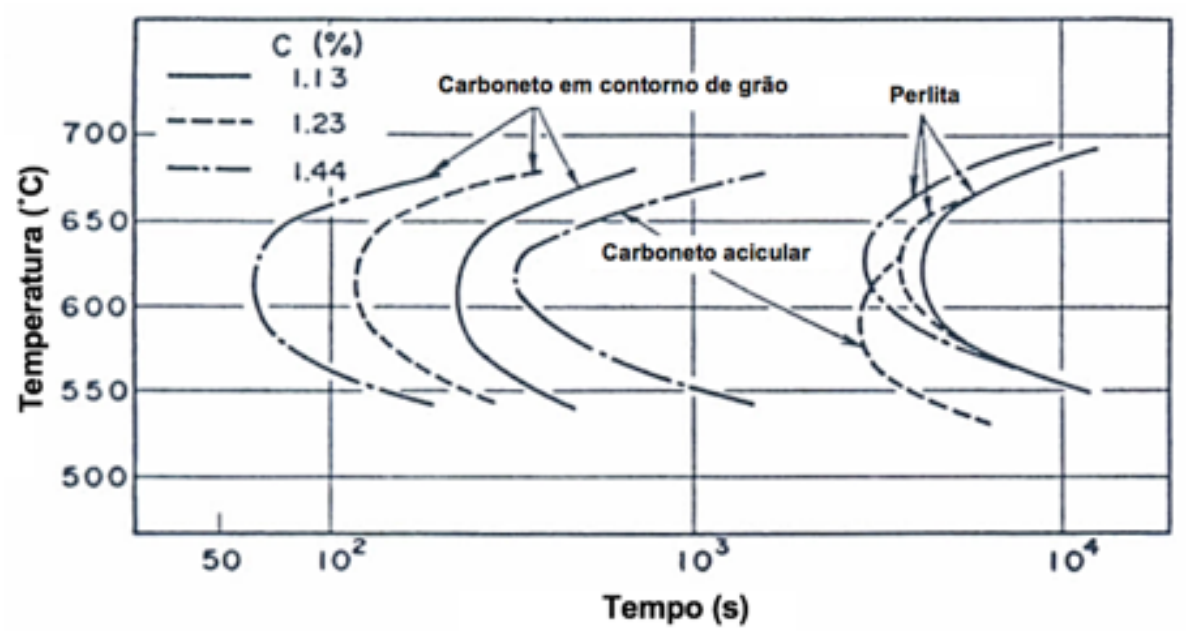

Fonte: Tsujimoto, 1979

A adição de molibdênio no aço Hadfield também desloca a curva TTT para a direita, retardando a precipitação de carboneto em contorno de grão (TSUJIMOTO, 1979) e elevando a energia absorvida no ensaio de impacto Charpy (SANTOS et al., 2010; SUBRAMANYAM; SWANSIGER; AVERY, 1990).

\subsection{MECANISMOS DE DEFORMAÇÃO PLÁSTICA}

A resistência mecânica do material pode ser definida como a resistência à deformação plástica e à propagação de trinca (HORNBOGEN, 1977). A deformação plástica pode ocorrer por:

a) Escorregamento de discordâncias - slip;

b) Dobramento - kinking (HONEYCOMBE, 1975);

c) Maclação - twinning;

d) Transformação de fase por deformação - phase transformation. 
A transformação de fase por deformação ocorre em alguns aços austeníticos, havendo mudança local da estrutura cristalina. A mudança refere-se à transformação da estrutura cubica de face centrada para a tetragonal de corpo centrado. Essa transformação promove o aumento de volume em 1,5\% (ZUM GAHR, 1987). Vatavuk e Goldenstein mencionam que até os anos 60 o endurecimento do aço Hadfield eram associados a transformação de fase formando martensita alpha' (tetragonal de corpo centrado) e épsilon (hexagonal compacto). Nos anos 80 constatou-se que a transformação de fase por deformação plástica ocorria para aços austeníticos ao manganês com concentrações de Mn e C inferiores ao do aço Hadfield padrão (VATAVUK, J.; GOLDENSTEIN, 1986), por exemplo, aço com 0,6 \%C - 8,0 \%Mn (ZUIDEMA; SUBRAMANYAM; LESLIE, 1987) e aço com 1,0 \%C - 7,0 \%Mn (HE et al., 1987). A Figura 2.9 mostra uma ilustração dos mecanismos de deformação.

Figura 2.9. Sistemas de deformação plástica em estruturas cristalinas. a) Escorregamento de discordâncias. b) Dobramento. c) Maclação. d) Transformação de fase

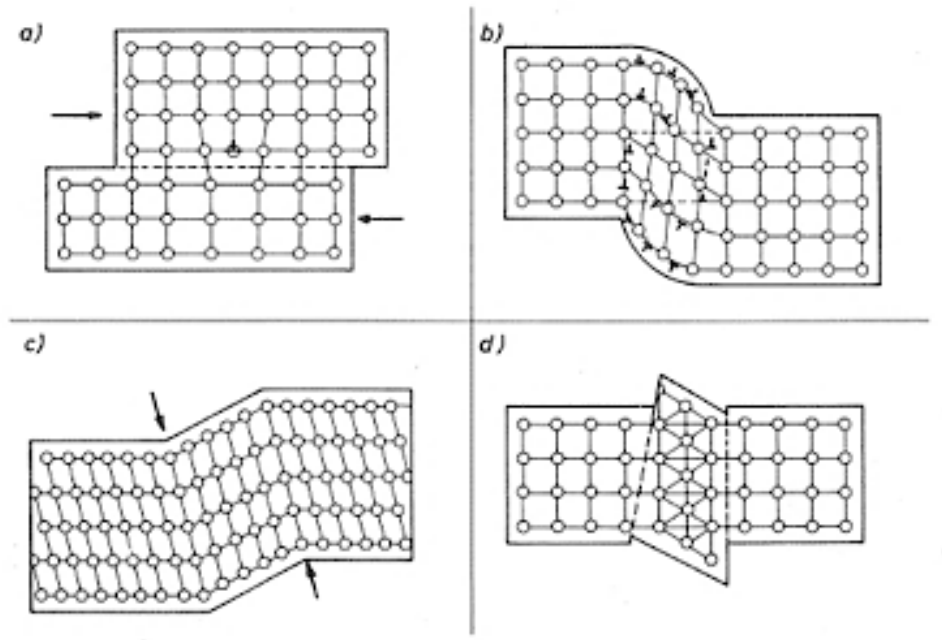

Fonte: Zum Gahr, 1987

A alteração no comportamento plástico do aço manganês austenítico quando fabricado com diferentes concentrações de manganês pode ser associada com a mudança da energia de defeito de empilhamento (EDE). De modo geral, para sistemas cúbicos, o mecanismo de deformação depende da EDE, da taxa e da temperatura de deformação (SANDIM, 2003). A maclação predomina em materiais de estrutura cúbica de face centrada quando a EDE é inferior a $25 \mathrm{~mJ} / \mathrm{m}^{2}$ (HUMPHEREYS; HATHERLY, 1995). 
Estudos realizados por Bracke et al. e Lu et al. mostraram que o valor de EDE de aços austeníticos ao manganês (com $\% C<0,5$ ) conduz a ocorrência de mecanismos de deformação plástica preferenciais (BRACKE; KESTENS; PENNING, 2007; LÜ et al., 2010): Transformação de fase (EDE < $\left.18 \mathrm{~mJ} / \mathrm{m}^{2}\right)$; Maclação $(18<$ EDE $<35 \mathrm{~mJ} / \mathrm{m}^{2}$ ) e Deslizamento (EDE $>35 \mathrm{~mJ} / \mathrm{m}^{2}$ ).

Ishida e Nishiyawa mostram que a $\operatorname{EDE}\left(\mathrm{y}_{\mathrm{I}}\right)$ do aço Hadfield $(1,2 \% \mathrm{C})$ varia em função do teor de manganês. Os autores mostraram ainda que a taxa de maclação é maior para a composição química de menor EDE, Figura 2.10a (ISHIDA; NISHIYAWA, 1974 apud ADLER; OLSON; OWEN, 1986).

Os autores (WHITE; HONEYCOMBE, 1962 apud ADLER; OLSON; OWEN, 1986) mostram o efeito do teor manganês no endurecimento por encruamento do aço Hadfield $(1,15 \% \mathrm{C})$ com $22,9 \%$ de deformação a frio, Figura $2.10 \mathrm{~b}$. Os resultados mostram o valor de máxima dureza em $15 \% \mathrm{Mn}$, o qual é associado ao gráfico da Figura 2.10a ao valor mínimo de EDE. Portanto, os gráficos sugerem que a concentração otimizada de manganês corresponde à menor EDE e, consequentemente, maior taxa de maclação (ADLER; OLSON; OWEN, 1986).

Figura 2.10. a) Aproximação da variação de energia livre (CFC $\rightarrow H C), \Delta G^{\gamma \rightarrow \varepsilon}$ e EDE $\left(\gamma_{1}\right)$ em relação a variação da concentração de $\mathrm{Mn}(1,15 \% \mathrm{C})$. b) Dureza (redução fixa) em relação a variação da concentração de $\mathrm{Mn}(1,2 \% \mathrm{C})$
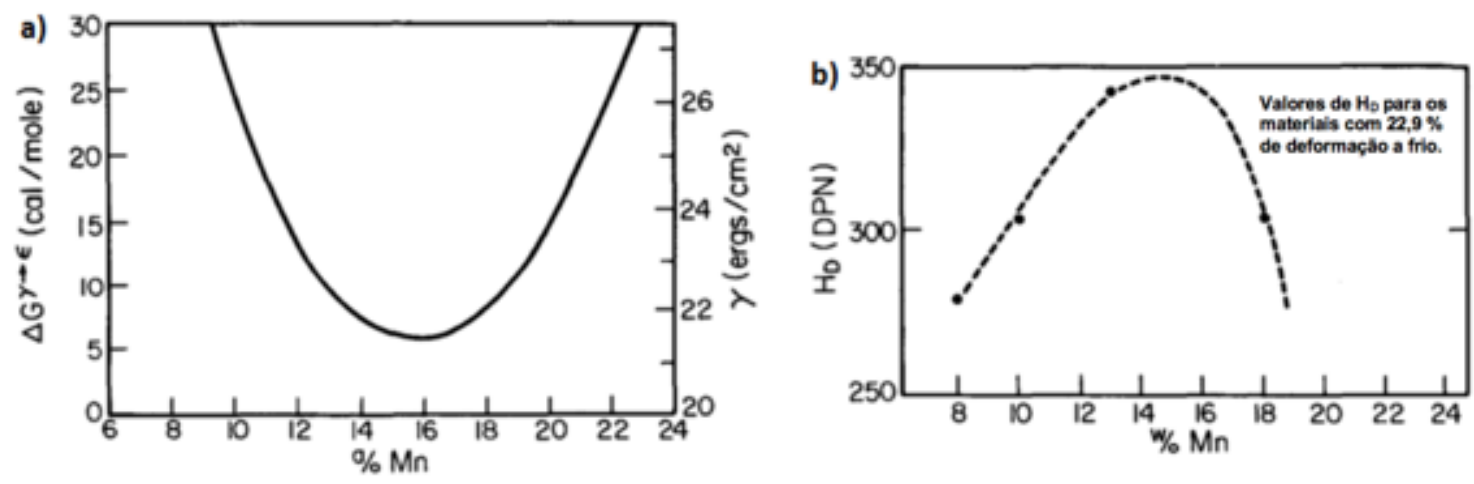

Fonte: Ishida e Nishiyawa, 1974 e White e Honeycombe, 1962. apud Adler et al., 1986

Segundo Bayraktar, Khalid e Levaillant EDE do aço Hadfield correspondente a $50 \mathrm{egrs} / \mathrm{cm}^{2}$ (ou $\mathrm{mJ} / \mathrm{m}^{2}$ ) para o aço Hadfield (BAYRAKTAR; KHALID; LEVAILLANT, 2004). Nesse trabalho os materiais em estudo foram caracterizados via MEV e TEM. Os resultados microestruturais obtidos após ensaios de tração com diferentes taxas de deformação e temperaturas, Figura 2.11, mostram a ocorrência de intensa maclação e nenhuma evidência de transformação de fase. 
Figura 2.11. Grãos austeníticos com deformação de 0,30 evidenciando maclas de deformação. a) MEV. b) TEM
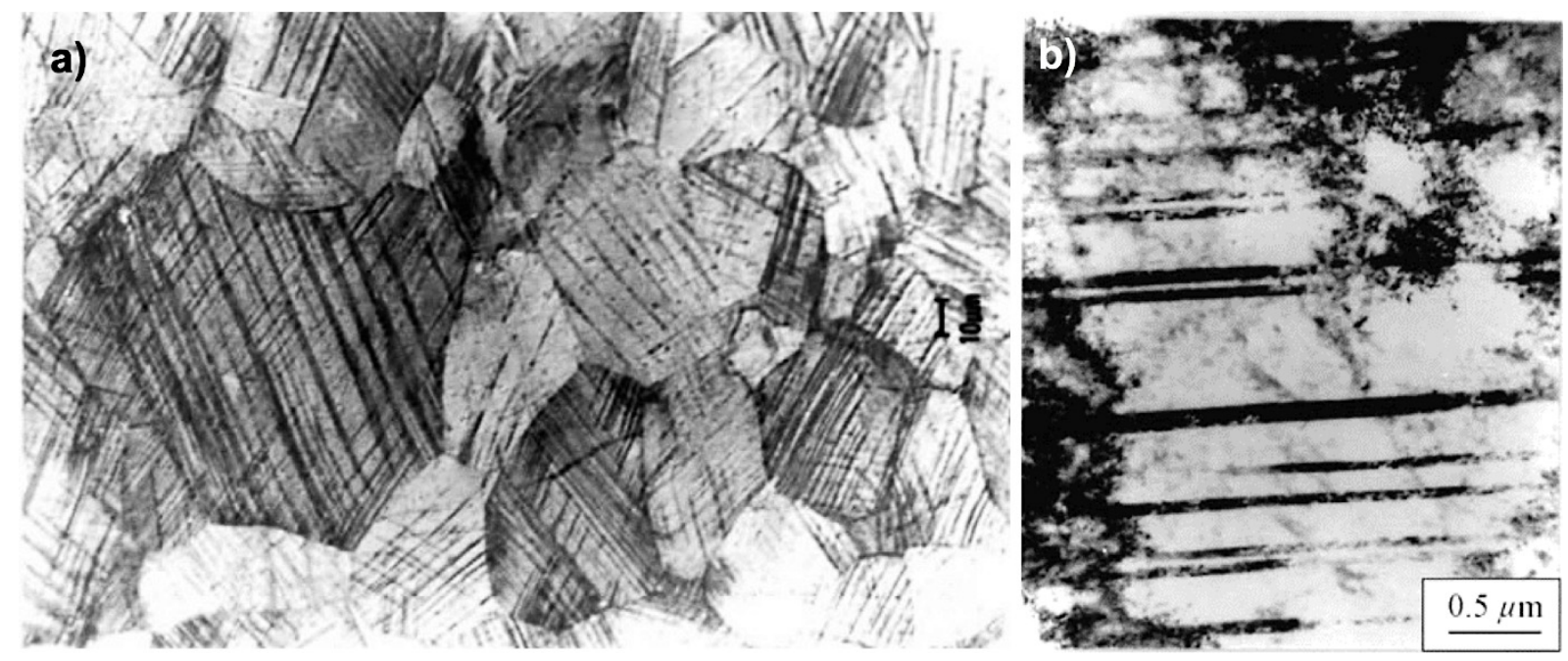

Fonte: Bayraktar et al., 2004

Karaman et al. estudaram esse comportamento sob cargas de tração avaliando insitu a microestrutura do Hadfield monocristalino. O carregamento foi aplicado longitudinal à direção [111], a Figura 2.12 mostra a evolução do mecanismo (KARAMAN et al., 2000a).

Na Figura 2.12a nota-se a ativação do sistema primário de maclação com inclinação de $51^{\circ}$. Ao atingir $25 \%$ de deformação o carregamento é aliviado e o sistema secundário de maclação se evidencia, Figura 2.12b.

Figura 2.12. Imagens de MO mostrando diferentes formações microestruturas em função da deformação sob tração ao longo da direção 111 . a) Sistema primário de maclas a $51^{\circ}$. b) Ativação do sistema primário e secundário de maclação com $25 \%$ de deformação

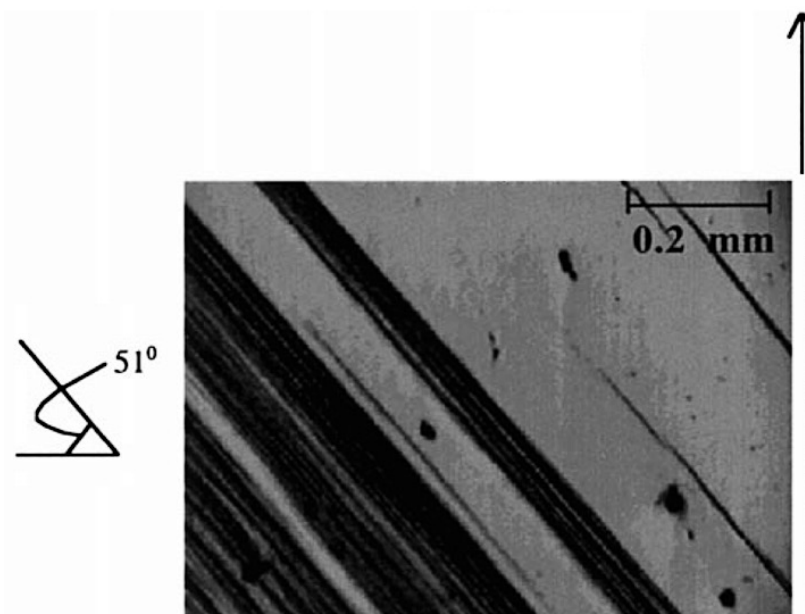

(a)

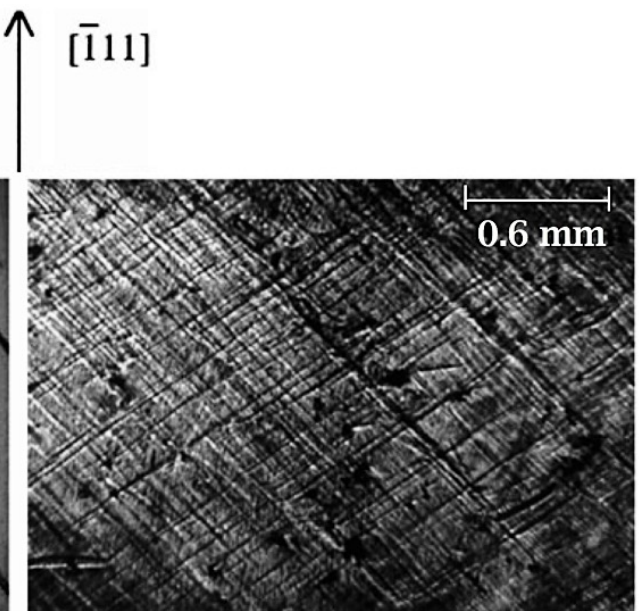

(b)

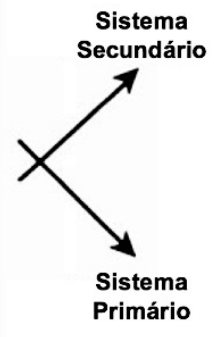

Fonte: Karaman et al., 2010 
A formação de maclas de deformação promove uma função importante, na qual corrobora o aumento da resistência mecânica do aço Hadfield deformado (KARAMAN et al., 2000a). Cooman, Chin e Kim associaram a maclação ao efeito Hall-Petch, considerando que a deformação plástica promove um efeito Hall-Petch dinâmico (dynamical Hall-Petch effect), Figura 2.13 (COOMAN; CHIN; KIM, 2011). Nos aços com características de maclação por deformação plástica (TWIP) tem-se a diminuição da mobilidade das discordâncias dentro do grão devido às novas fronteiras formadas em seu interior (maclas mecânicas ou de deformação). Este mecanismo tem o efeito semelhante a diminuição do tamanho grão.

Figura 2.13. Ilustração do efeito Hall-Petch dinâmico. O mecanismo de maclação forma-se devido à baixa EDE
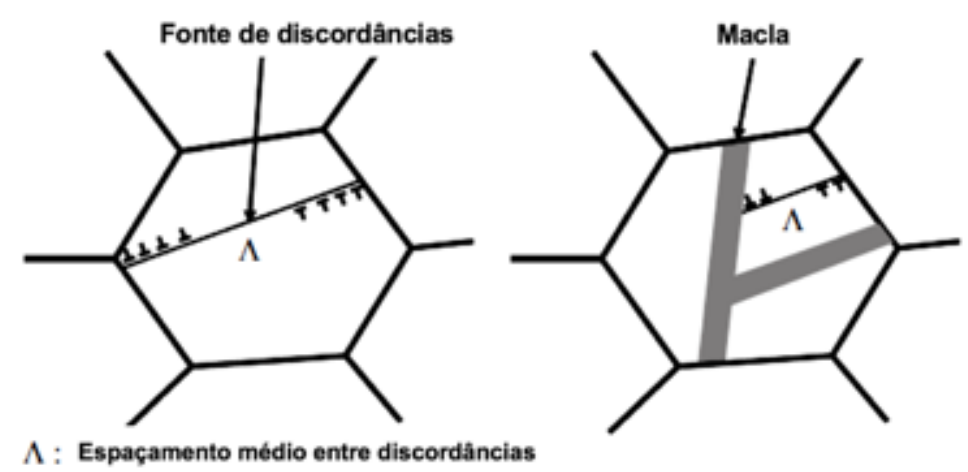

Fonte: Cooman et al., 2011

O endurecimento do aço Hadfield pode ocorrer por diferentes mecanismos, os quais são influenciados pela composição da liga, temperatura de tratamento e taxa de deformação. Diferentes composições químicas modificam a energia de falha de empilhamento e a sensibilidade da taxa de deformação, influenciando o comportamento do endurecimento por encruamento, que ocorre devido à maclação por deformação plástica do aço Hadfield (ADLER; OLSON; OWEN, 1986; COOMAN; CHIN; KIM, 2011; DASTUR; LESLIE, 1981; KARAMAN et al., 2000a).

\subsection{DESGASTE ABRASIVO}

O desgaste abrasivo é causado a partir do carregamento normal e movimentação lateral de partículas ou protuberâncias duras ao longo de uma superfície sólida (ASTM G40, 2014). A Figura 2.14 mostra sistemas em que a abrasão é o modo de desgaste predominante, tais como: rolamento de corpos sólidos, sistemas 
hidráulicos contaminados com partículas, extrusão, fragmentação de rochas (britador de mandíbula), desgaste da matriz em metalurgia do pó e corpo abrasivo movimentando-se contra outro corpo (ZUM GAHR, 1987).

Figura 2.14. Tribossistemas relacionados ao desgaste abrasivo
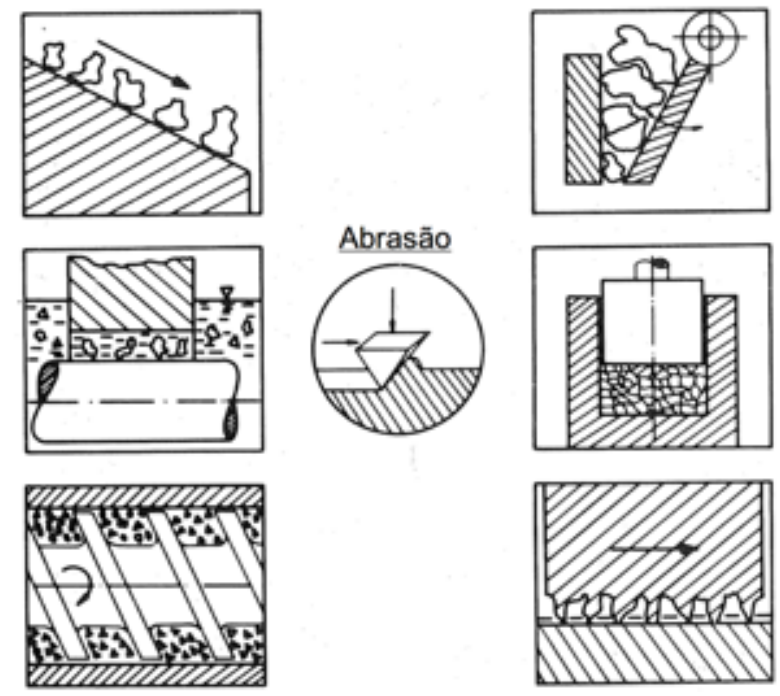

Fonte: Zum Gahr, 1981

Diferentes sistemas físicos podem ser relacionados à abrasão. $E$ as propriedades dos corpos e do meio são consideradas variáveis (partículas abrasivas, ângulo de ataque, etc). Em relação à interação das interfaces com as partículas sólidas tem-se a classificação de abrasão a dois corpos ou escorregamento de partículas fixas e abrasão a três corpos ou rolamento de partículas soltas. Na Figura 2.15a é mostrado o modelo da abrasão a dois corpos, causada por uma protuberância (podendo ser uma partícula sólida encrustada na superfície) do corpo que interage com o contra corpo.

Figura 2.15. Desgaste abrasivo a dois e a três corpos
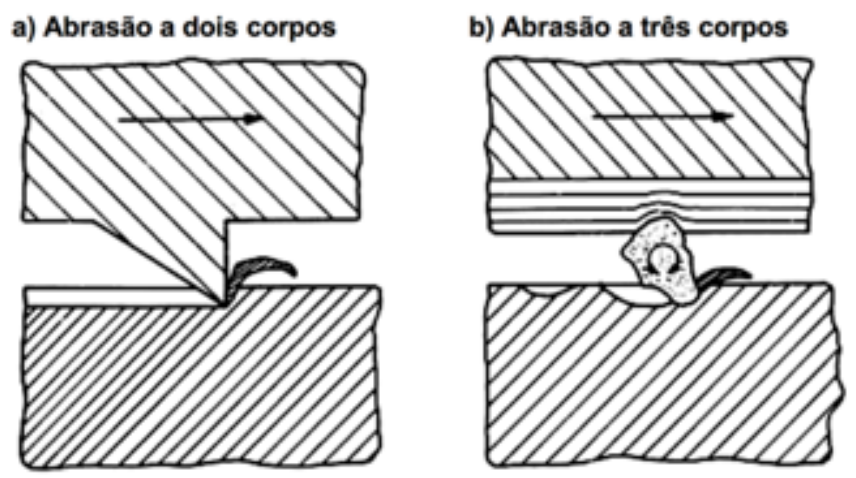

Fonte: Zum Gahr, 1987 
$\mathrm{Na}$ Figura 2.15b tem-se o modelo para a abrasão a três corpos em que as partículas agem como elemento interfacial entre o corpo e o contra corpo. Hutchings descreve estes modos de abrasão como deslizamento e rolamento da partícula abrasiva, respectivamente, (HUTCHINGS, 1992).

De acordo com Wahl, Wellinger, Uetz, Föhl apud Zum Gahr o desgaste abrasivo pode ocorrer em dois tipos de regimes: moderado ou severo, os quais são dependentes da razão entre a dureza do abrasivo e a dureza da superfície a sofrer desgaste $\mathrm{H}_{a} / \mathrm{H}$, dureza relativa, (UETZ; FOHL, 1969; WAHL, 1951; WELLINGER; UETZ, 1955; ZUM GAHR, 1987).

Khruschov apresentou um gráfico relacionando a perda de volume por abrasão com a razão de dureza (KHRUSCHOV, 1974). Zum Gahr fez um gráfico semelhante, Figura 2.16, mostrando a tendência do desgaste abrasivo em função da razão de dureza para materiais homogêneos e heterogêneos (Zum Gahr, 1987). O valor de $\mathrm{H}_{a} / \mathrm{H}$ influencia o regime do sistema que pode ser moderado, transição ou severo. $E$ dependendo do tipo do material variáveis do sistema a transição de desgaste pode ocorrer com valores diferentes de dureza relativa.

Figura 2.16. Desgaste abrasivo em função da razão entre a dureza de partículas abrasivas e a dureza de material desgastado

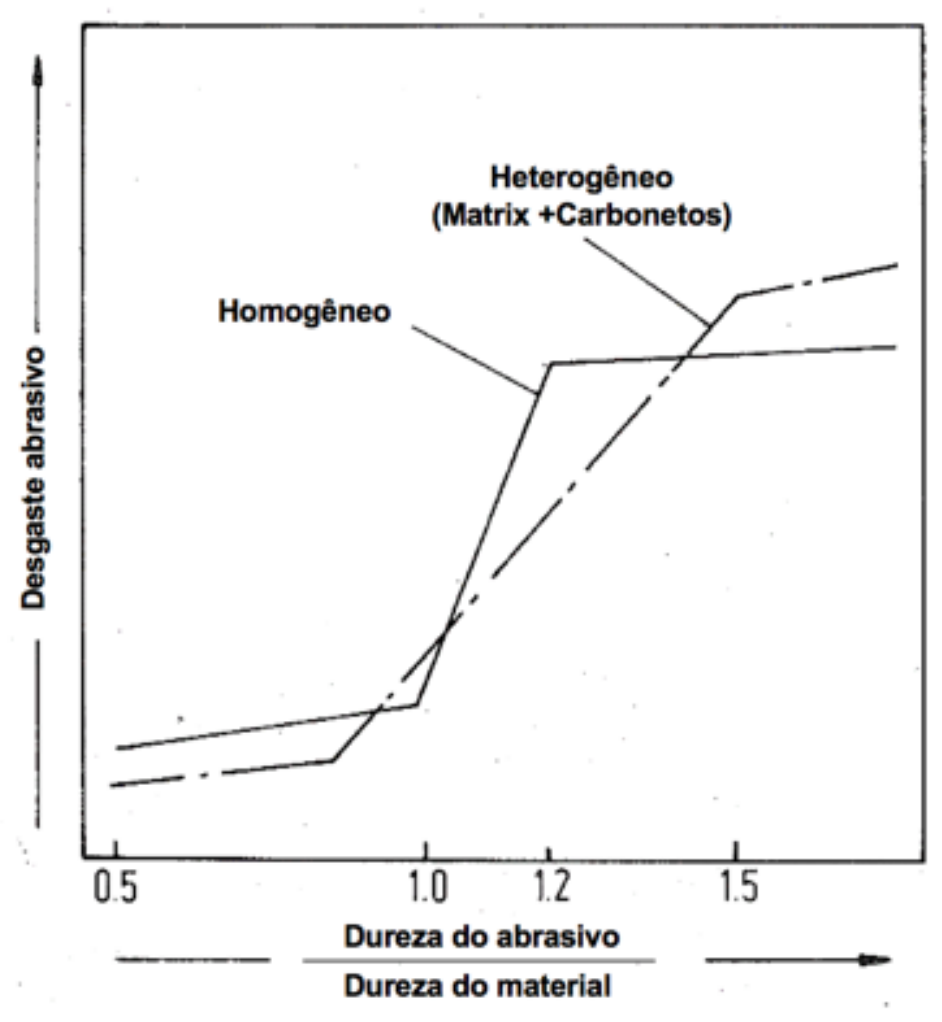

Fonte: Zum Gahr, 1987 
Para os materiais homogêneos a transição do regime ocorre quando a dureza do abrasivo se iguala à dureza do material desgastado. E para os não homogêneos a transição de regime inicia e termina quando as durezas da matriz e dos carbonetos (ou das fases mais duras) são respectivamente excedidas pela dureza do abrasivo. Richardson (RICHARDSON, 1968) refere-se aos abrasivos como macios e duros, sendo macios quando sua dureza é igual ou inferior à dureza da superfície desgastada e duro quando sua dureza é superior à da dureza da superfície desgastada. No entanto, Zum Gahr definiu que o abrasivo será duro se possuir dureza $50 \%$ superior à da superfície (inicial) e $20 \%$ superior ao valor da dureza da superfície desgastada (deformada) (Zum Gahr, 1987).

$\mathrm{O}$ modo de desgaste é associado ao mecanismo de desgaste. $\mathrm{Na}$ abrasão os mecanismos são divididos em três tipos: microsulcamento, microcorte e microtrincamento, Figura 2.17.

Figura 2.17. Micromecanismos de desgaste entre partícula abrasiva e superfície do material

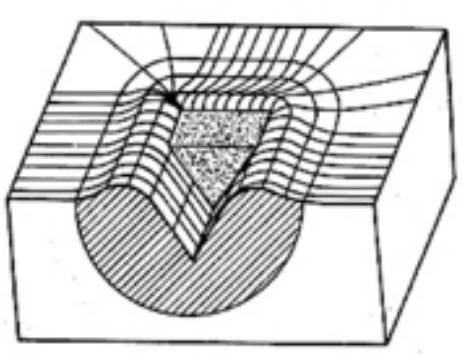

Microsulcamento

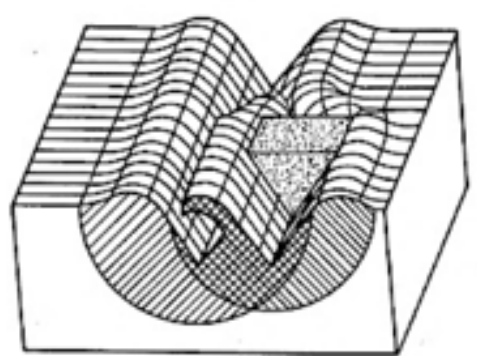

Microfadiga

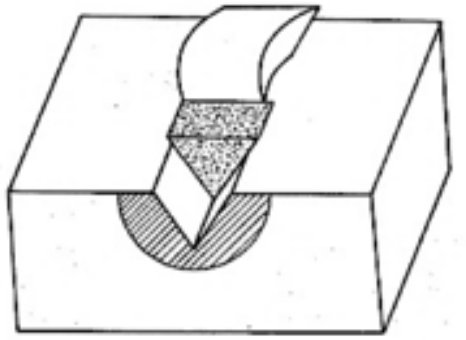

Microcorte

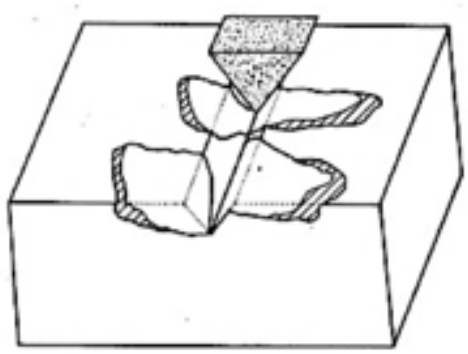

Microtrinca

Fonte: Zum Gahr, 1987

A seguir tem-se o conceito de cada micromecanismo (ZUM GAHR, 1987):

- Microsulcamento: caracterizado pelo deslocamento de material para frente e lateral da partícula abrasiva, resultando em formação de um sulco que está associado a deformação plástica do material. No entanto, com multieventos abrasivos pode ocorre a formação do micromecanismo de microfadiga, com remoção de material; 
- Microcorte: ocorre a remoção de material em forma de partículas de desgaste (debris) e cavacos podendo haver deslocamento lateral de material. Mecanismo similar ao processo de usinagem;

- Microtrinca: remoção de material por processo de corte com fratura subsuperficial causada pela interação da partícula abrasiva com materiais de características frágeis, resultando em remoção adicional por spalling.

A Figura 2.18 mostra os três micromecanismos de desgaste abrasivo (microsulcamento, microcorte e microtrinca) na superfície de um aço desgastado por ação abrasiva de partículas sólidas.

Figura 2.18. Micrografias (MEV) da interação de abrasivos minerais com superfícies de aços: (a) microsulcamento, (b) microcorte e (c) microtrinca

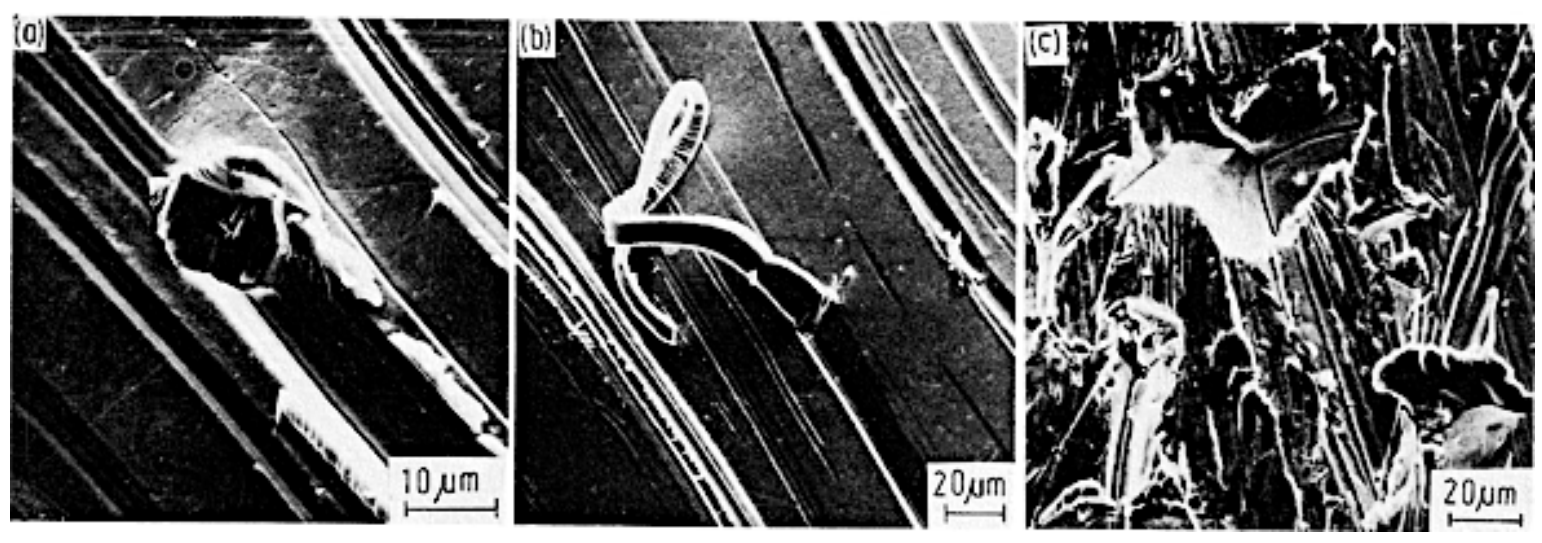

Fonte: Zum Gahr, 1987

A transição de micromecanismos (microsulcamento - microcorte) pode ser associada com o ângulo entre a face da partícula sólida e a superfície. O ângulo de ataque é uma variável importante nesse contexto, pois ao atingir um valor crítico, teoricamente, tem-se uma transição abrupta de micromecanismos de desgaste (microsulcamento para microcorte). Entretanto, na prática existe uma transição gradual entre os micromecanismos, como observa-se no gráfico da Figura 2.19 (ZUM GAHR, 1987). Esse gráfico mostra que os mecanismos são distribuídos proporcionalmente dependendo do ângulo de ataque, sempre havendo uma fração de microsulcamento e microcorte, com exceção dos extremos. 
Figura 2.19. Razão do microcorte e do microsulcamento em função da razão do ângulo de ataque e o ângulo de ataque crítico

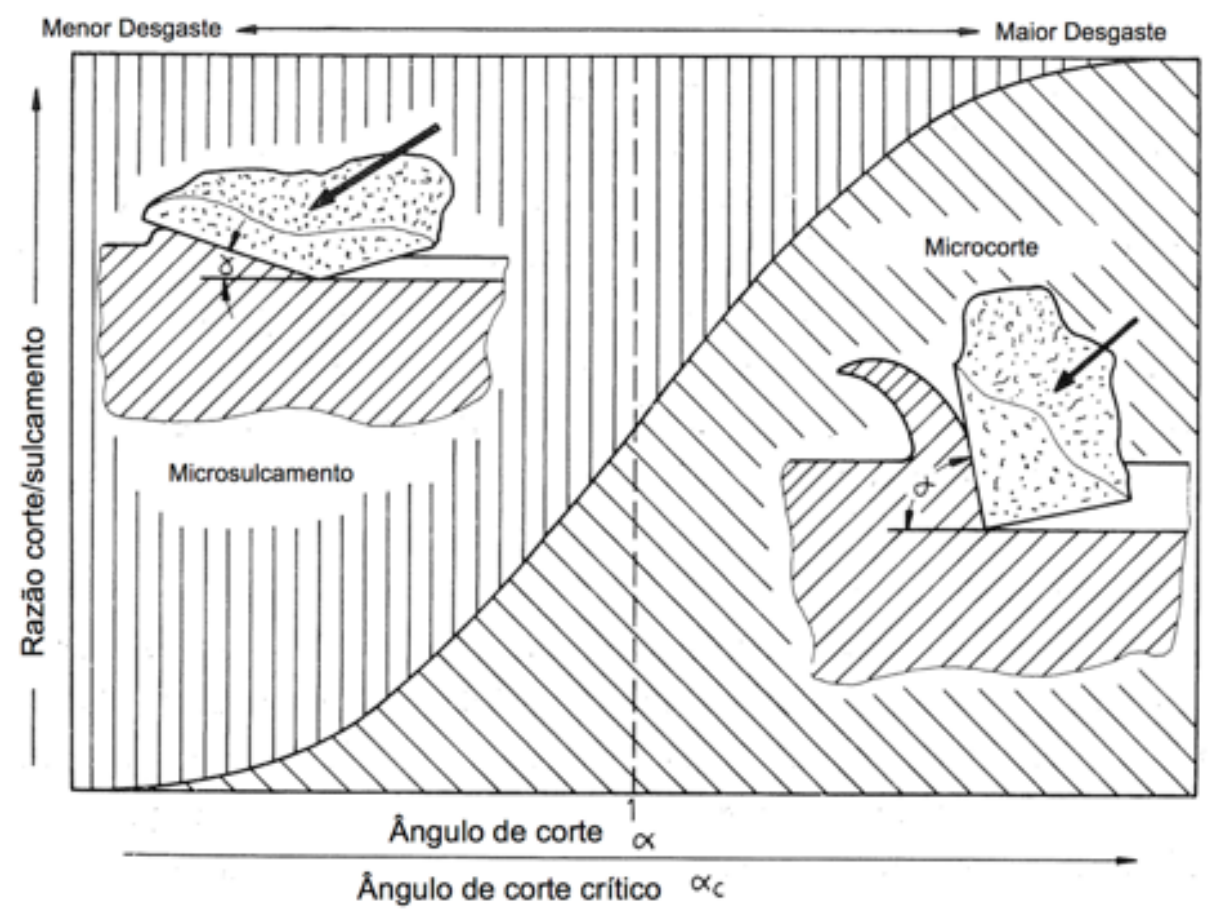

Fonte: Zum Gahr, 1987

\subsubsection{Efeito do encruamento}

Khruschov apresentou resultados em 1957 do efeito da dureza volumétrica (antes da deformação por abrasão) na resistência à abrasão de alguns metais (Khruschov, 1957). Zum Gahr sintetizou em forma esquemática o efeito da dureza, variação de carbono (para aços) e da deformação a frio na resistência à abrasão de materiais metálicos, cerâmicos e polímeros, Figura 2.20. Os resultados indicaram que o aumento da dureza de metais por deformação a frio não promoveu variação significativa de resistência à abrasão. Nota-se também que os aços com maior concentração de carbono têm resistência à abrasão superior aos aços com menores concentrações de carbono (ZUM GAHR, 1987). 
Figura 2.20. Resistência à abrasão em função da dureza para vários tipos de materiais submetidos a testes de abrasão de alta tensão

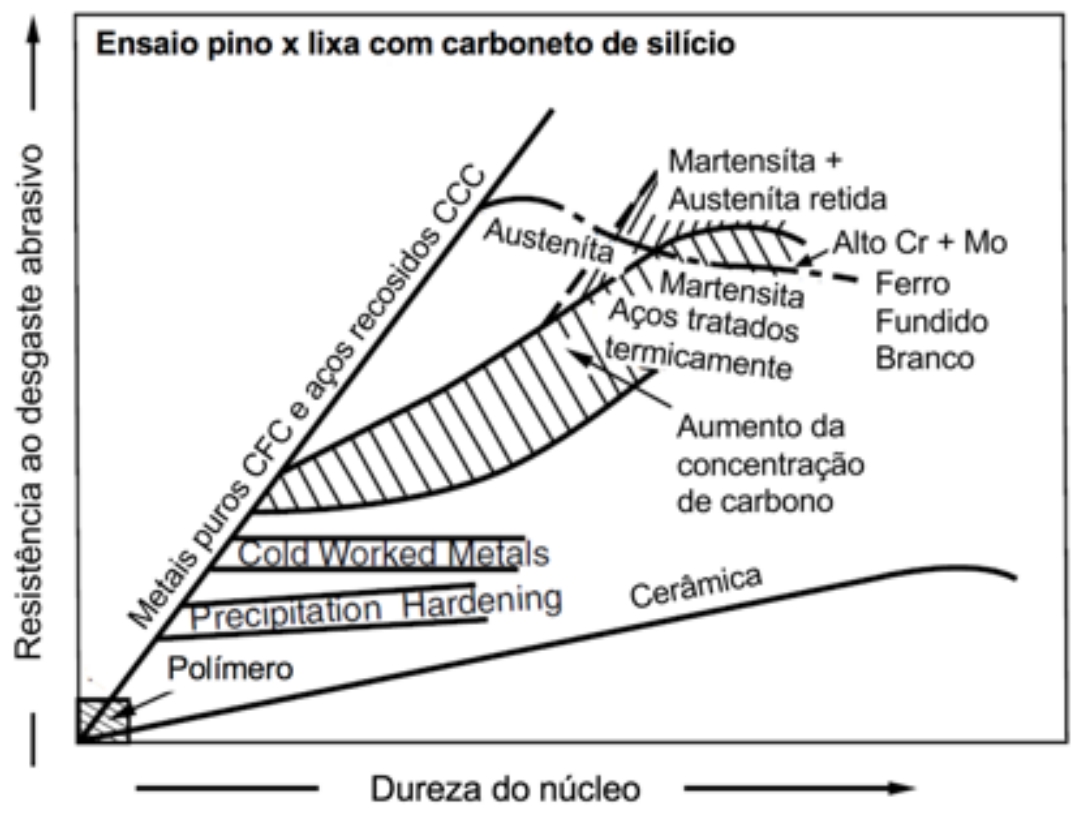

Fonte: Zum Gahr, 1987

Challen, Oxley e Doyle demonstram a partir de análise matemática e experimental que o endurecimento prévio aplicado em dois metais (aço ferramenta endurecido por precipitação e latão endurecido por encruamento) promove a diminuição do ângulo de ataque crítico (CHALLEN; OXLEY; DOYLE, 1983). Esse comportamento é mostrado para o aço ferramenta na Figura 2.21.

Figura 2.21. Diminuição do ângulo crítico para o aço ferramenta - ensaio de esclerometria linear.

a) Revenido a $400^{\circ} \mathrm{C}$ por 30 min (518 HV30). b) Revenido a $300{ }^{\circ} \mathrm{C}$ por 30 min (637 HV30).

c) Como recebido (854 HV30)
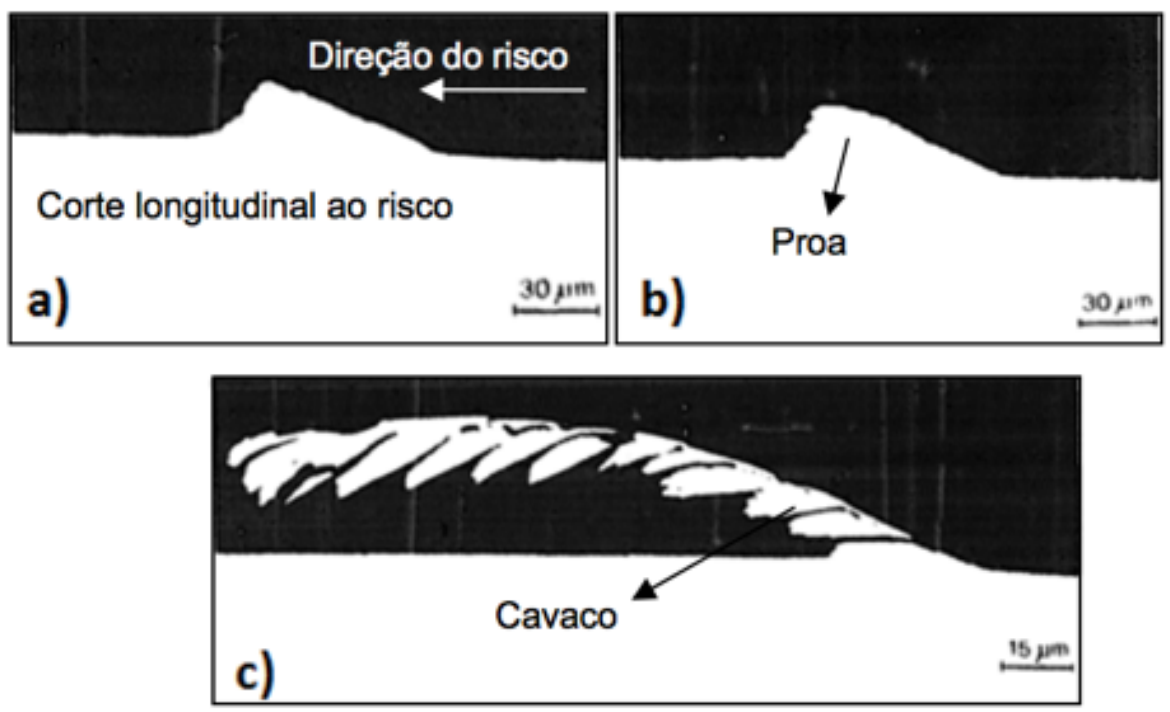

Fonte: Challen; Oxley; Doyle, 1983 
O gráfico da Figura 2.22 mostra que o material encruamento antes do ensaio apresenta um aumento pequeno (esclerometria linear) ou nulo (pino $x$ lixa) na resistência à abrasão. Nota-se também um resultado contraditório nos resultados de esclerometria, o ligeiro aumento na resistência à abrasão é acompanhado pelo aumento da razão entre microcorte e microsulcamento $\left(f_{a b}\right)$. $O$ autor associa esse comportamento à redução de capacidade plástica do material (Zum Gahr, 1987). O aumento do $f_{a b}$ em função do aumento da dureza é justificado com os resultados de Challen, Oxley e Doyle citado no parágrafo anterior.

Figura 2.22. Resistência ao desgaste abrasivo em esclerometria linear e pino x lixa do aço X5 Ni-Cr-Ti deformado

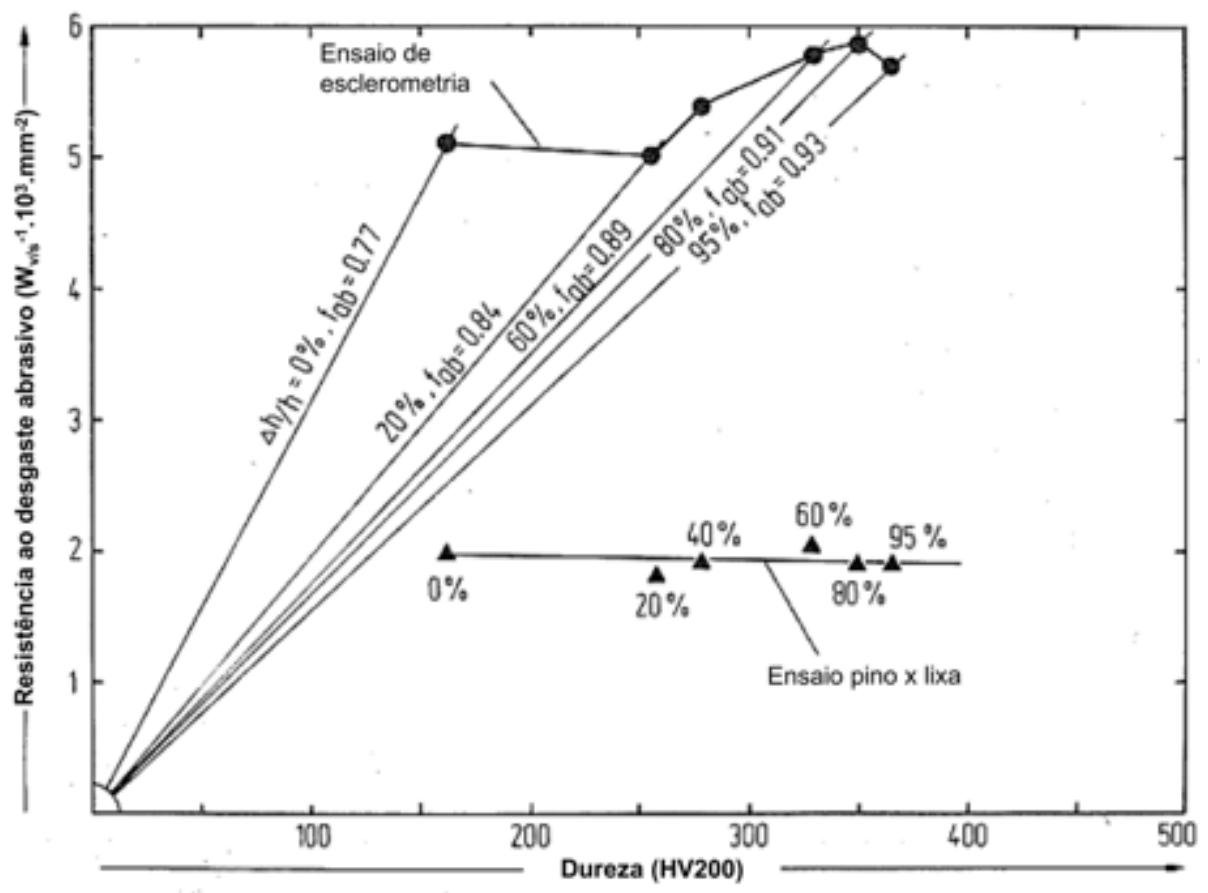

Fonte: Zum Gahr, 1987

A formação de uma camada encruada na superfície de materiais aplicados para resistir desgaste tem sua importância por minimizar a penetração do abrasivo. No entanto, o encruamento promove a variação de ângulo crítico para ocorrência de microcorte (CHALLEN; OXLEY; DOYLE, 1983), ou seja, por mais que o material mais encruado tenha maior valor de dureza e, consequentemente, resista mais à penetração de um abrasivo, menor é o seu ângulo crítico para prover o microcorte, micromecanismo de maior severidade que o microsulcamento. Os resultados de Zum Gahr, Figura 2.20 e Figura 2.22, mostraram que não há variação da resistência ao desgaste abrasivo, em uma condição de multieventos (pino x lixa), para materiais 
encruados. Entretanto, o mesmo autor mostrou que para um evento abrasivo (esclerometria linear) o aumento da dureza promove aumento da resistência ao desgaste apesar do aumento do valor de $f_{a b}$, Figura 2.22 (ZUM GAHR, 1987).

\subsubsection{Desgaste por riscamento}

Os materiais utilizados como revestimento em equipamentos de mineração sofrem desgaste por erosão e/ou abrasão, nas condições de alta e baixa tensão. Segundo Zum Gahr a resistência à abrasão tem relação a uma série de fatores relacionadas ao sistema tribológico, como a natureza do sistema (carga aplicada, tipo de movimento, a temperatura e o meio), condição de operação (área de contato, condições da superfície do componente e regime de lubrificação), tipo de abrasivo (dureza, geometria, tamanho e ductilidade) e material (composição da liga, microestrutura, endurecimento superficial e revestimento) (ZUM GAHR, 1987).

O modelo de desgaste de Rabinowicz e Mutis mostra que o desgaste $Q\left(\mathrm{~mm}^{3} / \mathrm{mm}\right)$ depende do coeficiente de desgaste $K$, força normal $\left(F_{n}\right)$ e $H$ da dureza do material, Equação (2.1), (RABINOWICZ, E.; MUTIS, 1965).

$Q=K \cdot F_{n} /_{H}$

No modelo da Figura 2.23 tem-se a interação de uma partícula sólida, representada por uma ponta cônica, com uma superfície. As forças atuantes (normal e tangencial) promovem a endentação e o deslocamento da partícula. Como resultado tem-se a profundidade $(h)$ e o comprimento $(L)$. O risco formado representa o desgaste que pode ser associado a perda de massa ou variação geométrica do corpo. 
Figura 2.23. a) Modelo de desgaste abrasivo. b) Risco em aço Hadfield com endentador cônico de ponta esférica
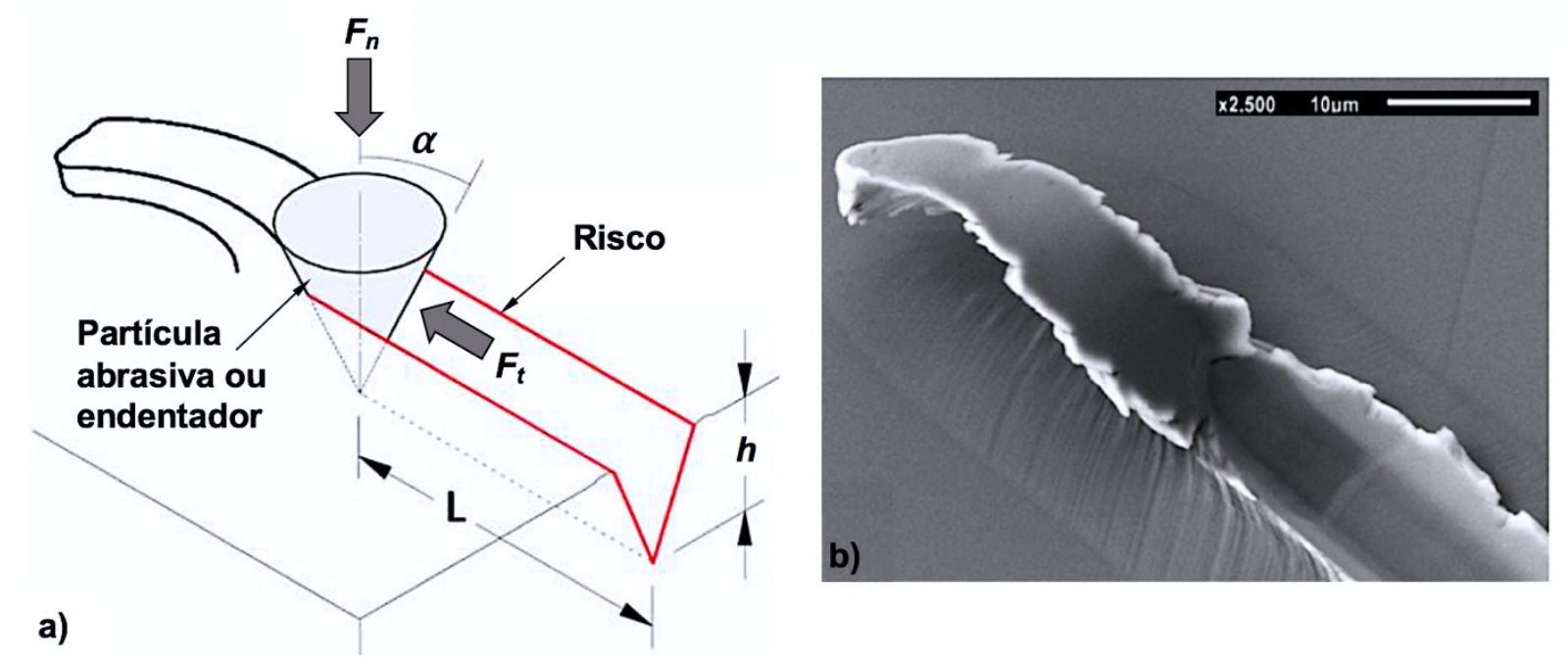

Fonte: a) Adaptado de Rabinowicz et al., 1961, Kato e Adachi, 2001 e Penagos, 2016

Stroud e Wilman observaram que na abrasão de metais dúcteis apenas uma fração do volume do sulco é convertido em debris e o restante é deformado plasticamente para as bordas (STROUD; WILMAN, 1962). Buttery e Archard apresentaram o método para cálculo de fração de material removido - $f_{a b}$ que objetiva quantificar a remoção de material (BUTTERY, T.C.; ARCHARD, 1970), conforme a Equação (2.2).

$f_{a b}=1-\frac{A_{\text {pile-up }}}{A_{\text {hole }}}$

Onde $\circ A_{\text {pile-up }}$ é a área transversal correspondente ao material deslocado que permaneceu no corpo e o $A_{\text {hole }}$ refere-se a área de material deslocado. A Figura 2.24 mostra o perfil transversal do risco evidenciando as áreas de interesse.

Figura 2.24. Perfil transversal de um risco em aço Hadfield indicando a formação de pile-up e do hole

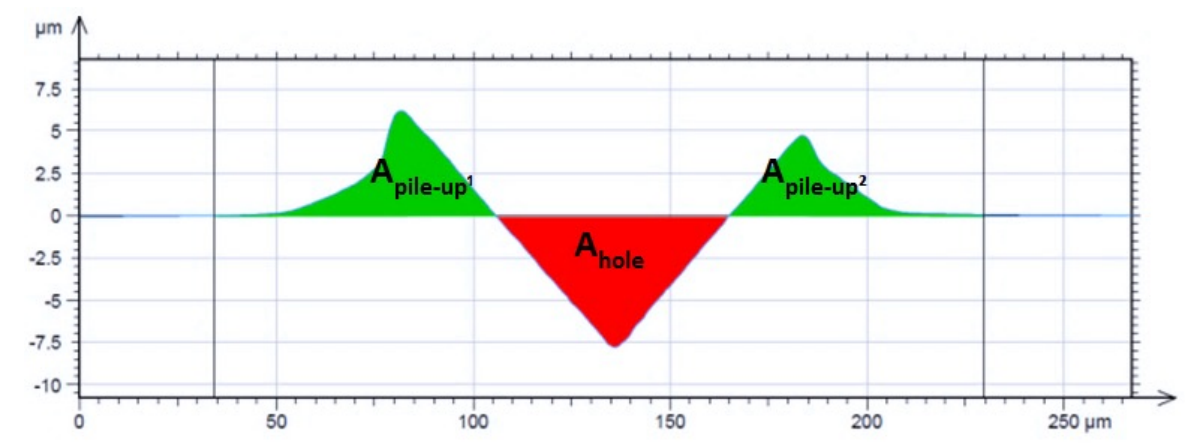


A resistência ao desgaste abrasivo $\left(W_{v / s}^{-1}\right)$ em condições conhecidas é descrita por Zum Gahr como o inverso da perda volumétrica em função do comprimento do risco, de acordo com a Equação (2.3).

$W_{V / S}^{-1}=\frac{1}{f_{a b} \cdot A_{\text {hole }}}$

Como parâmetro de severidade do desgaste de um determinado tribossistema podese encontrar o coeficiente de desgaste $\left(k_{a b}\right)$, o qual depende das variáveis: forma de abrasivo, distribuição granulométrica, tipo, propriedade do material em desgaste, modo de interação da partícula com a superfície, etc. Segundo Rabinowicz os valores de coeficiente de desgaste podem atingir $10^{-2}$ a $10^{-3}$ em desgaste abrasivo por escorregamento de partículas e valores na ordem de $10^{-5}$ para abrasão por rolamento de partículas (RABINOWICZ, 1984). Zum Gahr descreve o coeficiente de desgaste de acordo com a Equação (2.4) (ZUM GAHR, 1987). O $k_{a b}$ equivale ao coeficiente de desgaste $(K)$ indicado na Equação (2.1), sendo obtido a partir das Equações (2.2) e (2.3).

$k_{a b}=f_{a b} \cdot \frac{A_{h o l e} \cdot H}{F_{n}}$

Onde: $H=$ dureza $(\mathrm{MPa})$ e $F_{n}=$ força normal $(\mathrm{N})$.

\subsubsection{Efeito do micromecanismos de desgaste no coeficiente de atrito}

Hokkirigawa et al. mostraram que o coeficiente de atrito depende do micromecanismo de desgaste (HOKKIRIGAWA; KATO, 1988; HOKKIRIGAWA; KATO; LI, 1988). Os autores fizeram diagramas de mecanismos de desgaste, os quais correlacionam o ângulo de ataque e o grau de penetração $\left(D_{p}=h / a\right.$, onde: $h=$ profundidade de penetração e $a=$ raio do endentador projetado em relação à superfície) com a dureza (esclerometria com endentador de diamante) ou a resistência ao cisalhamento da interface - $f$ (esclerometria com endentador de aço), Figuras 2.25a e 2.25b, respectivamente. 
Figura 2.25. Diagramas de micromecanismos de desgaste (a) em função da dureza $(H)$ e (b) em função da resistência cisalhante superficial $(f)$
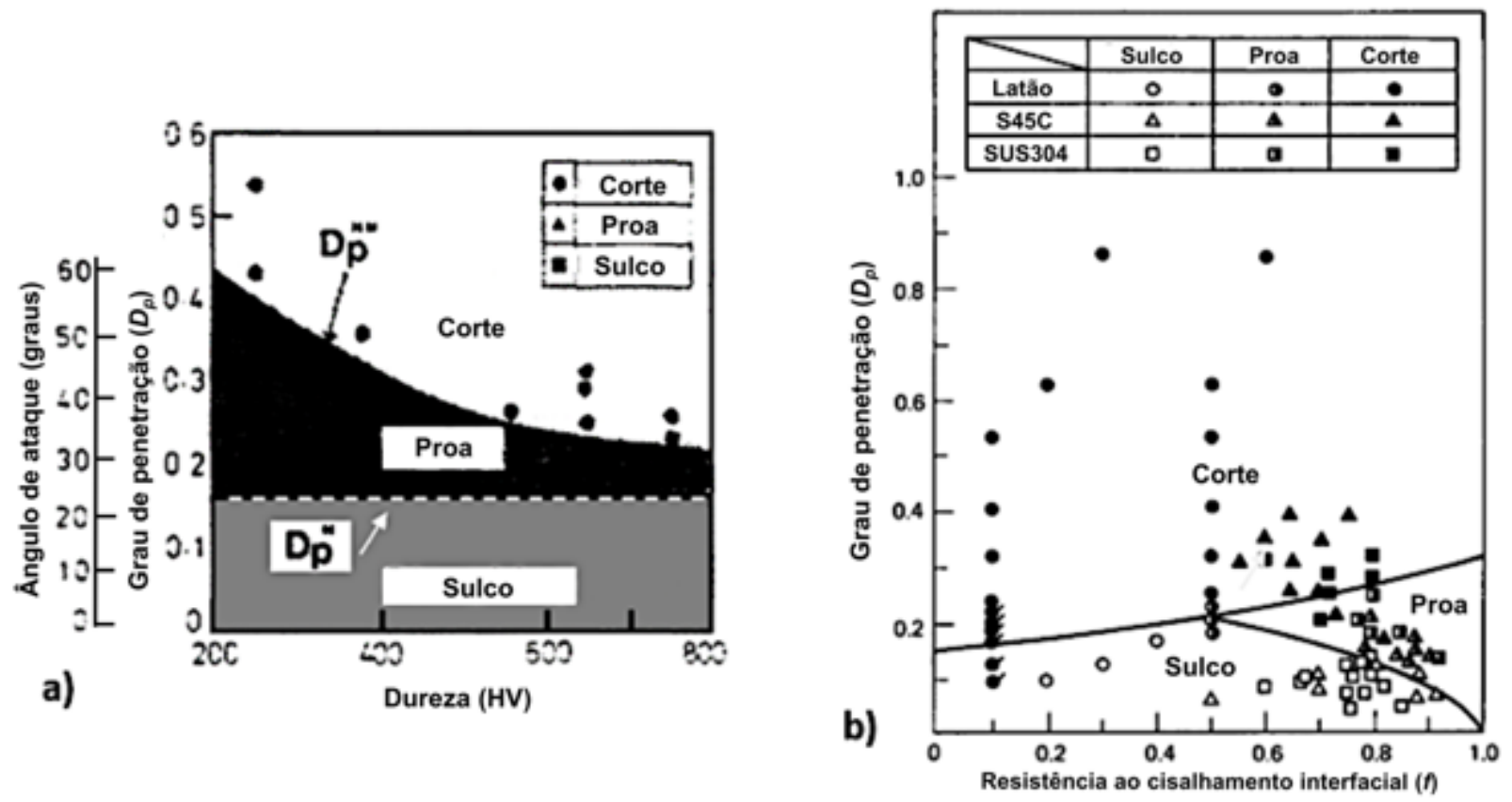

Fonte: Hokkirigawa et al., 1988

Os resultados de Hokkirigawa et al., Figura 2.25a, mostram que o aumento da dureza do material provoca a diminuição do ângulo de ataque crítico e do grau de penetração associado à transição de micromecanismos (HOKKIRIGAWA; KATO; LI, 1988). A Figura $2.25 b$ mostra que a transição de micromecanismo ocorrem com menor grau de penetração para menores valores de tensão de cisalhamento interfacial ( $f$ ). Esses resultados confirmam os estudos realizados por Challen et al., os quais destacam a diminuição do ângulo de ataque crítico em função do encruamento de material metálico (CHALLEN; OXLEY; DOYLE, 1983).

Ao correlacionar a tendência de transição de micromecanismo apresentado nas Figuras 2.25a e $2.25 b$ tem-se que o aumento da dureza ou a diminuição da resistência cisalhante da interface provocam a diminuição do grau de penetração ou do ângulo de ataque crítico. Essas considerações indicam que para as condições com menor $f$ ou maior dureza do corpo a transição de micromecanismo de desgaste é associada a menores ângulos de ataque (crítico). Ou seja, aumento da severidade do desgaste (regime de desgaste).

Outra consideração importante feita por Challen et al. refere-se à resistência ao cisalhamento da interface (CHALLEN; OXLEY; DOYLE, 1983). Os autores consideram essa variável igual a zero para endentador de diamante (material rígido). 
Essa informação esclarece a forma com que foi apresentado o diagrama de micromecanismos de desgaste da Figura 2.25a, sem a variável $f$, pois os experimentos foram realizados com endetador de diamante (HOKKIRIGAWA; KATO; $\mathrm{LI}, 1988)$. Os experimentos referentes ao mapa de micromecanismo da Figura 2.25b foram realizados com endentador de aço temperado (HOKKIRIGAWA; KATO, 1988). A alteração do regime de desgaste pode ser associada à variação do micromecanismo atuante, conforme estudos de Hokkirigawa et al. (HOKKIRIGAWA; KATO; LI, 1988), Figura 2.26. Os autores mostraram que o micromecanismo de formação de proa (wedge) tem maior coeficiente de atrito que o microsulcamento e microcorte. Franco mostrou uma transição de micromecanismo de desgaste para o ferro fundindo cinzento via ensaio de esclerometria. $O$ autor observou a transição de microsulcamento para microcorte sem formação de proa (FRANCO, 2015).

Figura 2.26. Correlação do coeficiente de atrito e grau de penetração para esclerometria com endentador de pino de aço e disco de aço temperado

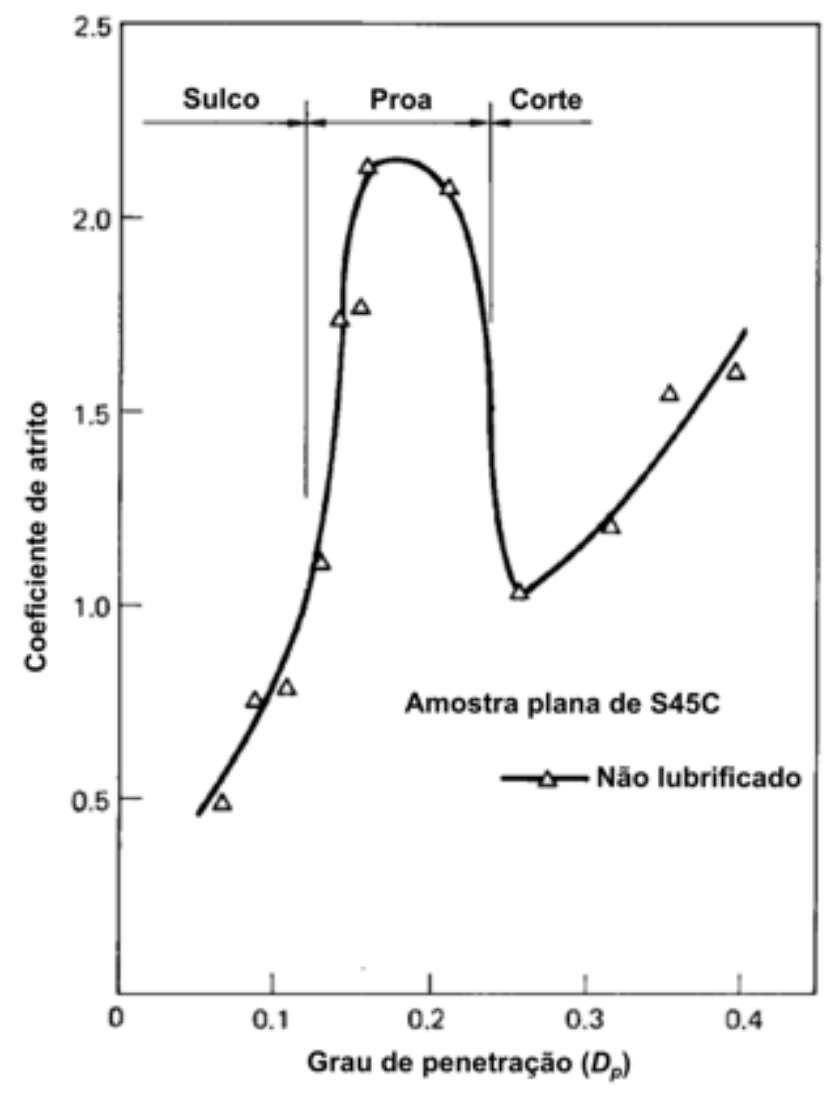

Fonte: Hokkirigawa et al., 1988 


\subsection{A ABRASÃO E O AÇO HADFIELD}

O aço Hadfield apresenta uma instabilidade mecânica. Quando submetido a solicitações mecânicas e/ou térmicas, eventuais deformações plásticas produzem transformações de fase ou maclação, das quais resultam mudanças microestruturais, com a alteração de algumas propriedades físicas do metal aumentando a resistência ao desgaste (ZUM GAHR, 1987).

O uso na indústria mineradora dos aços Hadfield e austeníticos alto manganês é justificado por sua boa resistência ao desgaste abrasivo sob altas tensões (com fratura do abrasivo - gouging abrasion - (AVERY, 1974; GATES, 1998)) presentes nos equipamentos de cominuição primária de minério. Esses materiais apresentam alto nível de tenacidade após tratamento térmico de solubilização, com resfriamento rápido em água, os quais diminuem ou eliminam a presença de carbonetos no contorno de grão. A segunda fase presente no contorno de grão é responsável pela diminuição da tenacidade em função da preferência para a formação e propagação de trinca intergranular (SANTOS et al., 2010).

Rotondaro em 1989 estudou o efeito da variação do tipo de abrasivo (granito, hematita e calcário) no desgaste do aço Hadfield e ferro fundido branco via ensaio de britador de mandíbulas. O desgaste do aço Hadfield foi maior com o granito, intermediário para a hematita e menor para o calcário, assim, havendo maior desgaste para a condição de ensaio com maior dureza do abrasivo (ROTONDARO, 1989).

Haakonsen estudou o aço Hadfield com adição de teores de vanádio e de agentes refinadores a base de cério com alumínio, visando o refinamento de grão, e aplicou tratamentos térmicos com o objetivo de desenvolver um aço com melhor resistência ao desgaste que o aço Hadfield. No entanto, os resultados não apresentaram diferença significativa em relação à resistência ao desgaste abrasivo do aço Hadfield (HAAKONSEN, 2009).

Testes de esclerometria linear de aços Hadfield com concentrações de 6 e 12 \% com diferentes acabamentos superficiais (polimento eletrolítico - PE e por polimento abrasivo - PA) mostraram diferentes comportamentos para os aços, Figura 2.27. As superfícies polidas de ambos os aços apresentaram 180 HV10 e a largura dos riscos foi menor para amostra de aço com $6 \% \mathrm{Mn}$ com acabamento PA. Bauschke, Hornbongen e Zum Gahr mostraram relação destes resultados com o endurecimento 
por transformação de fase (BAUSCHKE; HORNBONGEN; ZUM GAHR, 1981 apud ZUM GAHR, 1987), Figura 2.28.

Figura 2.27. Imagens das superfícies dos aços Hadfield (6-12\%Mn) submetidas ao ensaio de desgaste por risco (esclerometria linear) causado pelo deslizamento de um diamante na superfície nas amostras: (a), (c) Fe - 6 \% Mn (6,3\%Mn, 0,91 \%C, 1,03\%Mo) e (b), (d) $\mathrm{Fe}-12 \% \mathrm{Mn}(11,9 \% \mathrm{Mn}$, $1,44 \% \mathrm{C}, 0,49 \% \mathrm{Mo})$. Superfícies tratadas antes do ensaio por polimento eletrolítico (a) e (b), e por polimento abrasivo (c) e (d)

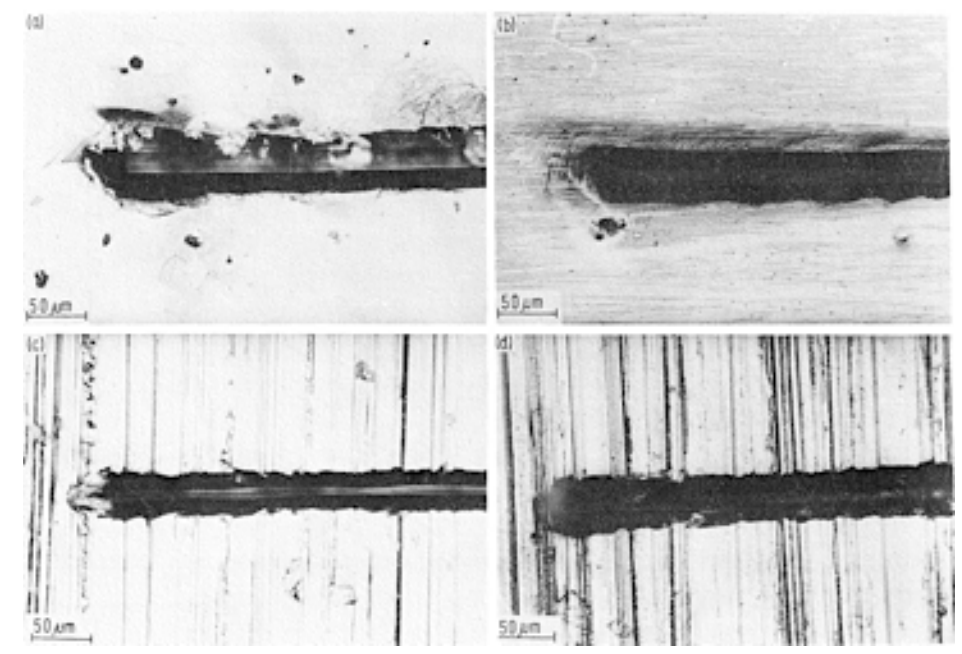

Fonte: Bauschke; Hornbongen; Zum Gahr, 1981

A Figura 2.28 mostra o difratograma dos aços Hadfield (6 e $12 \% \mathrm{Mn}$ ) com acabamento de polimento eletrolítico e polimento abrasivo. Os autores observaram que o material com $6 \% \mathrm{Mn}$, submetido ao polimento abrasivo, apresentou $92 \% \mathrm{em}$ volume de fase martensítica decorrente de transformação de fase por deformação.

Figura 2.28. Difratogramas de aços austeníticos (6 e $12 \% \mathrm{Mn}$ ) com polimento eletrolítico e polimento abrasivo
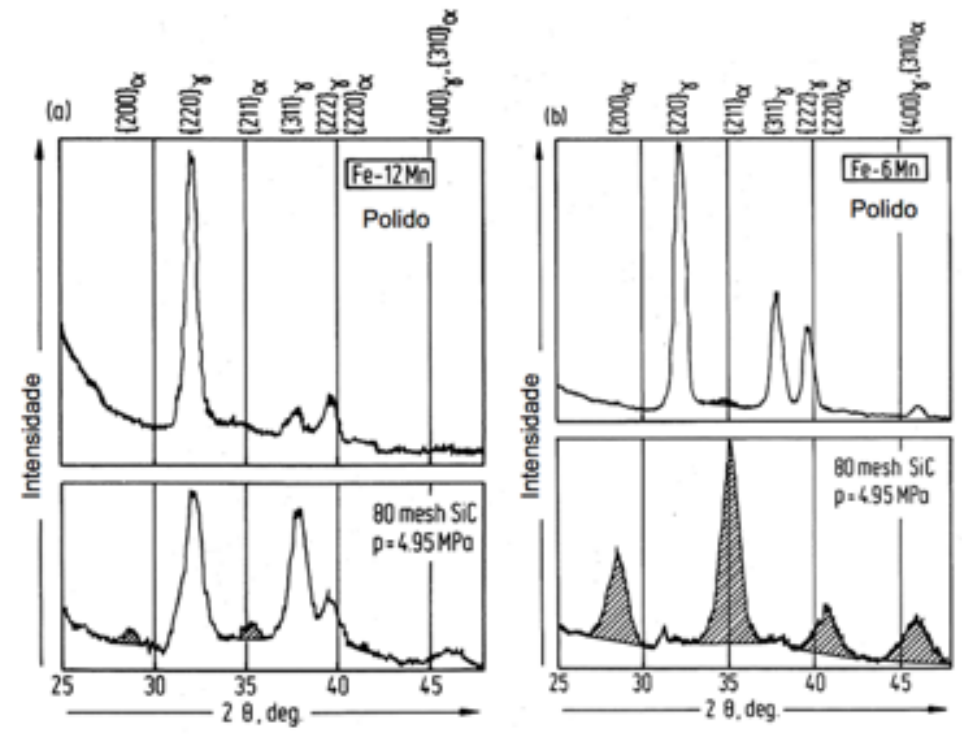

Fonte: Bauschke et al., 1981 apud Zum Gahr, 1987 
Lindroos et al. avaliaram a resistência à abrasão via esclerometria circular do aço Hadfield com $16 \%$ Mn previamente deformado com diferentes taxas de deformação $\left(10^{-3}\right.$ a $\left.4.10^{3} \mathrm{~s}^{-1}\right)$. Os autores concluíram que as altas taxas de desgaste não estão necessariamente associadas à maior resistência à abrasão, pois o aquecimento adiabático afeta a dureza do material. Além disso, os autores observaram que os grãos do aço deformados tiveram diferentes intensidades de maclação mecânica, as quais provocam diferentes resultados de coeficiente de atrito.

Outro resultado importante sobre a resistência à abrasão do aço Hadfield é associada ao aumento do teor de carbono. Sinatora e Albertin observaram, a partir dos resultados de Diesburg e Borik, que a perda de massa relativa em ensaio de britador de mandíbula atingiu $30 \%$ de redução com o aumento do teor de carbono (DIESBURG, D. E.; BORIK, F., 1974; SINATORA A.; ALBERTIN E., 2015). A resistência ao desgaste aumenta $10 \%$ para cada $0,1 \%$ de carbono dissolvido na matriz do aço Hadfield, Figura 2.29.

Figura 2.29. Relação entre perda de massa relativa e concentração de carbono do aço Hadfield. Ensaio de mandíbula

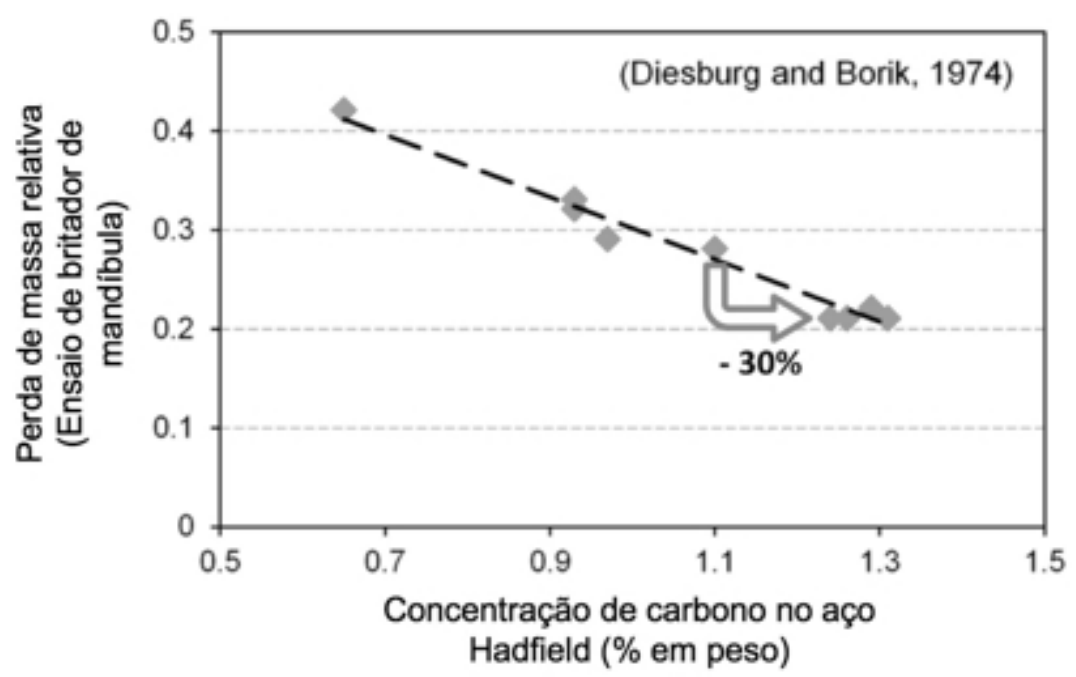

Fonte: Sinatora; Albertin, 2015

Kuyucak, Zavadil e Newcombe apresentaram resultados de resistência ao impacto em função do percentual de carboneto contínuo em contorno de grão para três classes do aço Hadfield com boa correlação, Figura 2.30 (KUYUCAK; ZAVADIL; NEWCOMBE. P., 2001a; ZAVADIL; KUYUCAK, 2002). E destacam que a energia absorvida em ensaio de impacto Charpy com entalhe diminui com uma taxa de 3,5 J a cada percentual de carboneto contínuo em contorno de grão. Os autores 
apresentam a seguinte relação entre observação metalográfica e resistência ao impacto: baixa tenacidade (< $20 \mathrm{~J}$ ) para mais de $50 \%$ de contorno de grão com carboneto e excelente tenacidade (> $100 \mathrm{~J}$ ) para menos de $20 \%$ de contorno de grão com carboneto.

Figura 2.30. Efeito do percentual de carboneto contínuo em contorno de grão na resistência ao impacto

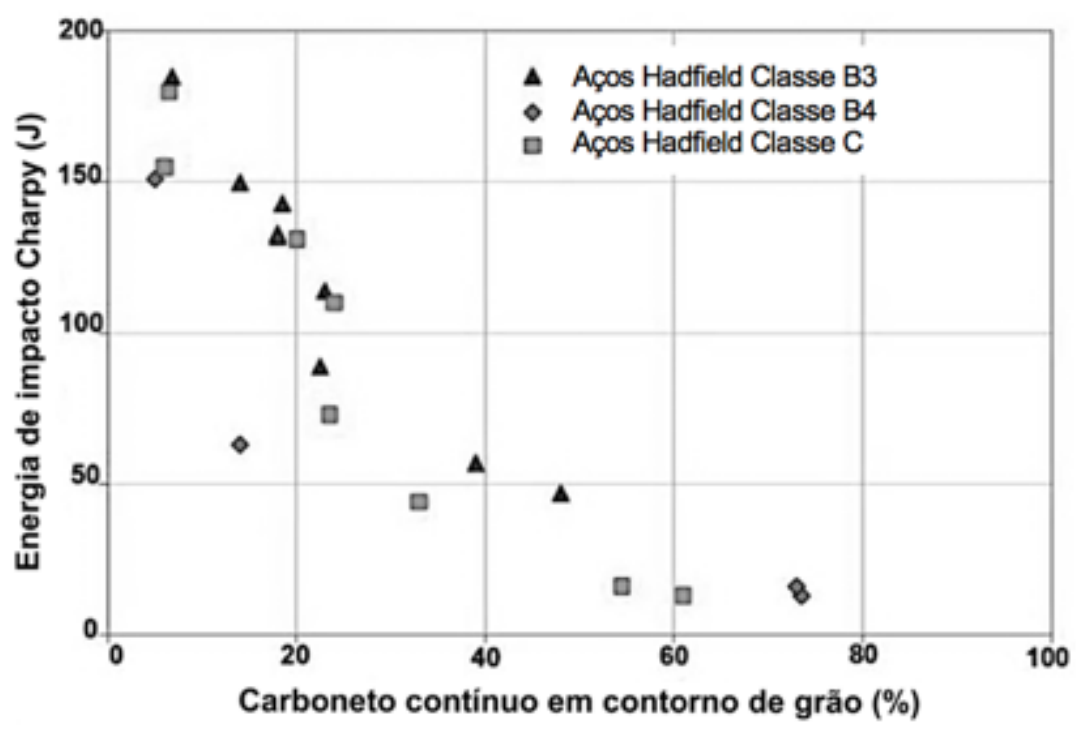

Fonte: Kuyucak, 2004

De acordo com Fuoco et al. a capacidade de absorção de energia por impacto (ensaio Charpy) de aços Hadfield é avaliada para evitar falhas catastróficas em operação (FUOCO et al., 2012; SANTOS et al., 2010).

Santos et al. realizaram tratamento isotérmico com diferentes temperaturas em aços Hadfield com o objetivo de simular as microestruturas de reprecipitação e avaliar a resistência ao impacto Charpy (SANTOS et al., 2010). Os autores observaram que a falha produzida no ensaio de impacto Charpy evidenciam carbonetos contínuos no contorno de grão com morfologia dendrítica, Figura 2.31. 
Figura 2.31. Morfologia dendrítica de carbonetos reprecipitados em contorno de grão de aço Hadfield evidenciados após ensaio Charpy. $E=10 \mathrm{~J}$. MEV-SE. a) 2.500X. b) 10.000X

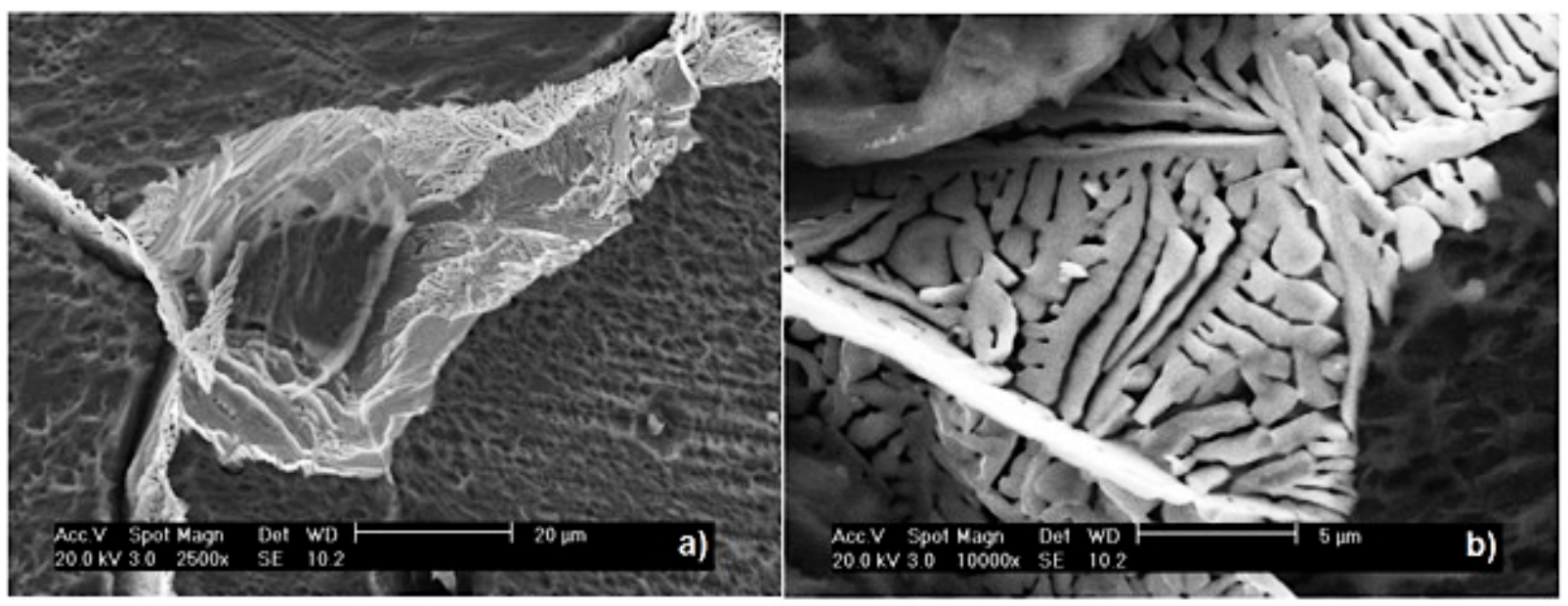

Fonte: Santos et al., 2010

A Figura 2.32 mostra fratura transgranular para o aço Hadfield sem carbonetos em contorno de grão e fratura intergranular para o aço Hadfield com carboneto contínuo reprecipitado. Os autores mostram que as amostras submetidas ao tratamento isotérmico a $750{ }^{\circ} \mathrm{C}$ por 1 minuto tiveram energia de absorção no ensaio de impacto Charpy equivalente a $204 \mathrm{~J}$, enquanto que as amostras submetidas a mesma temperatura por 20 minutos o valor de energia foi igual a $10 \mathrm{~J}$.

Figura 2.32. Microestrutura das fraturas de amostras tratadas em isoterma de $750{ }^{\circ} \mathrm{C}$. a) Transversal -1 minuto. b) Topografia - 1 minuto. c) Transversal - 20 minutos. d) Topografia - 20 minutos
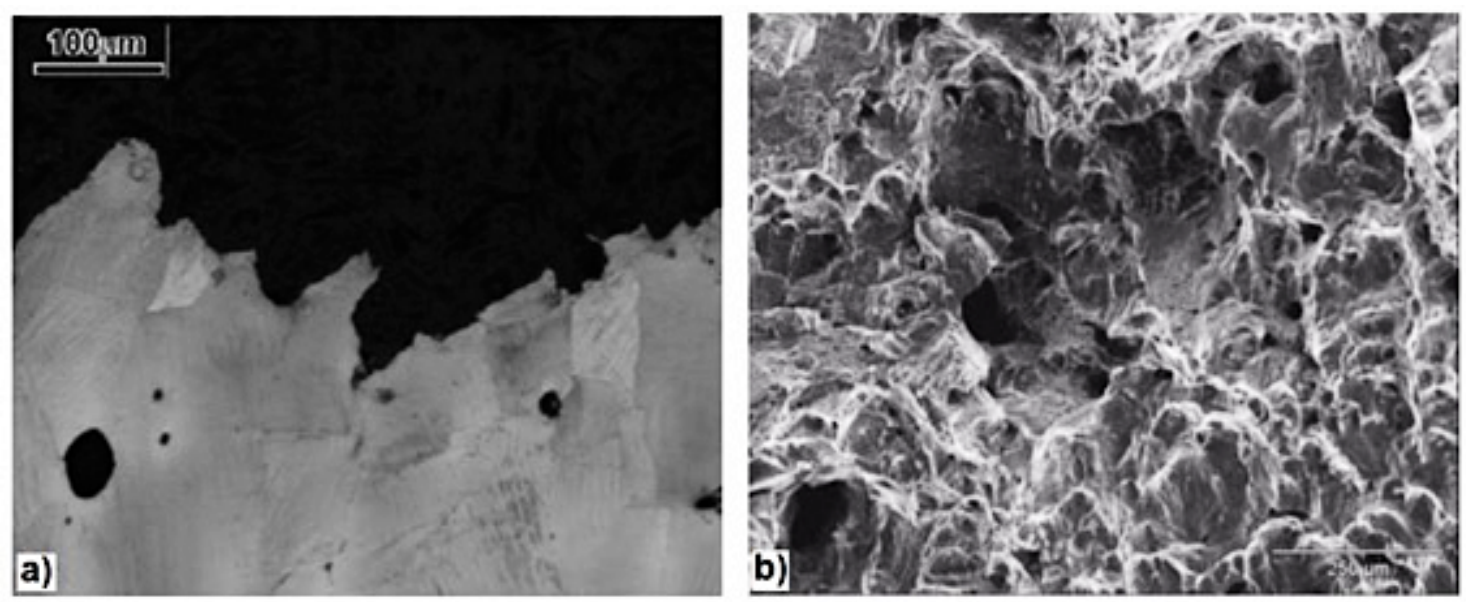

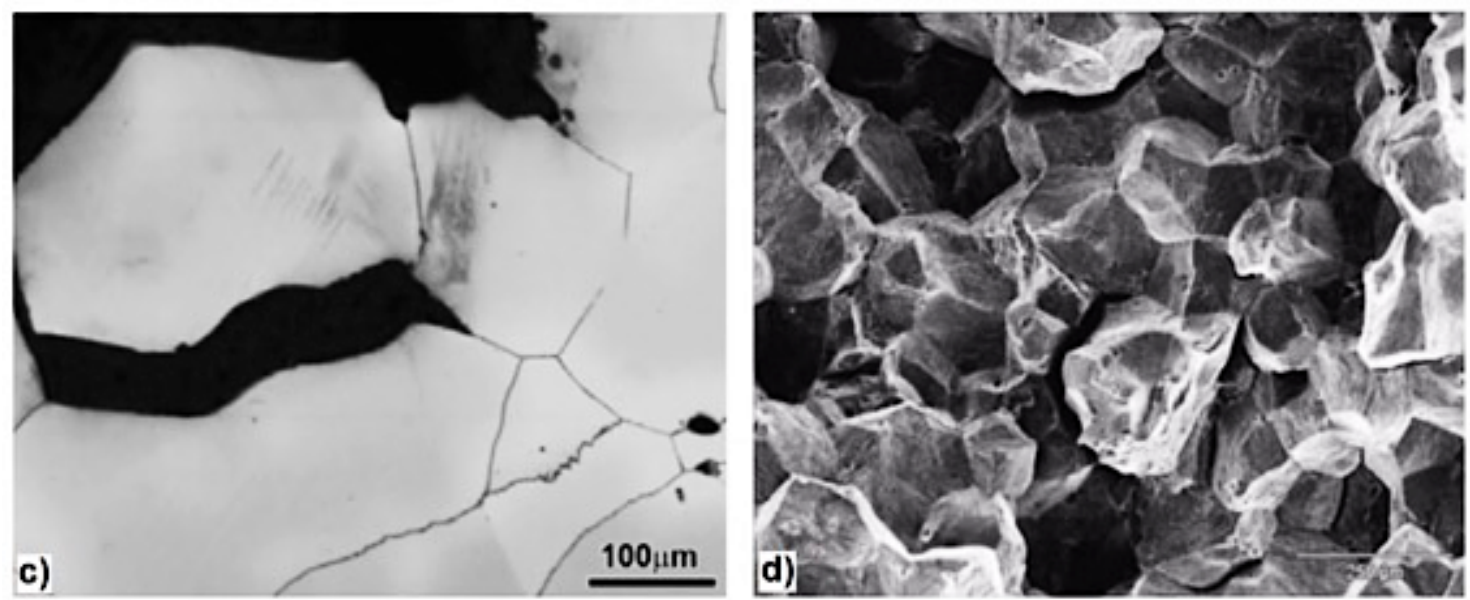

Fonte: Santos et al., 2010

Diesburg e Borik avaliaram a resistência ao impacto e perda de massa relativa em ensaio de abrasão por goivadura de aços Hadfield com diferentes concentrações de carbono (DIESBURG, D. E.; BORIK, F., 1974). Os resultados dos autores obtidos para o aço austenítico ao manganês foram avaliados e comparados às suas respectivas energias de impacto. Os resultados da Figura 2.33 mostram que o desgaste de britador de mandíbula de laboratório não apresenta correlação com a capacidade de absorção de energia por impacto $\left(R^{2}=0,4\right)$. Essa constatação não foi descrita pelos autores e tem importância científica e de aplicação tecnológica dos materiais analisados, principalmente, no entendimento do mecanismo de falha e dano dos revestimentos de britadores fabricados com aço Hadfield. Nota-se no gráfico que os resultados de impacto acima de $100 \mathrm{~J}$ são para aços com menores concentrações de carbono $(0,65,0,95$ e 1,09\%). Este resultado pode estar relacionado com a reprecipitação de carbonetos em contorno de grão do aço Hadfield. A diminuição do teor de carbono ajuda a evitar a reprecipitação de carbonetos durante o resfriamento (TSUJIMOTO, 1979) aumentando a resistência ao impacto (ZAVADIL; KUYUCAK, 2002), entretanto, diminui a resistência à abrasão, como observa-se no gráfico (Figura 2.33). A presença de carbonetos contínuos em contorno de grão, responsáveis pela diminuição da resistência ao impacto (KUYUCAK; ZAVADIL; NEWCOMBE. P., 2001b; SANTOS et al., 2010), pode não afetar a resistência à abrasão por goivadura em escala laboratorial, apesar de se saber que os carbonetos contínuos participam do mecanismo de dano e remoção de massa em casos reais de britagem, além de serem responsáveis pela falha catastrófica de revestimentos em operação. Nota-se, também, na Figura 2.33 
que o efeito do carbono sobre a resistência à abrasão, como mostrado na Figura 2.29.

Figura 2.33. Desgaste relativo (razão entre a perda de massa do material em análise e a perda de massa do material de referência) por goivadura (gouging wear ratio) em função da resistência ao impacto Charpy

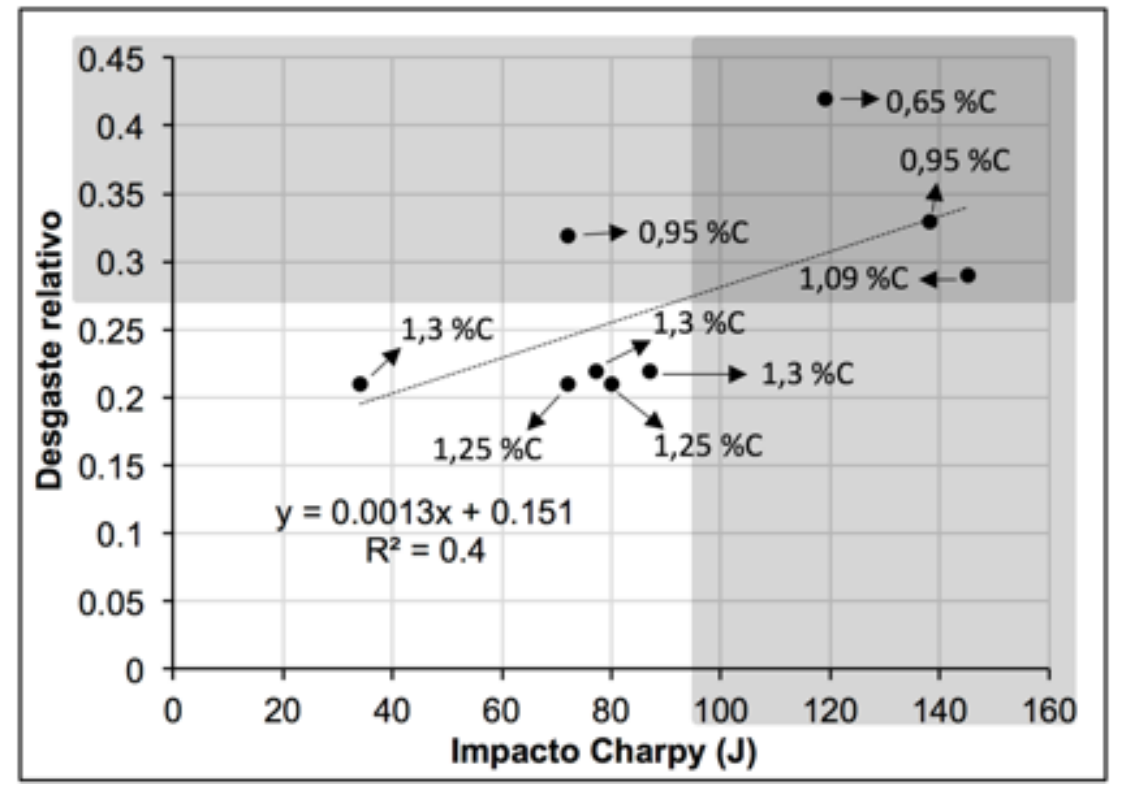

\subsubsection{Desgaste em britador de mandíbula}

Tanaka realizou exame de desgaste superficial em revestimento de britador de mandíbula, Figura 2.34 (TANAKA, 2011). Segundo o autor os danos superficiais gerados pelos mecanismos de desgaste atuantes são compostos por riscos com formação de proa (seta amarela) e "enrugamento" (seta azul), deformação à frente da proa. Lindroos et al. mostraram formação de trincas intergranulares, maclas de deformação e bandas de deformação na subsuperfície do aço Hadfield desgastado em campo (LINDROOS et al., 2015a). Os autores mencionaram que as trincas intergranulares, associadas ao aço Hadfield com carboneto contínuo em contorno de grão, são um dos mecanismos de falha da superfície. Lindqvist e Everton, e Pintaúde mostram que o micromecanismo de desgaste nas mandíbulas fixa e móvel do britador de mandíbula são diferentes. Na mandíbula fixa o micromecanismo predominante é o microcorte com intensa deformação plástica, enquanto na mandíbula móvel predomina microendentações (LINDQVIST; EVERTSSON, 2003; PINTAÚDE, 1998). 
Figura 2.34. Detalhe da superfície desgastada de mandíbula (britador). a) risco de abrasão com formação de proa (seta amarela). b) "enrugamento", deformação do material (seta azul) na frente da proa
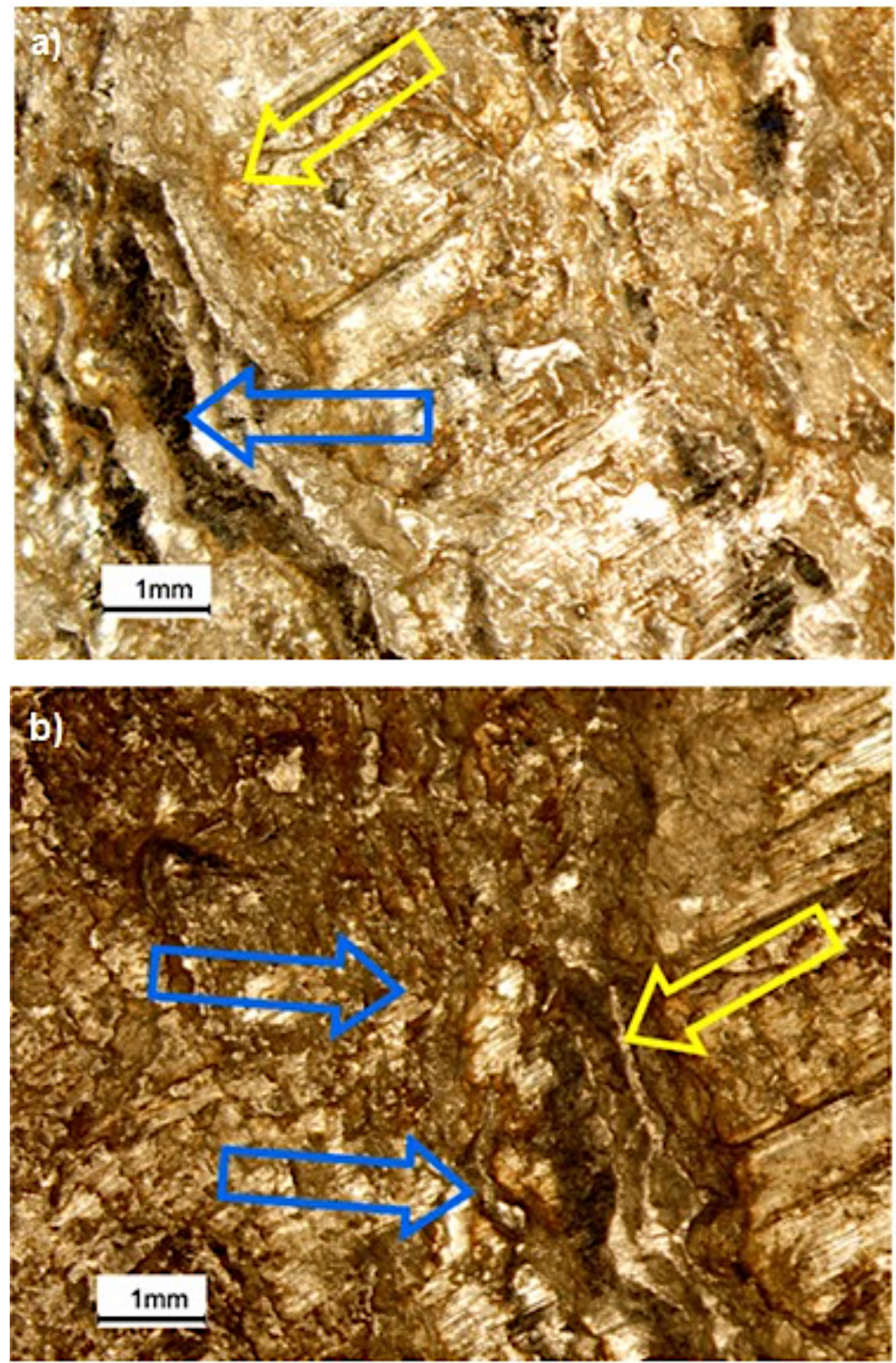

Fonte: Tanaka, 2011

Os revestimentos de britadores são submetidos a intensas deformações plásticas com consequente endurecimento superficial e subsuperficial, e se tratando do aço Hadfield o gradiente de dureza tem profundidade de 7 a $8 \mathrm{~mm}$ (LINDROOS et al., 2015a; TANAKA, 2011; TSUJIMOTO, 1979). Os valores máximos de dureza podem 
variar conforme a solicitação mecânica. Lindroos et al. obtiveram um valor máximo de dureza próximo à superfície equivalente a $700 \mathrm{HV0,2}$ com estabilização do valor de dureza em $7 \mathrm{~mm}$ com 300 HVO,2, Figura 2.35a (LINDROOS et al., 2015a). Tanaka examinou diferentes pontos da superfície de um revestimento de britador de mandíbula desgastado em campo obtendo perfis de dureza com valor máximo de 600 HV0,3 e estabilização da dureza em 7 mm com 250 HV0,3, Figura 2.35b (TANAKA, 2011). Tsujimoto obteve perfis de dureza de britadores com diferentes solicitações mecânicas, Figura 2.35c. No britador de martelos os impactos produzidos pelo processo de cominuição proporcionaram menor dureza máxima (350 HV) e menor comprimento do perfil de variação de dureza $(5 \mathrm{~mm})$ que os observados nos revestimentos de britador giratório (525 HV e $8 \mathrm{~mm}$ ) e de mandíbula (500 HV e $7 \mathrm{~mm}$ ), respectivamente (TSUJIMOTO, 1979). Apesar dos poucos detalhes sobre os equipamentos, nota-se que o britador giratório proporcionou endurecimento superior que os demais britadores. 
Figura 2.35. Perfis de dureza (ao longo da seção transversal da superfície deformada) do aço Hadfield deformado em diferentes condições. a) Britador de mandíbula. b) Britador de mandíbula. c) Britador giratório, de mandíbula e por impacto
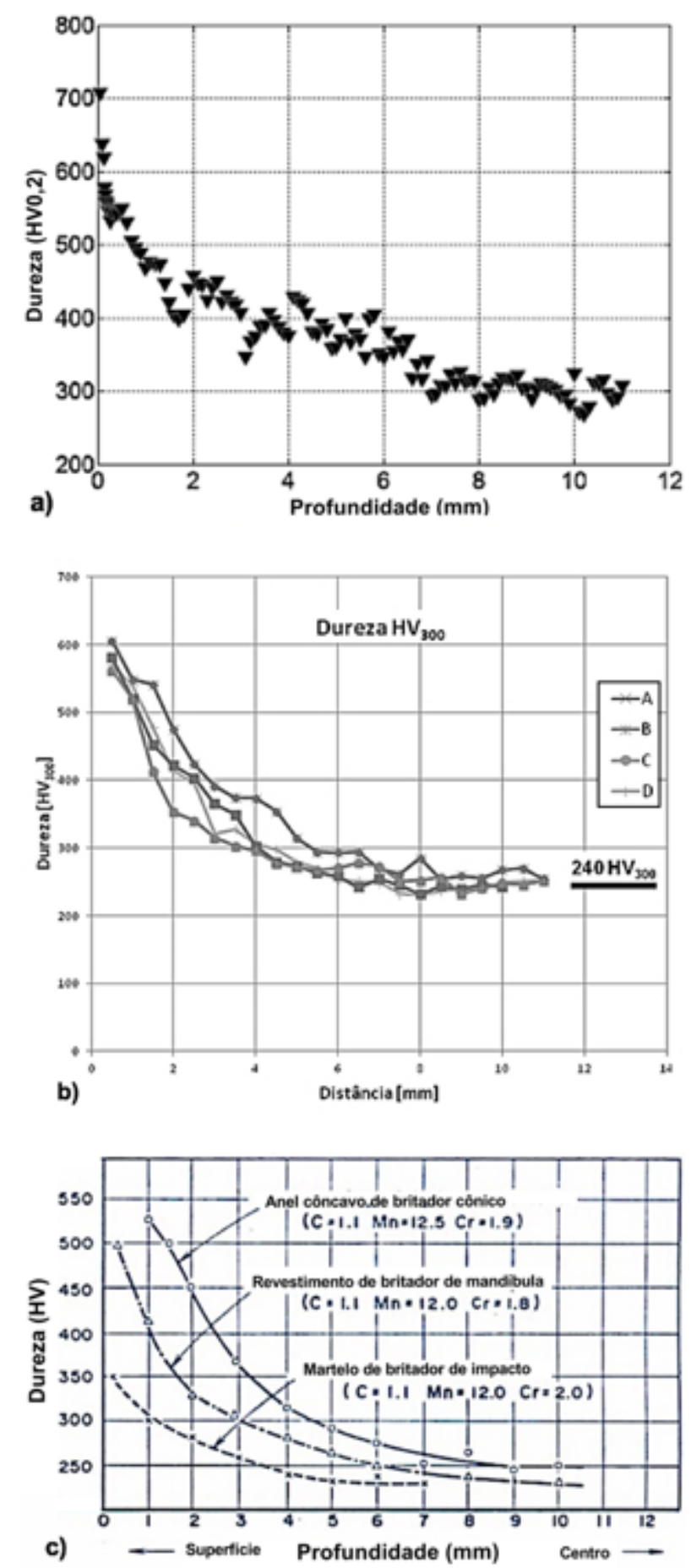

Fonte: a) Lindroos et al., 2015. b) Tanaka, 2011. c) Tsujimoto, 1979

Nota-se que a caracterização da seção transversal da superfície desgastada tornase importante para o entendimento dos mecanismos de remoção de material que são associados ao endurecimento da superfície, nucleação e propagação de trinca (danos subsuperficiais). 


\subsection{RECRISTALIZAÇÃO}

Segundo Padilha e Siciliano a recristalização é um fenômeno ativado termicamente que depende, principalmente, do potencial termodinâmico associado à energia armazenada na deformação (driving force) (Padilha \& Siciliano, 2005). Haratani et al., e Weidner e Klimanek observaram que as heterogeneidades de deformação na microestrutura (bandas de escorregamentos ou cisalhamento e maclas de deformação) são sítios preferenciais para início da recristalização (HARATANI et al., 1998; WEIDNER; KLIMANEK, 1998). De acordo com Burke e Turbull para ocorrer a recristalização deve-se ter uma deformação mínima no material; quanto maior o grau de deformação menor a temperatura para início da recristalização e menor será o tamanho de grão (Burke e Turbull, 1952 apud Padilha \& Siciliano, 2005).

Segundo Moore o fenômeno de desgaste abrasivo gera calor na interface abrasivo/material a partir do atrito entre os corpos alterando as propriedades físicas, químicas e mecânicas do material (MOORE, 1970). Burton mostrou que o aumento de temperatura da interface de dois corpos em deslizamento está associado à deformação elástica na superfície (asperezas) e à deformação plástica abaixo da superfície (BURTON, 1980). A maior parte da energia de deformação plástica (90\%) pode ser convertida em calor em condições de altas taxas de deformação, segundo Meyers e Chawla este fenômeno trata-se do aquecimento adiabático (adiabatic heating) (MEYERS; CHAWLA, 1998). Meyers et al. mostraram que a microestrutura de bandas de cisalhamento adiabática (adiabatic shear band), em aço AISI 304L, sofre recristalização dinâmica formando grãos de escala nanométrica (MEYERS et al., 2003). Feng et al. relacionam o aumento de temperatura de até $150{ }^{\circ} \mathrm{C}$ durante operação de serviço do aço Hadfield aplicado em sistemas de mudança de via ferroviária (jacaré - crossing) com o fenômeno de recuperação dinâmica (FENG et al., 2013a).

Zum Gahr mostrou que cavacos de alumínio puro e zinco puro gerados por desgaste originam microestrutura policristalina conforme as imagens de difração da Figura 2.36 (ZUM GAHR, 1987). O autor associou a formação desta microestrutura do cavaco ao fenômeno de recristalização dinâmica. 
Figura 2.36. Imagens de MET de cavaco de alumínio puro (a) e de zinco puro (c), as imagens b e d mostram as respectivas imagens de difração
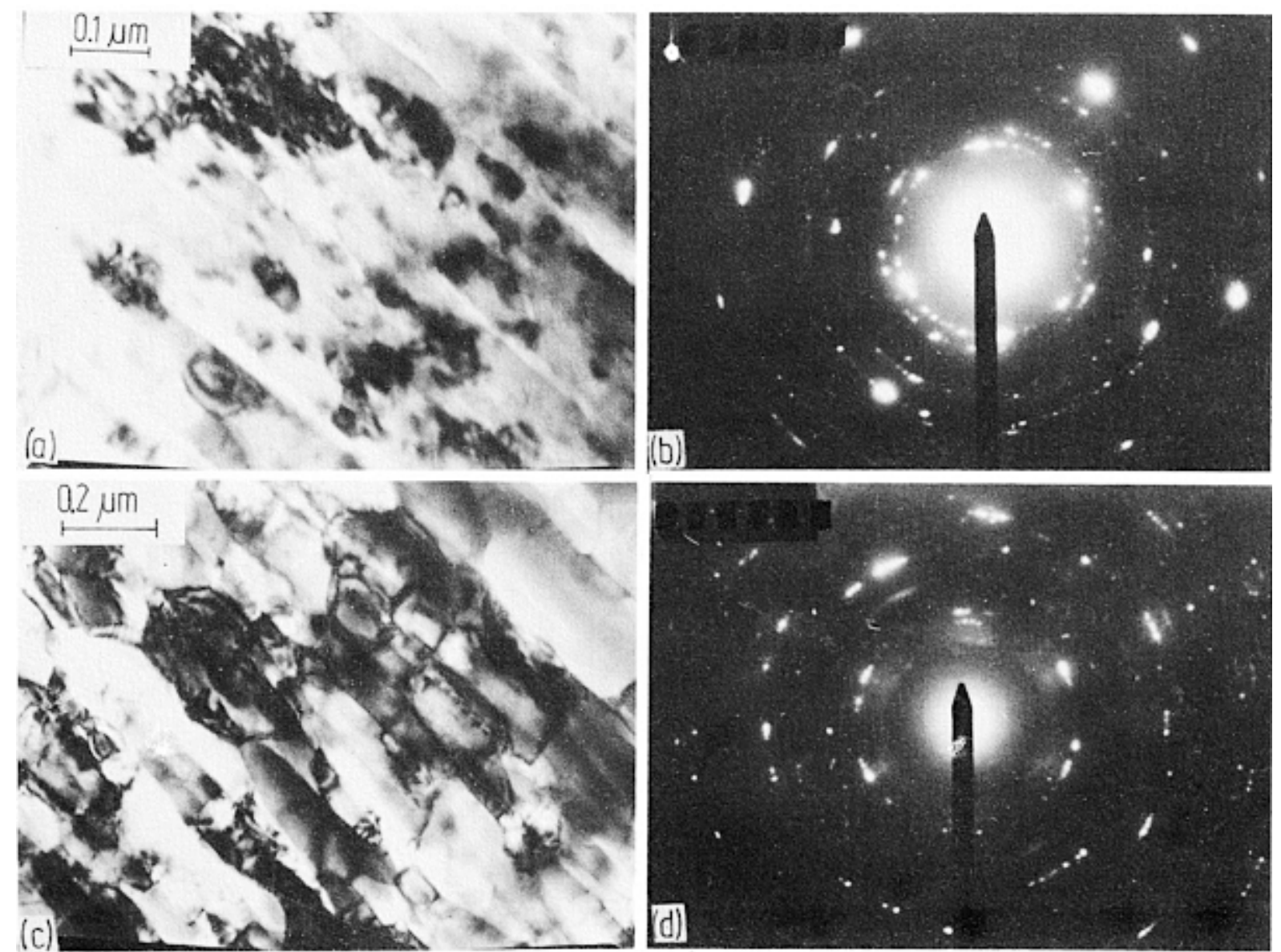

Fonte: Zum Gahr, 1987

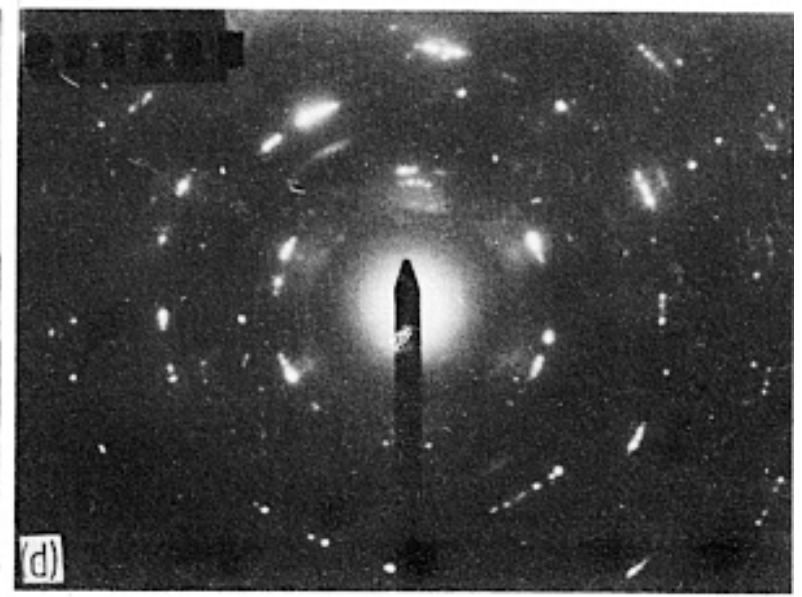

Tratando-se da superfície desgastada, Zum Gahr mostra que a formação de arranjos de discordâncias na superfície desgastada de latão, Figura 2.37a, e células de discordâncias, floresta de discordâncias e núcleo de recristalização em uma superfície desgastada de cobre puro, Figura 2.37b (ZUM GAHR, 1987). 
Figura 2.37. Imagens de MET de superfície desgastada de latão, $\mathrm{Cu}-40 \% \mathrm{Zn}(\mathrm{a})$, e cobre puro (b)
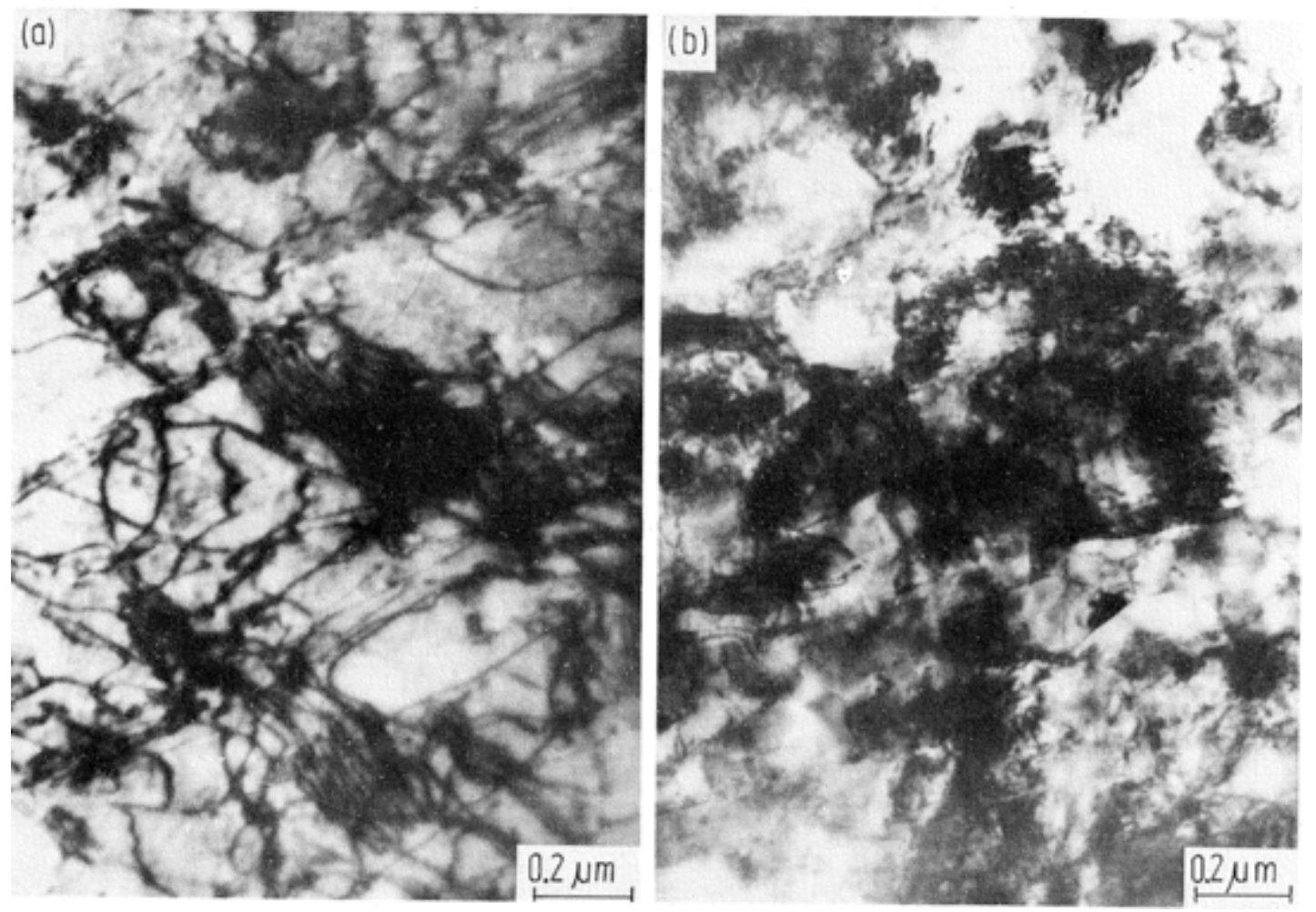

Fonte: Zum Gahr, 1987

Emge et al. observaram via FIB e MET grãos "submicrométricos" (ultrafinos) na camada subsuperficial de cobre desgastado em ensaio de pino sobre disco (aço inoxidável e cobre, respectivamente), Figura 2.38 (EMGE; KARTHIKEYAN; RIGNEY, 2009). Os autores associaram a formação de grãos ultrafinos ao fenômeno de recristalização dinâmica, no entanto, sem discussão da causa do fenômeno. Nesta pesquisa será discutida a causa da formação de grãos ultrafinos por recristalização dinâmica na superfície de desgaste. 
Figura 2.38. a) Micrografia obtida via FIB, corte transversal à superfície desgastada do disco de cobre. b) Imagem de MET - Campo claro da camada subsuperficial e imagem de difração de uma área recíproca da camada de grãos ultrafinos
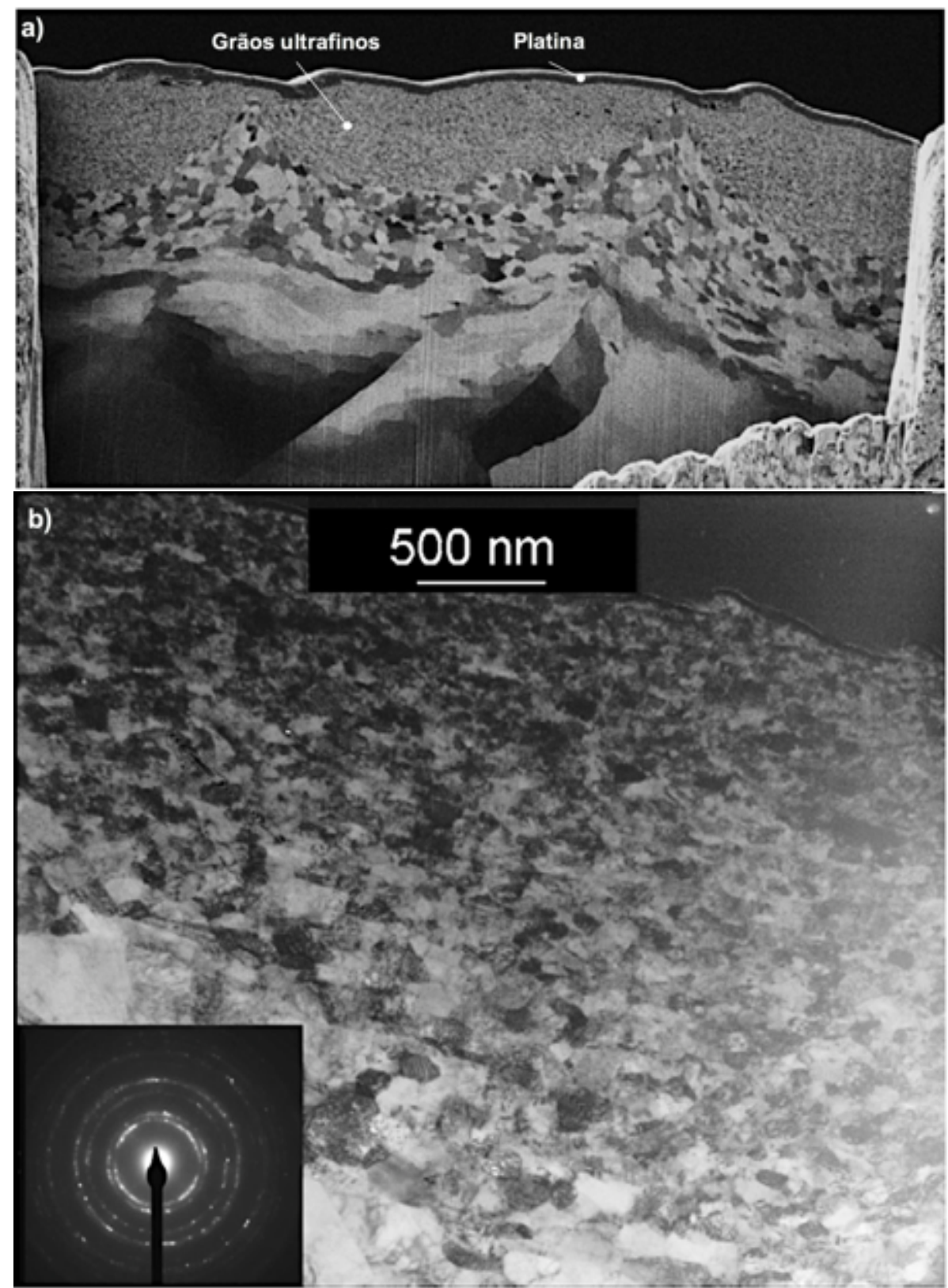

Fonte Emge; Karthikeyan; Rigney, 2009

Segundo Sakai et al. as técnicas de deformação plástica severa (SPT - severe plastic deformation), tais como, ECAP (equal channel angular pressing), HPT (high pressure torsion), MDF (mult-directional forging) e ARB (accumulative roll bonding) foram desenvolvidas para produzir grãos ultrafinos (UFG - ultrafine grained) em materiais metálicos, a partir do fenômeno de recristalização dinâmica (SAKAl et al., 2014). Na revisão sobre esse tema realizada pelos autores é indicado dois modelos 
para formação de grãos ultrafinos sob deformação a frio. A Figura 2.39 mostra estes modelos de formação de UFG por SPT.

Figura 2.39. Modelos de formação de grãos ultrafinos por deformação plástica a frio

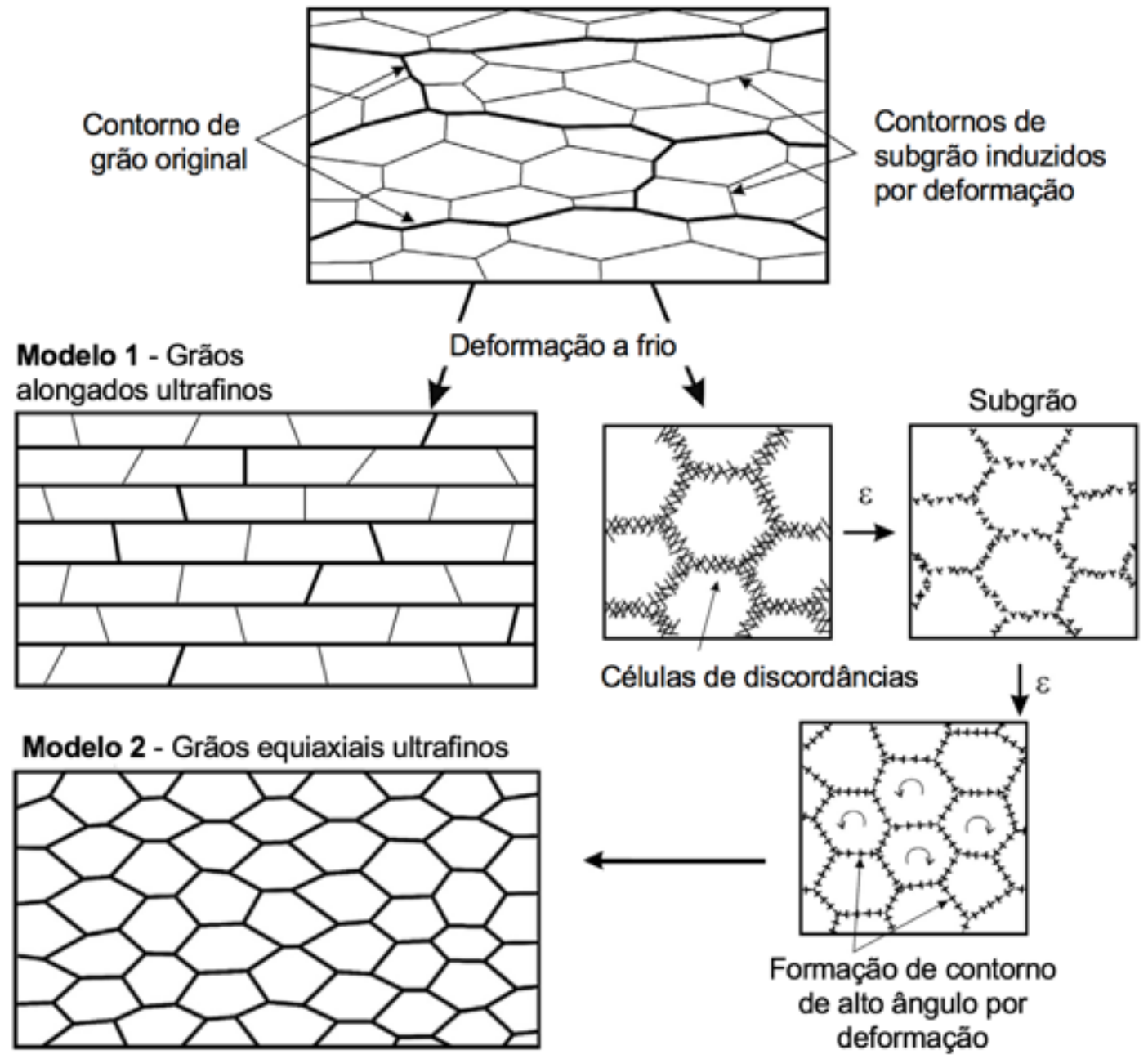

Fonte: Adaptado de Sakai et al., 2014

O primeiro modelo (1) é relacionado à laminação a frio ou ECAP, na qual promove o achatamento e alongamento dos grãos na direção de deformação, aumentando a densidade de discordâncias nas paredes dos subgrãos até ocorrer a formação de novos grãos alongados e ultrafinos com contornos de baixo $\left(<15^{\circ}\right)$ e alto ângulo $\left(>15^{\circ}\right)$. Huphreys et al. mostram este fenômeno em ligas de alumínio deformadas por ECAP, onde observou-se via MET grãos menores que $1 \mu \mathrm{m}$, alongados (relação de aspecto de 1,5 a 3) e livres de discordâncias (HUMPHREYS et al., 1999). A partir de resultados de EBSD foi mostrado que os materiais têm uma fração alta de contornos de alto ângulo, semelhante à textura de ligas recristalizadas. 
No segundo modelo (2) a formação de UFG está relacionada principalmente ao processo HPT, no qual as pesquisas (VALIEV et al., 1996; VALIEV; ISLAMGALIEV; ALEXANDROV, 2000; ZHILYAEV et al., 2003) mostraram que as subestruturas (células de discordâncias e subgrãos) formadas por deformação moderada são substituídas por grãos ultrafinos no decorrer do processo de SPD. A Figura 2.39 mostra a sequência de alteração microestrutural durante a formação de UFGs por deformação plástica severa. A deformação a frio forma células de discordâncias, as quais evoluem para subgrãos devido o aumento da densidade de discordâncias nas paredes das células. Segundo Sakai et al. as discordâncias com vetor de Burgers situado no plano dos contornos promovem o deslizamento e cisalhamento dos contornos de grão, enquanto as demais discordâncias são responsáveis pelo aumento da misorientação conforme a deformação, atingindo de contornos de alto ângulo (> 15 $)$ (SAKAl et al., 2014).

Outro modelo (3) de recristalização dinâmica por deformação é o rotation dynamic recrystallization introduzido por Derby (DERBY, 1992) e discutido por Meyers e Pak (M. Meyers \& Pak, 1986 apud M. A. Meyers et al., 2003) como mecanismo de formação de grãos na ordem de $0,1 \mu \mathrm{m}$, a partir da rotação dos contornos de subgrão. A Figura 2.40 mostra o modelo apresentado por Meyers et al. (MEYERS et al., 2003).

Figura 2.40. Modelo de recristalização dinâmica por rotação. a) Quebra do contorno de subgrão alongados. b) Rotação do contorno de subgrãos em $30^{\circ}$ recristalizando o material e formando grãos equiaxiais

(a)

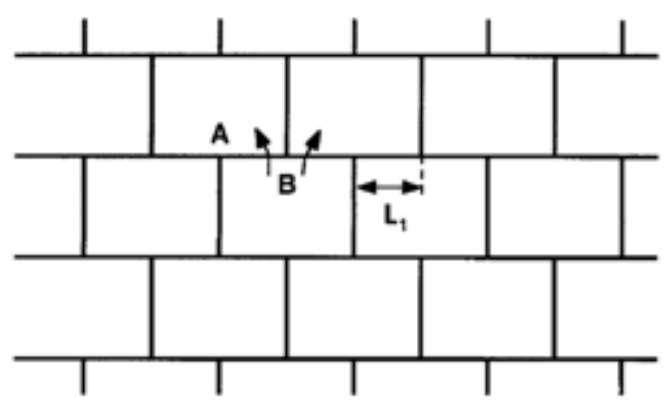

(b)

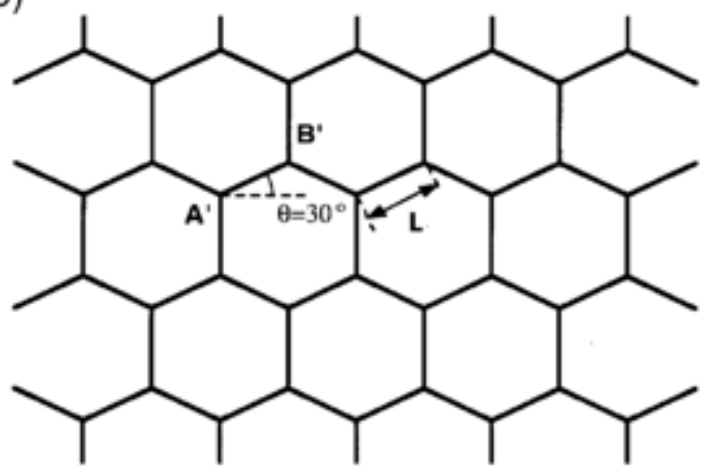

Fonte: Meyers et al., 2003

O estágio mais avançado de formação dos subgrãos é mostrado na Figura 2.40 a, onde os subgrãos encontram-se alongados e com subdivisões perpendiculares. A 
partir deste estágio, a recristalização do material ocorre com a reorientação dos segmentos dos contornos, ou seja, o segmento $A B$ com comprimento $L_{1}$ rotaciona $30^{\circ}$ formando o segmento $A^{\prime} B^{\prime}$ de comprimento $L$. Meyers et al. utilizam este modelo para descrever a formação de grãos ultrafinos no interior de bandas de cisalhamento adiabáticas, considerando que $90 \%$ da energia associada a deformação é convertida em calor (MEYERS et al., 2003).

\subsection{EFEITO DA ORIENTAÇÃO CRISTALOGRAFICA NA ABRASÃO}

Zum Gahr estudou o efeito da orientação cristalográfica de uma liga metálica Ti 8,5 \%Al na esclerometria linear (ZUM GAHR, 1982 apud ZUM GAHR, 1987). As orientações basais e transversais do cristal hexagonal compacto foram avaliadas. Conforme a Figura 2.41 a largura do risco variou com a orientação do cristal, apresentando menor largura para a orientação transversal e maior largura para a orientação basal, havendo diferentes níveis de desgaste.

Figura 2.41. Desgaste por riscamento em Ti - 8,5\%Al com polimento eletrolítico. Ponta de aço com $30^{\circ}$ e $0,25 \mathrm{~N}$. a) textura basal. b) textura transversal

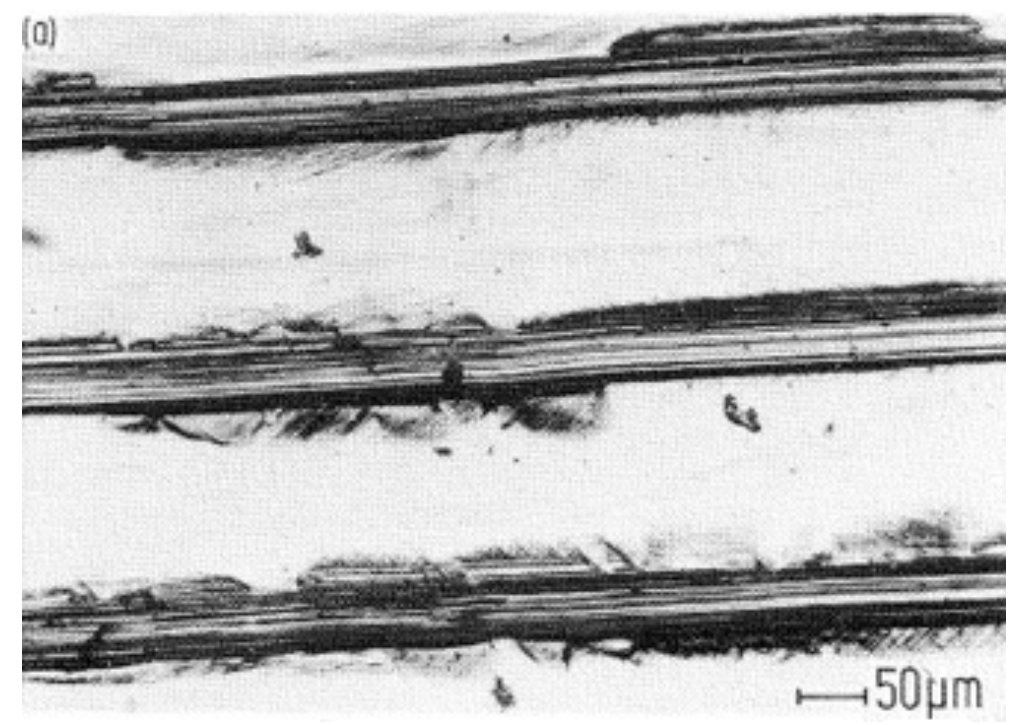




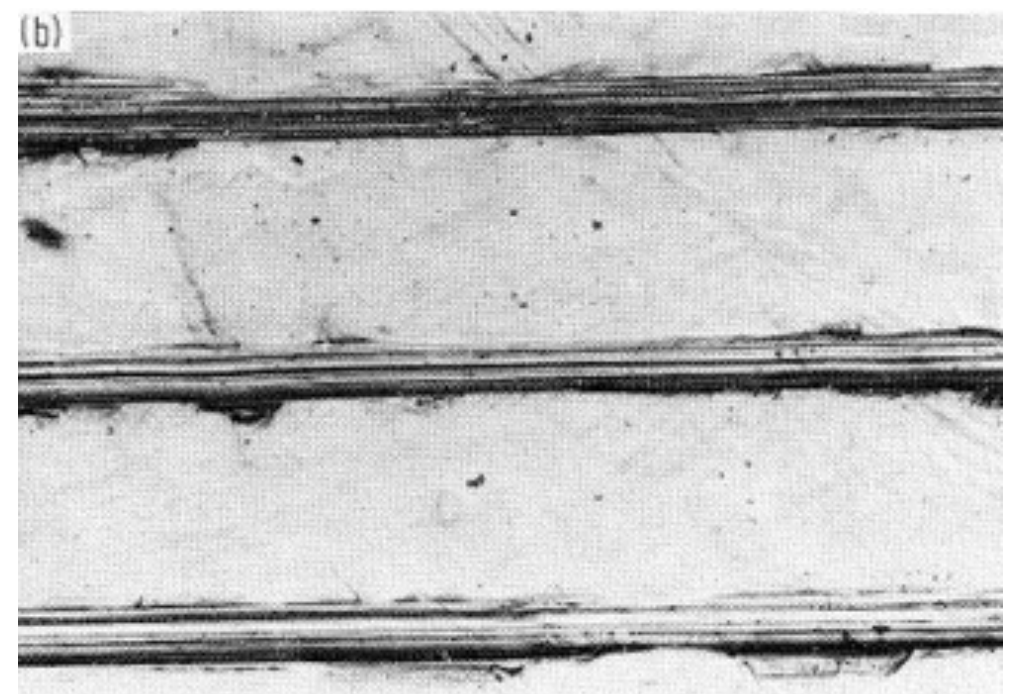

Fonte: Zum Gahr, 1982

O efeito da anisotropia cristalina na abrasão de um aço ( $\mathrm{Fe}-38 \% \mathrm{Ni}-6 \% \mathrm{Al})$ foi mostrado por Zum Gahr (ZUM GAHR, 1987). O autor destaca que a largura e a profundidade do risco dependem da orientação cristalográfica de cada cristal, Figura 2.42 .

Figura 2.42. Risco no aço ( $\mathrm{Fe}-38 \% \mathrm{Ni}-6 \% \mathrm{Al})$ produzido no ensaio de esclerometria com $0,25 \mathrm{~N}$

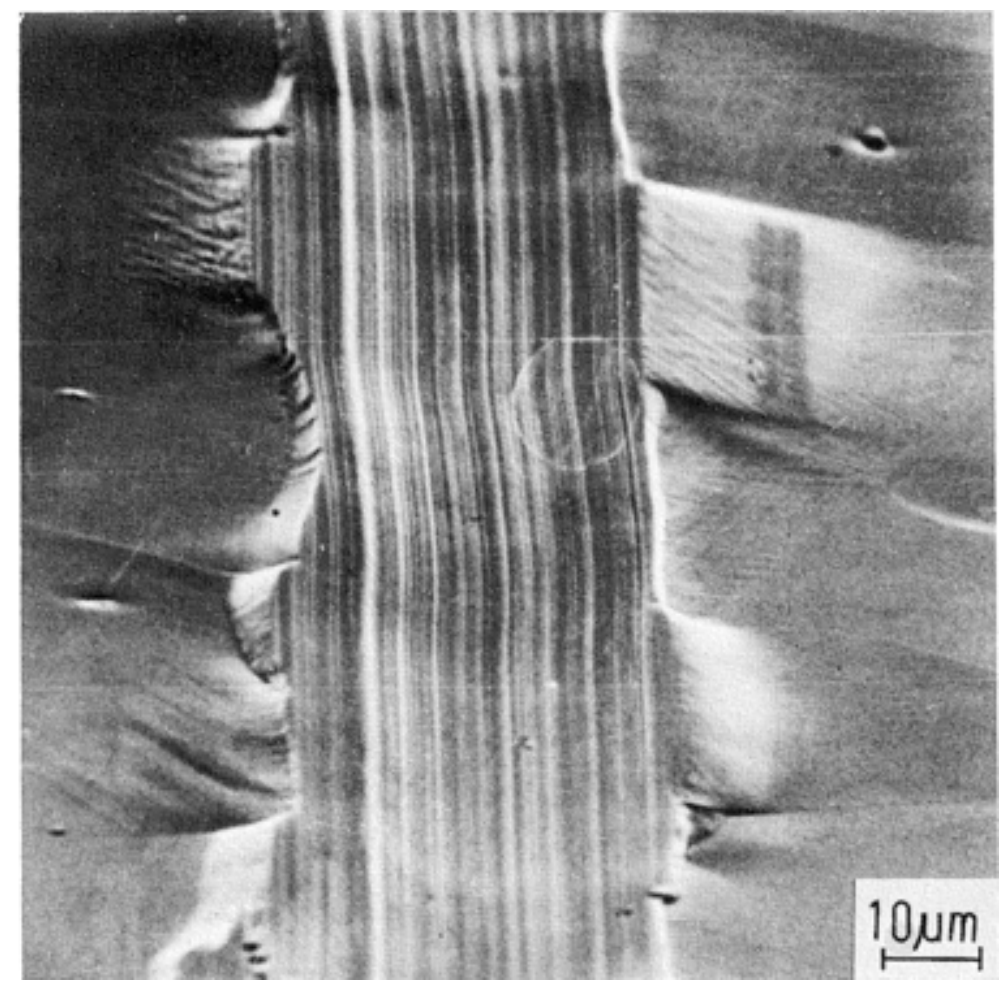

Fonte: Zum Gahr, 1987 
Karaman et al. mostraram que a direção 111 do aço Hadfield sob compressão tem maior resistência e menor deformação que a direção [001] (KARAMAN et al., 2000a).

Pierce et al. obtiveram diferentes módulos de elasticidade para os planos cristalográficos (001), (111) e (101) do Fe - $22 \% \mathrm{Mn}-3 \% \mathrm{Al}-3 \% \mathrm{Si}$. Os valores foram iguais a $178 \mathrm{GPa}, 196 \mathrm{GPa}$ e $195 \mathrm{GPa}$, respectivamente (PIERCE et al., 2013). Outra pesquisa que relaciona o comportamento mecânico de metal CFC à orientação cristalográfica foi realizada por Wang et al. (WANG et al., 2004). Os autores observaram em análise experimental e numérica de nanoendentação que o campo de deformação formado depende do plano cristalográfico do monocristal metálico, neste caso o cobre. A nanoendentação no plano (111) mostrou maior profundidade do campo de deformação que no plano (001).

Choi et al. mostrou diferente comportamento mecânico de um aço TWINP para as direções [2 110$]$ e $\left[\begin{array}{lll}19 & 8 & 21\end{array}\right]$ ensaiadas no teste de microcompressão via Nanoindenter com endentador de ponta reta (CHOI et al., 2017). Os autores prepararam corpos de prova (micropilar) via FIB com diâmetros de 1 a $10 \mu \mathrm{m}$. Os resultados mostram que a deformação na direção [2 11 10] favoreceu a maclação, enquanto na direção [19 8 21] a predominância foi do escorregamento de planos cristalinos, Figura 2.43.

Figura 2.43. a) Imagem de MEV-SE do micropilar deformado na direção [2 1 10]. b) Imagem de campo escuro via MET da seção paralela à (001) transversal do micropilar deformado na direção [2 1 10]. c) Imagem de MEV-SE do micropilar deformado na direção [19 8 21]. d) Imagem de IPF com as direções cristalográficas de ensaio e suas indicações no tetraedro de Thompson.
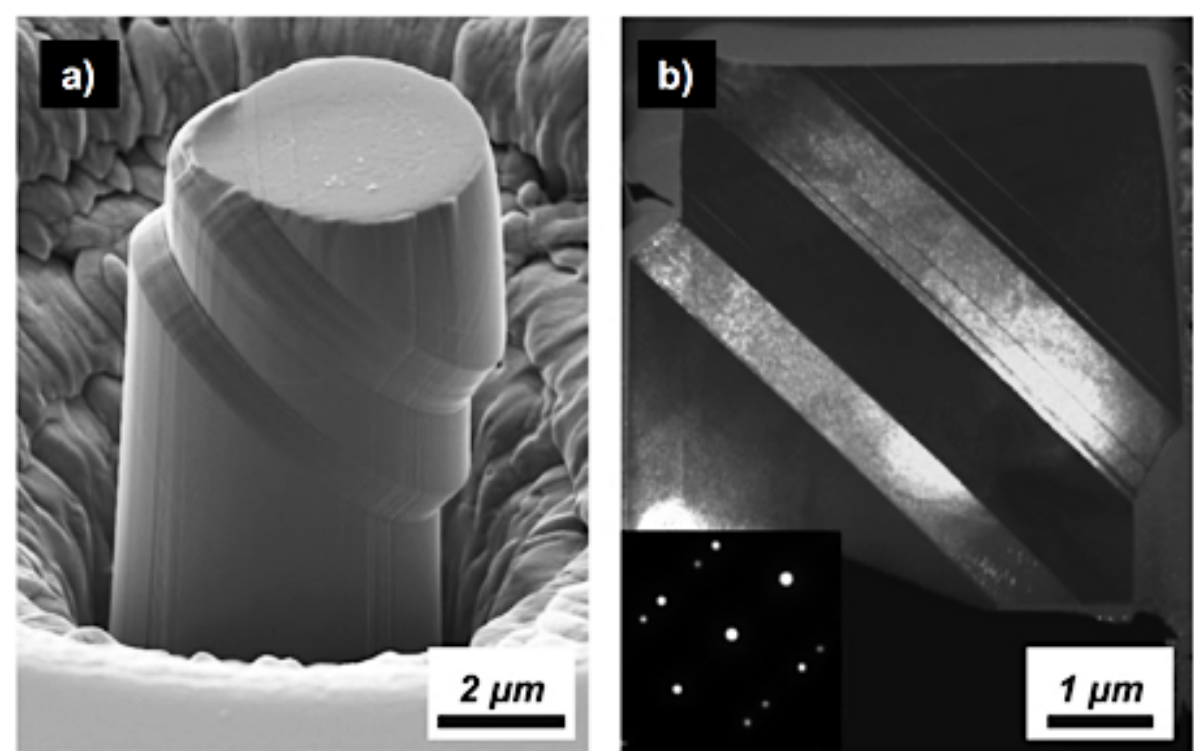


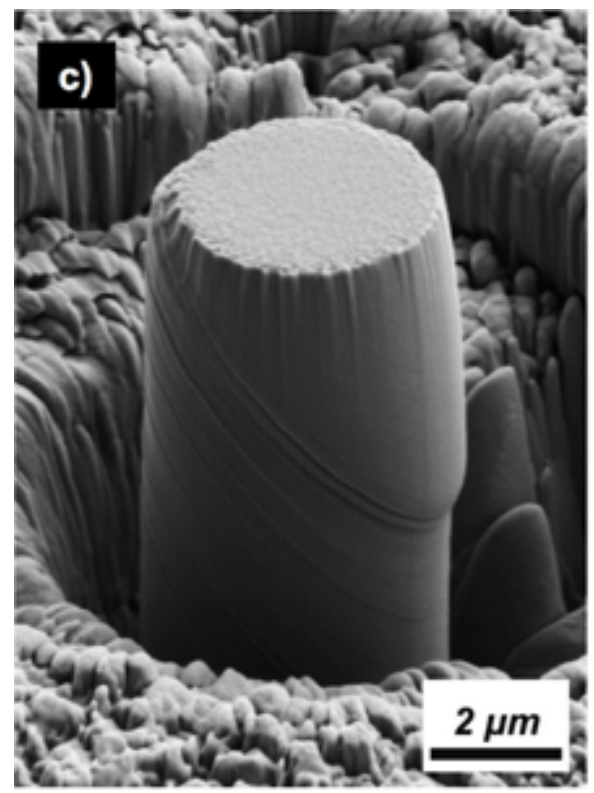

\section{d)}

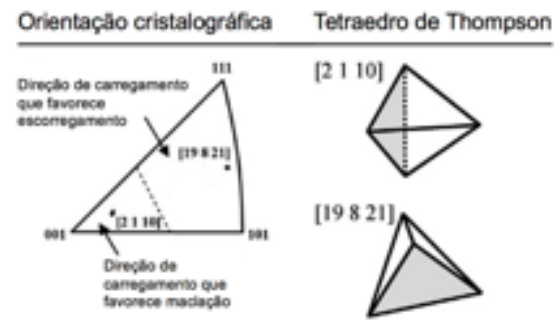

Fonte: Adaptado de Choi et al., 2017

A literatura mostrou que os estudos de resistência ao desgaste de aço Hadfield com diferentes ensaios (britador de mandíbula, roda de borracha e esclerometria) fizeram comparações de desempenho deste material com outros materiais ferrosos, limitando-se na análise do micromecanismo de desgaste e dureza, não avaliando a microestrutura da subsuperfície ou alguma componente metalúrgica. Por outro lado, a literatura que discute as propriedades mecânicas do aço Hadfield avaliaram os efeitos de variáveis de metalurgia física, tais como: energia de defeito de empilhamento, mecanismos principais de deformação, etc. Nesta pesquisa, o estudo de desgaste abrasivo tem o objetivo de fazer um estudo envolvendo as saídas do sistema tribológico considerando variáveis de metalurgia física, avaliando mais a fundo as alterações microestruturais da subsuperfície deformada e o efeito da orientação cristalográfica na abrasão. Deste modo, pretendesse estudar: o desempenho dos aços com $12 \% \mathrm{Mn}$ e $20 \% \mathrm{Mn}$ em condição de desgaste abrasivo via ensaio de britador de mandíbula; o efeito do encruamento e o efeito da orientação cristalográfica no desgaste via esclerometria linear para os aços $12 \% \mathrm{Mn}$ e $20 \% \mathrm{Mn}$; e a microestrutura da subsuperfície do aço com 12\%Mn após desgaste abrasivo nas escalas macro (revestimento usado em campo), meso (ensaio de laboratório) e micro (ensaio de laboratório). 
Capítula 3. DESGASTE ABRASNO DOS ACOS AULSTENITICOS $12 \%$ MnE $20 \% \mathrm{Mn}$ VIA ENSAIO DE BRITADORDE MANDIBUUA

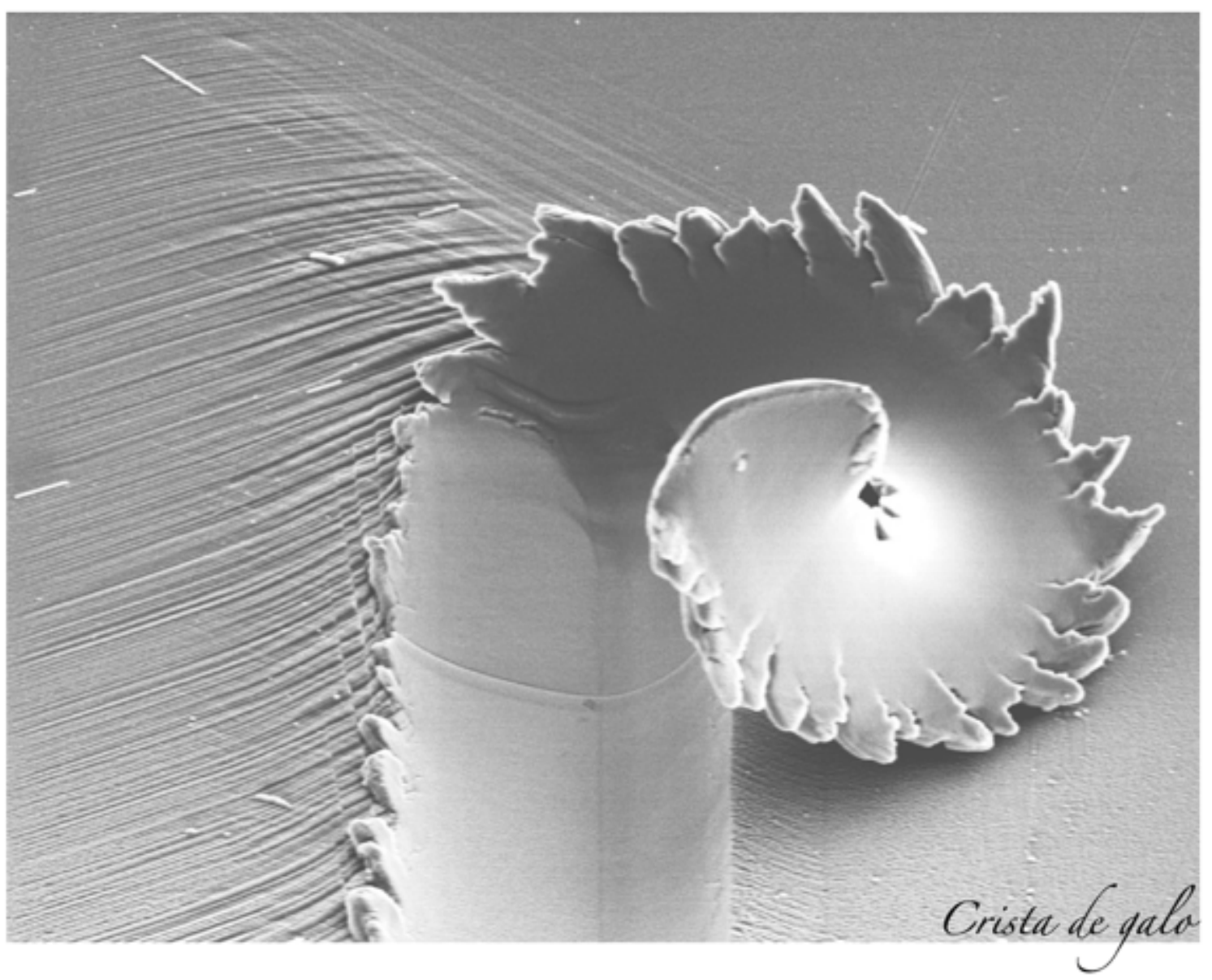




\section{Resumo}

O estudo do desgaste abrasivo de dois aços austeníticos com 12,4 \%Mn (12Mn) e com 19,9 \% Mn (20Mn) foi realizado via ensaio de britador de mandíbula, utilizou-se por ensaio $100 \mathrm{~kg}$ de abrasivo (brita), com tamanho médio de 14,3 mm. A caracterização do desgaste dos materiais foi realizada com a avaliação da perda de massa, perfil de dureza e da superfície desgastada com uso das técnicas de interferometria óptica, microscopia óptica e de varredura. A microestrutura da subsuperfície foi caracterizada via FIB após o desgaste. A granulometria do abrasivo foi caracterizada antes e depois do ensaio, tendo uma redução de $37 \%$. Os resultados de perda de massa mostraram uma diferença de $64 \%$ entre a mandíbula fixa (MF) e a mandíbula móvel (MM) do aço $12 \mathrm{Mn}$ e $45 \%$ para o aço $20 \mathrm{Mn}$. Os valores médios de perda de massa dos materiais foram estatisticamente iguais para MF e MM, considerando o intervalo de confiança de 95 \%. No entanto, ao considerar o intervalo de confiança de $90 \%$, tem-se diferença significativa entre as mandíbulas fixas dos aços. O perfil de dureza para MF e MM de ambos materiais tiveram profundidade de encruamento de $1,5 \mathrm{~mm}$. O micromecanismo de desgaste predominante na MF foi o microcorte e microsulcamento paralelo ao fluxo de abrasivo e para a MM, microendentação. Os resultados de interferometria óptica mostraram que a topografia da superfície desgastada é isotrópica na região central das mandíbulas fixas e móveis e com anisotropia na região de saída da MF. Os resultados de FIB mostraram que a microestrutura na subsuperfície tem grãos ultrafinos e maclas de deformação.

Palavras-chave: Aço austenítico. Desgaste abrasivo. Britador de mandíbula.

\subsection{OBJETIVO}

\subsubsection{Geral}

Avaliar o desempenho dos aços austeníticos com 12 \% Mn e 20 \%Mn em condição de desgaste abrasivo via ensaio de britador de mandíbula. 


\subsubsection{Específicos}

- Avaliar a distribuição do tamanho do abrasivo antes e depois do processo de fragmentação (ensaio de britador de mandíbula);

- Avaliar a perda de massa dos materiais submetidos ao ensaio de britador de mandíbula;

- Avaliar o perfil de microdureza dos revestimentos após ensaio;

- Caracterizar a superfície desgastada via estereoscopia, MEV e CCl;

- Caracterizar a microestrutura da subsuperfície desgastada.

\subsubsection{Diagrama de blocos}

O diagrama da Figura 3.1 mostra o diagrama de blocos indicando os ensaios e métodos de caracterização utilizados neste Capítulo.

Figura 3.1. Diagrama de blocos

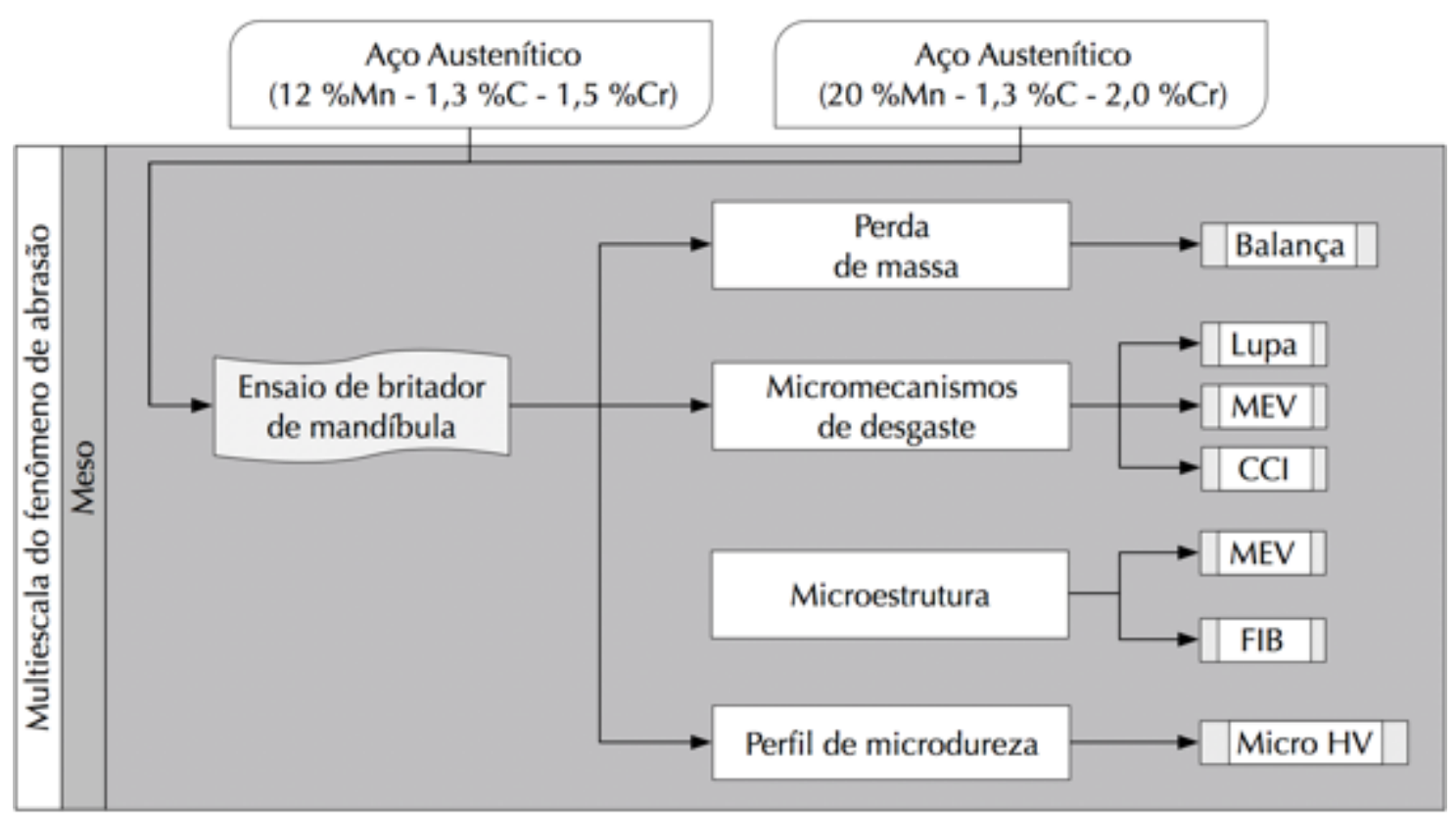




\subsection{MATERIAIS E MÉTODOS}

\subsubsection{Obtenção e preparação de amostra}

As amostras para ensaio de britador de mandíbula foram fabricadas com o aço austenítico Hadfield classe C (ASTM G128, 2012) nomeado de 12Mn e com aço austenítico com 19,9 \%Mn, nomeado de $20 \mathrm{Mn}$. As composições químicas obtidas via espectroscopia óptica realizada na empresa Metso são mostradas da Tabela 3.1. A macrodureza dos aços $12 \mathrm{Mn}$ e $20 \mathrm{Mn}$ são $202 \pm 10$ HV30 e $226 \pm 10$ HV30, respectivamente.

Tabela 3.1. Composição química dos aços em estudo (\% em p
\begin{tabular}{cccccccc}
\multicolumn{8}{c}{$\mathbf{1 2 M n}$ (\% em peso) } \\
\hline $\mathrm{C}$ & $\mathrm{Mn}$ & $\mathrm{Si}$ & $\mathrm{P}$ & $\mathrm{S}$ & $\mathrm{Cr}$ & $\mathrm{Mo}$ \\
1,3 & 12,4 & 0,87 & 0,05 & 0,003 & 1,5 & 0,1 \\
\multicolumn{7}{c}{$\mathbf{2 0 M n}(\%$ em peso) } \\
\hline $\mathrm{C}$ & $\mathrm{Mn}$ & $\mathrm{Si}$ & $\mathrm{P}$ & $\mathrm{S}$ & $\mathrm{Cr}$ & $\mathrm{Mo}$ \\
1,3 & 19,9 & 0,6 & 0,04 & 0,002 & 2,1 & 0,6
\end{tabular}

A Figura 3.2a mostra o britador de laboratório e suas mandíbulas originais com ranhuras. A Figura $3.2 b$ mostra o desenho com cotas das mandíbulas (revestimentos) de face plana utilizadas no experimento. A mandíbula fixa tem dimensões de 120 × 80 x 27 mm e a mandíbula móvel tem dimensões de 114 x 75 x $20 \mathrm{~mm}$.

Figura 3.2. a) Britador e mandíbulas. b) Desenho das mandíbulas móvel e fixa

a)

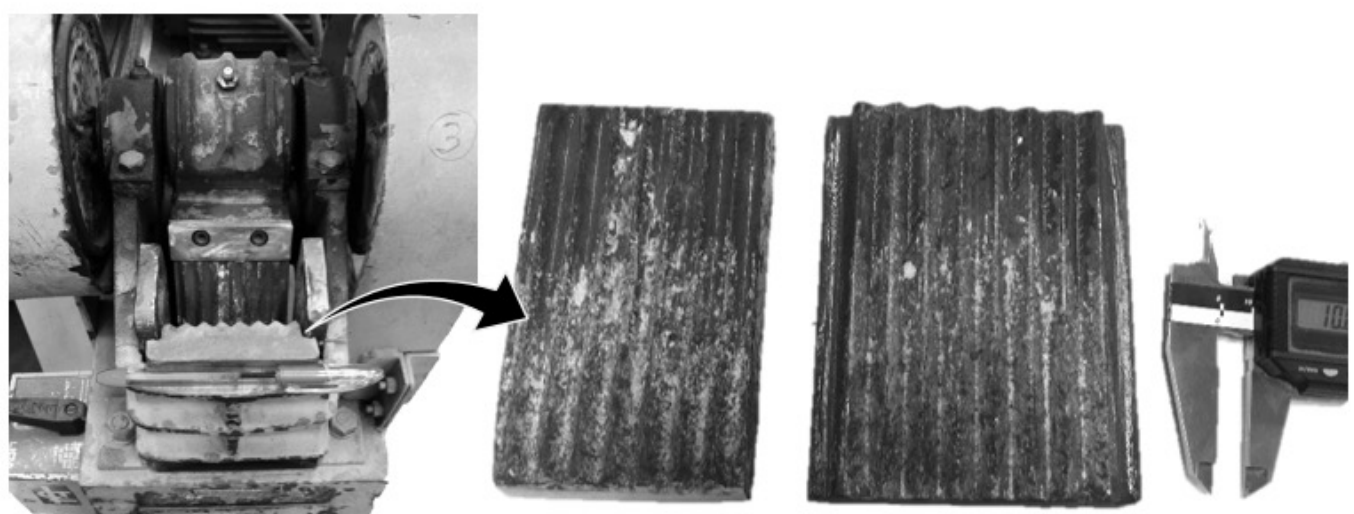


Mandibula Fixa

b)
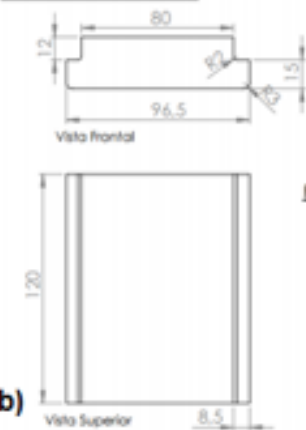

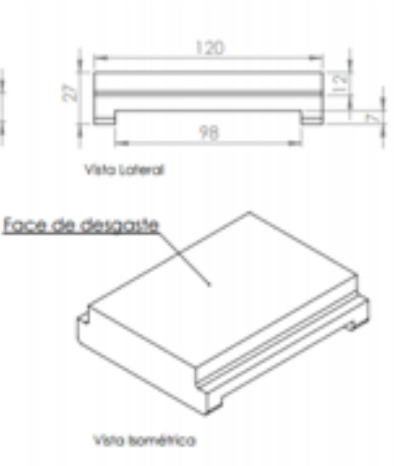

Mandibula Móvel

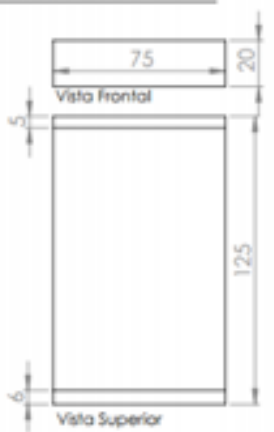

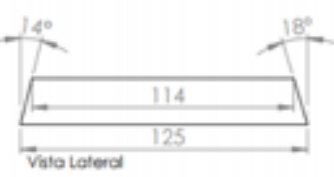

Face de deraoste

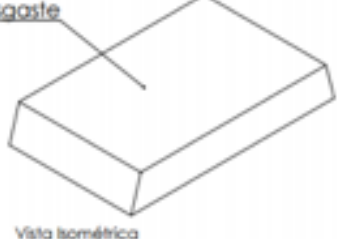

A fabricação das mandíbulas foi realizada por fundição em molde de areia na empresa METSO em Sorocaba - SP. O modelo das mandíbulas (Figura 3.3), utilizado no processo de fundição, foi fabricado em madeira com capacidade de fabricação de 12 pares de lingotes de mandíbula por vazamento. O modelo tem de dois lados, o lado A com as réplicas das mandíbulas fixas e móveis, e com o canal de vazamento, Figura 3.3a. E o lado $\mathrm{B}$ disposto com as áreas para o massalote e canais de liberação de gases. O modelo dos lingotes das mandíbulas fixa e móvel foi projetado com dimensões maiores que as apresentadas na Figura 3.3b, com o objetivo de gerar microestrutura semelhantes às encontradas em revestimentos de britadores de escala industrial.

Figura 3.3. Modelo para fundição em molde de areia das mandíbulas fixa e móvel. a) Lado A. b) Lado B

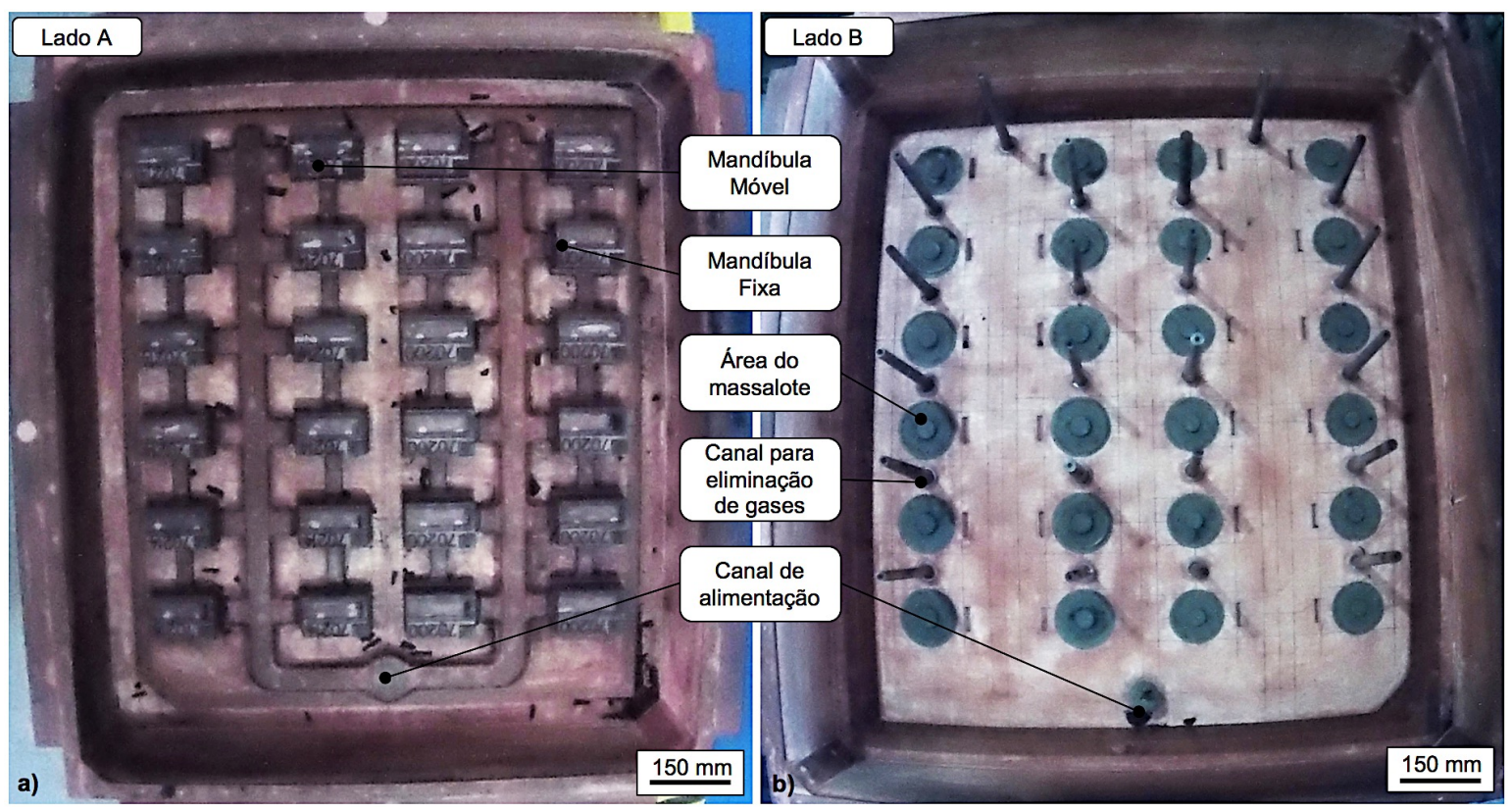

A Figura 3.4 mostra os lingotes após o resfriamento, correspondendo a 12 pares de mandíbulas. 
Figura 3.4. Mandíbulas fundidas desmoldadas. a) Bloco da mandíbula fixa. b) Conjunto fundido. c) Bloco da mandíbula móvel
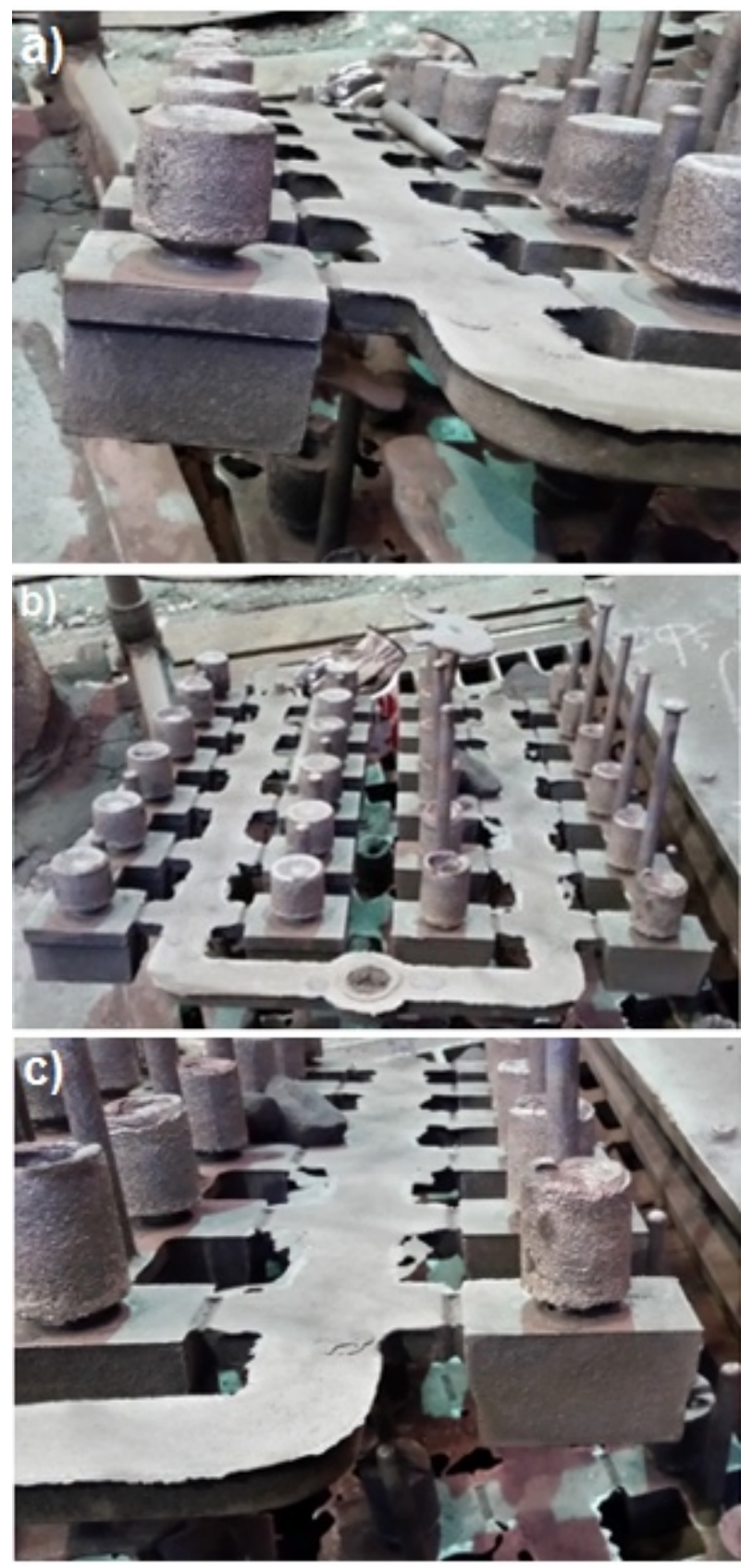

Após o resfriamento completo do material bruto de fundição, os fundidos foram submetidos ao processo de tratamento térmico isotérmico a $1.100{ }^{\circ} \mathrm{C}$ para dissolver em matriz austenítica os carbonetos contínuos, carbonetos aciculares, carbonetos eutéticos e colônias perlíticas (KUYUCAK; ZAVADIL; NEWCOMBE. P., 2001c). Ao final do tratamento as peças passaram pelo processo de resfriamento rápido em água para evitar a reprecipitação de segunda fase em contorno de grão. 
Os lingotes mostrados na Figura 3.4 foram cortadas com eletro-erosão à fio para obtenção da geometria final das mandíbulas. O acabamento das faces de desgaste foi realizado com retifica para conferir a padronização da superfície, Figura 3.5.

Figura 3.5. Mandíbulas fixas e móveis retificadas

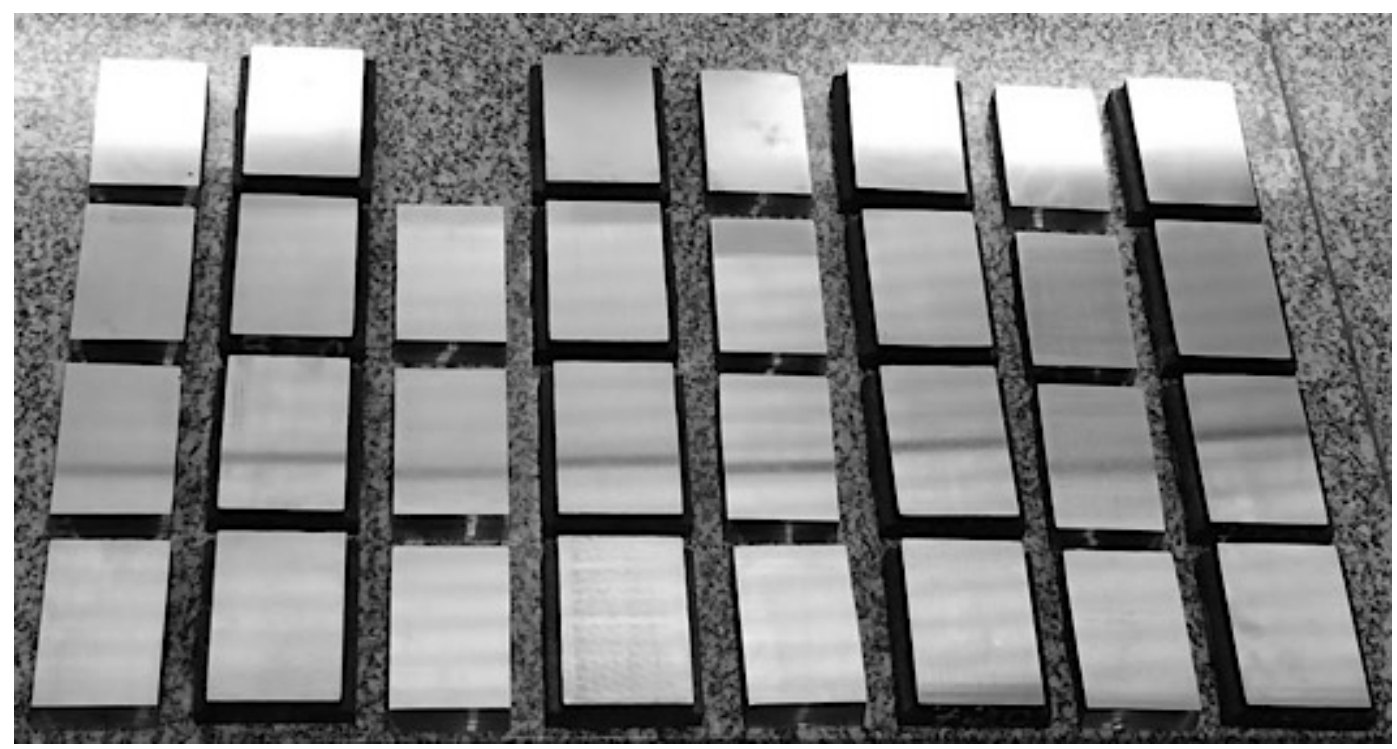

\subsubsection{Ensaio de britador de mandíbula}

O ensaio de britador de mandíbula foi realizado em um britador de laboratório, a Figura 3.6 mostra um desenho simplificado da vista lateral do britador de mandíbula com indicação dos seus parâmetros dimensionais ( $L=$ comprimento da câmara; $\mathrm{AA}=$ abertura de alimentação; APA = abertura de saída (posição aberta); APF = abertura de saída (posição fechada) e; $\alpha$ = ângulo de esmagamento). A norma (ASTM G81, 2007) sugere procedimentos e parâmetros para este tipo de ensaio. Os principais pontos da norma a serem destacados são: uso de material de referência durante o ensaio e a utilização de $908 \mathrm{~kg}$ de abrasivo por ensaio. 
Figura 3.6. Desenho da vista lateral do britador de mandíbulas com indicação de parâmetros dimensionais. $L=$ comprimento da câmara; $A A$ = abertura de alimentação; APA = abertura de saída (posição aberta); APF = abertura de saída (posição fechada) e; $\alpha$ = ângulo de esmagamento.

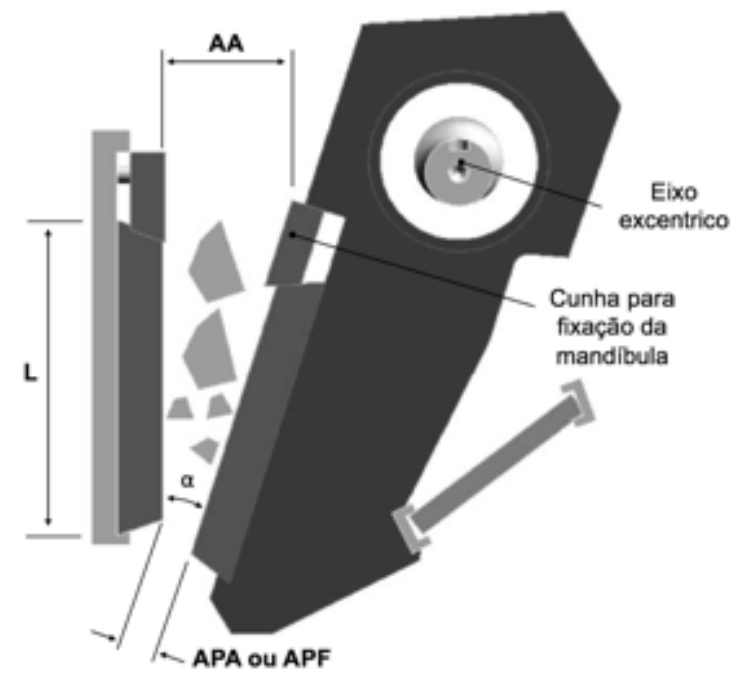

Fonte: Adaptado de Lindqvist; Evertsson, 2003

Blickensderfer, Madsen e Tylczac propuseram uma versão mais compacta que o proposto pela norma G81 (ASTM G81, 2007). Os autores utilizaram amostras de referência durante o ensaio, conforme indicação da norma, entretanto, apenas um décimo da massa de abrasivo proposta pela norma com a justificativa de que o britador (mandíbulas) tinha menores dimensões (BLICKENSDERFER; MADSEN; TYLCZAC, 1985). A Tabela 3.2 mostra os parâmetros e os valores de referência da norma e dos autores.

Tabela 3.2. Principais parâmetros de duas versões do ensaio de britador de mandíbula

\begin{tabular}{|c|c|c|}
\hline PARÂMETRO & ASTM G81-83(89) & Blickensderfer et al. \\
\hline \multicolumn{3}{|l|}{ ABRASIVO } \\
\hline Alimentação (mm) & $40-50$ & 18 \\
\hline Relação de Redução & NF & NF \\
\hline Quantidade (kg) & 908 & 90 \\
\hline \multicolumn{3}{|l|}{ CONDIÇÕES } \\
\hline Abertura (mm) & $3,2 \pm 0,8$ & 3,2 \\
\hline Carga $(\mathrm{N})$ & NF & 12500 \\
\hline Duração (min) & NF & $50-70$ \\
\hline Velocidade (ciclos/min) & NF & 260 \\
\hline \multicolumn{3}{|l|}{ PEÇA - Dimensões (mm) } \\
\hline FIXA & $137 \times 191 \times 22$ & $135 \times 75 \times 25$ \\
\hline MÓVEL & $132 \times 216 \times 18$ & $135 \times 75 \times 25$ \\
\hline
\end{tabular}

NF: não fornecido

Fonte: Pintaúde, 1998 
Sare, Arnold e Constantine mostraram que a avaliação do desgaste abrasivo de uma serie de materiais metálicos via ensaio de britador de mandíbula independe de um material de referência (SARE; ARNOLD, 1989; SARE; CONSTANTINE, 1997). Diesburg e Borik utilizaram material de referência de acordo com as especificações da norma G81, assim como massa de abrasivo (DIESBURG, D. E.; BORIK, F., 1974). Pintaúde realizou ensaio de britador de mandíbula com $150 \mathrm{~kg}$ de abrasivo sem material de referência para as mandíbulas (PINTAÚDE, 1998). Enquanto, Tolfree utilizou 454 a 908 kg de abrasivo e material de referência (TOLFREE, 2004). A literatura relacionada à metodologia do ensaio de britador de mandíbula mostra que cada pesquisa tem seus próprios parâmetros de ensaio, como por exemplo, quantidade de abrasivo, dimensões e geometria das mandíbulas. Estas observações mostram que os parâmetros de ensaio ainda estão em discussão pela comunidade científica.

Os valores dos parâmetros dimensionais mostrados na Figura 3.6 foram $\mathrm{L}=120 \mathrm{~mm}, \mathrm{AA}=50 \mathrm{~mm}, \mathrm{APA}=12 \mathrm{~mm}$ e APF $=3 \mathrm{~mm}$. A massa de abrasivo para cada ensaio foi definida a partir de um ensaio com mandíbulas de referência fabricadas de aço Hadfield classe B-4 (ASTM G128, 2012).

Nesta pesquisa uma bancada de alimentação de abrasivo foi projetada e fabricada na oficina de máquinas operatrizes do Departamento de Mecatrônica da Escola Politécnica de USP-SP. A bancada é constituída por um funil de alimentação e um alimentador vibratório, os quais alinhados a um britador de mandíbula de escala laboratorial formam um sistema de britagem para realização do ensaio, Figura 3.7. 
Figura 3.7. Sistema de britagem - ensaio de britador de mandíbula

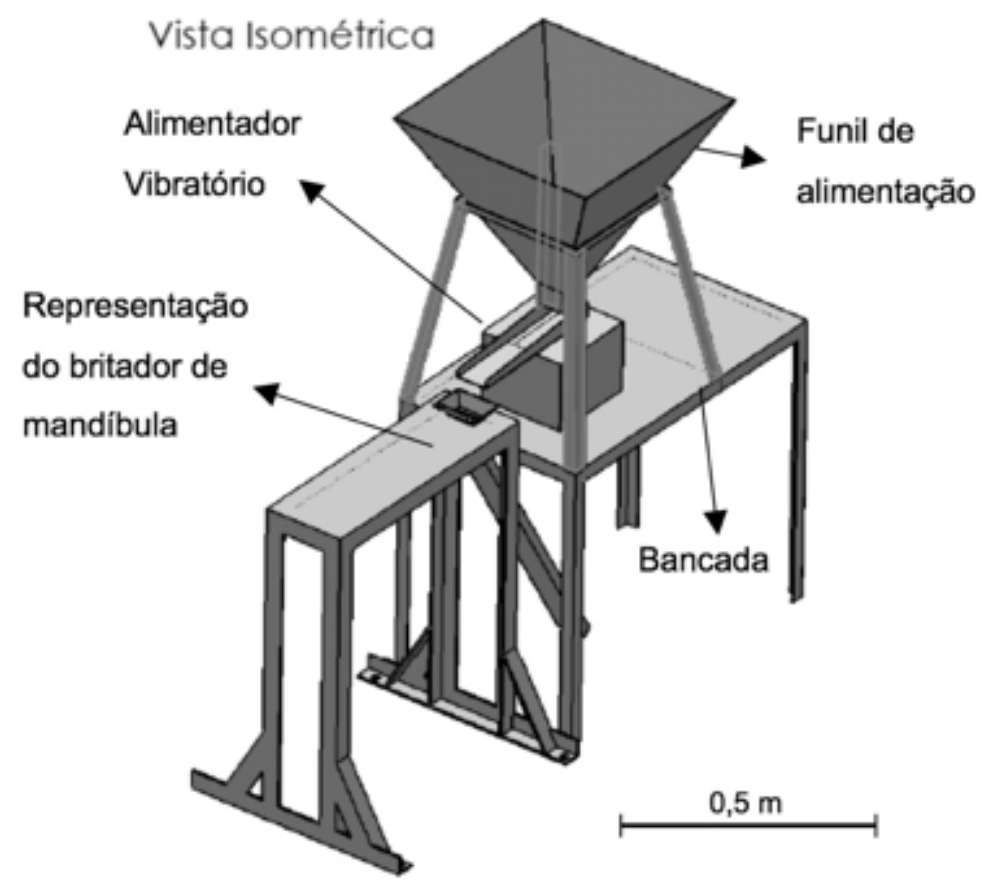

A massa de abrasivo a ser utilizada no ensaio foi definida com um ensaio preliminar interrompido com mandíbula de aço Hadfield classe B-4. A perda de massa das mandíbulas foi obtida a cada $40 \mathrm{~kg}$ de abrasivo britado, totalizando $240 \mathrm{~kg}$. A Figura 3.8 mostra o gráfico de perda de massa em função da massa de abrasivo britado, observa-se que para o intervalo de 40 a $240 \mathrm{~kg}$ a perda de massa das mandíbulas fixa e móvel tem comportamento linear, deste modo, a massa de abrasivo do ensaio pode ter um valor que esteja contido no intervalo de massa avaliado. O uso desta metodologia (ensaio interrompido para obter a massa de abrasivo para o ensaio) não foi observado nas pesquisas realizadas pelos autores (DIESBURG, D. E.; BORIK, F., 1974; SARE; ARNOLD, 1989; SARE; CONSTANTINE, 1997; TOLFREE, 2004).

Outro resultado que esta metodologia mostrou está relacionado ao running in, observa-se que o coeficiente linear das equações de regressão linear é negativo para a perda de massa da MF $(-0,2)$ e da MM $(-0,1)$. Deste modo, no running in a taxa de desgaste é inferior a taxa do regime permanente de desgaste. Este resultado pode estar associado ao acabamento de retífica que confere à superfície encruamento prévio. 
Figura 3.8. Perda de massa das mandíbulas fixa e móvel acumulada em função do peso de abrasivo britado. Ensaio interrompido para levantamento de massa de abrasivo

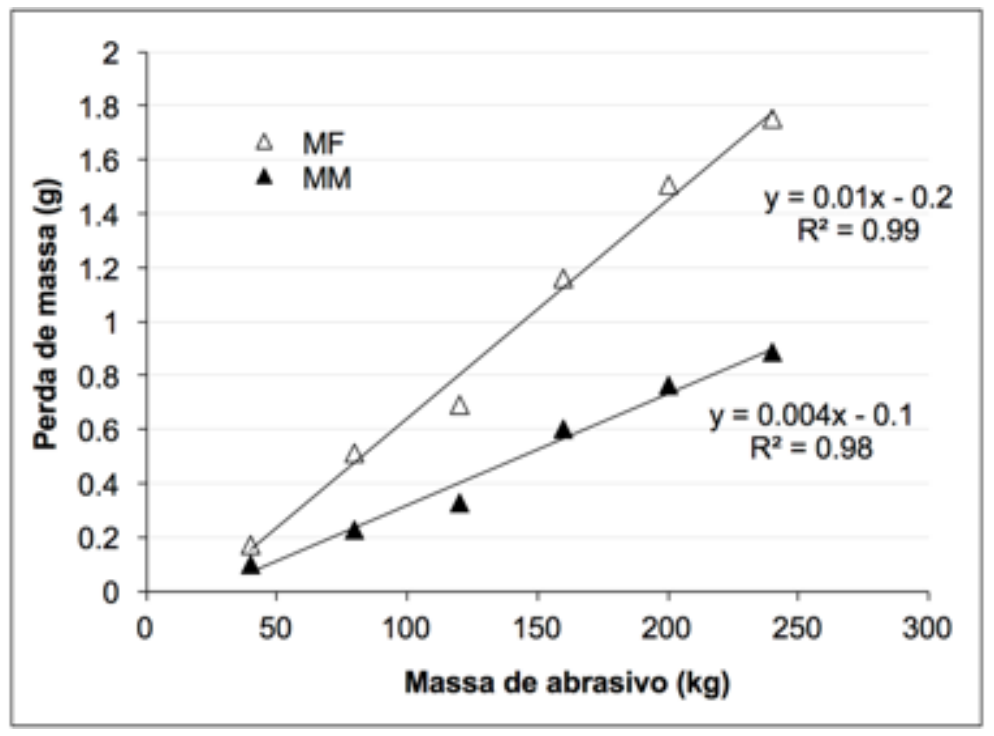

A quantidade de abrasivo por ensaio foi definida em $100 \mathrm{~kg}$. O abrasivo utilizado foi a brita tipo 1 com tamanho médio (média ponderada) de 14,3 mm (+6,35 -19,05) e umidade de $0,5 \%$. Os gráficos de percentual acumulado de abrasivo retido em função da abertura da peneira (a) e de percentual de abrasivo retido (b) são mostrados na Figura 3.9.

Figura 3.9. Resultados da classificação por peneiramento do abrasivo para o ensaio. a) Percentual acumulado de abrasivos retidos. b) Percentual de abrasivos retidos.

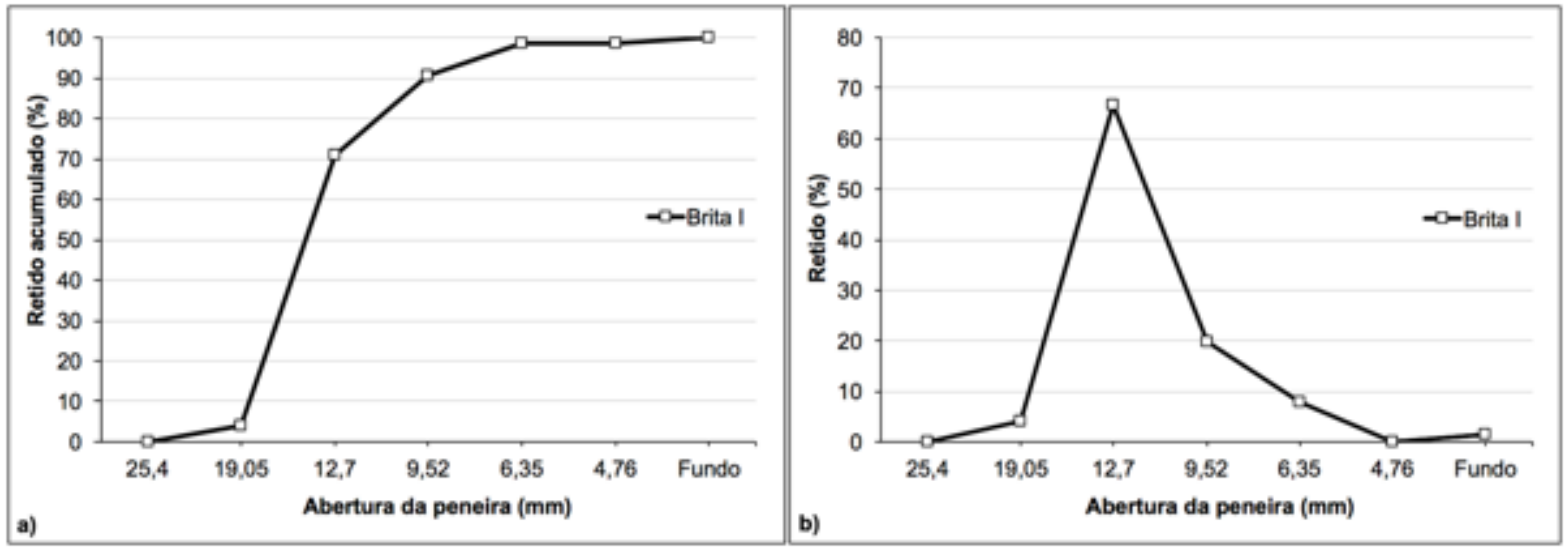

O experimento foi realizado com três repetições para cada material, sem o preenchimento total da mandíbula para evitar travamento do britador. O fluxo de abrasivo de $8,5 \mathrm{~kg} / \mathrm{min}$ foi aferido com o alimentador vibratório ERIEZ Magnetics modelo 10A-26. O preenchimento incompleto da mandíbula resulta em maior força no contato abrasivos-revestimentos (mandíbula fixa - MF e mandíbula - móvel), 
devido ao menor número de pontos para distribuição de carga. A alimentação de abrasivo foi realizada de forma interrompida com britagem de $50 \mathrm{~kg}$ seguido de parada para controle da abertura de saída na posição fechada (APF) das mandíbulas em $3 \mathrm{~mm}$ e, em seguida, britagem dos $50 \mathrm{~kg}$ restantes.

A pesagem das amostras foi realizada antes e após o ensaio com uma balança marca CHYO, modelo MJ3000, com capacidade de $3.100 \mathrm{~g}$ e resolução de $0,01 \mathrm{~g}$ (LFS - PME-Poli/USP). Antes da pesagem limparam-se as mandíbulas com ultrassom por 10 minutos com álcool etílico 99 \%. Na Figura 3.2 observou-se que as áreas das mandíbulas fixa e móvel tem áreas superficiais (superfície de desgaste) distintas. A mandíbula fixa tem $0,0096 \mathrm{~m}^{2}$, enquanto a mandíbula móvel $0,0077 \mathrm{~m}^{2}$, havendo uma diferença de $20 \%$ entre as áreas das mandíbulas fixa e móvel. Portanto, para comparar a perda de massa entre as mandíbulas fixa e móvel, a perda de massa será corrigida com o valor de área da face de desgaste da respectiva mandíbula, ou seja, será avaliado o desgaste relativo que equivale à razão entre a perda de massa e a área da face de desgaste para $100 \mathrm{~kg}$ de abrasivo britado.

O sistema de britagem foi instalado na empresa Serveng (Baruerí-SP) para realização dos ensaios. O britador utilizado de marca FURLAN foi disponibilizado pelo Laboratório de Caracterização Tecnológica - LCT (Engenharia de Minas e Petróleo - Poli/USP). A Figura 3.10a mostra o sistema de britagem em operação. Na Figura $3.10 b$ é mostrado a vista superior da alimentação de abrasivo.

Figura 3.10. a) Sistema de britagem em operação. b) Vista superfior da alimentação de abrasivo
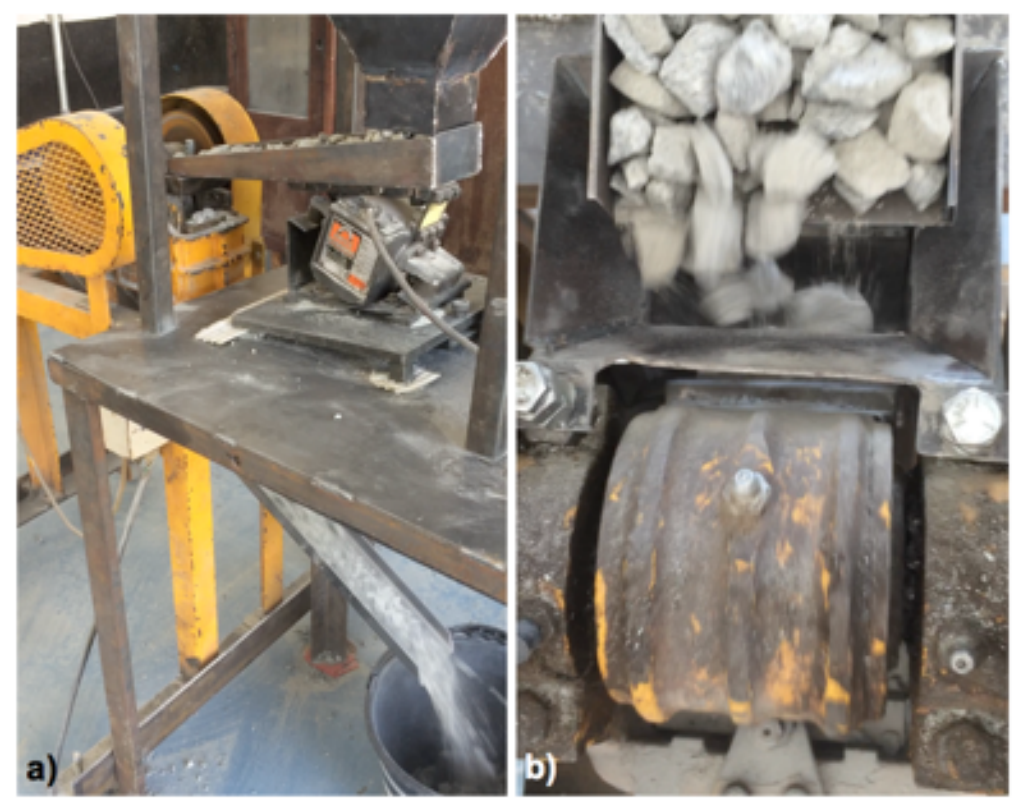
Os abrasivos utilizados nos ensaios foram fornecidos pela empresa Serveng tendo como origem a frente de lavra da unidade Baruerí-SP. A análise petrográfica do abrasivo, realizada pelo Laboratório de Materiais de Construção Civil do IPT-SP, mostrou que sua natureza é ígnea e tem composição mineralógica de 35 a 40 \% de plagioclásio (feldspato de família sódica [albita] e de família cálcica [anortita]), $25 \%$ de microclínio (feldspato de família potássica), $20 \%$ de quartzo, 10 a $15 \%$ de biotita (mica) e outros minerais em menor quantidade. Para confirmar os dados da análise petrográfica foi realizado no Laboratório de Caracterização Tecnológica (Engenharia de Minas e Petróleo - Poli/USP) a análise de difração de raio-X do abrasivo com o equipamento X'Pert PRO Panalytical com detector X'Celerator e tubo Cu-Ka. Para esta análise utilizou-se os seguintes parâmetros: $45 \mathrm{kV}, 40 \mathrm{~mA}$, ângulo de varredura de $2^{\circ}$ a $90^{\circ}$, passo de $0,02^{\circ}$ e tempo por passo de $50 \mathrm{~s}$. O difratograma do material do abrasivo, Figura 3.11, obteve os padrões para dois tipos de feldspato (albita e microclínio), biotita e quartzo. Assim, confirmando os resultados da análise petrográfica.

A análise de tensão de ruptura do abrasivo via ensaio de compressão axial (NBR6953, 1990), realizada pelo Laboratório de Materiais de Construção Civil do IPT-SP, obteve um valor médio de 180,2 $\pm 8,0 \mathrm{MPa}$ ou $1.837 \pm 81 \mathrm{kgf} / \mathrm{cm}^{2}$ para seis repetições do experimento.

Figura 3.11. Difratograma do abrasivo

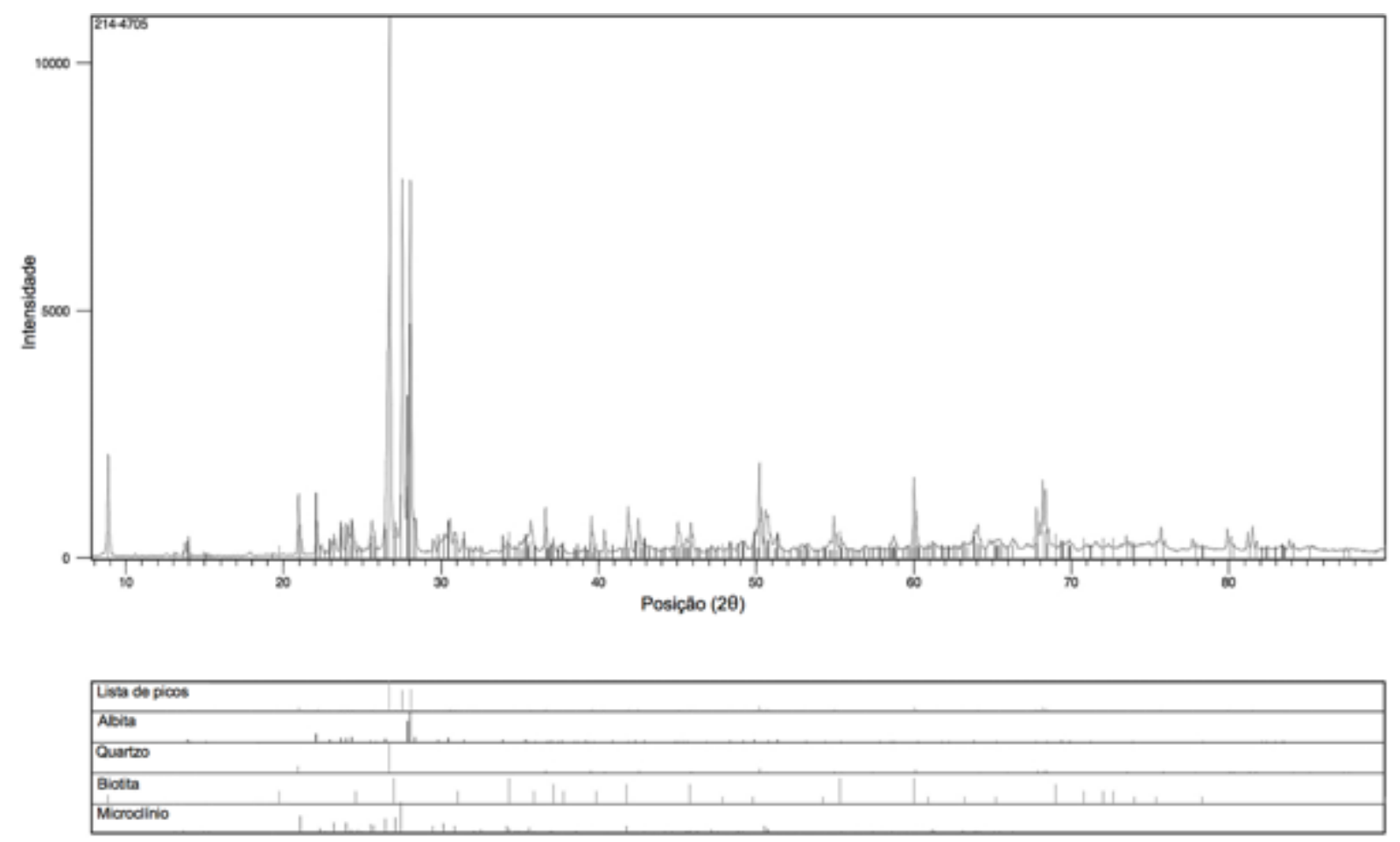




\subsubsection{Caracterização microestrutural}

A preparação das amostras para análise microestrutural passou por etapas sucessivas de metalografia: lixamento semi-automático com lixas de $\mathrm{SiC} \# 80$ a \#1.200, polimento semi-automático com solução de diamante de $10 \mu \mathrm{m}$ a $1 \mu \mathrm{m}$ e ataque químico por imersão com reagente picral $4 \%$.

As micrografias foram obtidas via Microscopia Óptica (MO) com microscópico OLYMPUS BX60M com câmera JVC TK-1380 do LFS (PME-Poli/USP). As micrografias da subsuperfície foram obtidas via FIB (FEI QUANTA 3D FEG - IPT).

$O$ software Imagem $\mathrm{J}$ foi utilizado para quantificar a porosidade e o tamanho de grão do aço de acordo com a metodologia de intercessão descrita na norma ASTM E112 (ASTM E112, 2014).

\subsubsection{Caracterização do micromecanismos de desgaste}

A caracterização dos micromecanismos de desgaste foi realizada nas regiões de entrada, central e de saída das faces de trabalho das mandíbulas fixa e móvel, Figura 3.12. Nota-se que o desgaste das mandíbulas é concentrado na região central e de saída, devido o preenchimento incompleto de abrasivo.

As técnicas empregadas para caracterização das superfícies desgastadas foram a estereografia óptica com o equipamento NIKON SMZ800, câmera digital DXM1200F (LFS - PME-Poli/USP) nas regiões de entrada, central e de saída da mandíbula (Figura 3.12), interferometria óptica 3D com o equipamento CCI TAYLOR ROBSON (LFS - PME-Poli/USP) nas regiões central e de saída; e microscopia eletrônica de varredura com o equipamento JEOL JSM-6010LA (LFS - PME-Poli/USP) na região de saída, local de maior desgaste das mandíbulas. Os parâmetros de análise e o pré-processamento de imagem utilizados na análise de interferometria foram: objetiva 10X, resolução de 512 x 512 (modo: xyz), área de $72,25 \mathrm{~mm}^{2}(8,5 \times 8,5 \mathrm{~mm})$ com matriz $6 \times 6$ (procedimento: stitching), preenchimento de pontos não medidos $(<2,5 \%)$ e nivelamento da superfície. 
Figura 3.12. Mandíbula fixa e móvel após ensaio de britador de mandíbula. A caracterização de micromecanismo de desgaste foi realizado na região de saída das mandíbulas

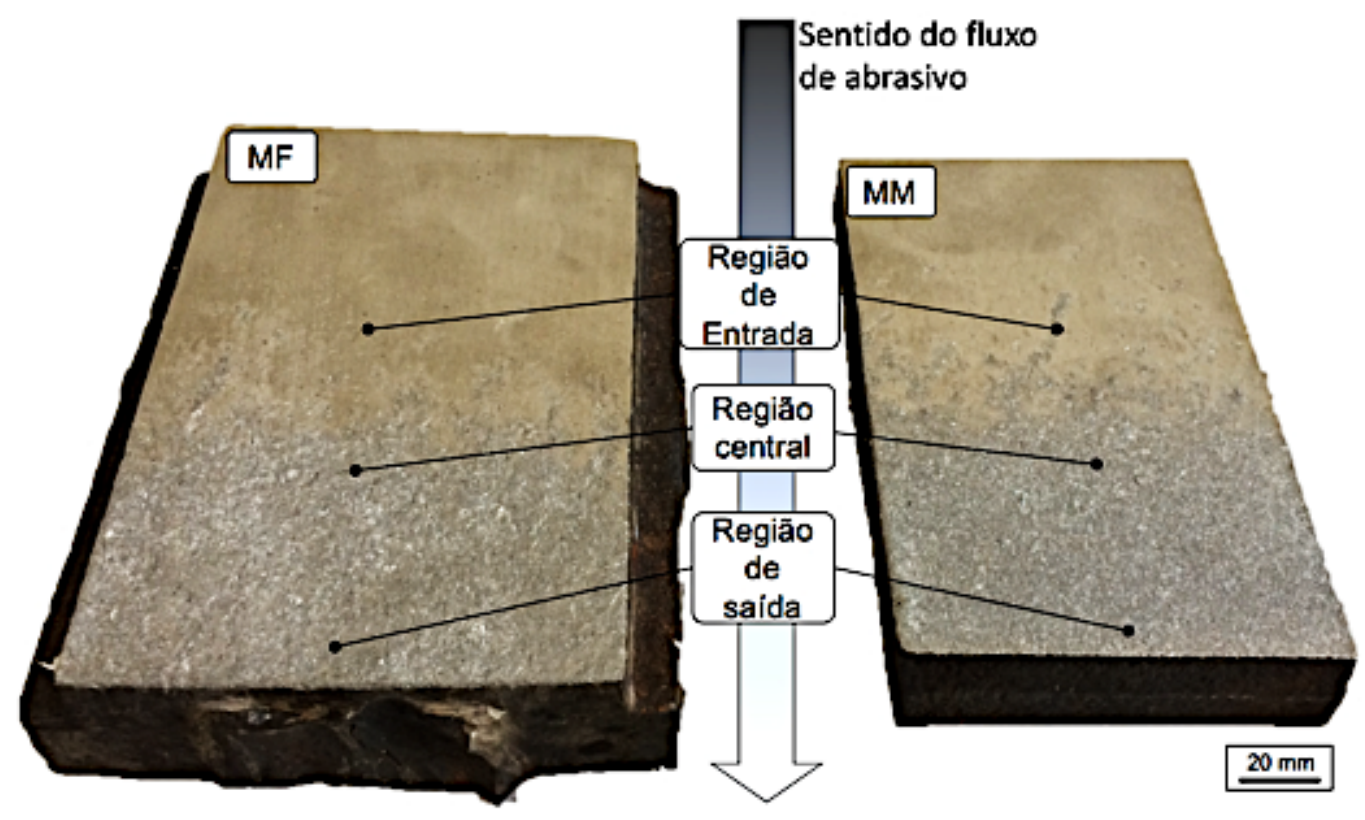

\subsubsection{Macrodureza e perfil de microdureza}

Os ensaios de macrodureza foram feitos conforme a norma (ASTM E384, 2012) com os durômetros Buehler VMT-7 do LFS (PME-Poli/USP), força normal de 30 kgf e 5 repetições.

O perfil de microdureza Vickers foi realizado na seção transversal da amostra, logo abaixo da superfície desgastada da região de saída. Para os ensaios foi utilizado o microdurômetro Buehler MMT-3 (LFS - PME-Poli/USP) com carga de 0,3 kgf e 4 repetições para cada posição (distância da superfície desgastada). A distância analisada foi de $7 \mathrm{~mm}$ com espaçamento de $0,25 \mathrm{~mm}$ até a distância $3,5 \mathrm{~mm}$ e espaçamento de $0,5 \mathrm{~mm}$ até a distância $7 \mathrm{~mm}$. 


\subsection{RESULTADOS E DISCUSSÕES}

\subsubsection{Microestrutura dos aços}

A Figura 3.13 mostra as micrografias (MO) das mandíbulas fixa e móvel para os aços $12 \mathrm{Mn}$ e $20 \mathrm{Mn}$.

Figura 3.13. Micrografias das mandíbulas fixa e móvel para os aços $12 \mathrm{Mn}$ e $20 \mathrm{Mn}$. 50X
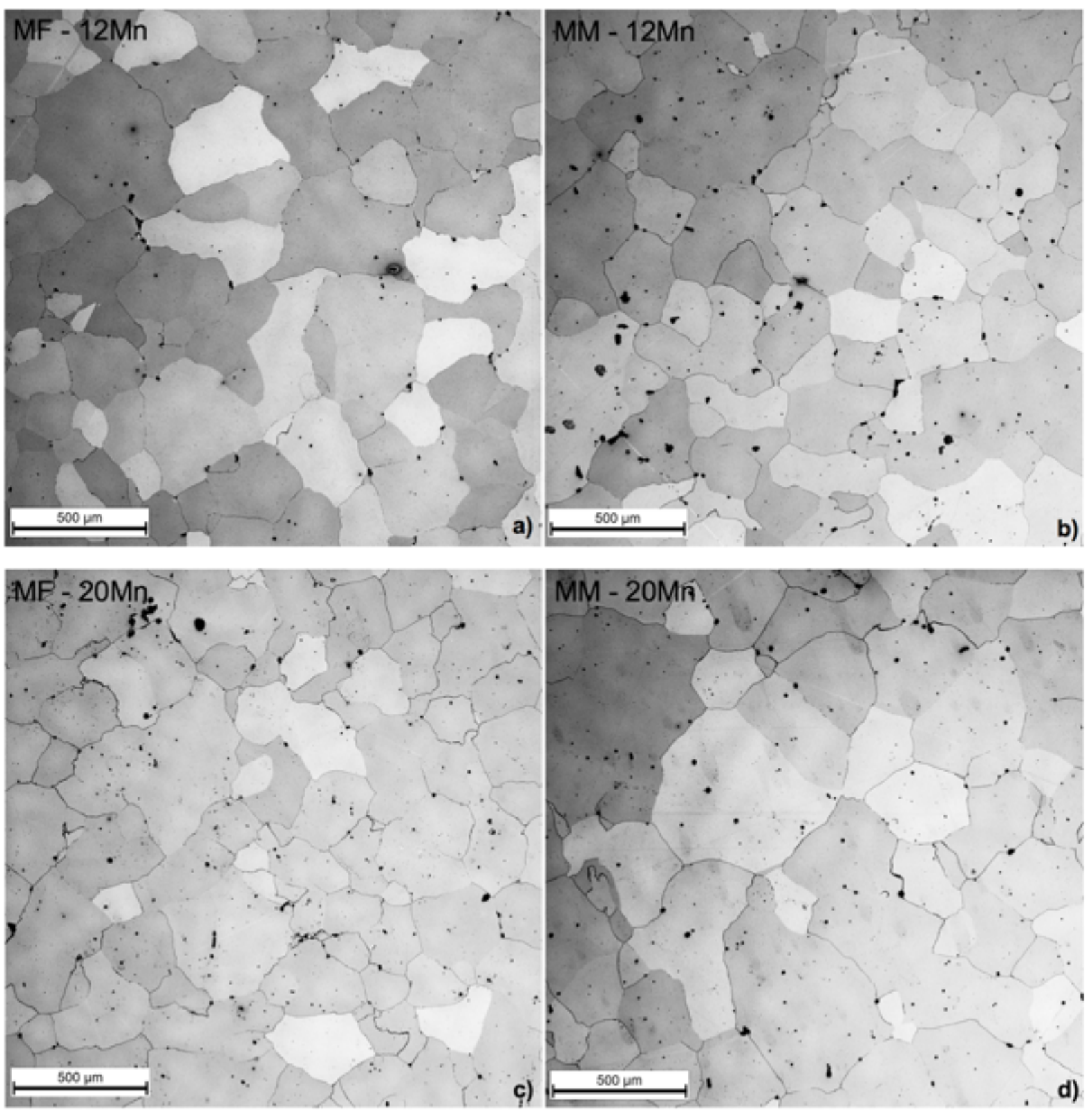

O tamanho de grão médio do par de mandíbulas para os aços $12 \mathrm{Mn}$ e $20 \mathrm{Mn}$ equivale a $191 \pm 9 \mu \mathrm{m}$ e $219 \pm 16 \mu \mathrm{m}$, respectivamente. Estes resultados mostram que o uso do modelo de mandíbulas com maior volume no processo de fundição foi 
eficaz. O tamanho de grão do aço Hadfield de um revestimento de britador (escala macro) analisado nesta pesquisa equivale a $247 \pm 9 \mu \mathrm{m}$, apenas $17 \%$ de diferença entre o valor médio dos aços $12 \mathrm{Mn}$ e $20 \mathrm{Mn}$. A porosidade dos aços $12 \mathrm{Mn}$ e $20 \mathrm{Mn}$ foram iguais, no entanto, ao comparar entre as mandíbulas fixa e móvel tem-se $41 \%$ de diferença, indicando que os fatores associados ao processo de fabricação (volume do molde e massalote, por exemplo) são os que tem efeito sobre o resultado de porosidade, Tabela 3.3.

Tabela 3.3. Porosidade (\%) dos aços $12 \mathrm{Mn}$ e $20 \mathrm{Mn}$

\begin{tabular}{ccccc} 
& \multicolumn{4}{c}{ Porosidade (\%) } \\
\cline { 2 - 5 } & \multicolumn{2}{c}{$12 \mathrm{Mn}$} & \multicolumn{2}{c}{$20 \mathrm{Mn}$} \\
\cline { 2 - 5 } & MF & MM & MF & MM \\
\hline Média & $0,28 \pm 0,02$ & $0,50 \pm 0,06$ & $0,29 \pm 0,03$ & $0,47 \pm 0,03$
\end{tabular}

\subsubsection{Distribuição granulométrica dos abrasivos britados}

Os gráficos comparativos de percentual acumulado de abrasivo retido em função da abertura da peneira (a) e a distribuição percentual de abrasivo retido (b) para antes e depois da britagem são mostrados na Figura 3.14. O abrasivo após britagem (ensaio) teve distribuição de tamanho com valor médio ponderado de 9,0 $\mathrm{mm}$, com uma curva de distribuição mais achatada (distribuição de tamanhos mais homogênea) que a curva para o material antes do ensaio, Figura 3.14b. A redução do tamanho médio de abrasivo foi de $37 \%$.

Figura 3.14. Percentual acumulado de abrasivos retidos em função da abertura da peneira (a) e percentual de abrasivos retidos (b) antes e depois do processo de britagem

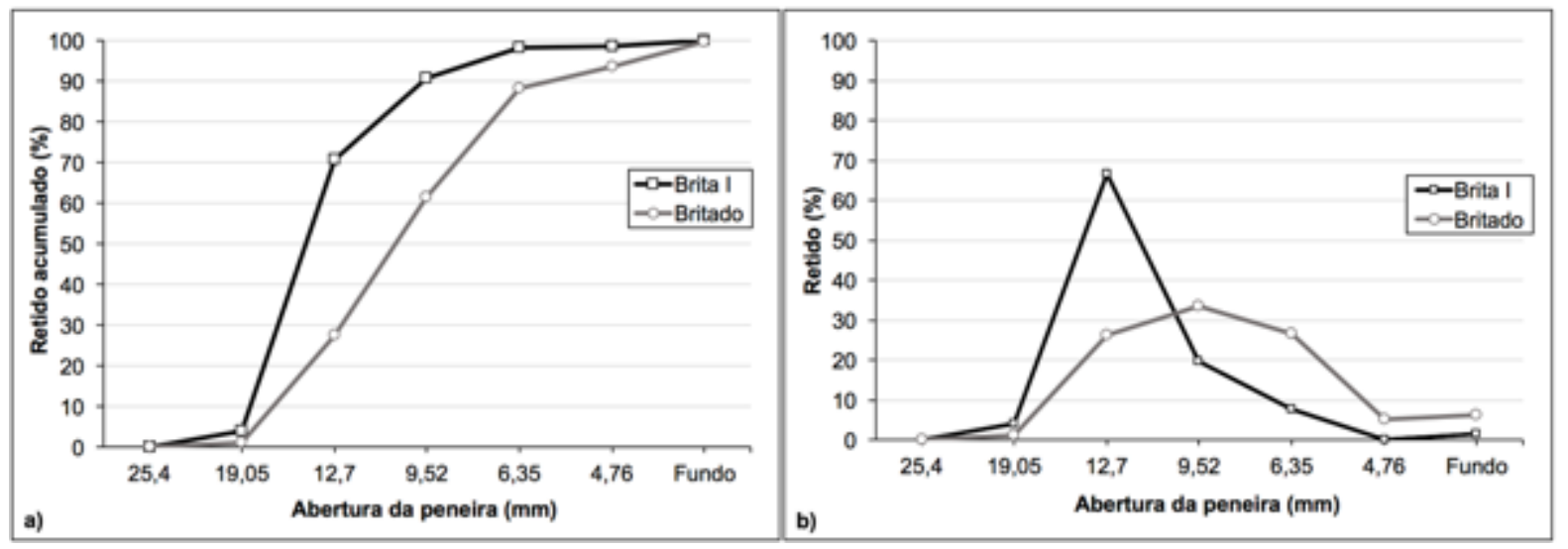




\subsubsection{Desgaste dos revestimentos das mandíbulas}

\subsubsection{Perda de massa}

Os resultados de perda de massa para as mandíbulas fixa e móvel dos materiais $12 \mathrm{Mn}$ e $20 \mathrm{Mn}$ são mostrados na Tabela 3.4. Os valores de erro mostrados nesta Tabela e nos demais resultados desta tese são referentes aos seus respectivos valores de incerteza da média, os quais representam o erro para o valor médio. A incerteza da média é calculada a partir da divisão do valor do desvio padrão das amostras pela raiz quadrada do número de amostras, esta metodologia permite comparar valores médios de uma determinada grandeza tendo uma referência correta dos valores de erro (incerteza da média). No Apêndice $D$ é descrito um exemplo desta questão.

Tabela 3.4. Desgaste relativo $\left(\mathrm{g} / \mathrm{m}^{2}\right)$ das MF e MM para $100 \mathrm{~kg}$ de abrasivo britado

\begin{tabular}{ccccccccc} 
& \multicolumn{8}{c}{ Desgaste relativo $\left(\mathrm{g} / \mathrm{m}^{2}\right)^{*}$} \\
\cline { 2 - 9 } Aços & E.1 & E.2 & E.3 & Média & E.1 & E.2 & E.3 & Média \\
\hline 12Mn & 137 & 158 & 147 & $147 \pm 6$ & 85 & 61 & 53 & $66 \pm 10$ \\
20Mn & 107 & 142 & 124 & $124 \pm 10$ & 80 & 109 & 67 & $85 \pm 13$
\end{tabular}

* perda de massa para $100 \mathrm{~kg}$ de abrasivo britado corrigido com o valor de área superficial da respectiva mandíbula, fixa ou móvel.

Nota-se que a mandíbula fixa tem maior desgaste relativo que a mandíbula móvel, com a diferença de $55 \%$ para $12 \mathrm{Mn}$ e $32 \%$ para $20 \mathrm{Mn}$, correspondendo à razão (MF/MM) de 2,2 e 1,5, respectivamente. Pintaúde teve uma diferença de $68 \%$ (MF/MM = 3,2) entre a perda de massa das mandíbulas fixa e móvel de aço $2 \% \mathrm{Cr}-$ 1,5\%Si - 0,5\%Mo ensaiadas com brita tipo 1 e abertura 3 mm (APF) (PINTAÚDE, 1998). Enquanto Siriane obteve a razão de 1,72 entre a perda de massa das mandíbulas fixa e móvel de aço Hadfield ensaiadas em laboratório (SIRIANE, 1989). O gráfico com os resultados de desgaste relativo para as mandíbulas fixa e móvel (Tabela 3.4) é mostrado na Figura 3.16. Ao avaliar via teste de hipótese os valores de perda de massa considerando apenas os resultados de desgaste relativo das mandíbulas fixas dos aços $12 \mathrm{Mn}$ e $20 \mathrm{Mn}$, por apresentar maior diferença, Figura 3.15. Na Figura 3.15a observa-se, para o intervalo de confiança de $95 \%$ $(\alpha=0,05)$, que não há diferença significativa entre os resultados 
$\left(t_{0}=1,93<t_{c r}=2,13\right)$. No entanto, considerando o intervalo de confiança de $90 \%$ $(\alpha=0,1)$, tem-se diferença significativa $\left(t_{0}=1,93>t_{c r}=1,53\right)$, Figura 3.15b.

Figura 3.15. Resultados do teste de hipótese entre os resultados de perda de massa entre os aços $12 \mathrm{Mn}$ e 20Mn para (a) MF $\operatorname{com} \alpha=0,05$ e (b) MF $\operatorname{com} \alpha=0,1$

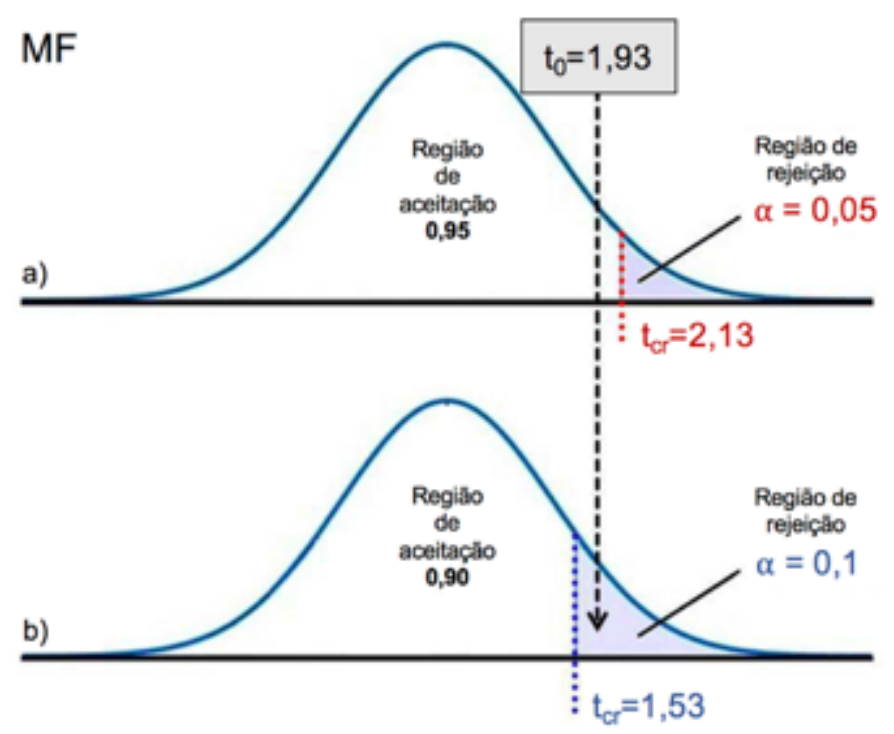

Figura 3.16. Desgaste relativo das mandíbulas fixa e móvel para os aços $12 \mathrm{Mn}$ e $20 \mathrm{Mn}$

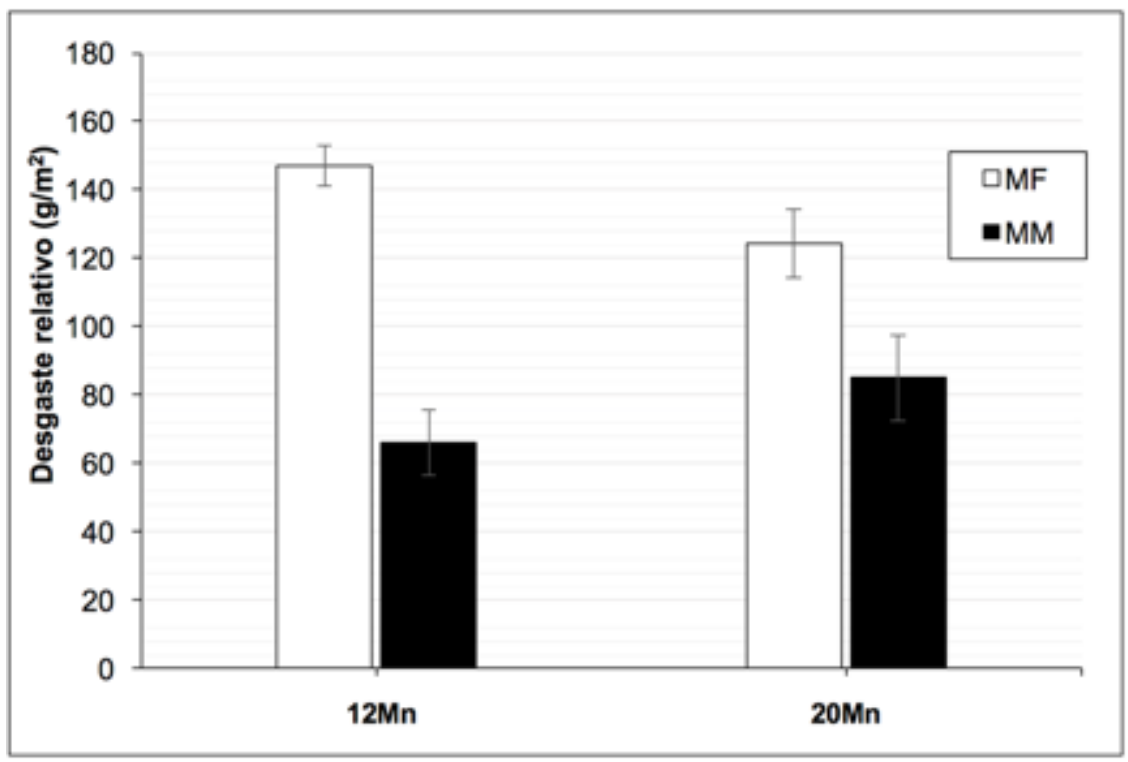

No apêndice é mostrado os resultados de desgaste relativo para o aço Hadfield classe B-4, mesmo material usado para definição de massa de abrasivo, e de um aço austenítico com $23 \% \mathrm{Mn}$, os quais foram ensaiados durante a bateria de teste dos aços $12 \mathrm{Mn}$ e $20 \mathrm{Mn}$. 
De acordo com estes resultados, considerando a metodologia empregada, o uso de revestimentos de britador com maior concentração de manganês (produto de maior valor econômico) pode não ser justificado pela diferença na resistência ao desgaste britador em relação ao aço Hadfield que tem menor concentração de manganês.

\subsubsection{Perfil de microdureza}

Os resultados dos perfis de microdureza para as mandíbulas fixa e móvel dos materiais $12 \mathrm{Mn}$ e $20 \mathrm{Mn}$ são mostrados na Figura 3.17. Os perfis de dureza das mandíbulas fixa e móvel para os dois materiais apresentaram profundidade de encruamento de 1,5 mm. Na Figura 3.17a observa-se que o valor de microdureza para a mandíbula fixa entre as distâncias de $0,25 \mathrm{~mm}$ a $1,5 \mathrm{~mm}$ é sistematicamente superior aos valores de microdureza da mandíbula móvel. O valor médio na posição mais próxima à superfície desgastada para MF foi de $715 \mathrm{HV}$, enquanto para MM foi $607 \mathrm{HV}$. As mandíbulas fixa e móvel do material 20Mn, Figura 3.17b, apresentaram valores semelhantes de dureza próximo à superfície ( $681 \mathrm{HV})$, mas ao longo do perfil os valores de dureza da mandíbula fixa mantiveram o mesmo comportamento observado no $12 \mathrm{Mn}$, sistematicamente superiores aos valores da mandíbula móvel.

Figura 3.17. Perfil de microdureza para mandíbula fixa e móvel dos materiais $12 \mathrm{Mn}$ e $20 \mathrm{Mn}$

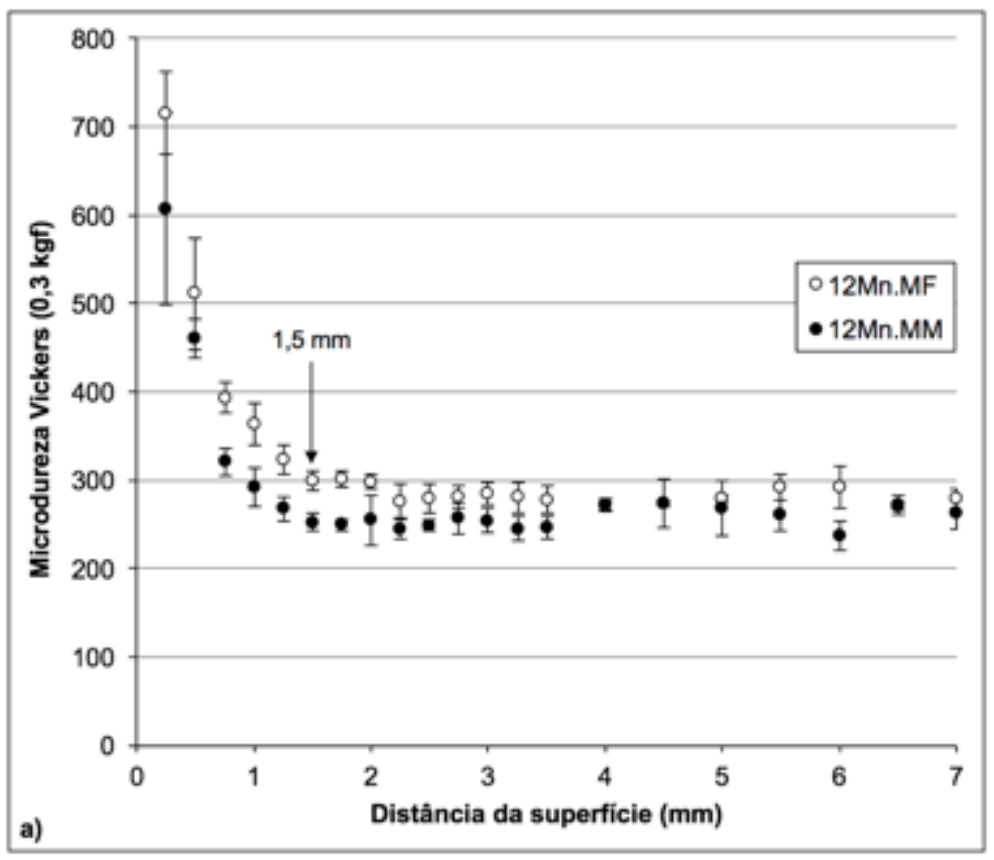




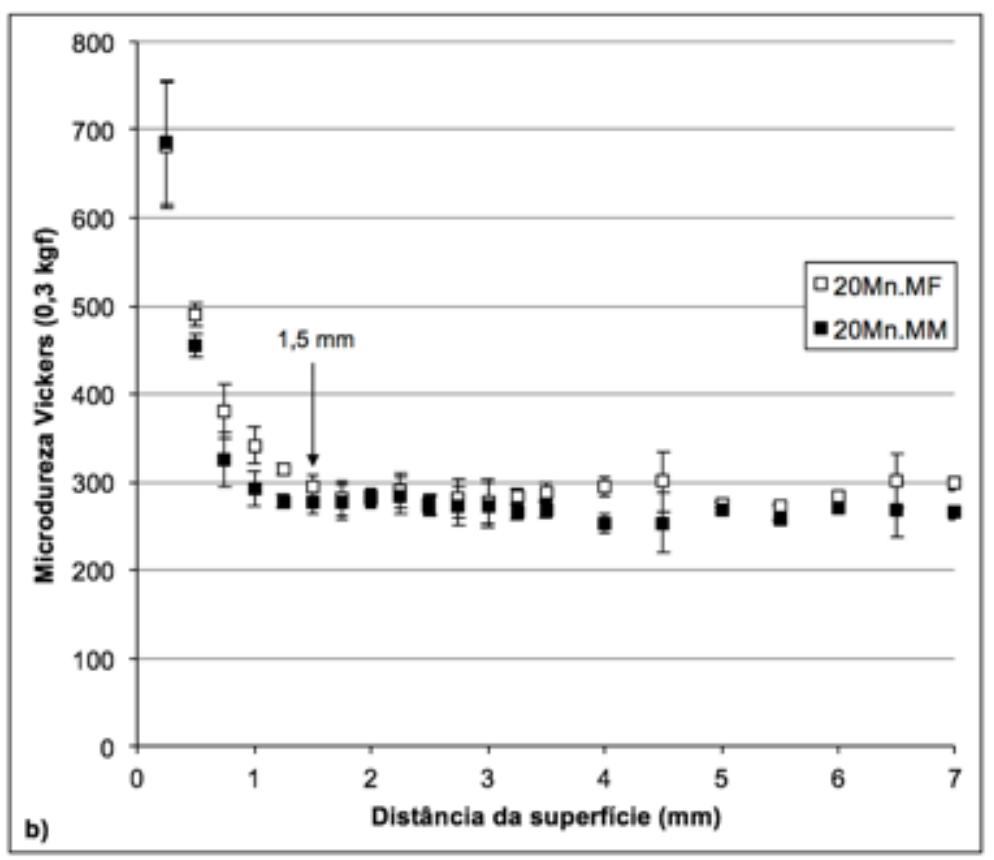

A maior dispersão dos resultados foi observada na região de maior encruamento, a $0,25 \mathrm{~mm}$ da superfície. Este comportamento pode estar relacionado às diferentes densidades de maclas de deformação de acordo com a orientação cristalina de cada grão, como observado por Karaman et al. (KARAMAN et al., 2000b).

O perfil de microdureza de aços Hadfield (classe B-1 e C) desgastados em britadores de campo atingem valores máximos de dureza semelhantes aos observados nos revestimentos desgastados em laboratório, Figura 3.18. No entanto, o perfil de dureza gerado pelo desgaste em laboratório se estabiliza em 1,5 mm, nos casos analisados de campo observam-se estabilidade a partir de $5 \mathrm{~mm}$, oscilando em torno de $300 \mathrm{HV0,3}$. Lindroos et al. e Tanaka observaram estabilidade do valor de dureza no perfil encruado em britador de mandíbula na distância de $7 \mathrm{~mm}$ (LINDROOS et al., 2015a; TANAKA, 2011). Avery mostrou que o perfil de dureza do aço Hadfield deformado por explosão para aplicação em sistemas de conversão de via ferroviária, jacaré (crossing), estabiliza a parti de $2 \mathrm{~mm}$ e tem valor máximo de aproximadamente 400 HB (AVERY, 1949). Tressia realizou ensaio de roda de borracha a úmido em aço Hadfield com diferentes granulometrias de abrasivo e carga normal constante (130 N) (TRESSIA, 2015). O autor mostrou que o perfil de microdureza para o maior abrasivo $(+1,2-2,4 \mathrm{~mm})$ teve 0 valor máximo de 670 HV0,3 e estabilizou em $135 \mu \mathrm{m}$, enquanto que para o menor abrasivo $(+0,15-0,30 \mathrm{~mm})$ os valores foram de $420 \mathrm{HV} 0,3$ e $35 \mu \mathrm{m}$, respectivamente. 
Figura 3.18. Perfil de microdureza de revestimento de britador desgastado em campo para aços Hadfield classe B-1 e classe C

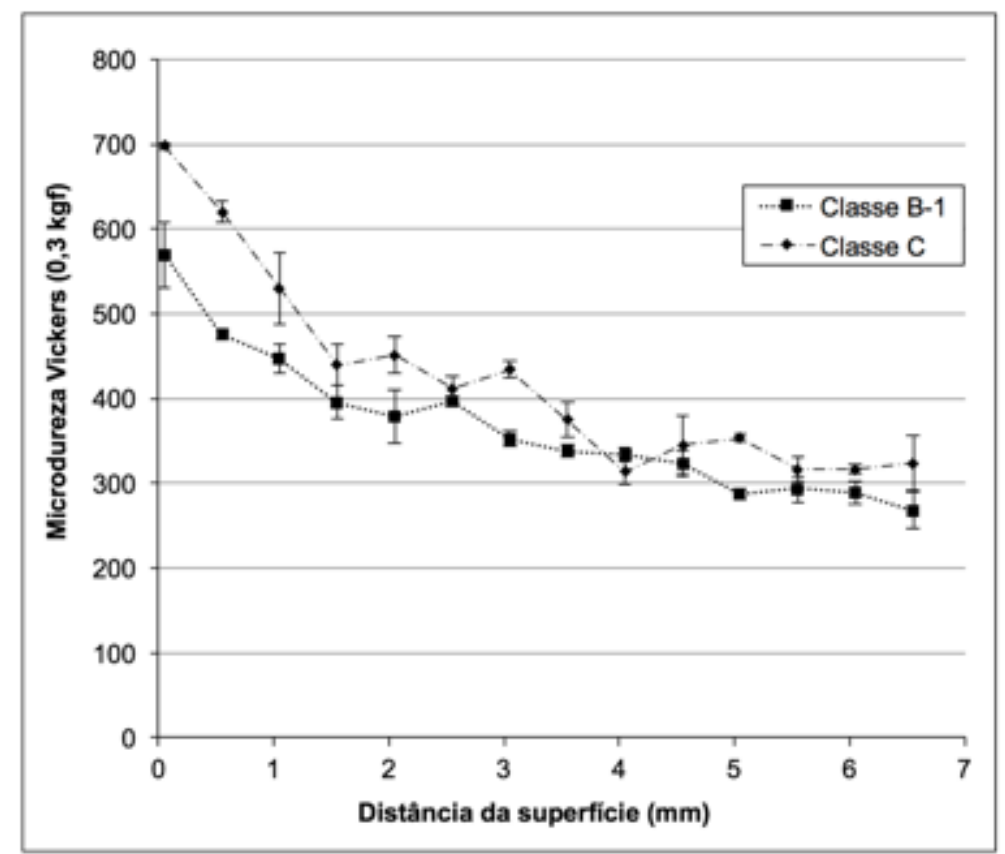

\subsubsection{Micromecanismo de desgaste}

As imagens da superfície desgastada das mandíbulas foram orientadas na direção do fluxo de abrasivo indicada na Figura 3.12, sentido norte-sul. Na ocasião de diferente orientação da imagem será indicado o sentido do fluxo de abrasivo.

A superfície desgastada das mandíbulas fixa e móvel do aço $12 \mathrm{Mn}$ obtida via estereografia são mostradas nas Figuras 3.19, 3.20 e 3.21, para as regiões de entrada, central e de saída, respectivamente.

As Figuras 3.19a e 3.19b mostram as superfícies da região de entrada da MF e da $\mathrm{MM}$, nas quais foram observados os mecanismos de desgaste. Nota-se que nesta região a superfície retificada, inicial, ainda é visível na superfície das mandíbulas desgastadas. Isto permitiu observar os mecanismos isolados com um número de eventos abrasivos reduzido. Nesta região, de entrada, da mandíbula os mecanismos têm dimensões macroscópicas. Estes resultados têm relação ao tamanho inicial dos abrasivos, os quais são fragmentados ao longo das faces das mandíbulas fixa e móvel. Portanto, notam-se para os mecanismos de desgaste diferentes escalas do fenômeno de abrasão (multiescala) ao longo das faces das mandíbulas fixa e móvel do britador de laboratório (mesoescala). 
Figura 3.19. Imagens de estereografia da região de entrada para MF (a) e MM (b), respectivamente. Aço 12Mn. 5X

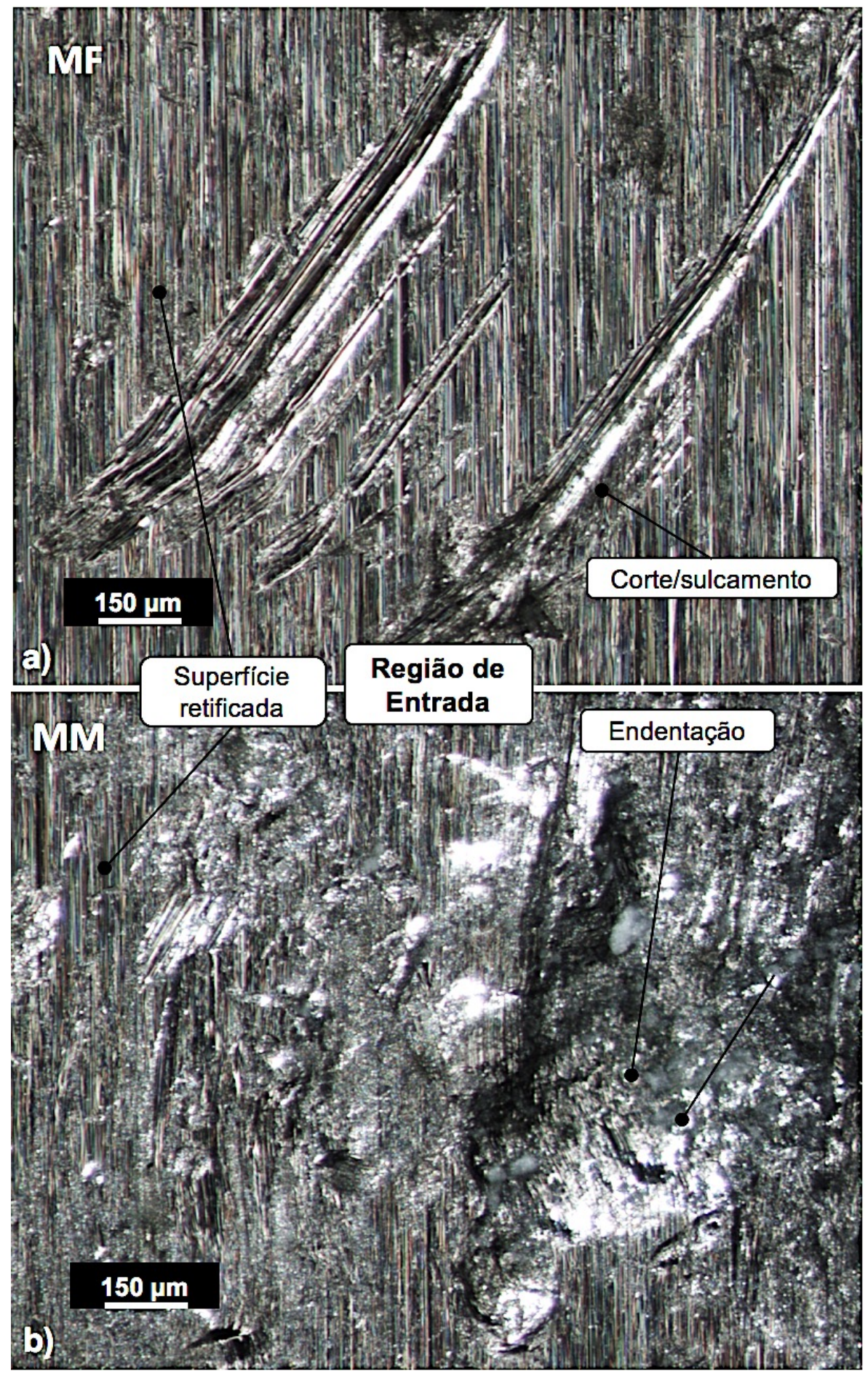

Na Figura 3.20a, região central da MF, observam-se os micromecanismos de corte/sulcamento (formação de bordas) e microendentação, na mesma região para MM observam-se apenas endentações com abrasivo encrustado na superfície, Figura 3.20b. Como já mencionado Lindqvist e Everton, e Pintaúde observaram os mesmos mecanismos de desgaste, corte/sulcamento com intensa deformação 
plástica na MF e endentações na MM (LINDQVIST; EVERTSSON, 2003; PINTAÚDE, 1998).

Figura 3.20. Imagens de estereografia da região central para MF (a) e MM (b), respectivamente. Aço 12Mn. 5X

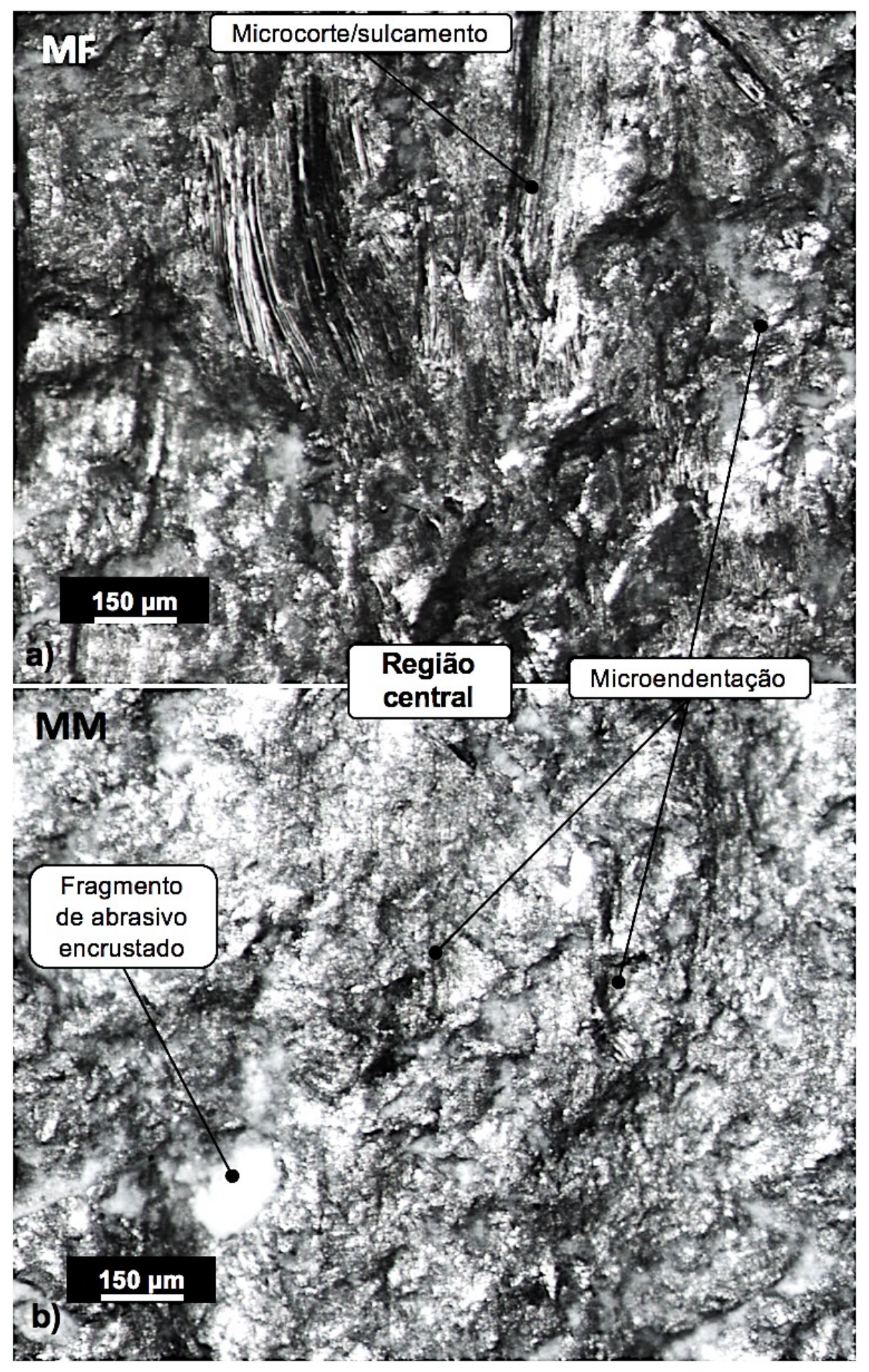

$\mathrm{Na}$ região de saída do britador observam-se os micromecanismos de microcorte e microendentação para a MF (Figura 3.21a) e microendentações e microsulcamento 
para MM (Figura 3.21b). A região de saída tem maior desgaste que as regiões de entrada e central das mandíbulas fixa e móvel (PINTAÚDE, 1998; SARE; ARNOLD, 1989; SIRIANE, 1989) havendo um desgaste desigual das mandíbulas ao longo de seu comprimento.

Figura 3.21. Imagens de estereografia da região de saída para MF (a) e MM (b), respectivamente. Aço 12Mn. 5X

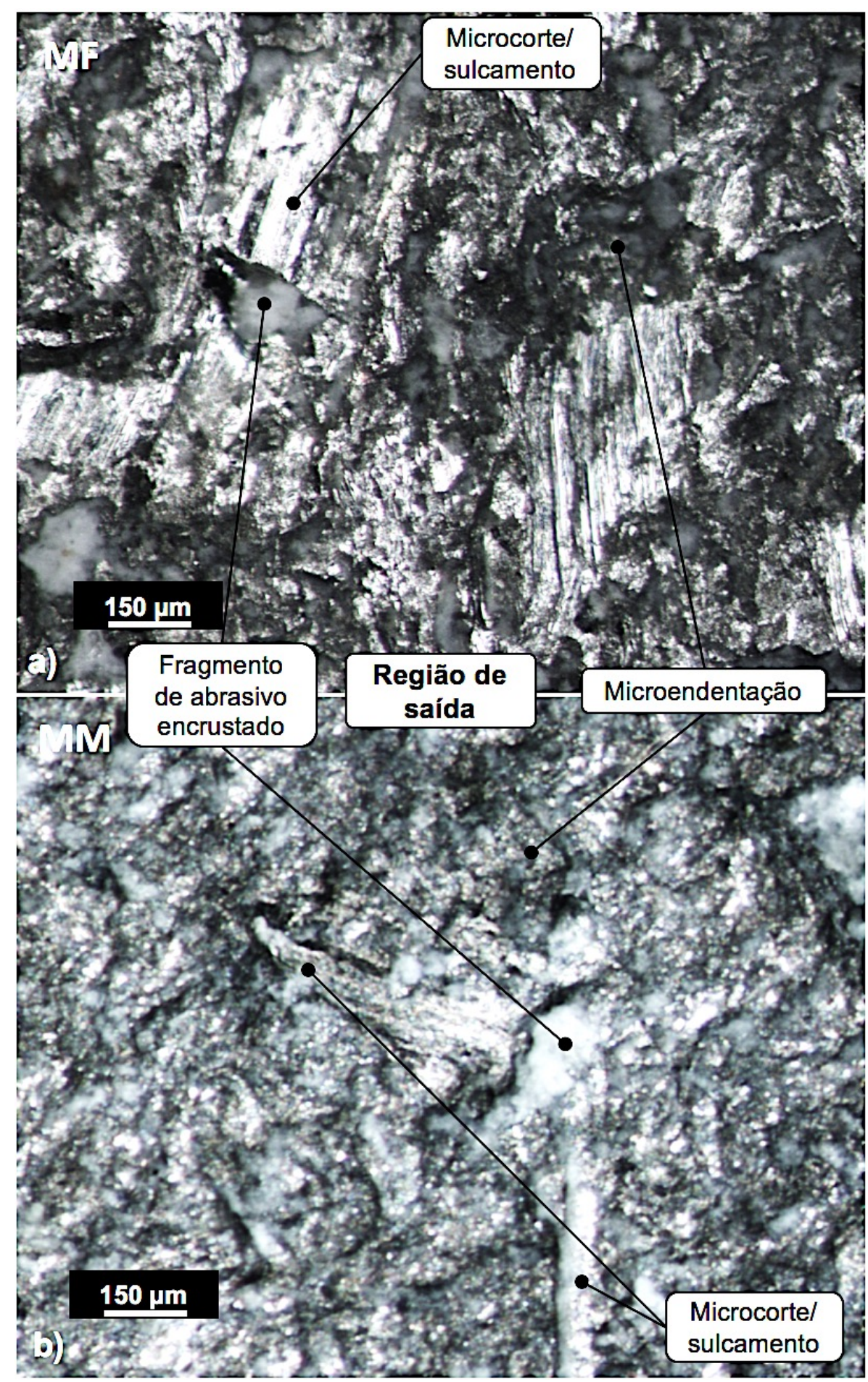


Lindqvist e Evertsson realizaram ensaio laboratorial de britador com a mandíbula fixa instrumentada, possibilitando a aquisição das forças normal e tangencial ao longo da face de trabalho. Os autores mostraram que a região de saída tem o maior valor de carregamento mecânico (LINDQVIST; EVERTSSON, 2003).

A superfície desgastada das mandíbulas fixa e móvel do aço $20 \mathrm{Mn}$ via estereografia são mostradas nas Figuras 3.22, 3.23 e 3.24, para as regiões de entrada, central e de saída, respectivamente. Nota-se que os mecanismos de desgaste abrasivo nas superfícies das mandíbulas fixa e móvel nas três regiões são semelhantes aos observados para o aço $12 \mathrm{Mn}$, com predominância de microcorte e microsulcamento para a MF e microendentação para a MM. 
Figura 3.22. Imagens de estereografia da região de entrada para MF (a) e MM (b), respectivamente. Aço 20Mn. 5X

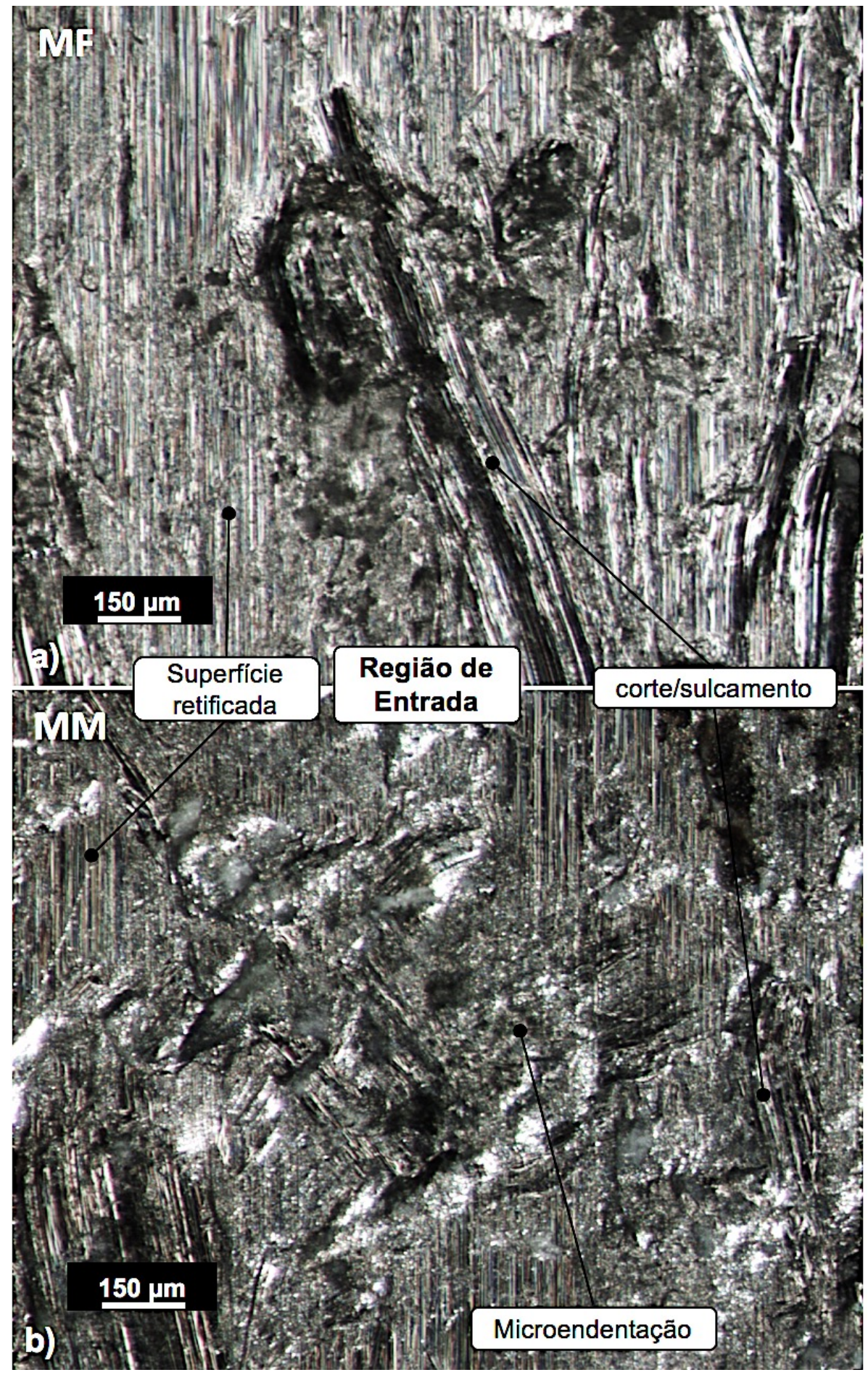


Figura 3.23. Imagens de estereografia da região central para MF (a) e MM (b), respectivamente. Aço 20Mn. 5X

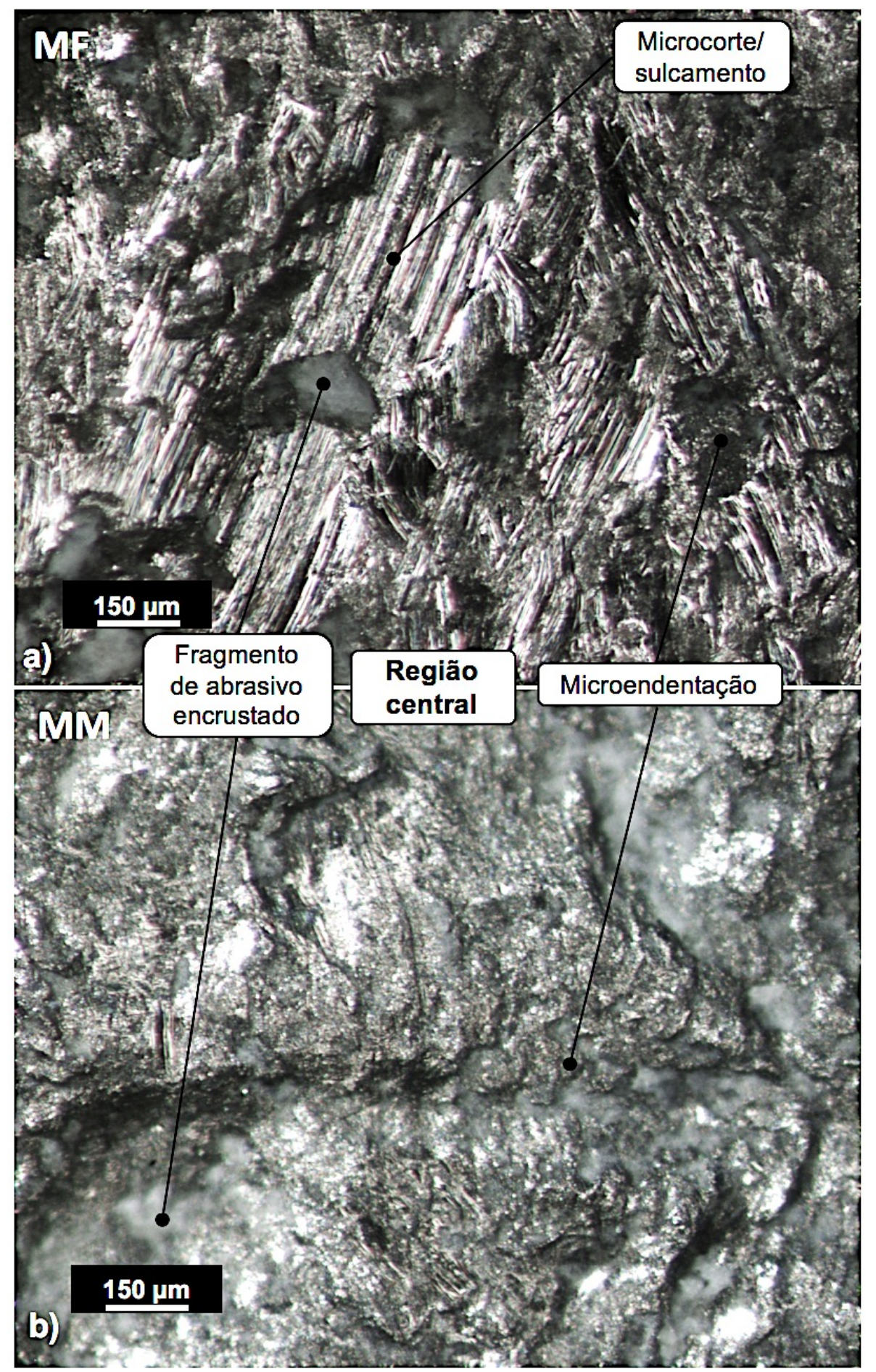


Figura 3.24. Imagens de estereografia da região de saída para MF (a) e MM (b), respectivamente. Aço 20Mn. 5X

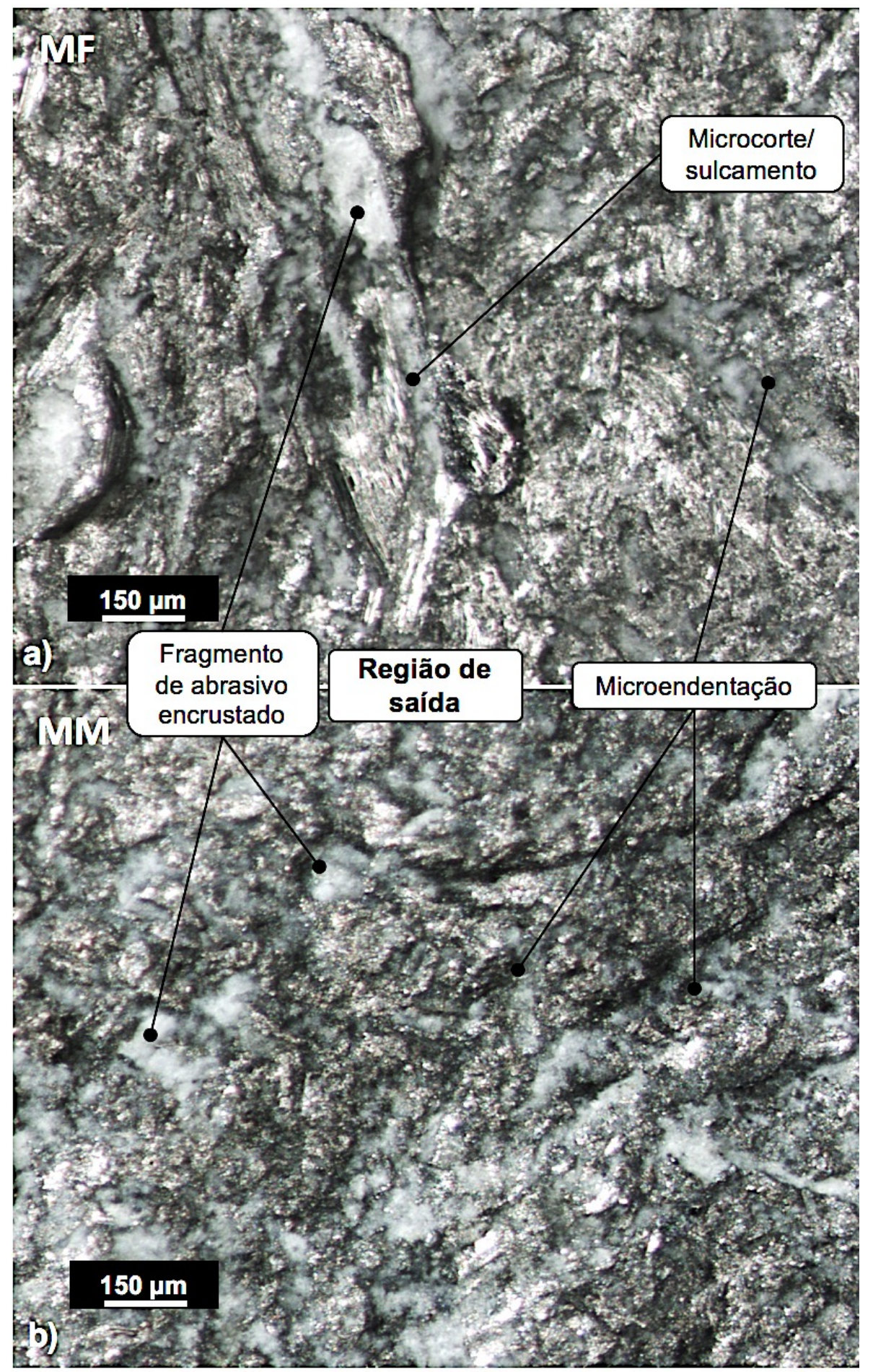

As imagens de MEV-SE das superfícies desgastadas das mandíbulas fixa e móvel na região de saída dos aços $12 \mathrm{Mn}$ e $20 \mathrm{Mn}$ são mostradas nas Figuras a seguir em diferentes aumentos. 
A Figura 3.25 mostra a superfície desgastada das mandíbulas fixa (a) e móvel (b) do aço $12 \mathrm{Mn}$ com $50 \mathrm{X}$ de aumento. Nota-se significativa quantidade de fragmentos do abrasivo encrustados na superfície das MF e MM (pontos mais claros nas imagens).

Figura 3.25. Imagens de MEV-SE da superfície desgastada das MF (a) e MM (b) na região de saída para o aço $12 \mathrm{Mn} .50 \mathrm{X}$

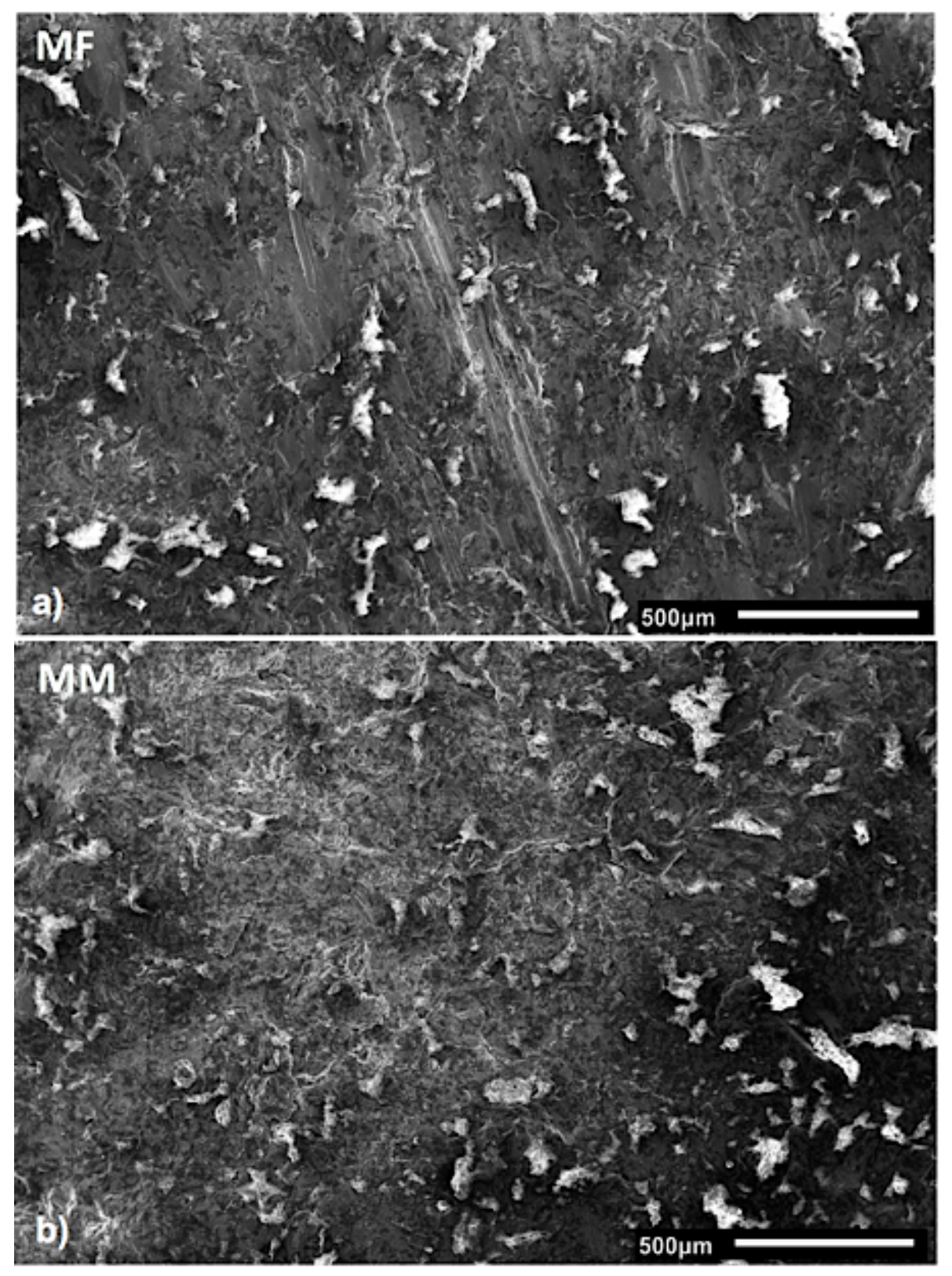

A Figura 3.26 mostra a superfície desgastada das mandíbulas fixa (a) e móvel (b) do aço $12 \mathrm{Mn}$ com 100X e 200X de aumento, respectivamente. Os mecanismos de desgaste descritos a partir das imagens de estereoscopia são visíveis nestas imagens de MEV com maior contraste. Os micromecanismos de microcorte e 
microsulcamento são predominantes na mandíbula fixa e microendentações na mandíbula móvel como observam-se nas Figuras 3.26a e 3.26b, respectivamente.

Figura 3.26. Imagens de MEV-SE da superfície desgastada da MF (a) e MM (b) na região de saída para o aço $12 \mathrm{Mn}$. a) $100 \mathrm{X}$. b) $200 \mathrm{X}$

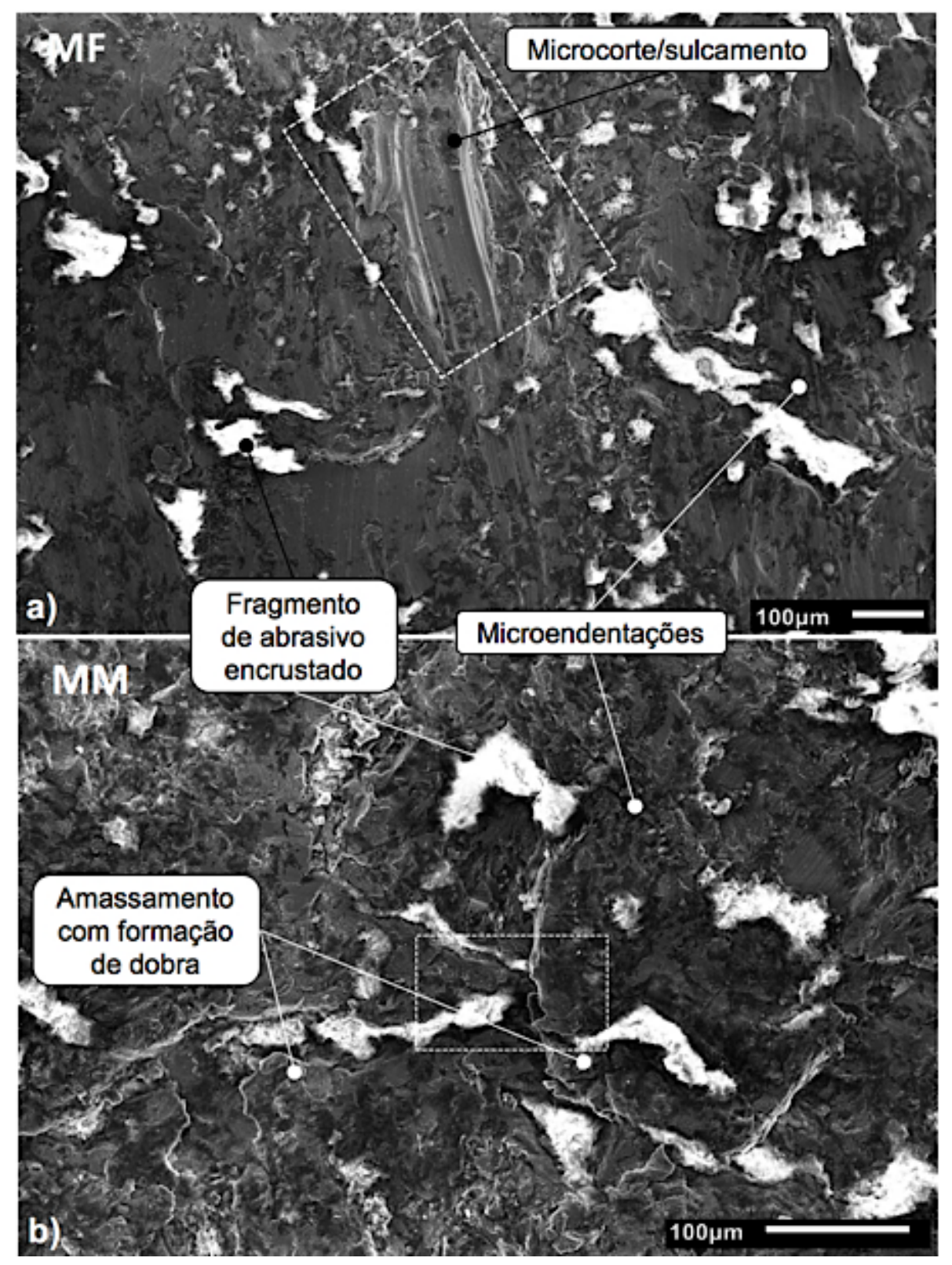

A Figura 3.27 mostra a ampliação dos quadros em destaque nas Figuras 3.26a e 3.26b. Na Figura 3.27a observam-se partículas de desgaste geradas pelo corte e formação de borda por deformação plástica na superfície da MF. Na MM, Figura 3.27b, a microendentação foi o micromecanismo predominante com amassamento e formação de dobras no material, como pode ser observado nas imagens de elétron secundário e retroespalhados. 
Figura 3.27. Imagens de MEV-SE da superfície desgastada da MF (a) e MM (b) na região de saída para $12 \mathrm{Mn}$. a) $300 \mathrm{X}$ com inclinação de $30^{\circ}$. b) Imagens com elétrons secundários e retroespalhados, $500 \mathrm{X}$

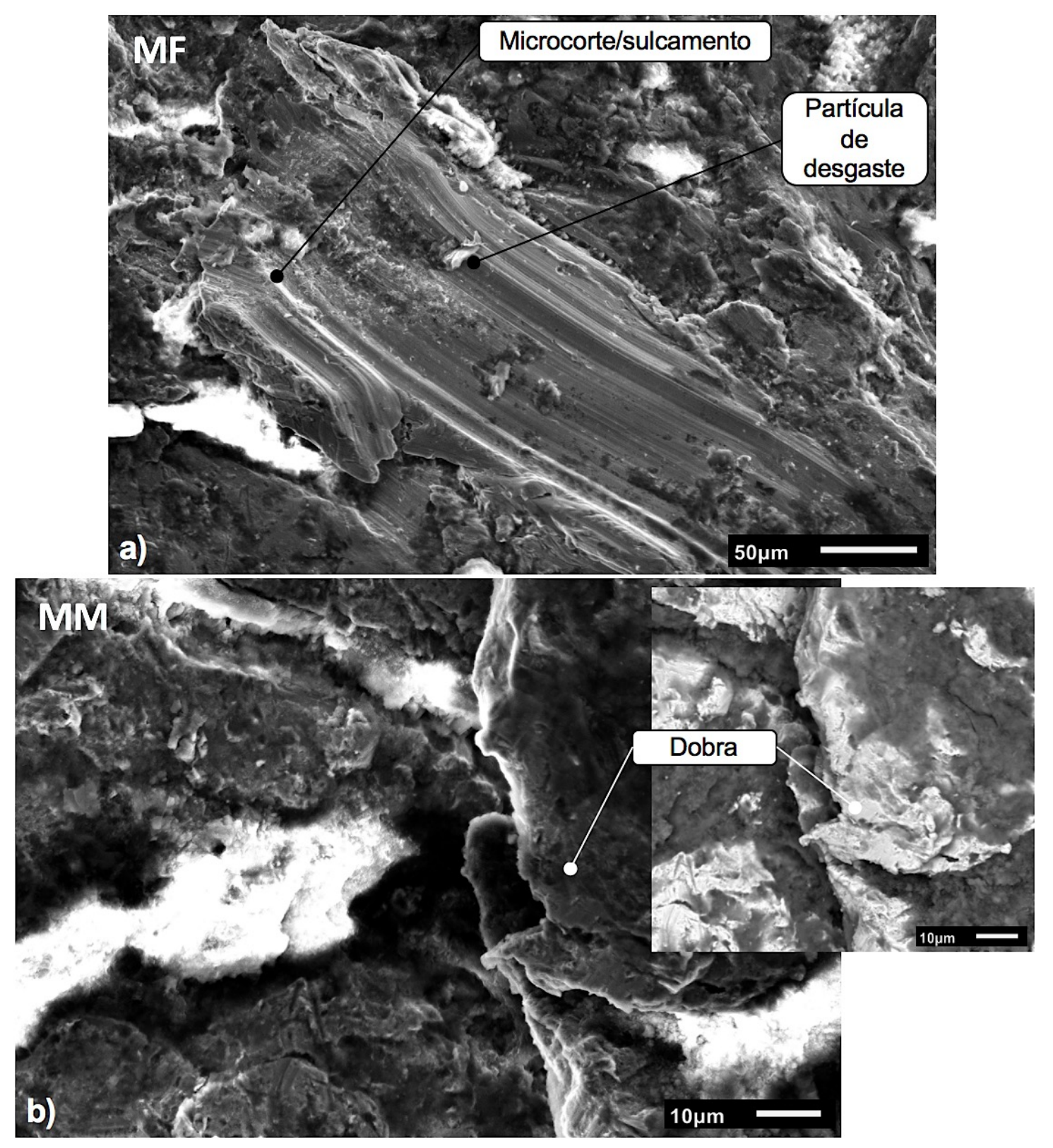

A superfície de desgaste da região de saída da MF e MM do aço $20 \mathrm{Mn}$ é mostrada nas Figuras a seguir em diferentes aumentos via MEV. A Figura 3.28 mostra a superfície desgastada com aumento de 50X. 
Figura 3.28. Imagens de MEV-SE da superfície desgastada da MF (a) e MM (b) na região de saída para $20 \mathrm{Mn} .50 \mathrm{X}$

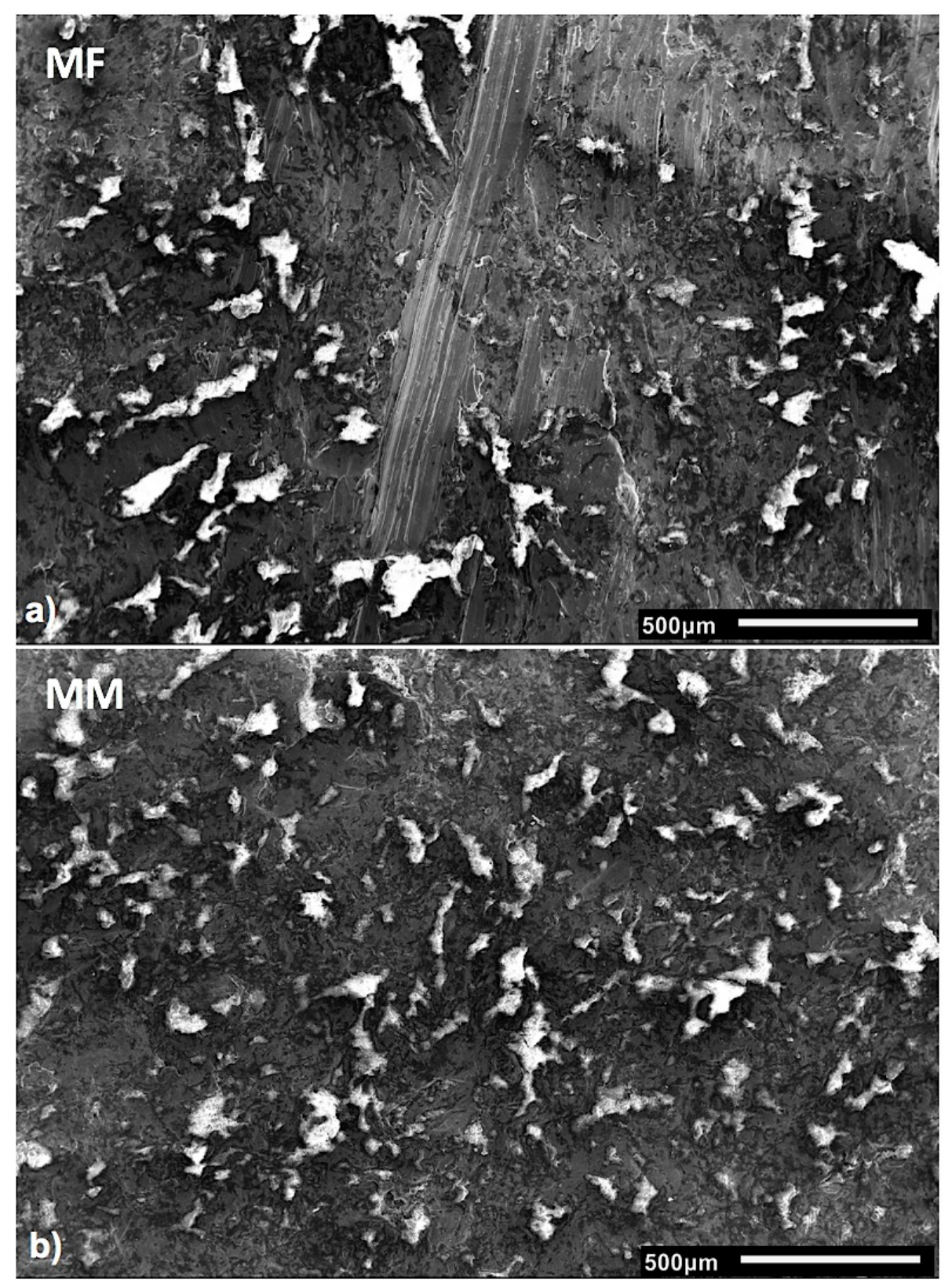

Na Figura 3.29a observa-se que o fragmento de abrasivo encrustado na superfície interage com o tribossistema, bloqueando o riscamento causado por partículas abrasivas. Com esta observação, pode-se considerar que as partículas encrustadas agem como uma segunda fase dura, protegendo a superfície e minimizando a formação de riscos longos. Os micromecanismos predominantes para a MF e MM do aço $20 \mathrm{Mn}$ são semelhantes aos observados nas mandíbulas do aço $12 \mathrm{Mn}$. 
Figura 3.29. Imagens de MEV-SE da superfície desgastada da MF (a) e MM (b) na região de saída para o aço $20 \mathrm{Mn}$. 100X

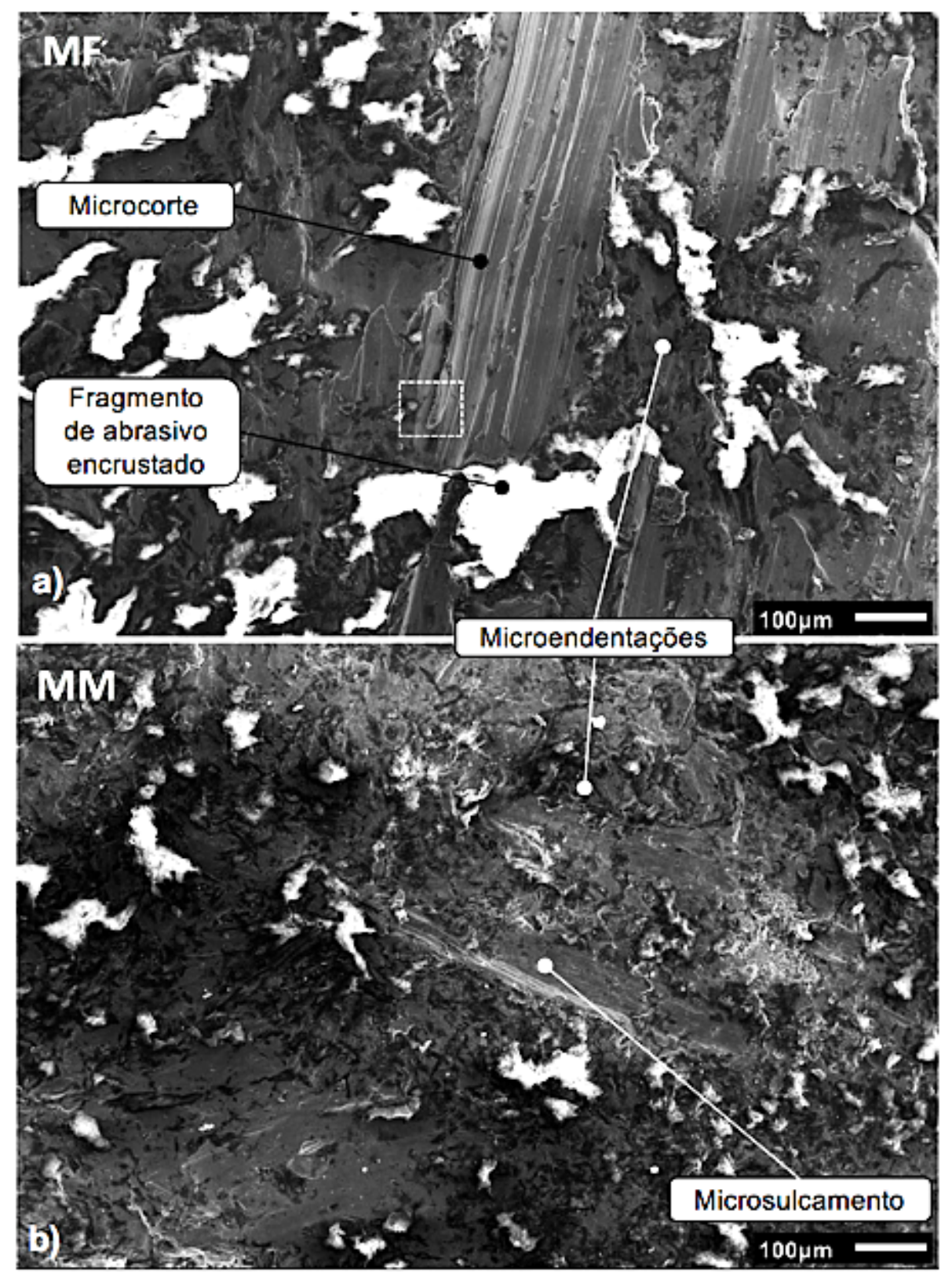

A Figura 3.30a mostra a ampliação da área indicada na Figura 3.30a, observa-se uma textura anisotrópica no interior do risco (riscos menores), formada pela interação das arestas do abrasivo. Além disto, é indicado na imagem microendentações e partículas de desgaste. A Figura 3.30b mostra uma região da MM com microsulcamento, sendo este um micromecanismo pouco observado na superfície desta mandíbula. 
Figura 3.30. Imagens de MEV-SE da superfície desgastada da MF (a) e MM (b) na região de saída para o aço $20 \mathrm{Mn}$. a) $1500 \mathrm{X}$. b) $200 \mathrm{X}$

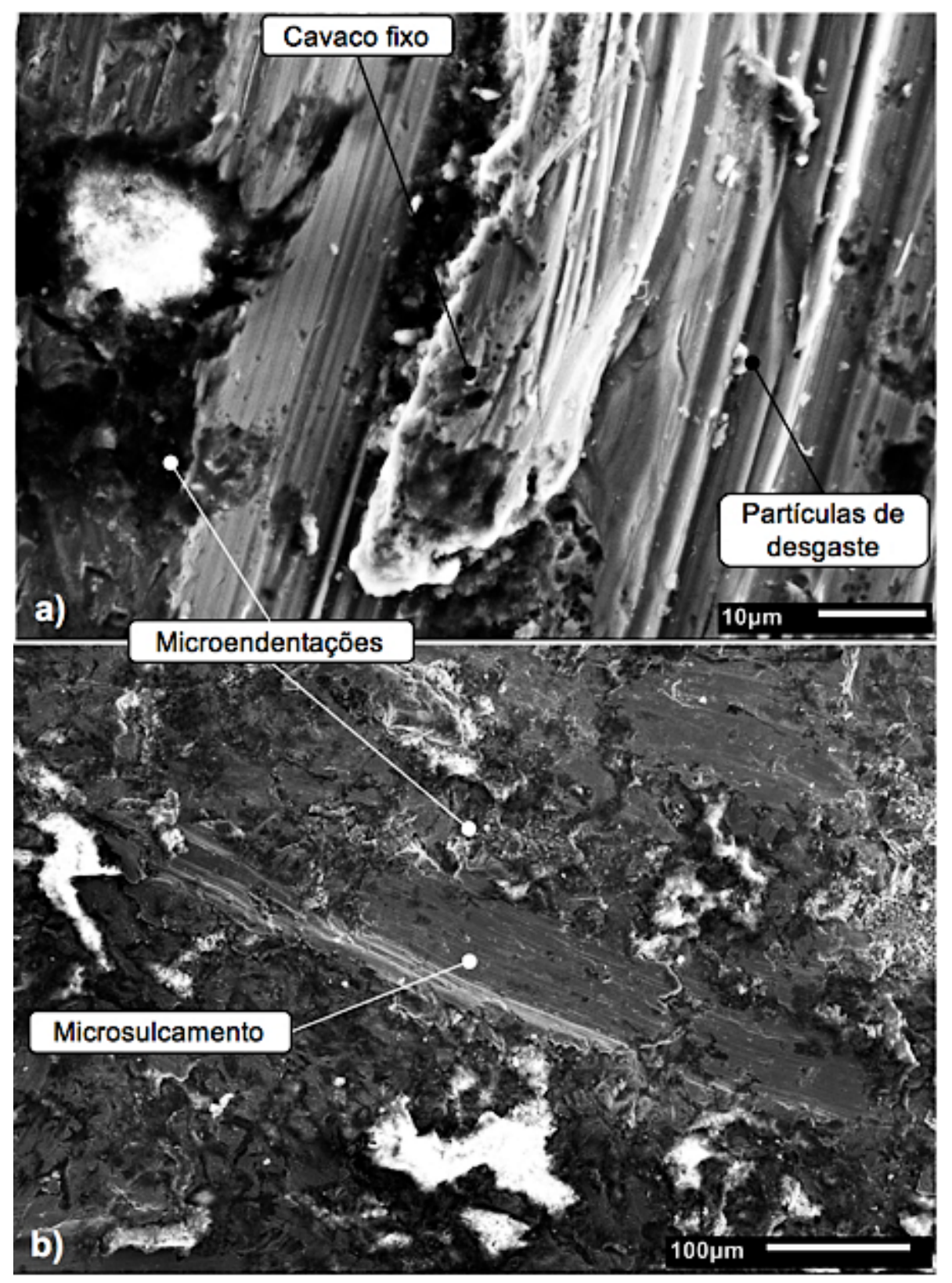

A Figura 3.31 mostra os resultados obtidos via interferometria óptica da superfície desgastada para a região central da MF e MM para o aço $12 \mathrm{Mn}$. A seta entre as Figuras indica a nova referência para o sentido do fluxo de abrasivo. As imagens de topografia das mandíbulas fixa e móvel são acompanhadas de seus respectivos mapas de direções preferenciais da superfície desgastada e valor de isotropia (obtido a parir do valor do parâmetro de rugosidade $S_{t r}$, texture aspect ratio, (ISO 25178-2, 2012). Os resultados de isotropia foram $86 \%$ para MF e $95 \%$ para MM. 
Figura 3.31. Resultados de interferometria para a região central da MF e MM do aço $12 \mathrm{Mn}$

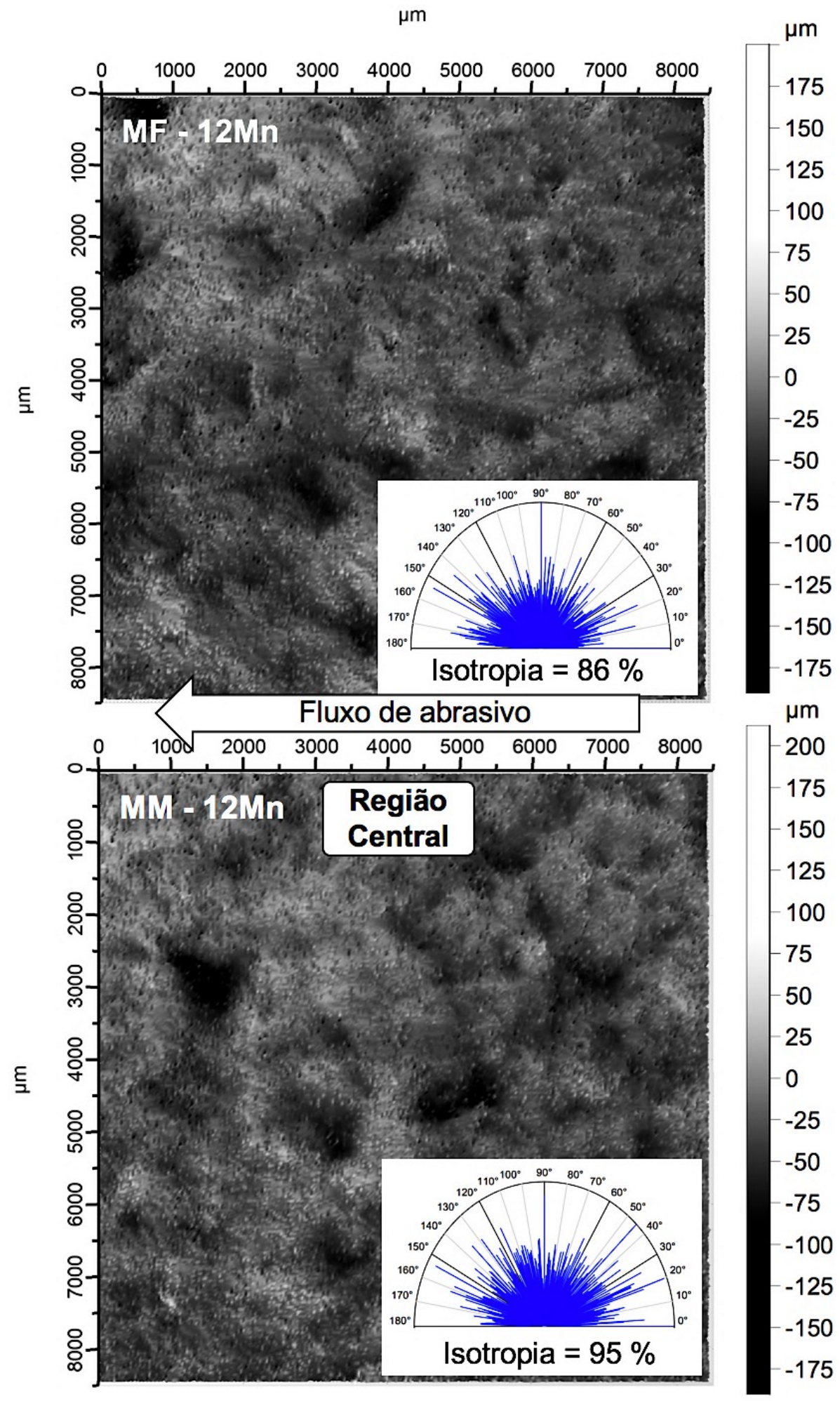

A Figura 3.32 mostra a topografia da região central do par de mandíbula para o aço $20 \mathrm{Mn}$. Os resultados mostraram semelhança no valor de isotropia para as mandíbulas fixa e móvel, $88 \%$ e 89 \%, respectivamente. 
Figura 3.32. Resultados de interferometria para a região central da MF e MM do aço $20 \mathrm{Mn}$

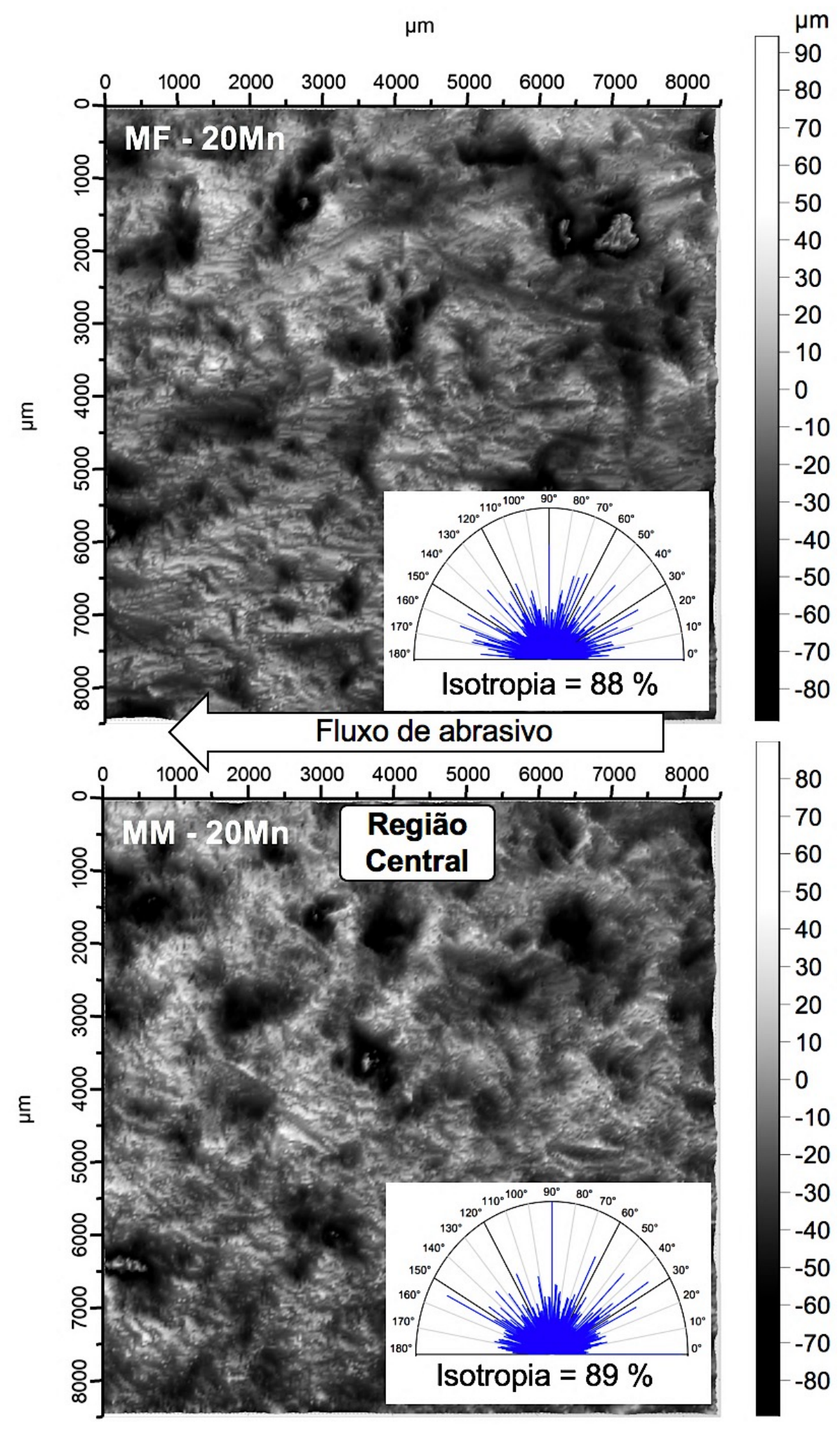

A Figura 3.33 mostra os resultados de interferometria óptica para a região de saída das mandíbulas fixa e móvel para o aço 12Mn, e na Figura 3.34 para o aço 20Mn. 
Figura 3.33. Resultados de interferometria para a região de saída da MF e MM do aço 12Mn

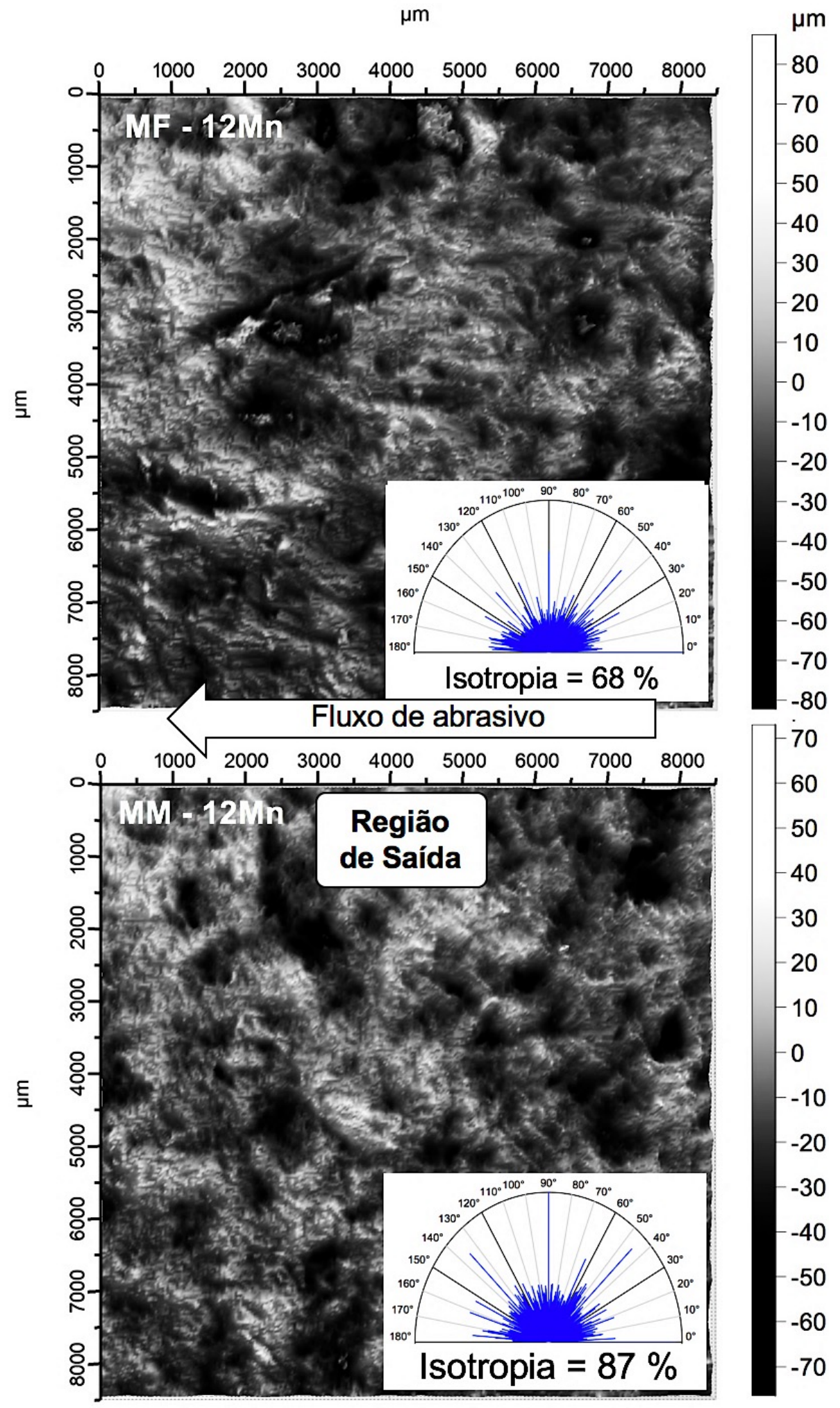

Os valores de isotropia associados à topografia das mandíbulas fixa e móvel na região de saída para os dois materiais foram de: MF = 68 \% (12Mn) e 66 \% (20Mn); $\mathrm{MM}=87 \%(12 \mathrm{Mn})$ e $84 \%(20 \mathrm{Mn})$. Ao comparar estes resultados com a região 
central, observam-se menores valores para a região de saída, principalmente para a MF. Este resultado é associado à predominância dos micromecanismos de microcorte e microsulcamento, dispostos longitudinalmente ao fluxo de abrasivo, na região de saída da MF. Os micromecanismos de desgaste associados aos riscos proporcionam a formação de uma topografia com menor isotropia.

A Tabela 3.5 mostra os valores de isotropia (\%) das áreas das superfícies analisadas para os aços $12 \mathrm{Mn}$ e $20 \mathrm{Mn}$.

Tabela 3.5. Isotropia da rugosidade para MF e MM nas regiões central e de saída - aços $12 \mathrm{Mn}$ e $20 \mathrm{Mn}$

Isotropia (\%)

\begin{tabular}{ccccc}
\cline { 2 - 5 } & \multicolumn{2}{c}{ Região Central } & \multicolumn{2}{c}{ Região de Saída } \\
\cline { 2 - 5 } Aço & MF & MM & MF & MM \\
\hline $12 \mathrm{Mn}$ & 86 & 88 & 68 & 66 \\
$20 \mathrm{Mn}$ & 15 & 89 & 87 & 84
\end{tabular}


Figura 3.34. Resultados de interferometria para a região de saída da MF e MM do aço $20 \mathrm{Mn}$

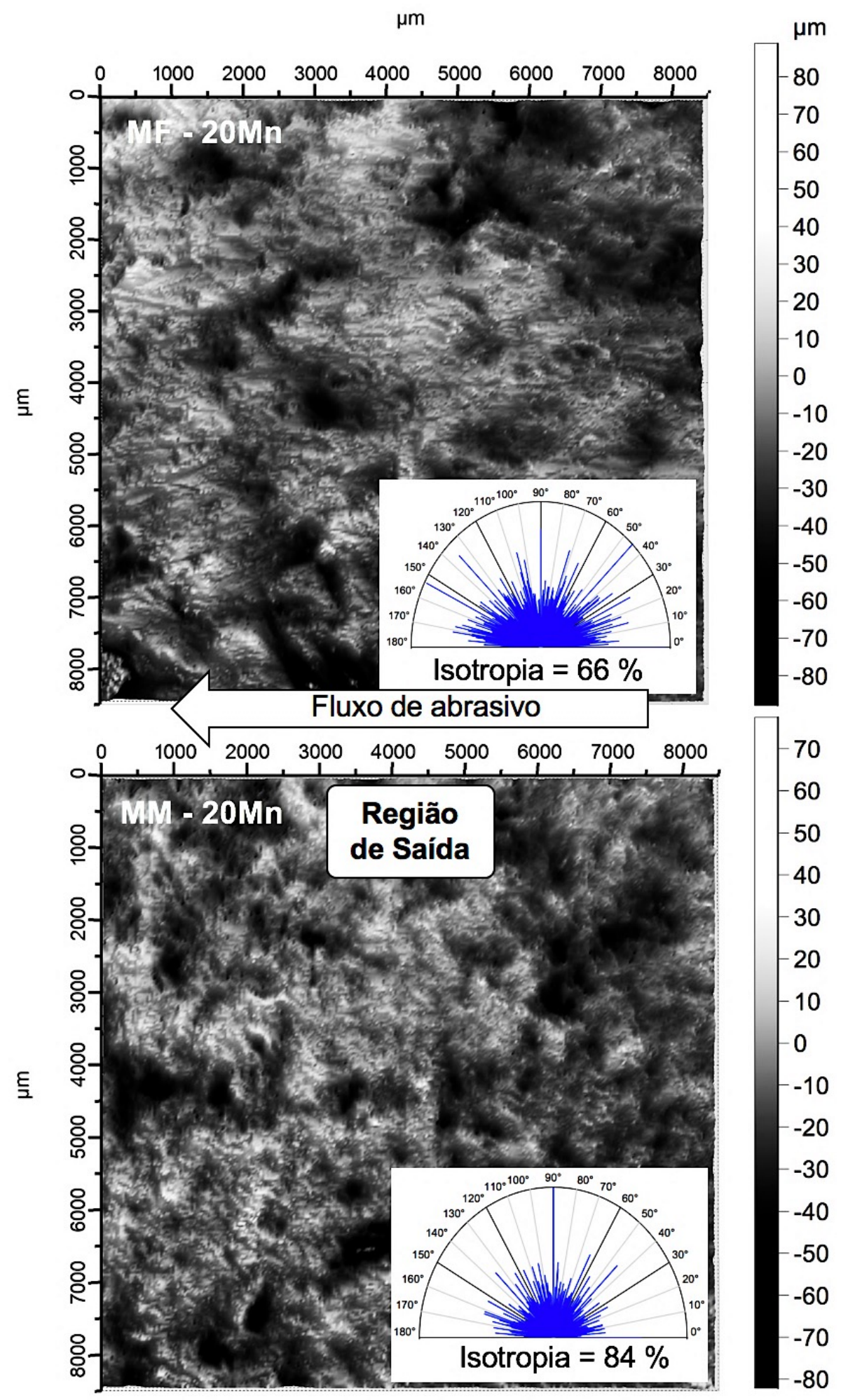

Os valores de rugosidade média das áreas analisadas são mostrados na Tabela 3.6. Os resultados de $S_{a}$ da MF para $12 \mathrm{Mn}$ e $20 \mathrm{Mn}$ foram maiores que da $\mathrm{MM}$, com exceção da região central para $20 \mathrm{Mn}$. Comparando os valores de $S_{a}$ entre as regiões central e de saída observam-se maiores valores na região central. Este resultado 
sugere que os abrasivos maiores fragmentados nesta região produzem uma rugosidade com maior valor médio que a rugosidade da região de saída para MF e MM dos aços $12 \mathrm{Mn}$ e $20 \mathrm{Mn}$. Nota-se, também, que as mandíbulas do aço $12 \mathrm{Mn}$ tiveram valores de $S_{a}$ superiores aos obtidos para $20 \mathrm{Mn}$ nas regiões central e de saída.

Tabela 3.6. $S_{a}$ das superfícies desgastadas na região central e de saída da MF e MM para os aços $12 \mathrm{Mn}$ e $20 \mathrm{Mn}$

\begin{tabular}{ccccc} 
& \multicolumn{4}{c}{$S_{a}(\mu \mathrm{m})$} \\
\cline { 2 - 5 } Aço & Região Central & \multicolumn{2}{c}{ Região de Saída } \\
\cline { 2 - 5 } & MF & MM & MF & MM \\
\hline $12 \mathrm{Mn}$ & 23 & 22 & 17 & 13 \\
$20 \mathrm{Mn}$ & 17 & 17 & 15 & 12
\end{tabular}

\subsubsection{Microestrutura da subsuperfície de desgaste}

As micrografias obtidas via FIB da superfície desgastada e a microestrutura da subsuperfície da mandíbula fixa do aço $12 \mathrm{Mn}$ é mostrada na Figura 3.35. A microestrutura da subsuperfície, Figura 3.35b, é ampliada em duas imagens, uma mais próxima à superfície deformada (Figura 3.35c) e outra mais afastada (Figura 3.35d), onde observam-se duas camadas com diferentes microestruturas. A primeira camada tem grãos ultrafinos e a segunda, subsequente, tem grãos ultrafinos e maclas de deformação. Nota-se o material deformado com microestrutura semelhante à camada de grãos ultrafinos que envolve um pedaço de abrasivo, como indicado na Figura 3.35c. Rotondaro nomeou este tipo de mecanismo encontrado em superfícies de aço Hadfield degastado por abrasão como língua de deformação (ROTONDARO, 1989). Nesta tese este mecanismo foi nomeado como onda de material deslocado, uma vez que ele tem formato semelhante a uma onda marítima quebrando em uma praia e pode ter ou não evidência de deformação plástica. A Figura 3.35d mostra com maior aumento a área de transição das camadas. 
Figura 3.35. Imagens de FIB da superfície desgastada do aço 12Mn. a) Local de análise, 5.000X. b) Microestrutura da subsuperfície, 10.000X. c) Ampliação da região próxima à superfície, 20.000X.

d) Ampliação da região a $10 \mu \mathrm{m}$ da superfície, 30.000X
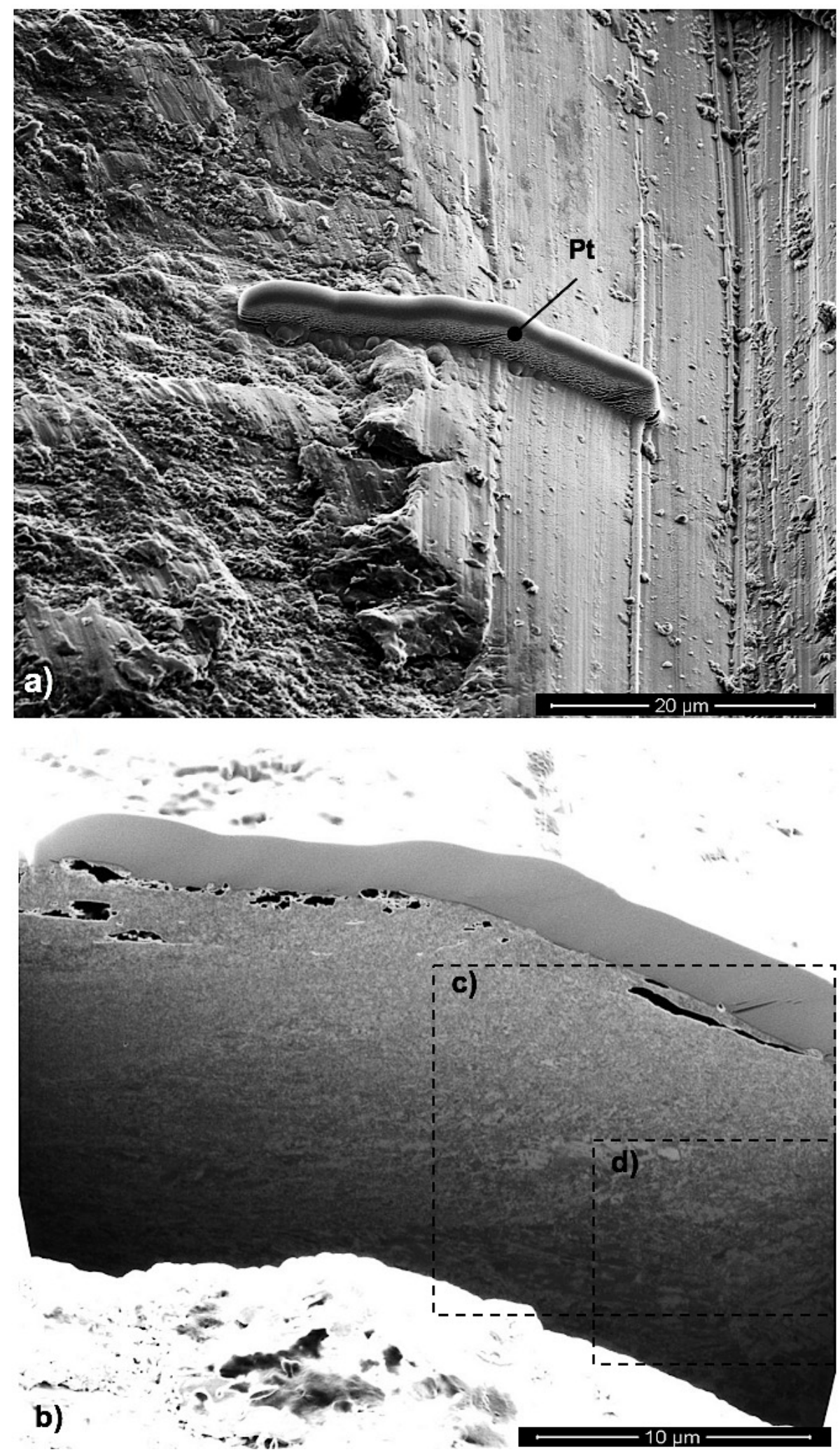

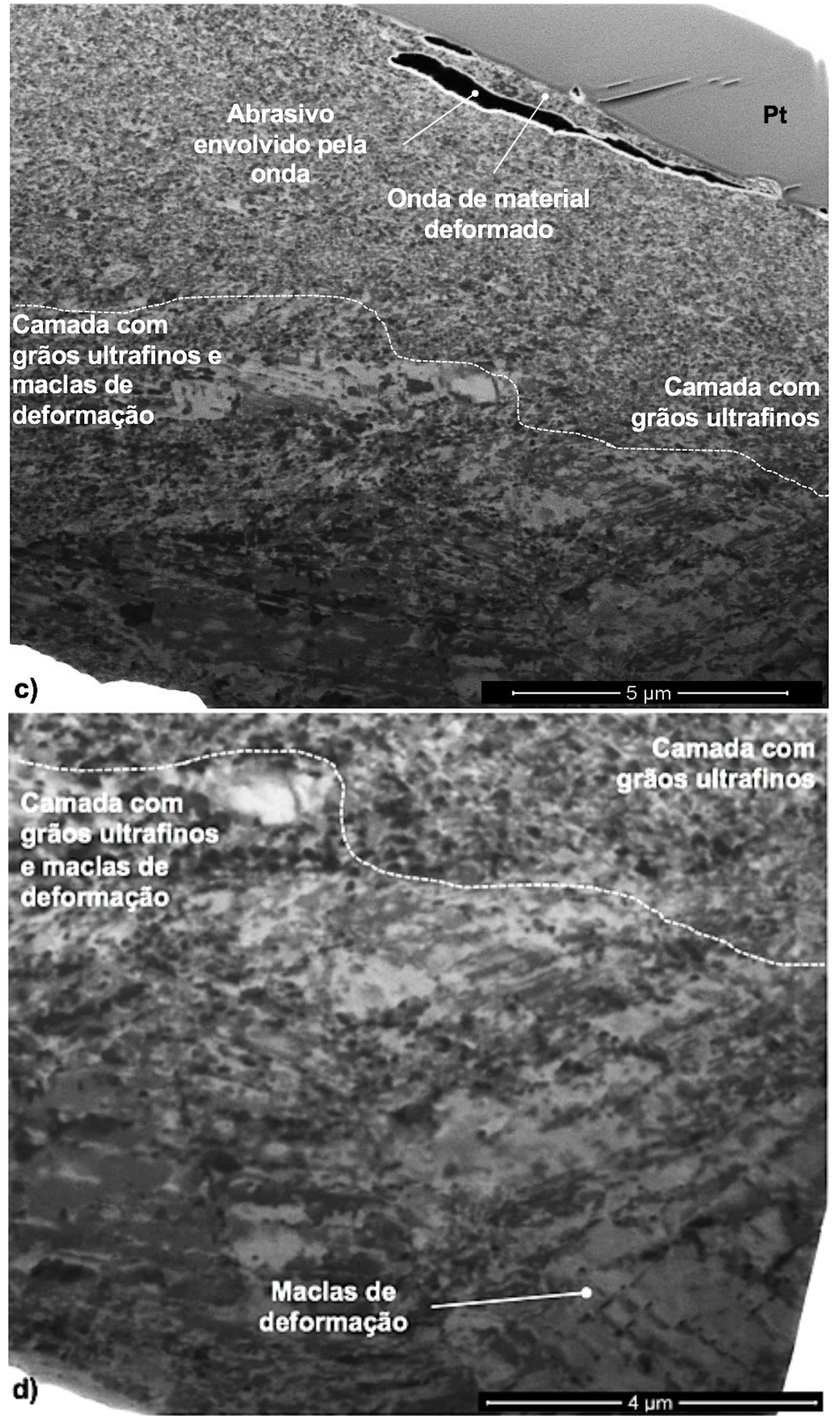

A superfície desgastada da mandíbula fixa do aço $20 \mathrm{Mn}$ é mostrada na Figura 3.36a. A camada de platina depositada indica o local de análise da subsuperfície. A Figura 3.36b mostra o corte e a microestrutura do local. Duas áreas indicadas nesta imagem referem-se à uma região abaixo da superfície e outra a 
$10 \mu \mathrm{m}$ são mostradas nas Figuras $3.36 c$ e $3.36 d$ em maiores aumentos, $20.000 \mathrm{X}$ e 30.000X, respectivamente.

Figura 3.36. Imagens de FIB da superfície desgastada do aço 20Mn. a) Local de análise, 5.000X. b) Microestrutura da subsuperfície, 10.000X. c) Ampliação da região próxima à superfície, 20.000X. d) Ampliação da região a $10 \mu \mathrm{m}$ da superfície, 30.000X
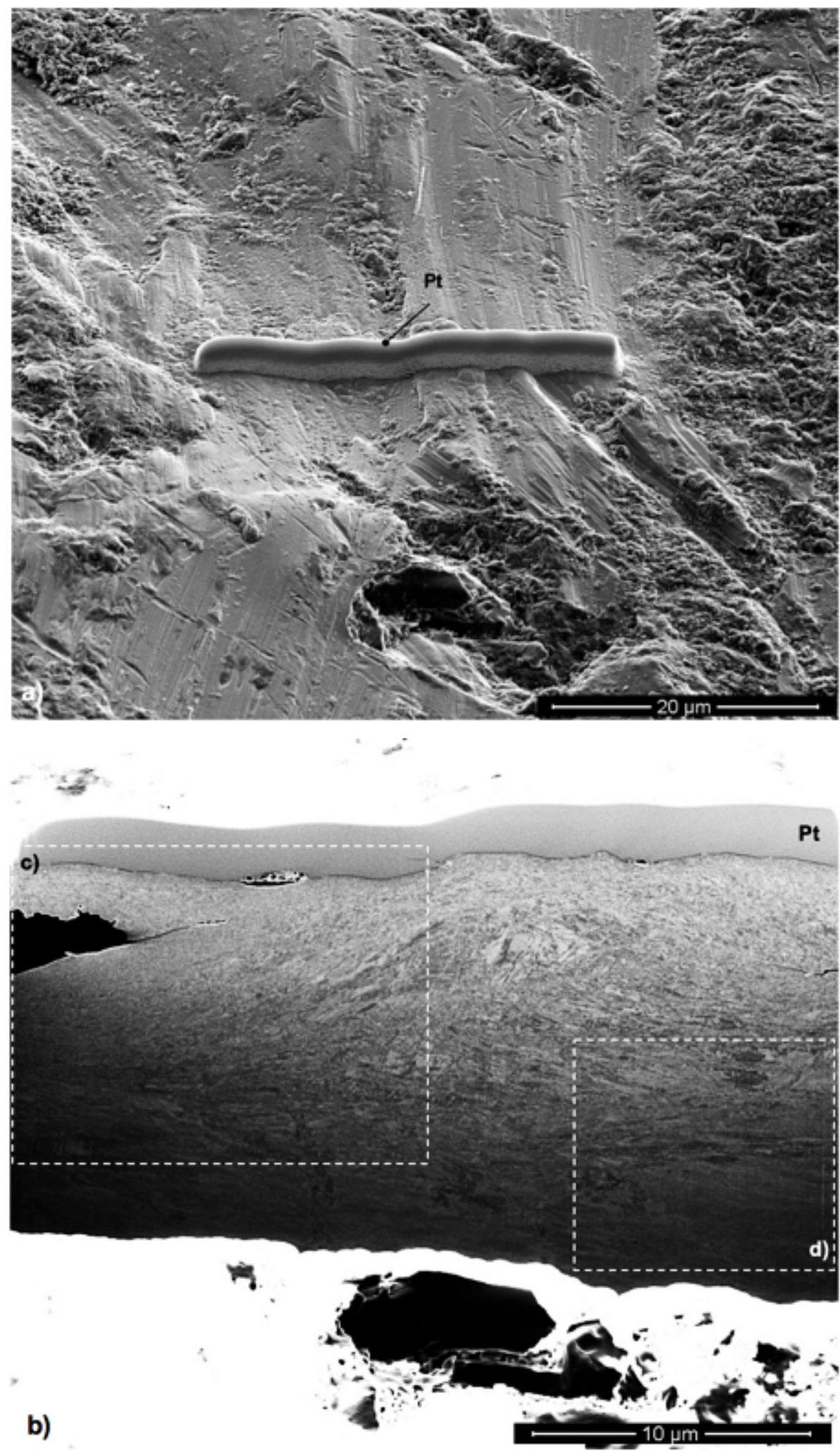

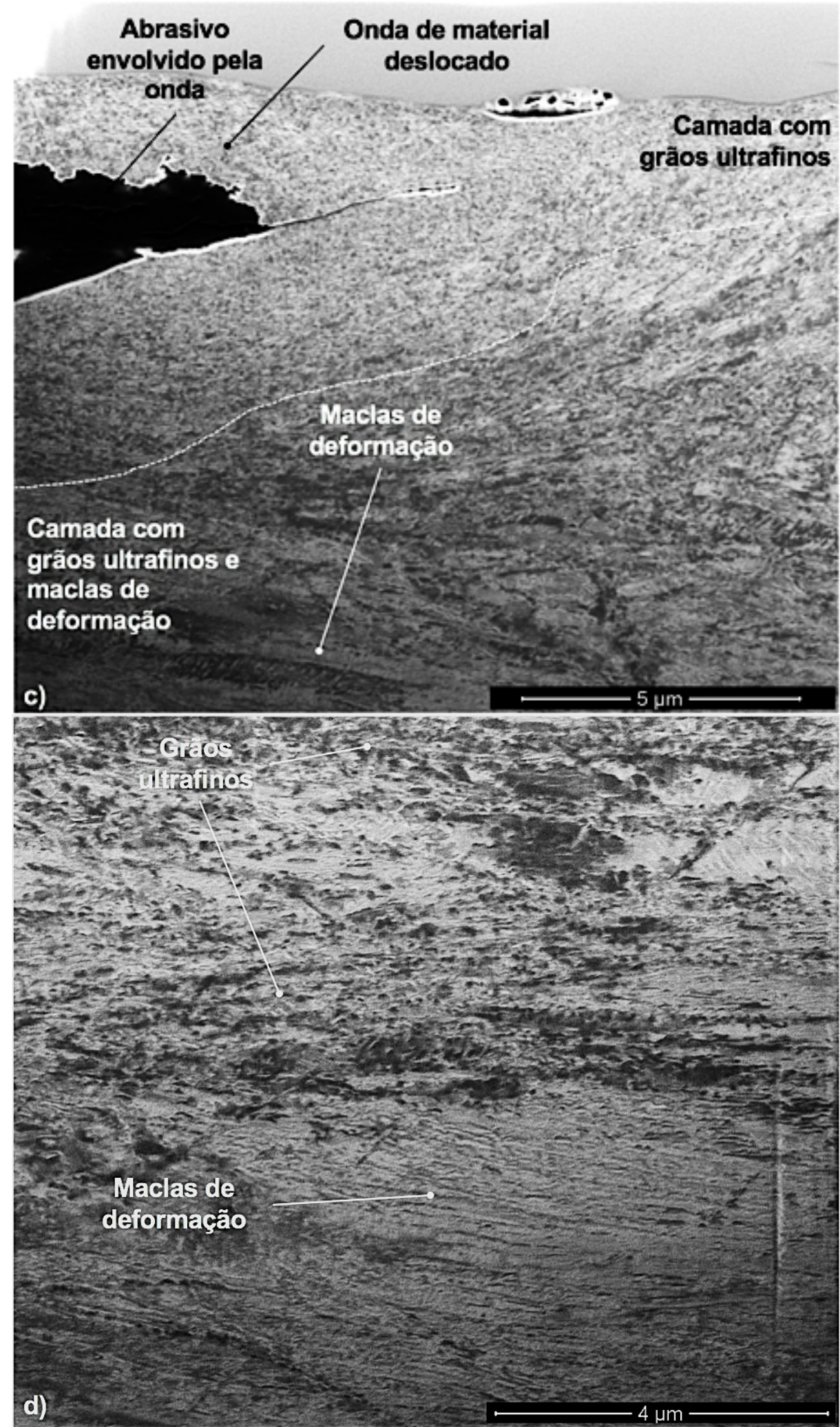

$\mathrm{Na}$ Figura 3.36c é indicado duas regiões distintas por terem diferentes microestruturas. Na camada mais externa, próxima à superfície, observam-se grãos ultrafinos e, abaixo desta região, maclas de deformação e grãos ultrafinos (Figura 3.36d), semelhante ao observado na microestrutura da subsuperfície do 
aço 12Mn. Os autores Feng et al. e Yan et al. também observaram a formação de uma camada de grãos ultrafinos na superfície de aços Hadfield deformados plasticamente (FENG et al., 2013a; YAN et al., 2009). A presença de maclas de deformação na subsuperfície era esperada por tratar-se do principal mecanismo de deformação plástica do aço Hadfield (KARAMAN et al., 2000a; SANT; SMITH, 1987). A microestrutura da subsuperfície do aço austenítico com $12 \% \mathrm{Mn}$ deformada em desgaste de campo e de laboratório é discutida com maior detalhe no Capítulo "MICROESTRUTURA DA SUBSUPERFÍCIE DO AÇO AUSTENITICO COM 12 \%Mn DEFORMADO POR DESGASTE ABRASIVO".

\subsection{CONSIDERAÇÕES FINAIS}

A estudo do desgaste abrasivo via ensaio de britador de mandíbula levou às seguintes conclusões:

- A britagem nas condições deste trabalho resultou na redução do abrasivo em $37 \%$;

- A perda de massa das mandíbulas fixa e móvel apresentaram diferenças de $64 \%(M F / M M=2,8)$ para $12 \mathrm{Mn}$ e $45 \%(M F / M M=1,8)$ para $20 \mathrm{Mn}$;

- Os resultados de perda de massa para os aços $12 \mathrm{Mn}$ e $20 \mathrm{Mn}$ foram estatisticamente iguais, segundo o teste de hipótese para um intervalo de confiança de $95 \%$, no entanto, as mandíbulas fixas dos aços apresentaram diferença estatística para o intervalor de confiança de $90 \%$;

- Os perfis de dureza das mandíbulas fixa e móvel para os dois materiais apresentaram profundidade de encruamento iguais $(1,5 \mathrm{~mm})$;

- O micromecanismo de desgaste predominante ao longo das mandíbulas fixa e móvel são diferentes. A mandíbula móvel tem predominância de microendentações, apesar de ter eventuais riscos, e a fixa, microcorte e microsulcamento;

- A topografia da superfície desgastada das mandíbulas fixa e móvel é isotrópica na região central. Enquanto a topografia da mandíbula fixa tem valores menores de isotropia na região de saída, local de maior desgaste; 
- O valor de rugosidade média diminui ao longo das mandíbulas fixa e móvel conforme a redução do tamanho do abrasivo durante o processo de fragmentação;

- A microestrutura da subsuperfície dos aços $12 \mathrm{Mn}$ e $20 \mathrm{Mn}$ é semelhante e varia de forma semelhante com a profundidade. A microestrutura mais próxima à superfície é constituída de grãos ultrafinos, mais abaixo coexistem maclas de deformação e grãos ultrafinos até a profundidade em que observase a predominância de maclas de deformação. 
Capítula 4. EFETTO DO ENCRUAMENTO E DA ORJENTACAAO CRUSTALOGRÁFCA NO DESGASTE PORRISCAMENTO DOS ACOS AUUSTENITICOS $12 \% \mathrm{Mn}$ E $20 \% \mathrm{Mn}$

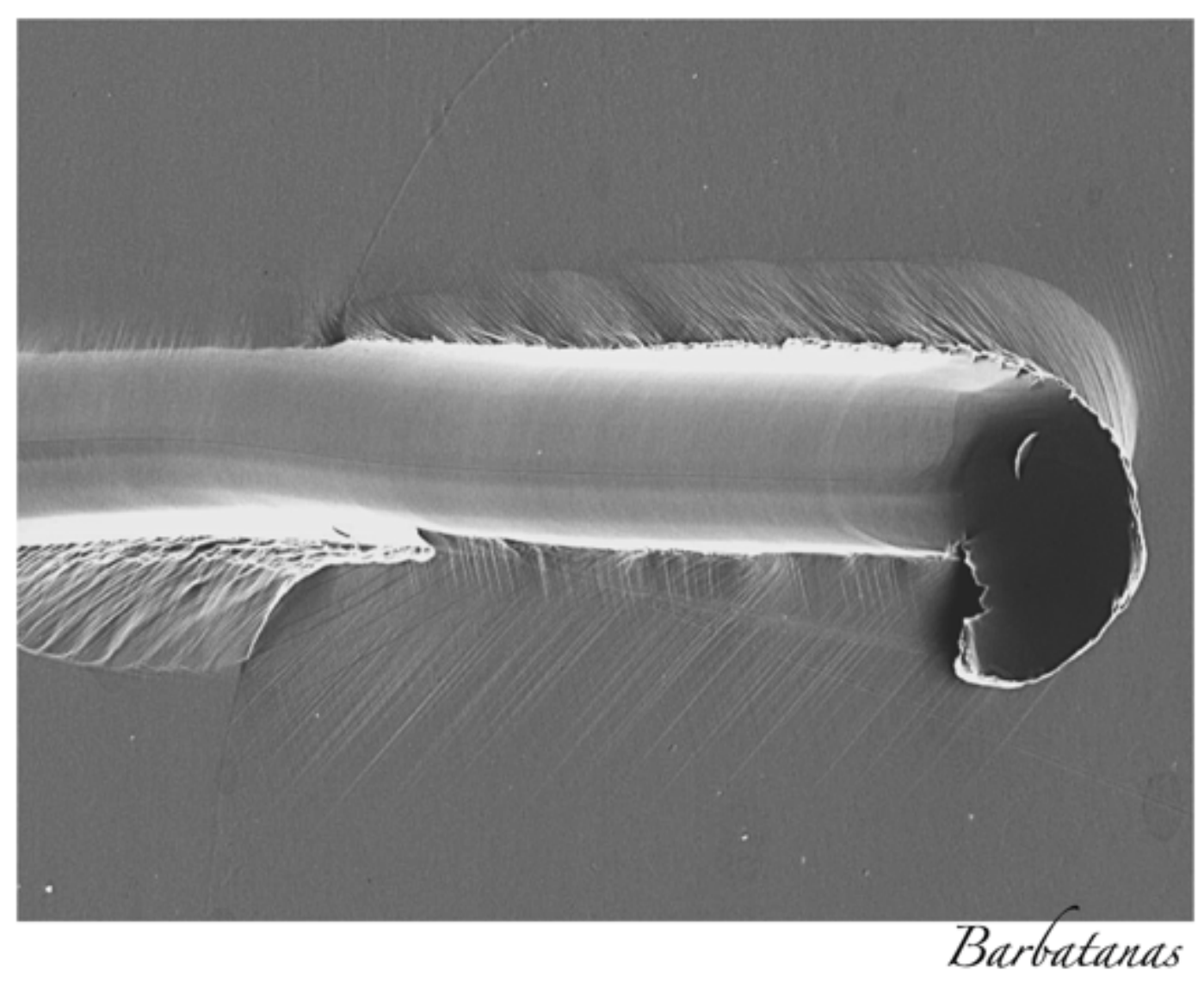




\section{Resumo}

O estudo do desgaste por riscamento do aço austenítico com $12 \% \mathrm{Mn}$ previamente deformado em condições de campo (macroescala) e o estudo do efeito da orientação cristalográfica no desgaste por riscamento de dois aços austeníticos com 12 \% Mn e 20 \%Mn são discutidos neste Capítulo. Os ensaios de esclerometria foram realizados nas escalas meso e micro com os endentadores piramidal e cônico de ponta esférica, respectivamente. A avaliação do efeito do perfil encruado na macroescala foi realizada na mesoescala e na microescala. $\mathrm{Na}$ análise de esclerometria os riscos foram realizados na superfície transversal com sentido do núcleo para a superfície, com comprimento de $7 \mathrm{~mm}$, carga constante de $8 \mathrm{~N}$ e velocidade de $1 \mathrm{~mm} / \mathrm{s}$. Na análise com microesclerometria foram realizados riscos, na superfície transversal, paralelos à superfície de desgaste ao longo de 1,6 $\mathrm{mm}$. Os parâmetros dos riscos foram $100 \mu \mathrm{m}$ de comprimento, velocidade de $3,3 \mu \mathrm{m} / \mathrm{s}$ e cargas de 20 a 250 mN. A avaliação do efeito da orientação cristalográfica dos aços austeníticos com $12 \% \mathrm{Mn}$ e $20 \% \mathrm{Mn}$ foi realizada com uma metodologia própria. A caracterização da orientação cristalográfica da microestrutura dos materiais foi realizada via EBSD. Os ensaios de microesclerometria com carga constante de $200 \mathrm{mN}$ foram realizados nos planos (001), (111) e (101), paralelos à superfície. As técnicas de MO, MEV e FIB foram utilizadas para caracterização do micromecanismo de desgaste e microestrutura da subsuperfície. Os resultados da análise esclerometria no perfil de encruamento, nas duas escalas estudadas, não mostraram efeito significativo da variação de microdureza no desgaste do material. No entanto, a orientação cristalográfica teve efeito sobre o sistema, com diferentes resultados para o coeficiente de atrito e energia do risco, os quais foram associados aos micromecanismos de desgaste e à alteração microestrutural da subsuperfície de cada orientação avaliada. No plano (001) ocorreu microsulcamento e formação de proa, com menor extensão da deformação lateral para o aço $20 \mathrm{Mn}$ que para o aço $12 \mathrm{Mn}$, resultando em diferentes resultados de coeficiente de atrita e energia. Nos planos (111) e (101) o microcorte foi predominante.

Palavras-chave: Esclerometria linear. Desgaste abrasivo. Orientação cristalográfica. 


\subsection{OBJETIVO}

\subsubsection{Geral}

Estudar os efeitos do encruamento e da orientação cristalográfica no desgaste por riscamento dos aços austeníticos ao manganês.

\subsubsection{Específicos}

- Avaliar o desgaste por riscamento do aço austenítico com $12 \% \mathrm{Mn}$ não deformado e deformado com carga constante na mesoescala;

- Caracterizar os riscos com interferometria óptica 3D, microscopia óptica e eletrônica de varredura;

- Avaliar o desgaste por riscamento dos aços austeníticos com $12 \% \mathrm{Mn}$ e $20 \% \mathrm{Mn}$ não deformado e deformado com carga constante na microescala;

- Identificar grãos com planos (111), (001) e (101) via EBSD para análise de desgaste por riscamento;

- Caracterizar os riscos a partir da profundidade do risco $(h)$, do micromecanismo via MEV e da microestrutura da subsuperfície via FIB. 


\subsubsection{Diagrama de blocos}

O diagrama da Figura 4.1 mostra os níveis da análise multiescala abordados neste Capítulo com indicação dos ensaios e das metodologias de caracterização utilizadas.

Figura 4.1. Diagrama de blocos

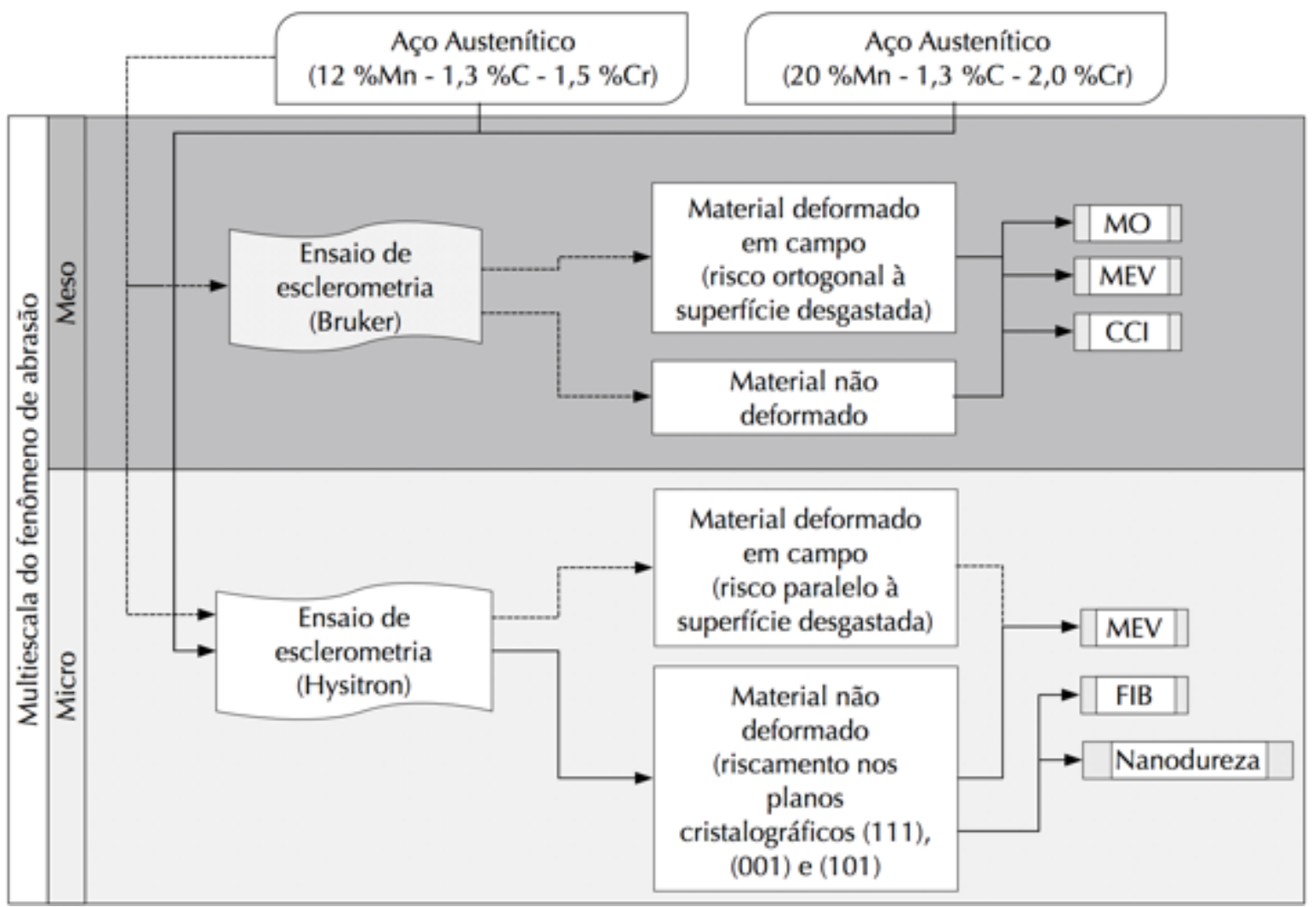

\subsection{MATERIAIS E MÉTODOS}

\subsubsection{Obtenção e preparação de amostra}

Um grupo de amostras para ensaio de esclerometria linear na escala meso e micro foram obtidas de revestimento britador de aço Hadfield classe C (ASTM G128, 2012), nomeado de $12 \mathrm{Mn}$. Outro grupo para ensaio de microesclerometria foram fabricadas de aço austenítico com 19,9\%Mn, nomeado de 20Mn. A Tabela 4.1 mostra as composições químicas dos dois aços obtidas via espectroscopia óptica na empresa Metso. 
Tabela 4.1. Composição química dos aços em estudo (\% em peso)

\begin{tabular}{ccccccc}
\multicolumn{7}{c}{ 12Mn (\% em peso) } \\
\hline $\mathrm{C}$ & $\mathrm{Mn}$ & $\mathrm{Si}$ & $\mathrm{P}$ & $\mathrm{S}$ & $\mathrm{Cr}$ & $\mathrm{Mo}$ \\
1,3 & 12,4 & 0,87 & 0,05 & 0,003 & 1,5 & 0,1 \\
\multicolumn{7}{c}{$\mathbf{2 0 M n}(\%$ em peso) } \\
\hline $\mathrm{C}$ & $\mathrm{Mn}$ & $\mathrm{Si}$ & $\mathrm{P}$ & $\mathrm{S}$ & $\mathrm{Cr}$ & $\mathrm{Mo}$ \\
1,3 & 19,9 & 0,6 & 0,04 & 0,002 & 2,1 & 0,6
\end{tabular}

As amostras do aço $20 \mathrm{Mn}$ foram obtidas de lingotes fundidos e tratados termicamente. Após o resfriamento completo do material bruto de fundição, os fundidos foram submetidos ao processo de tratamento térmico isotérmico a $1.100{ }^{\circ} \mathrm{C}$ para dissolver em matriz austenítica os carbonetos contínuos, carbonetos eutéticos e colônias perlíticas (KUYUCAK; ZAVADIL; NEWCOMBE. P., 2001c). Ao final do tratamento o lingote foi submetido ao processo de resfriamento rápido em água para evitar a reprecipitação de segunda fase em contorno de grão.

A retirada de amostras do revestimento de britador de aço Hadfield classe C provenientes de um britador giratório (manto) foi realizada com o processo de oxicorte na empresa VALE S/A. As amostras com menores dimensões e a proveniente de lingote fundido e tratado termicamente foram obtidas com os processos de corte a disco automatizado: i. STRUERS DISCOTOM-65 (LFS Poli/USP) com rotação de 2.150 RPM, disco STRUERS 40A30 e velocidade de avanço de $0,2 \mathrm{~mm} / \mathrm{s}$; e ii. BUEHLER ISOMET 5.000 (LFS Poli/USP) com rotação de 2.000 RPM, disco BUEHLER 11-2720 e velocidade de avanço de $0,02 \mathrm{~mm} / \mathrm{s}$.

A preparação das amostras para análise microestrutural passou por etapas sucessivas de metalografia: lixamento semi-automático com lixas de $\mathrm{SiC} \# 80$ a \#1.200, polimento semi-automático com solução de diamante de $10 \mu \mathrm{m}$ a $1 \mu \mathrm{m}$ e ataque químico por imersão com reagente picral $4 \%$.

\subsubsection{Macrodureza e perfil de microdureza}

As medições macro e microdureza Vickers (HV) foram realizadas conforme a norma (ASTM E384, 2012) com o durômetro Buehler VMT e MMT-3 do LFS (PMEPoli/USP), sendo utilizada as cargas de $30 \mathrm{kgf}$ e $0,3 \mathrm{kgf}$ com 5 repetições, 
respectivamente. O perfil de microdureza Vickers foi obtido até a distância de $7 \mathrm{~mm}$ da superfície desgastada com espaçamento de $0,5 \mathrm{~mm}$ entre endentações.

\subsubsection{Ensaio de esclerometria linear}

Os ensaios de esclerometria linear de passe simples (ASM-HANDBOOK VOL. 18, 2001) foram realizados em duas escalas dimensionais (meso e micro).

\subsubsection{Esclerometria}

O estudo de esclerometria (mesoescala) realizado nesta pesquisa foi realizado para verificar o comportamento do degaste por riscamento, com carga constante de $8 \mathrm{~N}$, ao longo do perfil encruado do aço $12 \mathrm{Mn}$ gerado em operação de fragmentação de minério de ferro.

\subsection{Metodologia de ensaio}

Os ensaios foram realizados com o tribômetro UMT-2 Bruker, Figura 4.2, com riscamento no sentido da aresta do endentador Vickers (ângulo de ataque de $19^{\circ}$ ). Os parâmetros de ensaio para o aço 12Mn (deformado em campo e não deformado) foram: $7 \mathrm{~mm}$ de comprimento do risco, velocidade de $1 \mathrm{~mm} / \mathrm{s}$ e carga normal constante de $8 \mathrm{~N}$. A taxa de aquisição de dados configurada para o ensaio foi de 179 pontos por segundo, totalizando 1.280 pontos, dos quais foram retirados os primeiros 27 pontos para cálculo do coeficiente de atrito médio. Estes pontos foram retirados para eliminar o período de running in presente nos primeiros $0,14 \mathrm{~s}$. 
Figura 4.2. a) Tribômetro UMT-2 Bruker. b) Câmara de ensaio UMT-2

a)

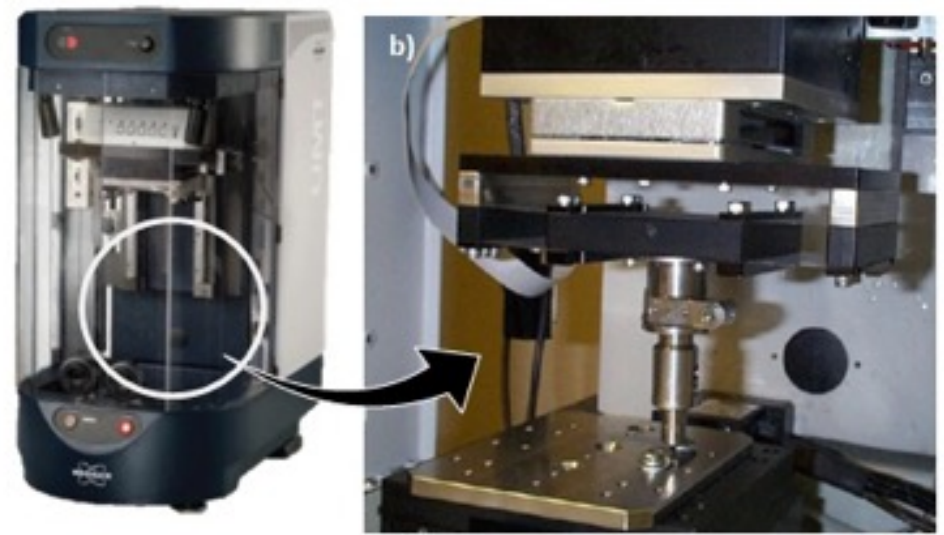

A metodologia do ensaio de esclerometria linear é mostrada na Figura 4.3. Os ensaios foram realizados na superfície transversal a de desgaste em campo, com direção de riscamento ao longo do perfil de encruamento, sentido do núcleo para a superfície e com $7 \mathrm{~mm}$ de comprimento.

Figura 4.3. a) Revestimento de britador cônico (liner superior). b) Seção do revestimento de britador.

c) Amostra do revestimento do britador (seção transversal) desgastada em campo, modelo da metodologia empregada no ensaio de esclerometria do perfil de encruamento
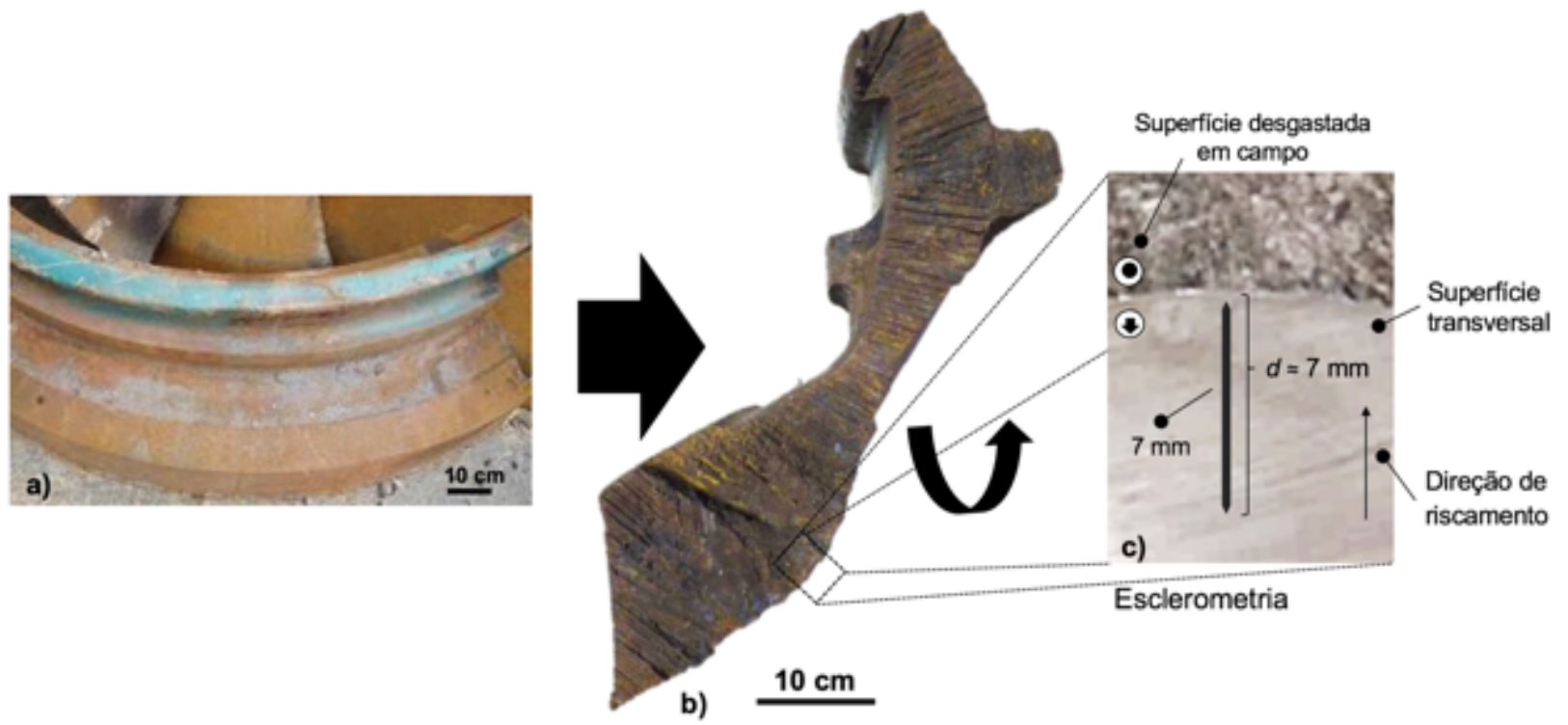


\subsection{Caracterização dos riscos}

Os riscos foram caracterizados via Microscopia Óptica (MO) com microscópico OLYMPUS BX60M com câmera JVC TK-1380 do LFS (PME-Poli/USP). A caracterização via Microscópio Eletrônico de Varredura (MEV) foi realizada com o equipamento JEOL JSM-6010LA (LFS PME-Poli/USP), as técnicas utilizadas foram a de elétrons secundários ( $\mathrm{SE}$ ), elétrons retroespalhados (BEC) e espectroscopia de energia dispersiva (EDS).

A análise topográfica das amostras após ensaios de abrasão foi realizada empregando-se a técnica de interferometria 3D com o equipamento Taylor-Hobson modelo CCI MP do LFS (PME-Poli/USP).

A técnica de interferometria óptica é uma ferramenta versátil para obter e avaliar resultados de geometria de riscos gerados em ensaio de esclerometria linear, sendo possível quantificar os parâmetros geométricos dos riscos. Na Figura 4.4 é mostrado o fluxo de operações que resultam na medida da geometria de riscos (1 Posicionamento da amostra e seleção de objetiva; 2 - Configuração do hardware e software; 3 - Processo de interferometria e mapeamento 3D; 4 - Obtenção de seções transversais ao longo do risco; e 5 - Quantificação de parâmetros geométricos).

Figura 4.4. Etapas do método de obtenção de perfil transversal via interferometria óptica 3D
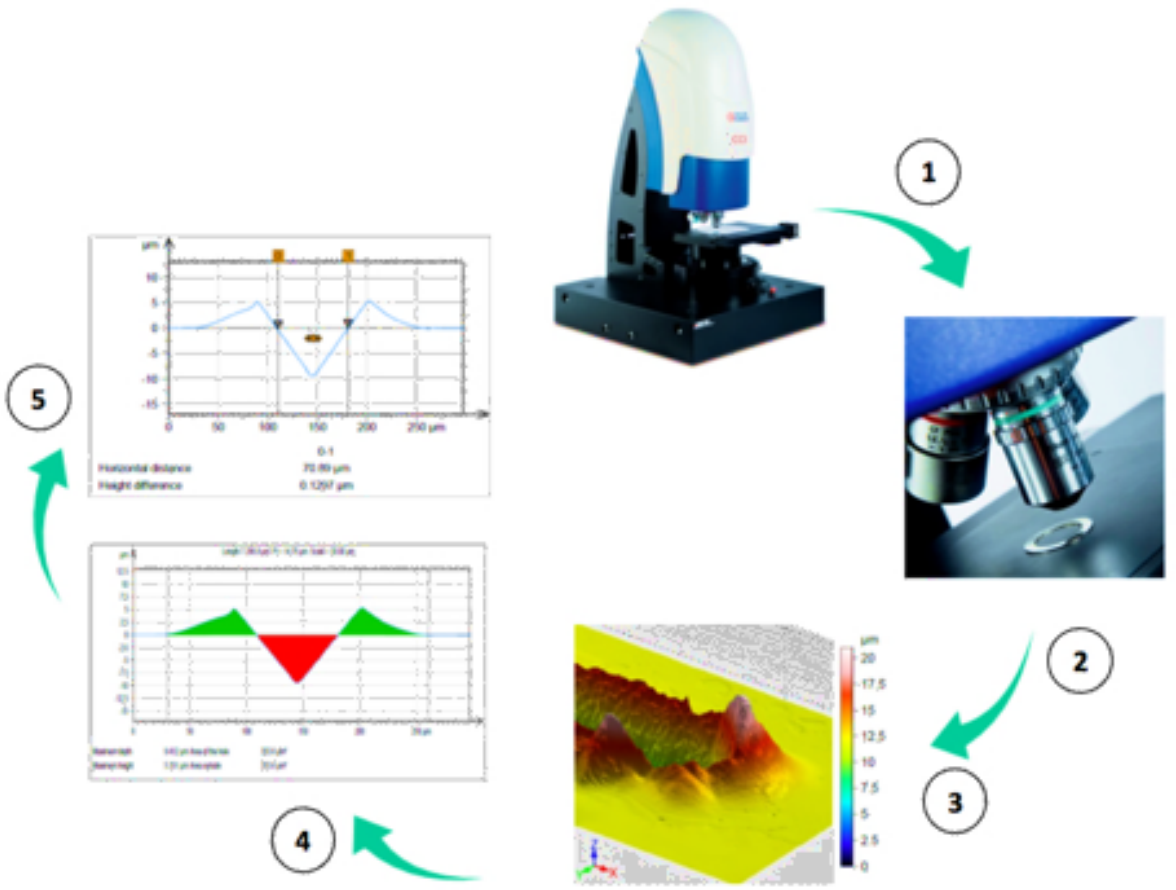
As medidas da área do hole e área de pile-up dos riscos foram obtidas empregandose o software Talymap. O protocolo para a obtenção desses parâmetros foi aplicado conforme a metodologia descrita por Franco que destaca dois tipos de larguras de risco possíveis de serem avaliadas, uma obtida no plano de referência $\left(w_{r}\right)$, Figura 4.5, e outra obtida entre os picos do pile-up (FRANCO, 2015).

Figura 4.5. Perfil médio de um risco e indicação de parâmetros geométricos

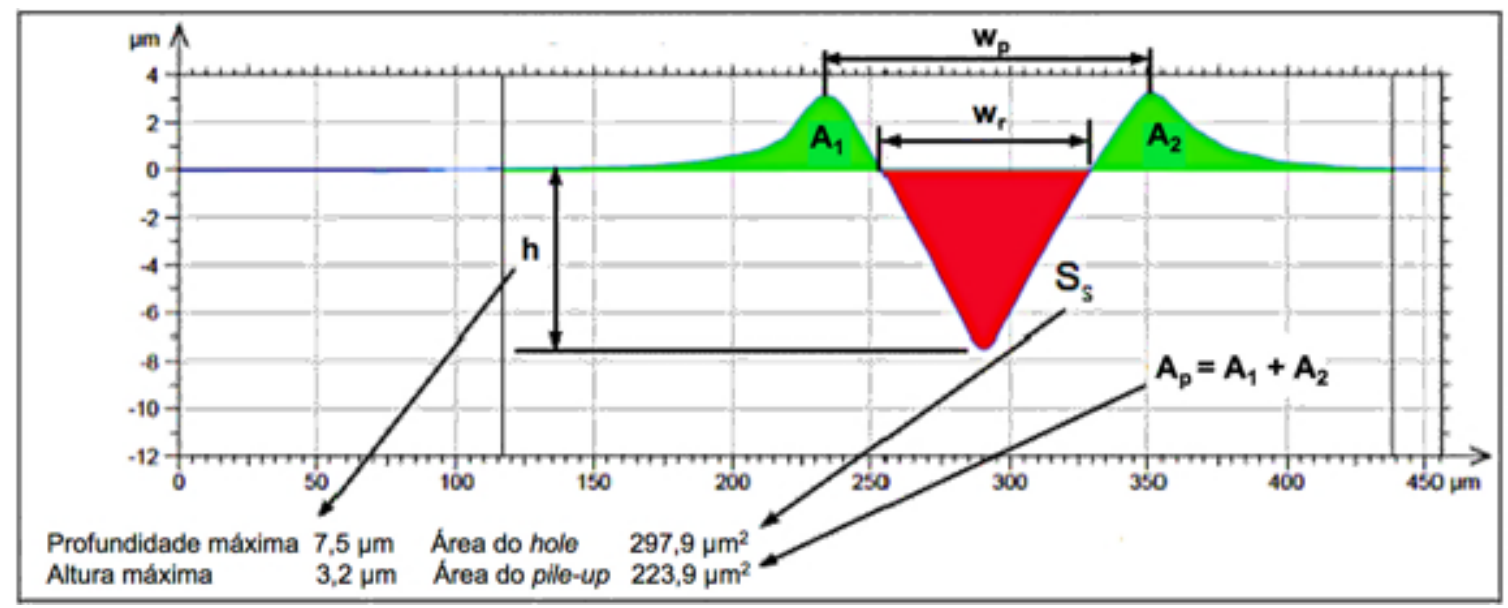

Fonte: Adaptado de Franco, 2015

Os riscos realizados na mesoescala foram caracterizados com a obtenção do perfil médio ao longo do comprimento do risco. Os perfis médios foram separados por $1 \mathrm{~mm}$ e correspondem um valor médio de 450 medidas (perfis) dentro de um único grão para uma posição específica. Desta forma, as áreas de pile-up e hole obtidas foram usadas para calculo de fração de material removido $\left(f_{a b}\right)$.

Nesta pesquisa foi adotada a largura do risco no plano de referência, devido às limitações da técnica. Por exemplo, em casos de microcorte a geometria do risco torna-se complexa para obtenção de valores precisos de largura entre picos via perfilometria ou interferometria, de forma que a área de pile-up obtida é maior que a área real. Isso ocorre pela presença de vazio abaixo da borda (chip) como mostra a Figura 4.6a (setas brancas). A Figura 4.6b mostra a seção transversal do risco na posição indicada pela seta preta (Figura 4.6a). Essas regiões são consideradas área, sendo responsáveis por gerar erro no resultado de área do pile-up. Desta forma, a fração $f_{a b}$ não foi calculada para o estudo com ensaio de microesclerometria, o qual gera riscos com formação de borda lateral (microcorte), Franco e Sinatora discutem este assunto em detalhe (FRANCO; SINATORA, 2017). 
Figura 4.6. Risco em escala micrométrica em aço Hadfield. a) Formação de borda (chip). b) Seção transversal do risco indicado pela seta preta (Figura a)
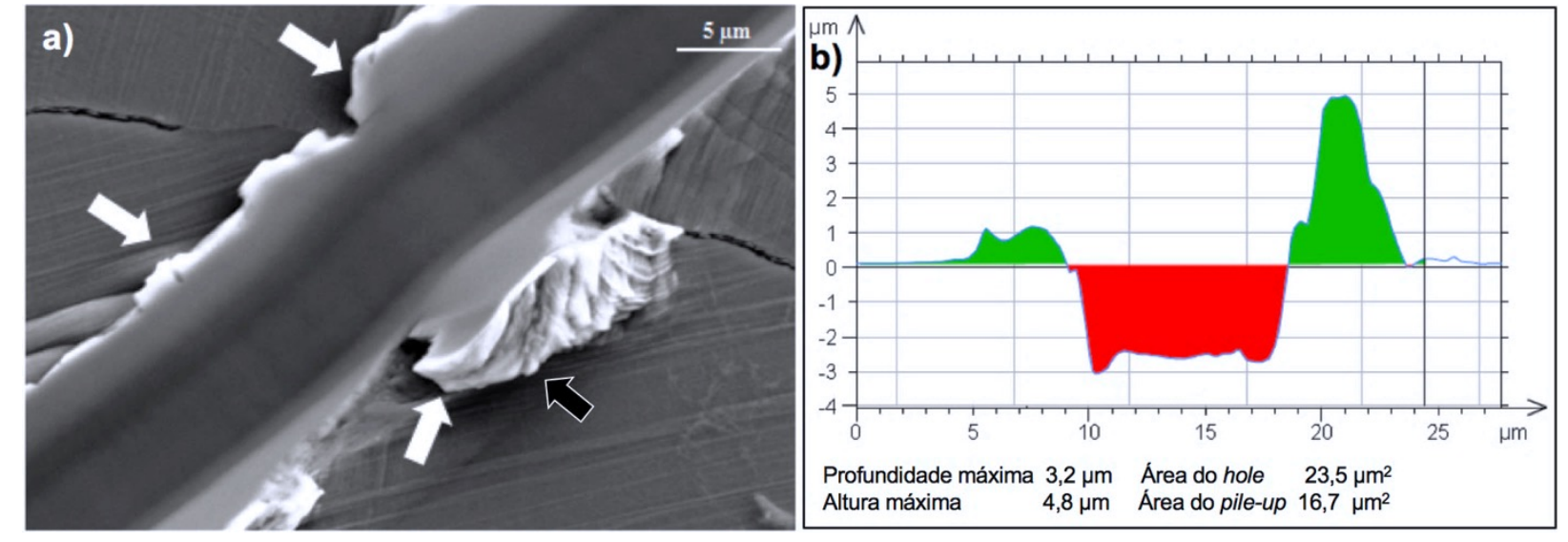

\subsubsection{Microesclerometria}

A análise de microesclerometria é utilizada para avaliar o efeito perfil de encruamento no desgaste por riscamento na região de maior variação de dureza. Assim como, avaliar o efeito da orientação cristalográfica.

\subsection{Metodologia de ensaio}

Para a escala micrométrica utilizou-se o nanoendentador 950 Tribolndenter Hysitron (LFS PME-Poli/USP) com ponta cônica (ângulo de ataque $60^{\circ}$ ) e raio de ponta de $5 \mu \mathrm{m}$, Figura 4.7. Os ensaios de microesclerometria foram realizados com comprimento de $100 \mu \mathrm{m}$, velocidade de 3,3 $\mu \mathrm{m} / \mathrm{s}$ e cargas constantes de 20, 50, 100, 150, 200 e $250 \mathrm{mN}$. O procedimento de ensaio de esclerometria neste equipamento pode ser dividido em cinco etapas: calibração da ponta (endentador), mapeamento da área de análise, posicionamento da ponta na superfície, perfilometria do local onde será realizado o risco e riscamento. A taxa de aquisição de dados configurada para o ensaio foi de 198 pontos por segundo, totalizando 6.000 pontos para cada etapa (perfilometria e riscamento) por ensaio, dos quais, para o riscamento, foram usados os últimos 3.500 pontos para cálculo do coeficiente de atrito e da profundidade média. Os pontos considerados para o calculo da média estão contidos no intervalo de 40 a $100 \mu \mathrm{m}$ do comprimento do risco. 
Figura 4.7. a) Nanoendentador Hysitron. b) Endentador cônico

a)

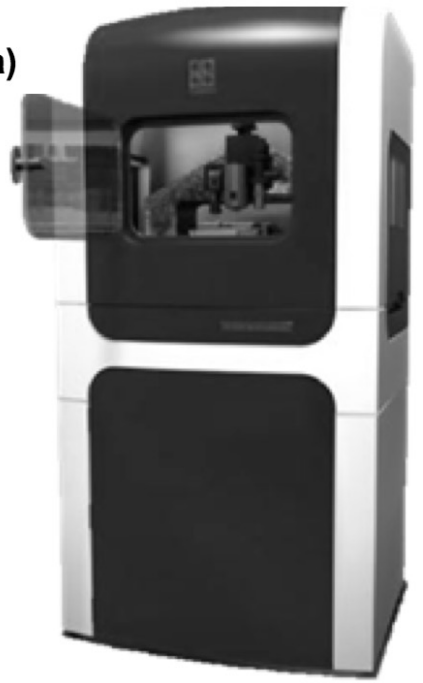

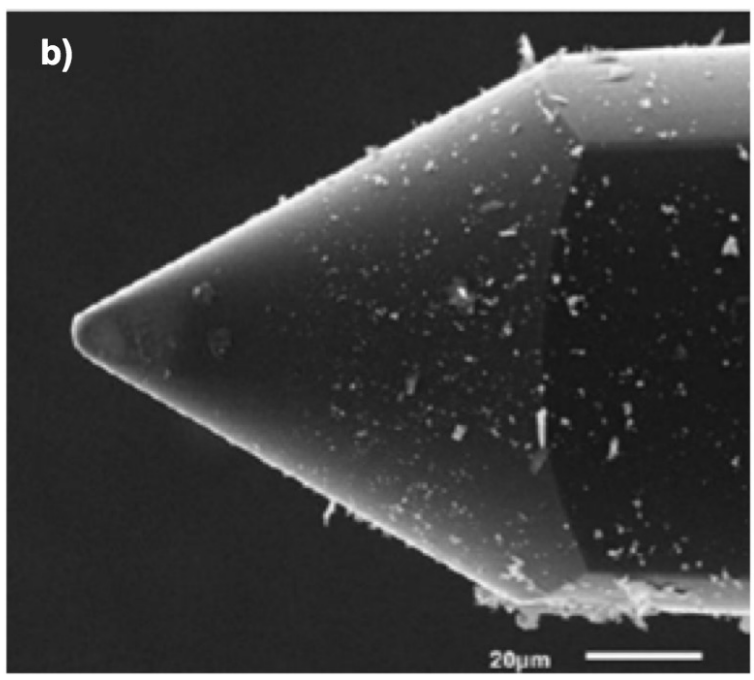

Fonte: a) Manual Hysitron Nanoindenter

A Figura 4.8 mostra o perfil do endentador e o modelo de ângulo de ataque. 0 ângulo de ataque do endentador com ponta esférica de $5 \mu \mathrm{m}$ varia de acordo com a profundidade de penetração. Por exemplo, para a profundidade de 0,5 $\mu$ m o ângulo de ataque equivale a $26^{\circ}$ e para uma profundidade de $2 \mu \mathrm{m}$ o ângulo é igual a $54^{\circ}$. O raio projetado na superfície (a) e o ângulo de ataque $\alpha$ são obtidos a partir das seguintes equações de regressão desenvolvidas nesta pesquisa: $a=2,9505^{\star} h^{\wedge} 0,4405$ e $\alpha=37,392^{*} h^{\wedge} 0,5208$; respectivamente. O ângulo do cone do endentador é $60^{\circ}$, o qual representa o ângulo máximo deste sistema. Esta configuração geométrica resulta em uma transição de geometria $\left(Z_{g t}\right)$ na profundidade de 2,5 $\mu \mathrm{m}$ (profundidade onde se tem a transição da esfera para o cone). $Z_{g t}$ é calculado com a Equação (4.1) (ASTM G171, 2012).

$Z_{g t}=r \cdot\left(1-\cos . \theta_{\text {deg }}\right)$

Onde $r$ é o raio da ponta do endentador, $\theta_{d e g}=1 / 2 .\left(180-\alpha_{d e g}\right)$, e $\alpha_{d e g}$ é o ângulo do vértice (em graus).

O grau de penetração $\left(D_{p}\right)$, Equação (4.2), foi calculado de acordo com o modelo de ângulo de ataque e a pesquisa de Hokkirigawa e Kato (HOKKIRIGAWA; KATO, 1988).

$D_{p}=h / a$ 
Onde $h$ é a profundidade de penetração e a é o raio projetado do endentador no nível da superfície.

Figura 4.8. Perfil da ponta cônica e modelo de ângulo de ataque.

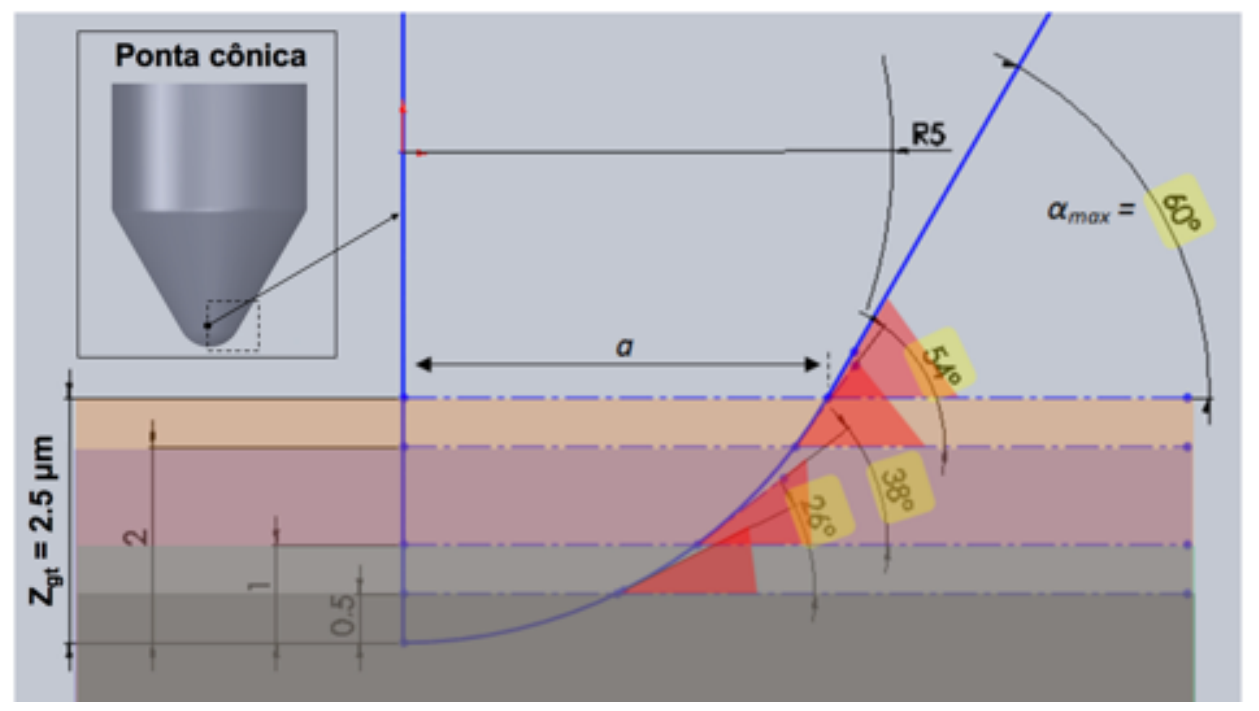

\subsection{Efeito do perfil de encruamento}

Nos ensaios de microesclerometria do perfil de encruamento (aço 12Mn) adotou-se a distância inicial de $100 \mu \mathrm{m}$ da superfície desgastada em campo e com espaçamentos de $500 \mu \mathrm{m}$ entre os riscos ao longo do perfil. Com a realização de 4 riscos ao longo da distância $(d)$ de 1,6 mm da superfície desgastada em campo, Figura 4.9. Essa metodologia foi utilizada para estudar a região de maior variação de microdureza. 
Figura 4.9. a) Seção do revestimento de britador. b) Amostra do revestimento do britador (seção transversal) desgastada em campo. c) Modelo da metodologia empregada no ensaio de microesclerometria do perfil de encruamento

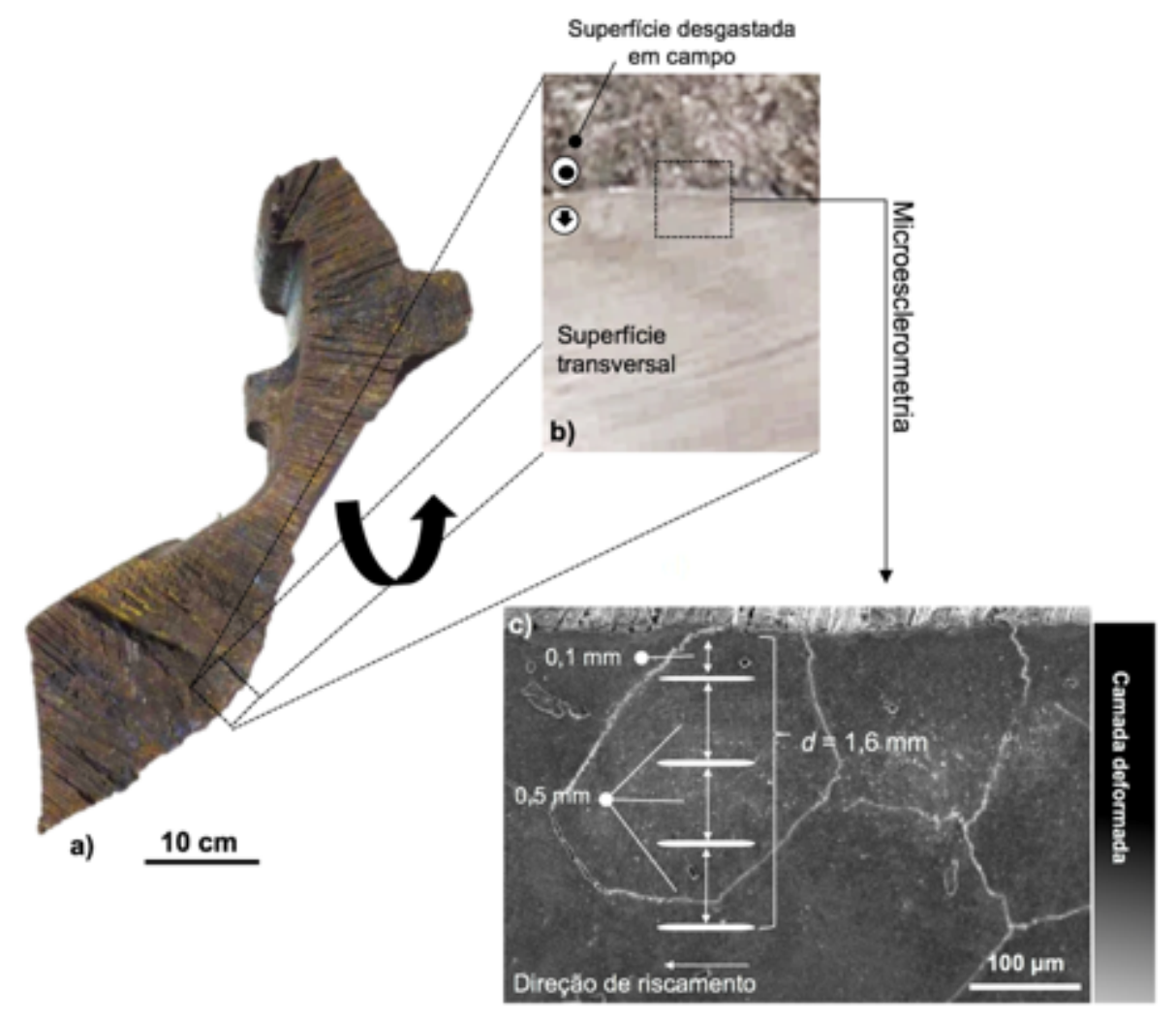

Foram realizadas duas séries para os ensaios de microesclerometria do perfil de encruamento: série i e série ii. A série i trata-se dos ensaios com as forças normais 20, 50, 100, 150, 200 e 250 mN com uma repetição para cada condição (força e distância da superfície desgastada ou valor de microdureza), totalizando 24 ensaios. A série ii foi realizada em outro momento após análise parcial dos resultados da série i. Desta forma, foram selecionadas as cargas 50, 100 e $200 \mathrm{mN}$ para obtenção de maior número de ensaios por condição, adotando-se três repetições para cada condição (carga e dureza), totalizando 36 ensaios.

O procedimento para a série ii é mostrado na Figura 4.10, o qual adota referência matricial de orientação. A superfície desgastada encontra-se ortogonal à superfície da folha. E a seção transversal (gradiente de dureza) é representado pelo gradiente em cinza. 
Figura 4.10. Modelo de distribuição de riscos adotado para os ensaios de microesclerometria

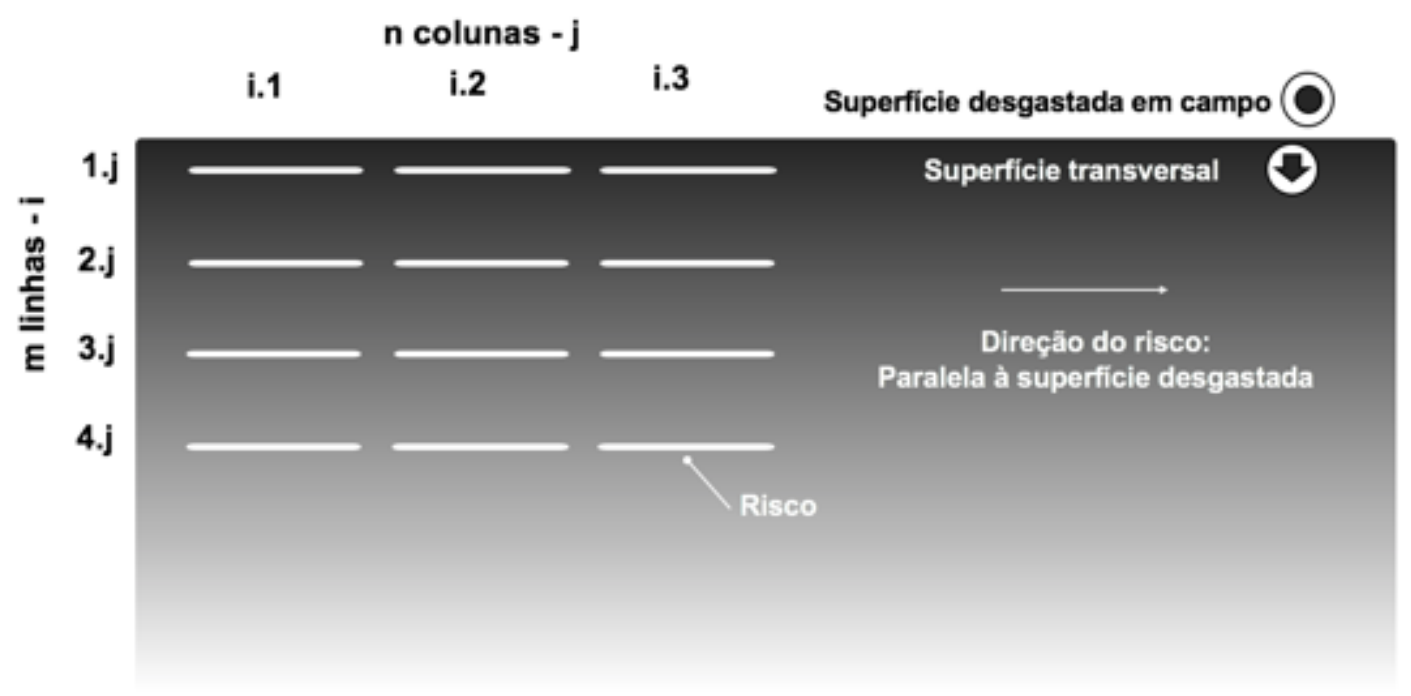

\subsection{Efeito da orientação cristalográfica}

Neste tópico os aços $12 \mathrm{Mn}$ e $20 \mathrm{Mn}$ não deformados são avaliados levando em consideração as orientações cristalográficas (001), (111) e (101), desta forma, cada orientação pode ser tratada como um monocristal. A metodologia adotada para realização deste estudo foi desenvolvida ao longo desta pesquisa. Essa metodologia representa uma inovação no estudo do efeito da anisotropia cristalina na resistência ao desgaste por microesclerometria para materiais policristalinos. A Figura 4.11 mostra o fluxograma com as etapas da metodologia de ensaio de microesclerometria nas orientações cristalográficas de interesse. 
Figura 4.11. Fluxograma da metodologia de microesclerometria em orientações cristalográficas conhecidas

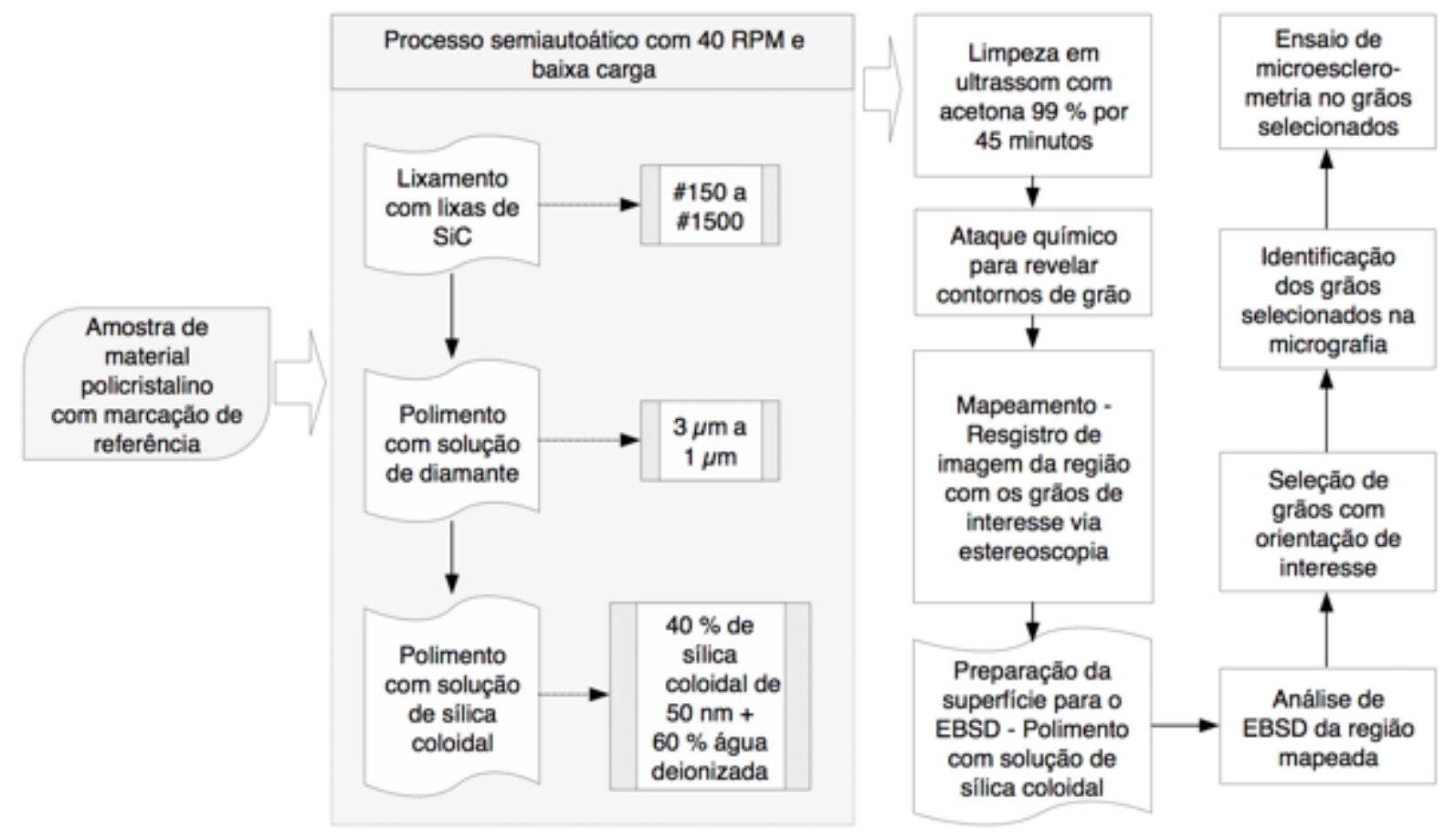

O uso desta metodologia é indicado para materiais metálicos com tamanho de grão grande, que possibilite a realização do ensaio de microesclerometria no interior dos grãos. Nesta pesquisa os tamanhos médios de grão dos aços $12 \mathrm{Mn}$ e $20 \mathrm{Mn}$ correspondem a $275 \mu \mathrm{m}$ e $511 \mu \mathrm{m}$, respectivamente.

Os parâmetros de ensaio foram os mesmos aplicados ao aço 12Mn deformado: $100 \mu \mathrm{m}$ de comprimento de risco, velocidade $(v)$ de $3,3 \mu \mathrm{m} / \mathrm{s}, 3$ repetições e força normal constante de $200 \mathrm{mN}$. A taxa de deformação $(\dot{\varepsilon})$ para estes ensaios foi calculada com a Equação (4.3) (JANKOWSKI et al., 2011) e equivale a $3,5 \cdot 10^{-1} \mathrm{~s}^{-1}$.

$\dot{\varepsilon}=v * w^{-1}$

Onde $v$ é a velocidade e $w$ é a largura do risco.

A energia gasta pelo riscamento $\left(e_{r}\right)$ foi calculada de acordo com a Equação (4.4).

$e_{r}=\int_{0}^{L} F_{t} \cdot d_{L}$

Onde $L$ é o comprimento do risco e $F_{t}$ é a força tangencial. 
A análise de difração de elétrons retroespalhados (EBSD) foi realizada no LABMICRO (PMT-Poli/USP) com o equipamento FEG (Field Emission Gun) Inspect 50 e câmera EDAX e step size de 0,5 $\mu \mathrm{m}$.

Os módulos de elasticidade (combinado) das orientações cristalográficas estudadas para os dois aços foram obtidos via ensaio de nanodureza realizados com o equipamento Hysitron Nanoindenter (LFS), com ponta Berkovich e carga normal de $2 \mathrm{mN}$, a partir do modelo Oliver Pharr (OLIVER; PHARR, 1992), foram realizadas 25 endentações para cada orientação cristalográfica estudada.

\subsection{Caracterização da microestrutura da subsuperfície}

A microestrutura da subsuperfície dos riscos nos planos cristalográficos (001), (111) e (101) dos aços $12 \mathrm{Mn}$ e $20 \mathrm{Mn}$ foi avaliada via FIB. O equipamento utilizado foi o FEI QUANTA 3D FEG do IPT. A Figura 4.12 mostra uma montagem do sistema de microesclerometria (corte transversal ao risco) para indicar na imagem de FIB a interface endentador/material, camada de platina, linha de referência da superfície, pile-up e sink-in.

Figura 4.12. Montagem do sistema de microesclerometria com identificação das regiões de imagem de FIB (corte transversal ao risco)

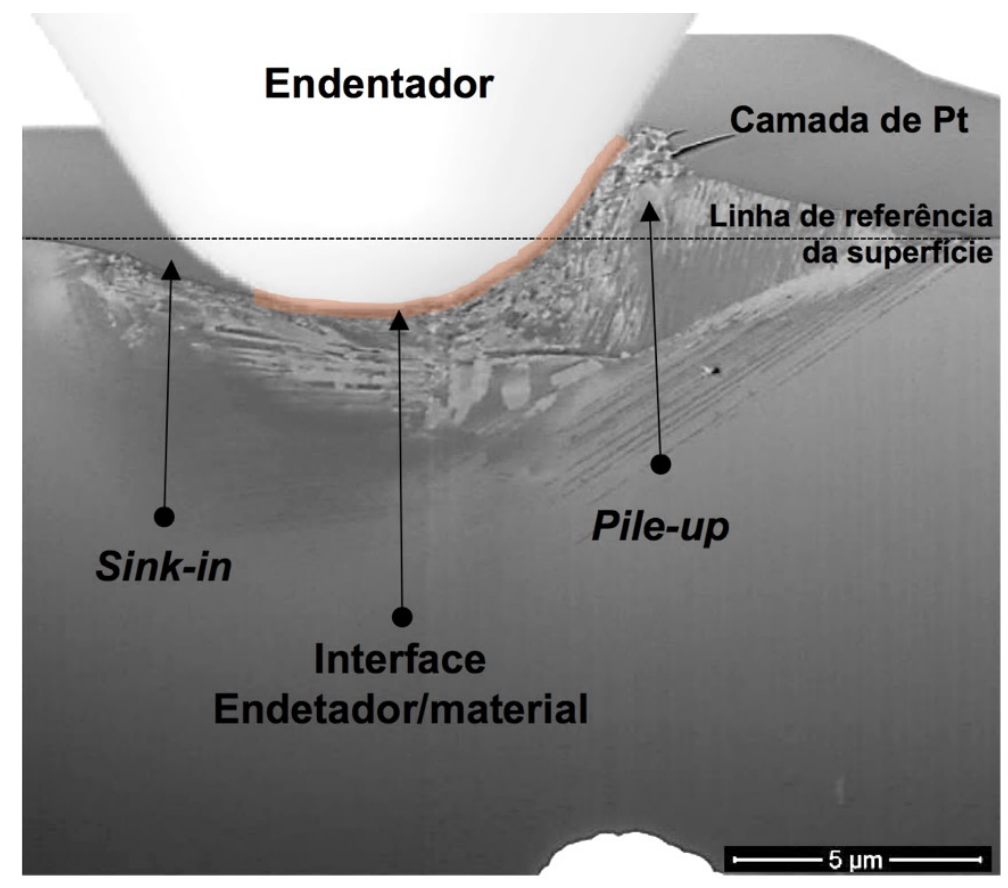




\subsection{RESULTADOS E DISCUSSÕES}

\subsubsection{Micrografia dos materiais}

A Figura 4.13 mostra a micrografia do aço 12Mn deformado e não deformado, e do aço $20 \mathrm{Mn}$. Os materiais têm microestrutura com carbonetos contínuos formados no processo de resfriamento após tratamento isotérmico (FUOCO et al., 2012; KUYUCAK; ZAVADIL; NEWCOMBE. P., 2001c). A macrodureza dos aços 12Mn e $20 \mathrm{Mn}$ são $202 \pm 1$ HV30 e $221 \pm 3$ HV30, respectivamente.

Figura 4.13. Micrografia dos aços $12 \mathrm{Mn}$ deformado (a) e não deformado (b), e $20 \mathrm{Mn}$ (c)
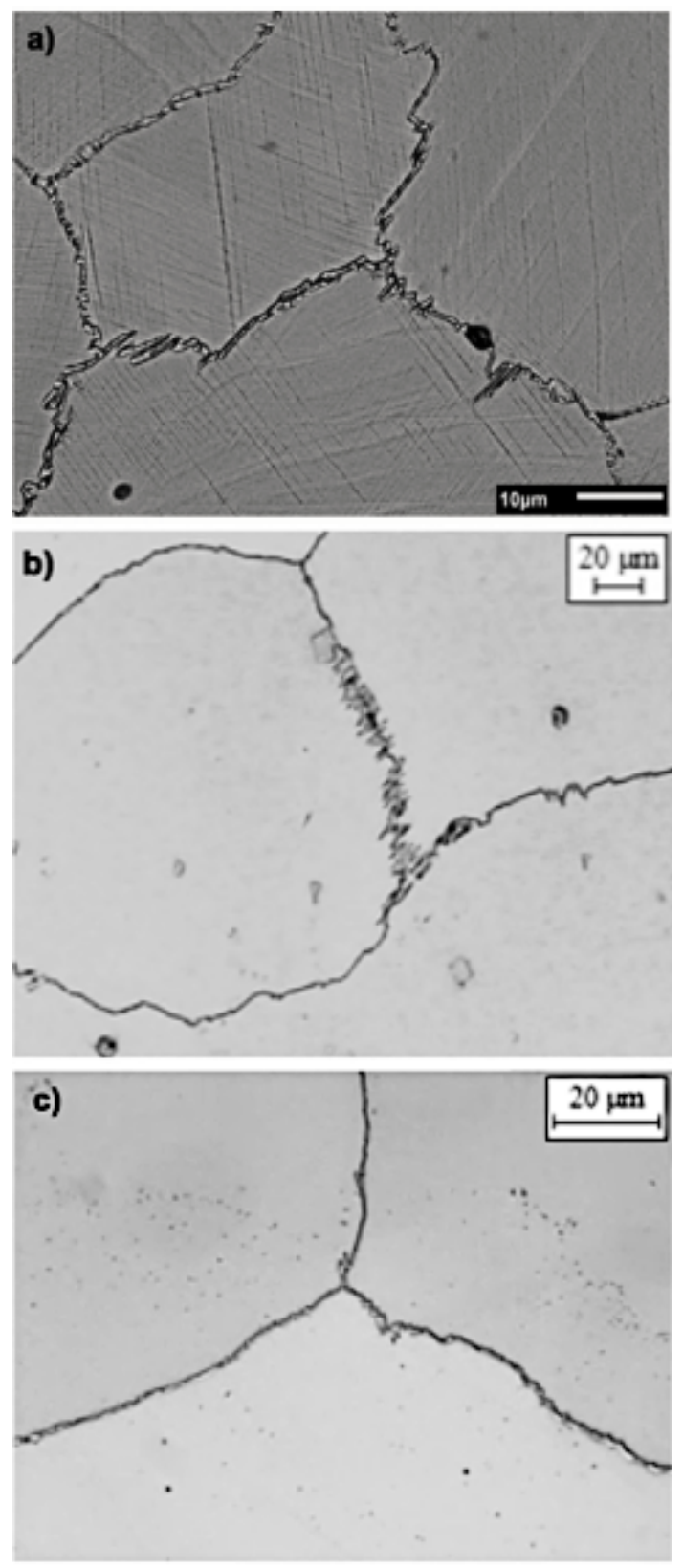


\subsubsection{Perfil de microdureza}

O perfil de microdureza, Figura 4.14, tem o valor máximo de $700 \mathrm{HV} 0,3$ próximo à superfície. A partir de aproximadamente $5 \mathrm{~mm}$ da superfície os valores de dureza passam a oscilar em torno de $330 \mathrm{HV} 0,3$. Lindroos et al. e Tanaka observaram estabilidade do valor de dureza de britadores de mandíbula na distância de $7 \mathrm{~mm}$ (LINDROOS et al., 2015a; TANAKA, 2011).

Figura 4.14. Perfil de microdureza Vickers do revestimento do britador

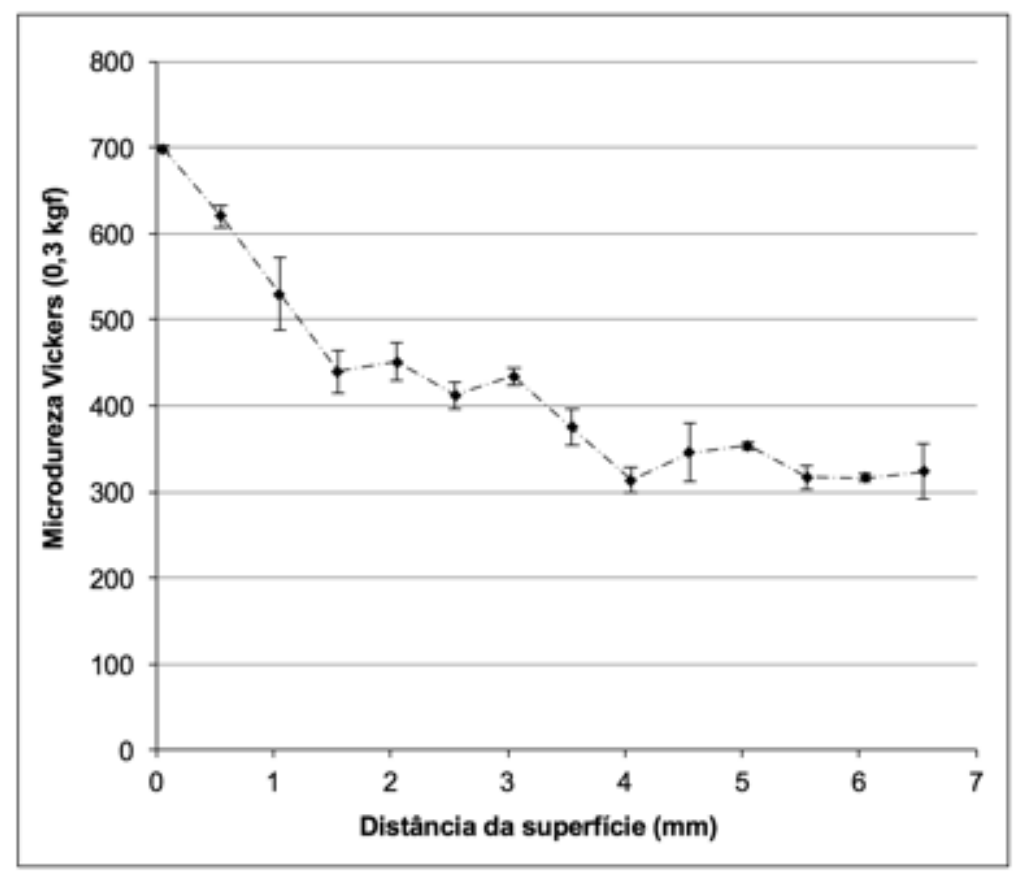

A elevação de dureza na região próxima da superfície decorre do encruamento devido à abrasão. Ou seja, a ação de escorregamento ou de endentação dos abrasivos promove deformação que resulta em aumento de dureza. A literatura aponta que no caso dos aços Hadfield a rápida elevação de dureza que ocorre simultaneamente ao fenômeno de abrasão se deve, principalmente, a maclação (ADLER; OLSON; OWEN, 1986; COOMAN; CHIN; KIM, 2011; DASTUR; LESLIE, 1981; KARAMAN et al., 2000a).

Como apresentado no Capítulo de revisão bibliográfica a prevalência dos mecanismos de deformação plástica são associados à energia de defeito de empilhamento, segundo alguns autores (ADLER; OLSON; OWEN, 1986; BAYRAKTAR; KHALID; LEVAILLANT, 2004; ISHIDA; NISHIYAWA, 1974; WHITE; HONEYCOMBE, 1962). 


\subsubsection{Esclerometria}

Neste tópico será avaliada a resistência ao desgaste por riscamento do aço $12 \mathrm{Mn}$ deformado e não deformado. A Figura 4.15 mostra um conjunto de micrografias dos riscos ao longo do perfil de encruamento. A extensão do risco cobre desde a região sem encruamento até a região de máxima dureza apresentada na Figura 4.14 para o aço 12Mn previamente encruado (fragmentação de minério de ferro).

No que se refere à largura dos riscos, nota-se que não há variação aparente desse parâmetro geométrico associada aos valores de microdureza do perfil encruado, ou seja, a largura dos riscos não apresenta correlação com o aumento de dureza ao longo do perfil de encruamento em serviço. Entretanto, observam-se variações de largura dos riscos associadas às mudanças de grão. Nota-se apreciável deformação plástica lateral com formação descontínua de pile-up. Essa constatação indica que a deformação gerada pelo processo de riscamento está associada à mudança de grão ao longo do risco. As imagens na Figura 4.15 mostram esse comportamento.

A estrutura policristalina isotrópica foi obtida em processo de solidificação em molde de areia, o qual não apresenta direção preferencial de extração de calor havendo nucleação e crescimento de grãos com orientação aleatória (CAMPOS; DAVIES, 1978).

A Figura 4.16 mostra o gráfico (com resultados de força normal, tangencial e coeficiente de atrito) e a projeção $3 \mathrm{D}$ da superfície do risco para o aço $12 \mathrm{Mn}$ deformado. As setas indicam que a variações de força tangencial e coeficiente de atrito estão relacionadas com a forma descontínua do pile-up formado em cada grão do material. 


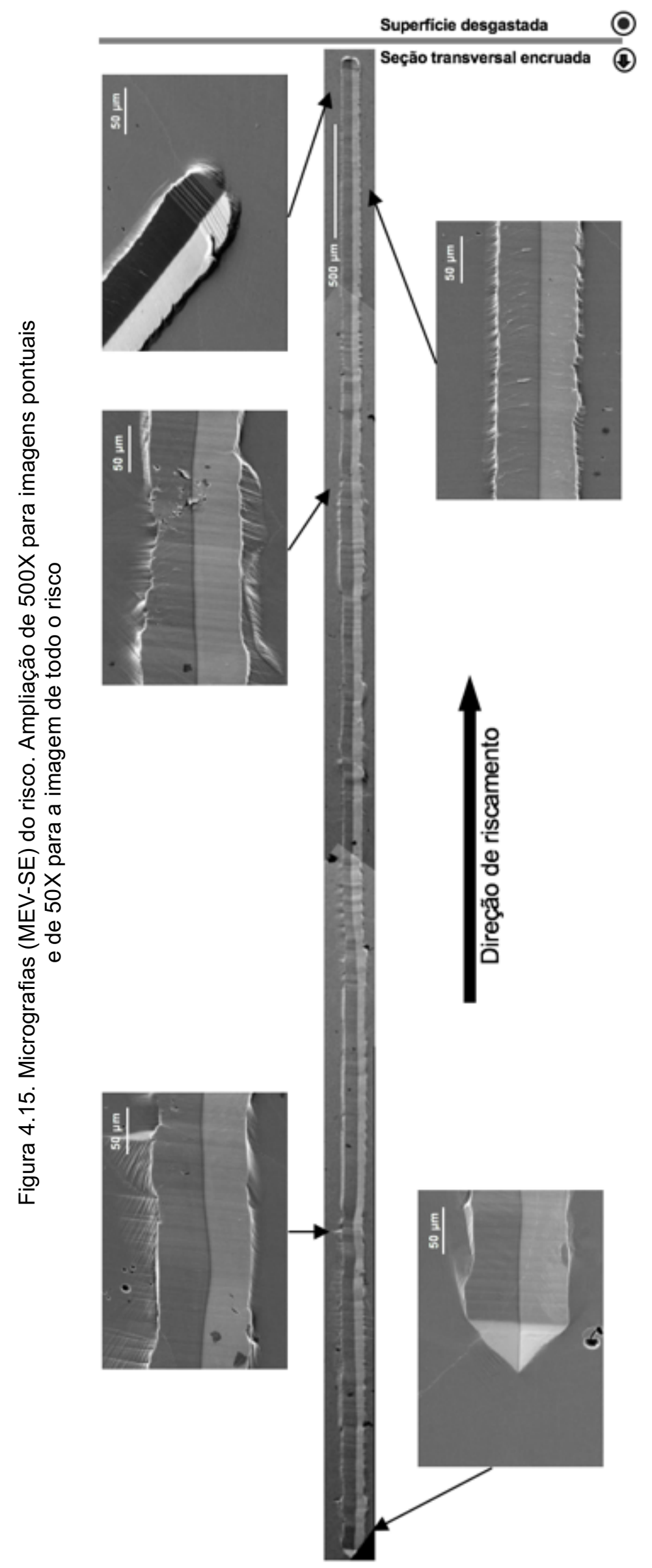


Figura 4.16. Resultados de força normal $\left(F_{n}\right)$, força tangencial $\left(F_{t}\right)$ e coeficiente de atrito $(C O F)$ em função do tempo (s) correlacionado à projeção 3D do risco (fator de amplificação de $25 \%$ )

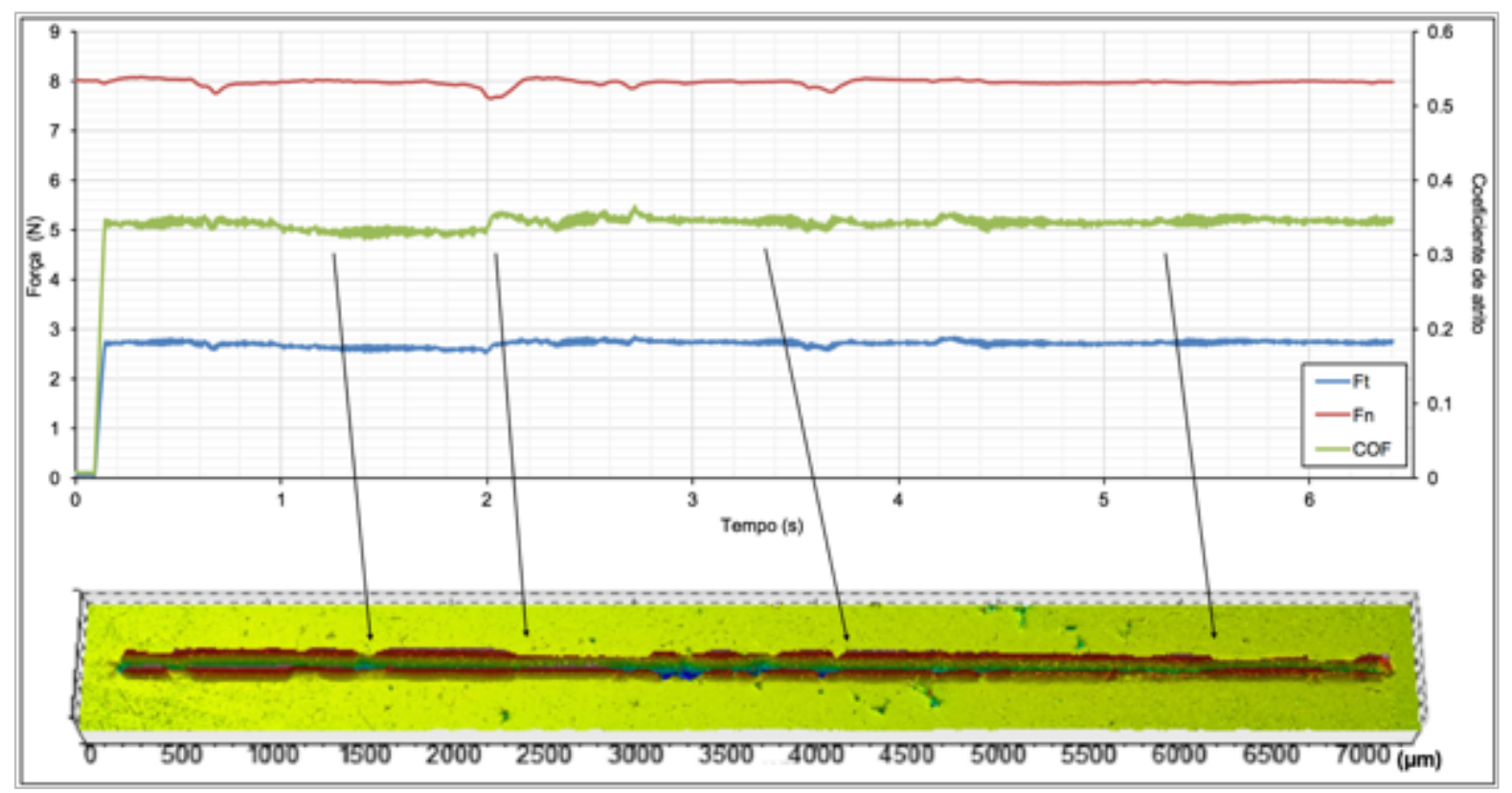

Os resultados de coeficiente de atrito e força normal, ao longo dos $7 \mathrm{~mm}$ do risco, apresentam pequenas variações, as quais ocorrem ao mudar de grão devido às diferentes orientações cristalográficas (aleatórias). No entanto, as pequenas variações de coeficiente de atrito observadas ao longo do risco não afetam o valor médio desta grandeza, uma vez que o número de amostragem é elevado.

A Figura 4.17 mostra a micrografia do risco obtida por microscopia óptica (Figura 4.17a), perfil longitudinal (Figura 4.17b) e perfis transversais (Figura 4.17c) dos riscos obtidos por interferometria óptica 3D. Os valores de coeficiente de desgaste e $f_{a b}$ obtidos nas posições 0,$5 ; 1,5 ; 2,5 ; 3,5 ; 4,5 ; 5,5$ e $6,5 \mathrm{~mm}$ ao longo do risco são indicados na imagem.

No que se refere à profundidade dos riscos, Figura 4.17b, é observada a variação desse parâmetro geométrico (distância da linha horizontal em amarelo até o fundo do risco) ao longo do perfil de dureza. Na maior parte do seu comprimento não depende do perfil de encruamento. No entanto, a partir da posição ( $p$ - distância entre a origem do risco e um ponto) $5 \mathrm{~mm}$ tem-se uma diminuição da profundidade que se mantem até a posição $7 \mathrm{~mm}$. Com essa evidência foi realizada uma análise de correlação da resistência ao desgaste $\left(W_{v / s}^{-1}\right)$ com a microdureza. 


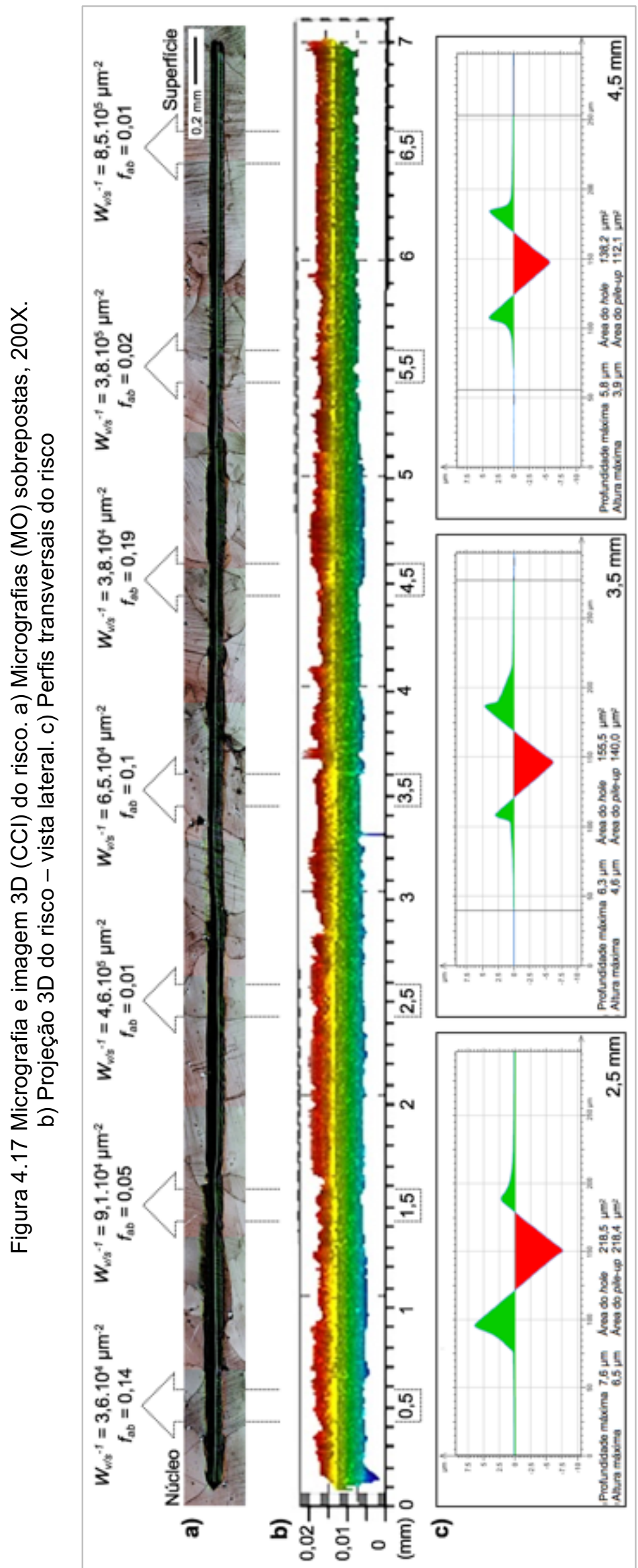


Os resultados da Figura 4.18 mostraram baixa correlação $\left(R^{2}=0,65\right)$ entre a resistência ao desgaste, calculada a partir da Equação (2.3), e o valor de microdureza. Este resultado reforça a hipótese de que tenha outra variável que causa efeito no comportamento plástico do material ao longo do perfil de encruamento.

Figura 4.18. Resultados de resistência ao desgaste em função de $f_{a b}$

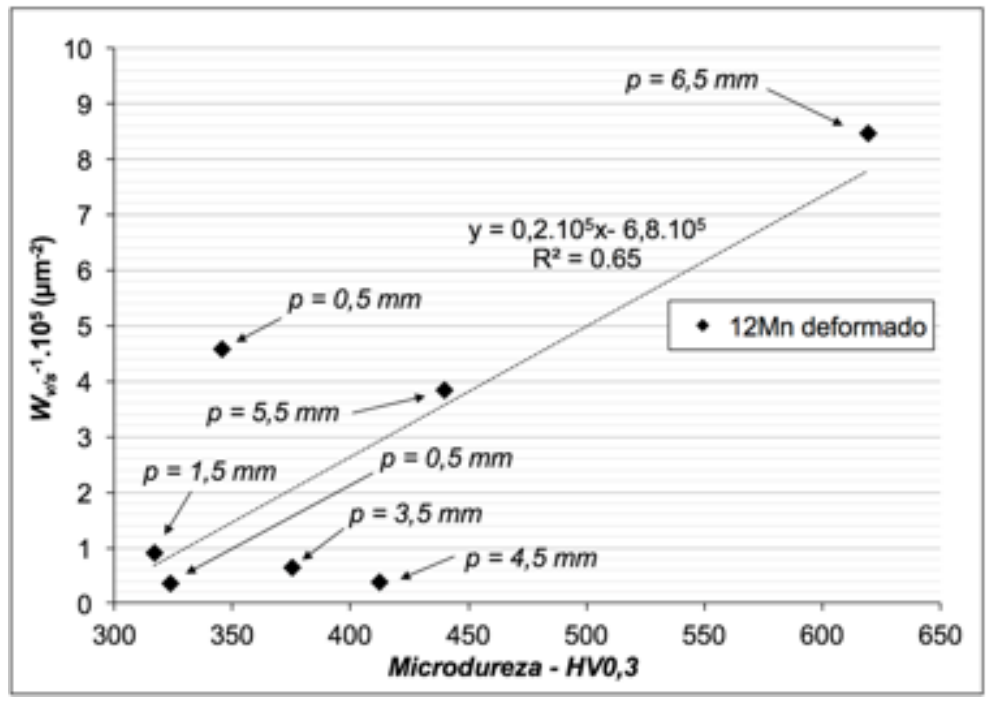

A Figura 4.19 mostra a relação do coeficiente de desgaste $\left(k_{a b}\right)$, calculado a partir da Equação (2.4), com o $f_{a b}$ para o aço $12 \mathrm{Mn}$ deformado e não deformado, as setas indicam as respectivas posições de alguns perfis ao longo do comprimento do risco para a amostra deformada. Esses resultados reforçam a hipótese de que outra variável tem efeito sobre o comportamento plástico do aço $12 \mathrm{Mn}$ deformado por abrasão (esclerometria). Os valores de $f_{a b}$ estão dispersos entre 0 e 0,19 indicando o microsulcamento como micromecanismo predominante. Esse resultado corresponde à resposta do sistema ao baixo ângulo de ataque do endentador Vickers $\left(19^{\circ}\right)$. A diminuição da capacidade de endurecimento em função do aumento de microdureza do material ao longo do perfil de encruamento não atingiu o valor crítico do ângulo de ataque, responsável pela transição de micromecanismo (microsulcamento para microcorte), conforme resultados de Challen et al. (CHALLEN; OXLEY; DOYLE, 1983). Os autores mostraram que o aumento da dureza diminui o ângulo de ataque crítico. Os maiores valores de $f_{a b}$ encontrados nesta pesquisa não estão, necessariamente, na região mais deformada do material. O maior valor de $f_{a b}$ obtido foi de 0,19 na posição 4,5 mm do risco, ou seja, a $\sim 1,5 \mathrm{~mm}$ da superfície deformada 
em campo. Apesar da posição $6,5 \mathrm{~mm}$ ter o menor coeficiente de resistência ao desgaste, a posição $2,5 \mathrm{~mm}$ tem o segundo menor valor, como indicado no gráfico. Nota-se também que os dados obtidos para o material não deformado tem variação significativa de $f_{a b}$. Portanto, pose-se concluir que a distribuição dos resultados de coeficiente de desgaste abrasivo é aleatória, assim como o processo de solidificação utilizado na fabricação dos revestimentos de britadores. Neste caso tem-se a orientação cristalina é a variável com efeito sobre o sistema de desgaste. Esta hipótese será avaliada no próximo tópico desta pesquisa.

Figura 4.19. Coeficiente de desgaste $\left(k_{a b}\right)$ em função do $f_{a b}$ para o aço $12 \mathrm{Mn}$ deformado em campo e não deformado

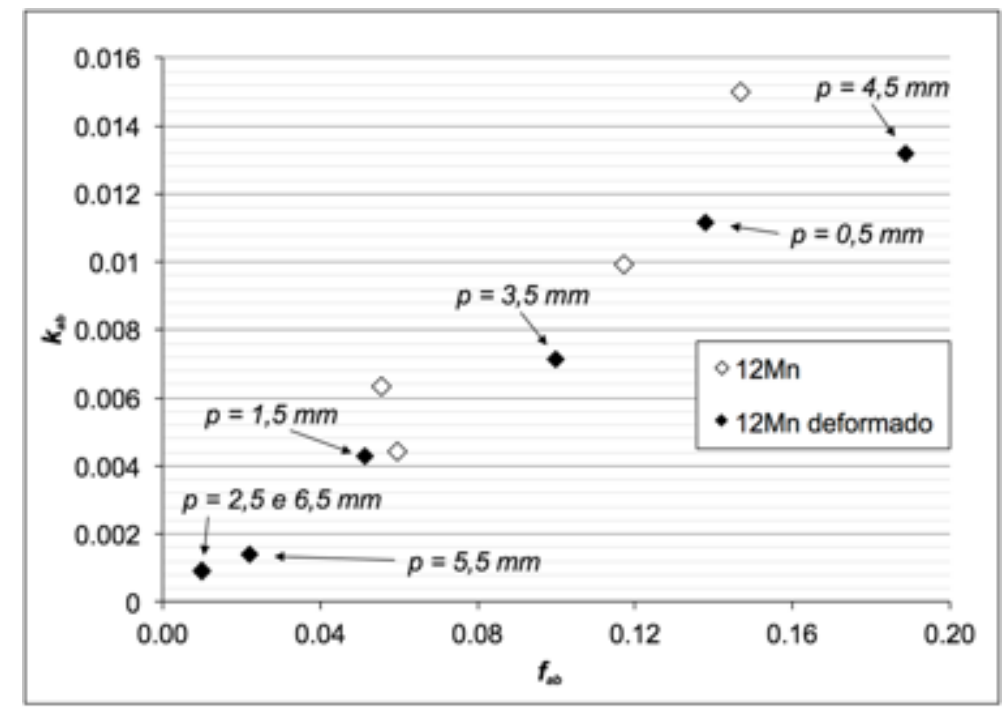

\subsubsection{Microesclerometria}

\subsubsection{Efeito do perfil de encruamento}

Este tópico trata-se da série i e ii da avaliação do perfil de encruamento gerado em campo para aço $12 \mathrm{Mn}$. Primeiramente será avaliado os resultados da série i, na qual foram realizados riscos de $100 \mu \mathrm{m}$ paralelos à superfície e com as forças normais 20, 50, 100, 150, 200 e 250 mN. A Figura 4.20 mostra a micrografia (MEV-SE) da superfície ensaiada (série i), perfil transversal da superfície deformada em campo, e o gráfico de perfil de microdureza referente à região em análise, na qual representa uma camada de 1,6 mm de espessura, a partir da superfície desgastada. Os ensaios 
apresentam um evento abrasivo para cada condição, carga e distância (d) da superfície de desgaste (microdureza).

Figura 4.20. Microesclerometria no perfil de encruamento $(d=1,6 \mathrm{~mm})$ com micrografia e perfil de dureza. MEV-SE. 100X

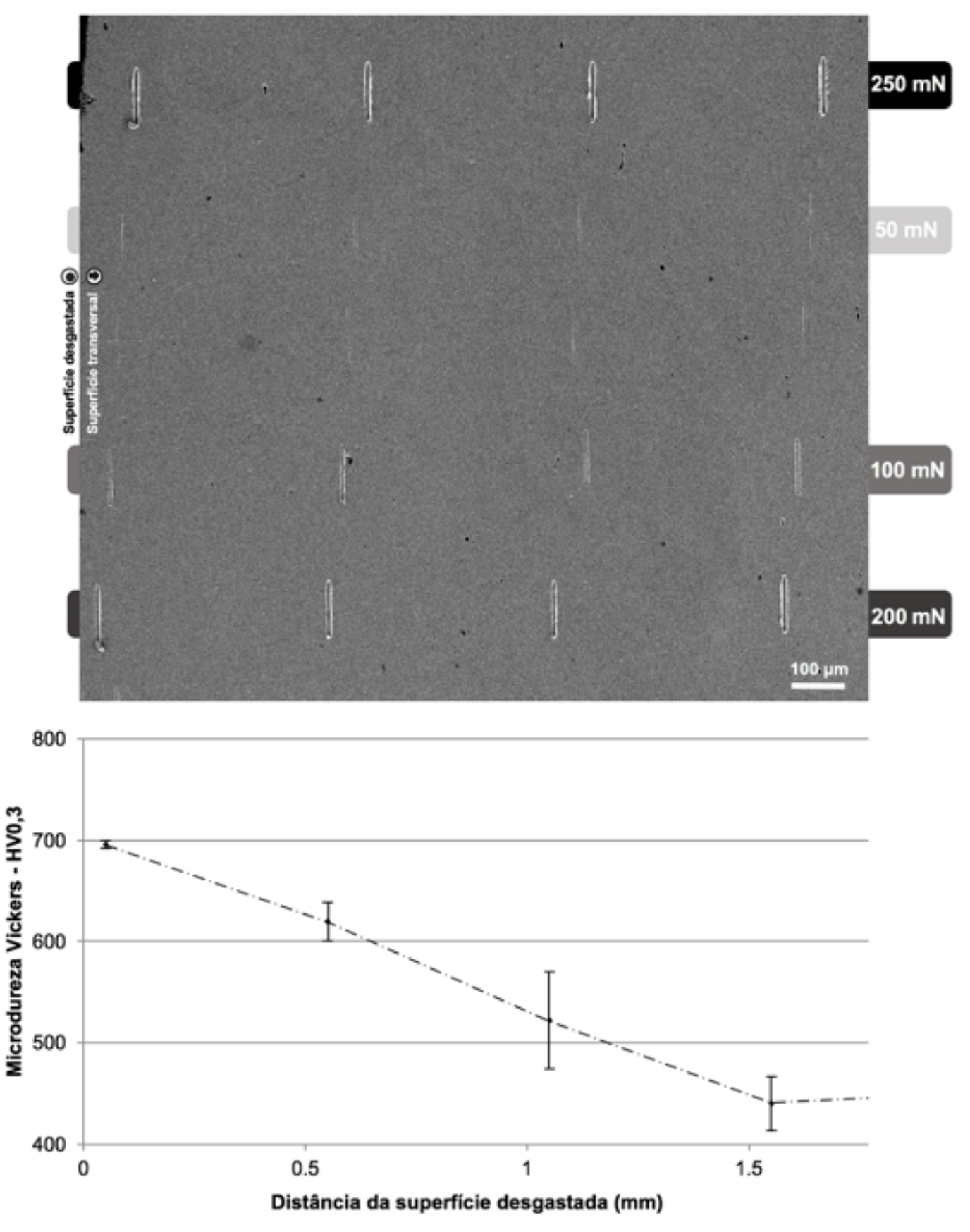

A camada em análise representa a região do revestimento do britador que foi submetida às maiores cargas dinâmicas do processo abrasivo de cominuição, apresentando a maior concentração de grãos com macla de deformação e os maiores valores de dureza do perfil de encruamento. 
A Figura 4.21 mostra o coeficiente de atrito médio para a série i de testes, com seis cargas ao longo do perfil de encruamento. Os valores de coeficiente de atrito aumentam com o aumento do carregamento normal, sendo um efeito da variação do ângulo de ataque e, consequentemente, do micromecanismo (HOKKIRIGAWA; KATO, 1988). Ao longo do gradiente de deformação não se nota diferença significativa para as menores cargas (20 e $50 \mathrm{mN}$ ), Figura $4.21 \mathrm{~b}$, as quais variam de 0,21 a 0,24; para as cargas de 100, 150, 200 e $250 \mathrm{mN}$, Figura 4.21a encontra-se uma variação não correlacionada ao perfil de microdureza.

Figura 4.21. Coeficiente de atrito em função da distância da superfície desgastada (série i). a) Forças normais: 20, 50, 100, 150, 200 e 250 mN. b) Forças normais: 20 e 50 mN
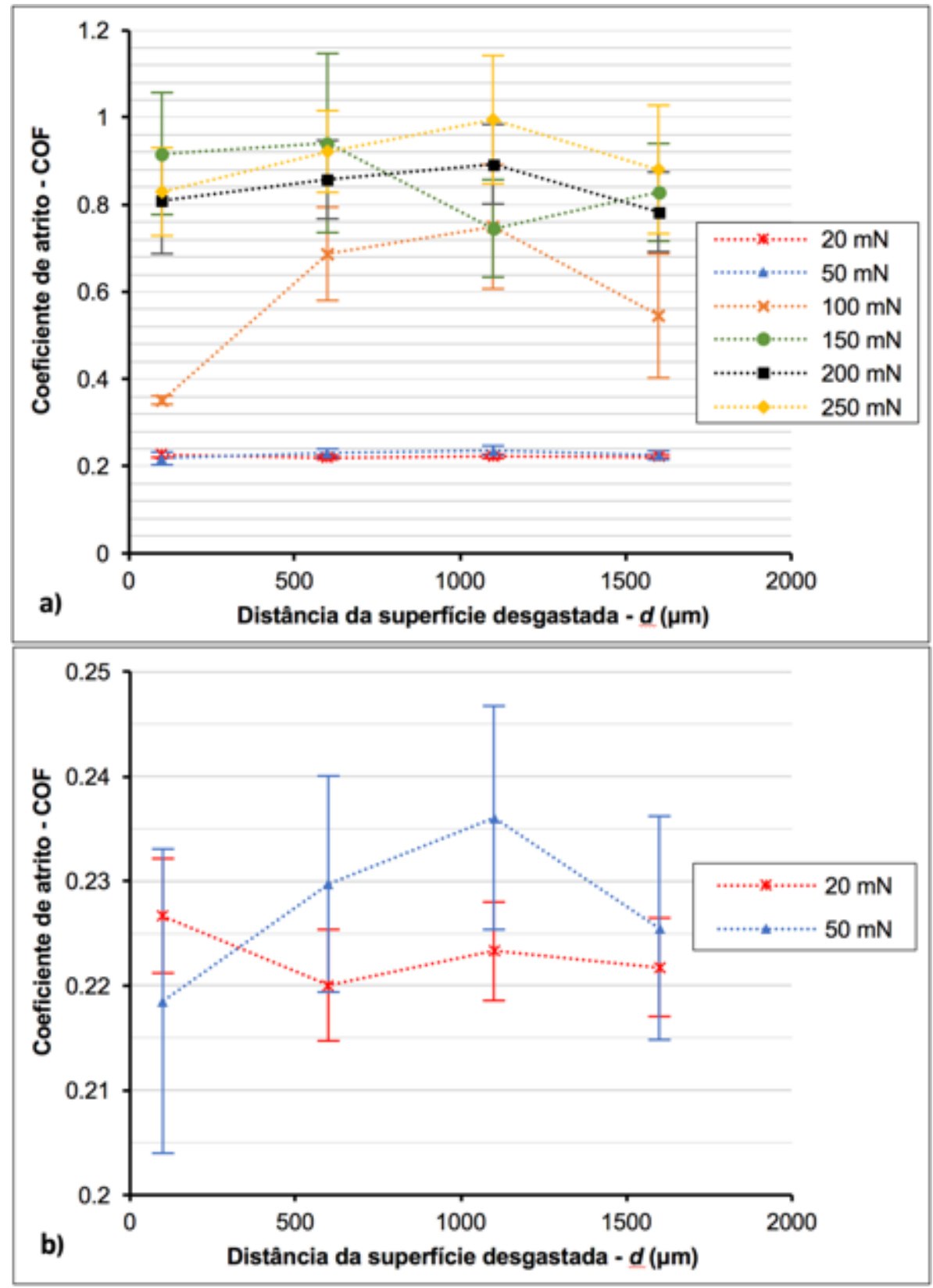
A carga de $100 \mathrm{mN}$, dentre as seis cargas, apresentou maior variação de COF para os ensaios realizados em distâncias diferentes em relação à superfície desgastada em campo $(0,1 ; 0,6 ; 1,1$ e 1,6 mm). Neste sistema de desgaste por riscamento esta carga representa o regime transição de desgaste. Assim, as cargas 20 e $50 \mathrm{mN}$ representam o regime moderado e as cargas 150, 200 e $250 \mathrm{mN}$ o regime severo para o tribossistema.

As micrografias dos riscos para a carga normal de 100 mN são mostradas na Figura 4.22, as imagens passaram por tratamento de imagem (ajustes dos parâmetros: nitidez, contraste e brilho) para destacar as orientações das maclas de deformação evidentes em cada micrografia. As diferenças encontradas nas orientações das maclas e bandas de escorregamento em relação aos riscos indicam que a orientação cristalográfica é diferente, ou seja, os ensaios foram realizados em grãos diferentes.

Figura 4.22. Micrografias dos riscos com carga normal de $100 \mathrm{mN}$ ao longo do perfil de encruamento. MEV-SE. 900X. (a) $d=0,1 \mathrm{~mm}$. (b) $d=0,6 \mathrm{~mm}$. (c) $d=1,1 \mathrm{~mm}$. (d) $d=1,6 \mathrm{~mm}$

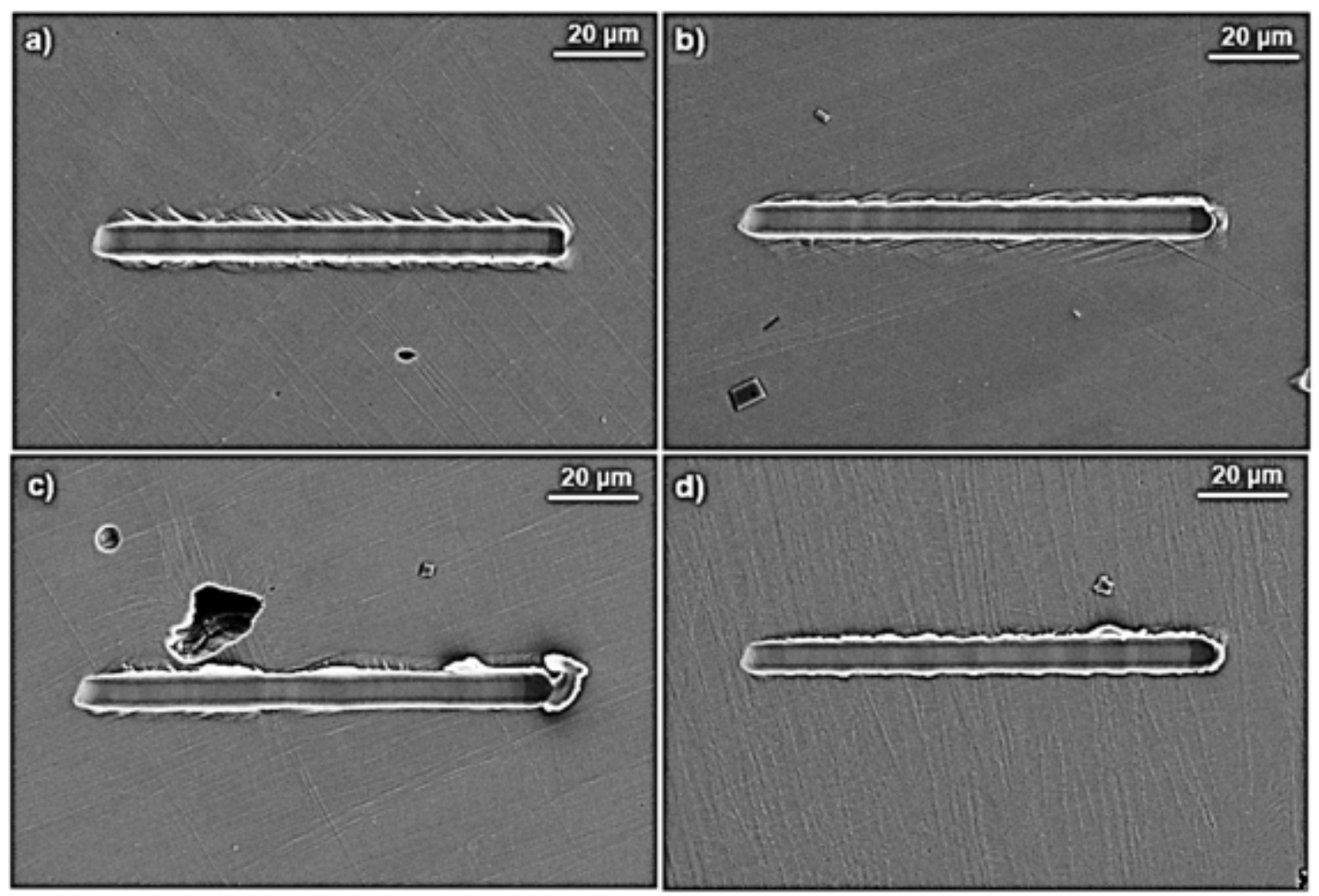

Os valores de COF dos riscos, profundidade média (Hysitron) e microdureza para cada posição são apresentados na Tabela 4.2. 
Tabela 4.2. Valores de COF e profundidade dos riscos para as forças normais de 50, 100 e $200 \mathrm{mN}$

Força normal

\begin{tabular}{cc|cc|cc|cc}
\cline { 3 - 7 } & \multicolumn{2}{c}{$50 \mathrm{mN}$} & \multicolumn{2}{c}{$100 \mathrm{mN}$} & \multicolumn{2}{c}{$200 \mathrm{mN}$} \\
\hline $\mathrm{mm}$ & $\mathrm{HV} 0,3$ & COF & $\mathrm{h}(\mu \mathrm{m})$ & COF & $\mathrm{h}(\mu \mathrm{m})$ & COF & $\mathrm{h}(\mu \mathrm{m})$ \\
0,1 & 698 & 0,22 & 0,37 & 0,35 & 0,91 & 0,81 & 2,68 \\
0,6 & 619 & 0,23 & 0,38 & 0,69 & 1,00 & 0,86 & 3,01 \\
1,1 & 529 & 0,24 & 0,36 & 0,75 & 1,09 & 0,89 & 2,50 \\
1,6 & 439 & 0,23 & 0,40 & 0,55 & 0,89 & 0,78 & 2,22
\end{tabular}

Os valores de profundidade dos riscos e microdureza do perfil transversal não apresentam correlação para as três cargas $50 \mathrm{mN}\left(R^{2}=0,25\right), 100 \mathrm{mN}\left(R^{2}=0,00\right)$ e $200 \mathrm{mN}\left(R^{2}=0,57\right)^{1}$ ou seja, não se observa a tendência de menores profundidades de risco para maiores microdurezas. Esse comportamento foi evidenciado na análise de esclerometria, tópico 4.3.3, sendo a profundidade do risco uma variável possivelmente dependente da orientação cristalográfica (grão) e independente da microdureza. Os resultados de COF e profundidade média dos riscos para as cargas $50 \mathrm{mN}, 100 \mathrm{mN}$ e $200 \mathrm{mN}$ também não apresentaram correlação $\left(R^{2}=0,17\right.$, $R^{2}=0,70$ e $R^{2}=0,19$, respectivamente).

As micrografias dos riscos com carga normal de $200 \mathrm{mN}$ são mostrados na Figura 4.23. Nas Figuras $4.23 \mathrm{c}$ e $4.23 d$ nota-se que ocorreu mudança de grão ao longo dos riscos. Com a alteração de orientação cristalográfica há variação do comportamento plástico do material, como pode ser observado nas imagens.

\footnotetext{
${ }^{1}$ Os gráficos de análise de correlação entre as variáveis (série i) profundidade do risco, coeficiente de atrito e microdureza do perfil transversal da superfície deformada em campo são mostrados na Figura B.1 no Apêndice B.
} 
Figura 4.23. Micrografia dos riscos para a carga de $200 \mathrm{mN}$. MEV-SE. 900X. a) $d=0,1 \mathrm{~mm}$. b) $d=0,6 \mathrm{~mm}$. c) $d=1,1 \mathrm{~mm}$. d) $d=1,6 \mathrm{~mm}$

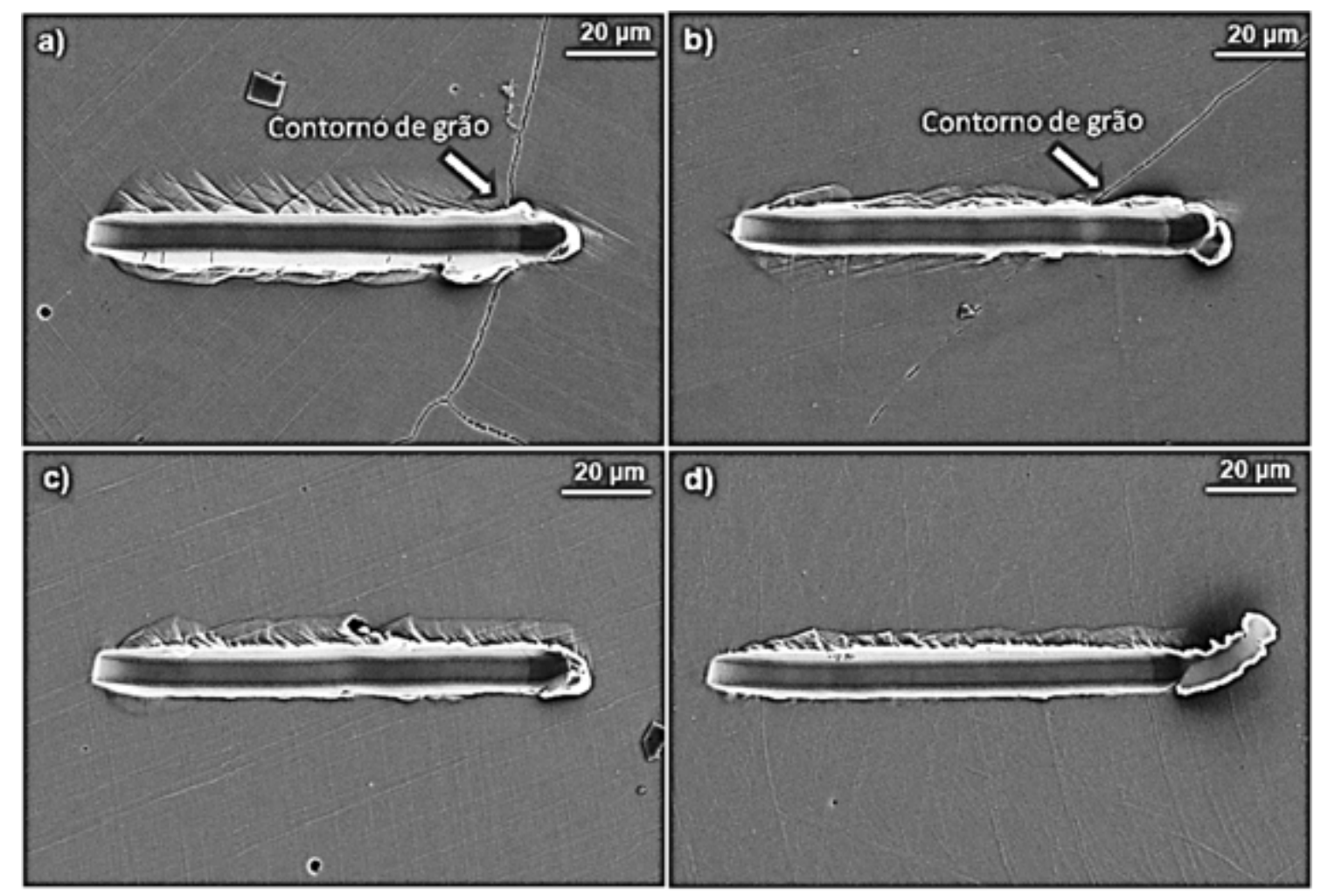

A curva de COF do risco na posição $0,6 \mathrm{~mm}$ (distância do risco à superfície desgastada em campo), Figura 4.23b, mostra o efeito da transição de orientação cristalográfica, inflexão na curva, associada ao contorno de grão (Figura 4.24). Os autores Hokkirigawa e Kato mostraram que uma rápida diminuição do COF é relacionado a formação de borda e subsequente deslizamento do endentador (HOKKIRIGAWA; KATO, 1988). Neste caso, o contorno de grão pode ter influenciado a alteração do escoamento de material ao longo do risco, contribuído com a variação no coeficiente de atrito. 
Figura 4.24. Curva de coeficiente de atrito ao longo do risco, com $F_{n}=200 \mathrm{mN}$ e $d=0,6 \mathrm{~mm}$

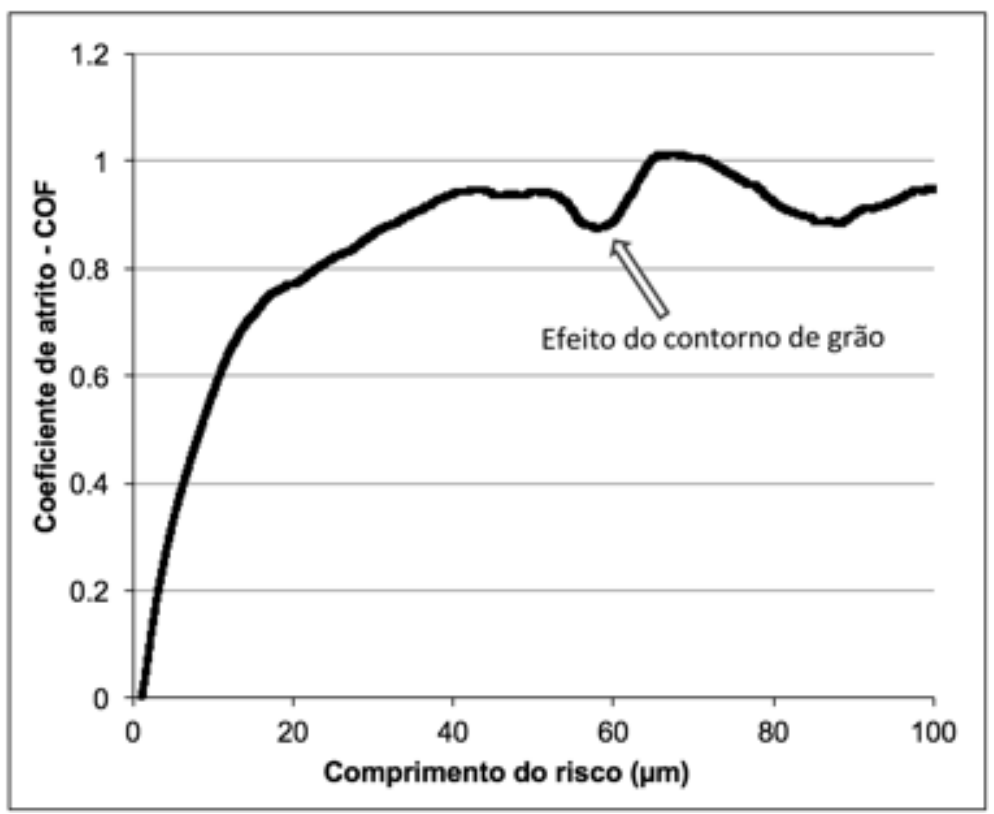

A dependência do grau de penetração $\left(D_{p}\right)$ e do ângulo de ataque à variação de carga normal para um endentador Rockwell foi observada em várias pesquisas (CHALLEN; OXLEY; DOYLE, 1983; HOKKIRIGAWA; KATO; LI, 1988). Os autores mostraram que a transição de regime de desgaste (moderado para severo) ocorre quando o ângulo de ataque crítico é atingido. Challen, Oxley e Doyle mostraram ainda que o aumento da dureza do material por encruamento ou tratamento térmico provocam diminuição no ângulo de ataque crítico (CHALLEN; OXLEY; DOYLE, 1983). A variação de dureza avaliada nesta pesquisa (440 a $700 \mathrm{HV}$ ) não apresentou efeito significativo no sistema de desgaste por riscamento como observado no gráfico da Figura 4.21. Como observou-se nas micrografias dos riscos, para a maior carga $(250 \mathrm{mN})$, condição de maior ângulo de ataque, observou-se formação de sulcamento e proa. Este resultado mostra que o ângulo crítico para alguns riscos em determinados grãos não foi alcançado, apesar de terem encruamento prévio.

Na Figura 4.24 é mostrado os resultados de coeficiente de atrito médio para cada força normal em função do grau de penetração. A distribuição dos resultados no gráfico mostra três regimes de desgaste: moderado, transição e severo.

A estabilidade do coeficiente de atrito para as menores cargas (20 e $50 \mathrm{mN}$ ) indica que para o sistema estas cargas representam o regime moderado de desgaste. $O$ aumento do COF observado nas maiores cargas (150, 200 e $250 \mathrm{mN})$ sugere a 
relação com os micromecanismos de desgaste e uma condição de regime severo. A variação do COF em um valor intermediário para a carga de $100 \mathrm{mN}$ ao longo do perfil de encruamento indica um regime de transição.

A classificação clássica do desgaste em regimes foi descrita por Khruschov e Zum Gahr como a resistência ao desgaste abrasivo em função da razão de dureza ( $H_{A} / H_{M}$, onde $H_{A}$ é a dureza do abrasivo e $H_{M}$ é a dureza do metal) (KHRUSCHOV, 1974; ZUM GAHR, 1987). Nesta pesquisa o método de análise utilizado foi o descrito por Hokkirigawa e Kato (HOKKIRIGAWA; KATO, 1988). A metodologia destes autores permite a avaliação da relação entre o COF e o micromecanismo de desgaste associados ao grau de penetração ou à força normal aplicada.

Figura 4.25. Coeficiente de atrito em função do grau de penetração (série i)

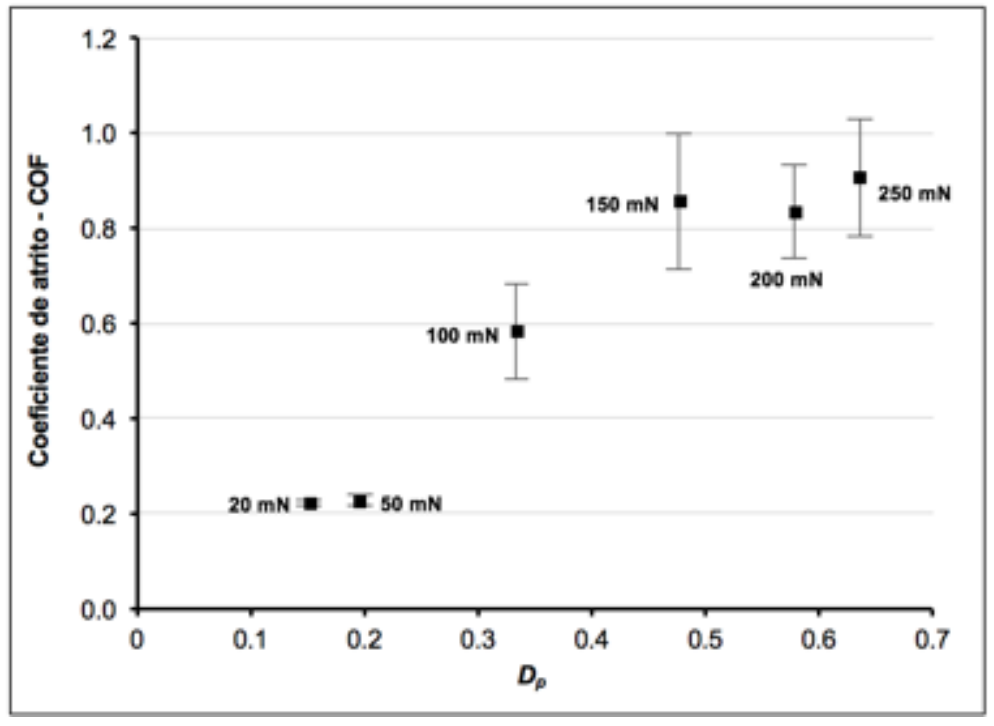

Os valores de COF para as maiores forças normais (100, 150, 200 e $250 \mathrm{mN}$ ), regime de transição e severo, têm maiores dispersão dos resultados. O valor do COF para cada carga é associado à formação do micromecanismo de desgaste (natureza da interação entre o endentador e o material, volume deslocado ou removido e o volume de material deformado abaixo do risco). Estes resultados podem ser analisados com o mapa de micromecanismo de desgaste proposto por Hokkirigawa, Kato e $\mathrm{Li}$, no qual o microcorte tem o maior COF, próximo de 1 (HOKKIRIGAWA; KATO, 1988; HOKKIRIGAWA; KATO; LI, 1988). Os valores de COF, grau de penetração e ângulo de ataque são mostrados na Tabela 4.3. Associando estes resultados com os obtidos por Hokkirigawa e Kato, observa-se que valores de $D_{p}$ acima de 0,33 são caracterizados com o microcorte como 
micromecanismo de desgaste predominante. A partir da carga de $200 \mathrm{mN}$ o ângulo de ataque médio atinge o valor máximo do sistema $\left(60^{\circ}\right)$.

Tabela 4.3. Coeficiente de atrito médio, grau de penetração $\left(D_{p}\right)$, ângulo de ataque e profundidade do risco

\begin{tabular}{c|cccc} 
Carga $(\mathbf{m N})$ & $\boldsymbol{C O F}$ & $\boldsymbol{D}_{\boldsymbol{p}}$ & $\boldsymbol{\alpha}$ & $\boldsymbol{h}(\boldsymbol{\mu m})$ \\
\hline 20 & $0,22 \pm 0,01$ & 0,15 & 18 & $0,24 \pm 0,01$ \\
50 & $0,23 \pm 0,01$ & 0,20 & 22 & $0,38 \pm 0,03$ \\
100 & $0,58 \pm 0,10$ & 0,33 & 37 & $0,97 \pm 0,11$ \\
150 & $0,86 \pm 0,14$ & 0,48 & 51 & $1,84 \pm 0,18$ \\
200 & $0,84 \pm 0,10$ & 0,58 & 60 & $2,60 \pm 0,11$ \\
250 & $0,91 \pm 0,12$ & 0,64 & 60 & $3,08 \pm 0,13$
\end{tabular}

A Figura 4.26 mostra imagens de MEV-SE dos riscos para as seis cargas em estudo. A mudança do micromecanismo de desgaste de microsulcamento para microcorte é observado a partir da carga de $100 \mathrm{mN}$ (Figura 4.26c), nas cargas de 150, 200 e $250 \mathrm{mN}$ observam-se bordas laterais e cavaco no final do risco. Os riscos destas cargas apresentam formação descontínua e assimétrica de pile-up (setas). 
Figura 4.26. Micrografia dos riscos na camada deformada em campo para cada carga. $d=1,6 \mathrm{~mm}$. MEV-SE. 900X. (a) $F_{n}=20 \mathrm{mN}$. (b) $F_{n}=50 \mathrm{mN}$. (c) $F_{n}=100 \mathrm{mN}$. (d) $F_{n}=150 \mathrm{mN}$. (e) $F_{n}=200 \mathrm{mN}$.

(f) $F_{n}=250 \mathrm{mN}$
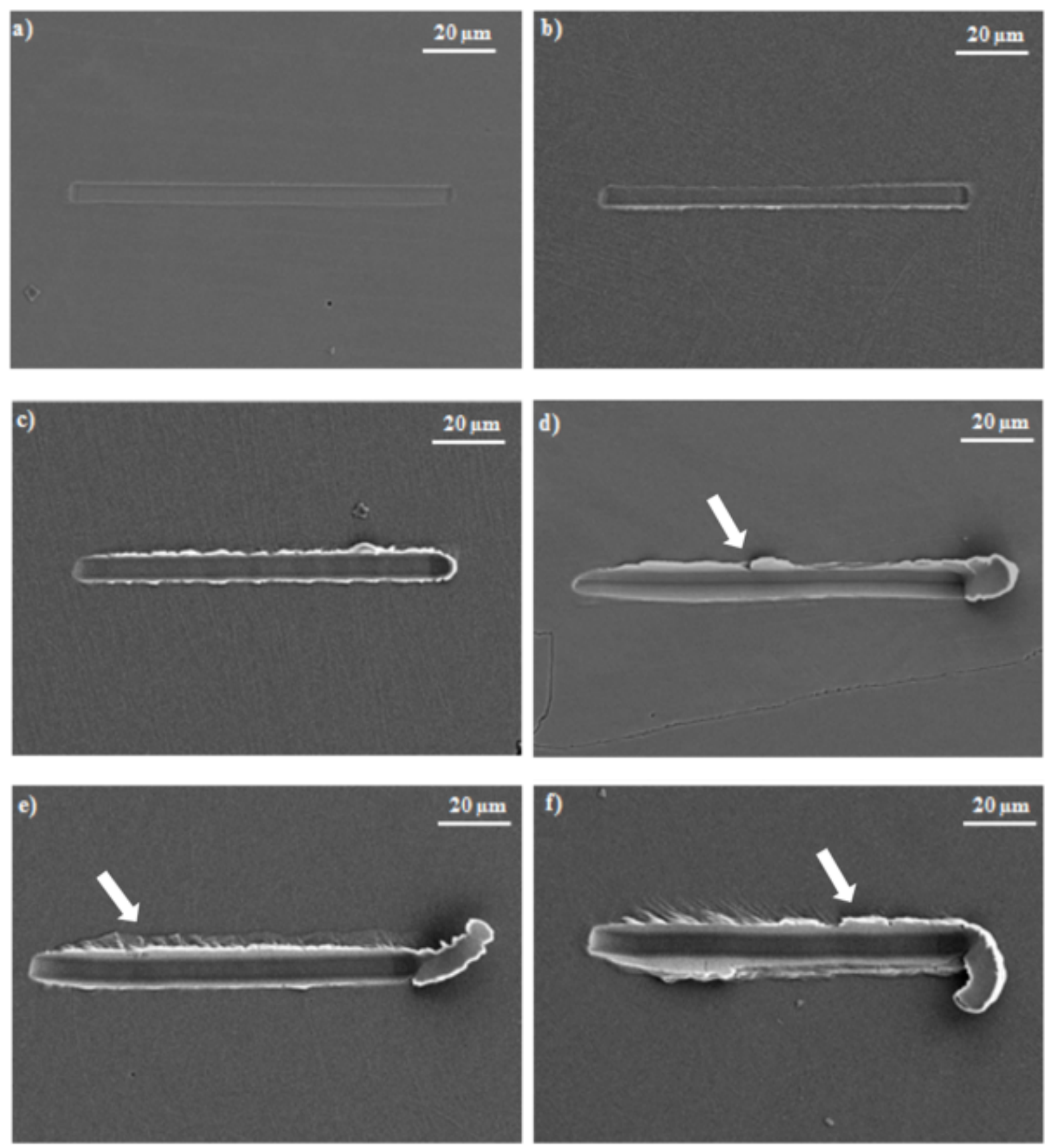

Os resultados da série i e ii para os valores médios de profundidade dos riscos, coeficiente de atrito, grau de penetração e ângulo de ataque são mostrados na Tabela 4.4. Nota-se que os resultados da série ii diferem da série i devido a nova posição dos testes ao longo da seção transversal da amostra. Esta observação pode ser associada à orientação cristalográfica aleatória dos grãos do aço Hadfield. Neste caso, de acordo com Lindroos et al. a dureza individual dos grãos tem valores 
diferentes dependendo de suas orientações cristalográficas (LINDROOS et al., 2013). Como apresentado no tópico anterior Karaman et al. observaram diferentes densidades de maclas de deformação associadas às orientações cristalográficas do aço Hadfield sob carregamento de compressão (KARAMAN et al., 2000a).

Para série ii os valores de profundidade dos riscos não mostraram correlação ${ }^{2}$ com a dureza para as três cargas $50 \mathrm{mN}\left(R^{2}=0,85\right), 100 \mathrm{mN}\left(R^{2}=0,82\right)$ e $200 \mathrm{mN}$ $\left(R^{2}=0,28\right)$, Tabela 4.4. No entanto, nota-se a tendência de menor profundidade para maior valor de dureza para as cargas de $50 \mathrm{mN}$ e $100 \mathrm{mN}$. O efeito deste comportamento pode ser observado na relação do coeficiente de atrito com a profundidade do risco, para as cargas de $50 \mathrm{mN}\left(R^{2}=0,93\right)$ e $100 \mathrm{mN}\left(R^{2}=0,98\right)$ observou-se correlação entre as variáveis. A carga de $200 \mathrm{mN}$ apresentou baixa correlação $R^{2}=0,70$. Este comportamento sugere que outra variável com efeito no sistema é ativada em condições de maior carga ou severidade de desgaste. A hipótese de que a orientação cristalográfica seja esta variável será discutida no tópico a seguir.

Tabela 4.4. Profundidade média dos riscos da série i e ii; grau de penetração e ângulo de ataque

\begin{tabular}{|c|c|c|c|c|c|c|c|c|c|}
\hline & \multirow[b]{2}{*}{$\begin{array}{c}\text { Carga } \\
(\mathrm{mN})\end{array}$} & \multirow[b]{2}{*}{ Series } & \multicolumn{4}{|c|}{$d(\mu \mathrm{m})$} & \multirow[b]{2}{*}{ Média } & \multirow[b]{2}{*}{$D_{p}$} & \multirow[b]{2}{*}{$\alpha$} \\
\hline & & & 100 & 600 & 1.100 & 1.600 & & & \\
\hline \multirow{6}{*}{$\underset{(\mu \mathrm{m})}{\boldsymbol{h}}$} & \multirow{2}{*}{50} & $\mathbf{i}$ & $0,37 \pm 0,02$ & $0,38 \pm 0,02$ & $0,36 \pm 0,02$ & $0,40 \pm 0,03$ & $0,38 \pm 0,03$ & 0,2 & 22 \\
\hline & & ii & $0,29 \pm 0,03$ & $0,35 \pm 0,06$ & $0,38 \pm 0,01$ & $0,38 \pm 0,03$ & $0,35 \pm 0,05$ & 0,19 & 22 \\
\hline & \multirow{2}{*}{100} & $\mathbf{i}$ & $0,91 \pm 0,04$ & $1,00 \pm 0,08$ & $1,09 \pm 0,09$ & $0,89 \pm 0,11$ & $0,97 \pm 0,11$ & 0,33 & 37 \\
\hline & & ii & $0,54 \pm 0,01$ & $0,64 \pm 0,03$ & $0,63 \pm 0,05$ & $0,68 \pm 0,09$ & $0,62 \pm 0,07$ & 0,26 & 29 \\
\hline & \multirow{2}{*}{200} & $\mathbf{i}$ & $2,68 \pm 0,11$ & $3,01 \pm 0,14$ & $2,50 \pm 0,21$ & $2,22 \pm 0,12$ & $2,60 \pm 0,11$ & 0,58 & 60 \\
\hline & & ii & $1,40 \pm 0,15$ & $1,97 \pm 0,16$ & $1,70 \pm 0,23$ & $1,84 \pm 0,11$ & $1,73 \pm 0,28$ & 0,46 & 50 \\
\hline \multirow{6}{*}{ COF } & \multirow{2}{*}{50} & $\mathbf{i}$ & $0,22 \pm 0,01$ & $0,23 \pm 0,01$ & $0,24 \pm 0,01$ & $0,23 \pm 0,01$ & $0,23 \pm 0,01$ & & \\
\hline & & ii & $0,19 \pm 0,01$ & $0,21 \pm 0,01$ & $0,22 \pm 0,01$ & $0,24 \pm 0,02$ & $0,22 \pm 0,02$ & & \\
\hline & \multirow{2}{*}{100} & $\mathbf{i}$ & $0,35 \pm 0,01$ & $0,69 \pm 0,11$ & $0,75 \pm 0,14$ & $0,55 \pm 0,14$ & $0,58 \pm 0,1$ & & \\
\hline & & ii & $0,20 \pm 0,01$ & $0,32 \pm 0,16$ & $0,33 \pm 0,08$ & $0,39 \pm 0,08$ & $0,31 \pm 0,12$ & & \\
\hline & \multirow{2}{*}{200} & $\mathbf{i}$ & $0,81 \pm 0,12$ & $0,86 \pm 0,09$ & $0,89 \pm 0,9$ & $0,78 \pm 0,09$ & $0,84 \pm 0,1$ & & \\
\hline & & ii & $0,44 \pm 0,08$ & $0,65 \pm 0,13$ & $0,67 \pm 0,16$ & $0,63 \pm 0,12$ & $0,6 \pm 0,16$ & & \\
\hline
\end{tabular}

${ }^{2}$ Os gráficos de análise de correlação entre as variáveis (série ii) profundidade do risco, coeficiente de atrito e microdureza do perfil transversal da superfície deformada em campo são mostrados na Figura B.2 no Apêndice B. 


\subsubsection{Efeito da orientação cristalográfica}

A análise de microesclerometria foi realizada nos planos (001), (111) e (101) do aço $12 \mathrm{Mn}$ e $20 \mathrm{Mn}$ não deformado de acordo com a metodologia descrita no tópico 4.2.3.2.3. Os grãos analisados para o aço $12 \mathrm{Mn}$ estão indicados com triângulos na Figura 4.27a. O quadro na Figura $4.27 b$ indica a região de análise na superfície da amostra.

Figura 4.27. Resultado da análise de EBSD para o aço 12Mn. Imagem de IPF (a) da região indicada na imagem estereográfica (b)

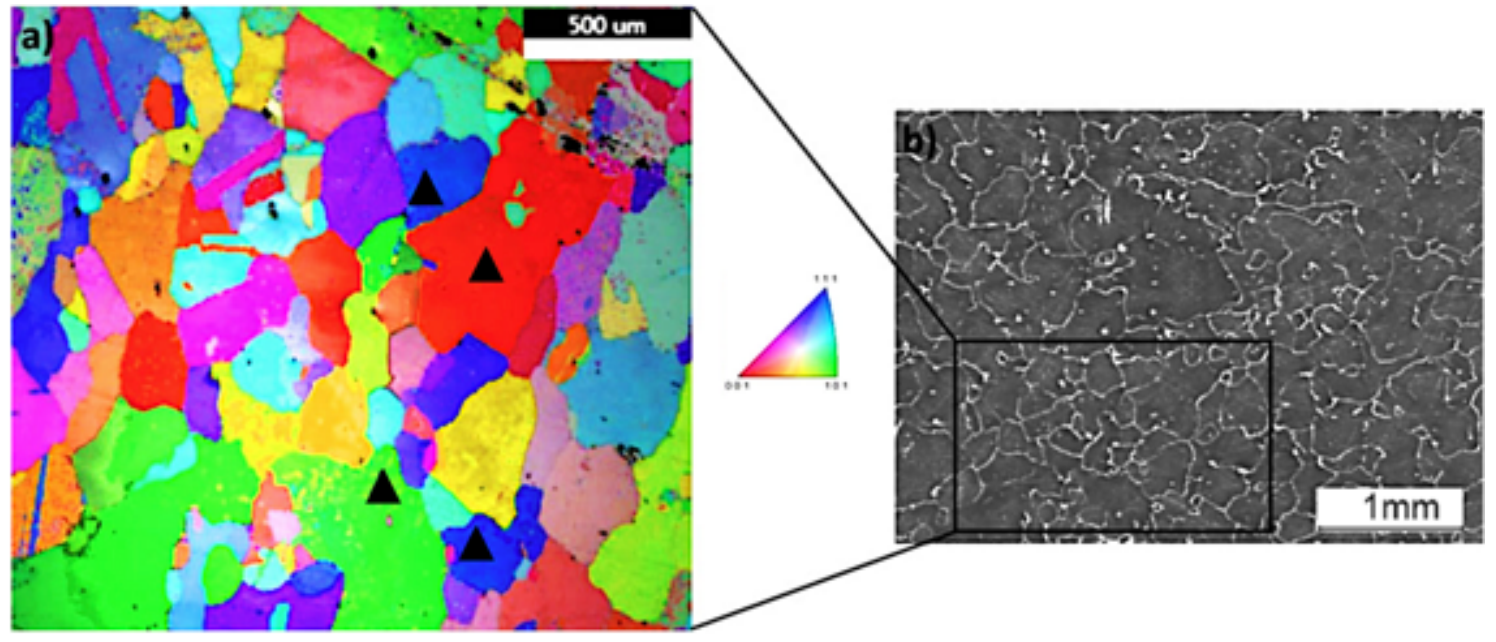

As curvas de coeficiente de atrito dos riscos nos planos (001), (111) e (101) para o aço $12 \mathrm{Mn}$ são mostradas no gráfico da Figura 4.28 a com as micrografias de cada risco, Figuras $4.28 b, 4.28 c$ e $4.28 d$, respectivamente. As micrografias dos riscos estão dispostas de acordo com a referência de origem e dimensão adotadas para o gráfico de coeficiente de atrito. O COF para o risco no plano (001) aumenta linearmente a partir de $20 \mu \mathrm{m}$ (linha vertical tracejada). Este aumento é acompanhado do aumento da largura da deformação lateral (pile-up) do risco. Para o risco no plano (111) observa-se um comportamento semelhante entre $15 \mu \mathrm{m}$ e $35 \mu \mathrm{m}$. A partir de $35 \mu \mathrm{m}$ o COF torna-se instável, surgindo dois picos com valores crescentes de coeficiente de atrito. Esses picos na curva de COF para o plano (111) são associados à formação de bordas proeminentes, Figura $4.28 \mathrm{c}$ (setas). Hokkirigawa, Kato e Li observaram a formação do micromecanismo de desgaste via MEV durante o riscamento, identificando a resposta do coeficiente de atrito para cada micromecanismo de desgaste (HOKKIRIGAWA; KATO; LI, 1988). Os autores 
mostraram que os picos no COF têm relação com a formação de cavaco com bordas serrilhadas, semelhante ao resultado observado nesta pesquisa.

Figura 4.28. a) Gráfico de coeficiente de atrito em função do comprimento dos riscos nos planos (001), (111) e (101) do aço 12Mn. b) Micrografia do risco no plano (001). c) Micrografia do risco no plano (111). d) Micrografia do risco no plano (101). 900X
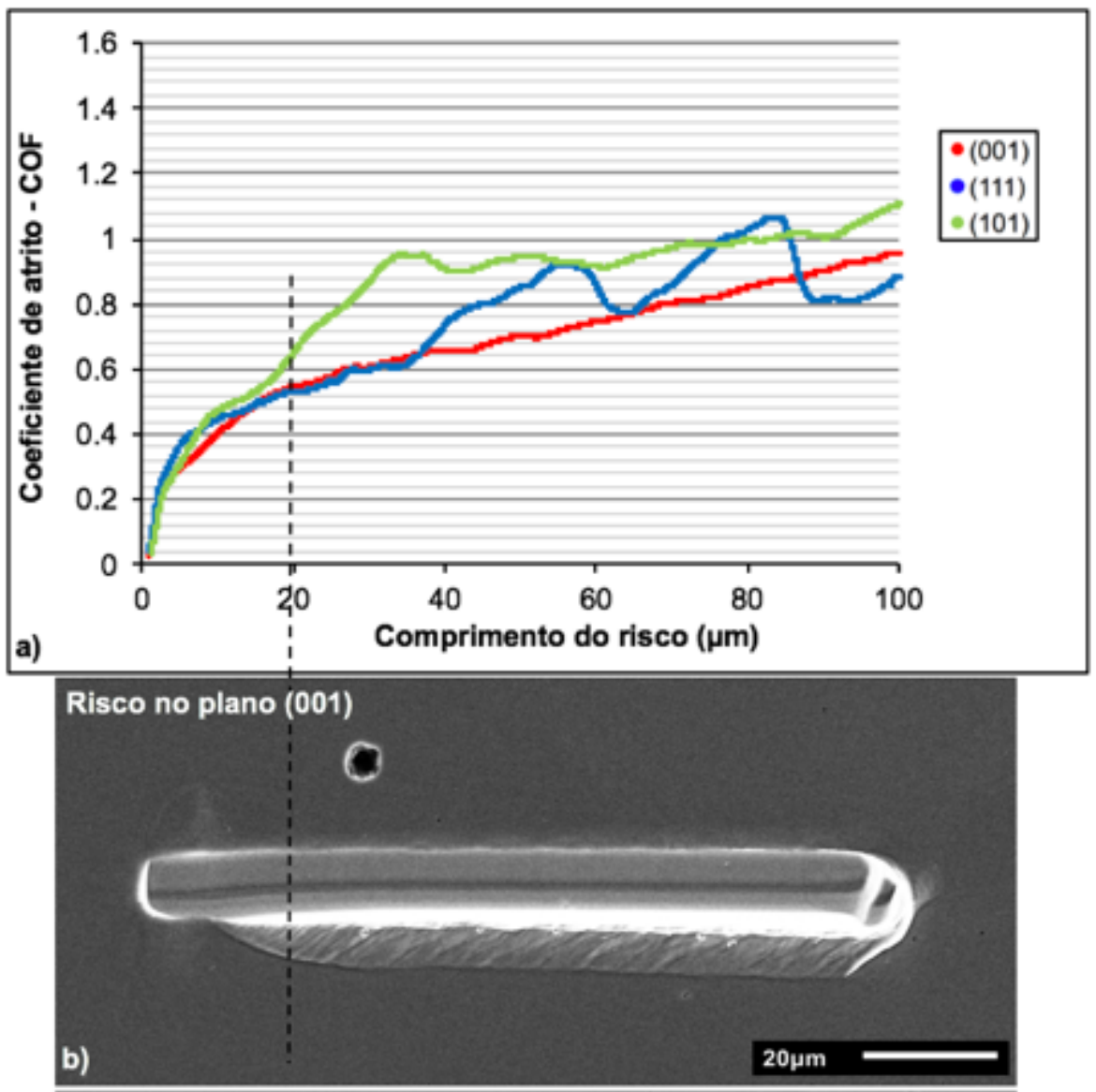

Risco no plano (111)

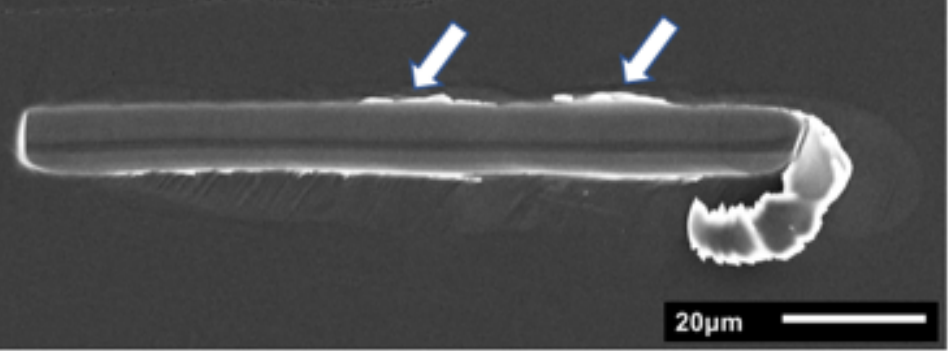

c)

$20 \mu \mathrm{m}$

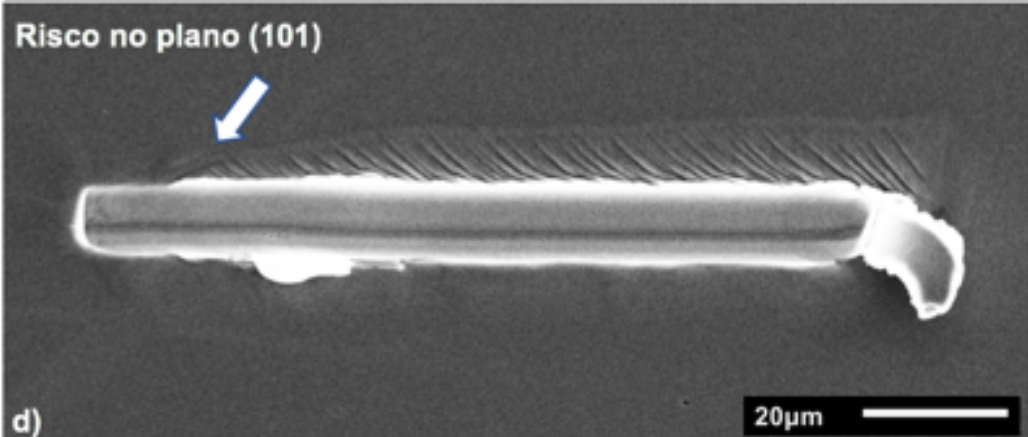


O comportamento do coeficiente de atrito para o risco no plano (101) até, aproximadamente, $20 \mu \mathrm{m}$ se assemelha à curva no plano (111). No entanto, a partir deste ponto o COF aumenta até 0,9 com poucas oscilações. Ao voltar a atenção para as bordas do risco (micromecanismo), nota-se que o início da deformação plástica lateral com formação de bordas laterais no risco, Figura 4.28d (seta), coincidem com o ponto de início de aumento de coeficiente de atrito. Para o risco no plano (001) observa-se a formação de pile-up estável no lado direito do risco a partir de $20 \mu \mathrm{m}$. Este comportamento do coeficiente de atrito em relação ao micromecanismo de desgaste foi observado para os demais riscos em cada plano de análise.

Os micromecanismos de microsulcamento e microcorte são observados em diferentes intensidades em cada orientação cristalográfica. No plano (001), como observa-se, o microsulcamento é o micromecanismo predominante, Figura 4.28a. A formação de pile-up foi identificada no lado direto e formação de proa no final do risco. A Figura 4.28c mostra o risco no plano (111) com predominância de microcorte, com bordas na lateral e cavaco no final do risco, assim como, para o risco no (101), Figura $4.28 d$. Os riscos nas três orientações mostram-se com deformação lateral crescente, havendo aumento da largura do pile-up. Como observado no gráfico da Figura 4.28a, os valores de coeficiente de atrito acompanham esta característica dos riscos.

A Tabela 4.5 mostra os resultados de coeficiente de atrito médio dos ensaios em cada plano cristalográfico. Os riscos no plano (001) têm coeficiente de atrito médio de 0,82 e predominância de microsulcamento. Enquanto os riscos nos planos (111) e (101) têm predominância de microcorte e valores de coeficiente de atrito de 0,88 e 0,96 , respectivamente.

Tabela 4.5. Coeficiente de atrito médio dos riscos nos planos cristalográficos (001), (111) e (101) para o aço $12 \mathrm{Mn}$

\begin{tabular}{ccccc} 
& \multicolumn{3}{c}{ COF - $12 \mathrm{Mn}$} & \multirow{2}{*}{ Média } \\
\cline { 2 - 4 } Plano & 1 & 2 & 3 & $0,82 \pm 0,01$ \\
\cline { 2 - 4 }$(001)$ & 0,81 & 0,82 & 0,83 & $0,82 \pm 0,01$ \\
$(111)$ & 0,88 & 0,89 & 0,87 & $0,88 \pm 0,01$ \\
$(101)$ & 0,98 & 0,95 & 0,96 & $0,96 \pm 0,01$
\end{tabular}


Estes resultados corroboram os resultados de Hokkirigawa, Kato e $\mathrm{Li}$ (HOKKIRIGAWA; KATO; LI, 1988). Os autores observaram uma relação entre COF e micromecanismo de desgaste, na qual o micromecanismo de microcorte tem o maior coeficiente de atrito, quando comparado com o micromecanismo de microsulcamento.

Os valores profundidade média dos riscos $(h)$ nos planos (001), (111) e (101) foram $2,05 \pm 0,04 \mu \mathrm{m}, 1,80 \pm 0,04 \mu \mathrm{m}$ e 2,09 $\pm 0,09 \mu \mathrm{m}$, respectivamente. Os riscos no plano (111) têm menores valores de profundidade que os riscos no plano (001) indicando menor deformação plástica na direção vertical. Karaman et al. mostraram que a direção [111] do aço Hadfield sob compressão tem maior resistência e menor deformação que a direção [001] (KARAMAN et al., 2000a). Nesta pesquisa o risco no plano 001 com predominância de microsulcamento obteve $D_{p}$ igual a 0,51 e $54^{\circ}$ de ângulo de ataque. Enquanto o risco no plano 111 teve o microcorte como micromecanismo predominante, $D_{p}$ igual a 0,47 e $51^{\circ}$ de ângulo de ataque, provavelmente devido ao menor alongamento na direção [111] sob compressão, como mostrado por (KARAMAN et al., 2000a). Os resultados de grau de penetração e ângulo de ataque para o risco no plano (101) foram 0,51 e $55^{\circ}$, respectivamente.

A Figura 4.29 mostra o perfil dos respectivos riscos da Figura 4.28. Observa-se que a profundidade dos riscos varia ao longo da extensão do desgaste, apesar da força normal constante.

Figura 4.29. Profundidade dos riscos nos planos (001), (111) e (101) ao longo do perfil longitudinal obtidos durante o evento abrasivo. Aço 12Mn

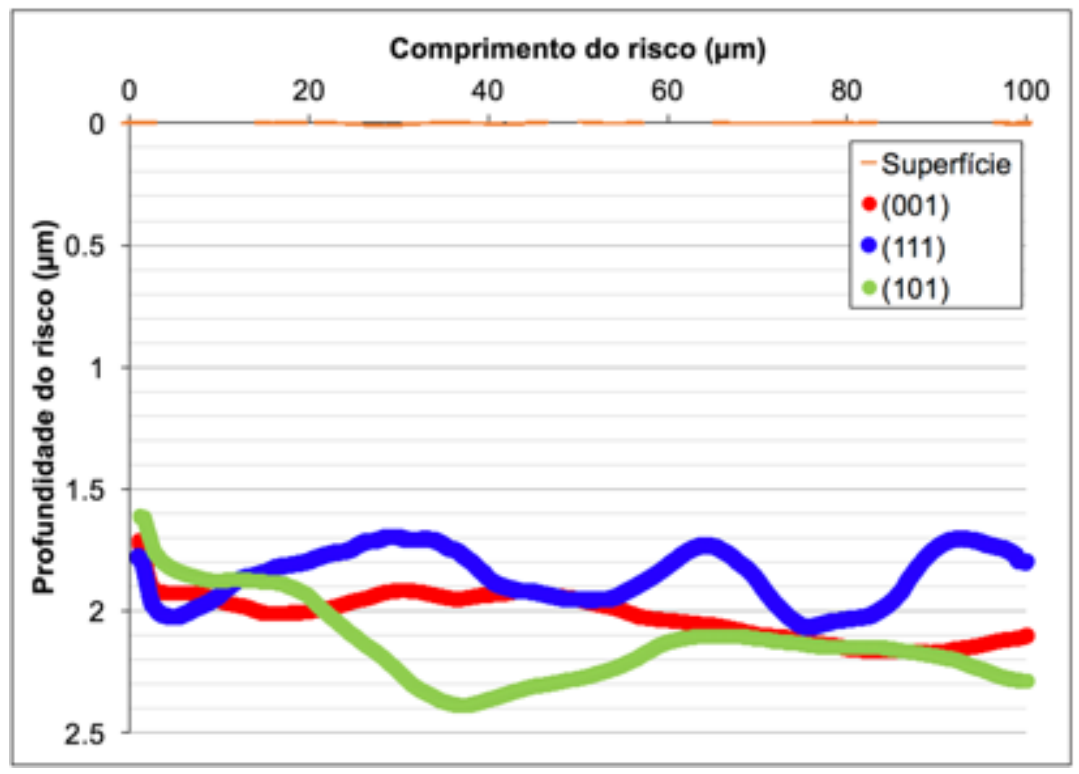


Ao comparar estes resultados com as curvas de atrito dos riscos de cada orientação cristalográfica, observa-se uma relação direta, oscilações no atrito são notadas na profundidade e, como já mostrado, na deformação lateral. Nota-se que a curva de profundidade para o risco no plano (001) tem menos oscilações que os riscos nos demais planos. No Apêndice $B$ é mostrado os gráficos de profundidade dos riscos para as repetições do ensaio.

O micromecanismo de desgaste predominante para o risco no plano (101) foi o microcorte, com formação de bordas laterais (Figura 4.28d) e cavaco, apesar de significativa deformação plástica lateral, como pode ser observado na parte superior da imagem (lado esquerdo do risco).

Estes resultados mostram o efeito da orientação cristalográfica no sistema abrasivo, onde o riscamento de um plano favorável a deformação plástica, (001), teve maior ângulo de ataque e grau de penetração com predominância de microsulcamento. $\mathrm{Ou}$ seja, o ângulo de ataque crítico para esta condição é superior à $54^{\circ}$.

A análise da microestrutura da subsuperfície via FIB dos mesmos riscos analisados anteriormente na Figura 4.28. A técnica de FIB contribuiu para avaliar o efeito nulo do polimento manual semi-automático na microestrutura da subsuperfície, como mostrado na seção transversal a $60 \mu \mathrm{m}$ do início do risco no plano (001), Figura 4.30a. O perfil do risco mostra a formação de sink-in à esquerda e pile-up à direita do risco, nota-se que na região ao lado do risco não há alteração microestrutural (seta). A camada com grãos ultrafinos localizada abaixo da interface material/endentador é destacada com uma linha branca tracejada e tem $8,3 \mu \mathrm{m}^{2}$. 
Figura 4.30. a) Imagem de FIB do perfil transversal do risco no plano (001), 15.000X. b) Aumento do lado direito do risco, 30.000X. c) Aumento do lado esquerdo do risco, 30.000X. Aço 12Mn
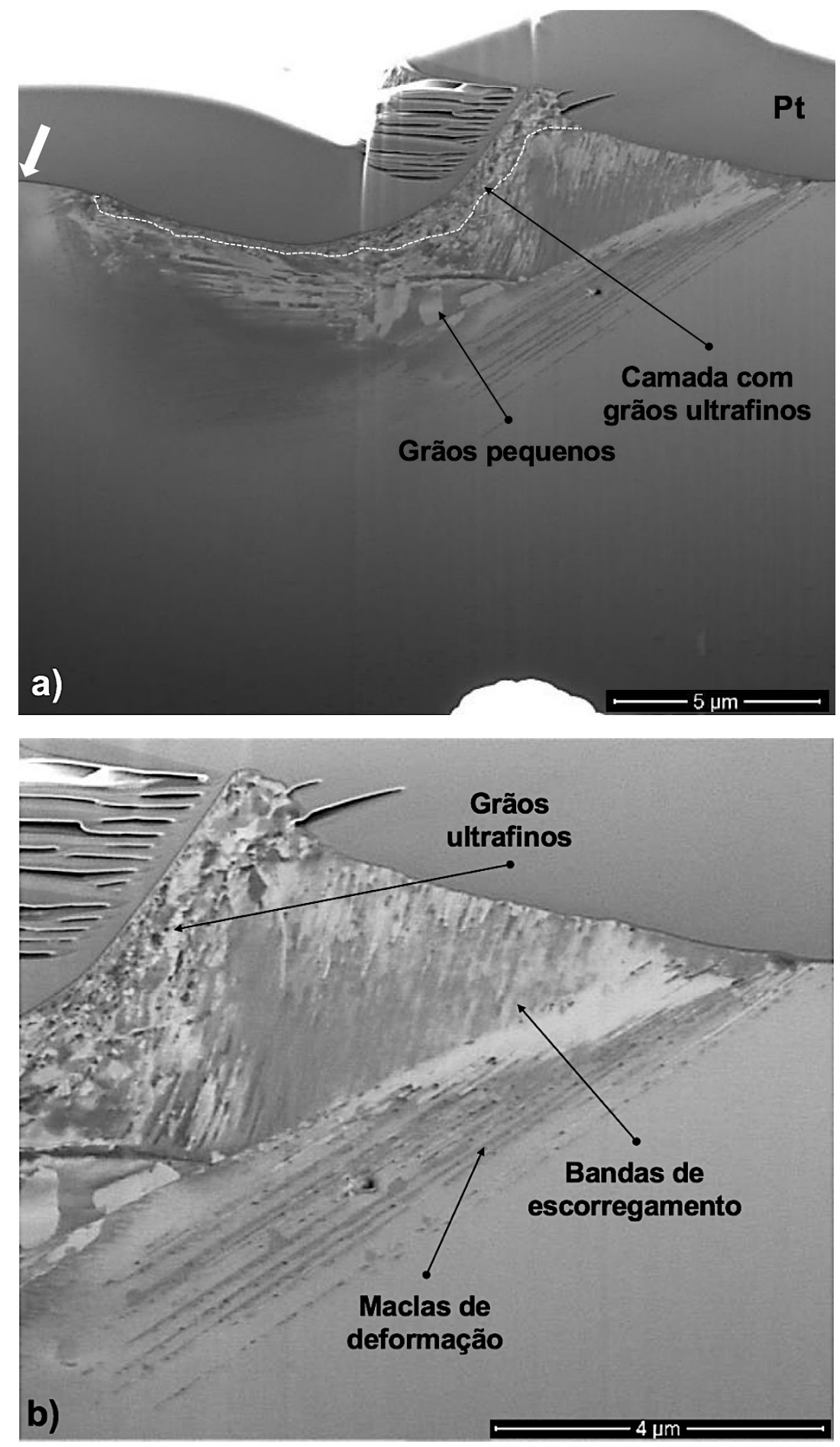


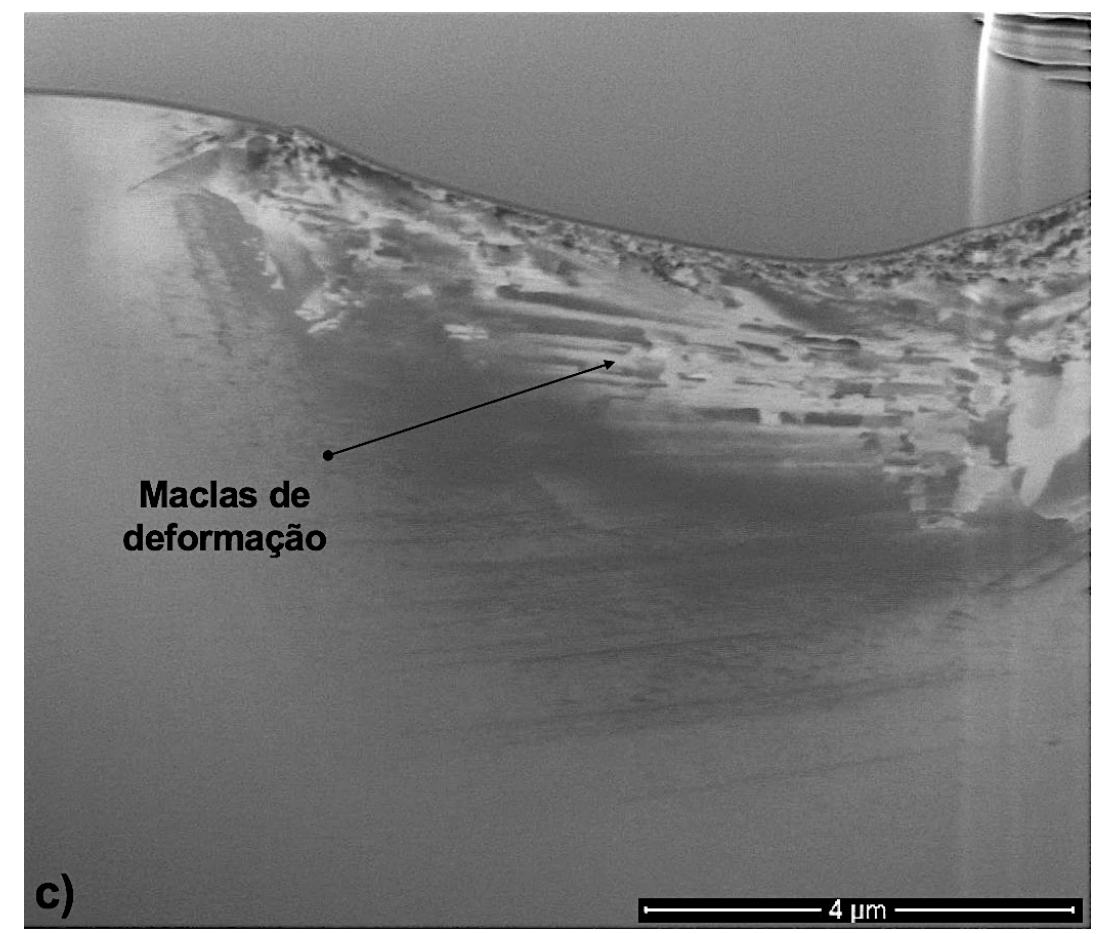

A Figura 4.30b mostra a microestrutura que sofreu alteração com o riscamento. A camada próxima a superfície, delineada pela linha tracejada (branca), tem grãos ultrafinos. Feng et al. observaram grãos com tamanho inferiores na região deformada aos sem deformação para o aço Hadfield e Okolo et al. observaram este comportamento da microestrutura para aço perlítico (FENG et al., 2013b; OKOLO et al., 2007). De acordo com Johnson, a região onde ocorrem as transformações microestruturais têm valores máximos de tensões principais trativas e compressivas (JOHNSON, 1985). Além disto, Burton; Guo et al. e Moore mostraram que o aumento de temperatura na interface de desgaste é ocasionada pela deformação plástica (BURTON, 1980; GUO et al., 2013; MOORE, 1970). Na subsequente região, abaixo da linha tracejada, observam-se maclas de deformação. A formação de maclas neste local está relacionada à máxima tensão cisalhante localizada próximo a superfície durante o riscamento (JOHNSON, 1985). A microestrutura abaixo do pile-up tem bandas de escorregamento. $\mathrm{Na}$ área indicada na Figura 4.30a observam-se grãos pequenos com uma ordem de grandeza inferior ao tamanho de grão original do material e maclas de deformação em torno desta região.

Bradby et al. mostraram que a deformação plástica de monocristais de germânio (metal CFC) ocorrem por maclação e formação de discordâncias. Estes mecanismos são mostrados nas imagens de FIB e XTEM da seção transversal de uma endentação esférica no plano (100), Figura 4.31 (BRADBY et al., 2002). 
Figura 4.31. Imagem da seção transversal (via XTEM) de monocristal de Ge com endentação com força normal de $50 \mathrm{mN}$. a) Imagem com campo claro. b) Imagem com campo escuro e imagem de difração da região com maclas.
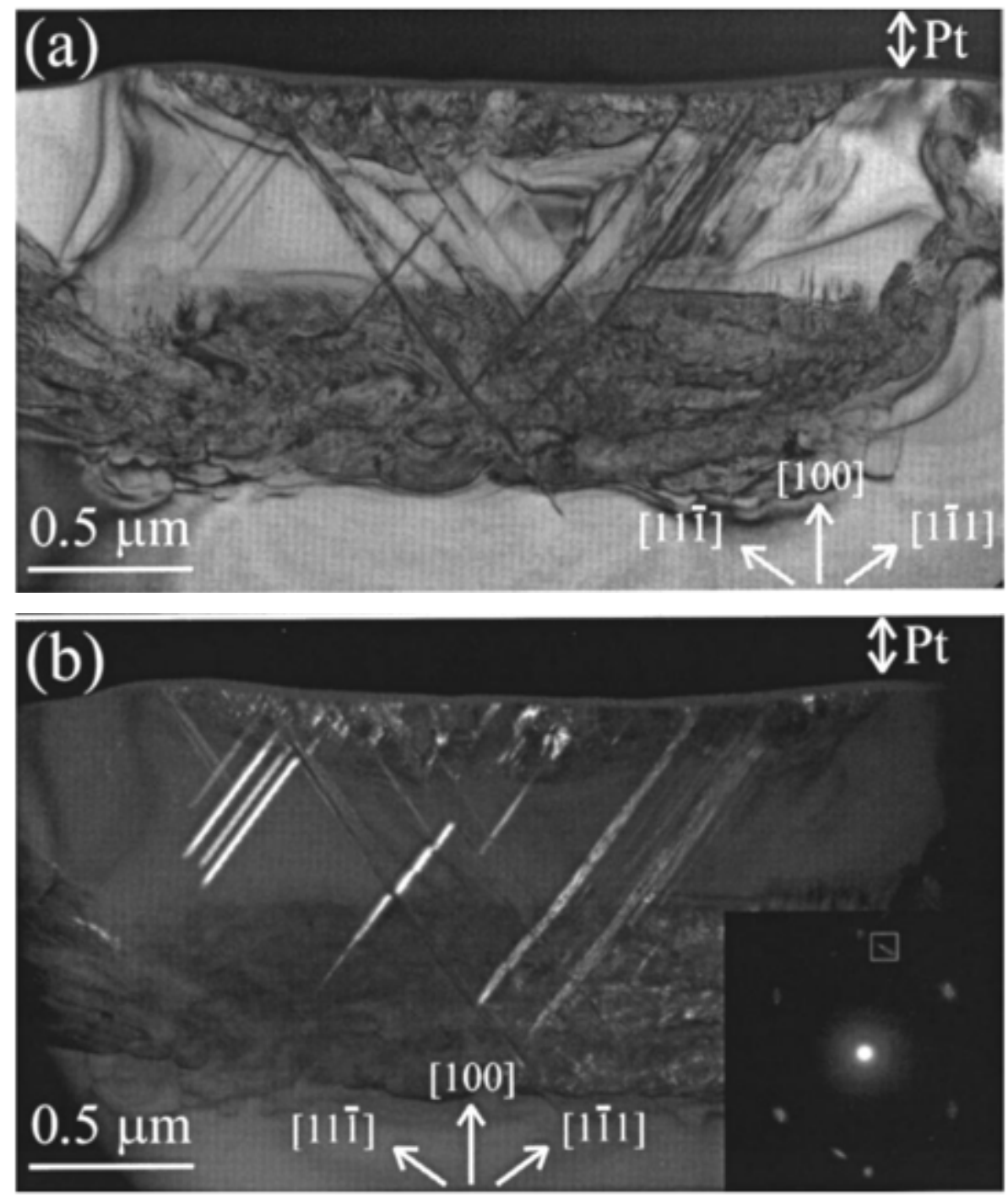

Fonte: Bradby et al., 2002

A microestrutura da subsuperfície do risco no plano (111) é mostrada na Figura 4.32. A camada de grãos ultrafinos localizada abaixo da interface material/endentador foi destacada com uma linha tracejada, Figura 4.32a. Esta camada tem $2,6 \mu \mathrm{m}^{2}$, sendo menor que a observada na microestrutura do risco no plano (001). Outra característica no risco no plano (111) é a formação simétrica de pile-up. Na região abaixo da camada com grãos ultrafinos as maclas de deformação estão distribuídas no centro e na direita do risco (imagem), ao longo da profundidade elas diminuem de comprimento. A região central da Figura 4.32a é mostrada em maior aumento na Figura $4.32 b$, nota-se que as maclas estão dispostas à $90^{\circ}$ do eixo vertical. A Figura $4.32 c$ mostra que apesar da simetria do pile-up (Figura 4.32a), a distribuição 
de maclas é assimétrica. Na região abaixo do pile-up à esquerda do risco não observam-se maclas. Nota-se também nesta imagem uma linha vertical considerada um artefato da técnica, formada durante o procedimento de abertura da cavidade.

Figura 4.32. a) Imagem de FIB do perfil transversal do risco no plano (111), 15.000X. b) Aumento do centro do risco, 30.000X. c) Aumento do lado esquerdo do risco, 30.000X. Aço 12Mn
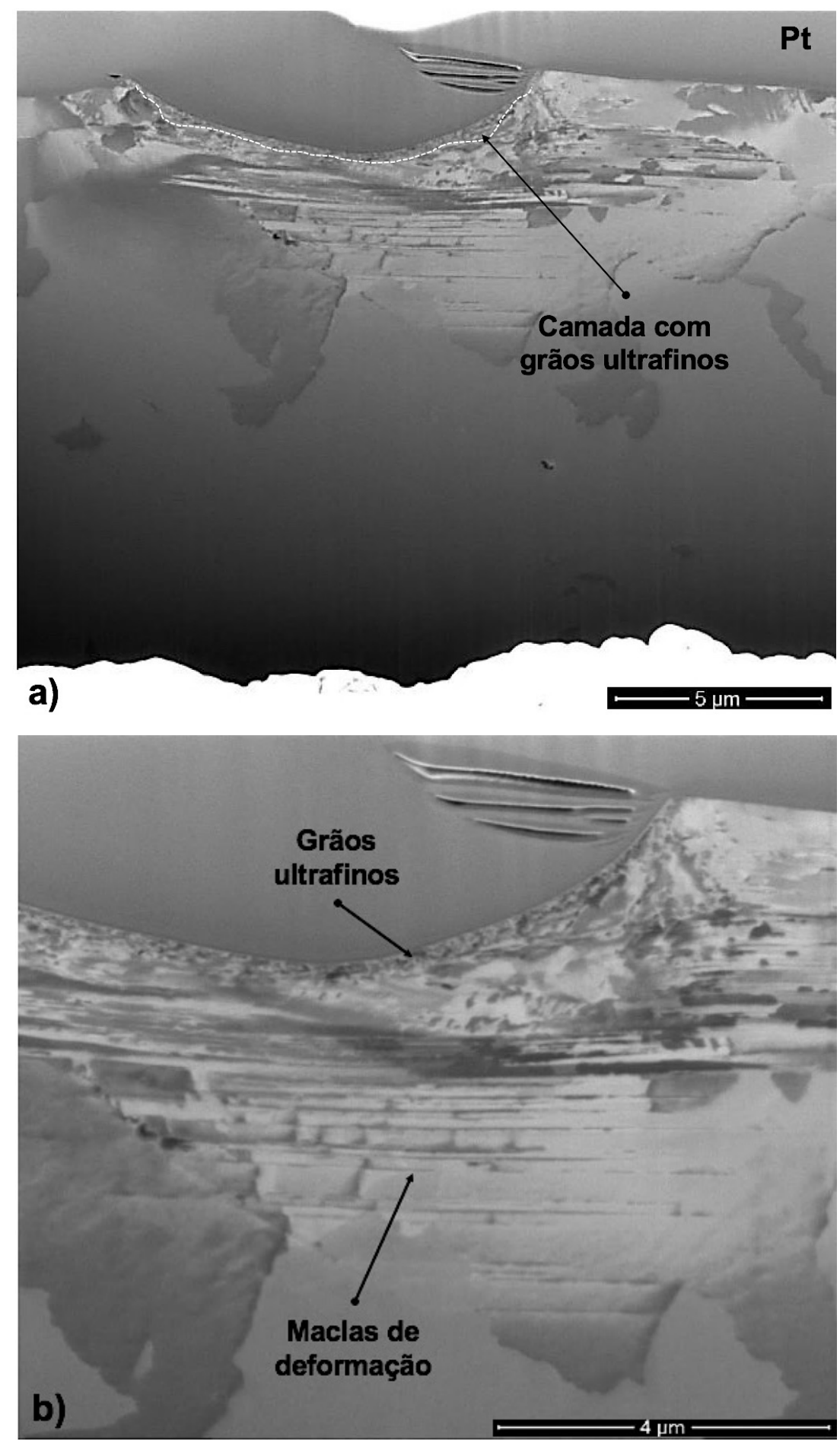


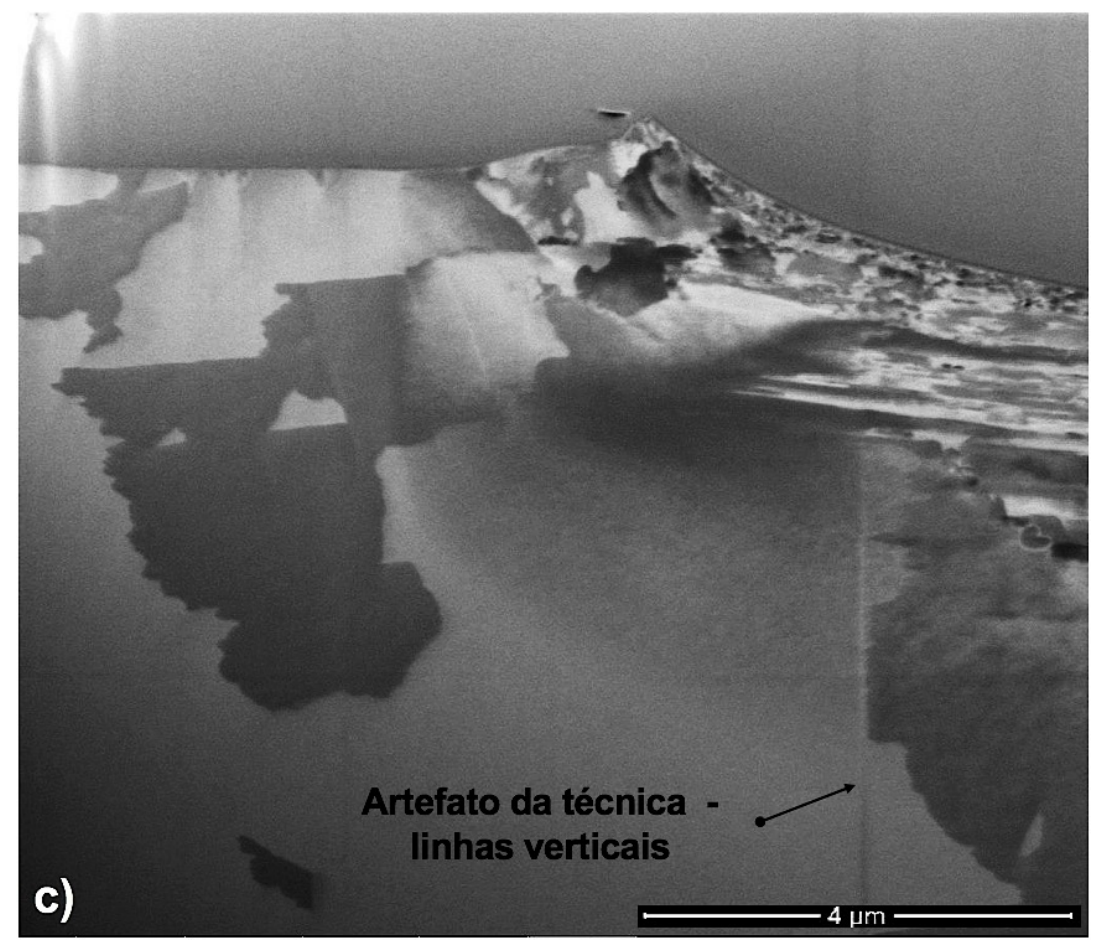

A microestrutura da subsuperfície do risco no plano (101) para o aço $12 \mathrm{Mn}$ é mostrada na Figura 4.33. A Figura 4.33a mostra a camada de grãos ultrafinos em destaque, o valor de área medido corresponde à $5,6{\mu \mathrm{m}^{2}}^{2}$, sendo um valor intermediário entre $8,3 \mu \mathrm{m}^{2}(001)$ e $2,6 \mu \mathrm{m}^{2}$ (111).

Figura 4.33. a) Imagem de FIB do perfil transversal do risco no plano (101), 15.000X. b) Aumento do lado esquerdo do risco, 30.000X. c) Aumento do lado direito do risco, 30.000X. Aço 12Mn

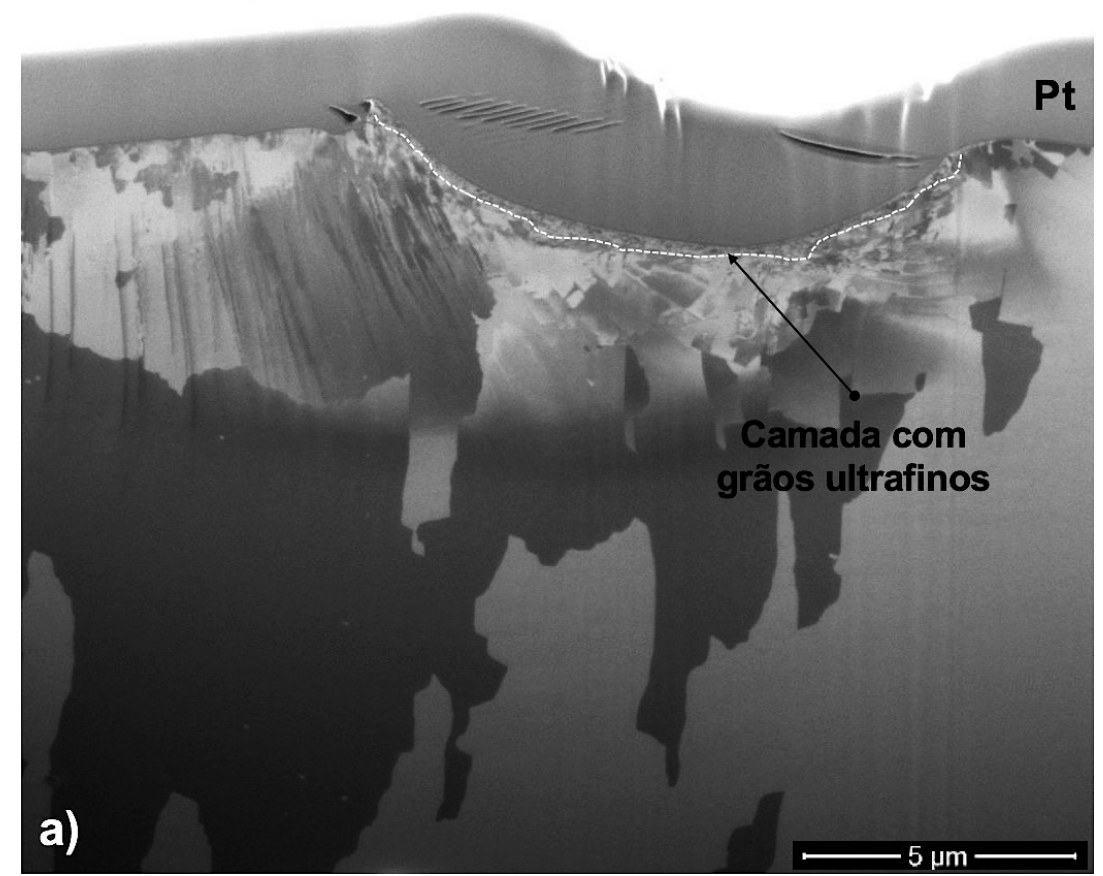



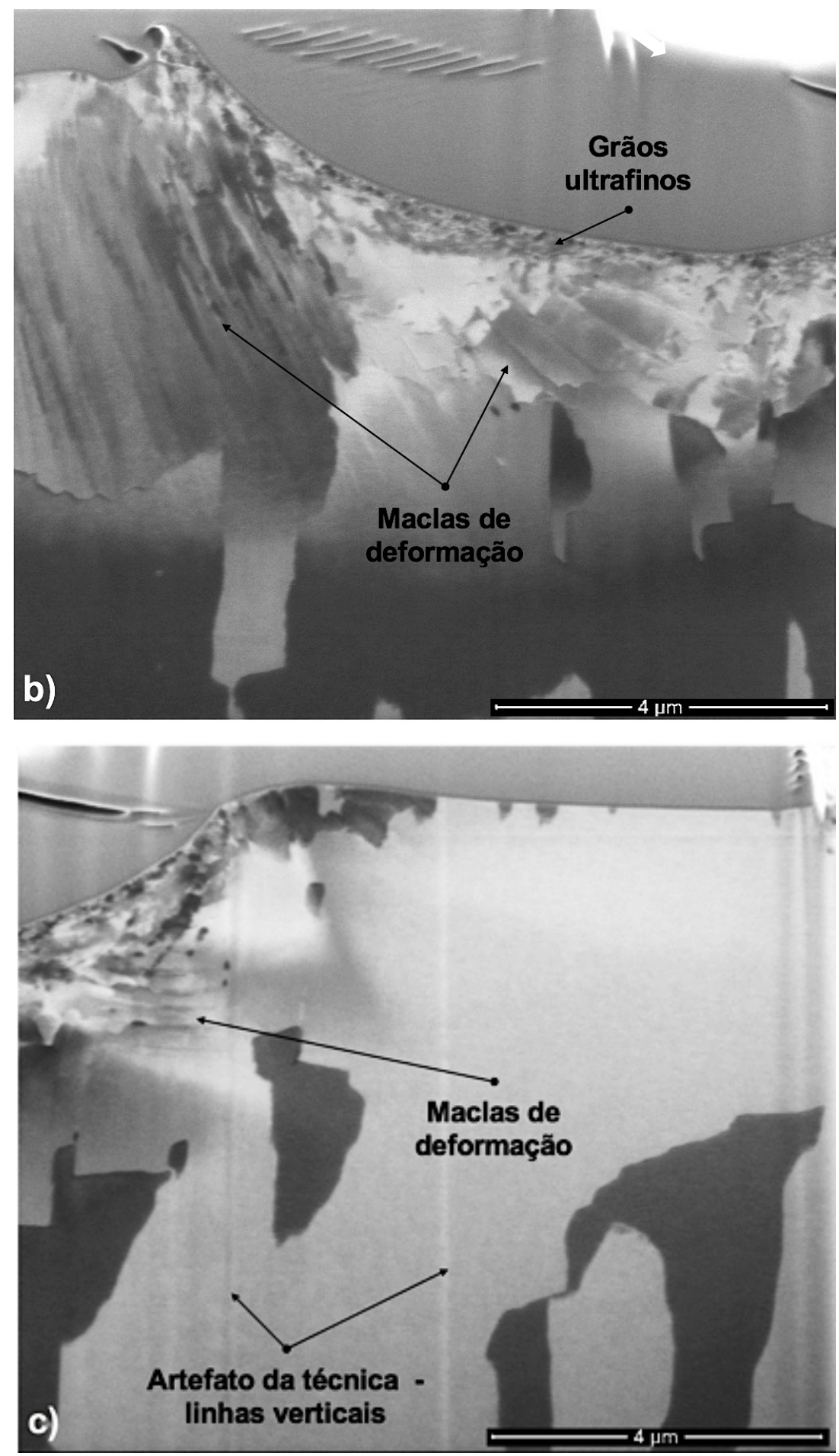

O perfil do risco tem formação de pile-up simétrica e distribuição de microestrutura assimétrica, mesmo comportamento observado para (111). As maclas de deformação são distribuídas em maior concentração à esquerda do risco, Figura 4.33b. No centro e à direita do risco observam-se bandas de escorregamento, Figura $4.33 b$ e $c$. 
A Figura 4.34 mostra a região final dos riscos nos planos (001), (111) e (101) do aço $12 \mathrm{Mn}$. Nesta região nota-se a formação de proa para o risco no plano (001), Figura 4.34a, assim como deformação plástica lateral com bandas de escorregamento. Nos riscos nos planos (111) e (101), Figura $4.34 b$ e $c$, nota-se formação de cavaco e deformação lateral. Na Figura $4.34 b$ destaca-se as bordas serrilhadas do cavaco, as quais são associadas às oscilações do COF conforme pesquisa de (HOKKIRIGAWA; KATO, 1988).

Figura 4.34. a) Deformação plástica lateral e proa do risco no plano (001). b) Deformação plástica lateral e cavaco do risco no plano (111). c) Deformação plástica lateral e cavaco do risco no plano (101). Imagens de FEG-SE. Aço 12Mn

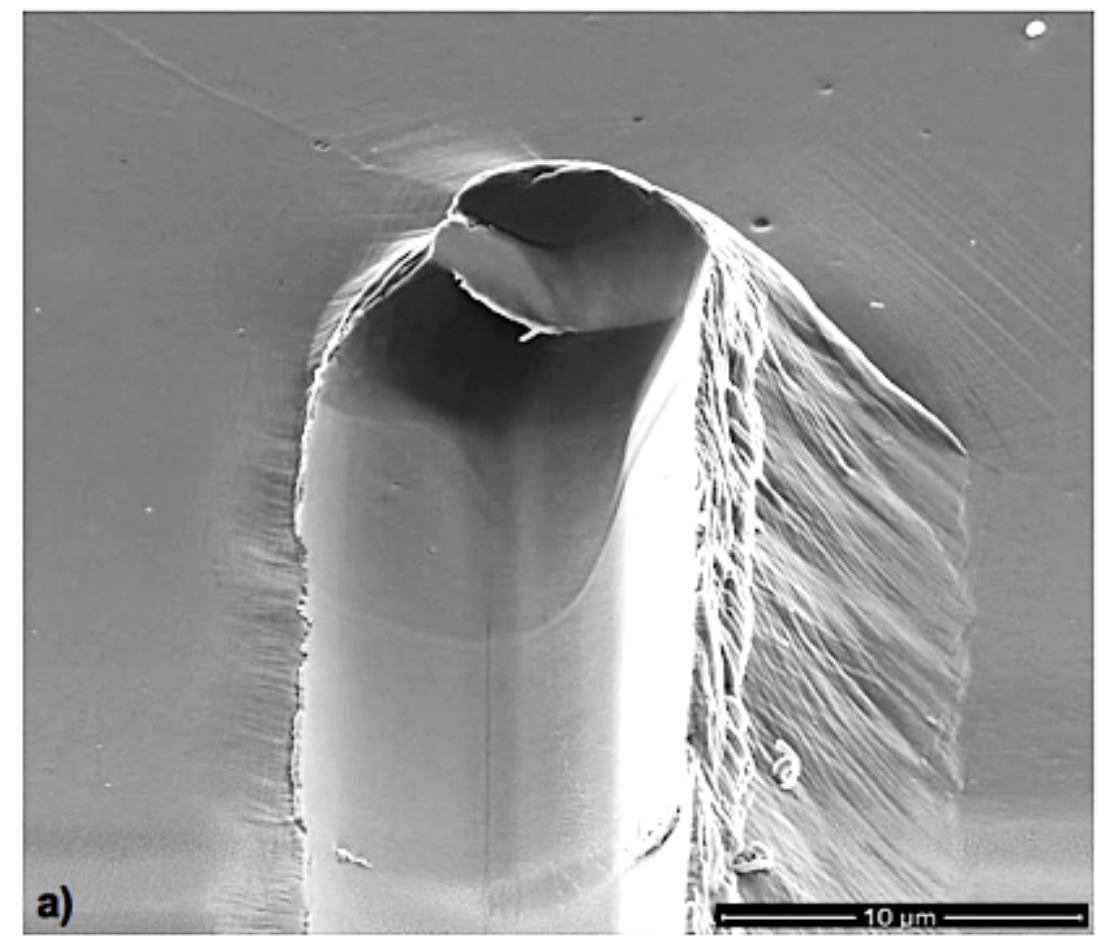



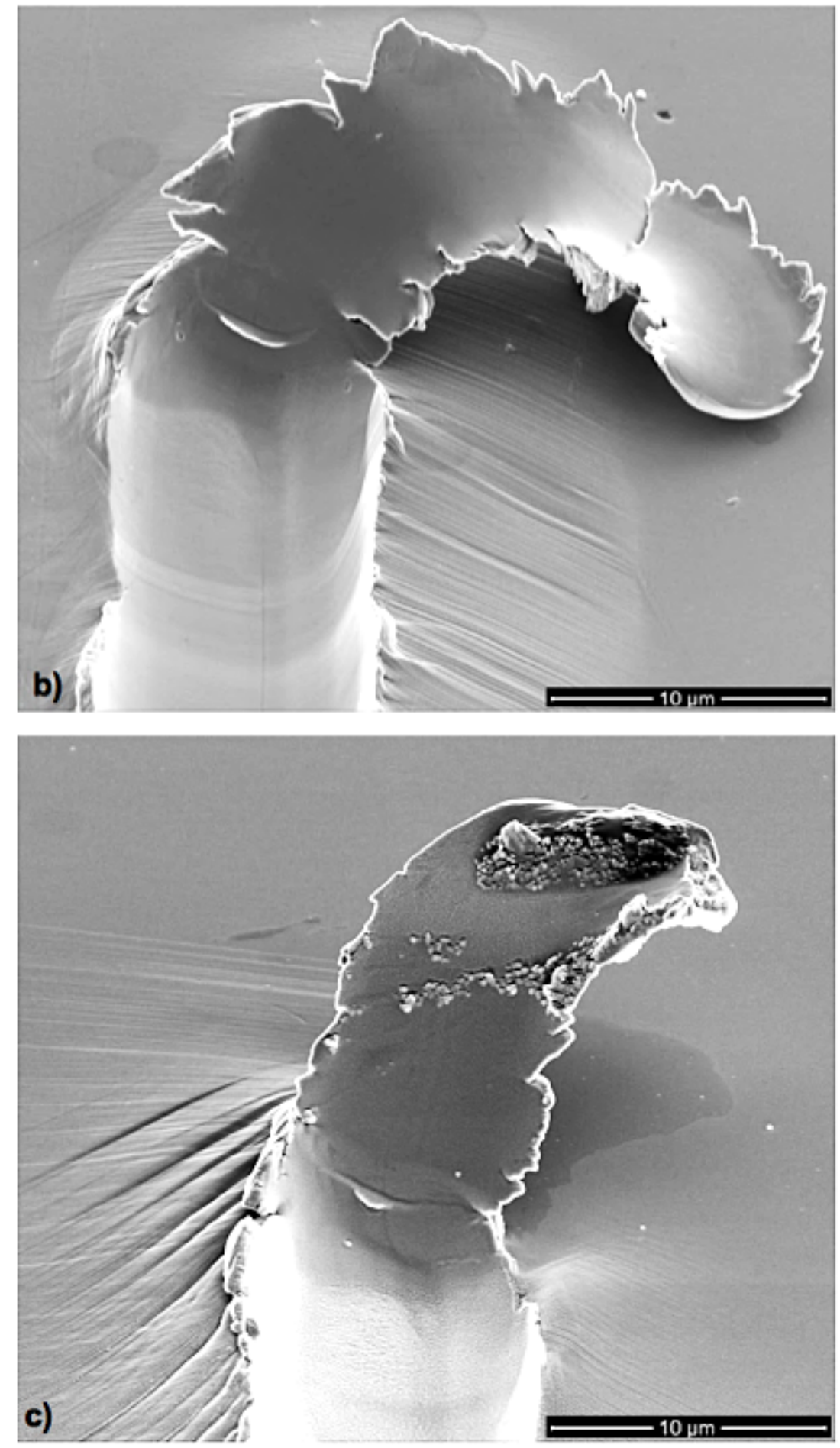

A alteração da microestrutura deformada, observada nesta pesquisa, pode ser associada ao potencial termodinâmico do sistema, no qual é constituído pelos defeitos pré-existentes e pela energia do evento abrasivo. Como demostrado, riscos em diferentes orientações cristalográficas tem diferentes níveis de transformação microestrutural. Por exemplo, a área de grãos ultrafinos foi maior para o plano (001) que para o (111) e (101) de riscamento. 
Os resultados do estudo de esclerometria linear nos planos cristalográficos (001), (111) e (101) para o aço 20Mn são apresentados e discutidos a seguir. Os grãos analisados do aço $20 \mathrm{Mn}$ são indicados na Figura 4.35a com triângulos em preto. A Figura $4.35 b$ mostra via estereoscopia a região de análise na superfície da amostra.

Figura 4.35. Resultado da análise de EBSD para o aço $20 \mathrm{Mn}$. Imagem de IPF (a) da região indicada na imagem estereográfica (b)

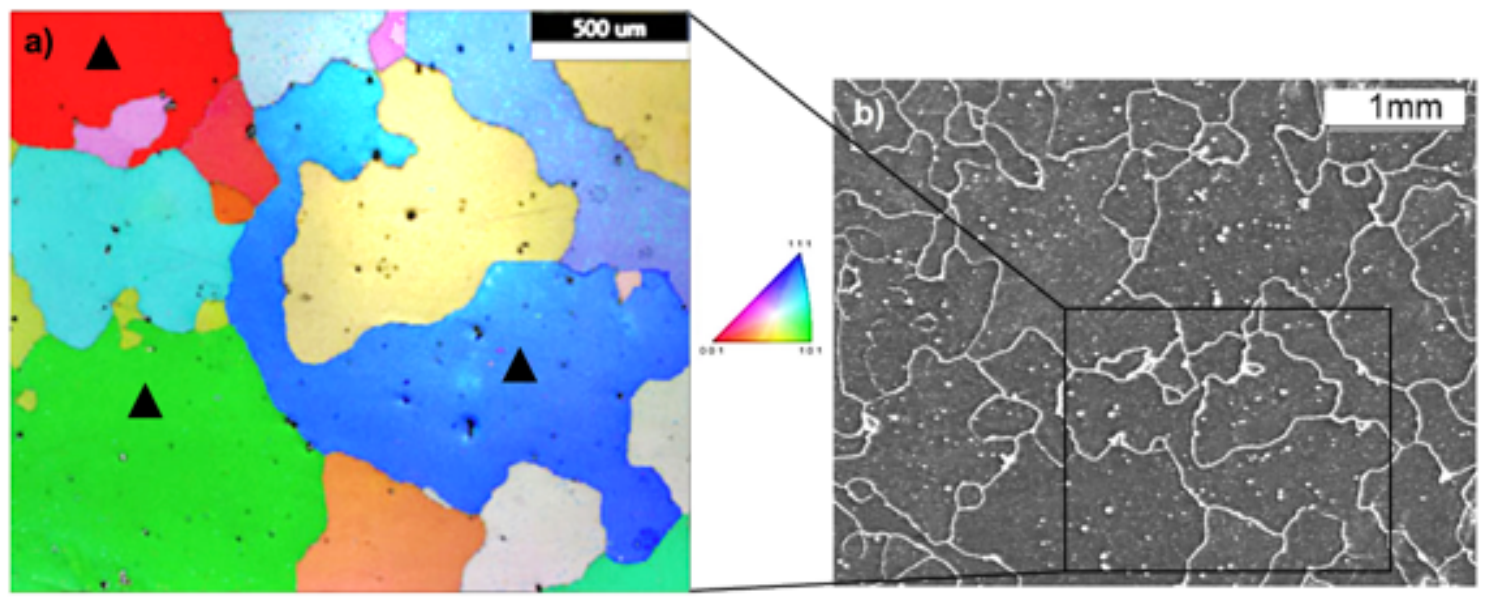

As curvas de coeficiente de atrito dos riscos nos planos (001), (111) e (101) para o aço 20Mn são mostradas no gráfico da Figura 4.36a com as micrografias, Figuras $4.36 b, 4.36 c$ e $4.36 d$ dos riscos de cada plano de análise, respectivamente. O COF para o risco no plano (001) aumenta continuamente até $100 \mu \mathrm{m}$ atingindo o valor máximo de 1,4. Este valor de coeficiente de atrito pode ser relacionado à formação de proa, conforme resultados de Hokkirigawa e Kato (HOKKIRIGAWA; KATO, 1988). Nota-se variações do COF ao longo do comprimento do risco, por exemplo, a inflexão na posição $20 \mu \mathrm{m}$ associada ao início de formação do pile-up. Observa-se que a deformação lateral para este material é mais contida, tendo menor largura comparada à deformação lateral dos riscos para o aço $12 \mathrm{Mn}$. O risco no plano (111) atingiu um valor máximo de 0,8 de COF com formação de cavaco e pileup a direita. Este valor foi obtido para o risco no plano (101), o qual teve maior deformação lateral também a direita do risco com pile-up na extremidade, no entanto, com formação de bordas proeminentes, sendo as responsáveis pelas oscilações da curva de coeficiente de atrito para o risco, Figura 4.36d. As bordas formadas pelo processo de abrasão no aço $20 \mathrm{Mn}$, aparentemente, não mostram crescimento semelhante ao observado para os riscos no aço $12 \mathrm{Mn}$, apesar de ter curvas de coeficiente de atrito crescente para (001), (111) e (101). 
Figura 4.36. a) Gráfico de coeficiente de atrito em função do comprimento dos riscos nos planos (001), (111) e (101) do aço 20Mn. b) Micrografia do risco no plano (001). c) Micrografia do risco no plano (111). d) Micrografia do risco no plano (101). 900X
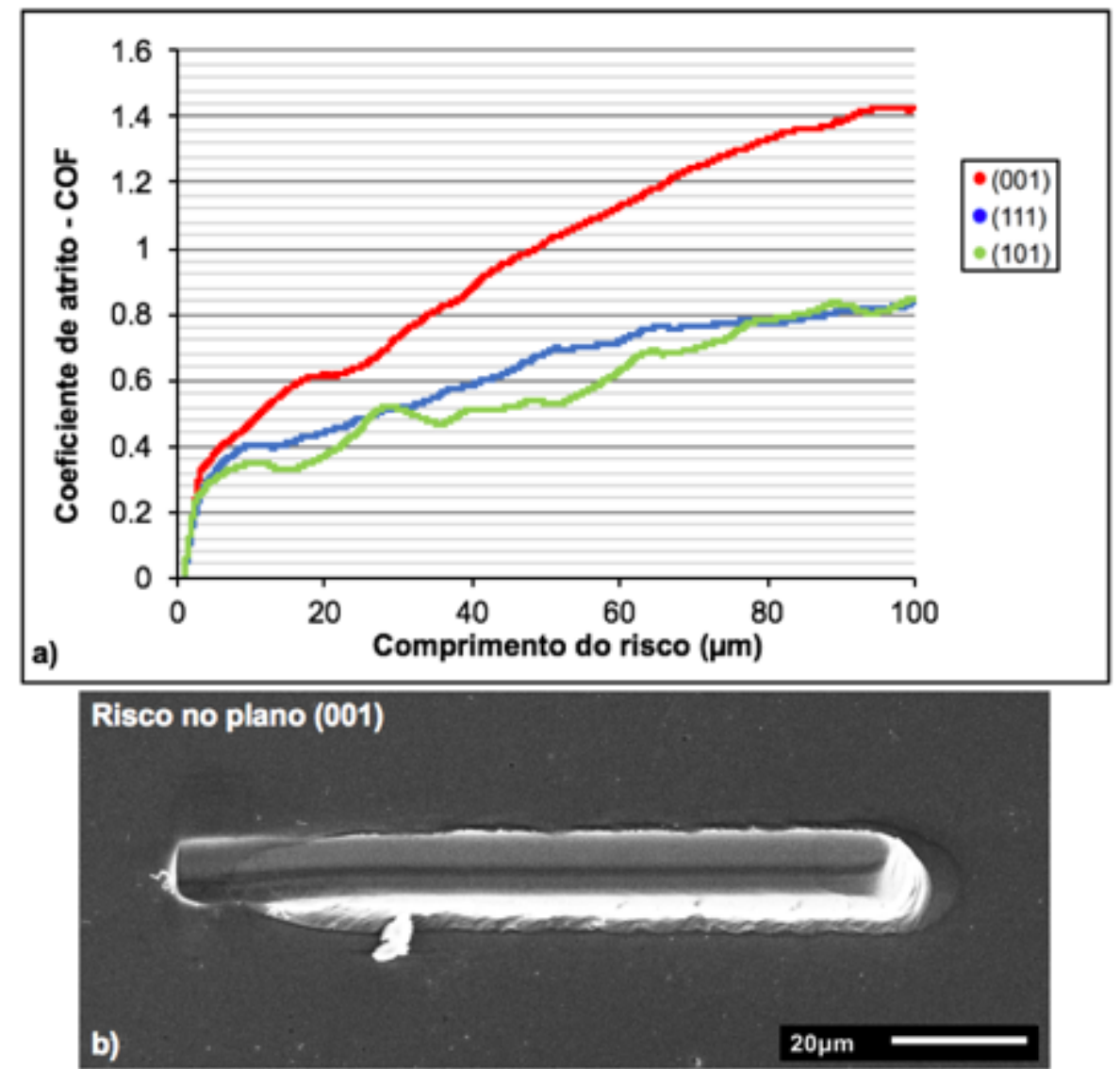

Risco no plano (111)
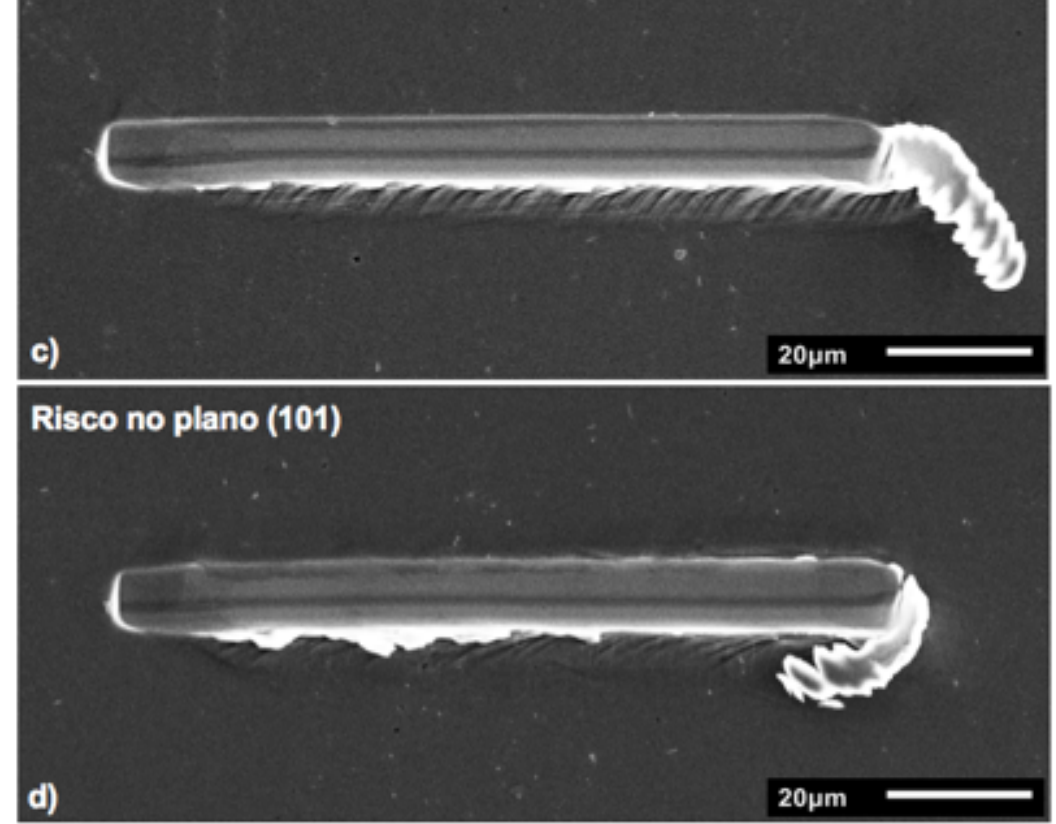

Os valores de COF de cada ensaio (valor médio e incerteza da média) dos riscos nos planos (001), (111) e (101) são mostrados na Tabela 4.6. O valor de coeficiente 
de atrito médio para os riscos no plano (001) foi de 0,99 , enquanto para os riscos nos planos (111) e (101) o coeficiente de atrito médio foi de 0,75 e 0,70, respectivamente.

Tabela 4.6. Coeficiente de atrito para os planos (001), (111) e (101). Aço 20Mn

\begin{tabular}{ccccc} 
& \multicolumn{3}{c}{ COF - 20Mn } & Média \\
\cline { 2 - 4 } Plano & 1 & 2 & 3 & $0,99 \pm 0,02$ \\
\hline$(001)$ & 0,97 & 1,01 & 0,98 & $0,99 \pm 0,75 \pm 0,01$ \\
$(111)$ & 0,75 & 0,75 & 0,77 & 0,75 \\
$(101)$ & 0,69 & 0,70 & 0,72 & $0,70 \pm 0,02$
\end{tabular}

Os valores de profundidade média dos riscos $(h)$ para o aço $20 \mathrm{Mn}$ nos planos (001), (111) e (101) foram $1,72 \pm 0,03 \mu \mathrm{m}, 1,73 \pm 0,03 \mu \mathrm{m}$ e 1,90 $\pm 0,02 \mu \mathrm{m}$, respectivamente. A Figura 4.37 mostra o perfil dos respectivos riscos da Figura 4.36. Observa-se que a variação da profundidade do risco tem uma pequena variação.

Figura 4.37. Profundidade dos riscos nos planos (001), (111) e (101) ao longo do perfil longitudinal obtidos durante o evento abrasivo. Aço $20 \mathrm{Mn}$

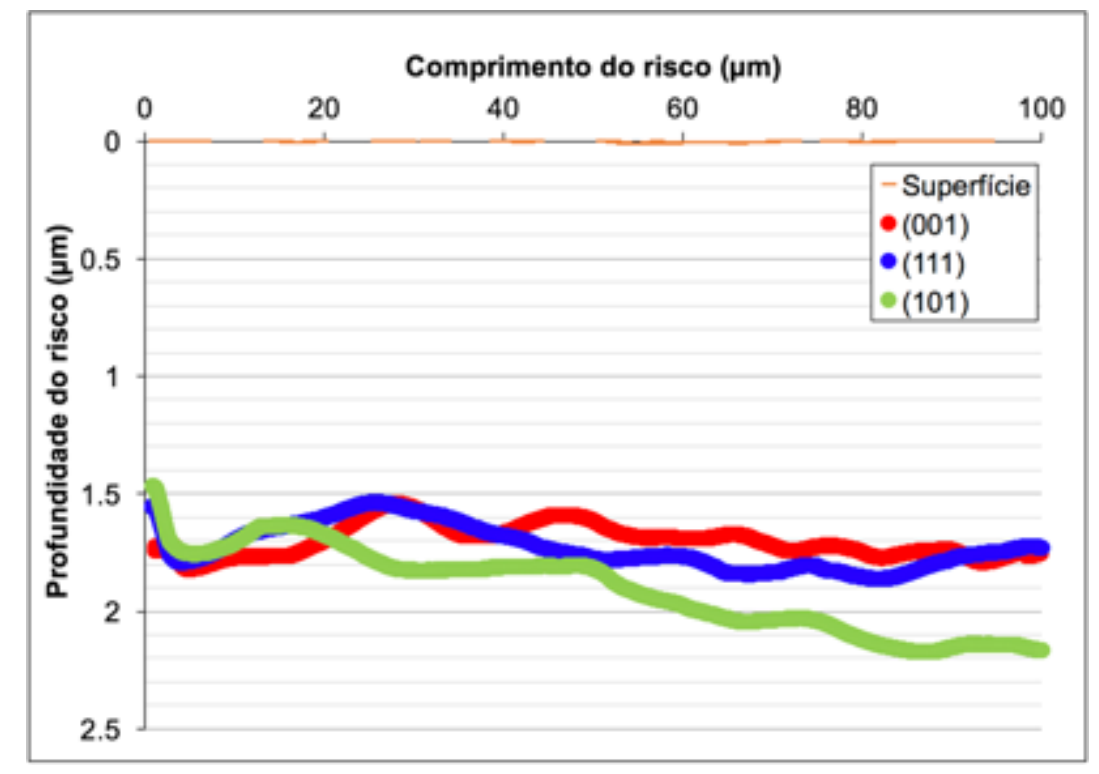

Como observado nos riscos no aço $12 \mathrm{Mn}$, existe uma variação da profundidade dos riscos do aço $20 \mathrm{M}$, as quais sofrem oscilações aparentemente relacionadas à formação do micromecanismo de desgaste.

O $D_{p}$ e ângulo de ataque para os planos (001) e (111) foram iguais, 0,46 e 50, respectivamente, apesar dos micromecanismos diferentes. Os resultados de grau de penetração e ângulo de ataque para o plano 101 foram 0,49 e $52^{\circ}$, respectivamente. 
Desta forma, observa-se que o aço $20 \mathrm{Mn}$ tem diferentes respostas ao fenômeno abrasão por riscamento quando comparado ao aço 12Mn. Além disso, nota-se novamente o efeito da orientação cristalográfica ao comparar os resultados de grau de penetração e ângulo de ataque dos riscos nos planos (001) e (111) com o micromecanismo predominante. $O$ ângulo de ataque de $50^{\circ}$ para o risco no plano (001) não é igual ou superior ao ângulo de ataque crítico para este sistema, no entanto, para o plano (111) este ângulo mostra-se igual ou superior ao crítico, como observado nos micromecanismo de desgaste.

A microestrutura da subsuperfície do risco no plano (001) para o aço 20Mn é mostrada na Figura 4.38a. Nota-se que a deformação plástica lateral foi assimétrica com formação de pile-up concentrada na direita do risco. Na microestrutura da subsuperfície tem-se uma camada de grãos ultrafinos próxima à interface endentador/material. Esta camada tem uma área equivalente à $5,1 \mu \mathrm{m}^{2}$. As áreas das camadas de grãos ultrafinos observados para (111) e (101) na Figura 4.39a e na Figura 4.40a foram $2,3 \mu \mathrm{m}^{2}$ e $3,8 \mu \mathrm{m}^{2}$, respectivamente. Para auxiliar a comparação entre os materiais a Tabela 4.7 mostra os valores de área da camada com grãos ultrafinos, profundidade média do risco, $D_{p}$ e ângulo de ataque para os riscos nos planos (001), (111) e (101) para os aços 12Mn e 20Mn.

\begin{tabular}{|c|c|c|c|c|}
\hline \multirow[b]{2}{*}{ Plano } & $\begin{array}{c}\text { Área da } \\
\text { camada }\left(\mu \mathrm{m}^{2}\right)\end{array}$ & $h(\mu \mathrm{m})$ & $D_{p}$ & $\begin{array}{l}\text { Ângulo de } \\
\left.\text { ataque ( }{ }^{\circ}\right)\end{array}$ \\
\hline & \multicolumn{4}{|c|}{$12 \mathrm{Mn}$} \\
\hline (001) & 8,3 & $2,05 \pm 0,04$ & $0,51 \pm 0,01$ & $54 \pm 0,6$ \\
\hline$(111)$ & 2,6 & $1,80 \pm 0,04$ & $0,47 \pm 0,01$ & $51 \pm 0,6$ \\
\hline \multirow[t]{2}{*}{ (101) } & 5,6 & $2,09 \pm 0,09$ & $0,51 \pm 0,01$ & $55 \pm 1,3$ \\
\hline & \multicolumn{4}{|c|}{$20 \mathrm{Mn}$} \\
\hline$(001)$ & 5,3 & $1,72 \pm 0,03$ & $0,46 \pm 0,01$ & $50 \pm 0,4$ \\
\hline$(111)$ & 2,3 & $1,73 \pm 0,02$ & $0,46 \pm 0,01$ & $50 \pm 0,3$ \\
\hline (101) & 3,8 & $1,90 \pm 0,02$ & $0,49 \pm 0,01$ & $52 \pm 0,3$ \\
\hline
\end{tabular}


Figura 4.38. a) Imagem de FIB do perfil transversal do risco no plano (001), 15.000X. b) Aumento do lado esquerdo do risco, 30.000X. c) Aumento do lado direito do risco, 30.000X. Aço 20Mn
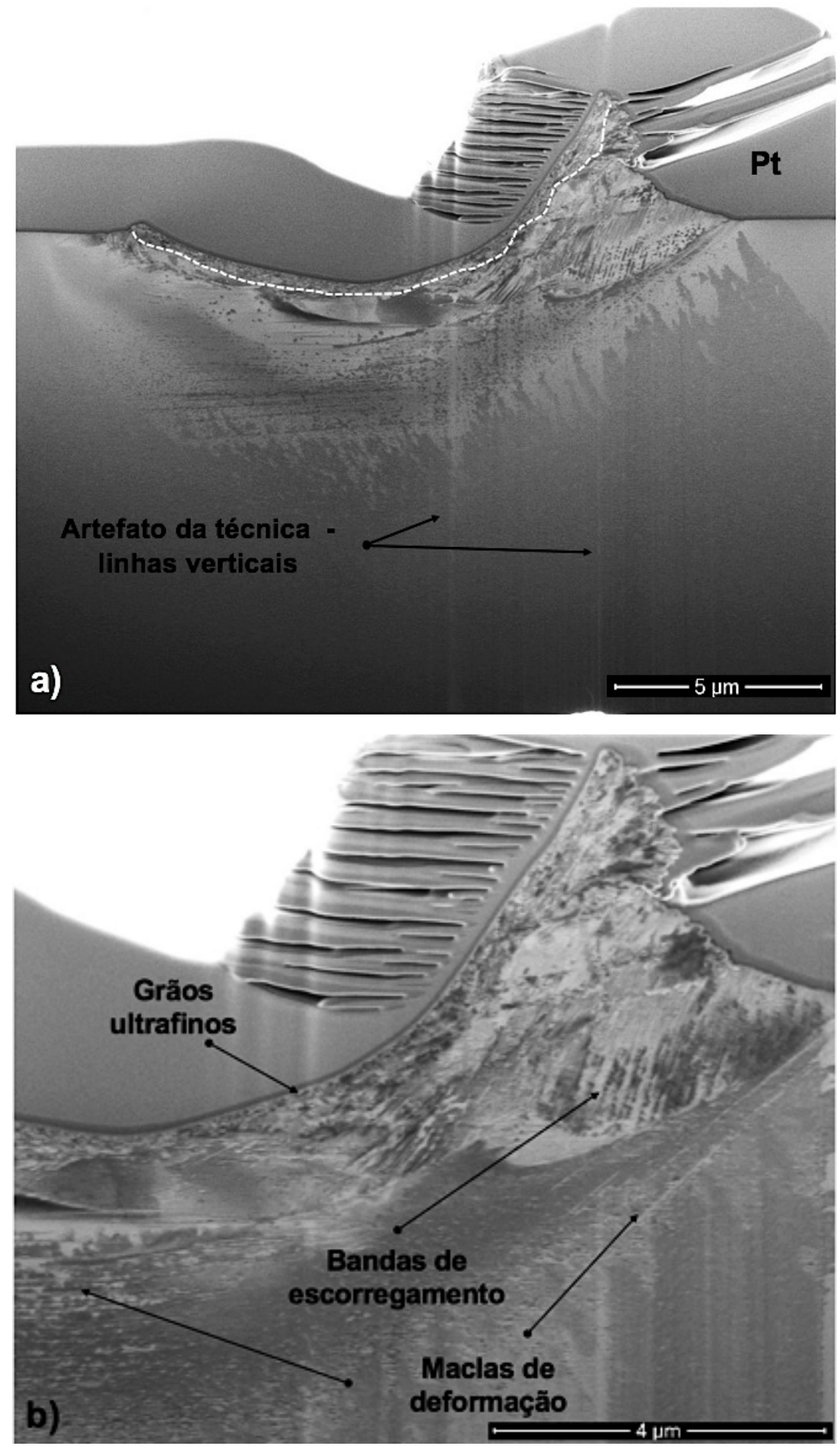


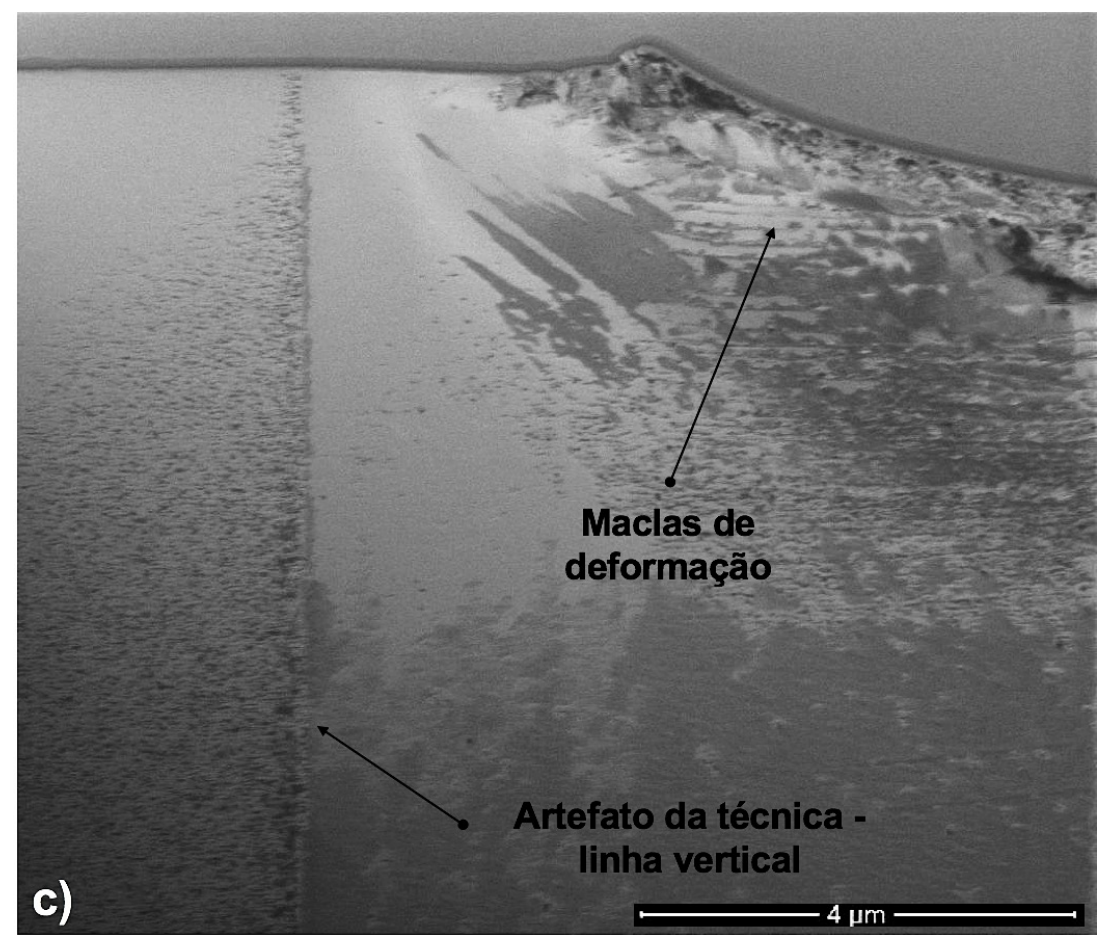

Nas Figuras $4.38 b$ e $4.38 c$ observa-se a camada de grãos ultrafinos na região ao longo da interface endentador/material. Abaixo da camada nota-se maclas de deformação e bandas de escorregamento em uma região que tem a de maior tensão de cisalhamento durante a deformação. A deformação lateral evidenciada pela formação de pile-up foi assimétrica, com pile-up na direita do risco.

A Figura 4.39a mostra a região deformada subsuperficial bem mais definida que as mostradas até o momento. Nela observa-se a camada com grãos ultrafinos e maclas de deformação. Novamente a deformação lateral encontra-se assimétrica, com pileup concentrado na direita do risco. 
Figura 4.39. a) Imagem de FIB do perfil transversal do risco no plano (111), 15.000X. b) Aumento do lado esquerdo do risco, 30.000X. c) Aumento do lado direito do risco, 30.000X. Aço 20Mn
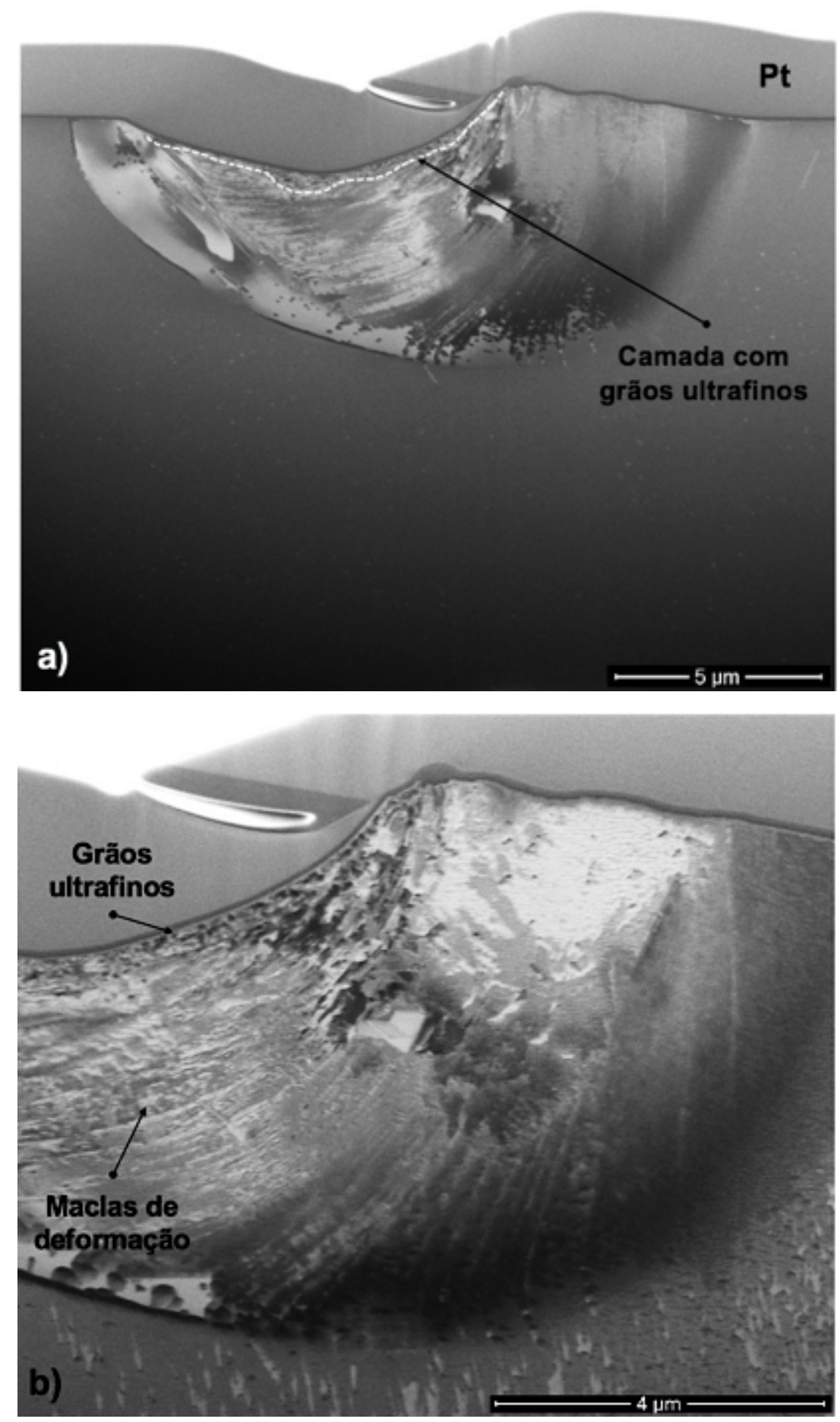


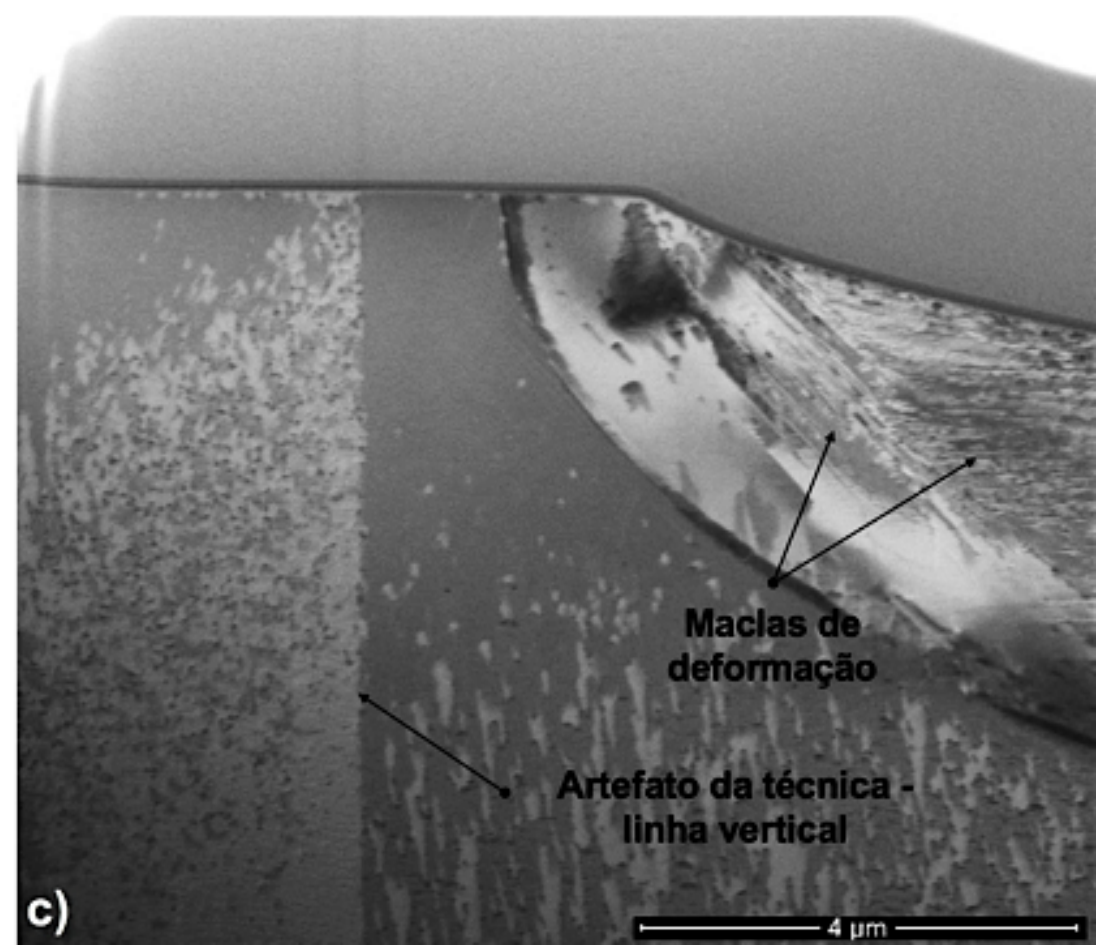

A Figura 4.40 mostra a microestrutura da subsuperfície para o risco no plano (101) do aço $20 \mathrm{Mn}$.

Figura 4.40. a) Imagem de FIB do perfil transversal do risco no plano (101), 15.000X. b) Aumento do lado esquerdo do risco, 30.000X. c) Aumento do lado direito do risco, 30.000X. Aço 20Mn

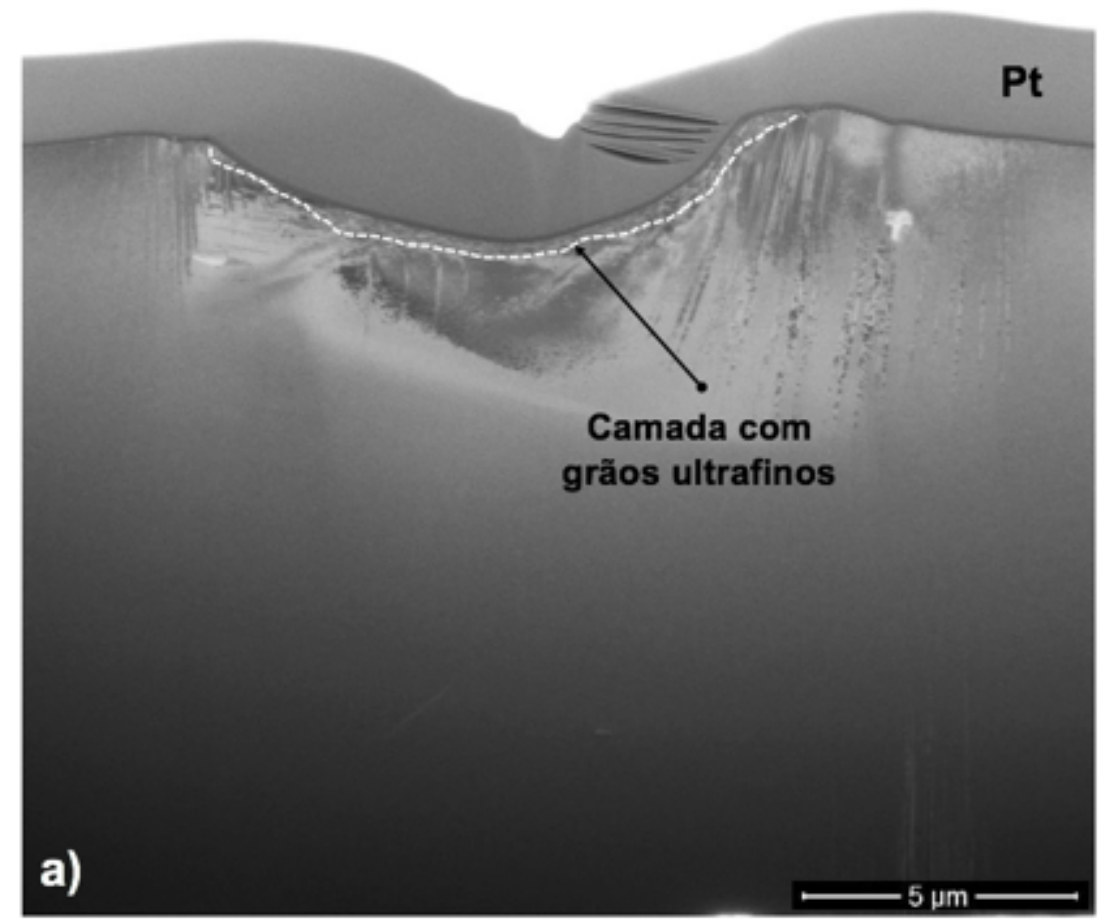



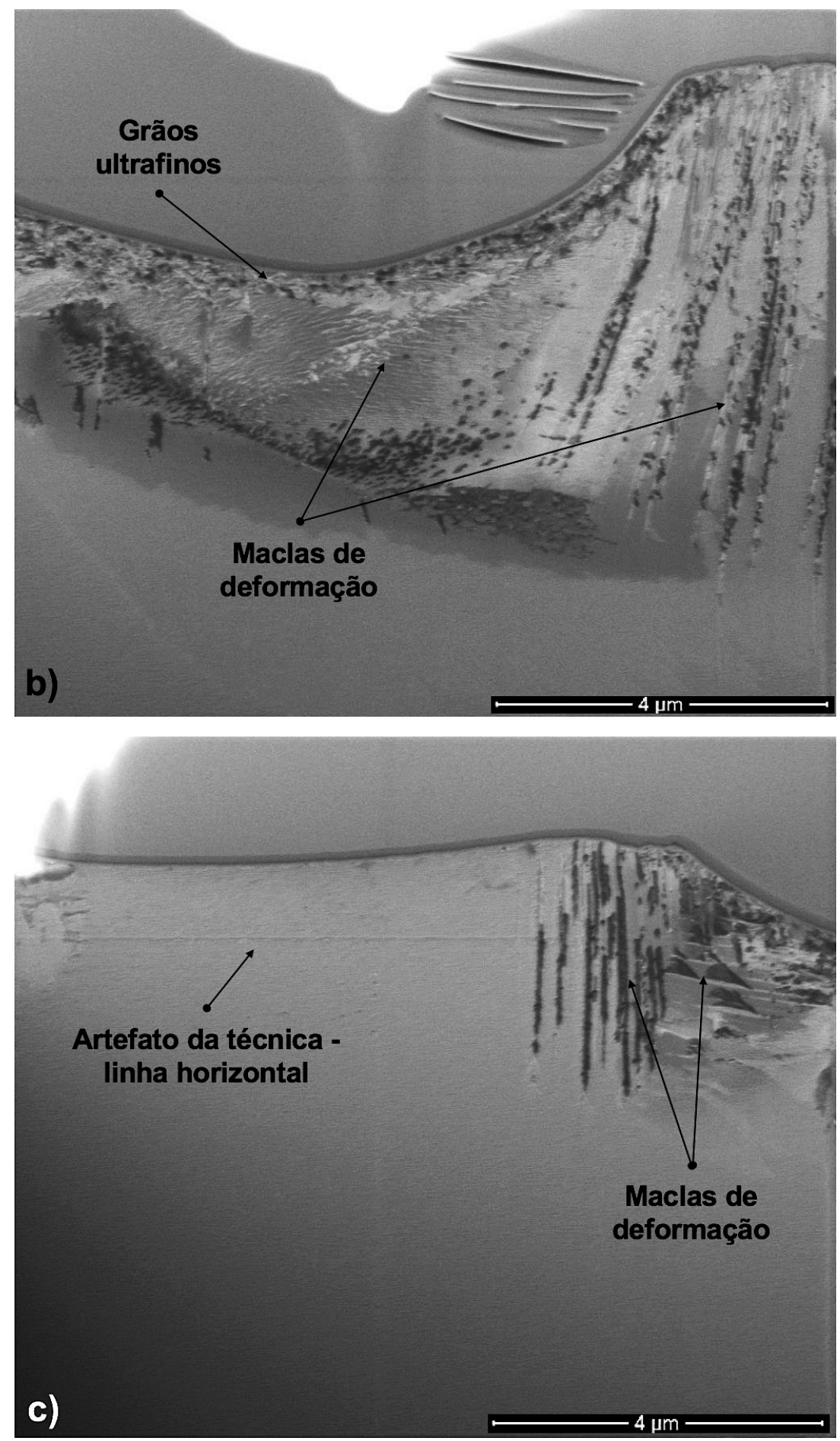

A microestrutura está distribuída de forma simétrica, com formação simétrica de pileup como observam-se nas Figuras 4.40a, 4.40b e 4.40c. Abaixo da camada de grãos ultrafinos observam-se maclas de deformação.

A Figura 4.41 mostra a superfície da região final dos riscos nos planos (001), (111) e (101) para o aço $20 \mathrm{Mn}$. Observa-se um comportamento semelhante aos micromecanismos dos riscos para o aço $12 \mathrm{Mn}$, mostrados na Figura 4.34. No risco no plano (001), Figura 4.41a, a deformação lateral se concentra próximo ao risco e 
observa-se uma proa, diferentemente dos riscos no plano (111) e (101), nos quais se vê formação de cavaco, Figuras $4.41 b$ e $4.41 c$, respectivamente. Na deformação plástica lateral para o risco no plano (111) tem-se bandas de escorregamento com formação do tetraedro de Thompson (Thompson, N., 1993 apud Padilha, 1997), Figura $4.41 b$ em destaque.

Figura 4.41. a) Deformação plástica lateral e proa do risco no plano (001). b) Deformação plástica lateral e cavaco do risco no plano (111). c) Deformação plástica lateral e cavaco do risco no plano (101). Imagens de FEG. Aço $20 \mathrm{Mn}$

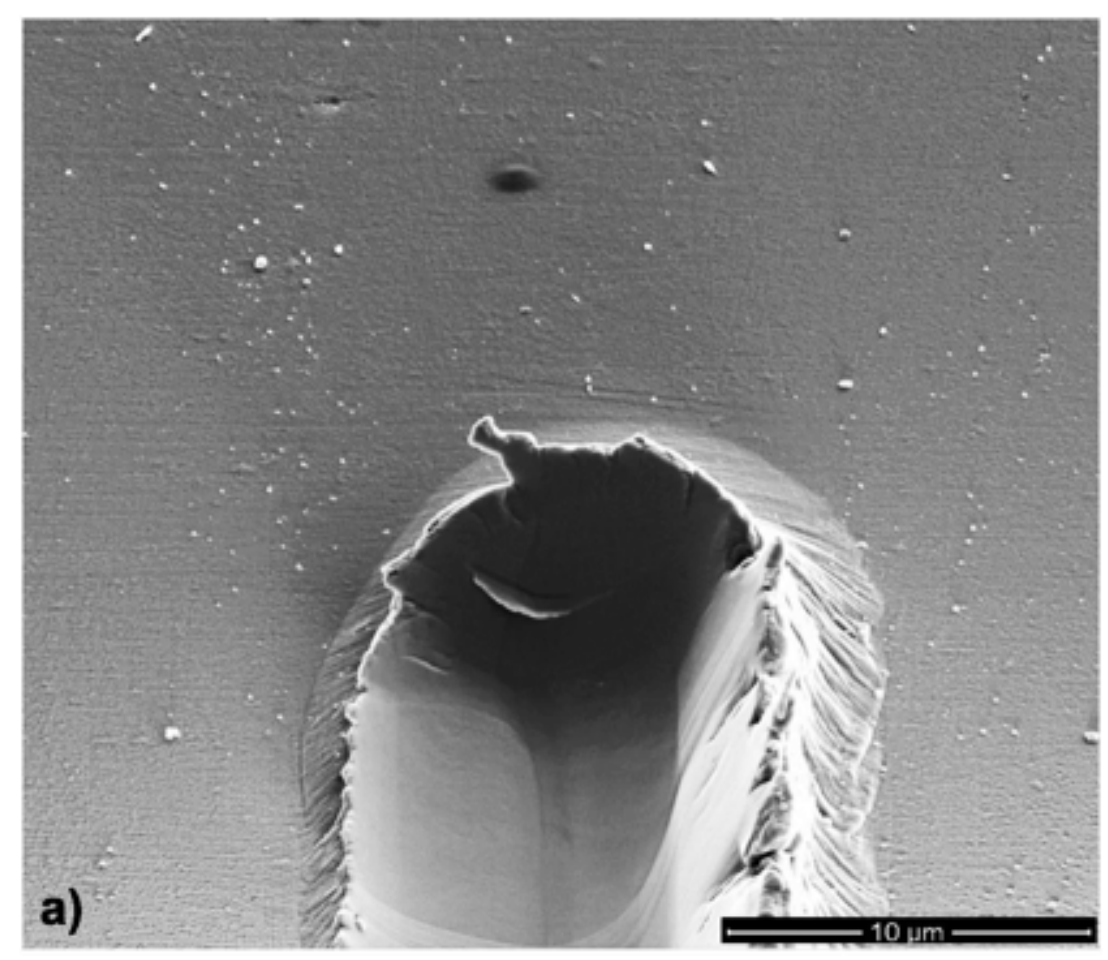



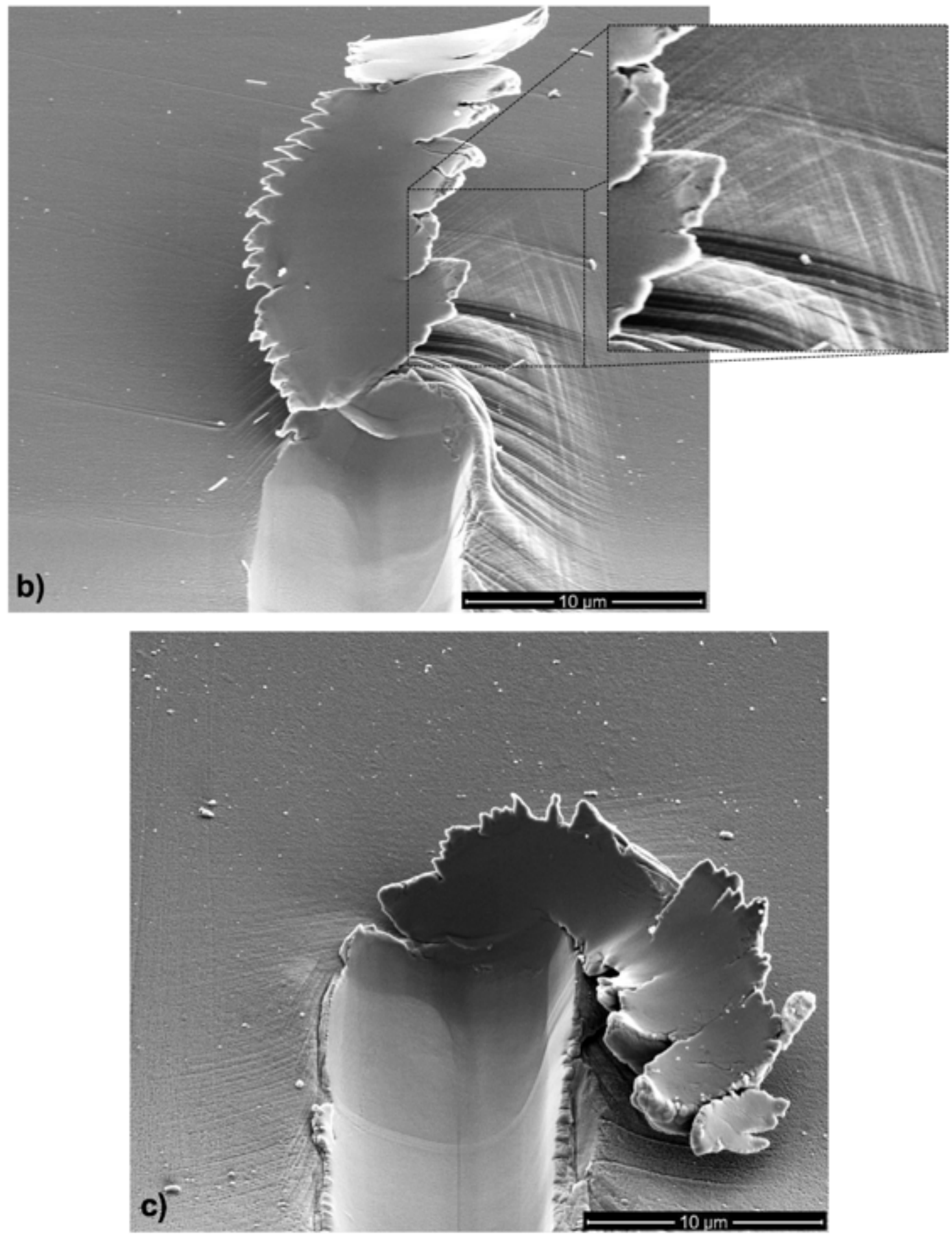

Ao comparar os resultados dos dois materiais (12Mn e 20Mn) evidencia-se que o comportamento mecânico é diferente entre os planos cristalográficos avaliados, revelando o efeito da anisotropia na abrasão. Outra variável possível de ser avaliada para os ensaios é a energia total gasta para realizar o risco $\left(e_{r}\right)$. Os resultados da energia gasta no riscamento (Equação 4.4) são mostrados na Tabela 4.8 e no gráfico da Figura 4.42. 
Figura 4.42. Energia dos riscos nos planos (001), (111) e (101) para os aços $12 \mathrm{Mn}$ e $20 \mathrm{Mn}$

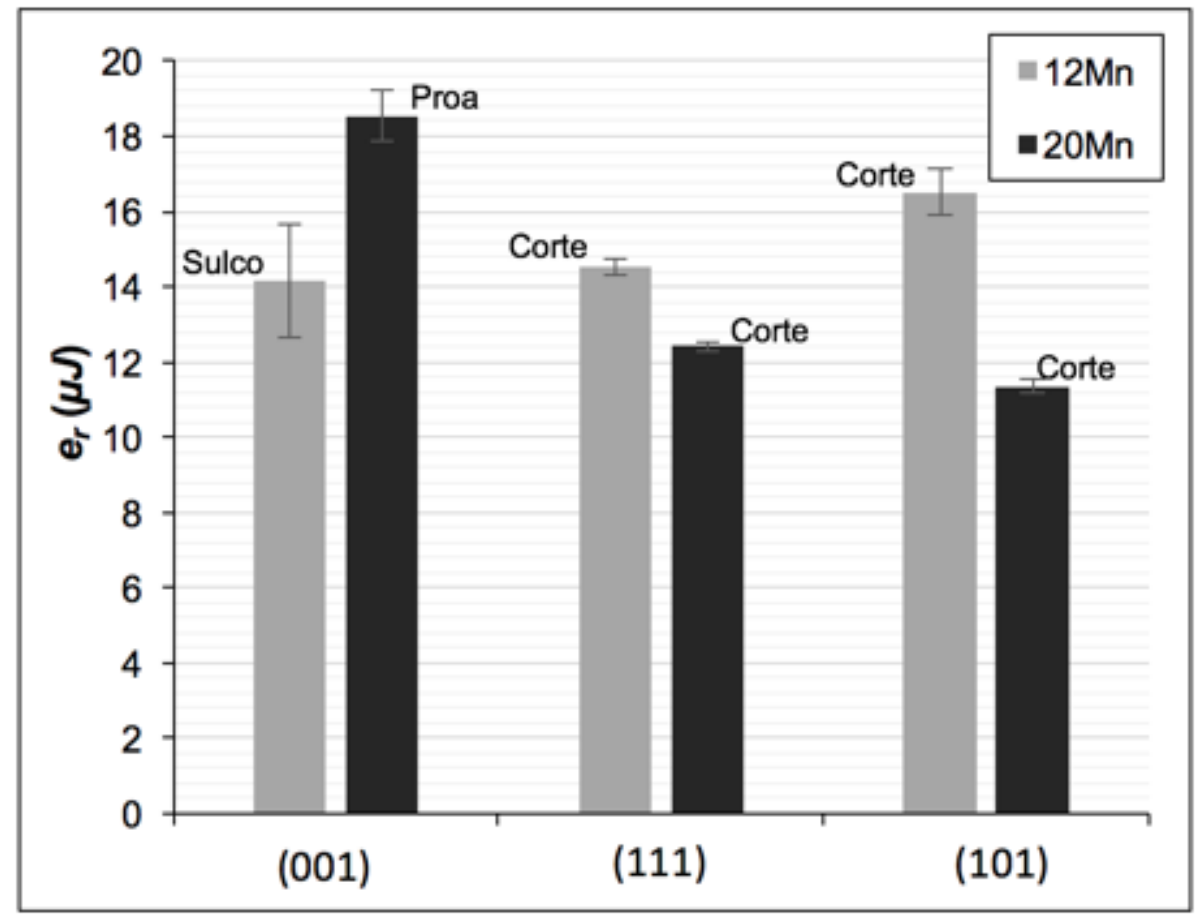

Tabela 4.8. Valores de energia gasta no riscamento dos planos (001), (111) e (101)

\begin{tabular}{ccc} 
& \multicolumn{2}{c}{$e_{r}(\mu \mathrm{J})$} \\
\cline { 2 - 3 } Plano & $12 \mathrm{Mn}$ & $20 \mathrm{Mn}$ \\
\hline$(001)$ & $14,2 \pm 1,1$ & $18,5 \pm 0,7$ \\
$(111)$ & $14,5 \pm 0,1$ & $12,4 \pm 0,1$ \\
$(101)$ & $16,5 \pm 0,3$ & $11,3 \pm 0,2$
\end{tabular}

Os resultados de energia do risco foram sensíveis à variação de orientação cristalográfica e dos materiais estudados. Como observado nos resultados de coeficiente de atrito os riscos no plano (001) do aço $20 \mathrm{Mn}$ consumiram maior energia que os demais. Este resultado foi associado à formação de proa.

Este gráfico mostra informações importantes relacionadas à orientação cristalográfica. Para o aço 12Mn os riscos nos planos (001) e (111) tiveram o mesmo gasto de energia, mas quando comparados aos riscos no plano 101 observa-se uma diferença de $12 \%$. Ao avaliar os resultados para o aço $20 \mathrm{Mn}$, nota-se que os planos riscados com o mesmo gasto de energia foram o (111) e (101), havendo uma diferença de $33 \%$ com os riscos no plano (001). Essa mudança de comportamento se deu em função do micromecanismos observado para os riscos no plano (001), os quais tem uma pequena diferença dentre os aços, transição sulco/proa. De acordo 
com Hokkirigawa e Kato, esta variação de micromecanismos causa uma grande variação de energia consumida no sistema (HOKKIRIGAWA; KATO, 1988)

Ao isolar a orientação cristalográfica e comparar os resultados para os dois aços, observa-se que a diferença de 40 \% de manganês em solução tem efeito sobre o comportamento mecânico do aço austenítico. Como visto na revisão bibliográfica Adler, Olson e Owen mostraram que o aumento da concentração de manganês no aço austenítico promove o aumento da energia de falha de empilhamento, alterando o comportamento mecânico do material (ADLER; OLSON; OWEN, 1986). As diferenças de energia para as orientações (001), (111) e (101) dos dois materiais foram $25 \%, 15 \%$ e $31 \%$, respectivamente.

A Tabela 4.9 mostra os resultados médios, para 25 repetições, de módulo de elasticidade combinado obtidos via nanodureza instrumentada (modelo de Oliver Pharr) para os planos (001), (111) e (101) dos aços 12Mn e 20Mn.

Tabela 4.9. Módulo de elasticidade combinado dos planos (001), (111) e (101) dos aços 12Mn e $20 \mathrm{Mn}$ obtido via nanodureza instrumentada

\begin{tabular}{ccc} 
& \multicolumn{2}{c}{$E(\mathrm{GPa})$} \\
\cline { 2 - 3 } Plano & $12 \mathrm{Mn}$ & $20 \mathrm{Mn}$ \\
\hline$(001)$ & $184 \pm 1$ & $174 \pm 1$ \\
$(111)$ & $193 \pm 1$ & $184 \pm 1$ \\
$(101)$ & $193 \pm 1$ & $184 \pm 1$
\end{tabular}

Os resultados mostraram que o módulo de elasticidade na direção [001] de carregamento é inferior às orientações [111] e [101] para os aços 12Mn e 20Mn, havendo uma diferença de $4 \%$ e $5 \%$, respectivamente. Os resultados de módulo de elasticidade dos planos (001), (111) e (101) são estatisticamente diferentes entre os materiais, conforme análise comparativa entre os valores de incerteza das médias. Os resultados de módulo de elasticidade corroboram os micromecanismos de desgaste observados para os riscos nos planos (001), (111) e (101). Visto que os micromecanismos foram o microsulcamento para (001) e o microcorte para (111) e (101). Entretanto, comparando os riscos no plano (001) para os dois materiais notouse uma diferença na extensão da deformação lateral associada ao pile-up, havendo uma deformação lateral maior para o aço 12Mn do que para o aço $20 \mathrm{Mn}$. Os valores medidos da linha de centro à extremidade direita do pile-up, Figura 4.30a (aço 12Mn) e Figura 4.38a (aço 20Mn), foram de 12,6 $\mu \mathrm{m}$ e $8,8 \mu \mathrm{m}$, 
respectivamente. Esta diferença de deformação lateral dos riscos pode ser observada também nas Figuras 4.34a e 4.41a.

Pierce et al. obtiveram, via nanodureza instrumentada, os valores de módulo de elasticidade reduzido equivalentes a $178 \mathrm{GPa}, 196 \mathrm{GPa}$ e $195 \mathrm{GPa}$ para os planos (001), (111) e (101), respectivamente, para uma liga metálica $\mathrm{Fe}-22 \% \mathrm{Mn}-$ $3 \% \mathrm{Al}-3 \% \mathrm{Si}$ (PIERCE et al., 2013), as quais corroboram os resultados obtidos para cada plano dos aços $12 \mathrm{Mn}$ e $20 \mathrm{Mn}$.

A microestrutura da subsuperfície do aço austenítico com $12 \% \mathrm{Mn}$ deformada em desgaste de campo e de laboratório é discutida com maior detalhe no próximo Capítulo: "MICROESTRUTURA DA SUBSUPERFÍCIE DO AÇO AUSTENÍTICO COM 12 \%Mn DEFORMADO POR DESGASTE ABRASIVO".

\subsection{Considerações Finais}

As seguintes considerações podem ser feitas a partir dos resultados do estudo do efeito do encruamento e da orientação cristalográfica no desgaste por riscamento para a mesoescala e para a microescala:

- A variação de dureza do perfil encruado não apresentou efeito significativo nos resultados de abrasão por riscamento para a mesoescala e para a microescala;

- O micromecanismo de desgaste predominante para os riscos no plano (001) nos aços $12 \mathrm{Mn}$ e $20 \mathrm{Mn}$ foi o microsulcamento, enquanto para os planos (111) e (101) foi o microcorte. Notou-se diferença na extensão da deformação lateral entre os riscos dos aços $12 \mathrm{Mn}$ e $20 \mathrm{Mn}$.

- A energia gasta ao longo do evento abrasivo nos planos (001), (111) e (101) do aço $12 \mathrm{Mn}$ foi superior à do aço $20 \mathrm{Mn}$, com exceção para os riscos no plano (001), onde verificou-se menor deformação lateral nos riscos do aço $20 \mathrm{Mn}$;

- Os micromecanismos de desgastes são sensíveis às alterações microestruturais da subsuperfície. Nos cortes transversais aos planos (001), (111) e (101) dos aços $12 \mathrm{Mn}$ e $20 \mathrm{Mn}$ observou-se a formação, com diferentes intensidades, da camada com grãos ultrafinos, maclas de deformação e bandas de escorregamento. 
Capitula 5. MICROESTRUTULRA DA

SULBSLIPEREICIE DO ACO AUUSTENITICO

COM 12 \% MU DEFORMADO PORDESGASTE ABRASIVO

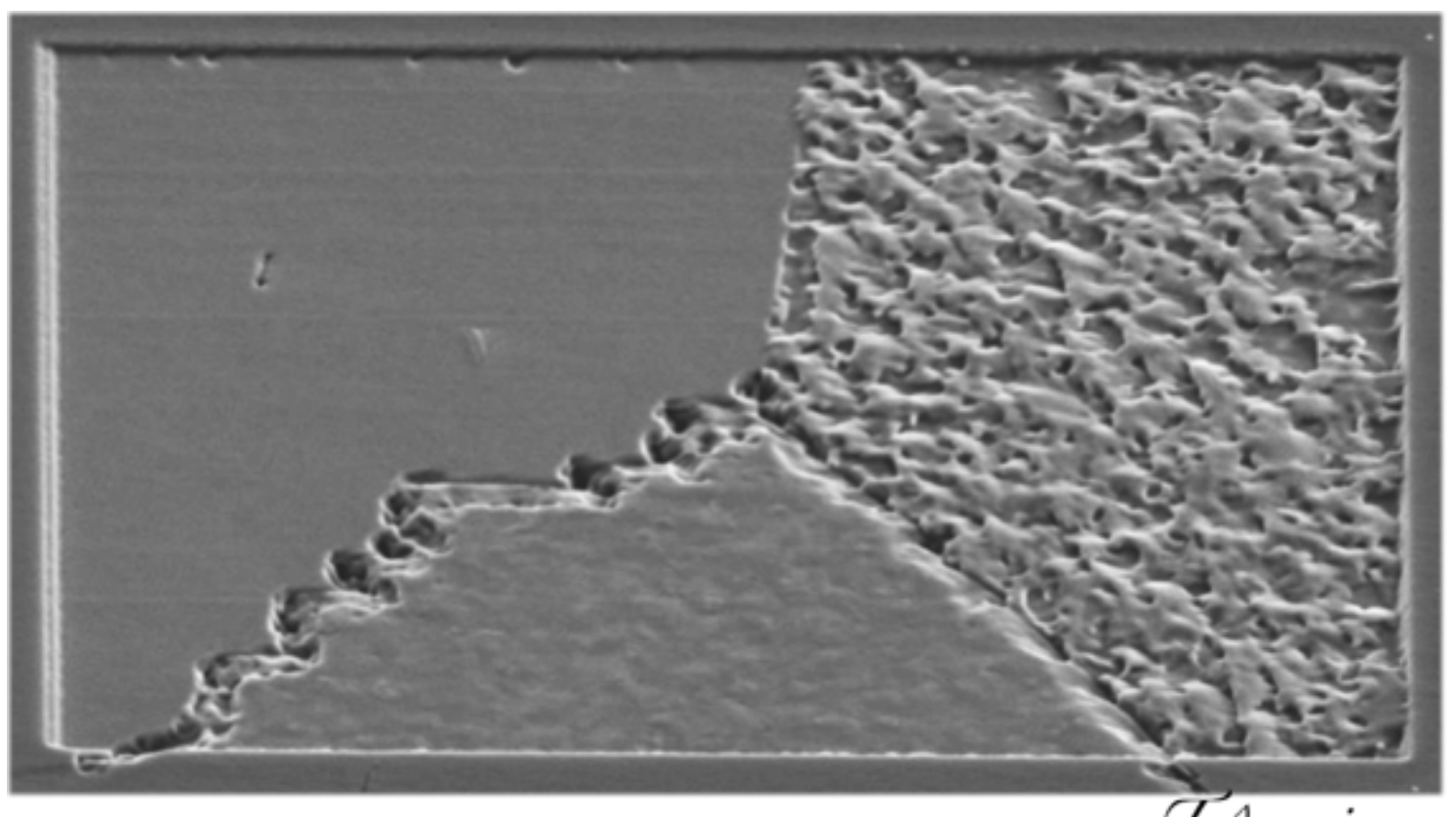




\section{Resumo}

O estudo da microestrutura da subsuperfície do aço austenítico com $12 \% \mathrm{Mn}$ deformado em diferentes condições de desgaste, de acordo com a multiescala do fenômeno de abrasão, escalas: macro (britador cônico), meso (ensaio de britador de mandíbula) e micro (ensaio de microesclerometria linear), é apresentada neste Capítulo. A subsuperfície do aço Hadfield classe $C$ desgastado foi estudada com as técnicas de MEV, EBSD, DRX, Nanoendentação, FIB e MET. Nesta pesquisa a metodologia de análise com FIB foi otimizada, utilizando o feixe de íons diretamente sobre uma superfície polida. O emprego deste método contribuiu com o aumento da velocidade e da área análise. O mecanismo de dano do revestimento de britador (escala macro) é constituído por nucleação superficial de trinca intergranular ou transgranular, propagação de trinca e destacamento de grão ou lascamento de material. A microestrutura da subsuperfície das amostras obtidas em cada escala da análise multiescala são compostas por uma camada de grãos ultrafinos, maclas de deformação e bandas de escorregamento. Nas escalas macro e meso foram observados que a forma dos grãos do aço não é alterada pela deformação plástica na região superficial, uma vez que a maclação mecânica trata-se do mecanismo prioritário de deformação. Na subsuperfície (macroescala) foram observadas regiões com microestrutura característica de recristalização e crescimento, com formação de grãos pequenos com carbonetos contínuos em contorno de grão, carbonetos aciculares e maclas de recozimento. Além disto, esta pesquisa discuti a causa da formação de grãos ultrafinos por recristalização dinâmica induzida pelo desgaste e associa a microestrutura recristalizada ao fenômeno de autoreparação.

Palavras-chave: Análise Multiescala. Desgaste abrasivo. Recristalização dinâmica. Autoreparação.

\subsection{OBJETIVO}

\subsubsection{Geral}

Estudar a microestrutura da subsuperfície do aço Hadfield após desgaste abrasivo nas escalas macro (revestimento usado em campo), meso (ensaio de laboratório) e micro (ensaio de laboratório). 


\subsubsection{Específicos}

- Analisar via MEV, FIB, EBSD, Nanodureza e DRX a microestrutura da subsuperfície do revestimento de britador cônico (manto) desgastado em condições operacionais de cominuição de minério;

- Analisar via FEG, FIB, EBSD e DRX a microestrutura da subsuperfície do revestimento de britador de mandíbula desgastado em ensaio laboratorial;

- Analisar via MEV, FIB e MET a microestrutura da subsuperfície de riscos gerados em ensaios de microesclerometria linear.

\subsubsection{Diagrama de blocos}

O diagrama da Figura 5.1 mostra os ensaios e métodos de caracterização utilizados neste Capítulo.

Figura 5.1. Diagrama de blocos na análise multiescala

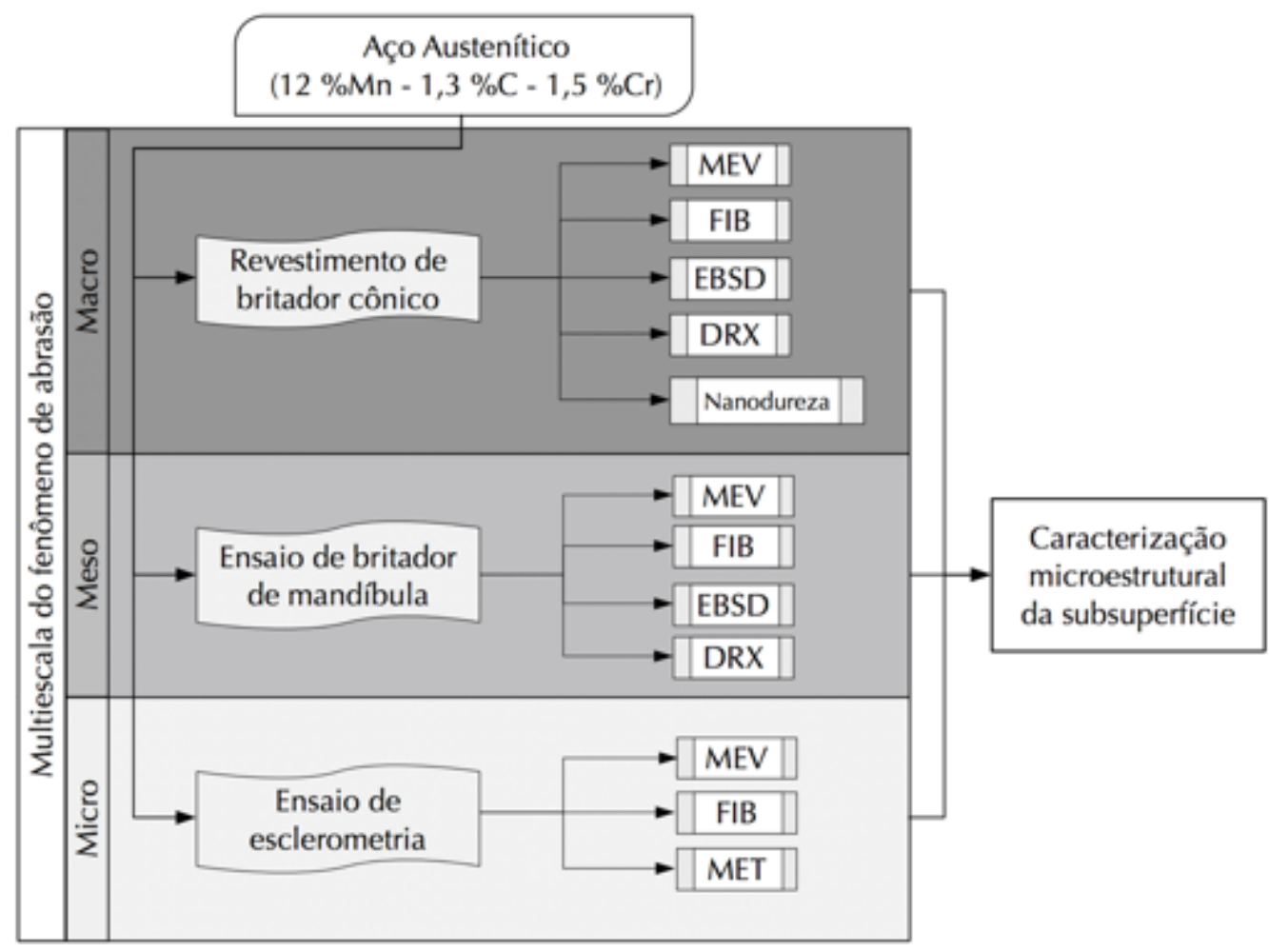




\subsection{MATERIAIS E MÉTODOS}

\subsubsection{Obtenção e preparação de amostra}

\subsubsection{Amostra de revestimento de britador cônico}

A obtenção das amostras de aço Hadfield classe C provenientes de um britador cônico (manto) foi realizada com o processo de oxicorte na empresa Vale S/A. As amostras com menores dimensões foram obtidas com os processos de corte a disco automatizado: i. STRUERS DISCOTOM-65 (LFS Poli/USP) com rotação de 2.150 RPM, disco STRUERS 40A30 e velocidade de avanço de 0,2 mm/s; e ii. BUEHLER ISOMET 5.000 (LFS Poli/USP) com rotação de 2.000 RPM, disco BUEHLER 112720 e velocidade de avanço de $0,02 \mathrm{~mm} / \mathrm{s}$. Este procedimento preservou a integridade da microestrutura do material analisado evitando os efeitos térmicos do oxicorte.

\subsubsection{Amostra de revestimento de britador de mandíbula (ensaio laboratorial)}

As amostras da mandíbula fixa da região de saída foram retiradas do revestimento após ensaio de britador de mandíbula. A região de saída foi escolhida para análise por apresentar maior desgaste (Capítulo 3). O ensaio foi realizado com alimentação contínua de $100 \mathrm{Kg}$ de abrasivo brita tipo 1 (+6,35 -19,05 mm) com tamanho médio de $14,3 \mathrm{~mm}$, com umidade de $0,5 \%$ e fluxo de alimentação de $8,5 \mathrm{~kg}$ por minuto. Os ensaios foram realizados na empresa Serveng (Baruerí-SP) com o britador do Laboratório de Caracterização Tecnológica - LCT (Engenharia de Minas e Petróleo Poli/USP) fabricado pela empresa FURLAN.

\subsubsection{Amostra de microesclerometria linear (ensaio laboratorial)}

As amostras para análise de microestrutura da subsuperfície dos riscos são as estudadas no Capitulo 4, como descrito nesse Capítulo os riscos foram gerados no 
ensaio de microesclerometria com o equipamento Hysitron Nanoindenter (LFS). Os ensaios foram feitos em grãos com planos cristalográficos (001), (101) e (111). Os parâmetros adotados nos ensaios foram: força normal constante de $200 \mathrm{mN}$, velocidade de $3,3 \mu \mathrm{m} / \mathrm{s}$, comprimento de risco de $100 \mu \mathrm{m}$ e endentador tipo Rockwell de $60^{\circ}$ com ponta esférica de $5 \mu \mathrm{m}$. A série de ensaios consistiu em 18 riscos, com três repetições para cada orientação cristalográfica.

\subsubsection{Corte em ângulo (taper section)}

As amostras dos revestimentos do britador de cônico e do britador de mandíbula laboratorial foram preparadas para análise de microscopia eletrônica (MEV, FIB e EBSD) com aplicação do corte em ângulo (taper section). Essa técnica de corte foi utilizada para ampliar a área da região de interesse da subsuperfície, as amostras foram cortadas com um ângulo de $45^{\circ}$ (britador cônico) e $20^{\circ}$ (britador de mandíbula). A Figura 5.2 mostra o procedimento de corte em ângulo.

Figura 5.2. Modelo metodológico de corte em ângulo (taper section) da superfície desgastada

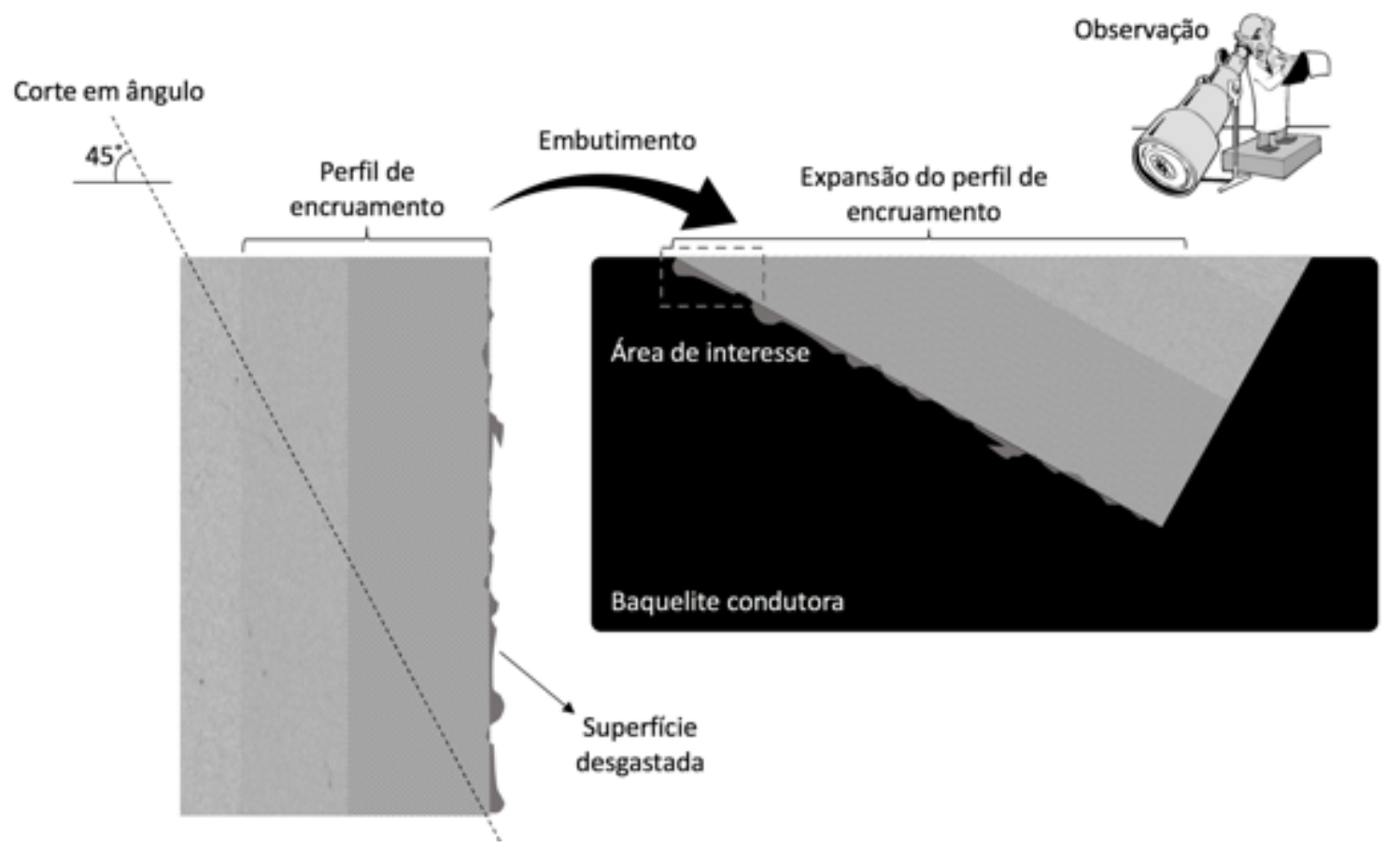




\subsubsection{Polimento e ataque}

As etapas sucessivas de metalografia aplicadas nas amostras embutidas foram o lixamento semi-automático com lixas de SiC \#80 a \#1.200, polimento semiautomático com solução de diamante de $10 \mu \mathrm{m}$ a $1 \mu \mathrm{m}$ e ataque químico por imersão com reagente picral $4 \%$.

As amostras para análise de EBSD e FIB (taper section) foram submetidas às etapas de lixamento e polimento descritas no parágrafo anterior e ao processo de polimento semi-automático com sílica coloidal de $50 \mathrm{~nm}$, água deionizada, rotação de 40 RPM e limpeza de ultrassom com acetona 99\% por 30 minutos.

A superfície desgastada das amostras de britador cônico para análise de FIB foi decapada com ácido $\mathrm{C} 3.1$ : $1.000 \mathrm{~mL}$ de ácido clorídrico $(\mathrm{HCl}), 20 \mathrm{~g}$ de trióxido de antimônio $\left(\mathrm{Sb}_{2} \mathrm{O}_{3}\right), 50 \mathrm{~g}$ de cloreto de estanho $\left(\mathrm{SnCl}_{2}\right)$ e $50 \mathrm{~g}$ de hidróxido de sódio (NaOH); (ASTM G1, 1999). O processo de decapagem foi aplicado para reduzir a camada de óxido e possibilitar a análise convencional de FIB com corte ortogonal à superfície.

\subsubsection{Lâmina para microscopia eletrônica de transmissão (MET)}

A análise de MET foi feita em uma lâmina retirada de um risco no plano cristalográfico (111). A obtenção da lâmina foi realizada com a aplicação de uma técnica de corte, afinamento, limpeza e remoção de amostra via FIB. A técnica empregada é dividida em dez passos: deposição de platina com 2,4 nA - 5 kV; abertura de duas cavidades simétricas de $35 \mu \mathrm{m}$ de comprimento, $20 \mu \mathrm{m}$ de largura e $15 \mu \mathrm{m}$ de profundidade (Figura 5.3b) com $30 \mathrm{nA}$ - $30 \mathrm{kV}$; duas etapas de limpeza da lâmina com $5 \mathrm{nA}$ - $30 \mathrm{kV}$ e $3 \mathrm{nA}$ - $30 \mathrm{kV}$, fixação da lâmina na ponta do equipamento Omniprobe com solda de platina, corte em $U$ para remoção da lâmina (Figura 5.3c), fixação da lâmina no porta amostra com solda de platina (Figura 5.3d), afinamento e limpeza da lâmina (Figura 5.3e). 
Figura 5.3. Etapas do procedimento de obtenção de lâmina para MET. a) Formação da cavidade no risco. b) Formação de cavidade simétrica à primeira. c) Fixação da lâmina na ponta Omniprobe com solda de Pt e corte em "U". d) Fixação da lâmina no porta amostra (grade de cobre) com solda de Pt. e) Afinamento e limpeza da lâmina

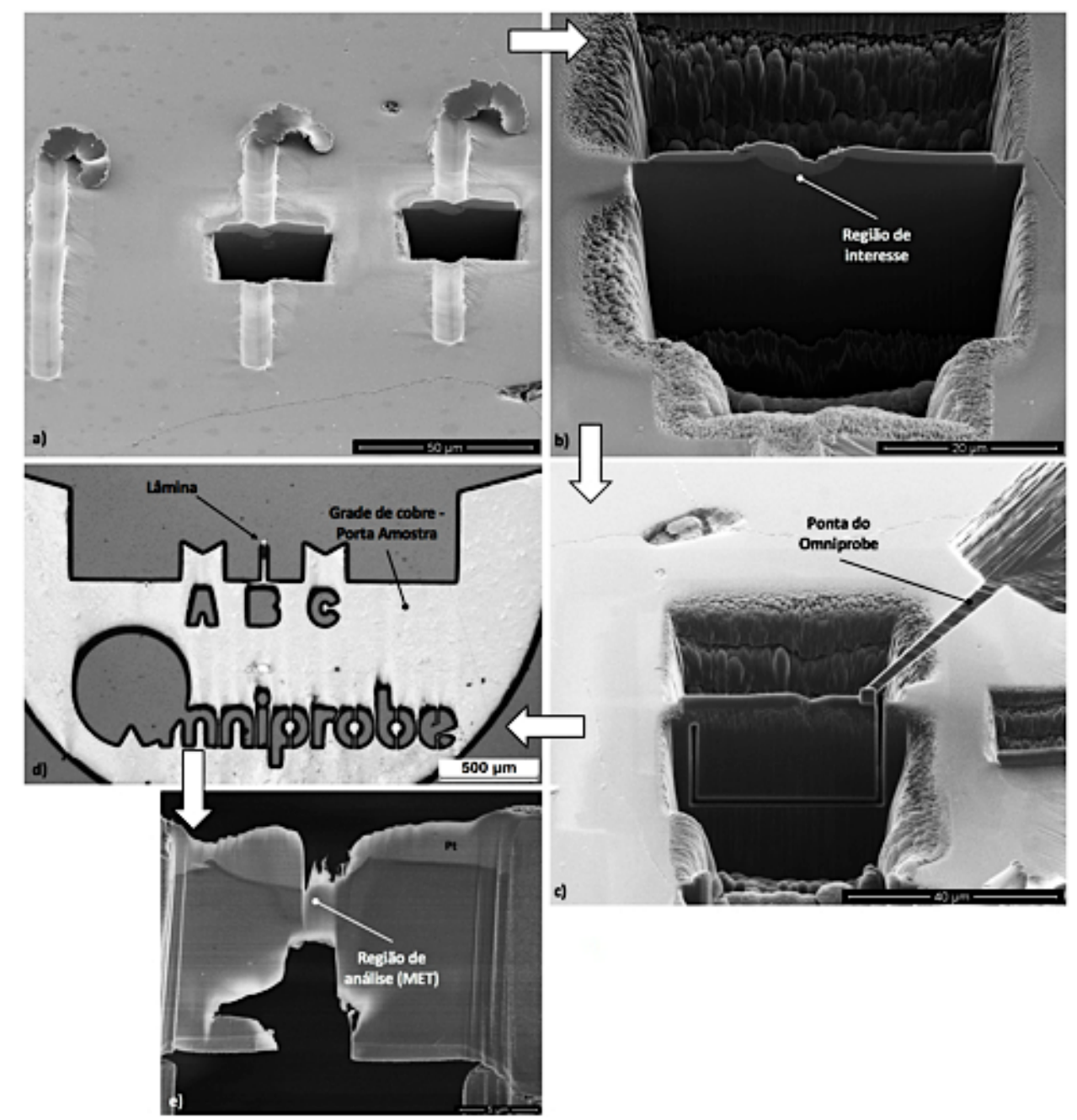

Na Figura 5.3e nota-se um buraco e um rasgo na lâmina formados pelo processo de afinamento para atingir a mais fina espessura possível na região abaixo do risco para realização da análise de MET.

\subsubsection{Caracterização microestrutural}

A caracterização da microestrutura foi realizada via microscopia eletrônica de varredura (JEOL JSM-6010LA - LFS), EBSD (FEI INSPECT 50 com câmera EDAX LabMicro), FIB (FEI QUANTA 3D FEG - IPT), DRX (X'Pert PRO Panalytical com detector X'Celerator e tubo Cu-Ka - LCT) e MET (JEOL JEM 2100 - IPEN). As análises de EBSD foram realizadas com step size de 0,04 $\mu \mathrm{m}$. A análise de difração 
de raio $X$ foi realizada com varredura ortogonal à superfície desgastada, voltagem de $40 \mathrm{kV}$, corrente de $40 \mathrm{~mA}$, intervalo de $10^{\circ}$ a $120^{\circ}$ e 20 segundos por passo $\left(2^{\circ}\right)$. A análise de FIB, com corte ortogonal, dos riscos (ensaio de microesclerometria) foram realizadas na posição de $60 \mu \mathrm{m}$ a partir do início do risco. A técnica de microscopia eletrônica de transmissão foi utilizada para análise da microestrutura da subsuperfície do risco no plano cristalográfico (111). O software Digital Micrograph (Quanta) foi utilizado para gerar as imagens de difração a partir das imagens em alta resolução obtidas via MET.

A técnica de FIB utiliza convencionalmente o feixe de íons de gálio para formação de uma cavidade, limpeza e ataque da superfície revelando a microestrutura. Além deste procedimento convencional, o feixe de íons de gálio foi utilizado na superfície de amostras com corte em ângulo agudo em relação à superfície, polidas e sem ataque químico. Os valores dos parâmetros tensão e corrente do feixe utilizados para revelar a microestrutura foram $30 \mathrm{kV}$ e $100 \mathrm{pA}$, respectivamente. Os objetivos deste procedimento, ainda não documentado na literatura científica e técnica, foram revelar a microestrutura, sem a necessidade de formação da cavidade, a partir da interação dos íons com a superfície polida do material (ion etching) em atmosfera de vácuo e adquirir imagem da microestrutura em alta resolução com feixe de íons de gálio.

Os resultados mostraram que esta metodologia é eficaz e eficiente. A ausência de oxigênio evita a oxidação da superfície, a qualidade das imagens é igual às imagens obtidas pela técnica convencional de FIB e não necessita gerar a cavidade para análise da microestrutura da subsuperfície, reduzindo o tempo de análise. A Figura 5.4 mostra uma sequência de imagens com sucessivas passagens do feixe, revelando a microestrutura do material. A microestrutura apresentada na Figura 5.4 foi obtida nesta pesquisa e será discutida mais a frente. 
Figura 5.4. Revelação e aquisição de microestrutura via FIB. a) Superfície polida. b) Ataque iônico com feixe de íons de gálio. c) Aquisição de imagem com feixe de íons de gálio

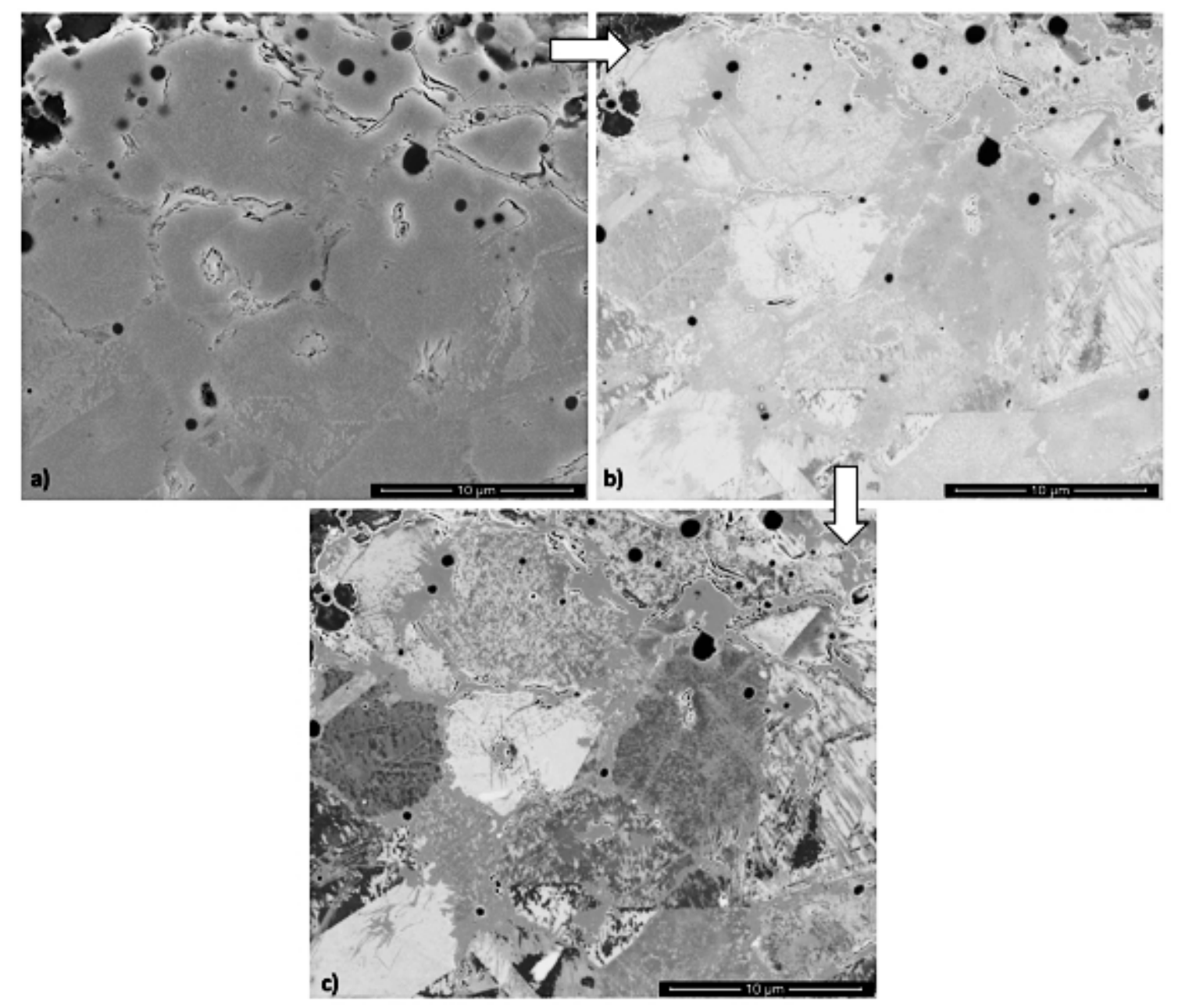

O software Imagem J foi utilizado para quantificar áreas e distâncias em imagens de FIB e para medir tamanho de grão do aço Hadfield de acordo com a metodologia de intercessão descrita na norma ASTM E112 (ASTM E112, 2014).

\subsubsection{Nanodureza instrumentada}

Os ensaios de nanodureza instrumentada na subsuperfície da amostra desgastada em campo foram realizados com o equipamento Hysitron Nanoindenter (LFS), com ponta Berkovich e força normal de $2 \mathrm{mN}$. Os resultados de nanodureza foram obtidos a partir do modelo de Oliver Pharr (OLIVER; PHARR, 1992). 


\subsection{RESULTADOS E DISCUSSÕES}

\subsubsection{Superfície de desgaste e microestrutura da subsuperfície do revestimento de britador cônico}

Na superfície da amostra retirada do revestimento de britador giratório, Figura 5.5, observa-se que os micromecanismos de desgastes responsáveis pela alteração são o microcorte, microsulcamento e microendentações. As imagens obtidas via MEV mostram os detalhes da superfície desgastada nos aumentos de 200X, 600X, 1.000X e 1800X. Os quadros sobescritos nas imagens destacam a área de análise da próxima imagem de maior aumento.

A Figura 5.5a mostra região com deformação plástica, caracterizada pelos mecanismos de microsulcamento e microcorte, os quais formam bordas e dobras na superfície. Na Figura $5.5 b$ é possível diferenciar com maios clareza, a partir da imagem gerada com detector de elétrons retroespalhados, as regiões com deformação e remoção de material (área clara) das que sofreram deformação por endentações, as quais têm material do abrasivo encrustado na superfície (área escura). Na Figura 5.5c nota-se partículas de desgaste geradas pelo microcorte, bordas nas laterais dos riscos, textura anisotrópica formada pelos riscos, microendentações e uma linha irregular (seta), esta linha é uma evidência de dobra ou trinca. Nas Figuras $5.5 d$ e $5.5 e$ observam-se em maior aumento, $1.000 \mathrm{X}$ e $1.800 \mathrm{X}$, respectivamente, as áreas indicadas com um quadro. 
Figura 5.5. Superfície desgastada do revestimento de britador cônico. a) 200X. b) 600X. c)1.000X. d) $1.800 \mathrm{X}$

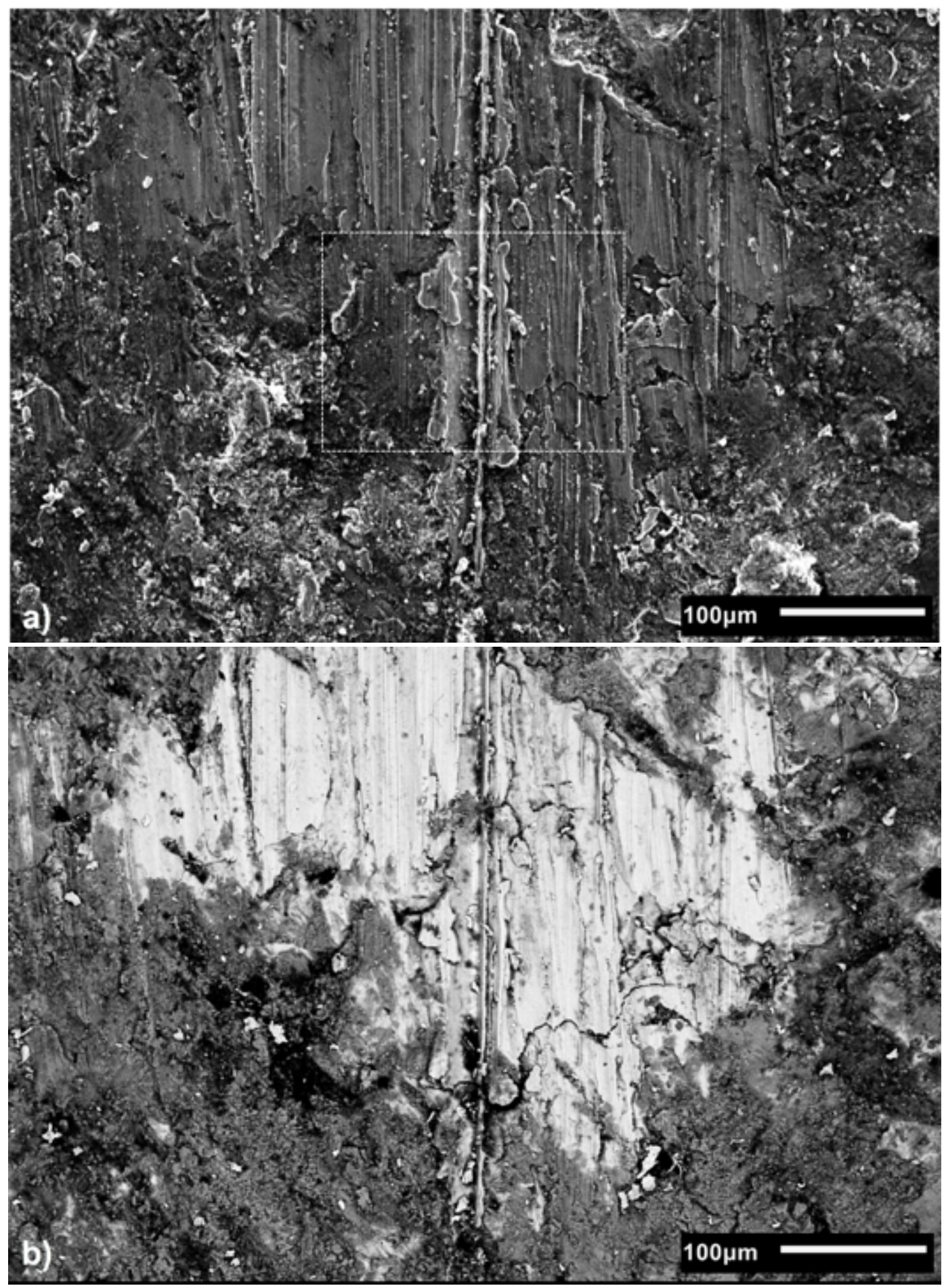




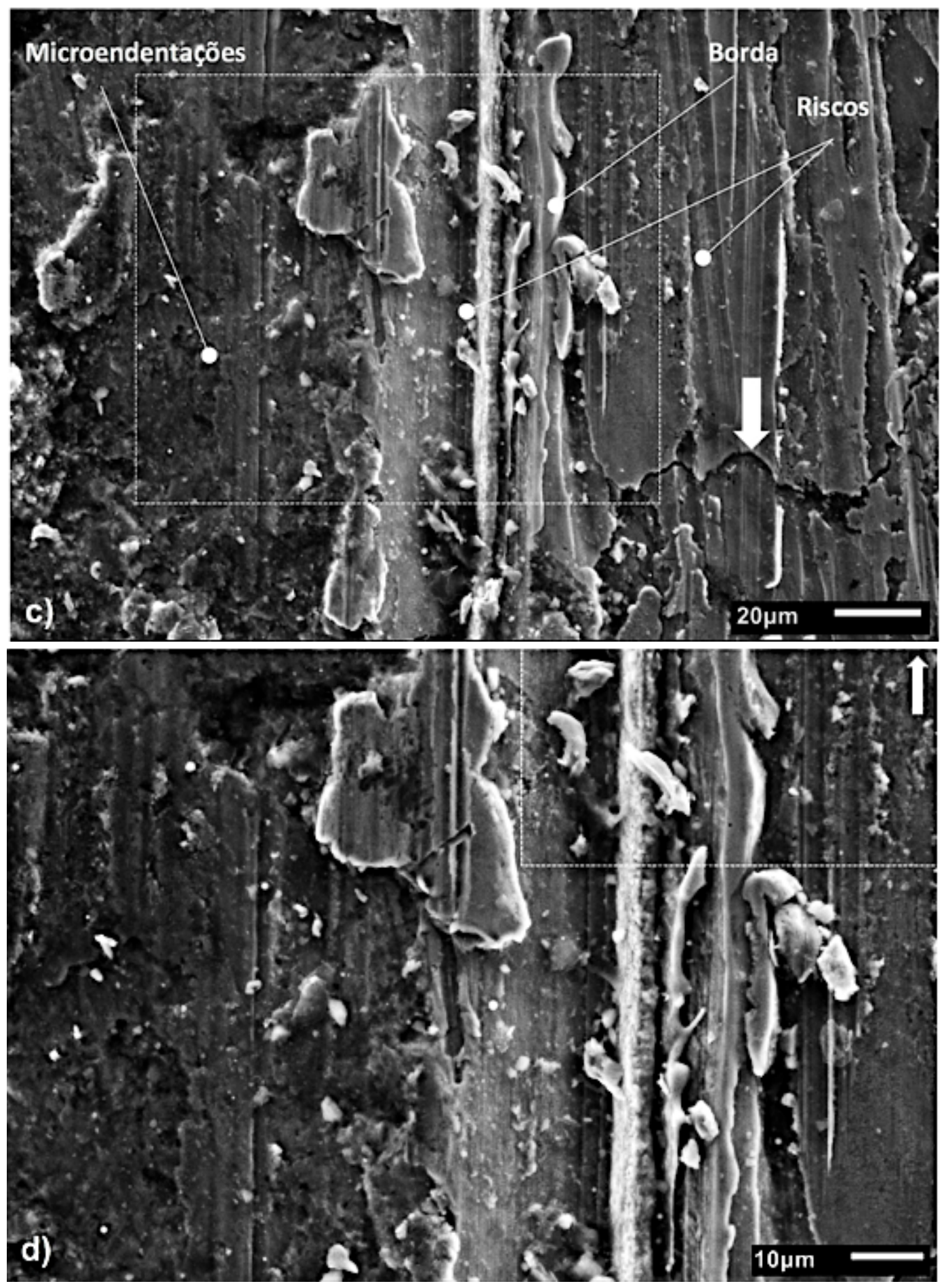




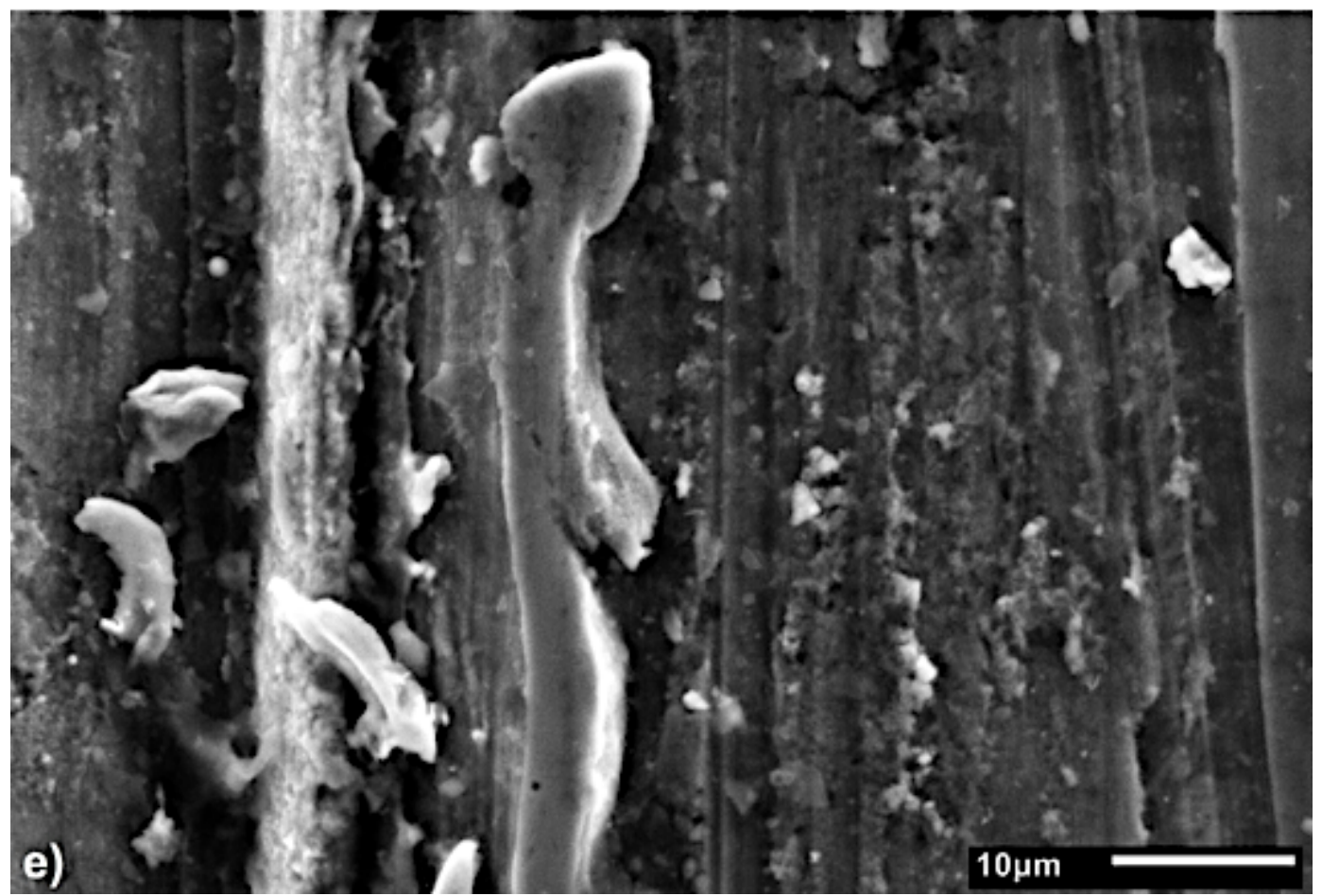

A micrografia da subsuperfície do aço Hadfield desgastado com corte em $45^{\circ}$, Figura 5.6a, mostra grãos de austenita e carboneto intergranular. A orientação do corte desta amostra é paralela a direção do desgaste superficial.

O tamanho de grão na região mais distante da superfície foi estimado em $275 \pm 14 \mu \mathrm{m}$. No interior dos grãos observa-se uma microestrutura deformada com maclas de deformação, bandas de escorregamento, trincas intergranulares e dobra de material deformado na superfície. A Figura 5.6b mostra um grão em processo de destacamento com trincas intergranulares. (LINDROOS et al., 2015a) mostraram trincas em contorno de grão em estágio inicial para o aço Hadfield desgastado em serviço. Segundo os autores as trincas são um dos mecanismos de falha da superfície, no entanto, eles não mostraram o estágio mais avançado deste mecanismo (trinca intergranular envolvendo um grão) como pode ser visto nas Figuras 5.6a e 5.6b. Feng et al. mostraram que as trincas de fadiga de contato de rolamento em aço Hadfield aplicado em sistemas de mudança de via ferroviária (jacaré - crossing) são paralelas à superfície a uma distância de 1,5 mm (FENG et al., 2013a), diferentemente das trincas intergranulares observadas nos revestimentos de britadores. Os autores descreveram que o mecanismo de dano inicia com o aumento da densidade de lacunas formando microporos que evoluem para trincas paralelas à superfície, as quais propagam-se para a superfície formando lascas (spalling). Na Figura 5.6c é mostrado o material deformado em formato de 
onda, nota-se que a microestrutura no interior da onda é diferente do material deformado da subsuperfície.

Figura 5.6. a) Microestrutura da subsuperfície de desgaste (corte em $45^{\circ}$ ), 50X. b) Trinca intergranular, 400X. c) Onda de aço Hadfield formada pelo processo de abrasão, 250X. d) Micrografia da área em destaque na Figura a, 100X

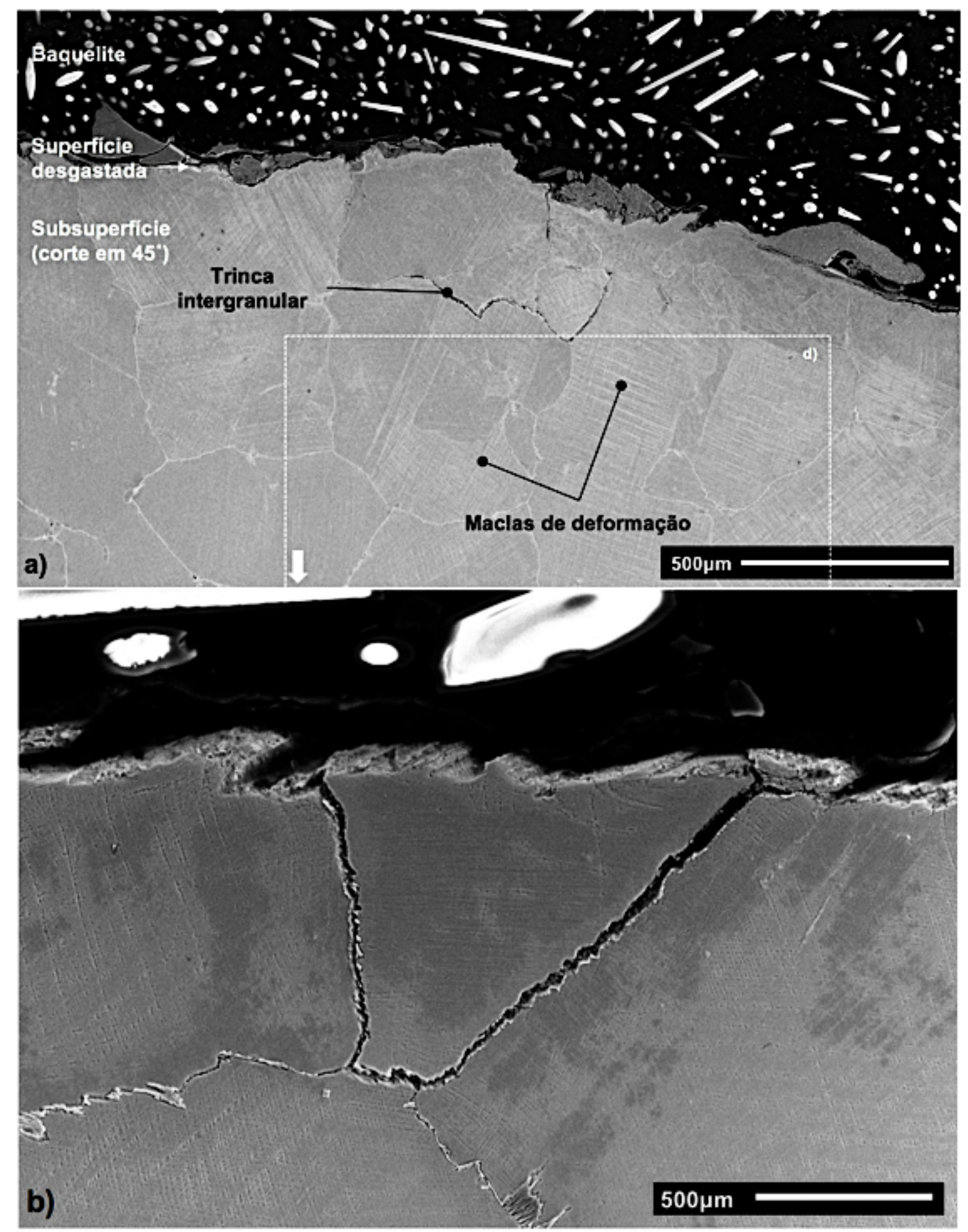



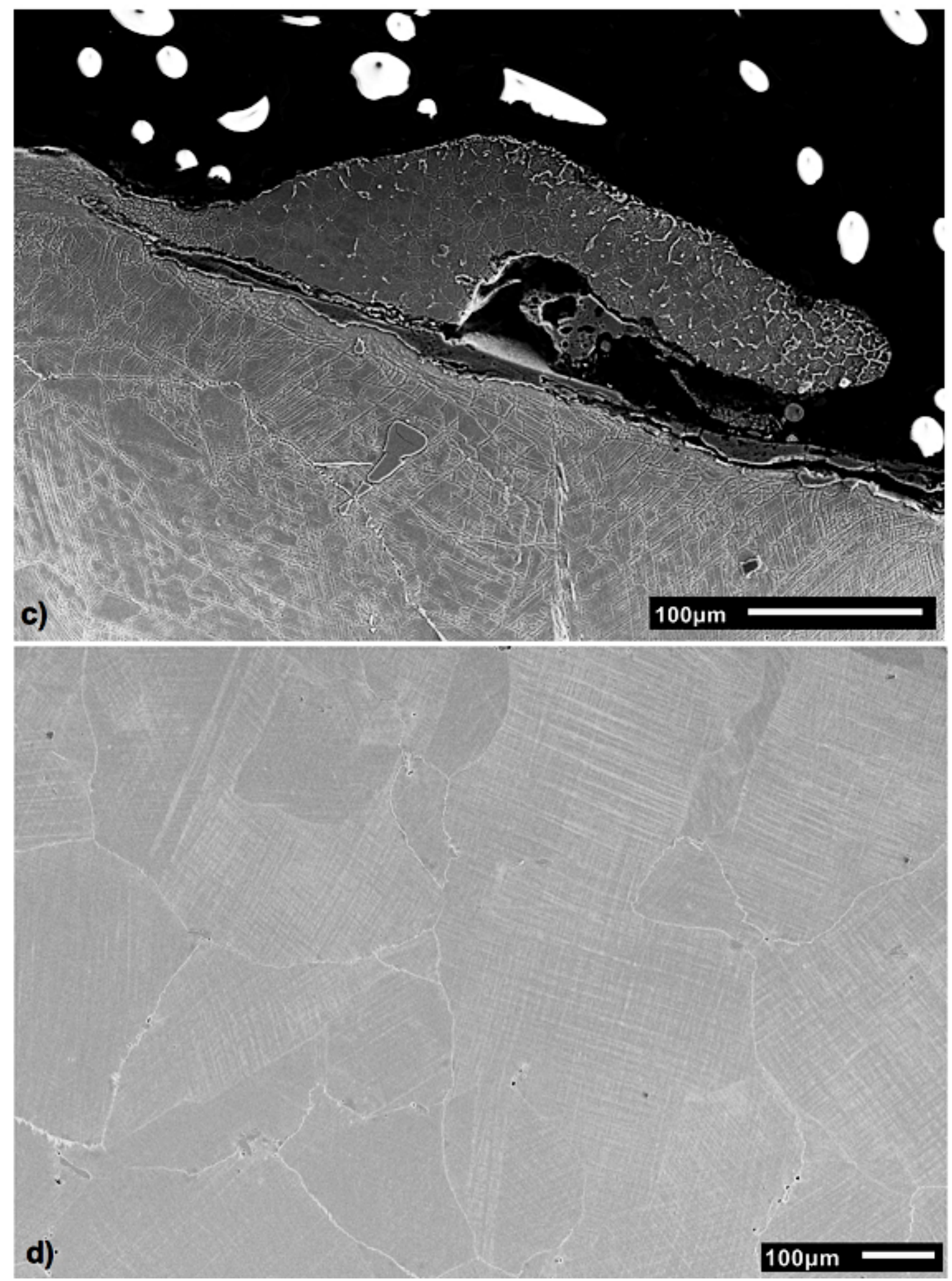

As micrografias da Figura 5.6 mostram que a forma equiaxial do grão original do aço Hadfield e a disposição dos carbonetos ao longo dos contornos em sua maioria não são alteradas pelo processo de deformação plástica causado pelo desgaste. Somente na região próxima à interface de desgaste nota-se um comportamento diferente, com dobramento do material. O mecanismo de deformação plástica 
predominante trata-se da maclação mecânica, como é característica de materiais metálicos de baixa energia de falha de empilhamento, apesar de ser um metal com estrutura CFC (MEYERS; CHAWLA, 1998). Contudo, existe uma grande diferença da microestrutura deformada de materiais metálicos que tem o deslizamento de planos cristalinos como mecanismo de deformação plástica predominante, como mostrado por Moore e Douthwaite no artigo Plastic deformation below worn surfaces (MOORE; DOUTHWAITE, 1976). Os autores fizeram amostras metálicas com laminas de cobre e solda de prata, assim, conferindo às amostras uma microestrutura lamelar padronizada, na qual favoreceu a análise via microscopia óptica da subsuperfície deformada por ação do desgaste abrasivo via teste de pino $\mathrm{x}$ lixa. A Figura 5.7 mostra a seção transversal da amostra deformada, nota-se que as lâminas curvaram na direção do desgaste e os grãos desta região sofreram alongamento na mesma direção, diferentemente do comportamento do aço Hadfield mostrado nesta pesquisa. Como observado existe deslocamento de material na direção do desgaste (onda), no entanto, a microestrutura deformada na subsuperfície (por exemplo: abaixo da onda) não acompanha esta direção.

Figura 5.7. Micrografia abaixo da superfície desgastada (corte transversal) no ensaio pino $\mathrm{x}$ lixa.

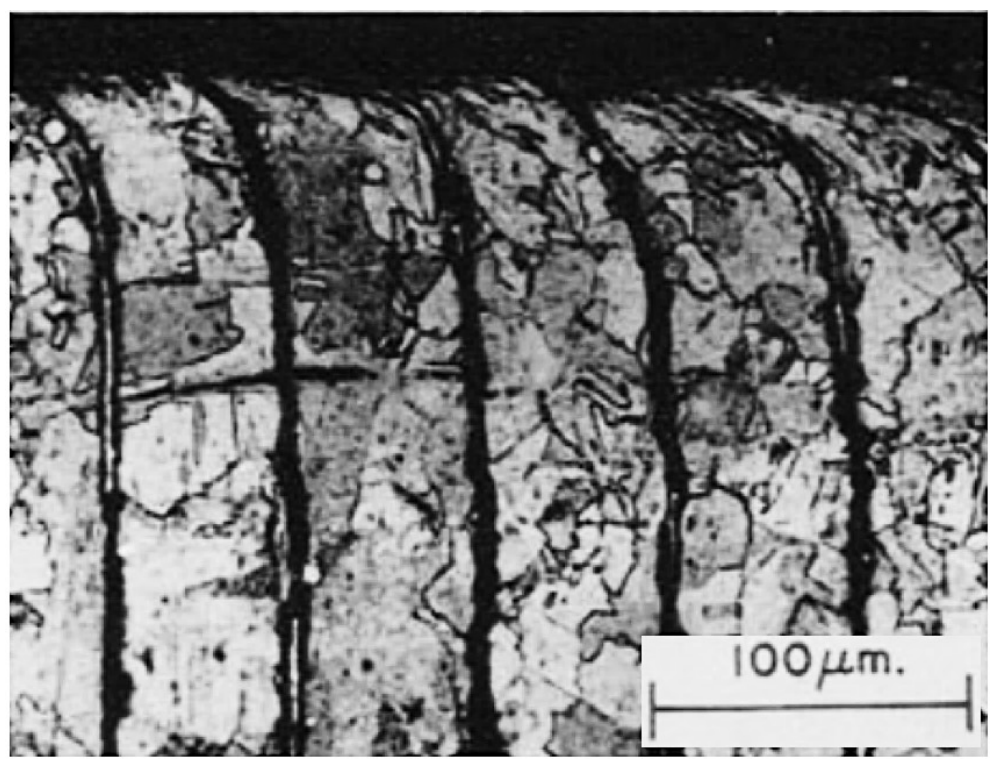

Fonte: Moore e Douthwaite, 1976

Pereira et al. mostrou a microestrutura da subsuperfície do revestimento de moinho semiautógeno desgastado em operação de campo (PEREIRA et al., 2017). Observase na Figura 5.8 que a microestrutura, assim como mostrado por Moore e 
Douthwaite (MOORE; DOUTHWAITE, 1976), curva de acordo com a direção da deformação promovida pelo fenômeno de desgaste.

Figura 5.8. Microestrutura da subsuperfície deformada de revestimento de moinho SAG. Corte ortogonal. MO. 100X

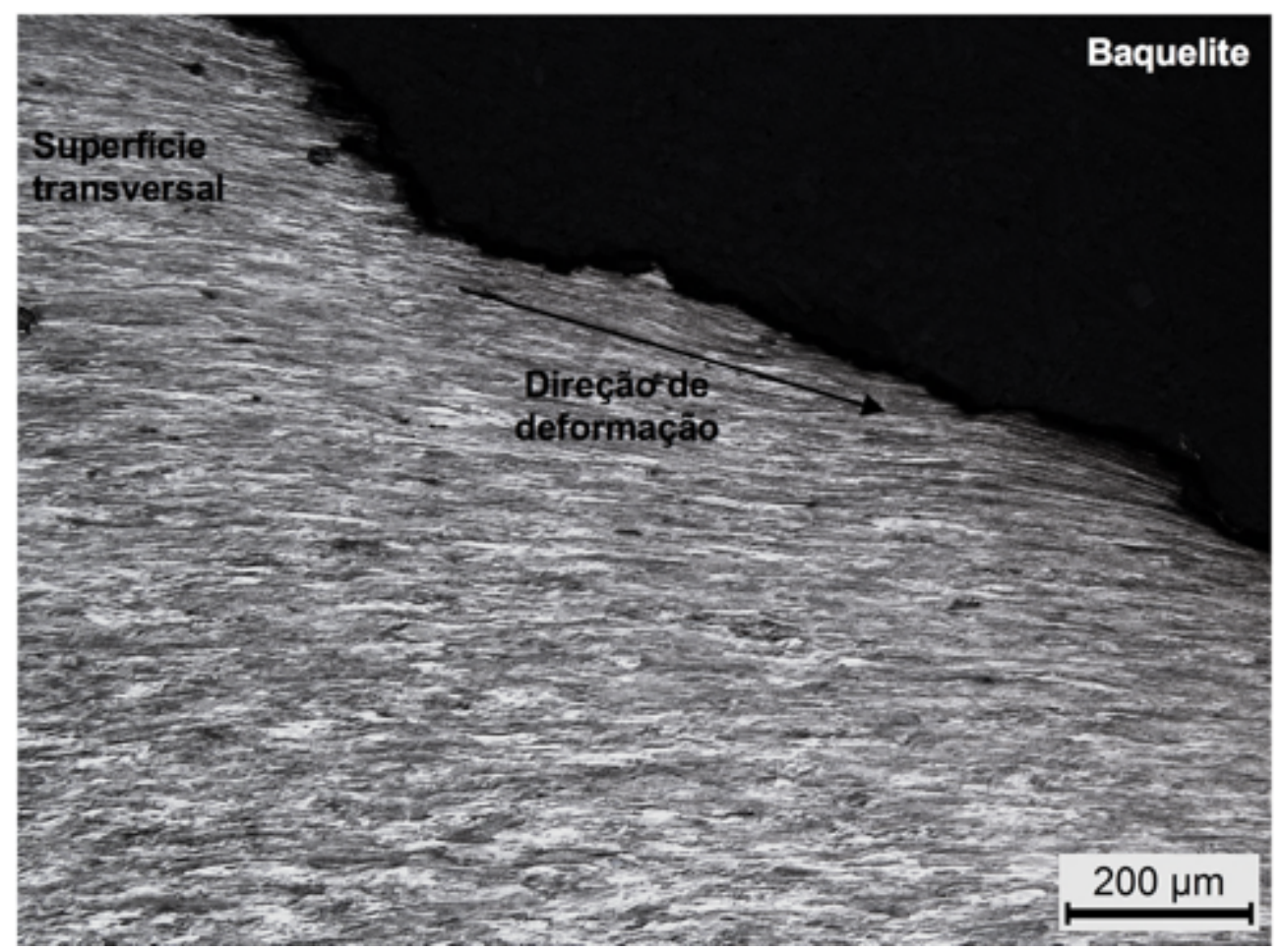

Fonte: Pereira et al., 2017

A Figura 5.9 mostra trincas transgranulares na subsuperfície. Observa-se na Figura $5.9 b$ (setas) que a nucleação de trincas ocorre na superfície. Na Figura 5.9c nota-se uma trifurcação da trinca transgranular (seta branca) e trinca transgranular paralela à superfície, semelhante às trincas observadas por Feng et al. (FENG et al., 2013a) na subsuperfície de "jacarés" de aço Hadfield. O mecanismo de dano da superfície de revestimento de britador mostrado nesta pesquisa pode ser descrito conforme as seguintes etapas: nucleação superficial de trincas intergranulares ou transgranulares, propagação de trincas e destacamento de grão ou lascamento de material. 
Figura 5.9. Imagens de MEV-SE (cross section). a) Trincas transgranulares, 100X. b) Local de nucleação da trinca e novos pontos de nucleação de trincas (setas), 1.500X. c) Trifurcação de trinca transgranular, $500 \mathrm{X}$

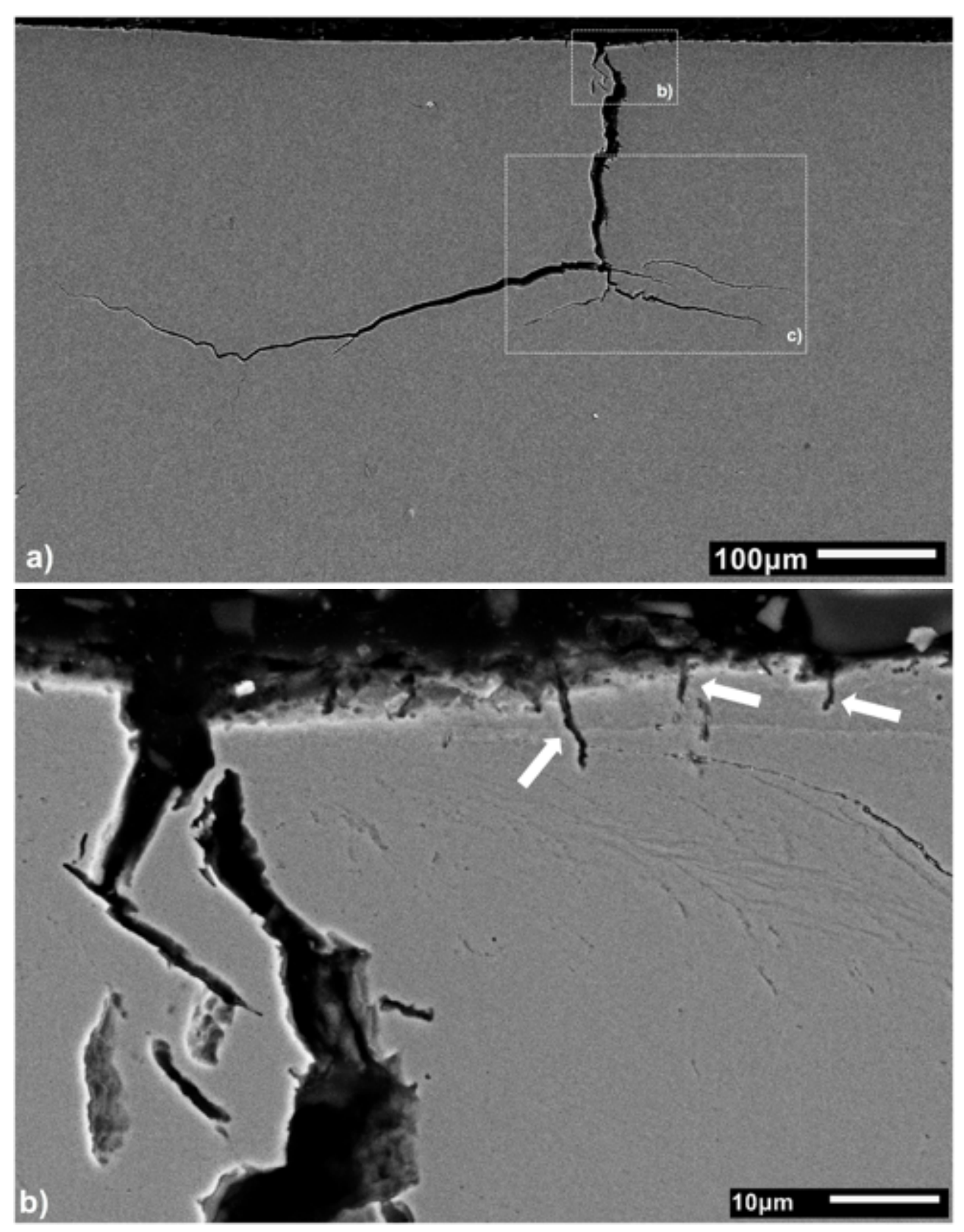




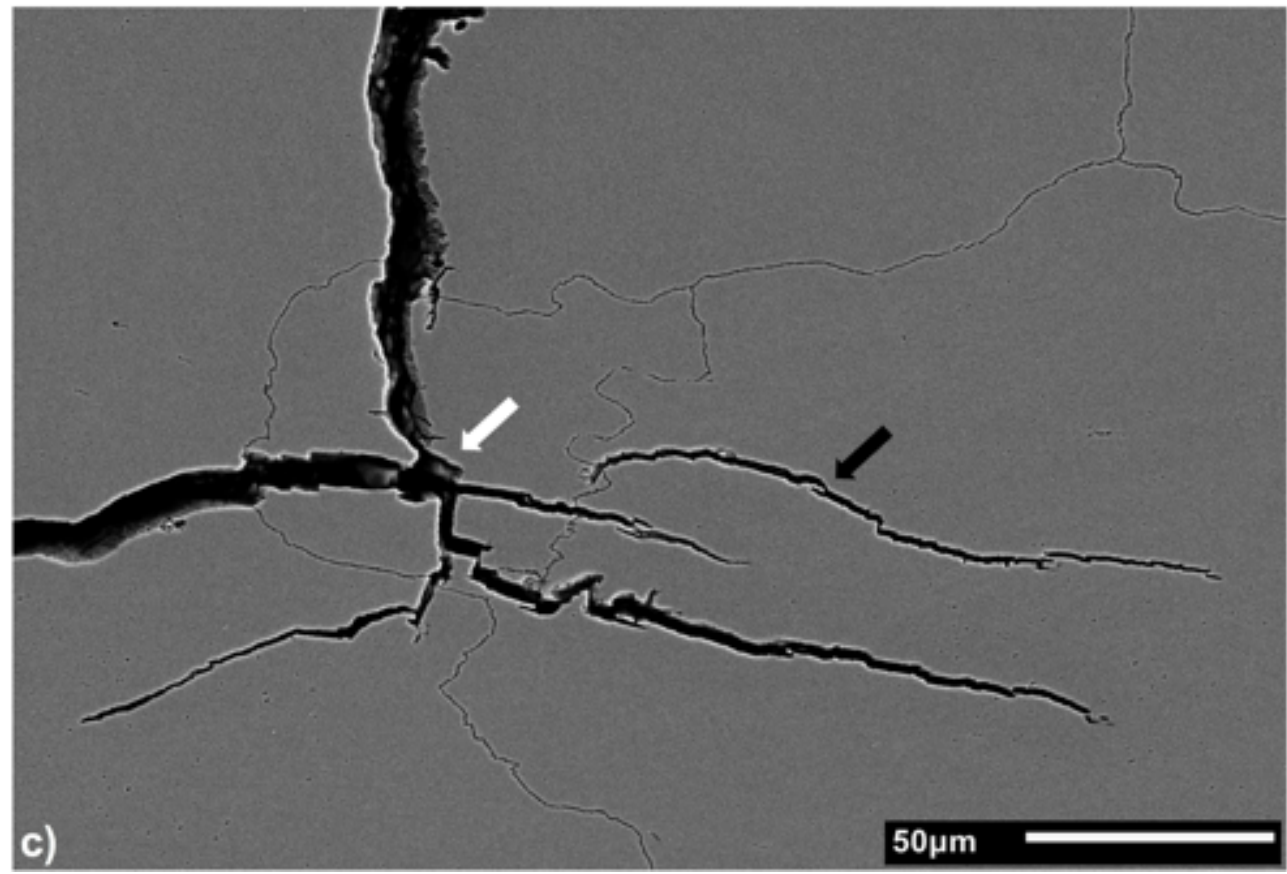

Com esta caracterização da subsuperfície deformada na escala macro observou-se que a subsuperfície divide-se em duas camadas com características particulares. A Figura 5.10 mostra a divisão das camadas.

Figura 5.10. Divisão das camadas 1 e 2 na subsuperfície deformada na escala macro (campo)

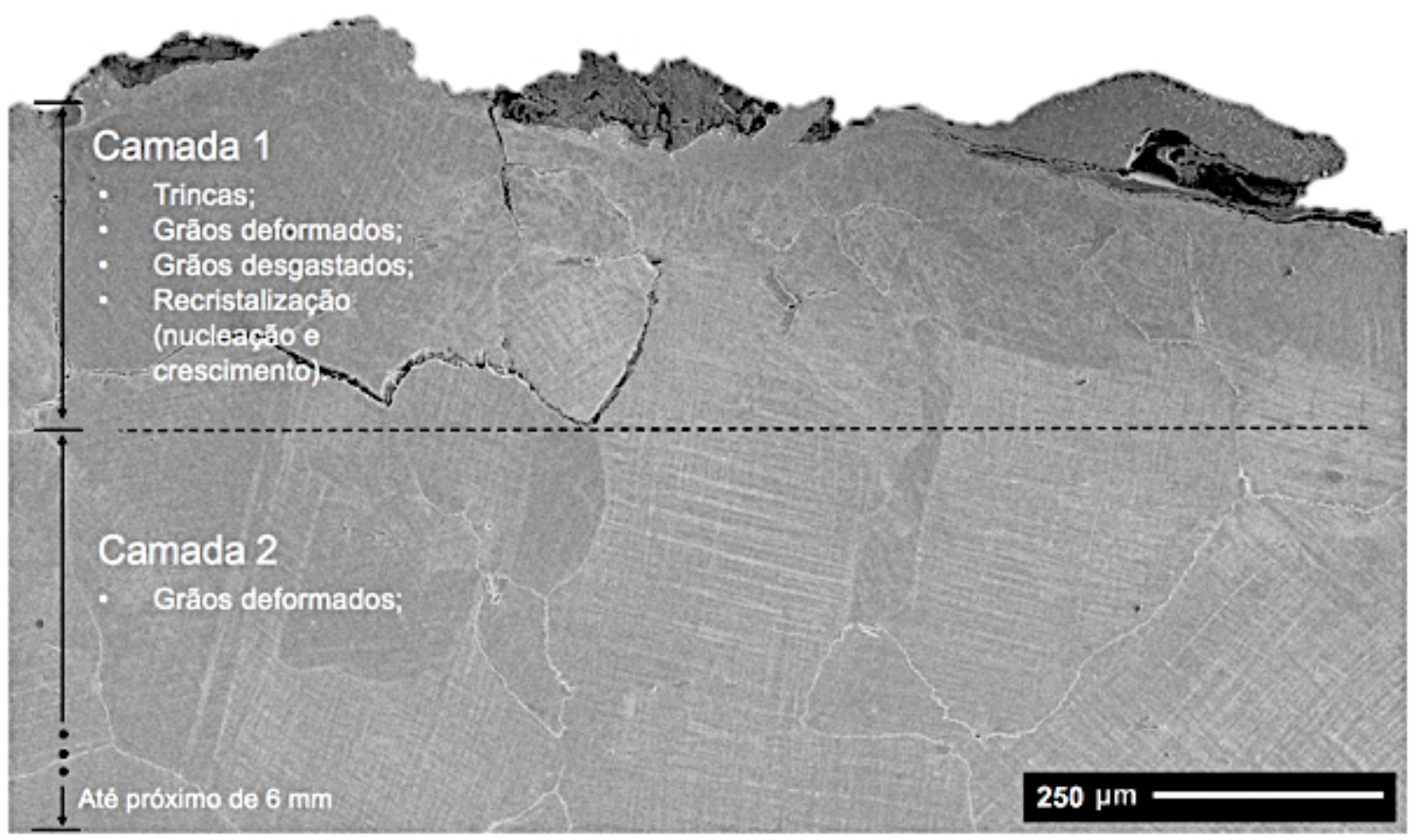


A camada 1 consiste na primeira fileira de grãos deformados equiaxiais, com uma superfície desgastada (interface abrasivo/material ou corpo/contra/corpo), a qual reduz o nível de restrições mecânicas, favorecendo a movimentação ou arrancamento do grão. Nesta camada observam-se trincas transgranular e intergranulares; grãos originais deformados com maclas mecânicas, grãos desgastados; e recristalização com crescimento de grão. Na camada 2, que se estende ao longo do perfil de encruamento até aproximadamente $6 \mathrm{~mm}$ de espessura, observam-se apenas os grãos equiaxiais (geometria original) deformados com diferentes intensidades de maclação mecânica.

Feng et al. mostraram a evolução da microestrutura na subsuperfície do aço Hadfield deformado por ultrasonic shot peening (FENG et al., 2013b), Figura 5.11. Nota-se que com o aumento do tempo de tratamento (USP), responsável pela deformação severa, tem-se a formação de maclas de deformação e bandas de escorregamento no interior dos grãos com 60 minutos, os quais são gradualmente substituídas por uma microestrutura sem evidências dos contornos de grãos originais e com bandas de escorregamento irregulares.

Figura 5.11. Micrografias ópticas da seção transversal do aço Hadfield sem deformação (a), com 60 minutos de deformação via USP e (b) com 240 minutos de deformação
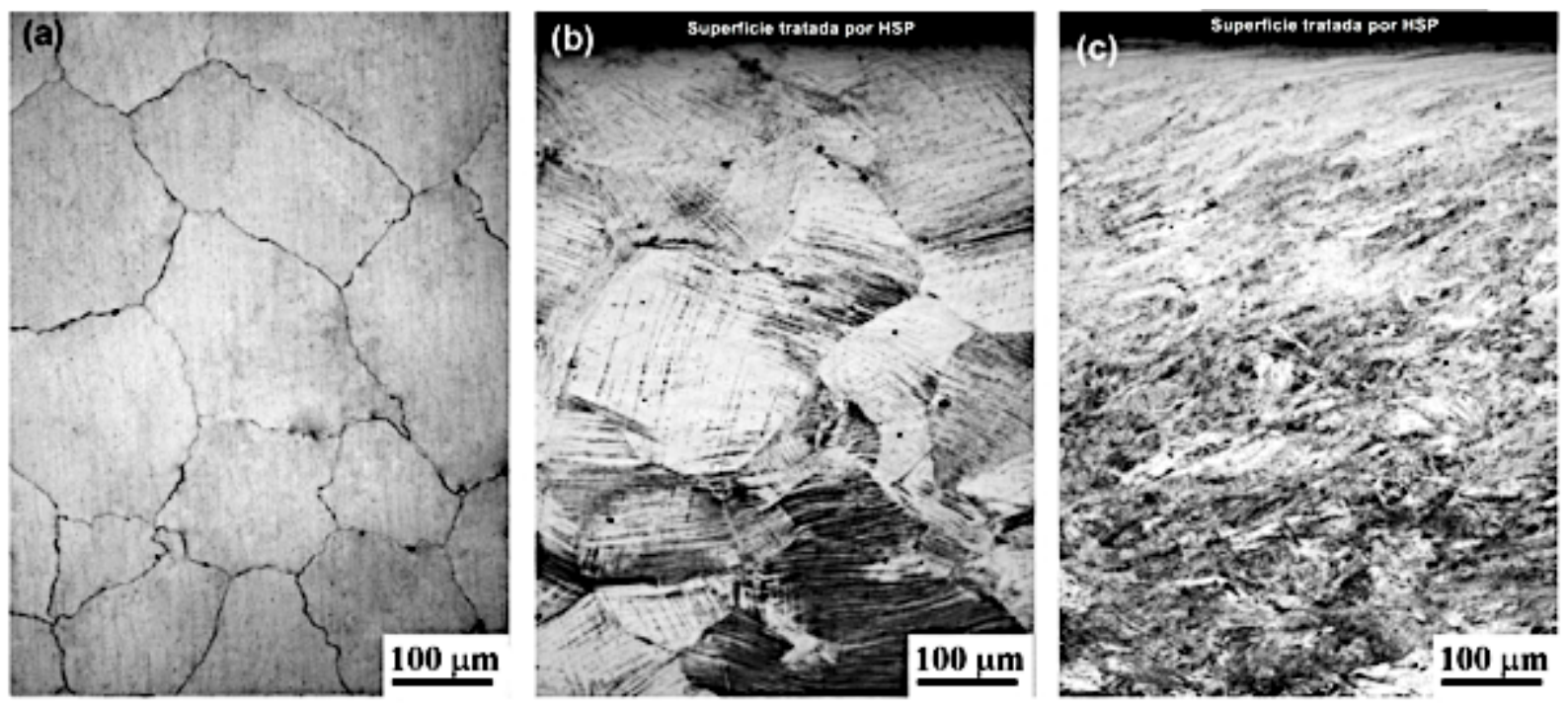

Fonte: Feng et al., 2013b

A Figura 5.12 mostra em maior detalhe a micrografia da onda. O material no interior da onda tem grãos equiaxiais e de menor tamanho que os grãos deformados da região subsuperficial. Nota-se que a onda está ligada à superfície deformada indicada pelo ponto 1 . 


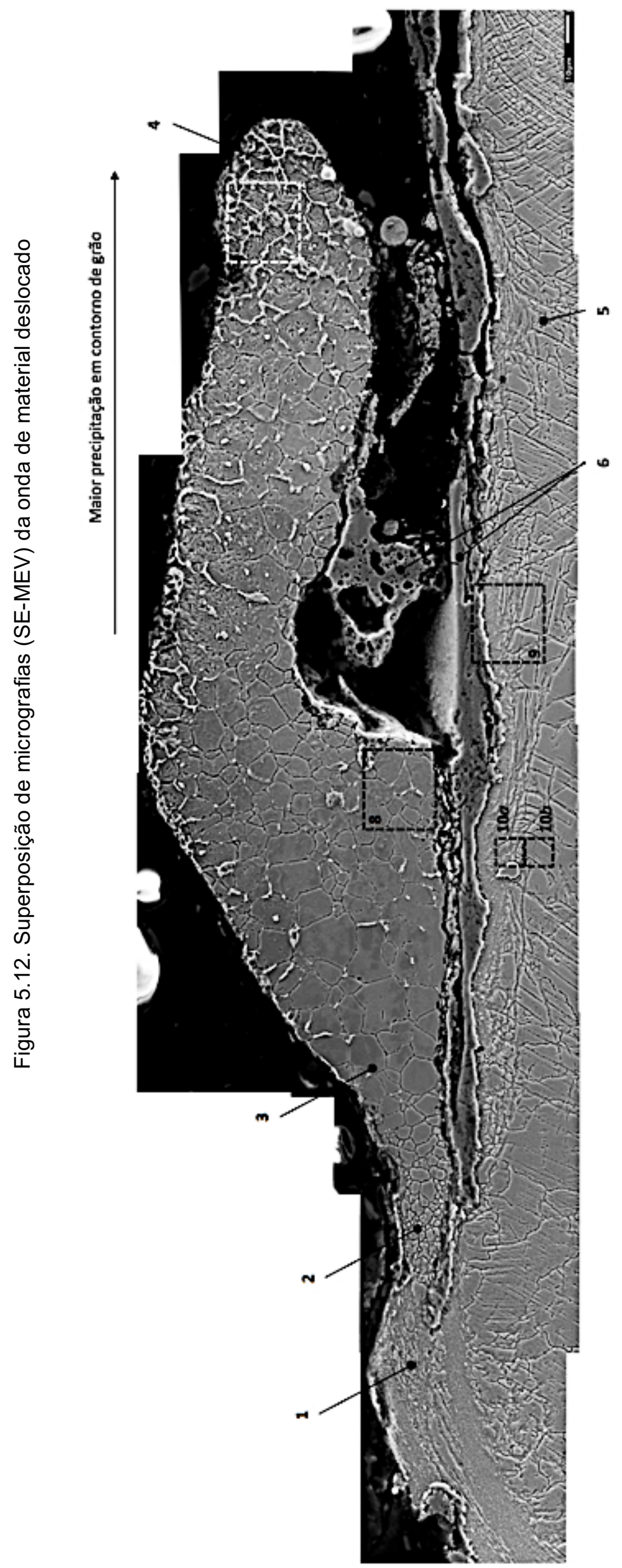


A região indicada pelo ponto 1 tem microestrutura que dá continuidade à estrutura deformada da superfície de trabalho. Nesta região nota-se que a microestrutura é indefinida, sem maclas de deformação ou grãos pequenos. No ponto 2 indica a microestrutura tem predominância de grãos pequenos e sucessivamente maiores a medida em que a distância do material base aumenta. Estes grãos são menores que os da região indicada pelo número 3. Na região indicada pelo ponto 4 (Figura 5.12), se observa maior concentração de precipitados em contorno de grão que a região do ponto 3 . O ponto 5 indica uma região da subsuperfície, como observado na Figura 5.6a. Os dois pontos indicados pelo número 6 indicam a existência de material diferente do aço Hadfield abaixo da onda. De acordo com o resultado da técnica de EDS, mapa de elementos, (Figura 5.13) o material indicado pelo número 6 tem significativa concentração de ferro, oxigênio e silício, podendo tratar-se de óxido de ferro (minério).

Figura 5.13. Mapa de elementos da área com a onda de material deslocado

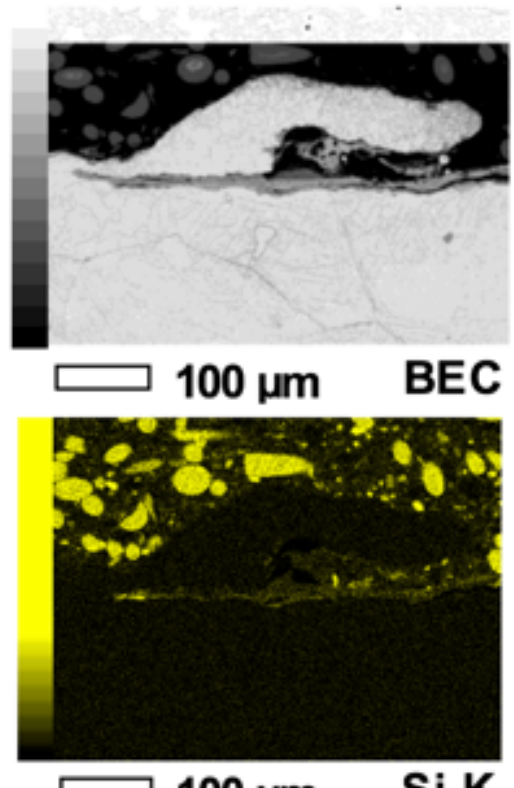

$100 \mu \mathrm{m}$

Si K

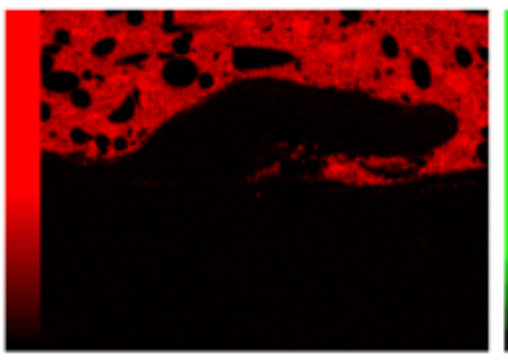

$0.2 \mathrm{mmC} \mathrm{K}$

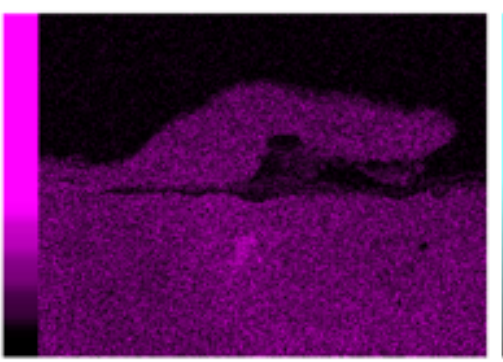

$100 \mu \mathrm{m}$

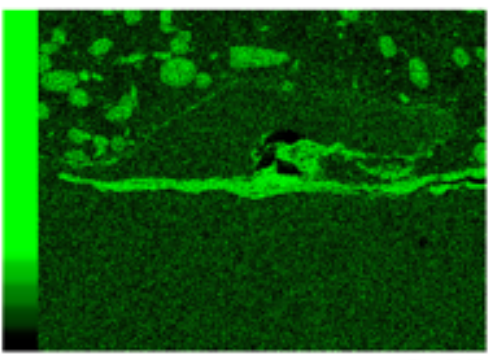

$0.2 \mathrm{mmO} \mathrm{K}$

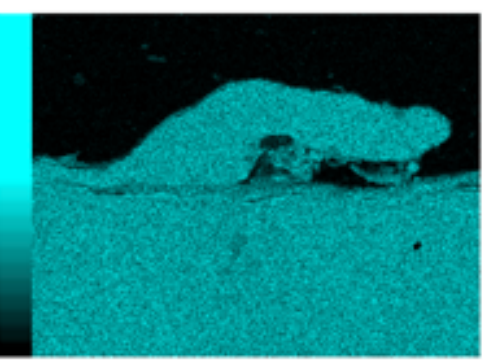

$100 \mu \mathrm{m} \quad \mathrm{Fe} \mathrm{K}$

As áreas dos quadros 7 e 8 na Figura 5.12 são de regiões específicas da onda: ponta e base, respectivamente. Essas áreas foram selecionadas por representarem regiões com características microestruturais distintas observadas ao longo da onda. A técnica de observação aplicada nas áreas foi a de ataque com íons de gálio via FIB. A Figura 5.14a e $b$ mostram as microestruturas das áreas indicadas pelos quadros 7 e 8 , respectivamente. 
Figura 5.14. Micrografias obtida via FIB de regiões da Figura 5.12. a) Quadro 7. b) Quadro 8
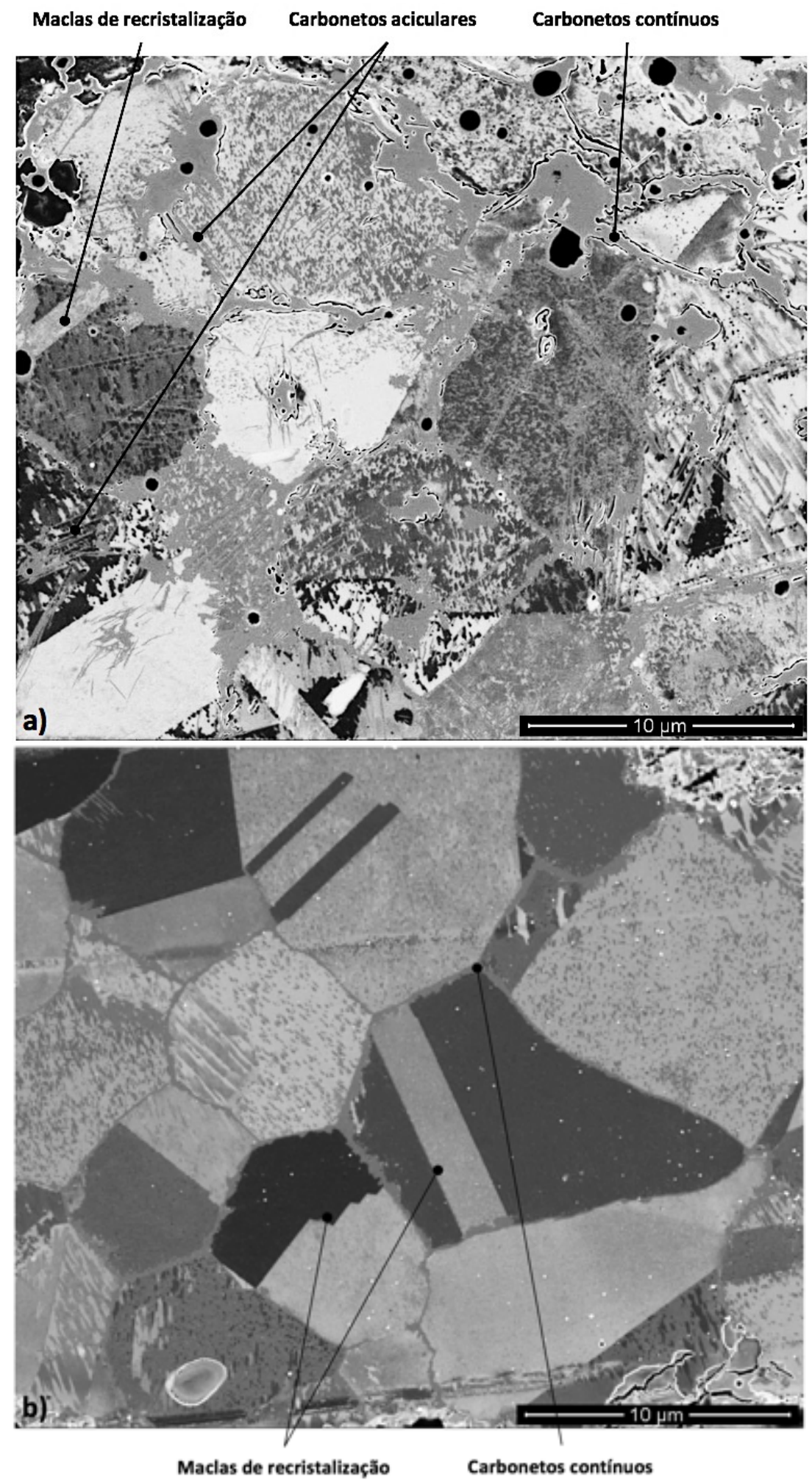

A micrografia na Figura 5.14a corresponde a ponta da onda, área 7 (Figura 5.12), tem microconstituintes semelhante à microestrutura do aço Hadfield como bruto de fundição com carbonetos aciculares, maclas de recozimento e carbonetos contínuos em contorno de grão (KUYUCAK; ZAVADIL; NEWCOMBE. P., 2001c). Neste caso, 
pode-se considerar que a temperatura na ponta da onda atingiu valores próximos ao de fusão do material. A micrografia da Figura 5.14b, referente à área 8 da Figura 5.12 (base da onda). Ao comparar as Figuras 5.14a e 5.14b, notam-se as diferenças entre as microestruturas das duas regiões da onda.

A distribuição da microestrutura na onda de material deslocado pode ser associada à diferentes níveis de temperatura/deformação (energia) atingida pelas regiões da base e da ponta da onda. Como visto na região da base existe uma variação de tamanho de grão, o qual é crescente em direção à ponta. Após a estabilização do tamanho de grão nota-se alteração da microestrutura como observado Figuras 5.14a e 5.14b. Na ponta da onda a microestrutura tem os mesmos microconstituintes de um aço Hadfield como no estado bruto de fundição (Figura 2.6), diferentemente da base. Ou seja, a energia atingida pela ponta da onda possibilitou a alteração microestrutural equivalente, por exemplo, à um tratamento isotérmico a $550^{\circ} \mathrm{C}$ por mais de $10^{3} \mathrm{~s}$, de acordo com diagrama de transformação isotérmico para aço Hadfield mostrado na Figura 2.8 (TSUJIMOTO, 1979), ou à fusão do material. A mesma relação pode ser feita para a região da base, na qual o tempo necessário para formar os carbonetos contínuos em contorno de grão equivaleria à $10^{2}$ segundos, considerando que os fenômenos ocorridos foram a recristalização dinâmica e crescimento de grão.

A Figura 5.15 mostra a microestrutura da subsuperfície desgastada, quadro 9 (Figura 5.12), obtida via FIB. Nota-se uma camada de óxido na parte superior, abaixo dessa camada a microestrutura consiste em uma camada de grãos ultrafinos (UFG) e grãos originais deformados (GD) com aparente descontinuidade, nota-se estas descontinuidades nas maclas de recozimento provenientes do processo de solidificação e tratamento térmico do material. Outra evidência é que as descontinuidades são formadas pela ação de nucleação de grãos ultrafinos, os quais aparentam envolver os fragmentos dos grãos originais deformados, como indicado na Figura 5.15. Com isto, a camada 1 da microestrutura do aço Hadfield deformado, mostrada na Figura 5.10, tem uma subcamada com grãos ultrafinos e outra, subsequente, de transição, com grãos originais deformados, fragmentados e envolvidos por grãos ultrafinos. 
Figura 5.15. Microestrutura da subsuperfície (quadro 9 na Figura 5.12)

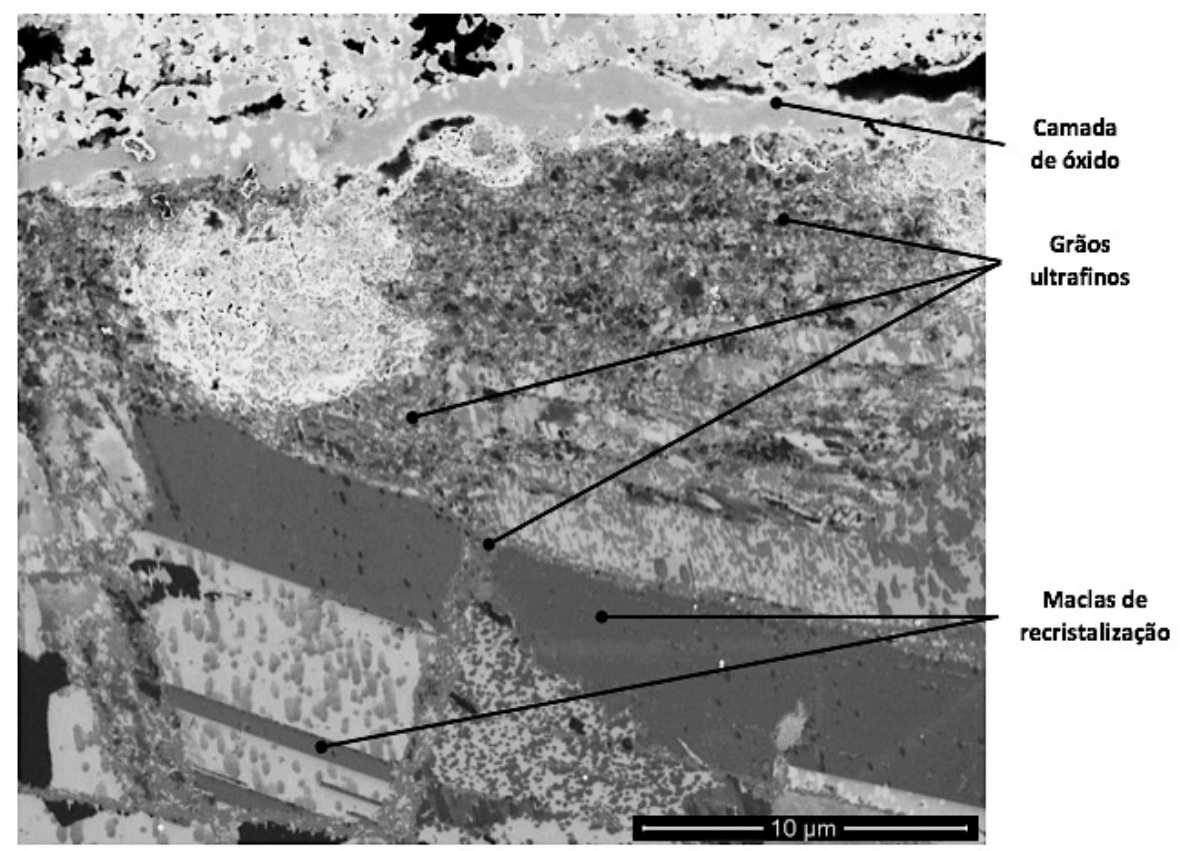

Estes resultados mostram que além da diferença entre as microestruturas da subsuperfície desgastada e da onda, existem diferenças nas microestruturas ao longo da onda. Esta diferença pode ser associada a diferentes níveis de energia absorvidos ao longo da onda de material deslocado. As características microestruturais indicadas são evidências de recristalização e de crescimento de grão.

Nas áreas indicadas pelos quadros $10 a$ e $10 b$ na Figura 5.12, onde a microestrutura se assemelha à mostrada na Figura 5.15 com grãos ultrafinos e grãos originais deformados, foram realizados ensaios de nanoendentação para avaliar a diferença de propriedade mecânica entre os pontos com grãos ultrafinos e com grão original deformado. A Figura 5.16a mostra as endentações na área do quadro 10a, nota-se que nos pontos mais claros, local com grãos ultrafinos, as endentações são menores, indicando maior dureza. A dureza média destes pontos foi de 7,4 \pm 0,2 GPa. A região mais escura corresponde aos grãos deformados originais do aço Hadfield, tiveram um valor médio de 5,8 $\pm 0,3 \mathrm{GPa}$. A diferença entre as duas regiões nesta área foi de $22 \%$. 
Figura 5.16. a) Nanoendentações na área 10a indicada na Figura 5.12. b) Gráfico de carregamento e descarregamento dos pontos indicados na Figura a
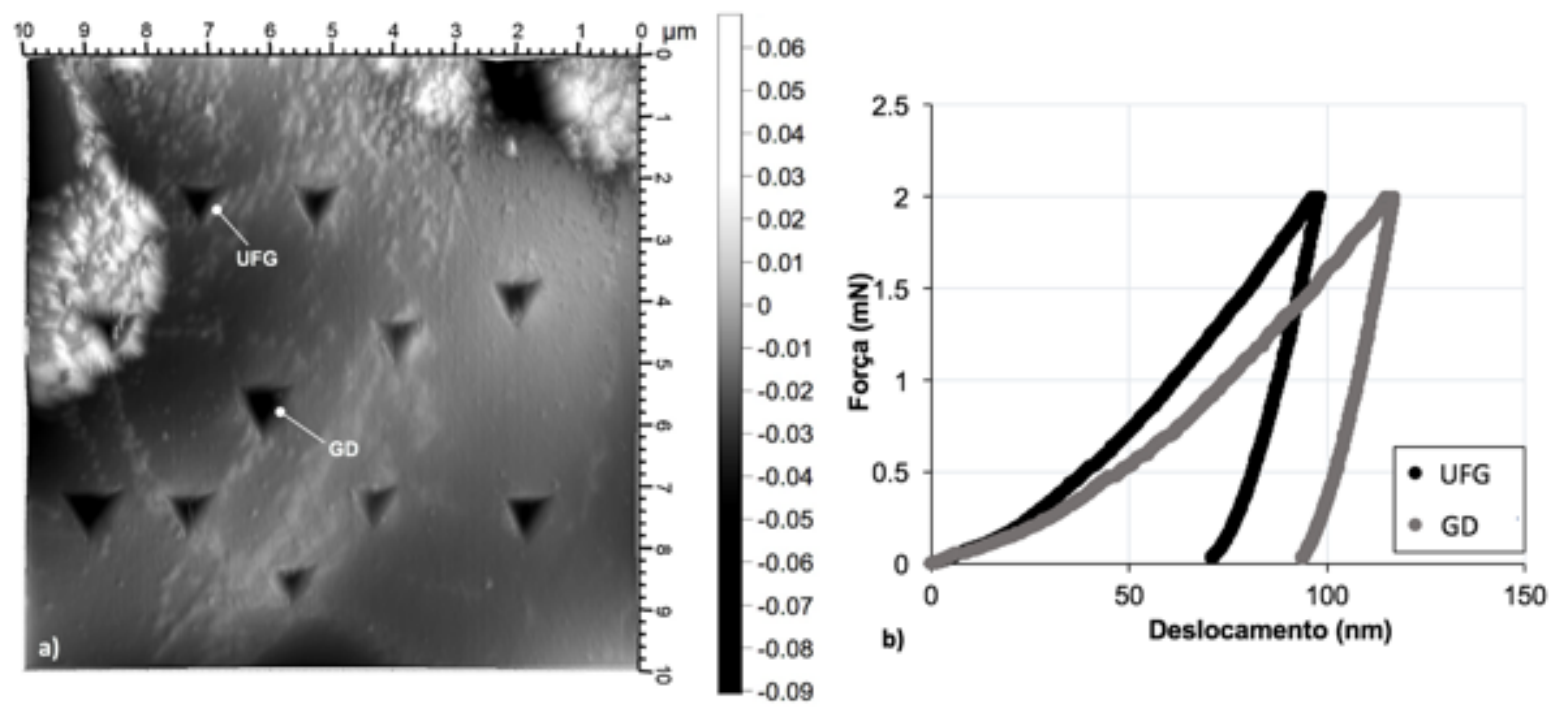

As endentações na área do quadro $10 b$ logo abaixo da área do quadro $10 a$, como indicado na Figura 5.12 são mostradas na Figura 5.17a. As curvas de carregamento e descarregamento para os pontos com microestrutura formada por UFG e por GD, indicados na Figura 5.17a, são mostradas no gráfico da Figura 5.17b. O valor médio para a região com grãos ultrafinos (clara) foi de 7,7 $\pm 0,5 \mathrm{GPa}$, enquanto para a região de grão original deformado (escura) foi de 5,1 $\pm 0,2 \mathrm{GPa}$, neste caso a diferença foi de $34 \%$ entre as regiões. Os resultados na região de grãos originais deformados nas duas áreas de análise, quadros 10a e 10b da Figura 5.12, mostram uma tendência de diminuição da dureza ao longo da seção transversal da superfície. Estes resultados eram esperados, conforme os resultados de microdureza do perfil encruado mostrado no tópico 4.3.2. Perfil de dureza do Capítulo 4 desta tese. Yan et al. obtiveram o valor de $774 \mathrm{HV}(0,05 \mathrm{kgf})$ para a camada de grãos ultrafinos (nanocrystalline layer) de aço Hadfield formada por 60 minutos de shot peening com estabilidade da dureza em $250 \mathrm{HV}$ a 0,4 mm (YAN et al., 2009), enquanto Feng et al. registraram um valor máximo de $750 \mathrm{HV}(0,05 \mathrm{kgf})$ com estabilização em 350 HV a $8 \mathrm{~mm}$ para o aço Hadfield submetido ao high speed pounding por 240 minutos (FENG et al., 2013b). Estes resultados podem ser associados ao efeito Hall-Petch dinâmico associadas às maclas de deformação, como descrito por Cooman, Chin e Kim (COOMAN; CHIN; KIM, 2011). No caso dos grãos ultrafinos o efeito Hall-Petch dinâmico aplica-se devido ao aumento quantitativo de contornos de alto ângulo. 
Figura 5.17. a) Nanoendentações na área $10 b$ indicada na Figura 5.12. b) Gráfico de carregamento e descarregamento dos pontos 1 e 7 da Figura a
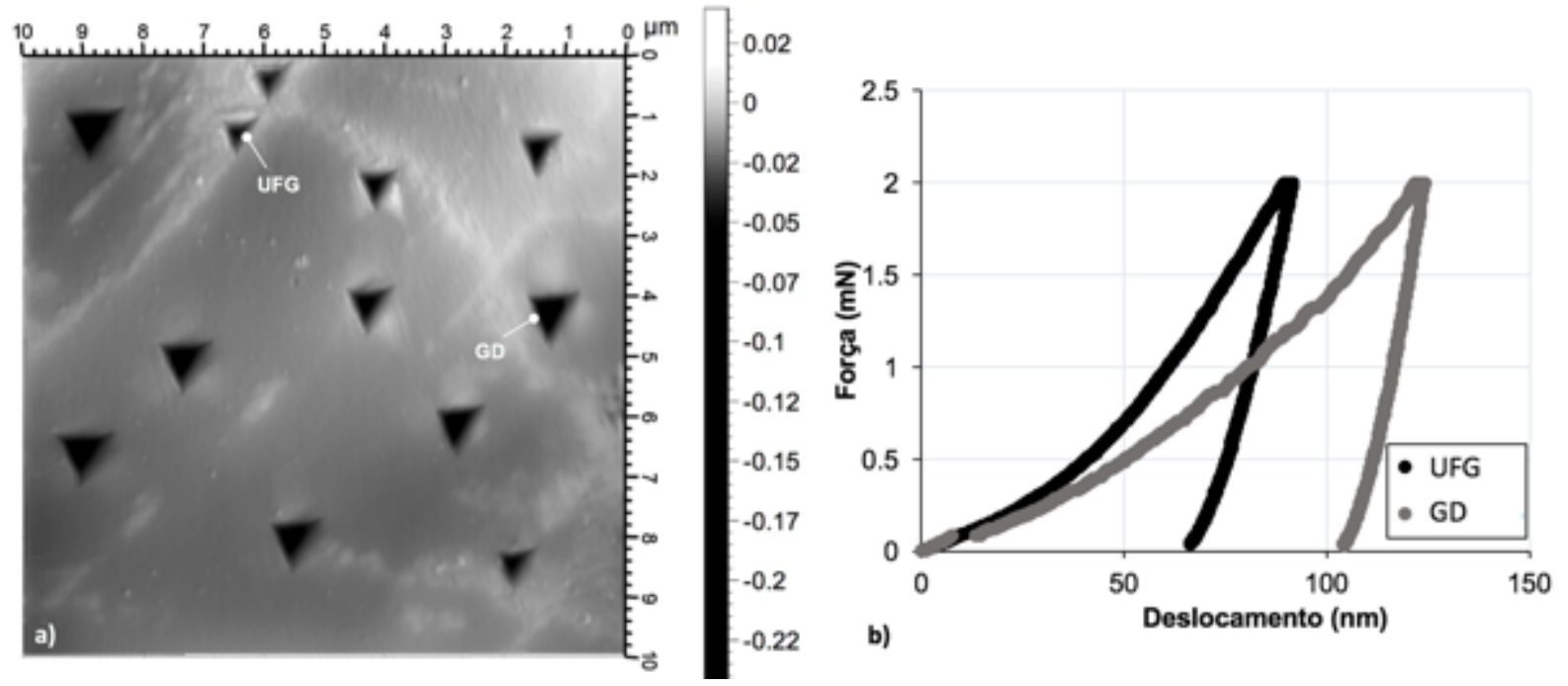

A Figura 5.18 mostra os resultados de figura de polo inverso (IPF) obtidos pela técnica de EBSD para a região deformada localizada aproximadamente a $1 \mathrm{~mm}$ da superfície desgastada (a) e para a região da base da onda (b). Nas duas regiões observam-se grãos equiaxiais e maclas de recristalização (indicado pelo ponto 1). A diferença mais evidente entre as regiões é o tamanho médio dos grãos, para região à $1 \mathrm{~mm}$ da superfície desgastada (ainda na camada deformada, a qual tem um perfil de $6 \mathrm{~mm}$ ) o tamanho médio de grão é de $275 \pm 14 \mu \mathrm{m}$, enquanto na região da base da onda tem 7,5 $\pm 1 \mu \mathrm{m}$ (97\% de diferença). Além disto, na região abaixo da superfície desgastada existe indicação de maclas de deformação (ponto 2 da Figura 5.18a) e desorientação do grão (gradiente de cores em uma determinada região dentro de um grão) sem a alteração da forma dos grãos austeníticos reforçando os resultados obtidos via MEV (Figura 5.10). Estas evidências de deformação não foram observadas na região da base da onda (Figura 5.18b), na qual notam-se maclas de recristalização (ponto 1) e carbonetos contínuos em contorno de grão (ponto 2). 
Figura 5.18. Resultado de EBSD-IPF da região deformada a $1 \mathrm{~mm}$ da superfície desgastada em campo (a) e da base da onda (b)

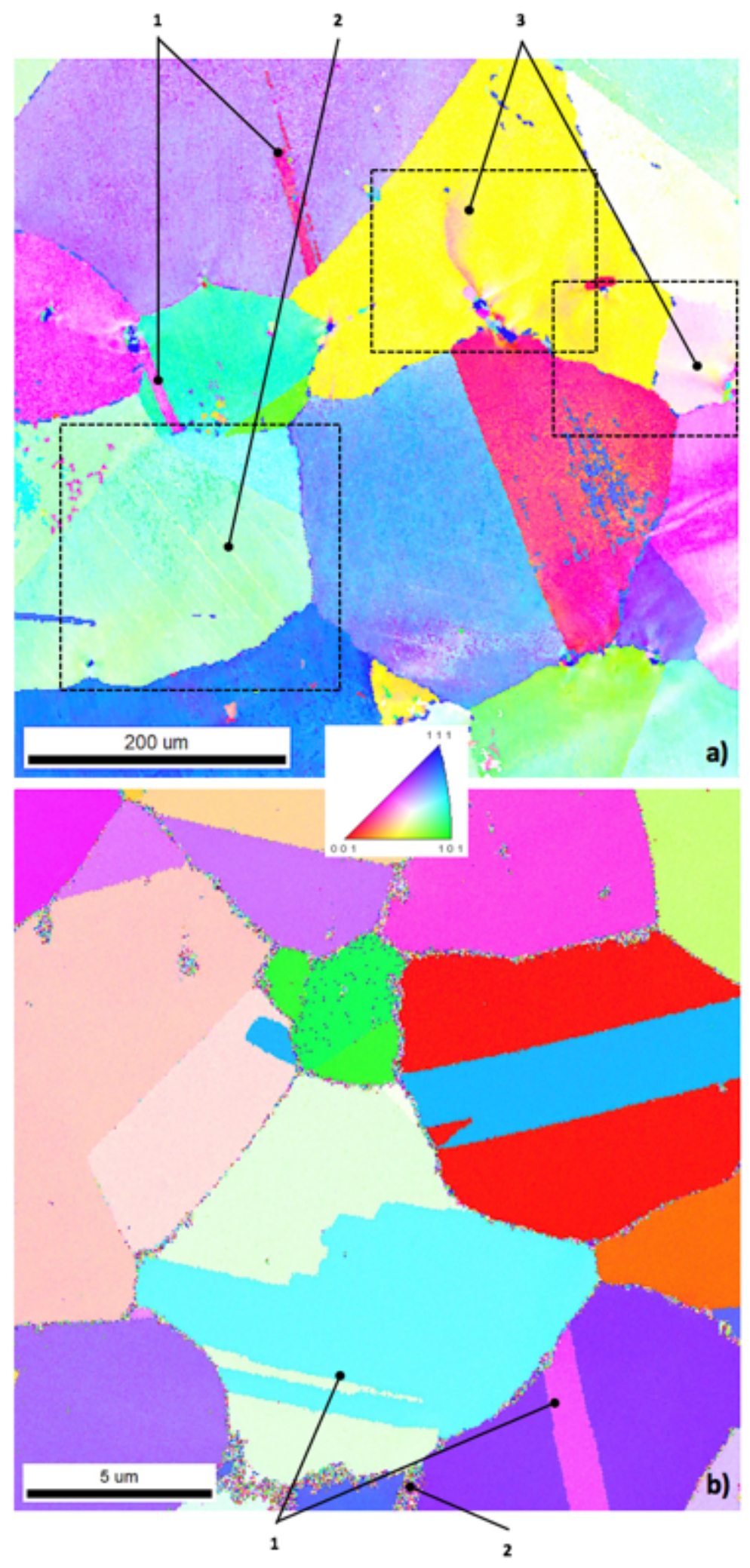

A desorientação identificada no interior de alguns grãos deformados, Figura 5.18a (pontos indicados pelo número 3), é mostrada na forma gráfica na Figura 5.19. Na 
Figura 5.19a o eixo representa o local de análise de desorientação, o qual é mostrado no gráfico da Figura 5.19b. O gráfico é composto por duas linhas, uma vermelha que representa a desorientação obtida de ponto a ponto, ou seja, indicando a desorientação de um ponto em relação ao seu antecessor; e uma linha azul, que representa a desorientação dos pontos tendo como referência à origem do eixo. Na Figura 5.19a o eixo com $50 \mu \mathrm{m}$ indica o local da análise e o gráfico da Figura $5.19 b$ mostra que maior valor de desorientação foi de $8^{\circ}$ na posição $25 \mu \mathrm{m}$. Este valor corresponde a cor amarela clara no interior do grão de cor rosa, sendo uma desorientação de baixo ângulo, menor que $15^{\circ}$. O eixo na Figura $5.19 \mathrm{c}$ passa por uma região do grão com variação de orientação cristalográfica. O gráfico de desorientação deste eixo, Figura $5.19 d$, mostra que o valor máximo se aproximou de $9^{\circ}$.

Figura 5.19. Imagens de IPF e gráfico de desorientação dos quadros indicados pelo número 3 (Figura 5.18a). a) Imagem de IPF com eixo de referência. b) Gráfico de desorientação em função da posição do eixo de referência da Figura a. c) Imagem de IPF com eixo de referência. d) Gráfico de desorientação em função da posição do eixo de referência da Figura $c$
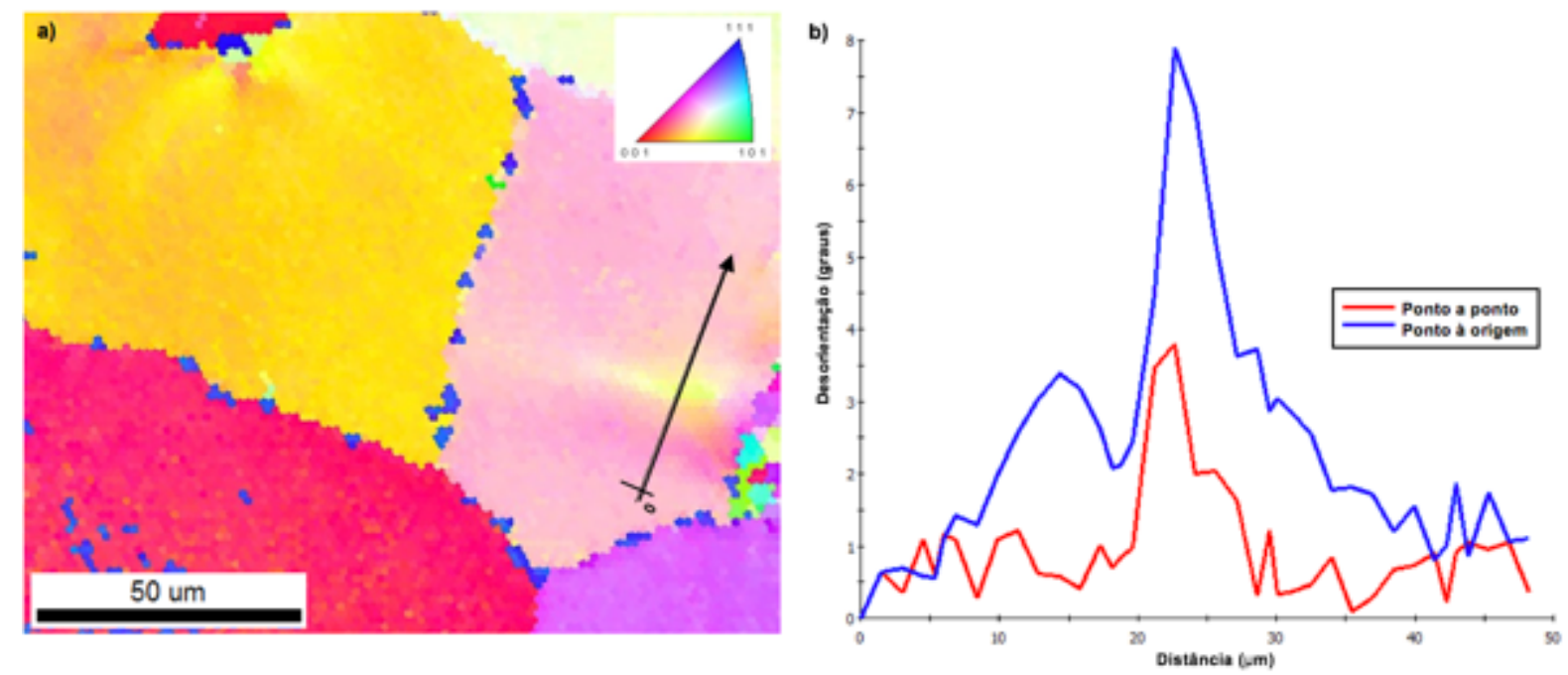

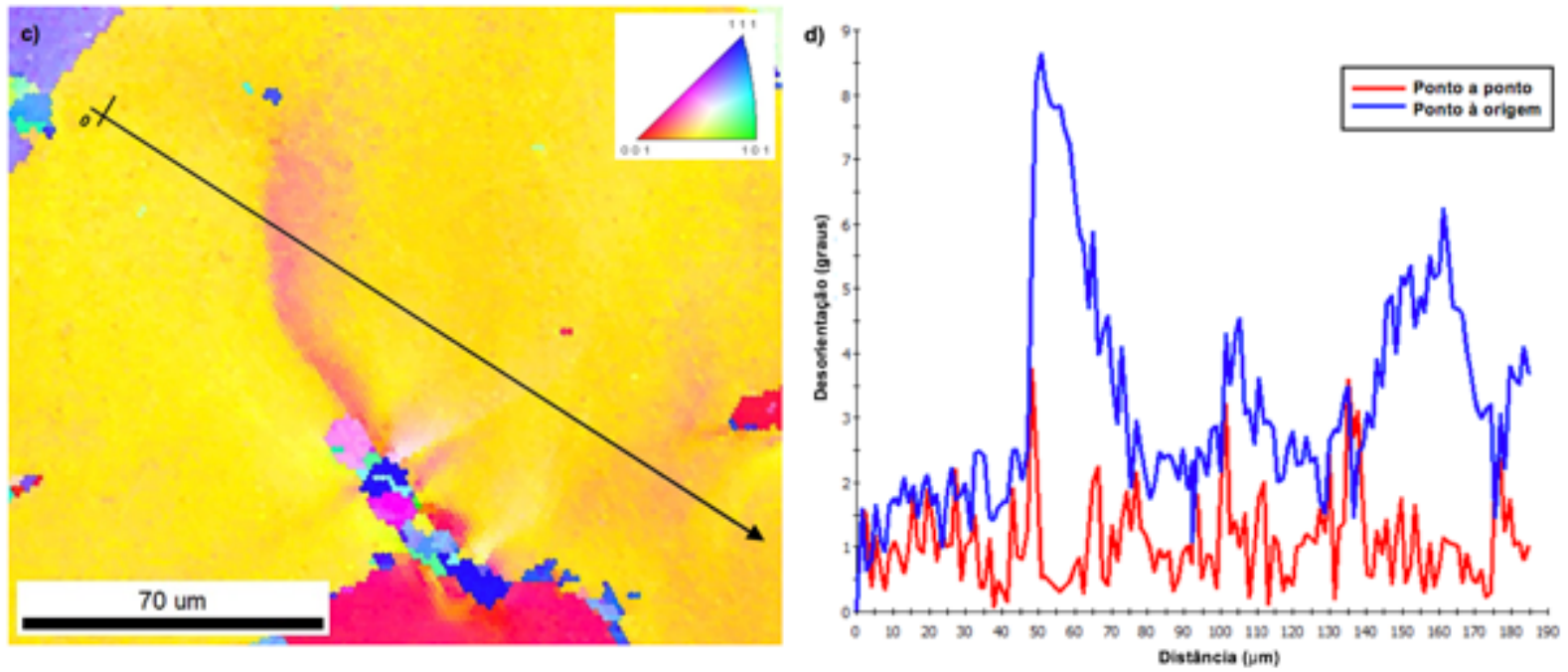

A desorientação da região com maclas de deformação indicada pelo número 2 (Figura 5.18a) também foi analisada. A Figura 5.20 mostra a imagem de IPF (a) e o gráfico de desorientação $(b)$ para o eixo indicado na figura. Os picos indicam a desorientação causada pelas maclas de deformação ao longo do eixo, atingido valores de $4,5^{\circ}$.

Figura 5.20. Imagens de IPF e gráfico de desorientação do ponto indicado pelo número 2 (Figura 5.18a)
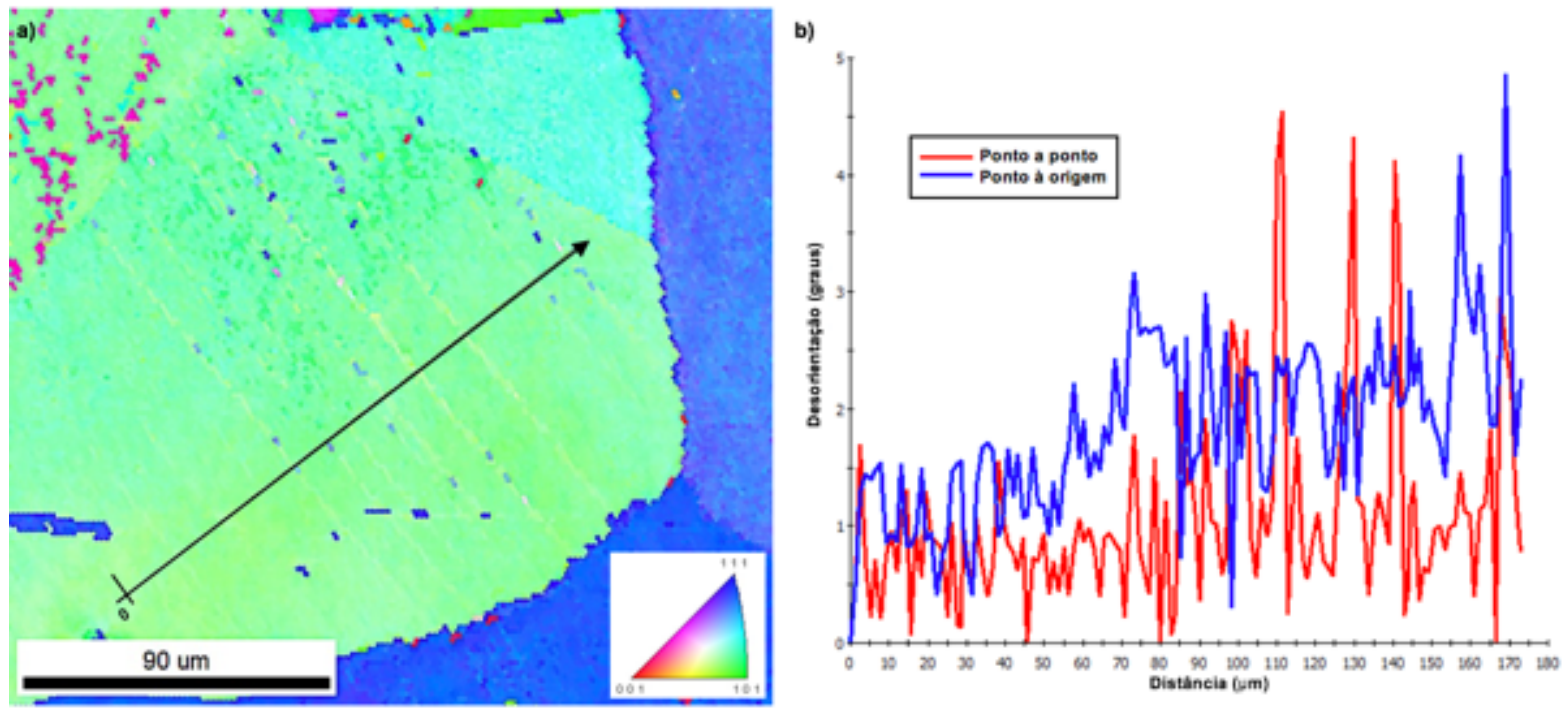

Uma região com contorno de alto ângulo, Figura 5.21a, foi selecionada na Figura 5.18 para ser analisada e tornar-se uma referência para as análises de desorientação. O gráfico na Figura $5.21 b$ mostra uma desorientação de alto ângulo de um contorno coerente de macla de recristalização. 
Figura 5.21. Imagens de IPF e gráfico de desorientação do grão maclado, Figura 5.18a
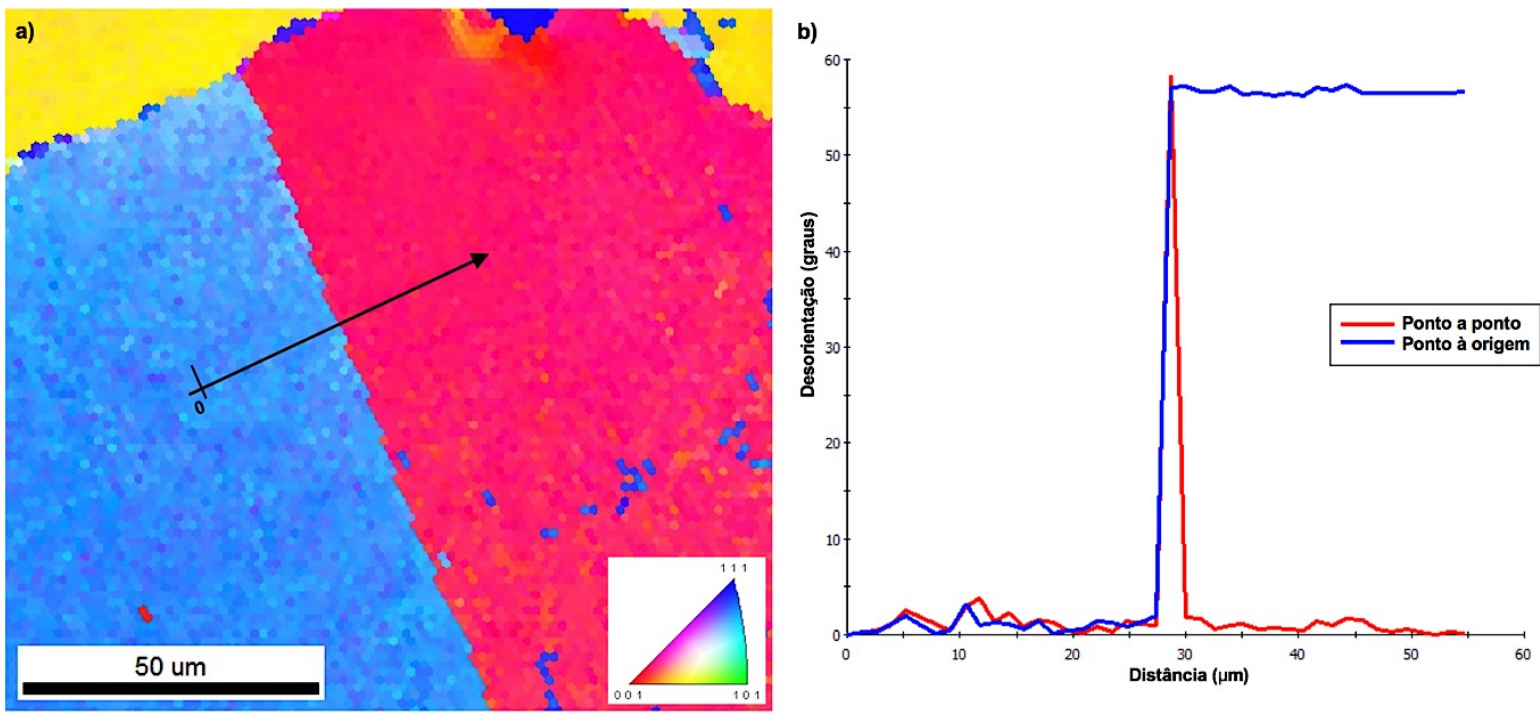

A região em destaque da Figura 5.18b, que representa a área da base da onda, é mostrada na Figura 5.22. O eixo de análise de desorientação foi posicionado ao longo do grão com macla de recristalização. O resultado da desorientação mostrado no gráfico da Figura 5.22b mostra que a microestrutura é livre de deformação e que a macla de recristalização tem desorientação de alto ângulo $\left(60^{\circ}\right)$ em relação a orientação do grão.

Figura 5.22. Imagens de IPF e gráfico de desorientação do grão com macla de recristalização indicado na Figura $5.18 b$

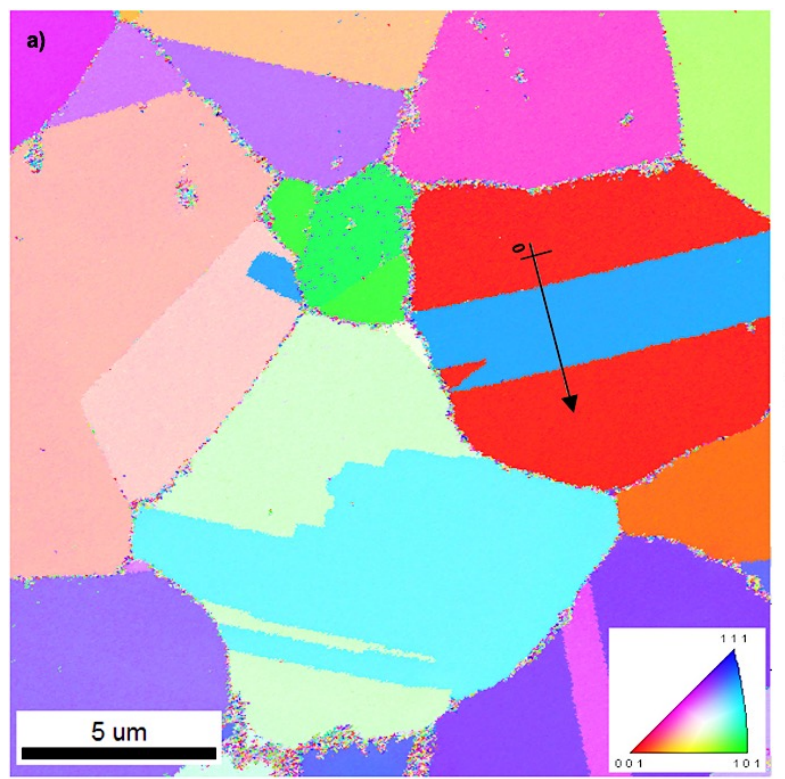

b)

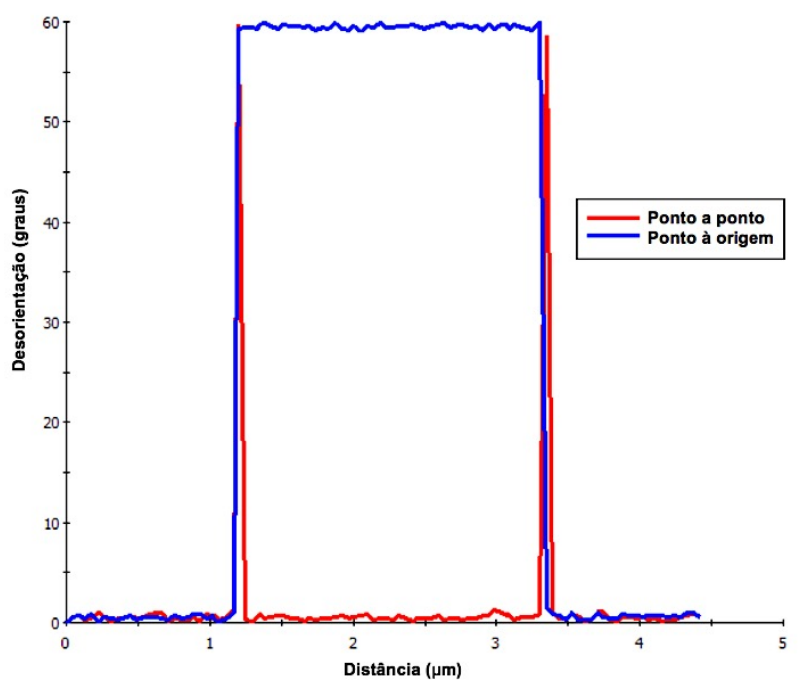


As micrografias da subsuperfície obtidas com a técnica de FIB com corte ortogonal são mostradas nas Figuras 5.23 e 2.24. Foram analisados pontos diferentes da superfície da amostra, estes pontos foram nomeados análise 1 e análise 2. As imagens da Figura 5.23 referem-se à análise 1 e a Figura 5.24 à análise 2.

$\mathrm{Na}$ análise 1, Figura 5.23, a microestrutura deformada tem camadas de grãos pequenos e ultrafinos que se intercalam. Assumindo a hipótese de recristalização e crescimento, os grãos pequenos mais próximos à superfície, Figura $5.23 c$, são resultado do processo de crescimento dos grãos ultrafinos. Nesta região também se observa maclas de deformação, como indicado na figura. Na Figura 5.23d, região a $10 \mu \mathrm{m}$ da superfície desgastada, a microestrutura é constituída por sub-regiões macladas, as quais são envolvidas por grãos ultrafinos. No interior destas subregiões nota-se grãos pequenos entre as maclas. Observa-se que essa camada tem espessura maior que a profundidade da cavidade gerada pela técnica de FIB (> $22 \mu \mathrm{m})$.

Figura 5.23. Microestruturas da subsuperfície do revestimento de britador cônico. a) Cavidade na superfície desgastada e decapada (análise 1). b) Microestrutura da subsuperfície. c) Ampliação da área do quadro $c$ na Figura $b$. d) Ampliação da área do quadro d na Figura $b$

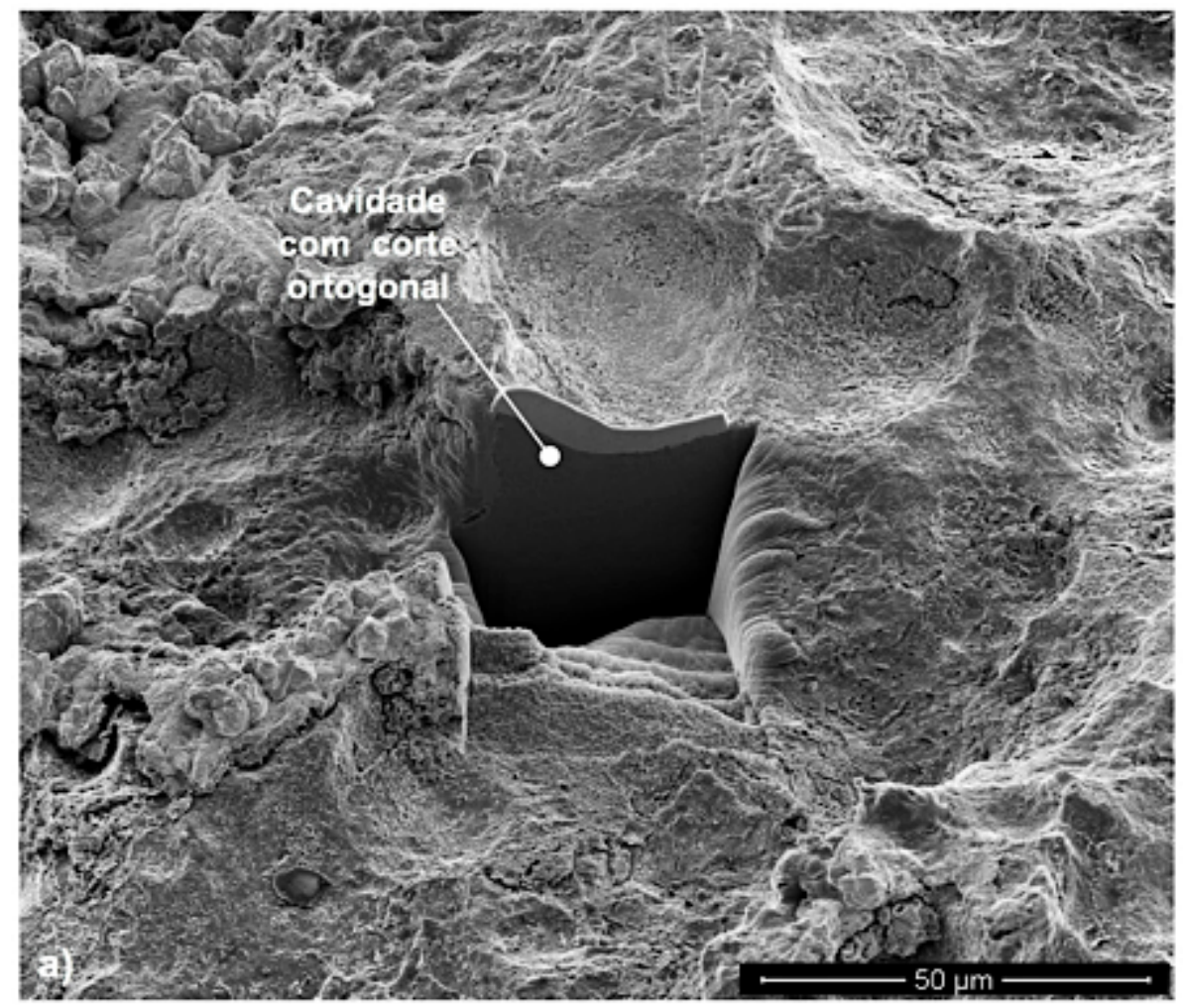



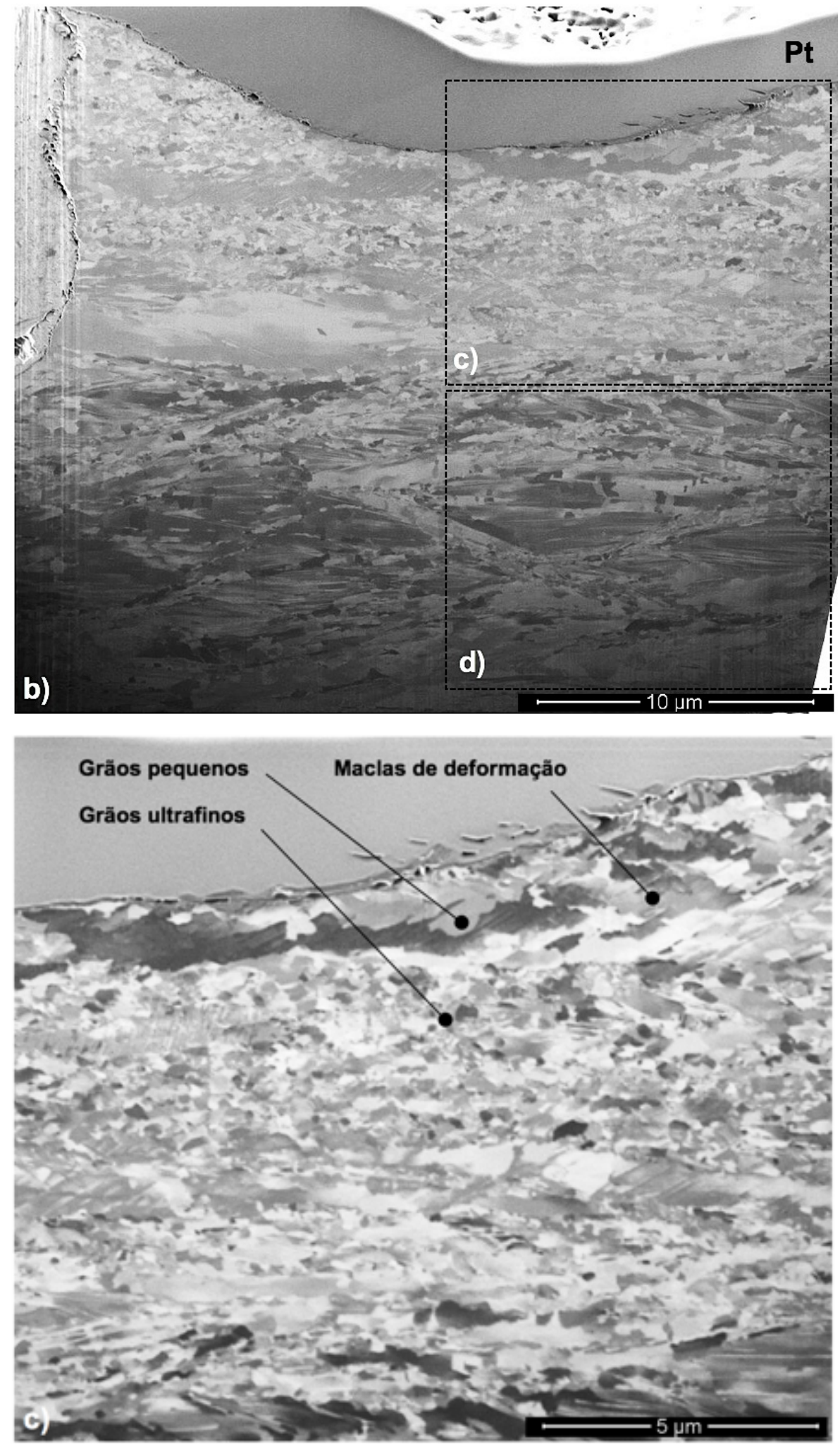


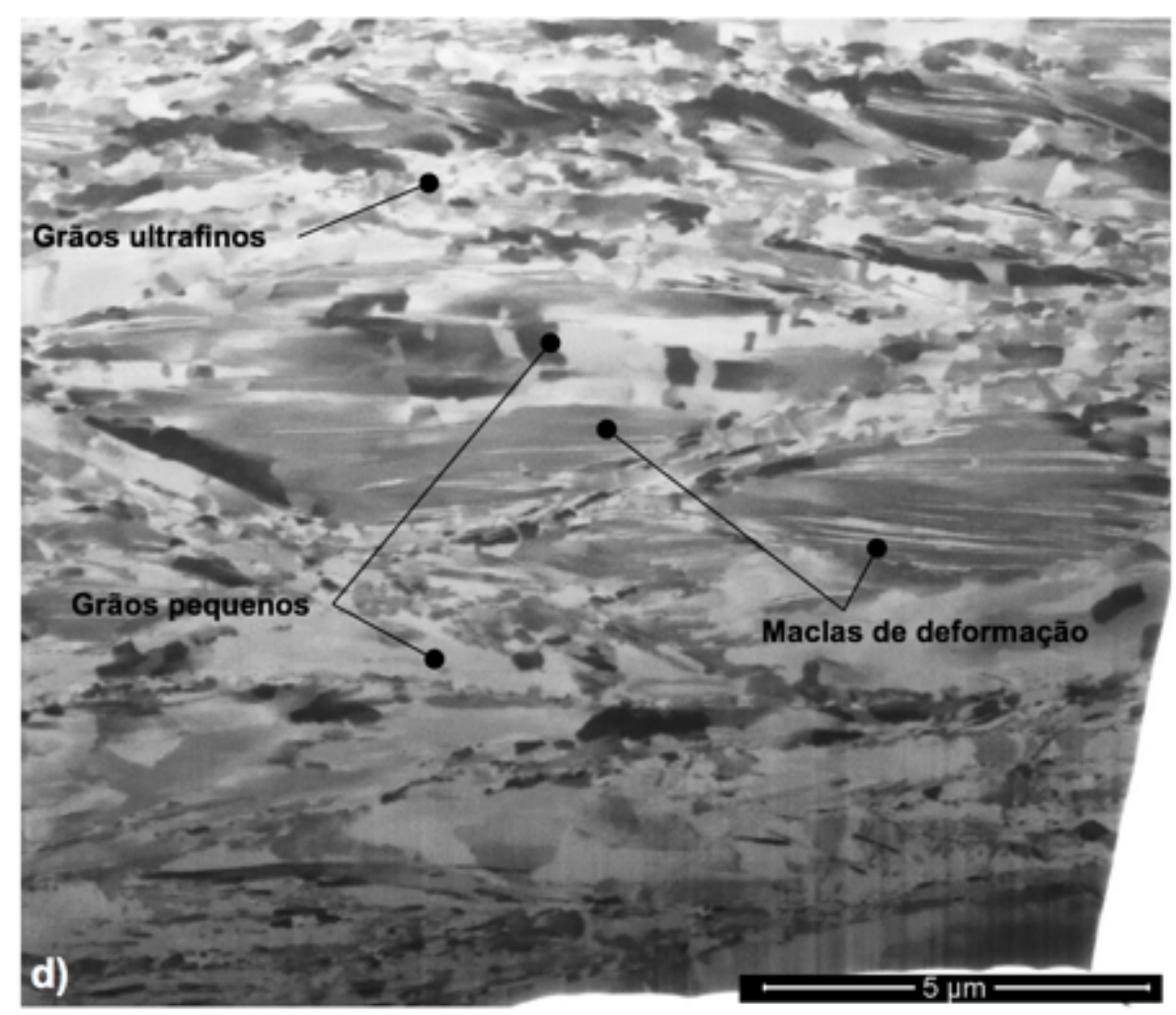

$\mathrm{Na}$ análise 2, Figura 5.24, a microestrutura com grãos pequenos é predominante na área de análise. O tamanho médio destes grãos é de $0,7 \pm 0,1 \mu \mathrm{m}$, eles são menores em duas ordens de grandeza que o grão original e maiores que os grãos ultrafinos. O tamanho destes grãos equivale ao tamanho dos grãos pequenos como indicado na análise 1, Figura 5.23. Desta forma, assumindo um referencial cronológico, a microestrutura da área da análise 2 é um estágio mais avançado do fenômeno de recristalização. A microestrutura na análise 2 tem grãos pequenos, equiaxial, com maclas de recristalização e sem evidências de deformação plástica.

O local da análise 2 tem tamanho de grão inferior aos observados na microestrutura da onda de material deslocado $(7,5 \mu \mathrm{m})$ com uma diferença de $91 \%$. Portanto, pode-se considerar que além do fenômeno de recristalização observado na subsuperfície do aço Hadfield desgasto, pode ter ocorrido crescimento de grão. Esse fenômeno também pode ser observado na Figura 5.13 pela diferença de tamanho de grão entre os pontos 2 e 3. 
Figura 5.24. Microestruturas da subsuperfície do revestimento de britador cônico. a) Cavidade na superfície desgastada e decapada (análise 2). b) Microestrutura da subsuperfície. c) Ampliação da área do quadro $c$ na Figura $b$
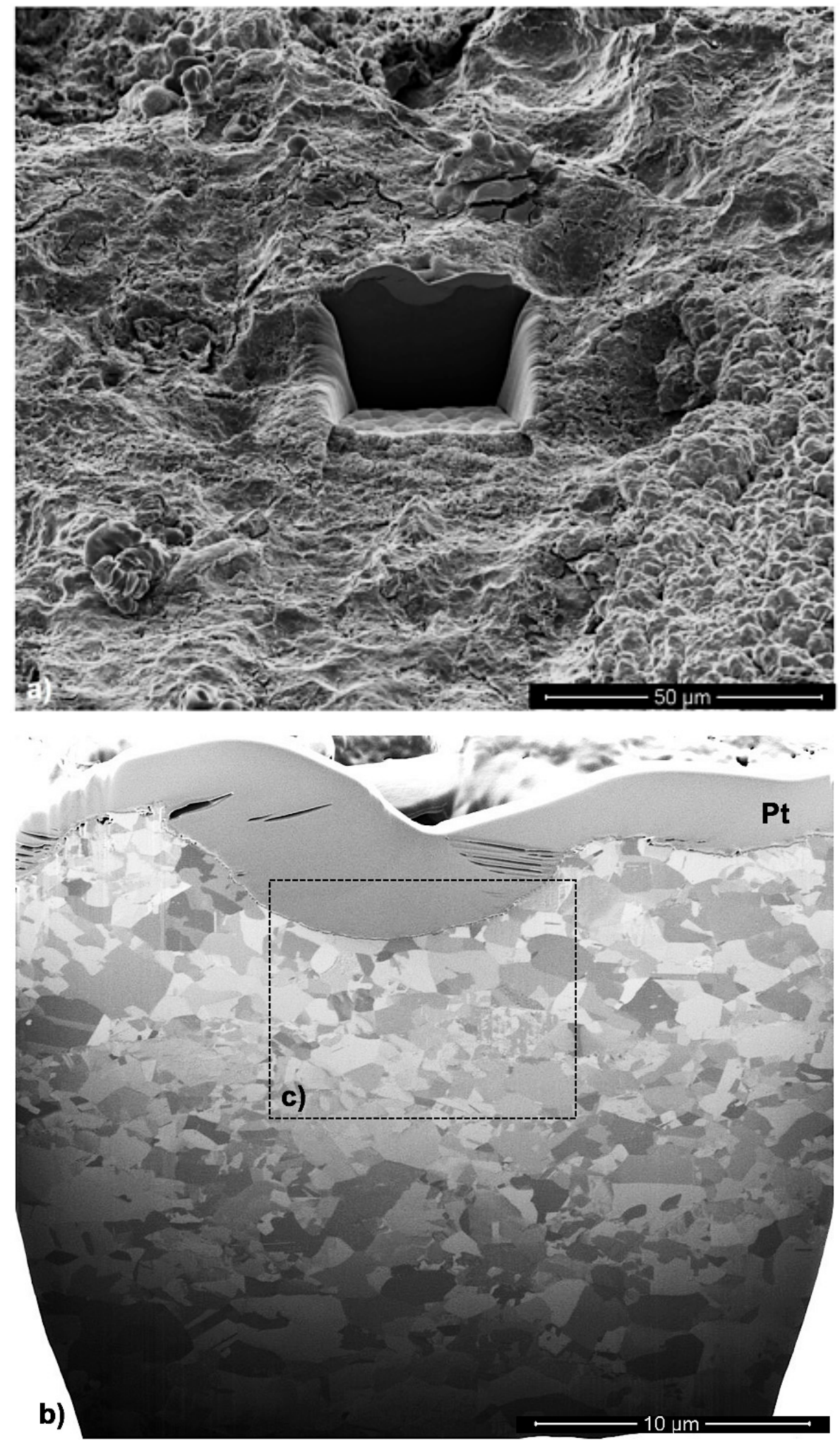


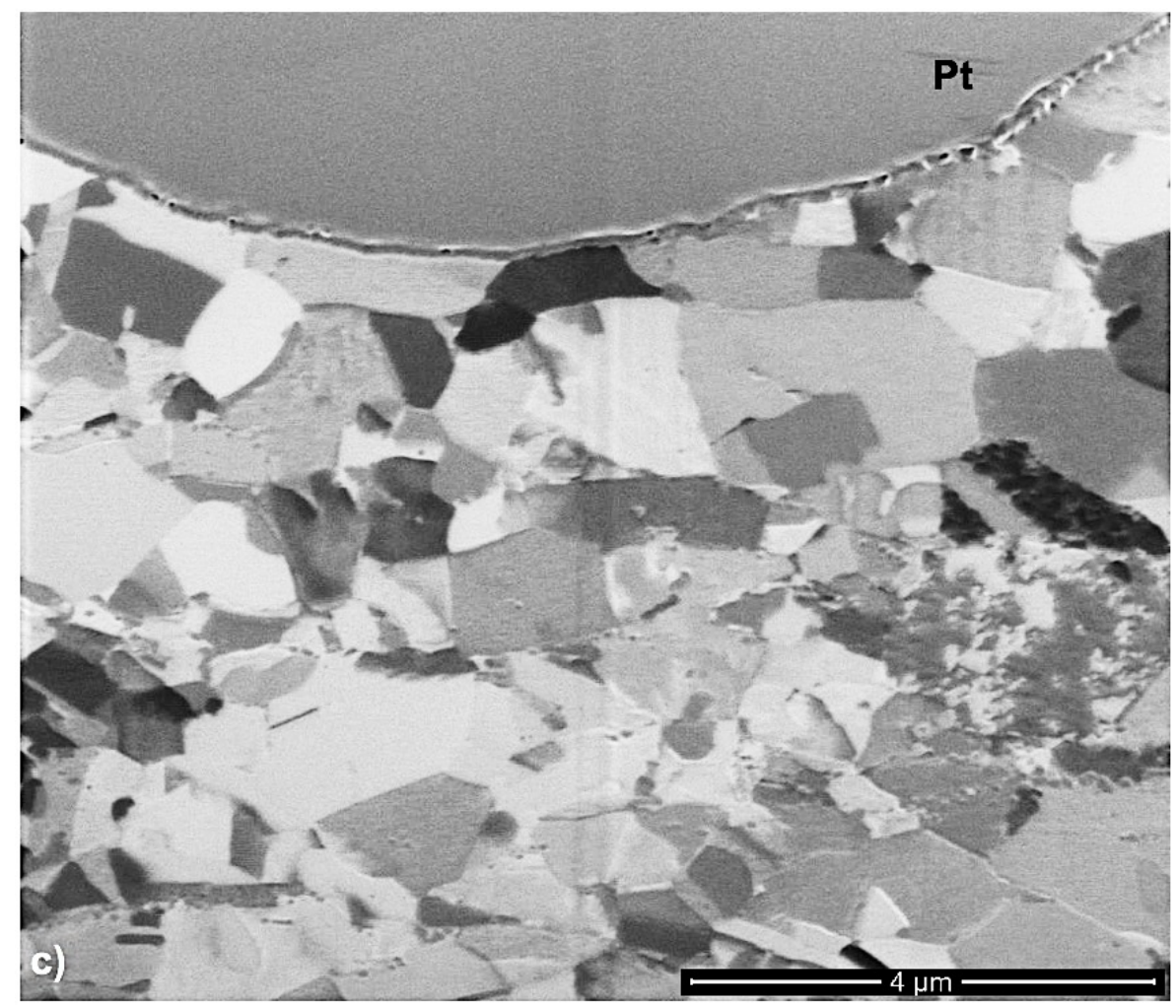

As observações mostraram que abaixo da superfície de desgaste (camada 1) existem regiões fortemente encruadas e regiões com grãos equiaxiais muito menores do que os grãos da região não afetada pela deformação $(0,7 \pm 0,1 \mu \mathrm{m}$ e $275 \pm 14 \mu \mathrm{m}$, respectivamente). A literatura mostrou por meio de evidências micrográficas, regiões deformadas na subsuperfície de amostras ensaiadas em laboratório e de amostras provenientes de campo. A literatura mostrou ainda, por meio de medidas de microdureza que ocorre encruamento em amostras retiradas de campo (ADLER; OLSON; OWEN, 1986; LINDROOS et al., 2015a; LV et al., 2012; TANAKA, 2011; TRESSIA, 2015). Entretanto, neste trabalho mostrou-se que existem regiões nas quais há grãos equiaxiais menores que os do interior do material. $O$ exame da subsuperfície do material e da onda mostradas nas Figuras 5.12 e 5.24c, respectivamente, sugere que ocorre recristalização e crescimento de grão simultaneamente ao fenômeno de desgaste. A literatura consultada não explicita a ocorrência destes fenômenos (ao menos para Hadfield). A existência de regiões com grãos pequenos traz o mecanismo de endurecimento por efeito Hall Petch como mecanismo possível para explicar a diferença de dureza de $33 \%$ entre os grãos ultrafinos e o grão deformado associado ao tradicional mecanismo de encruamento (multiplicação e bloqueio de movimentação de discordâncias). 
Caso o fenômeno de recristalização seguido ou não de crescimento de grão como os observados nas Figuras 5.12 e 5.24c não seja fortuito ele abre a perspectiva de desenvolvimento de uma classe de aços nas quais a subsuperfície evolua para uma estrutura refinada de grãos recristalizados recuperando e elevando, como se sabe, suas propriedades em relação às estruturas deformadas ou à estruturas de grãos grosseiros (PADILHA; SICILIANO, 2005), numa espécie de auto reparação dos danos sofridos pelo desgaste, o self healing effect (GHOSH, 2009). Segundo Ghosh a aplicação de tensões compressivas ou aquecimento podem aumentar a eficiência da autoreparação de locais deformados, eliminando defeitos. Este raciocínio pode ser aplicado na superfície desgastada, visto que a energia absorvida pelo material muda o arranjo microestrutural original.

A Figura 5.25 mostra o resultado de DRX para a amostra desgastada em campo. Os padrões indexados no difratograma correspondem à austenita, hematita e quartzo. Esse resultado corrobora as discussões anteriores, as quais não consideraram a hipótese de formação de martensita por deformação e os resultados das pesquisas (ADLER; OLSON; OWEN, 1986; AVERY, 1949). A identificação de hematita sustenta o resultado de EDS mostrado na Figura 5.13, comprovando a presença de abrasivo (minério de ferro) abaixo do material deformado e recristalizado (onda).

Figura 5.25. Resultado de DRX - amostra desgastada em campo

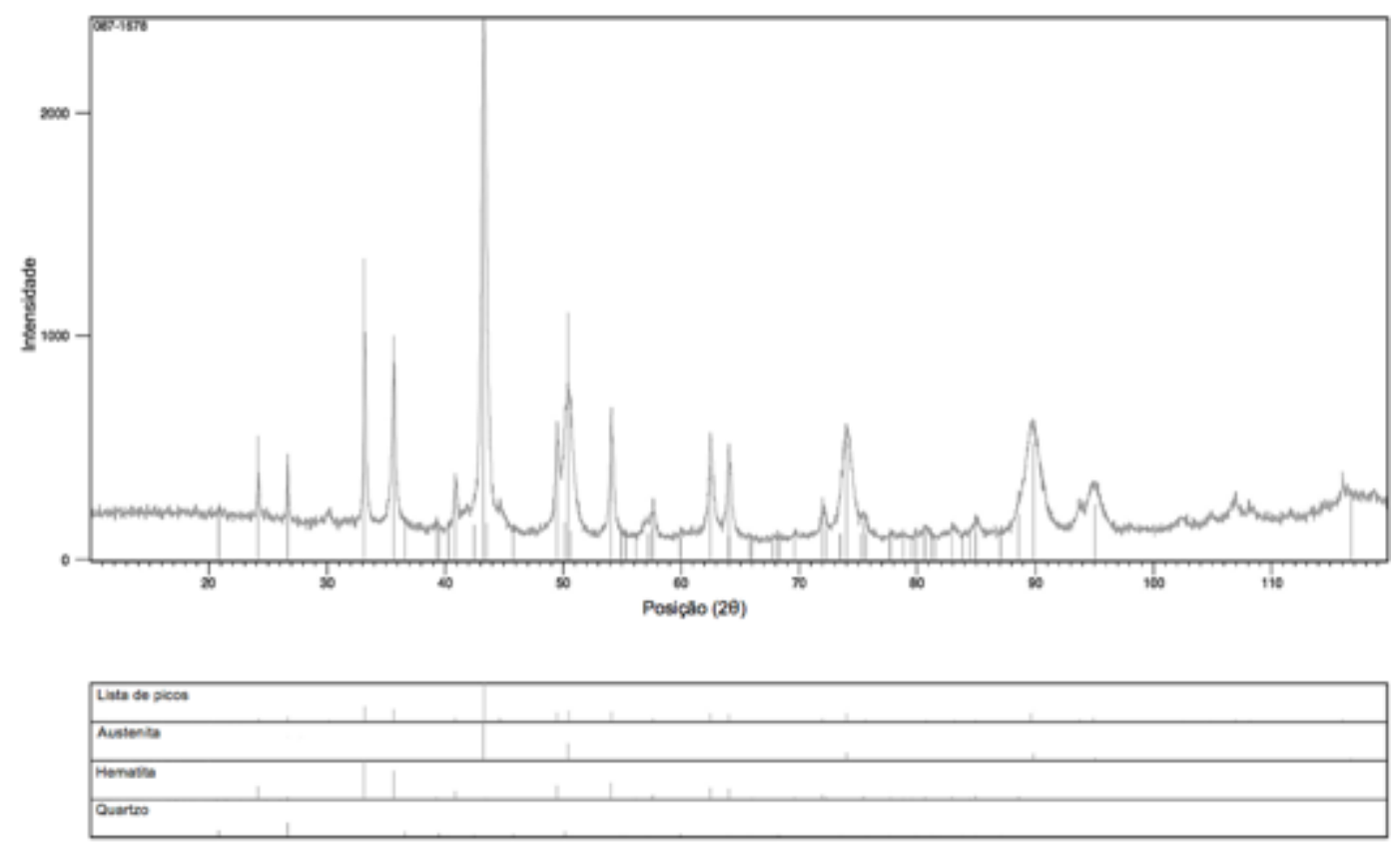


Para tentar reproduzir a formação de grãos recristalizados tentou-se um experimento que consistiu em gerar cavacos via processo de aplainamento da superfície do aço Hadfield deformada em campo. Os resultados são mostrados no Apêndice C.

\subsubsection{Microestrutura da subsuperfície do revestimento de britador de mandíbula (ensaio laboratorial)}

Neste tópico a sequência de apresentação de resultados é semelhante ao do tópico anterior, sendo adotada a seguinte sequência: MEV, FIB, EBSD e DRX. A região de saída da mandíbula móvel foi a região selecionada para o estudo, devido a maior severidade do desgaste nesta região. A microestrutura da subsuperfície da mandíbula fixa desgastada é mostrada na Figura 5.26. Semelhante à microestrutura da subsuperfície do revestimento desgastado de britador cônico (tópico anterior) observam-se as camadas 1 e 2 no revestimento de britador laboratorial.

$\mathrm{Na}$ microestrutura mostrada na Figura 5.26a observa-se que a geometria do grão deformado não é alterada, para isso considera-se que o perfil de encruamento do revestimento de britador laboratorial estabiliza-se com $1,5 \mathrm{~mm}$ (resultados apresentados no Capítulo 3 desta tese). Na Figura 5.26b, área em destaque na Figura a, nota-se que próximo à superfície desgastada a microestrutura tem característica de escoamento plástico, apesar das maclas de deformação, com contorno de grão descontínuo e bandas de escorregamento. Além disso, observamse trincas transgranulares e intergranulares fazendo parte dos mecanismos de dano e desgaste do material. A Figura 5.26c mostra com maior aumento a áreas em destaque na Figura 5.26b. 
Figura 5.26. Imagens de MEV-SE da subsuperfície da mandíbula fixa. Ensaio laboratorial de britador de mandíbula. Corte inclinado com $45^{\circ}$. a) 100X. b) 450X. c) 1.500X. d) $1.500 \mathrm{X}$
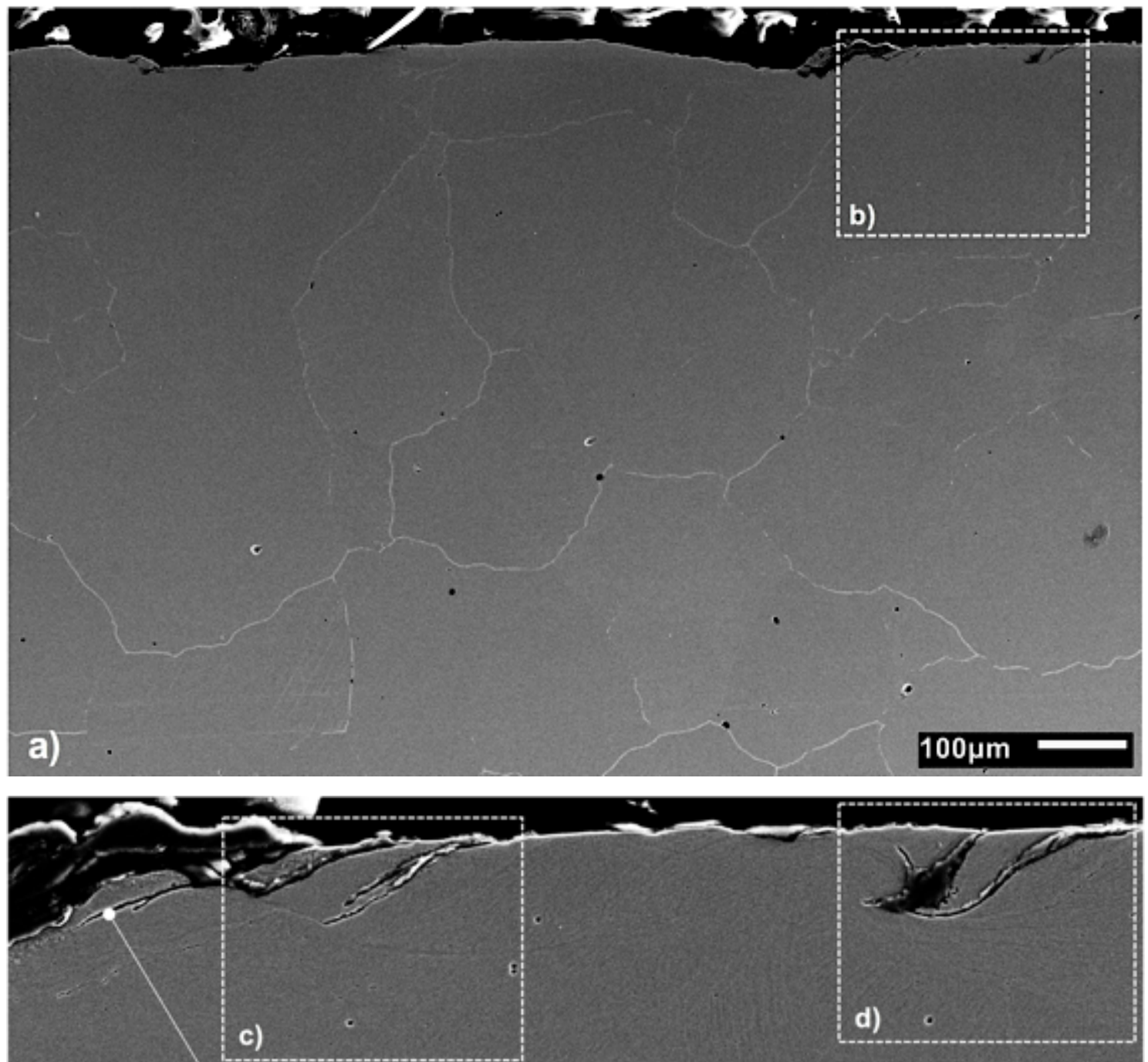

Trinca paralela

Contorno de grăo

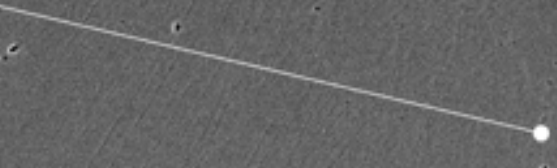

Maclas de deformação

b) 

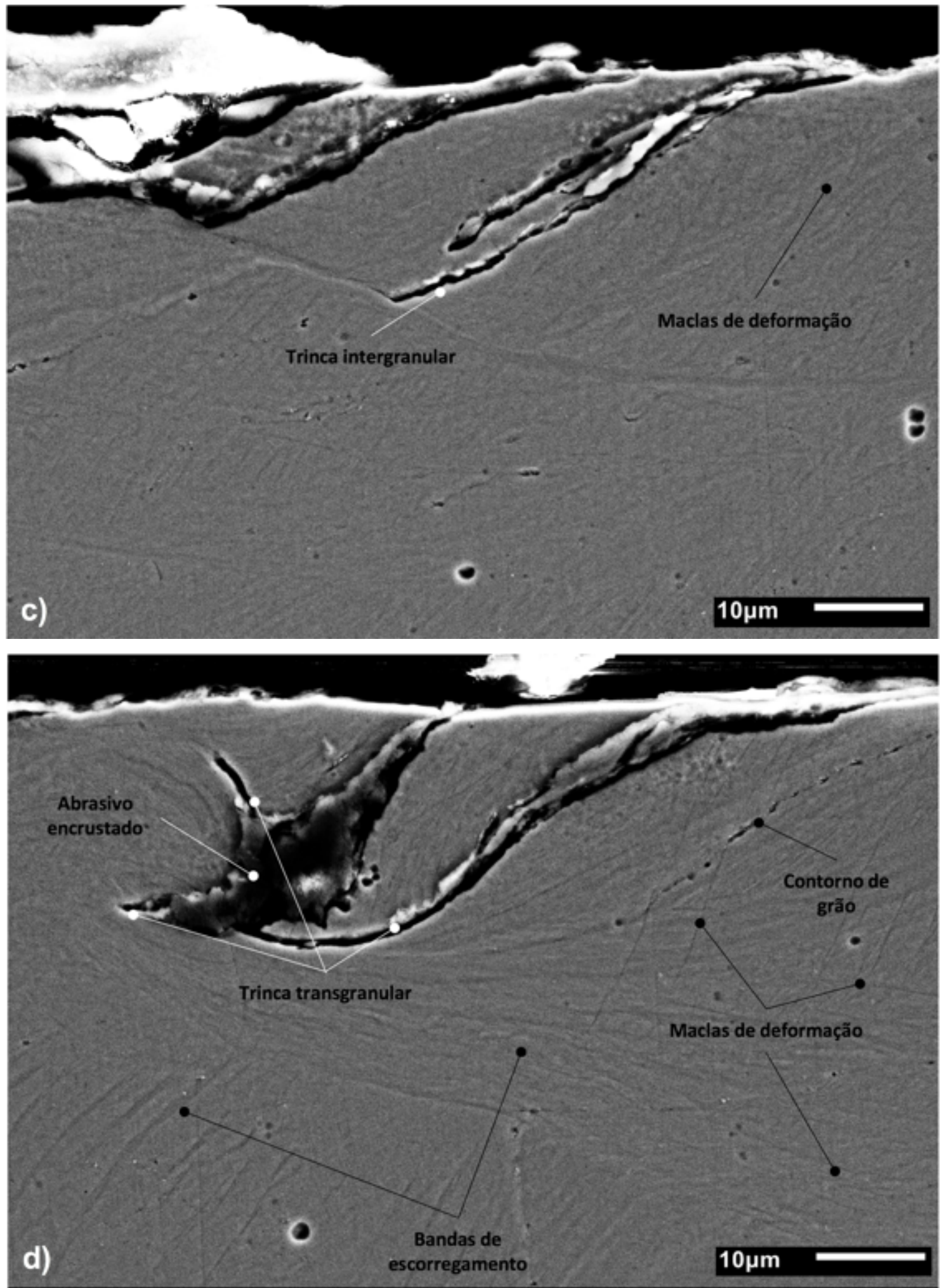

Os resultados da análise de FIB é mostrado na Figura 5.27. Na Figura 5.27a observa-se a superfície de desgaste da região de saída da mandíbula fixa, nota-se os micromecanismos de microcorte, microsulcamento e microendentações. Nesta Figura é indicado o local de análise pela deposição de platina, nota-se que a 
deposição abrange uma região com riscos e microendentações. A microestrutura da subsuperfície é mostrada na Figura 5.27b. As ampliações das áreas em destaque, uma mais próxima à superfície deformada e outra mais afastada, são mostradas nas Figuras 5.27 c e 5.27d. Observam-se nestas Figuras duas camadas no interior da camada 1 com características microestruturais diferentes. Estas subcamadas foram nomeadas subcamada 1.1 e 1.2. A primeira subcamada tem espessura de 7,6 $\pm 2 \mu \mathrm{m}$ com grãos ultrafinos e a segunda tem grãos ultrafinos e maclas de deformação. Nota-se também a formação de onda, neste caso de material deformado com microestrutura semelhante à subcamada 1.1 e com material proveniente do abrasivo no seu interior (oxido de silício - resultados de EDS), como observado no material desgastado em campo. A Figura 5.26d mostra com maior aumento a área de transição das subcamadas 1.1 e 1.2 .

Figura 5.27. a) Local de análise, 5.000X. b) Microestrutura da subsuperfície, 10.000X. c) Ampliação da região próxima à superfície, 20.000X. d) Ampliação da região a $10 \mu \mathrm{m}$ da superfície, 30.000X

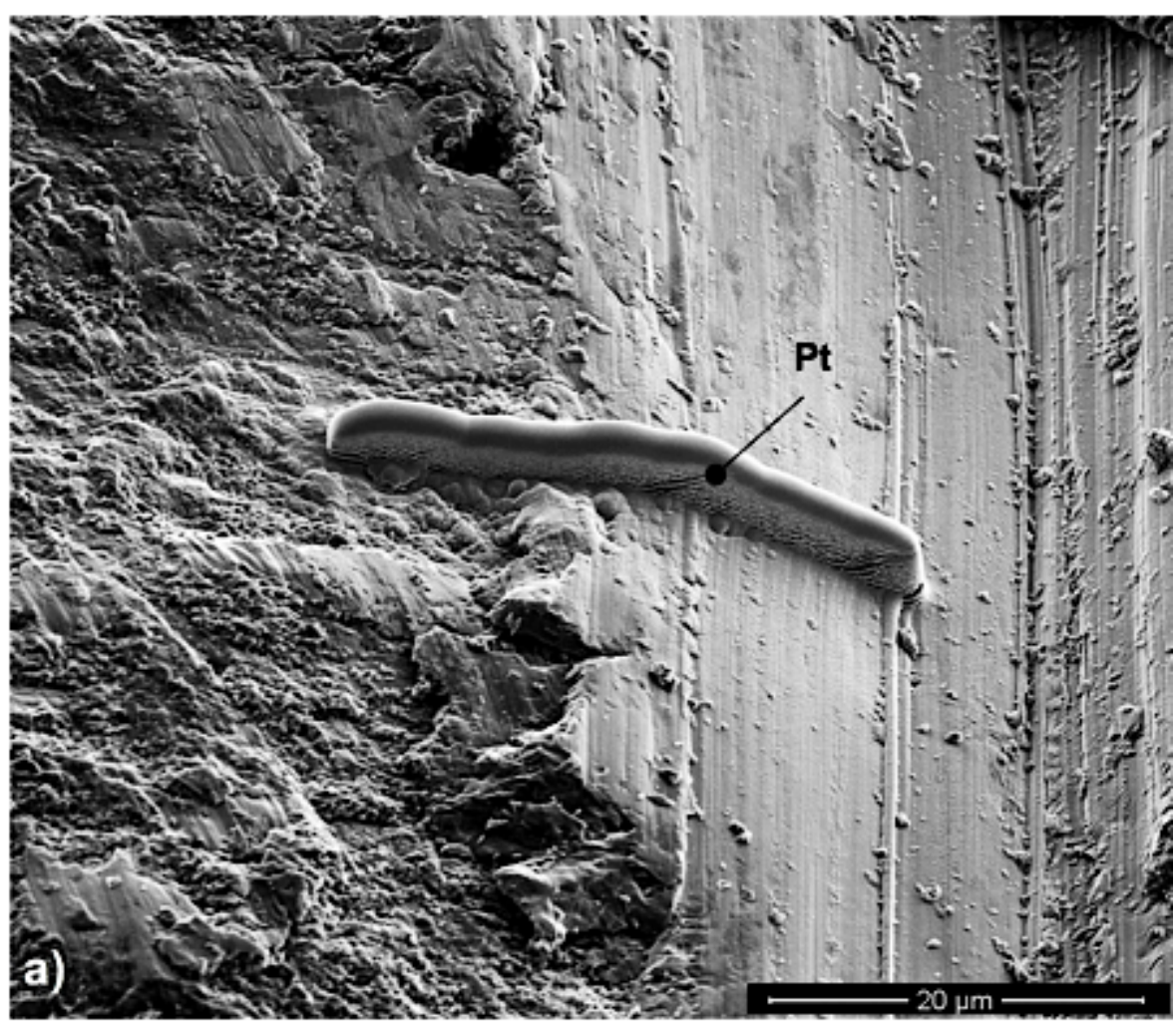



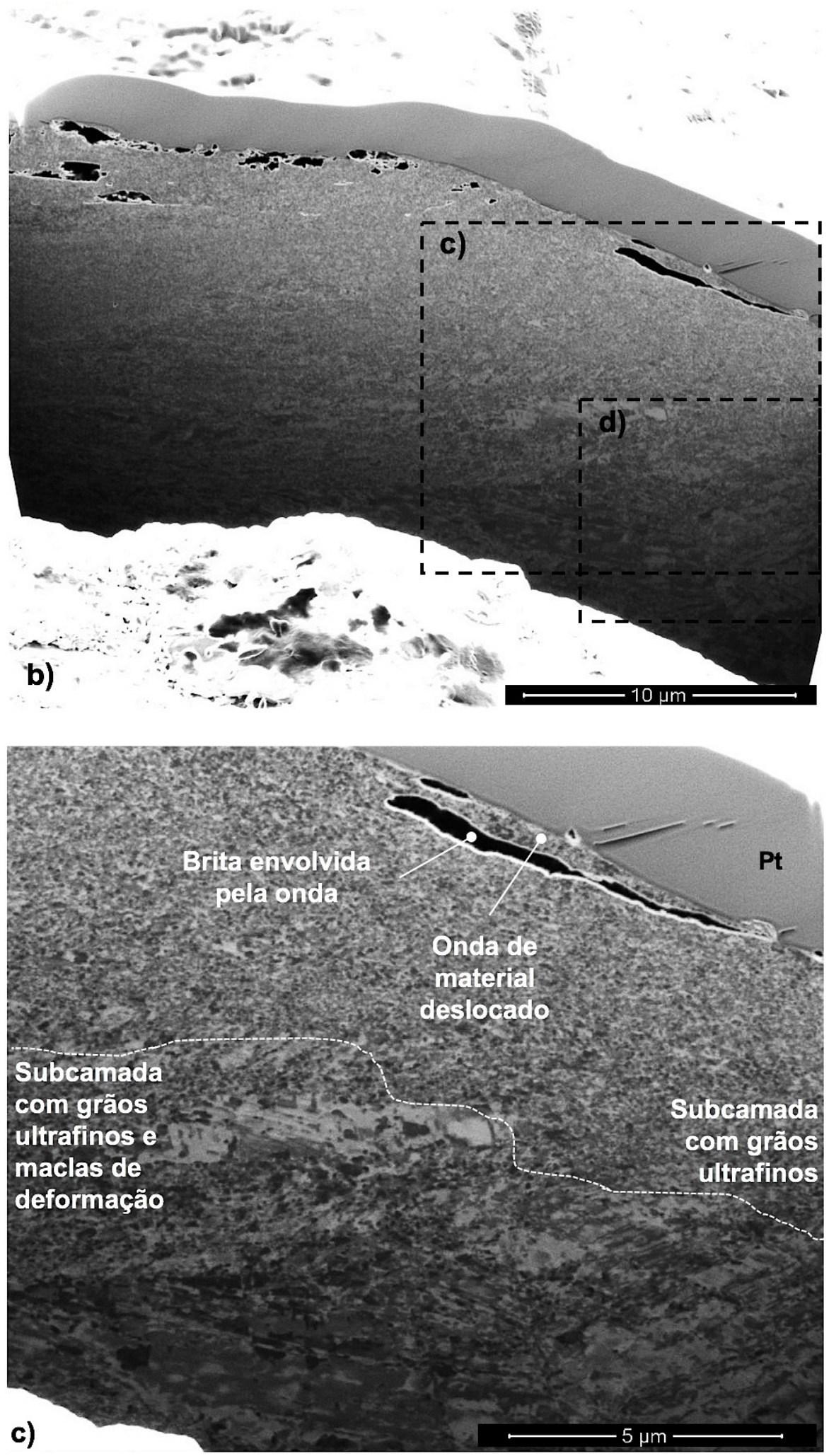


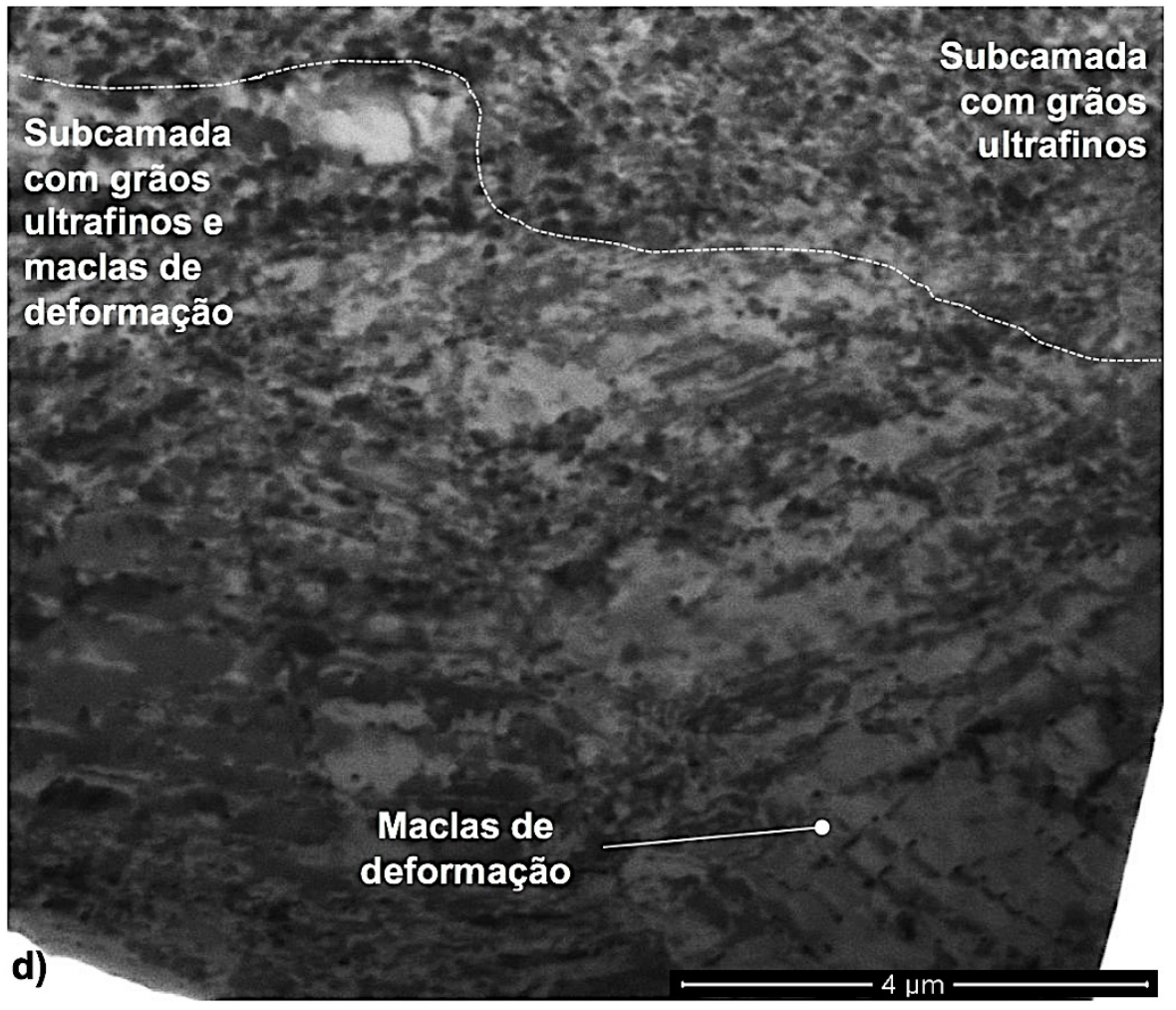

A observação da microestrutura da subsuperfície via FIB com formação da cavidade limita-se pela dimensão da cavidade (largura e profundidade). Desta forma, foi realizada a análise da subsuperfície via FIB com corte em $20^{\circ}$ (taper section) como descrito no tópico 5.2.2. A Figura 5.28 mostra a microestrutura nas distâncias $10 \mu \mathrm{m}$, $100 \mu \mathrm{m}, 150 \mu \mathrm{m}$ e $200 \mu \mathrm{m}$ da superfície desgastada, Figuras 5.28a, 5.28b, 5.28c e $5.28 d$, respectivamente. Na região mais próxima à superfície desgastada $(10 \mu \mathrm{m})$ observam-se grãos ultrafinos (pontos), Figura 5.28a. A Figura 5.28b mostra a microestrutura que antecede (cronologicamente e espacialmente) a microestrutura mostrada na Figura 5.28a, composta por bandas de escorregamento e maclas de deformação, as quais são maiores que os grãos ultrafinos. Na Figura $5.28 \mathrm{c}$ observam-se maclas de deformação. A microestrutura na Figura $5.28 d$ tem grãos ultrafinos em menor quantidade com predominância de maclas. 
Figura 5.28. Microestrutura da (a) subsuperfície $(10 \mu \mathrm{m})$ e das regiões nas posições (b) $100 \mu \mathrm{m}$, (c) $150 \mu \mathrm{m}$ e (d) $200 \mu \mathrm{m}$. 20.000X
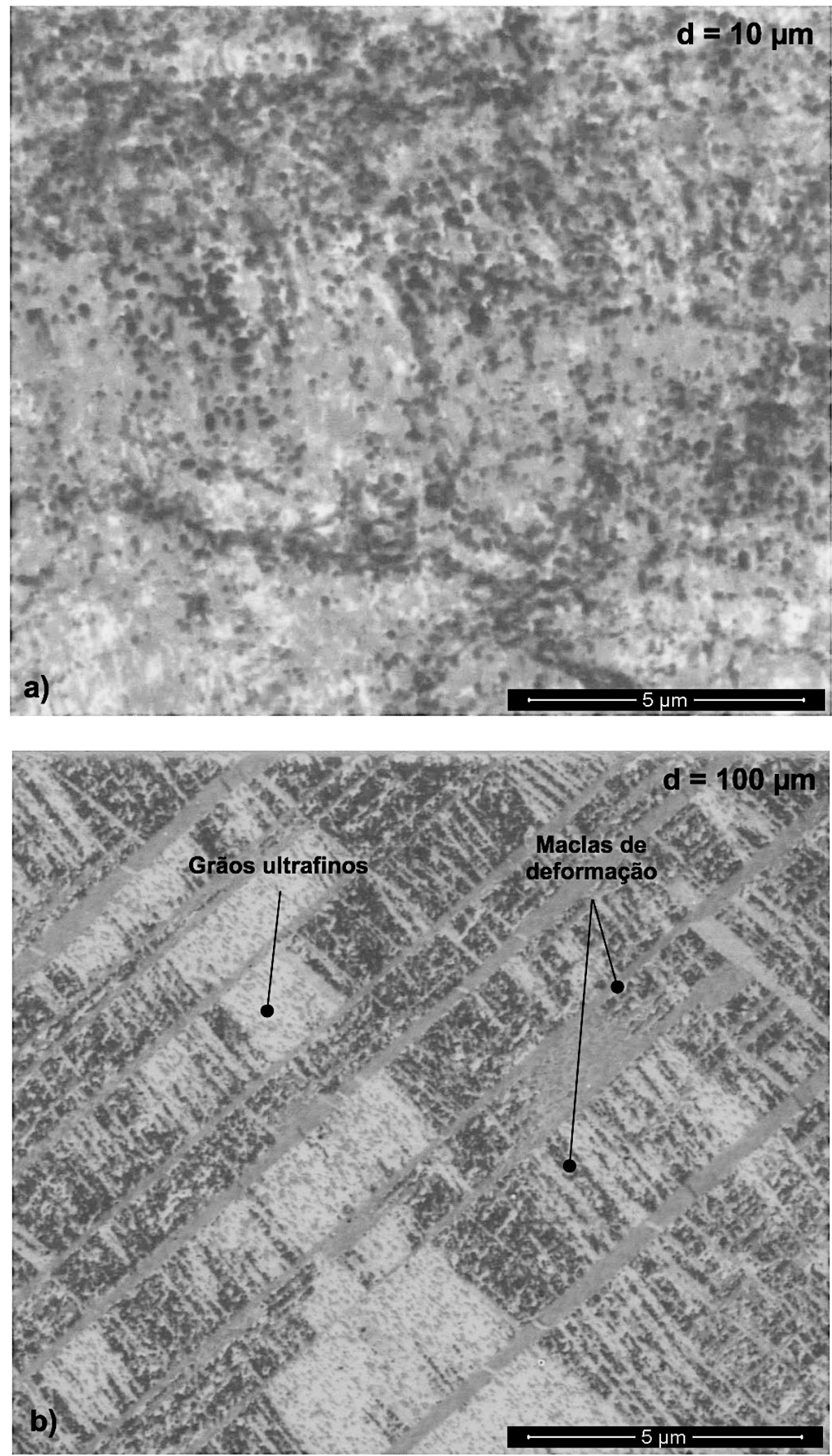

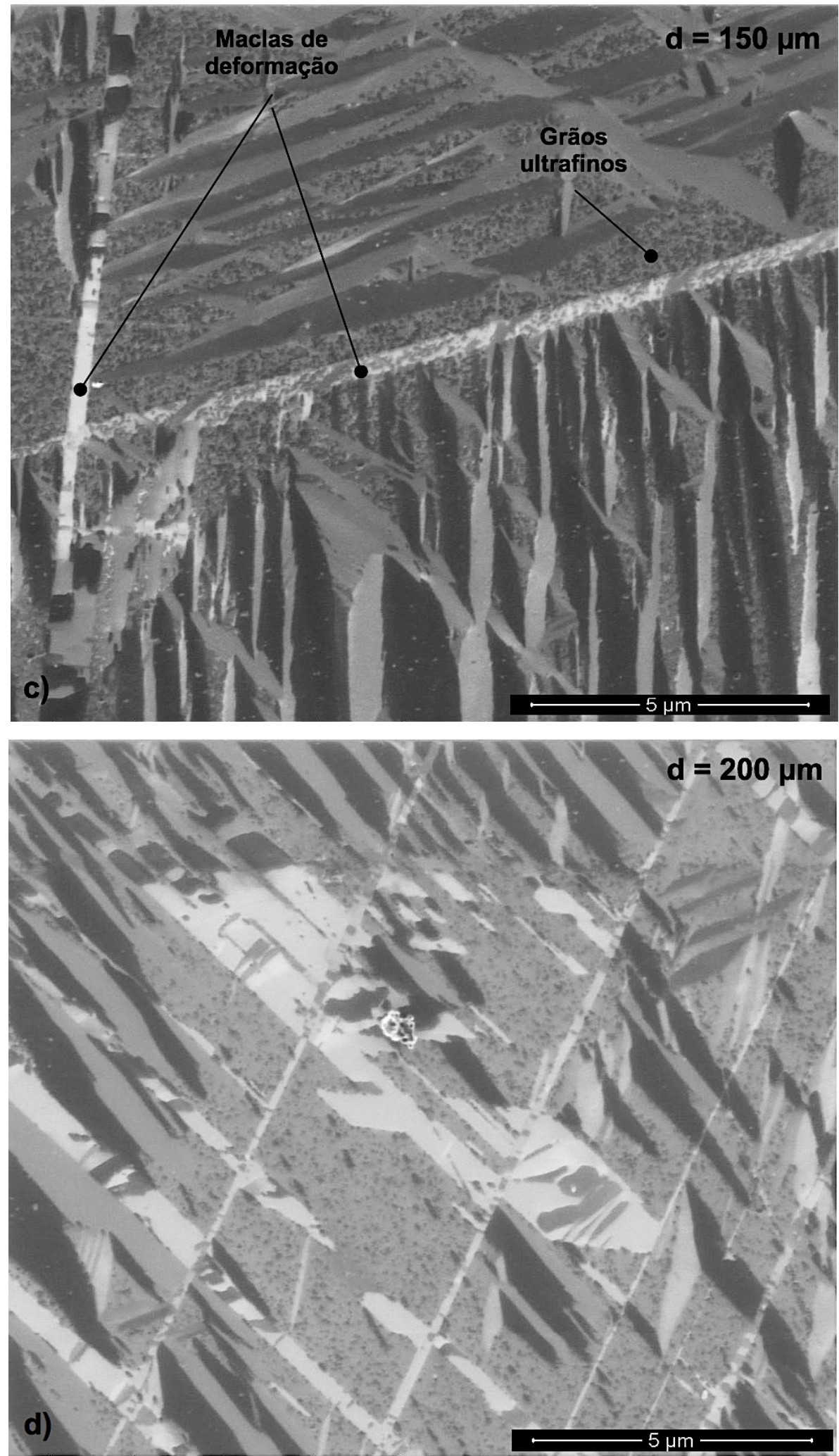

Na mesma superfície com corte em ângulo foram realizadas análises de EBSD nas posições com distâncias de $20 \mu \mathrm{m}, 100 \mu \mathrm{m}$ e $200 \mu \mathrm{m}$ da superfície desgastada, Figuras $5.29 a, 5.29 b$ e $5.29 c$, respectivamente. O resultado da análise realizada a $10 \mu \mathrm{m}$ da superfície desgastada, Figura 5.29a, teve em grande parte da área 
analisada orientação cristalográfica indefinida, devido, provavelmente, a limitação de resolução do equipamento para caracterizar a região com grãos ultrafinos. Meyers et al. não conseguiram caracterizar via EBSD a microestrutura do interior de bandas de cisalhamento devido o limite de resolução do equipamento de 0,2 $\mu \mathrm{m}$ (MEYERS et al., 2003). Na Figura 5.29 as regiões com orientação cristalográfica definida se referem à fase austenítica deformada. O gradiente de cores nestas regiões é característico da desorientação gerada pela deformação. Nota-se que estas regiões são envolvidas por pontos com orientação não definida, os quais referem-se aos grãos ultrafinos. Esta distribuição da microestrutura foi observada nas micrografias do britador cônico, Figura 5.15 (tópico 5.3.1). As Figuras $5.29 b$ e $5.29 c$ mostram o efeito da deformação na orientação cristalográfica do material (desorientação) com predominância da orientação (111).

Figura 5.29. Imagens de IPF-EBSD da subsuperfície de regiões com distâncias de (a) $10 \mu \mathrm{m}$, (b) $100 \mu \mathrm{m}$ e (c) $200 \mu \mathrm{m}$. 20.000X

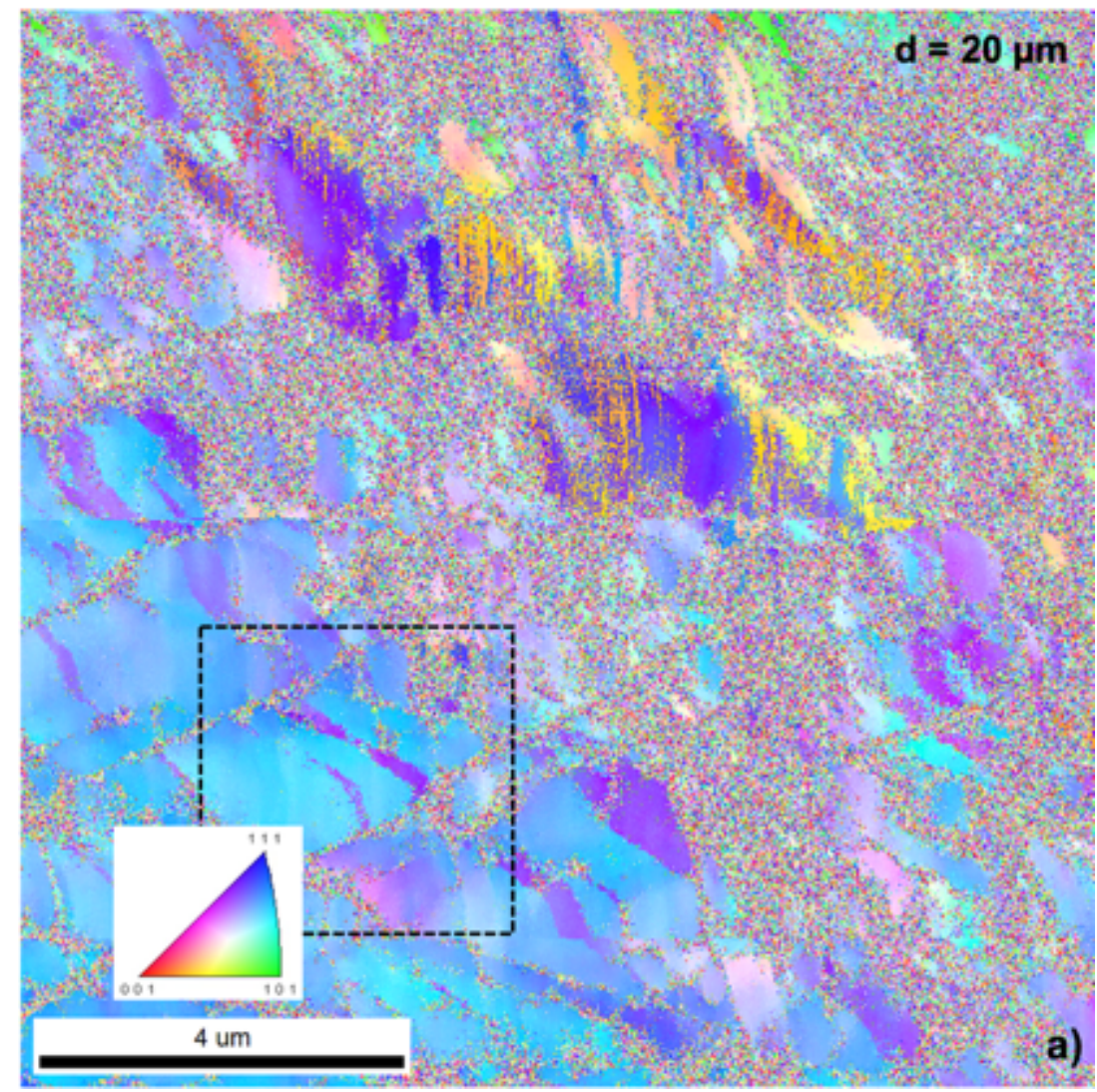



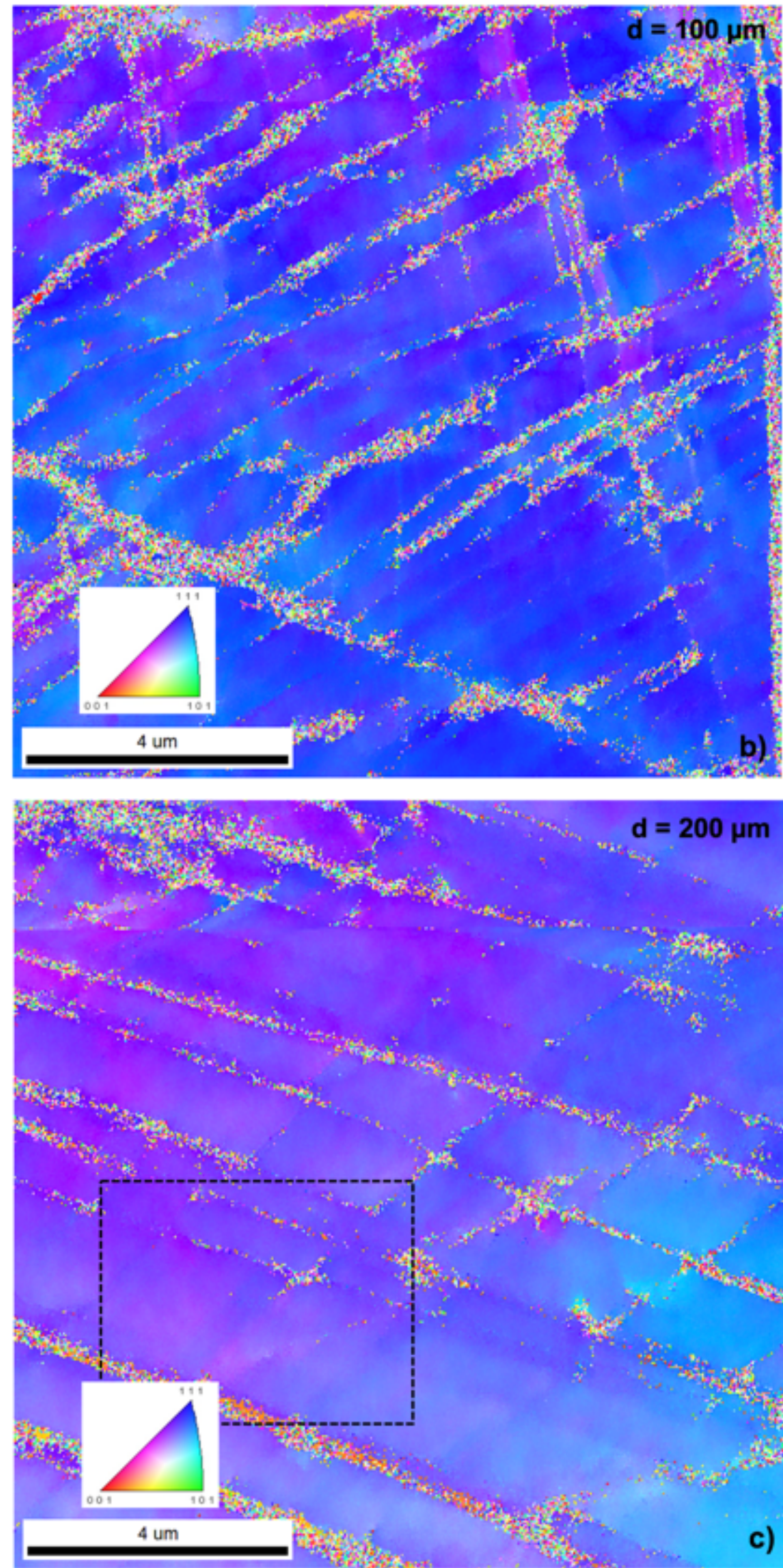

A região em destaque na Figura 5.29a (quadro) é mostrada na Figura 5.30a, o eixo indica o local de análise da desorientação. Observa-se no gráfico da Figura 5.30b 
que a desorientação é de alto ângulo ao longo do eixo de referência posicionado em uma região de grão original deformado.

Figura 5.30. Imagens de IPF e gráfico de desorientação da região em destaque na Figura 5.29a
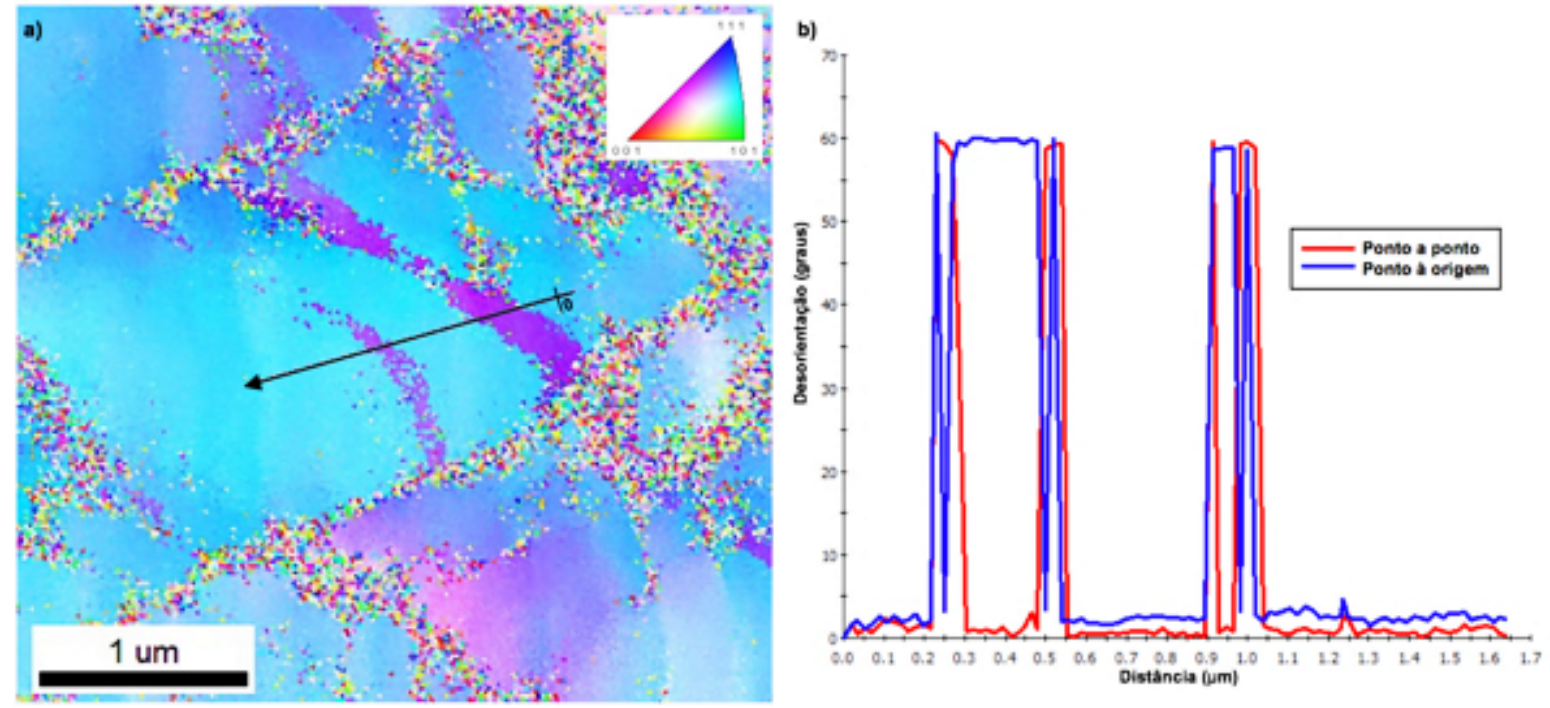

Na região a $200 \mu \mathrm{m}$ da superfície foi selecionada uma área, em destaque no quadro da Figura 5.29 c, para análise de desorientação. A Figura 5.31a mostra a área ampliada com o eixo de referência do gráfico na Figura 5.31b. Observa-se que a desorientação ao longo do eixo é de baixo ângulo $\left(<15^{\circ}\right)$, semelhante à desorientação no interior do grão da microestrutura deformada do britador giratório.

Figura 5.31. Imagens de IPF e gráfico de desorientação da região em destaque da Figura 5.29c
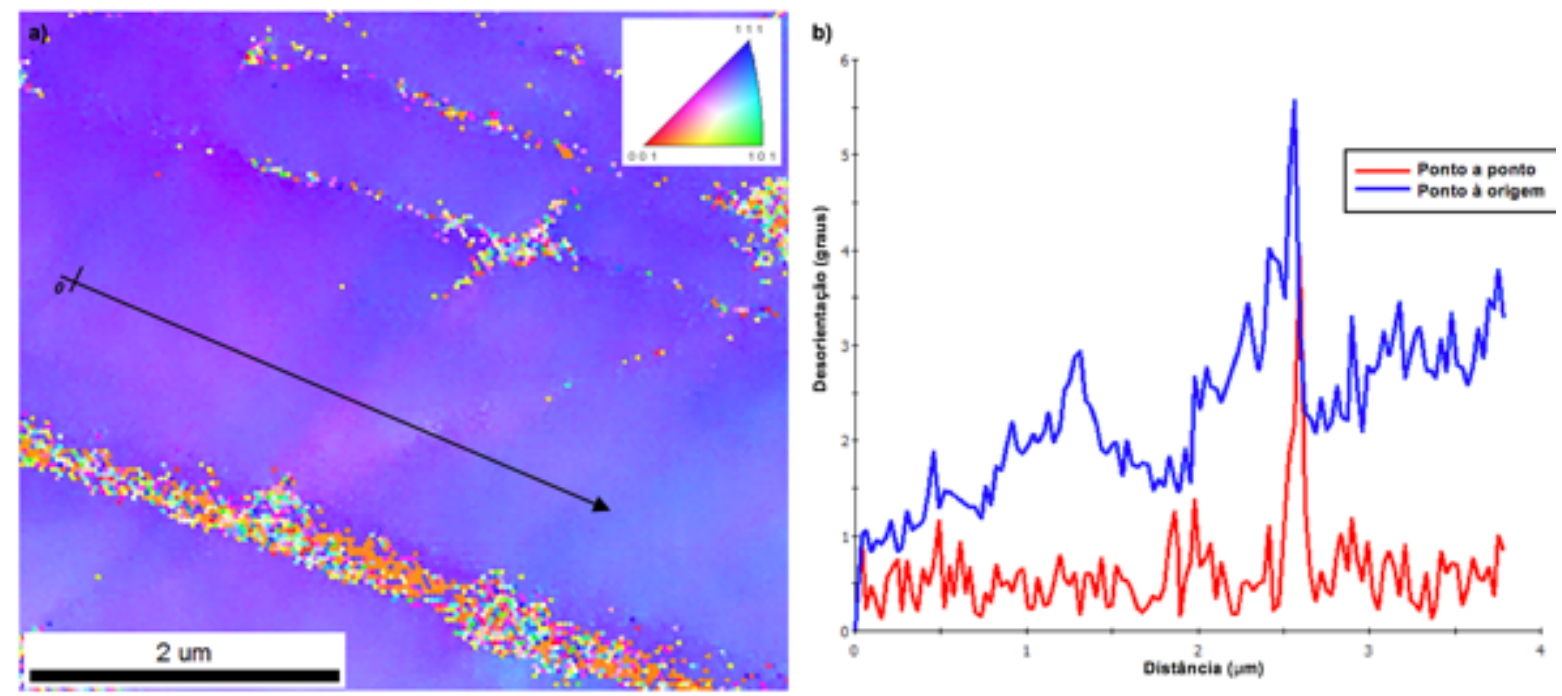

A Figura 5.32 mostra o resultado de DRX para a amostra desgastada em ensaio de britador de mandíbula. Os padrões indexados no difratograma correspondem à 
austenita, oxido de ferro e quartzo. Este resultado tem características semelhantes ao resultado do revestimento de britador cônico, com padrão de maior intensidade para a austenita e padrões de menor intensidade para a camada superficial de óxido e para o minério encrustado na superfície e envolvido por material deformado.

Figura 5.32. Resultado de DRX - amostra desgastada em ensaio de britador de mandíbula

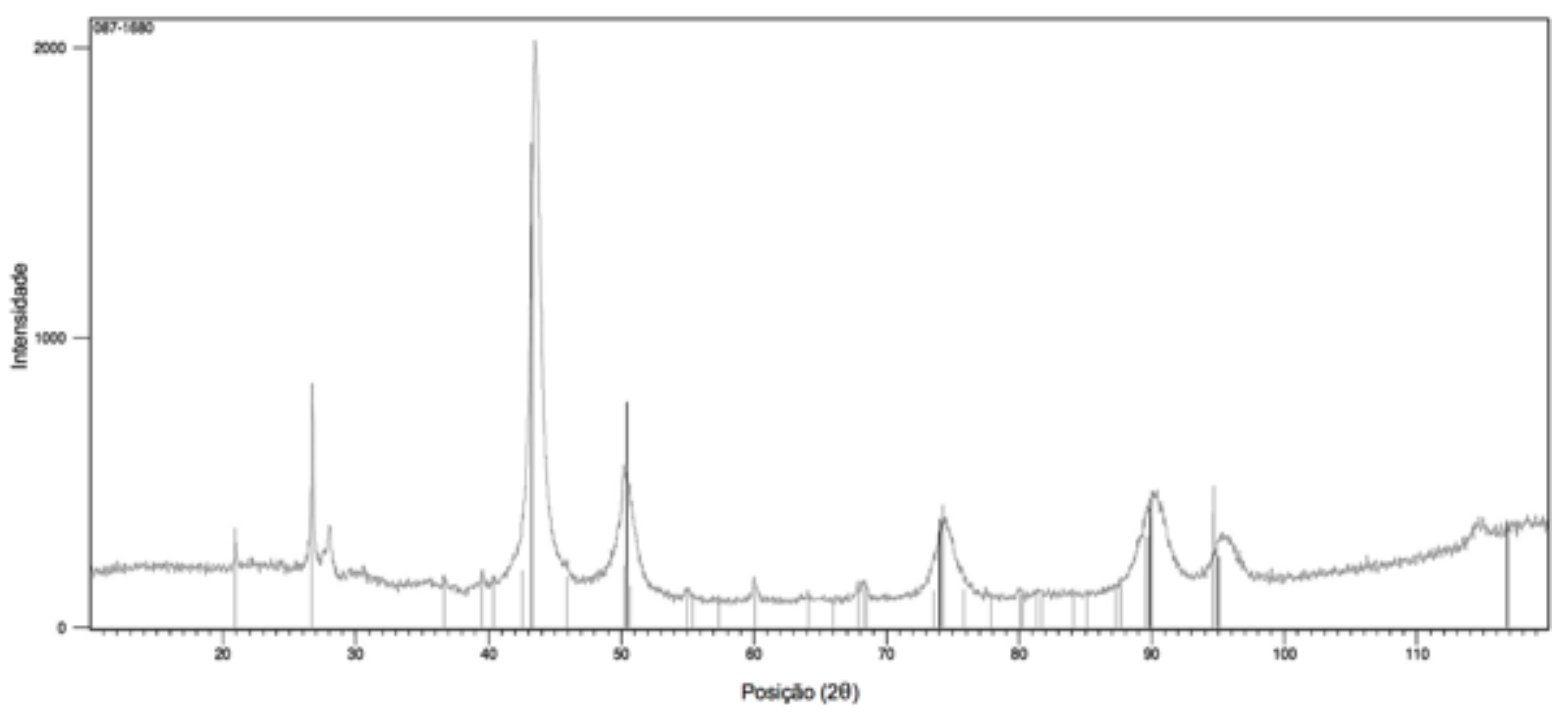

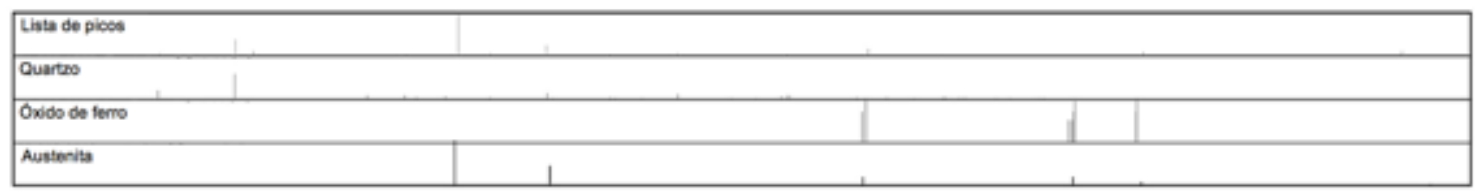

$\mathrm{Na}$ escala meso observou-se que as características da microestruturais presentes na camada 1 são: grãos deformados, grãos desgastados, grãos ultrafinos (recristalizados) e trincas. Na camada 2 observam-se apenas os grãos deformados. Nota-se que a diferença entre, não se observou o fenômeno de crescimento de grãos que sucede a recristalização na camada 1, assim como nucleação e propagação de trincas transgranulares e intergranulares, sendo estas as diferenças microestruturais entre as escalas macro e meso do fenômeno de abrasão. Portanto, deve-se considerar que o ensaio laboratorial de britador de mandíbula não retrata todas as alterações microestruturais existentes no processo de fragmentação real (escala macro), neste caso, sugere-se que a causa desta diferença microestrutural da subsuperfície esteja relacionada ao nível de energia associada a cada nível da multiescala. Este resultado mostra que o ensaio laboratorial de britador de mandíbula, apesar de reproduzir a dinâmica do movimento do caso real, não reproduz todos os fenômenos associados à microestrutura da subsuperfície. No 
entanto, este ensaio não deixa de ser uma ferramenta importante para comparar materiais quanto a resistência à abrasão por goivadura, como mostrado nos estudos de Diesburg e Borik (DIESBURG, D. E.; BORIK, F., 1974).

\subsubsection{Microestrutura da subsuperfície do risco (ensaio de microesclerometria)}

As micrografias dos riscos obtidas via MEV para cada orientação cristalográfica são mostradas na Figura 5.33. O micromecanismo predominante observado nos riscos foram microcorte com formação de cavaco e bordas laterais para os riscos nos planos cristalográficos (111) e (101), Figuras 5.33b e 5.33c; e microsulcamento com formação de pile-up e sink-in para o risco no plano 001, Figura 5.33a. A microestrutura na subsuperfície dos riscos (Figuras 5.34, 5.35 e 5.36) tem correlação com os micromecanismos observados.

Figura 5.33. Riscos nos planos cristalográficos a) (001), b) (111) e c) (101). 900X

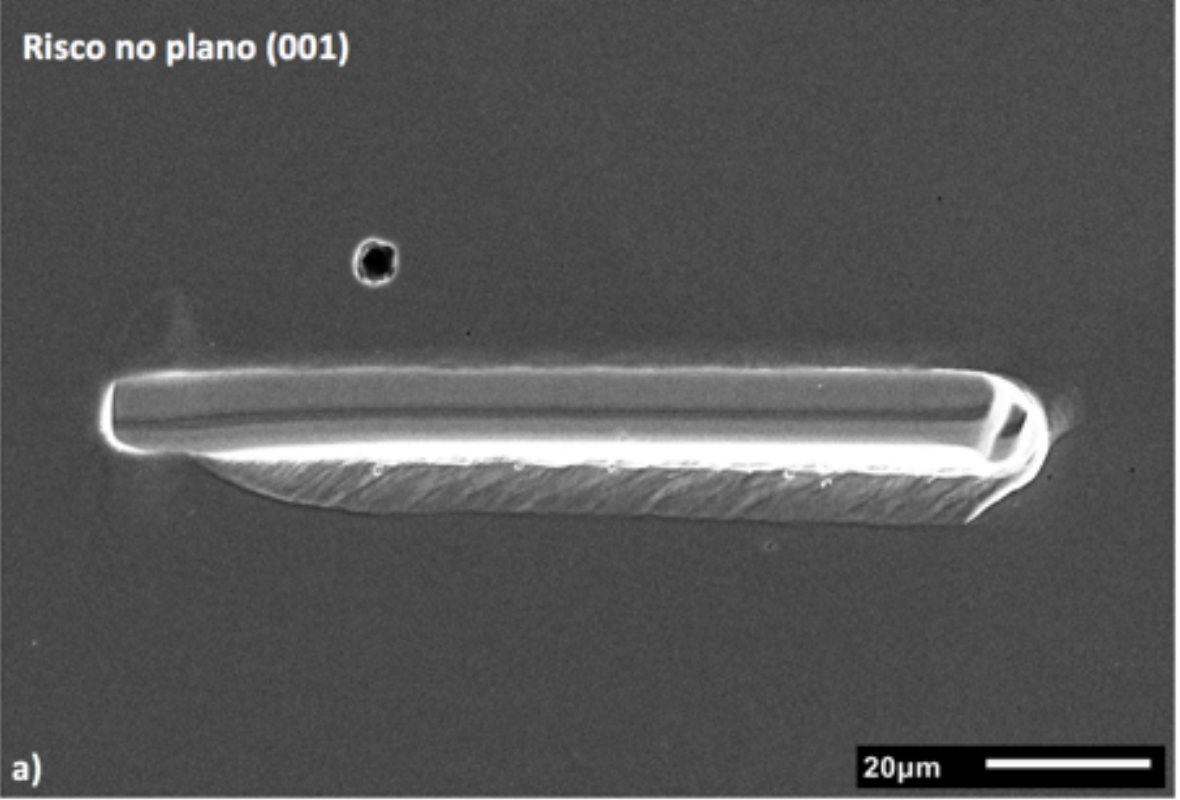



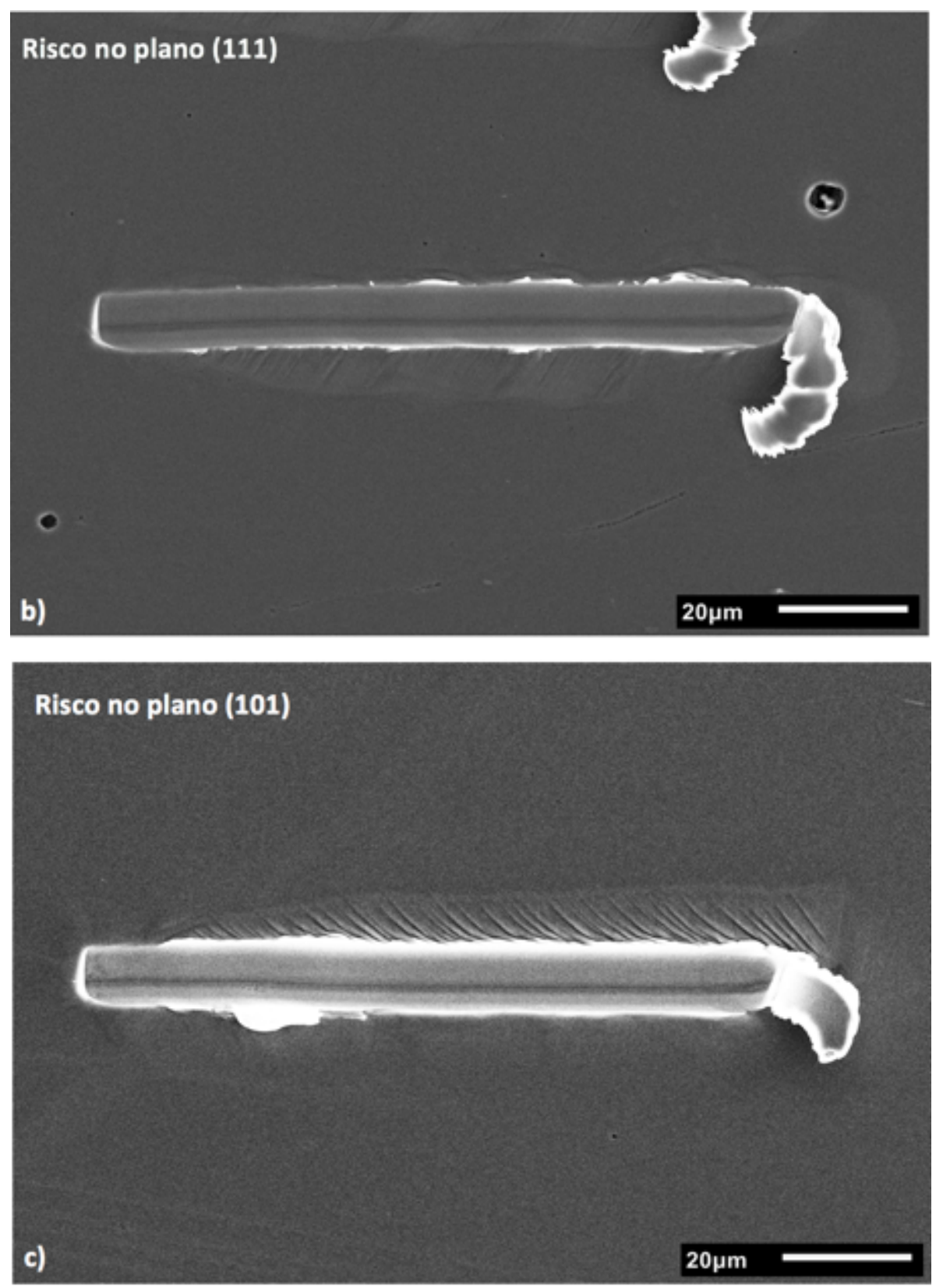

A Figura 5.34 mostra a microestrutura da subsuperfície do risco no plano cristalográficos (001). Observam-se bandas de escorregamento abaixo do pile-up e maclas de deformação com $90^{\circ}$ e $56^{\circ}$ (Figura 5.34b). 
Figura 5.34. Microestrutura da subsuperfície do risco no plano (001). 12Mn. a) 10.000X. b) 20.000X
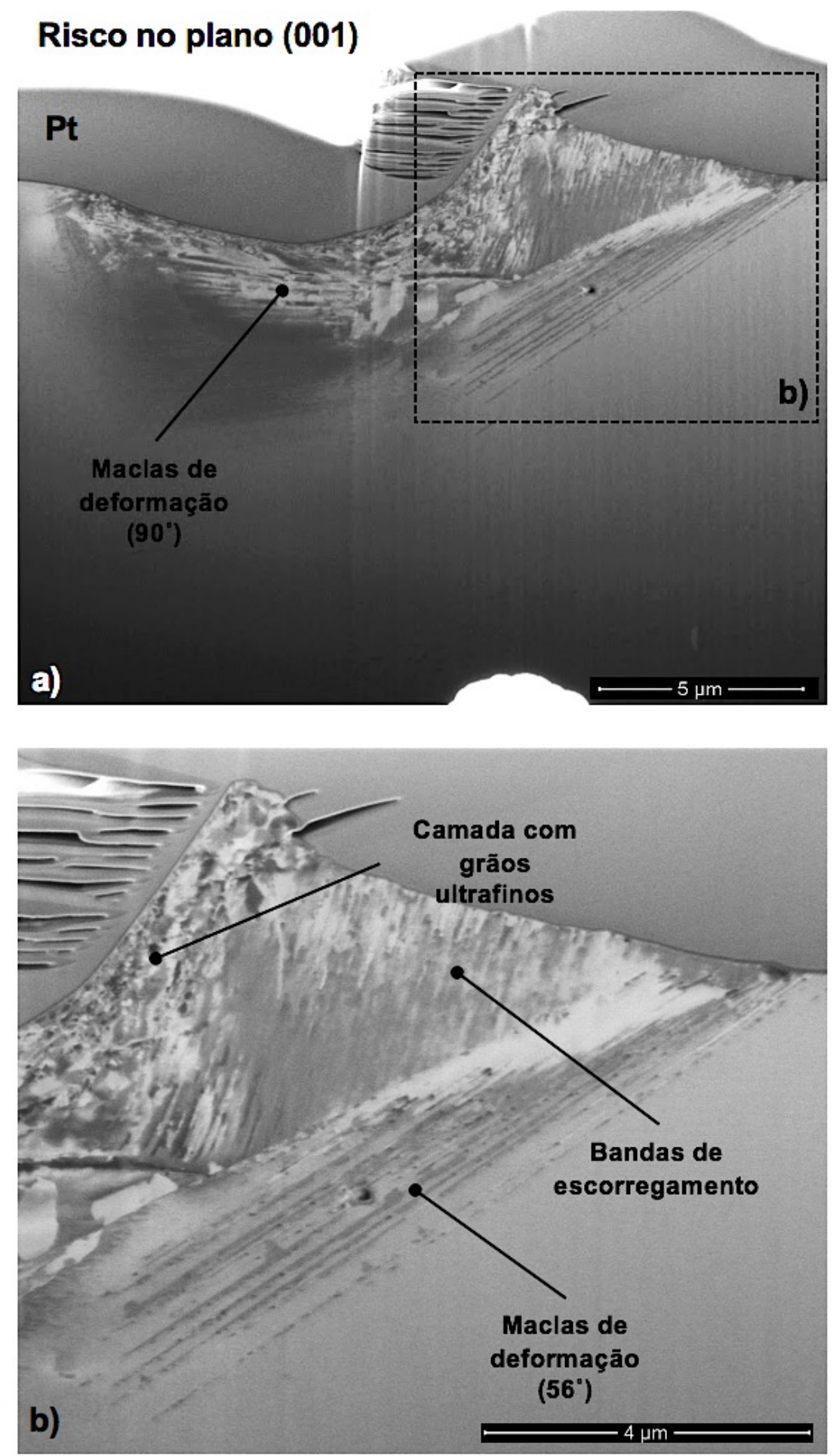

A Figura 5.35 mostra a microestrutura da subsuperfície do risco no plano cristalográficos (111). Observa-se na subsuperfície (abaixo da interface endentador/material) uma camada com grãos ultrafinos. Esta camada apresentou diferentes áreas de acordo com o plano cristalográfico de riscamento. 
Figura 5.35. Microestrutura da subsuperfície do risco no plano (111). 12Mn. a) 10.000X. b) 20.000X
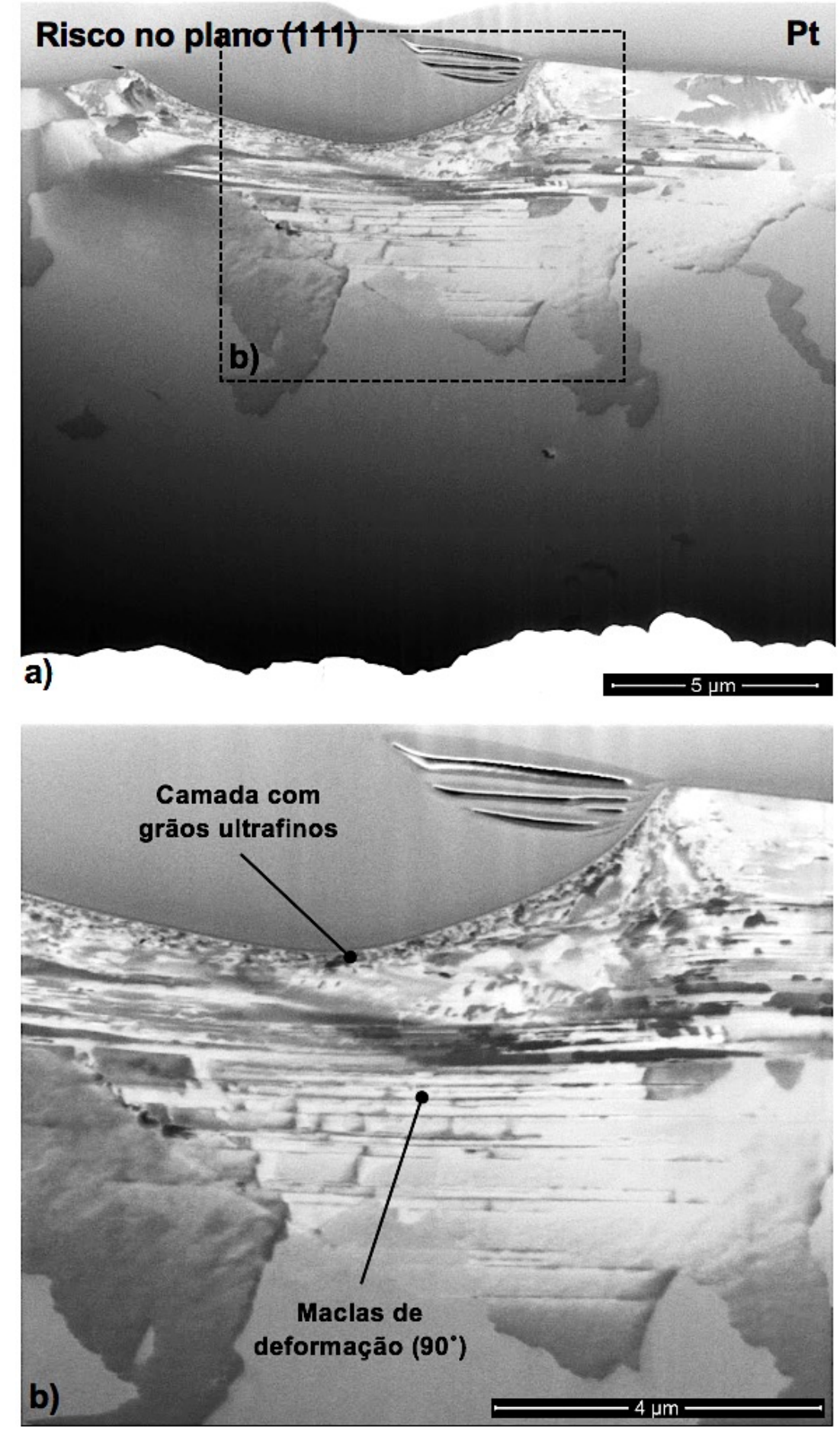

Os valores medidos da área da camada com grãos ultrafinos na subsuperfície dos riscos nos planos cristalográficos (001), (111) e (101) são: 8,3 $\mu^{2}, 2,6 \mu m^{2}$ e $5,6 \mu \mathrm{m}^{2}$, respectivamente. A profundidade da camada para (001), (111) e (101) foram $0,44 \mu \mathrm{m}, 0,30 \mu \mathrm{m}$ e $0,35 \mu \mathrm{m}$, respetivamente. A microestrutura abaixo da camada de grãos ultrafinos tem grãos pequenos com maclas de deformação e 
bandas de escorregamento. Na subsuperfície do risco no plano (111) observou-se maclas de $90^{\circ}$ em relação ao eixo vertical, Figura $5.35 b$.

A Figura 5.36 mostra a microestrutura da subsuperfície do risco no plano cristalográficos (101). Observam-se bandas de escorregamento e maclas de deformação com $20^{\circ}$ (Figura 5.36b).

Figura 5.36. Microestrutura da subsuperfície do risco no plano (101). 12Mn. a) 10.000X. b) 20.000X
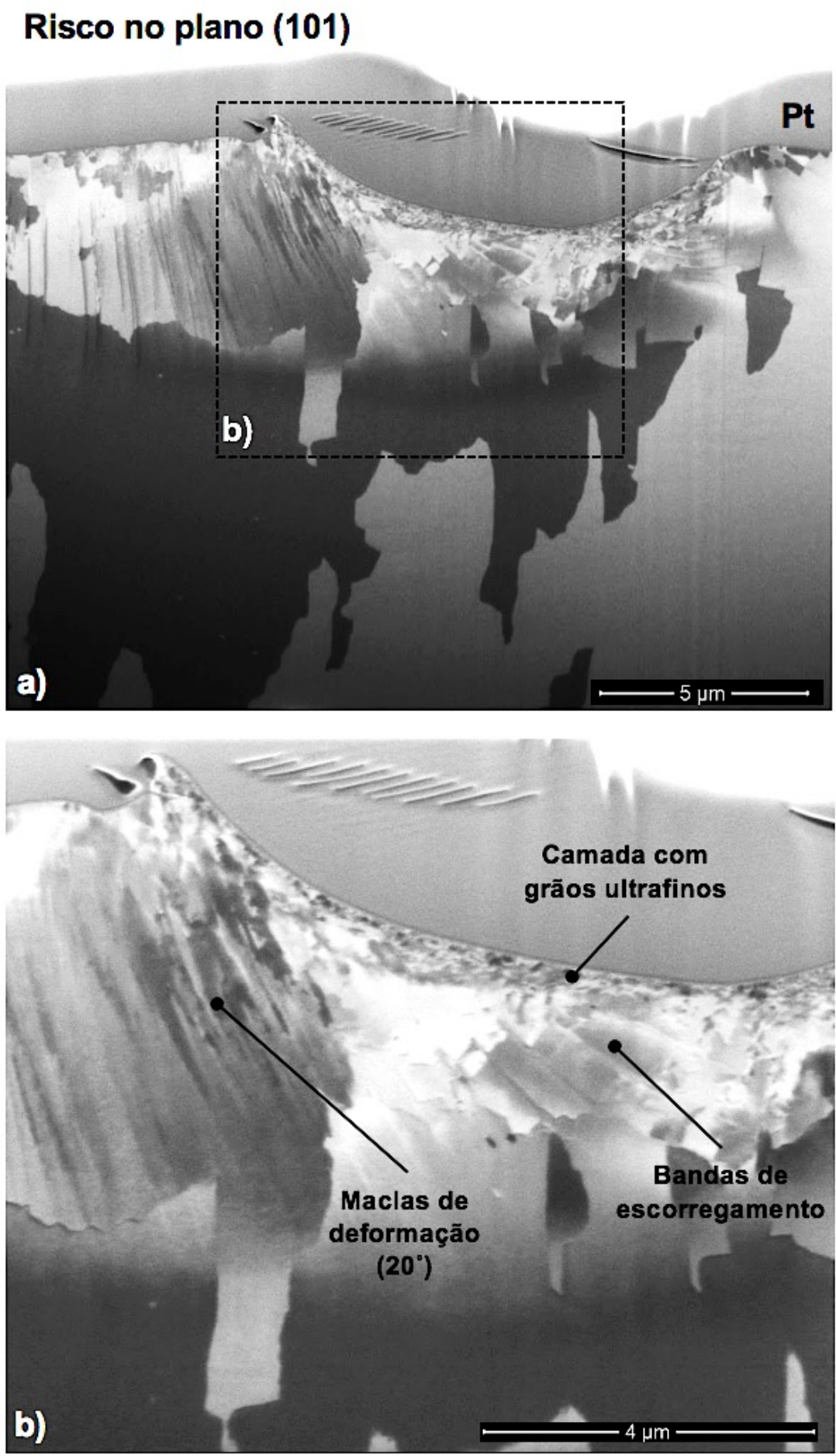
A subsuperfície do risco no plano cristalográfico (111) foi analisada via MET. As análises foram realizadas na camada com grãos ultrafinos e na região com maclas de deformação, abaixo da camada. A Figura 5.37 mostra imagens de transmissão com ampliações crescentes. A imagem de difração de elétrons referente à área de análise da Figura $5.37 d$ é mostrada na Figura 5.37e. O padrão da imagem de difração em forma de anel decorre de uma estrutura policristalina, ou seja, nestas condições o que se observa na Figura 5.37d é um domínio contendo vários cristais de dimensões nanométricas (grão ultrafino).

Figura 5.37. a) Imagem de MET - campo claro da camada com grãos ultrafinos. b) Ampliação da região indicada na Figura a. c) Ampliação da região indicada na Figura $b$. d) Ampliação da região indicada na Figura c. e) Imagem de difração da área de análise da Figura $d$

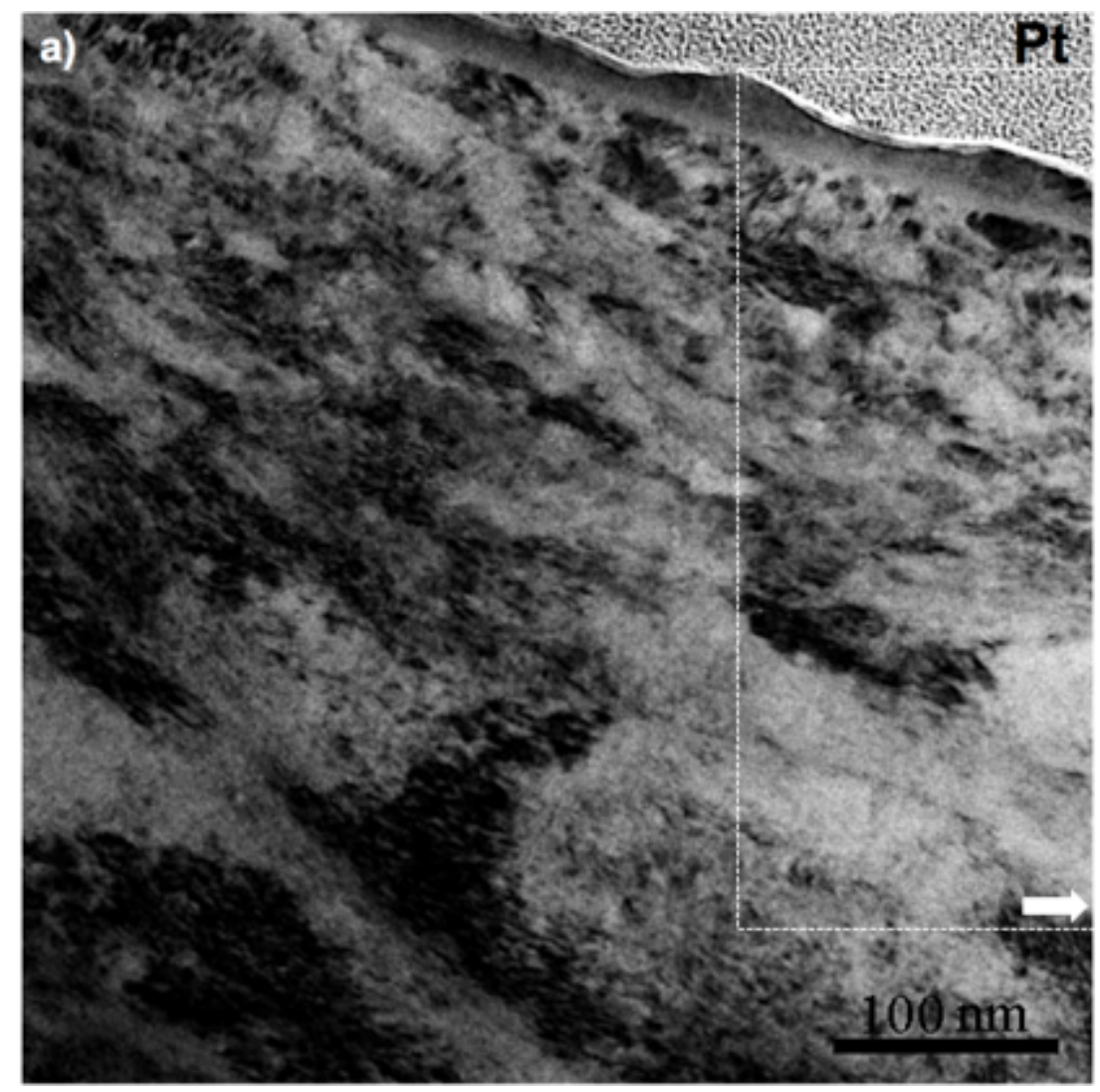



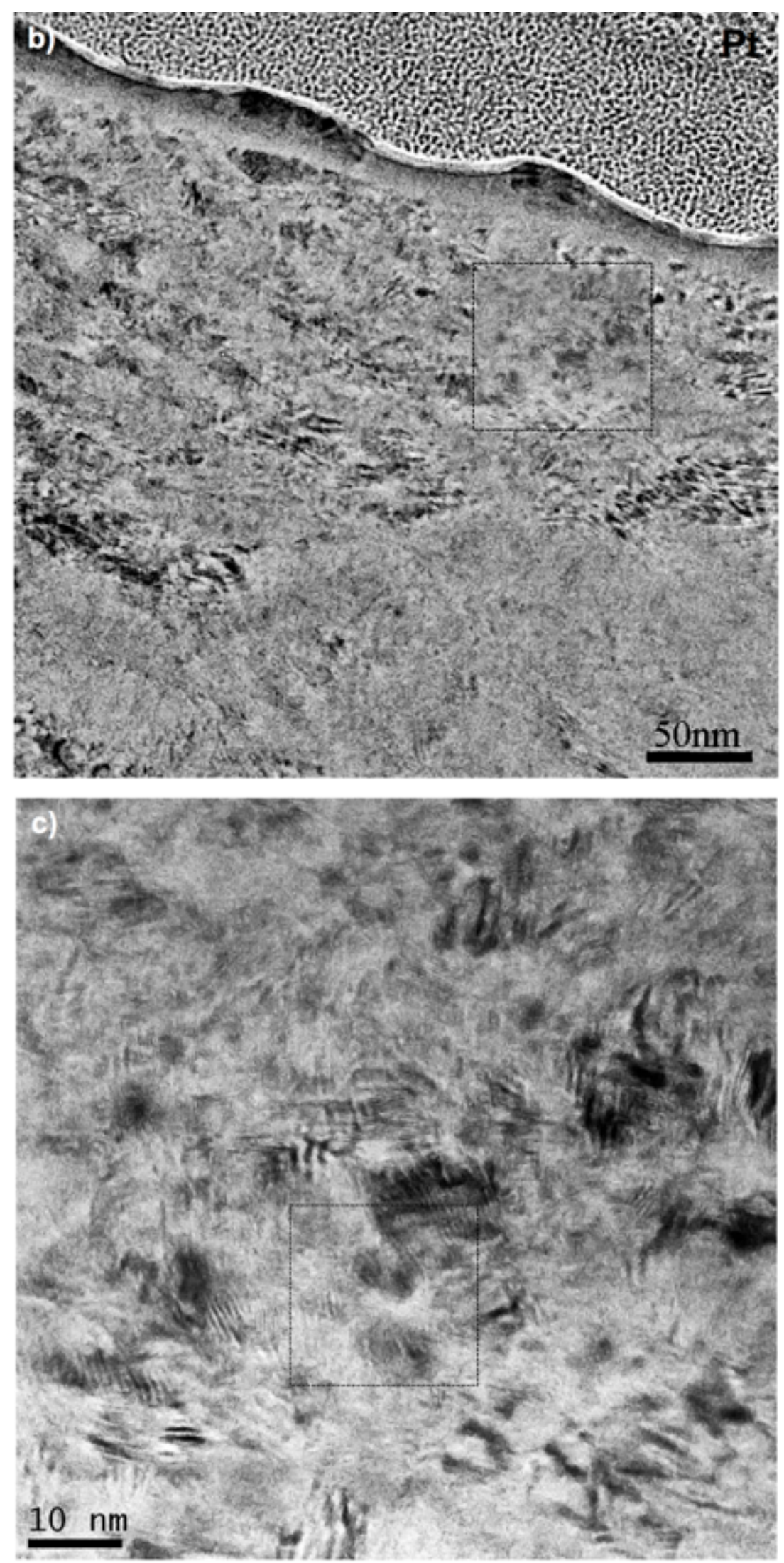

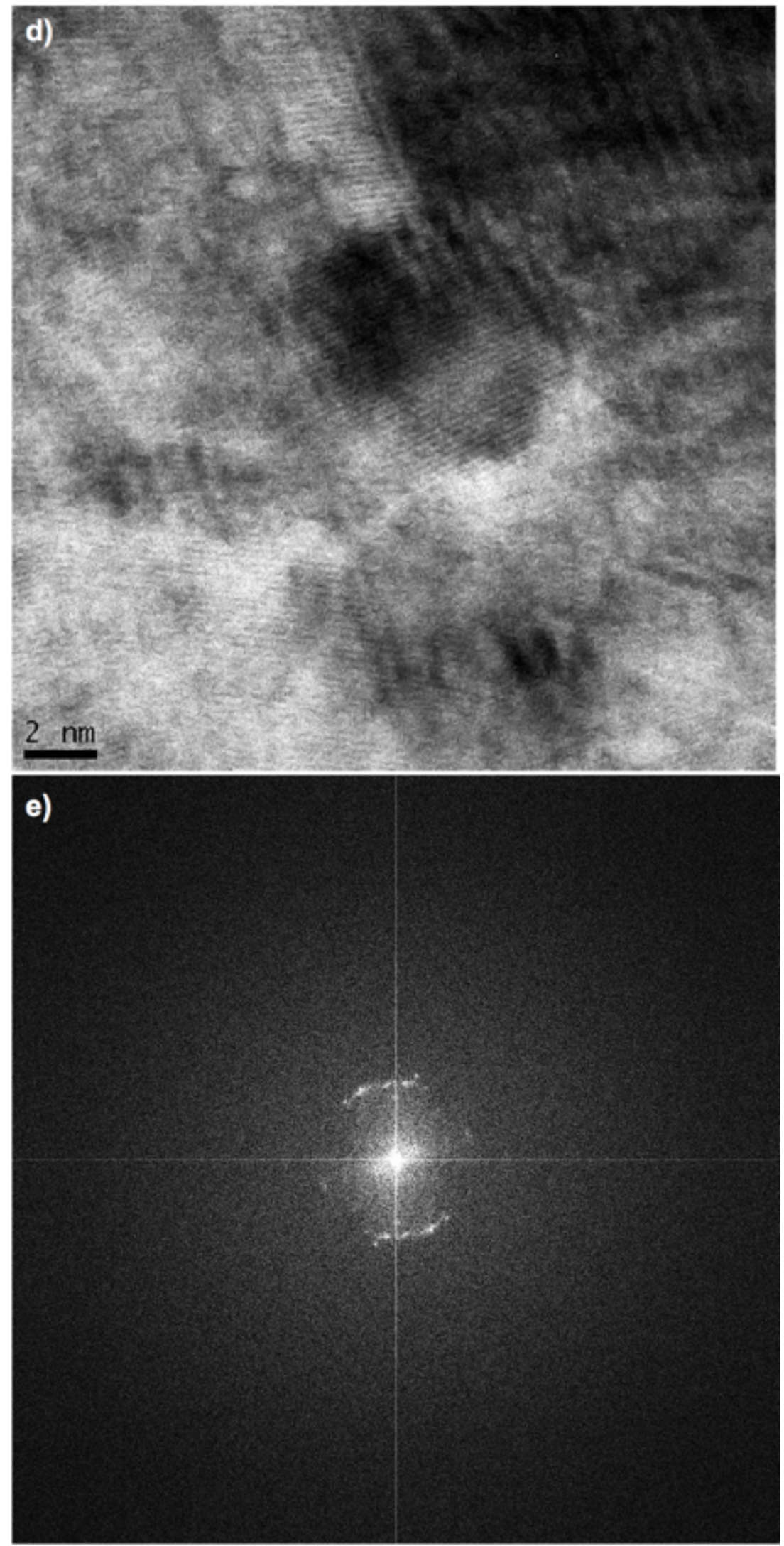
Os autores Feng et al. observaram tamanho médio de grão de $25 \mathrm{~nm}$ na subsuperfície de aço Hadfield (Figura 5.38) deformado por high-speed pounding (FENG et al., 2013b), enquanto, Yan et al. observaram em aço Hadfield uma camada nanocristalina com tamanho de grão de 3 a 17 nm (Figura 5.39) gerada por tratamento de shot peening (YAN et al., 2009). Os autores obtiveram tamanho de grão de $40 \mathrm{~nm}$ e $30 \mathrm{~nm}$ para os tempos tratamento de 2 e 30 minutos, respectivamente.

Figura 5.38. Aço Hadfield deformado por high-speed pounding. a) Imagem de MET (campo claro) e SAED da camada subsuperficial. b) Distribuição de tamanho de grão (Raio-X)
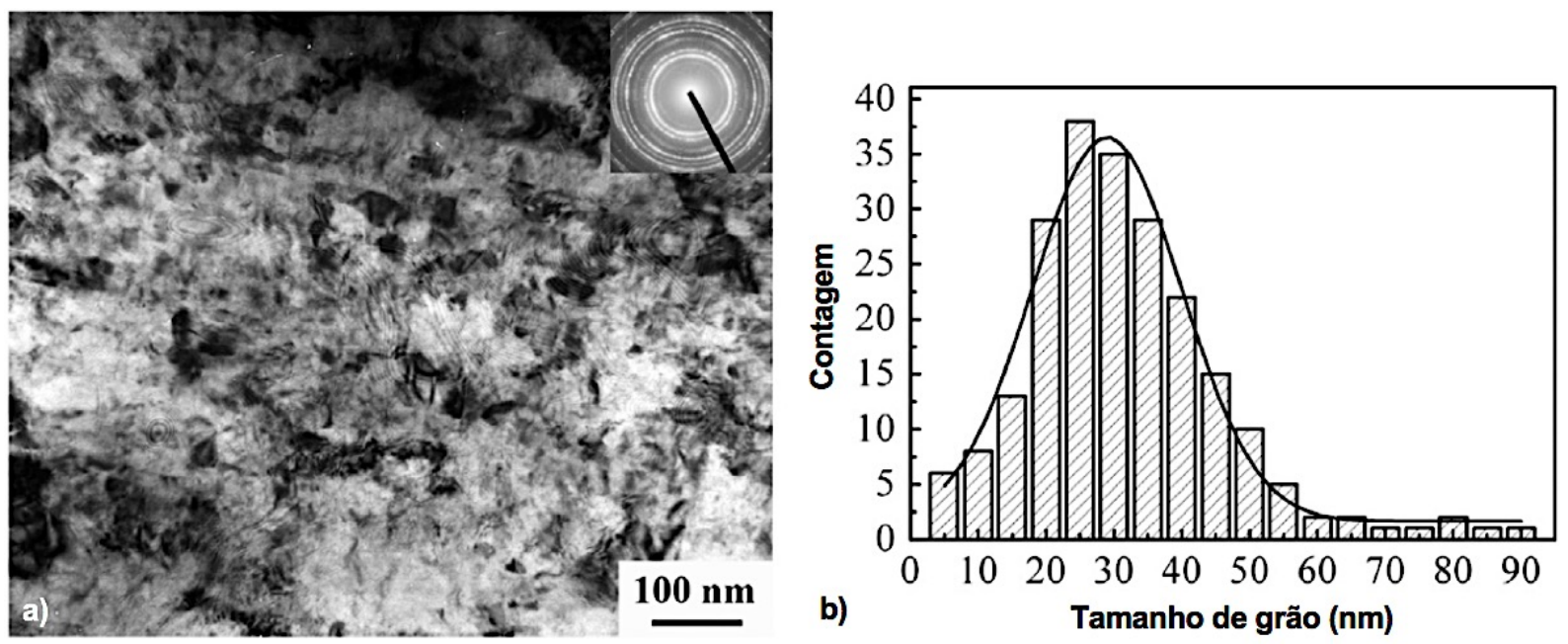

Fonte: Feng et al., 2013b

Figura 5.39. Aço Hadfield deformado por shot peening. Imagem de MET (campo claro) e SAED da camada subsuperficial. a) Dois minutos de shot peening. b) 30 minutos de shot peening.

c) 60 minutos de shot peening. d) Maior aumento da área da Figura $c$
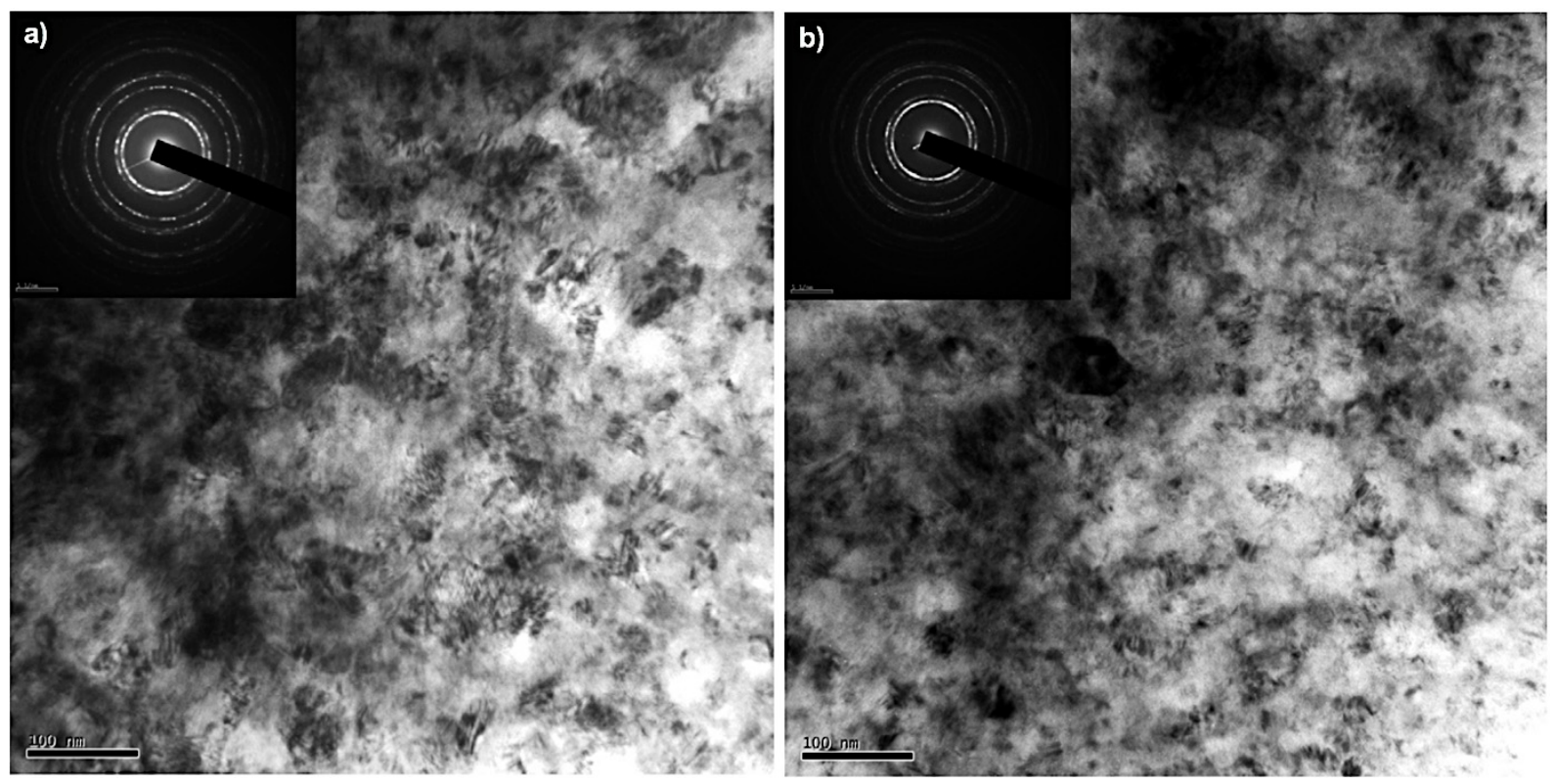

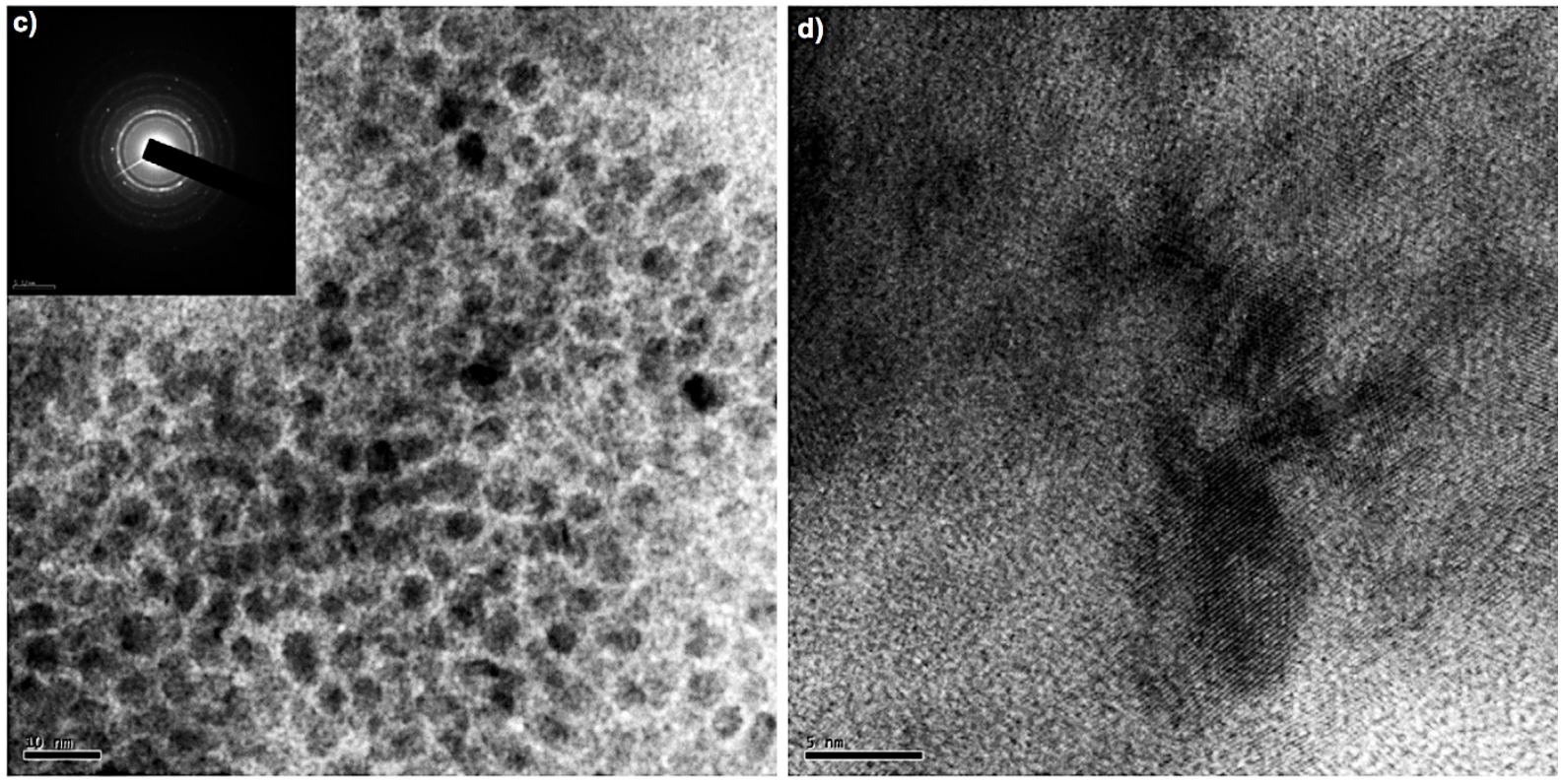

Fonte: Yan et al., 2009

Liu, Lu e Lu observaram grãos com até $10 \mathrm{~nm}$ na subsuperfície de aço inox 316L (Figura 5.40) deformado por ultrasonic shot peening, dependendo do tempo de tratamento os autores obtiveram diferentes tamanhos de grãos e associaram ao fenômeno de recristalização (LIU; LU; LU, 2000). Nota-se que a aplicação de altas taxas de deformação em metais CFC proporciona a formação de uma camada com grãos ultrafinos ou nanocristalina. A microestrutura de materiais metálicos nesta escala dimensional (nanométrica) também pode ser obtida com baixas taxas de deformação, na ordem de $10^{-2} \mathrm{~s}^{-1}$, via high-pressure torsion (SAKAl; HORITA; LANGDON, 2005). Sakai, Horita e Langdon observaram o refinamento dos grãos, que atingiram $150 \mathrm{~nm}$, de uma liga de alumínio deformada por high-pressure torsion, Figura 5.41. Estas pesquisas mostram a formação de grãos ultrafinos na subsuperfície dos materiais metálicos deformados plasticamente com diferentes taxas de deformação, entretanto, na maioria delas os autores não discutem o fenômeno metalúrgico que explica o surgimento desta microestrutura ou nanoestrutura. 
Figura 5.40. Imagem de MET e SAED da subsuperfície do aço inox $316 \mathrm{~L}$ deformado por ultrasonic shot peening. (a) e (b) $30 \mathrm{~s}$ de tratamento. (c) e (d) $810 \mathrm{~s}$
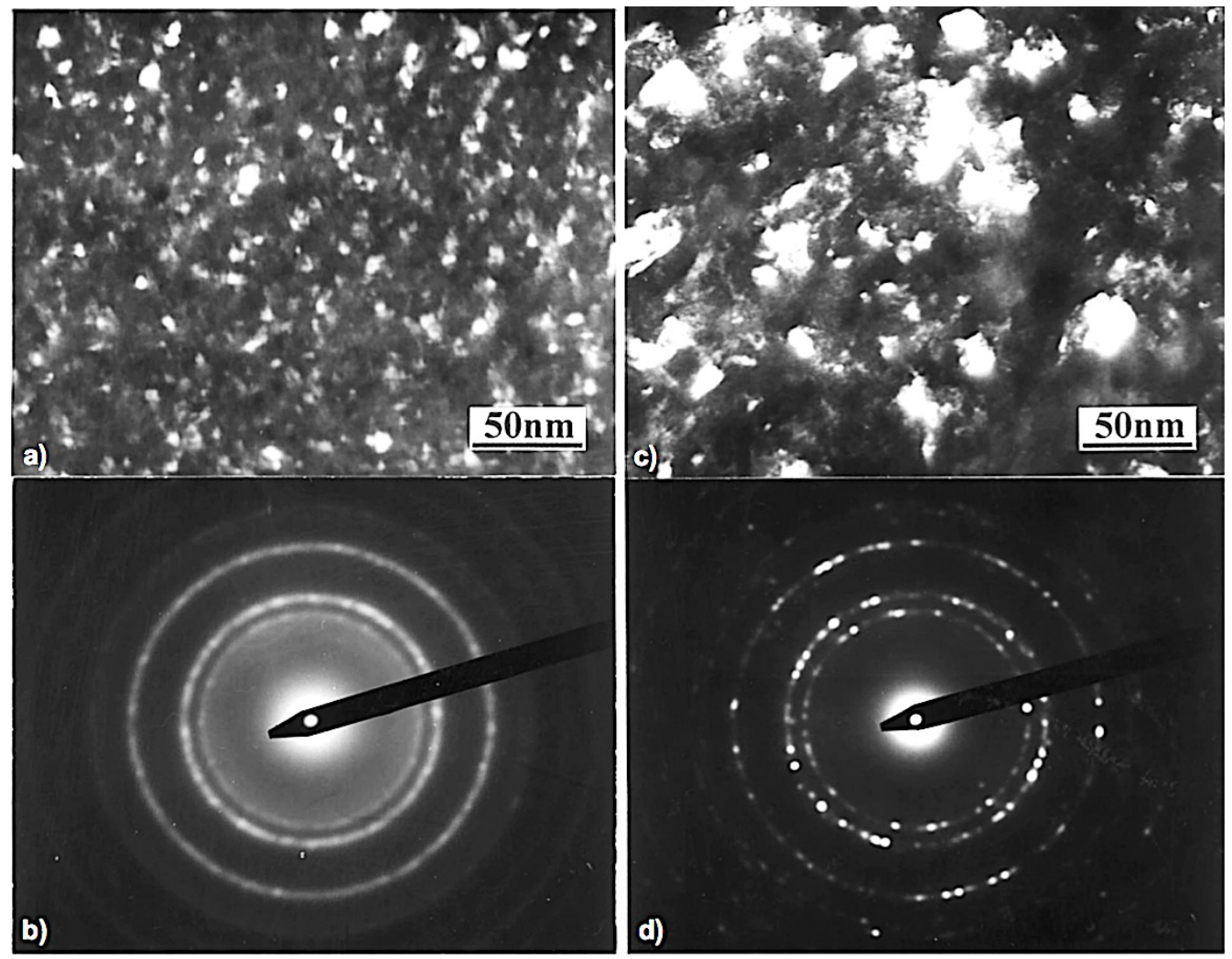

Fonte: Liu; Lu; Lu, 2000

Figura 5.41. Imagem de MET e SEAD para a subsuperfície de liga de alumínio deformada por highpressure torsion

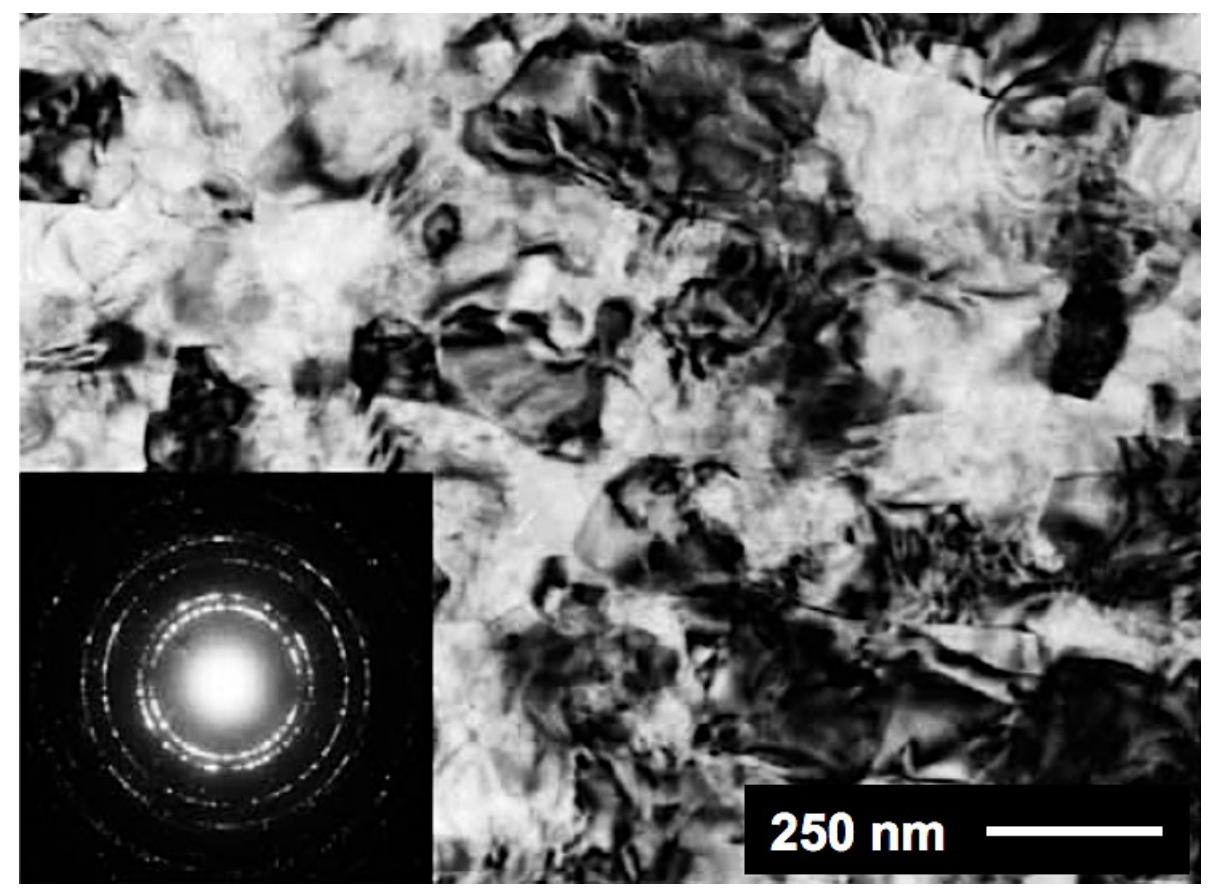

Fonte: Sakai; Horita; Langdon, 2005 
As Figuras 5.42a e 5.42b mostram imagens de transmissão com menor aumento da região de transição e região abaixo da camada de grãos ultrafinos. Nota-se na Figura 5.42a as interações dos grãos ultrafinos e discordâncias com as maclas de deformação, as quais agem como barreiras à movimentação de discordâncias. $\mathrm{Na}$ Figura $5.42 b$ observam-se os sistemas primários e secundários de maclação, e florestas de discordâncias.

Figura 5.42. Imagens de MET - campo claro da região de transição (a) e da região com maclas de deformação (b)

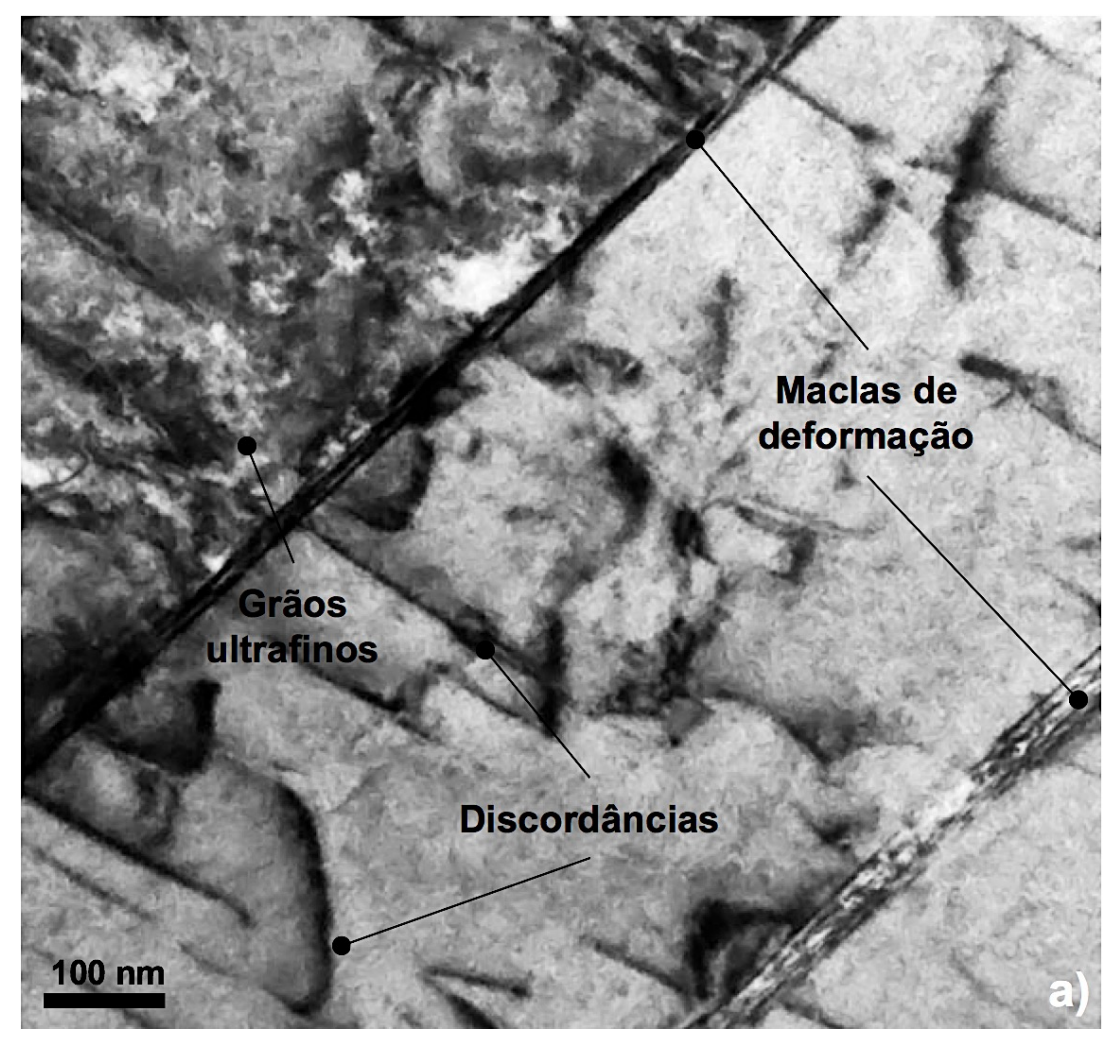




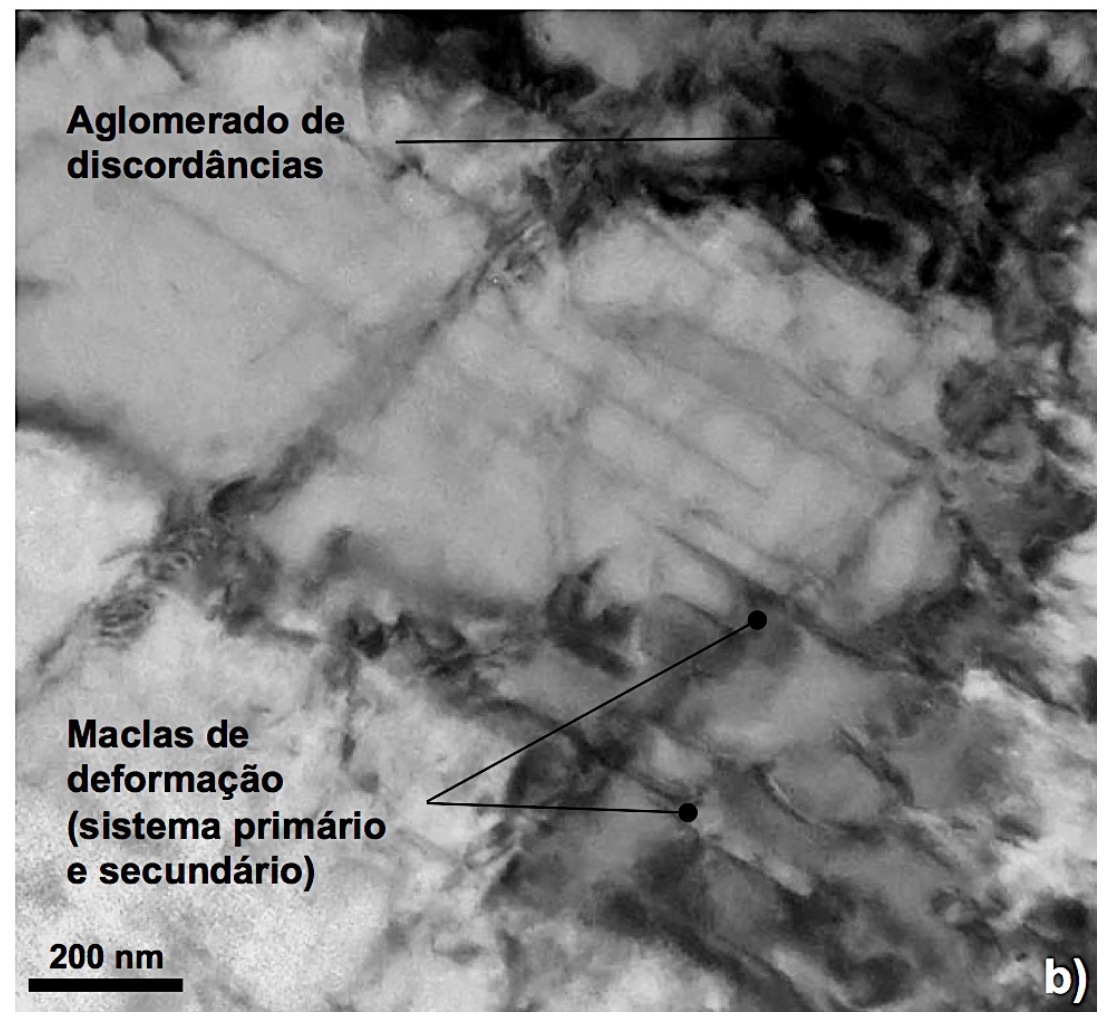

Segundo alguns autores, Adler, Olson e Owen; Hutchinson e Ridley; Sant e Smith, as maclas de deformação são o principal mecanismo de encruamento do aço Hadfield (ADLER; OLSON; OWEN, 1986; HUTCHINSON; RIDLEY, 2006; SANT; SMITH, 1987). Feng et al. observaram maclas de deformação com dimensões nanométricas na subsuperfície do aço Hadfield deformado (FENG et al., 2013b). Enquanto Karaman et al. registraram a formação de maclas de deformação no aço Hadfield monocristalino sob carregamento de tração na direção [1]11] e de compressão na direção [001] (KARAMAN et al., 2000a). Outros autores, Liu, Lu e Lu; Saldana et al.; Zhang et al., observaram via MET a formação de maclas de deformação em metais com estrutura CFC (LIU; LU; LU, 2000; SALDANA et al., 2009; ZHANG et al., 2003).

A região de transição em alta resolução é mostrada na Figura 5.43. Os quadros em destaques na imagem indicam a área de análise de difração, os resultados são mostrados nas Figuras $b, c, d$ e e. Nas imagens de difração das áreas recíprocas dos quadros $b$ e $c$, Figura 5.43a, observa-se o padrão de anel (microestrutura policristalina) na Figura 5.43b, enquanto Figura 5.43c observa-se o padrão de macla. 
Figura 5.43. a) Imagem de MET - campo claro da região de transição com quadros indicando áreas de análise de difração, Figuras $b, c, d$ e $e$
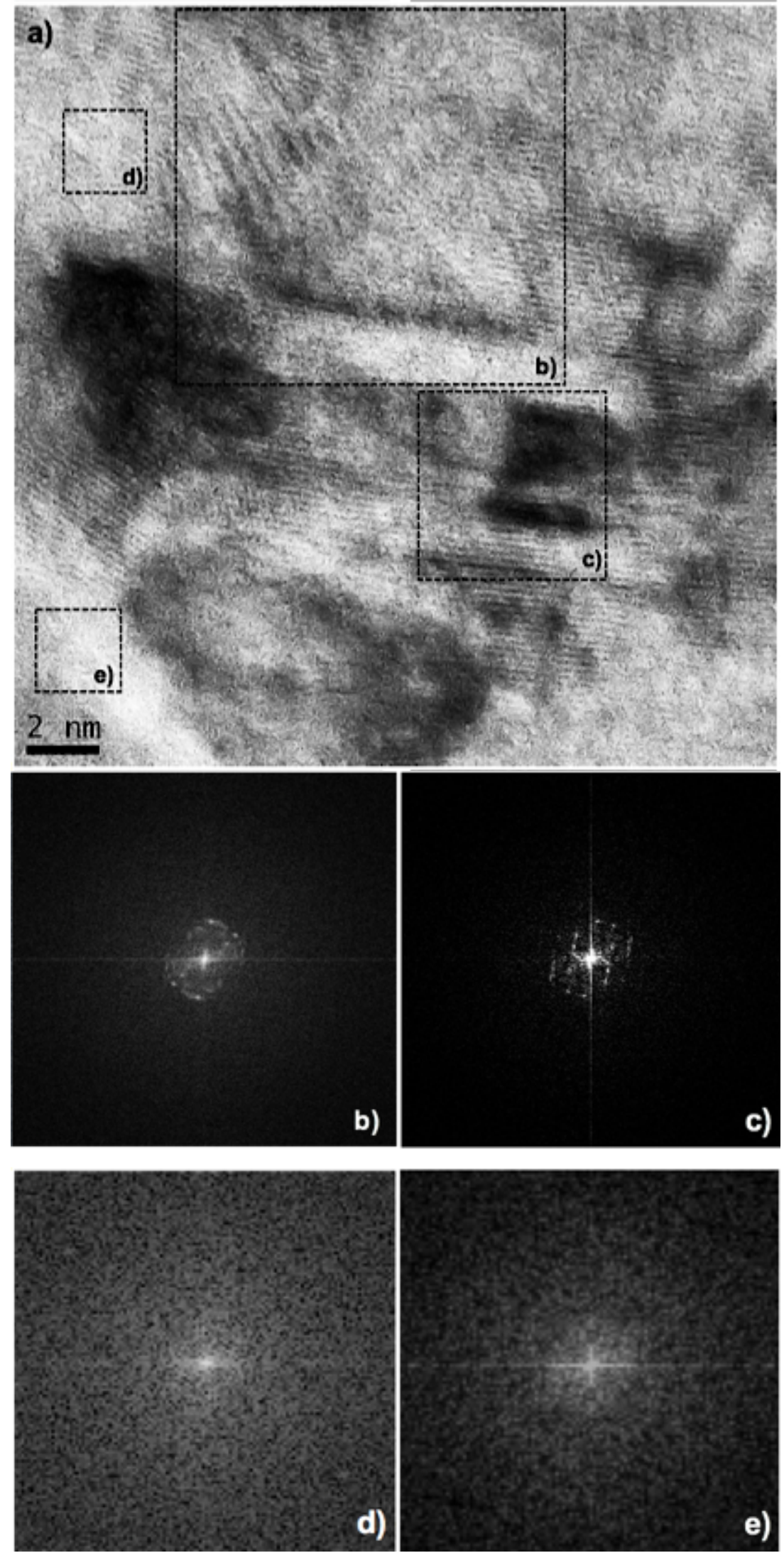
A imagem de difração da área recíproca do quadro $d$ (Figura 5.43a) é mostrada na Figura 5.43d não havendo padrões de planos cristalinos. O padrão desta figura se assemelha a um alo difuso, padrão característico de estruturas amorfas. Este resultado indica que pode ter ocorrido amorfização em alguns pontos da região deformada próximo à superfície desgastada. Petrov et al. observaram uma camada de material amorfo em meio à estrutura policristalina na subsuperfície do aço Hadfield desgastado por erosão, Figura 5.44 (PETROV et al., 2006).

Figura 5.44. Imagem de MET da camada deformada por erosão do aço Hadfield

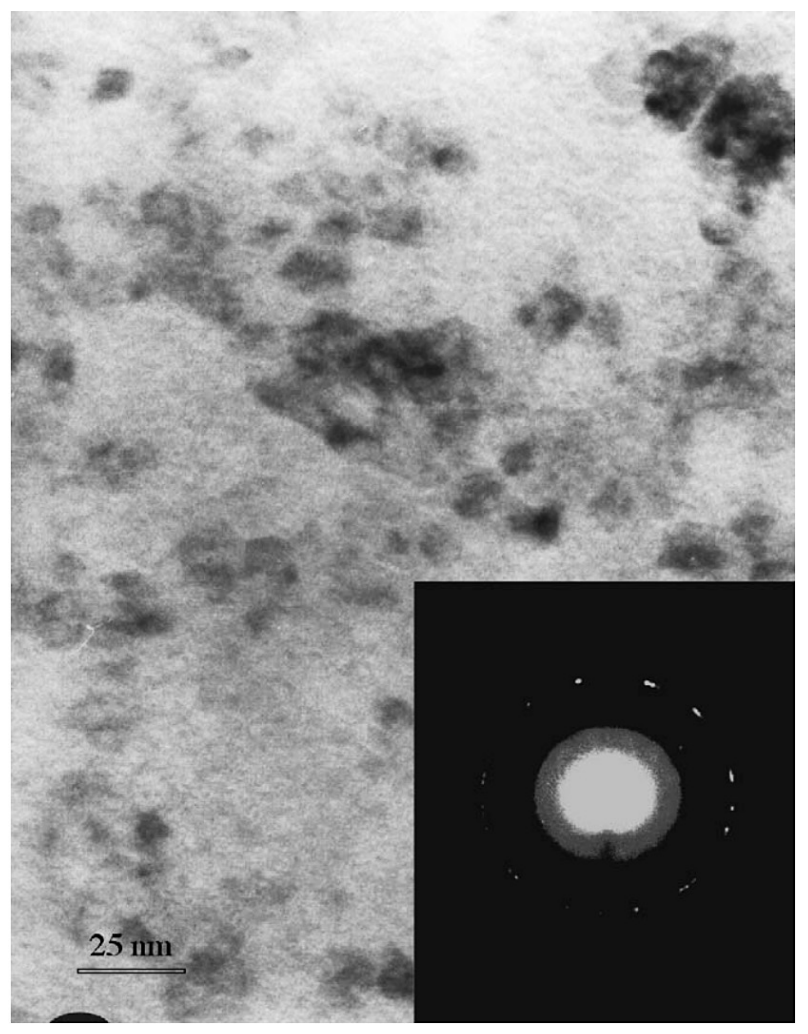

Fonte: Petrov et al., 2006

Meyers et al. identificaram pontos de amorfização no interior de bandas de cisalhamento, as quais tem microestrutura com tamanho de grão de escala nanométrica (MEYERS et al., 2003). Os autores demostraram que o surgimento de pontos amorfos no estado sólido está relacionado à alta taxa de deformação, na qual induz o aquecimento adiabático. Os surgimento de pontos amorfos foram explicados pelos autores a partir do modelo termodinâmico de Fecht e Johnson (FECHT, 1992; FECHT; JOHNSON, 1988). Na Figura 5.45 (imagens de MET) observam-se regiões nanocristalina e amorfa dentro da banda de cisalhamento (a) e suas respectivas 
imagens de difração ( $b$ e $c$ ). Na Figura $5.45 d$ os autores mostram uma imagem de transmissão da região amorfa em alta resolução.

Figura 5.45. a) Imagens de MET de regiões nanocristalina e amorfa de dentro da banda de cisalhamento. b) Imagens de difração da região amorfa. c) Imagem de difração da região de transição (amorfa e nanocristalina). d) Imagem de MET em alta resolução da região amorfa.

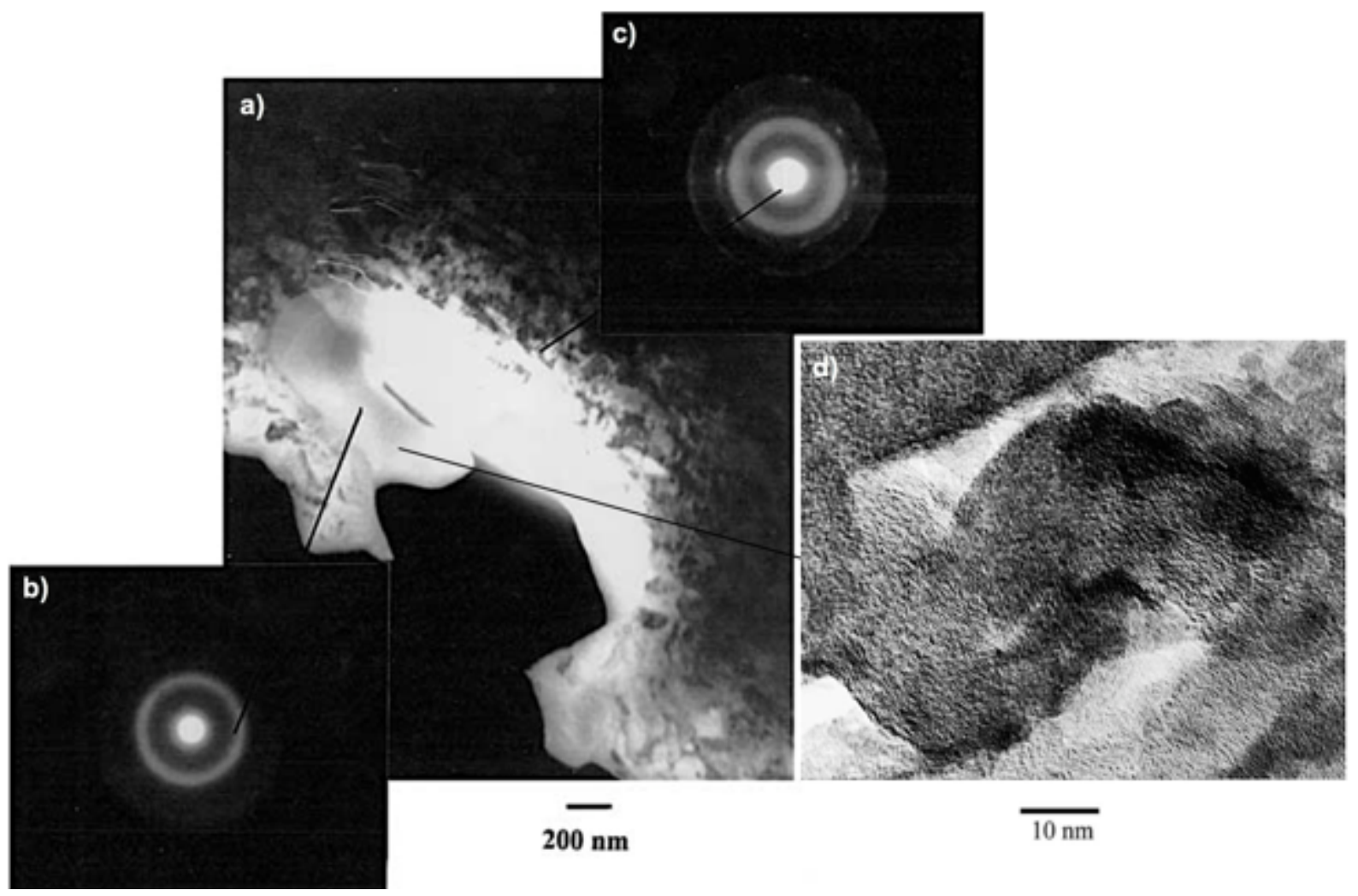

Fonte: Meyers et al., 2003

A Figura 5.46a mostra uma imagem em alta resolução de maclas de deformação em escala nanométricas da região abaixo da camada de grãos ultrafinos. A imagem de difração é mostrada na Figura 5.46b. Um padrão de difração semelhante a este foi obtido por Zhang et al. em aço inox 304 (ZHANG et al., 2003). 
Figura 5.46. a) Imagem de MET - campo claro da região com maclas de deformação. b) Imagem de difração de elétrons da área recíproca da Figura a

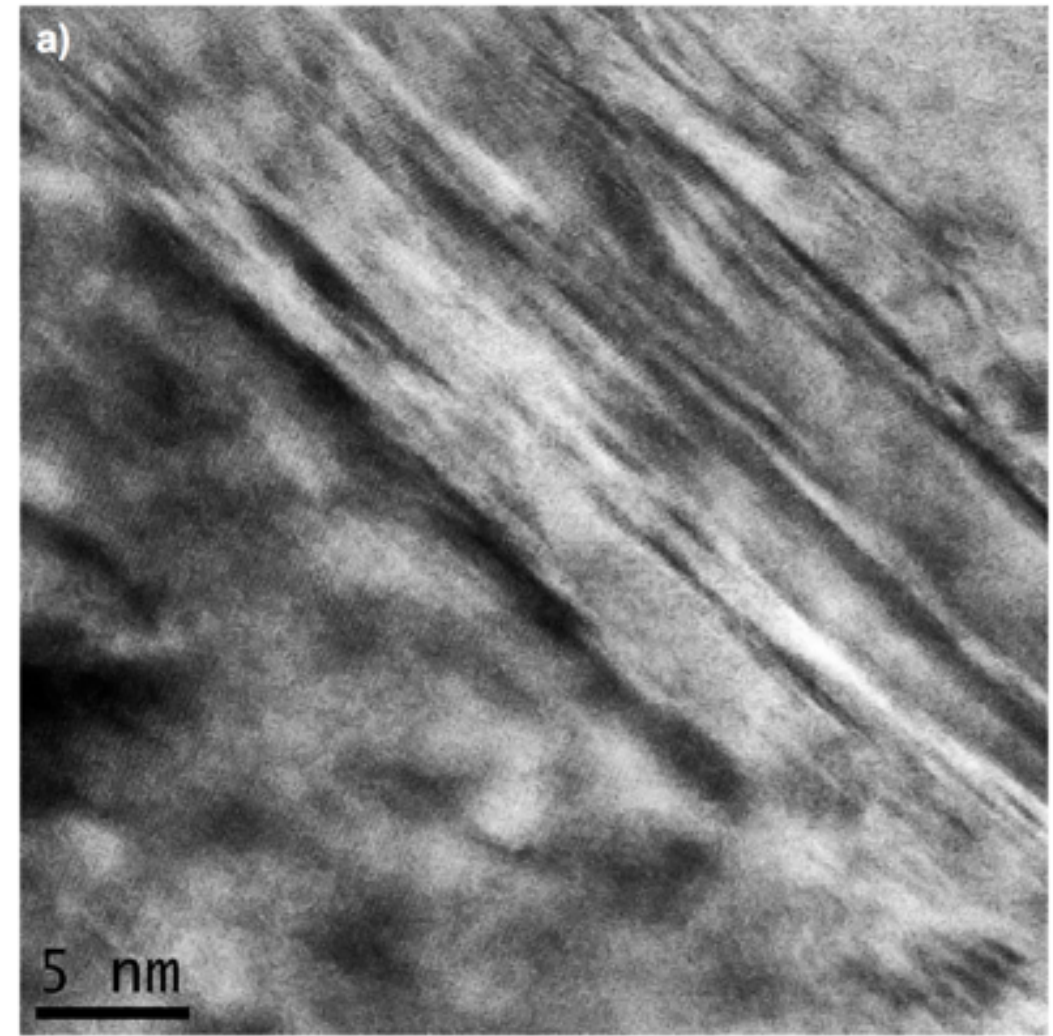

b) 
Arango discute a dissipação de energia na superfície deformada pelo desgaste, a partir de modelos termodinâmicos. O diagrama de dissipação de energia de Moore, Figura 5.47, é um exemplo, no qual relaciona a energia do fenômeno de desgaste abrasivo com as alterações na superfície e na subsuperfície. Na primeira linha estão os mecanismos primários de absorção de energia e na segunda os mecanismos secundários. Neste modelo as energias de dissipadas na forma de ruído e vibração foram consideradas desprezíveis. Nota-se que a deformação plástica e deformação elástica armazenada contribuem energeticamente com o fenômeno de recuperação e recristalização da camada deformada (ARANGO, 2010; MOORE, 1979). Czichos e Kostetsky consideraram em seus modelos de balanço de energia para sistema tribológico de desgaste por deslizamento o consumo de energia pela alteração microestrutural (CZICHOS, 1978; KOSTETSKY, 1992).

Figura 5.47. Diagrama de dissipação de energia

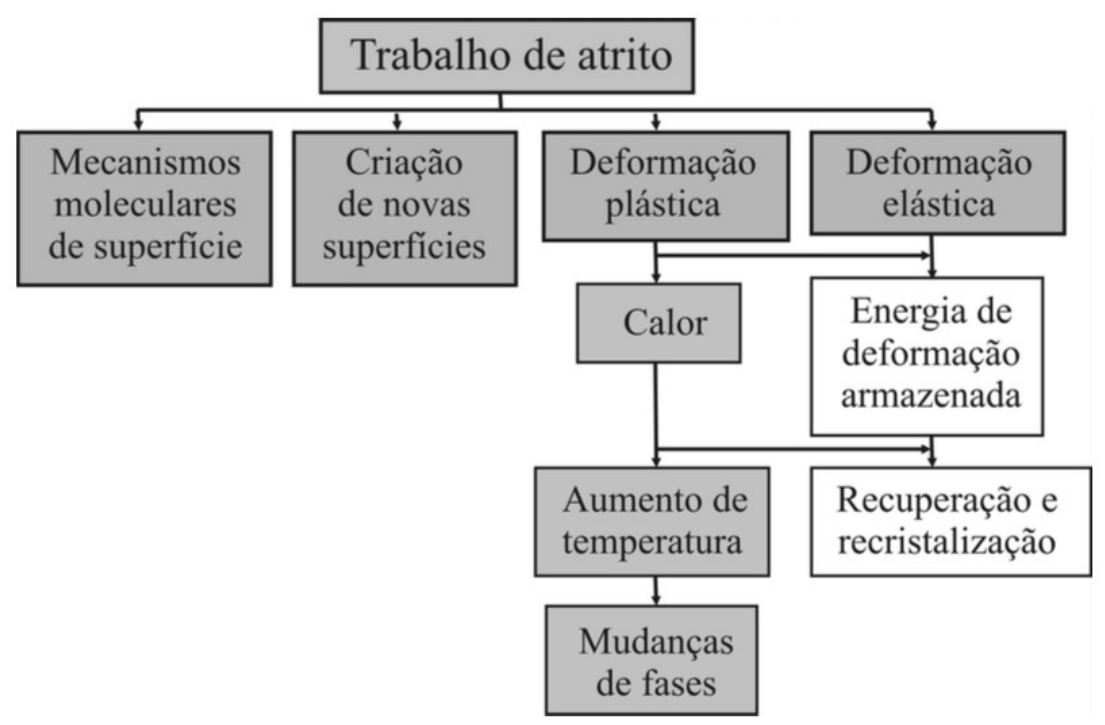

Fonte: Moore, 1979 apud Arango, 2010

A Figura 5.48 mostra um modelo de imagem conceitual que associa a causa e o efeito da recristalização dinâmica ao fenômeno de desgaste abrasivo com informações qualitativas intrínsecas do sistema. A causa pode ser relacionada à energia fornecida para o sistema, a partir do atrito e deformação plástica e o efeito ao armazenamento de parte desta energia em alterações microestruturais, encruamento e tensões residuais. Neste modelo de imagem observa-se a interação de um endentador (partícula abrasiva idealizada) com uma superfície inicialmente livre de deformação, na qual ocorrem alterações da microestrutura e de propriedade 
mecânica da camada próxima à superfície. O deslocamento tangencial do endentador, precedido pela endentação da superfície, transfere energia para o material na forma de deformação elástica e plástica. Como apresentado no Capítulo de revisão bibliográfica e no diagrama de dissipação de energia de Moore, parte da energia durante este tipo de interação é convertida em calor, no qual dependendo da taxa de deformação e da condutividade térmica do material pode-se ter o fenômeno de aquecimento adiabático. A tensão máxima cisalhante tende a ser máxima próximo à interface de contato da partícula com a superfície (JOHNSON, 1985), como indicado no modelo. As tensões compressivas e trativas atuantes durante a abrasão contribuem para a deformação plástica ativando sistemas de escorregamento, abaixo e a frente do endentador, onde a tensão de compressão atinge o valor máximo, o qual diminui no sentido oposto ao movimento, atingindo valor positivo, tracionando a superfície (LINDROOS et al., 2015b). Após o evento abrasivo, a superfície deformada plasticamente permanece tensionada com tensões residuais compressivas, as quais contribuem com o aumento da dureza local. Outro fator que favorece o aumento da dureza é o efeito Hall-Petch dos grãos ultrafinos, como observado nos resultados de nanodureza. As tensões residuais compressivas diminuem no sentido da superfície para o núcleo do material, tornando-se trativas (HERTZBERG, R., 1996; MEYERS; CHAWLA, 1998). O perfil de dureza indicado na Figura 5.48 representa qualitativamente os efeitos da alteração microestrutural e da tensão residual. Nota-se que a microestrutura da subsuperfície, após a abrasão, tem duas camadas, a primeira com grãos ultrafinos, de maior dureza, e a camada subsequente com grãos ultrafinos e maclas, sendo esta uma representação dos resultados obtidos via FIB e MET nesta pesquisa. Além disto, este modelo sugere que a formação da camada de grãos ultrafinos inicia na proa do risco. 


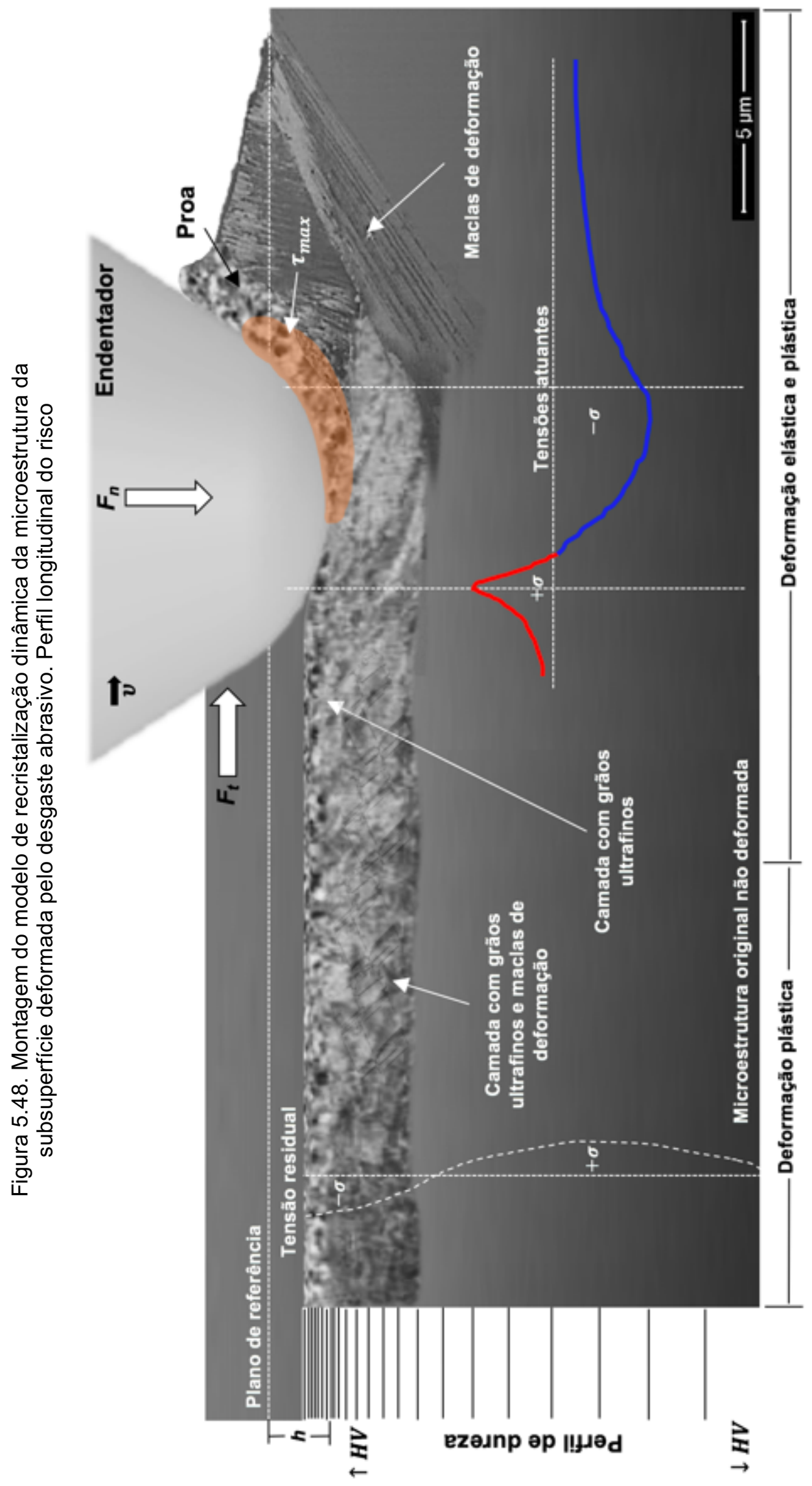


Lindroos et al. estimaram que a temperatura atingida pelo aquecimento adiabático do aço Hadfield deformado com as taxas de deformação de: 1, 2.200, 2.700 e $4.000 \mathrm{~s}^{-1}$, são de 52, 72, 91 e $75^{\circ} \mathrm{C}$, respectivamente (LINDROOS et al., 2015a). Estes resultados mostram que o aquecimento adiabático resulta em temperaturas relativamente baixas, mesmo para altas taxas de deformação, no entanto, esta pode ser uma parcela de energia importante para ativação da recristalização dinâmica. Segundo os autores o comportamento de aquecimento adiabático ocorre no aço Hadfield devido sua baixa condutividade térmica $\left(10\right.$ a $\left.15 \mathrm{~W}^{-1} \mathrm{mK}\right)$, visto que a superfície de revestimento de britadores atinge altas taxas de deformação, na ordem de $10^{3}$ a $10^{5} \mathrm{~s}^{-1}$, o aquecimento é um fenômeno a ser considerado no sistema.

Portanto, nesta pesquisa considera-se a formação de grãos nanométricos (ultrafinos) por recristalização dinâmica do material deformado pela ação do desgaste, levando em consideração os seguintes pontos:

- Taxa de deformação;

- Aumento de temperatura pelo atrito, deformação elástica, deformação plástica e aquecimento adiabático;

- Alteração da submicroestrutura (células de discordâncias e subgrãos) para grãos equiaxiais de dimensões nanométricas de acordo com os modelos de recristalização dinâmica por deformação plástica a frio.

A camada de grãos ultrafinos observada na subsuperfície do aço $12 \mathrm{Mn}$ desgastado variou conforme a escala de análise, apresentando diferentes profundidades: $>22 \mu \mathrm{m}$ para macroescala, 7,6 $\pm 2 \mu \mathrm{m}$ para mesoescala e 0,3 $\pm 0,1 \mu \mathrm{m}$ para microescala. Moore e Douthwaite mostraram os efeitos do tamanho de abrasivo e da força normal no aumento da camada deformada após o desgaste em ensaio pino $x$ lixa (MOORE; DOUTHWAITE, 1976). Este comportamento também foi observado por Tressia (TRESSIA, 2015) a partir do ensaio de roda de borracha a úmido de aço Hadfield com variação de tamanho de abrasivo (\#100 a \#16). Este comportamento pode ser observado nos resultados de perfil de dureza apresentados nesta pesquisa, os quais mostram que quanto maior a solicitação mecânica em cada escala (meso e macro), maior é a profundidade do perfil de dureza. Entretanto, no que se refere à espessura da camada de grãos ultrafinos, notou-se aumento de acordo com o nível de energia intrínseco a cada escala. A Tabela 5.1 mostra um 
resumo das alterações microestruturais associadas à multiescala do fenômeno de abrasão estudada nesta pesquisa, tais como: espessura da camada de grãos ultrafinos, recristalização, crescimento, maclação e trincas.

Tabela 5.1. Alterações microestruturais em função da escala de análise

\begin{tabular}{|c|c|c|c|c|c|c|}
\hline & & $\begin{array}{c}\text { Espessura da } \\
\text { camada de UFG }\end{array}$ & Recristalização & Crescimento & Maclação & Trincas \\
\hline 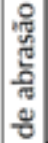 & 通 & $>22 \mu \mathrm{m}$ & & & & \\
\hline 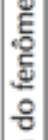 & $\frac{8}{\grave{y}}$ & $7,6 \mu \mathrm{m}$ & & 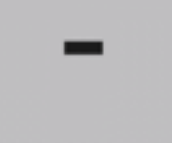 & & \\
\hline 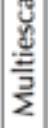 & $\frac{g}{y}$ & $0,3 \mu \mathrm{m}$ & & & & \\
\hline
\end{tabular}

Os resultados mostrados neste Capítulo e no anterior (Capítulo 4) contribuem para a descrição de um modelo de balanço de energia para um evento abrasivo. Desta forma, propõem-se que a energia envolvida $(e)$ neste fenômeno pode ser descrita pela Equação (5.1).

$$
e=e_{\varepsilon}+e_{A}+e_{d}
$$

Onde $e_{\varepsilon}$ é a energia dissipada pela deformação do material, $e_{A}$ é a energia dissipada pela adesão, de acordo com o modelo de Bowden e Tabor (BOWDEN; TABOR; MCFARLANE, 1950), e $e_{d}$ é a energia dissipada na forma de ruído e de vibração do sistema. A energia dissipada na deformação depende de outras componentes intrínsecas ao sistema, Equação (5.2):

$$
e_{\varepsilon}=e_{t}+e_{m}+e_{\varepsilon i}+e_{s}
$$

Onde $e_{t}$ corresponde a parcela de energia dissipada na forma de calor, em alguns casos, como mostrado pela literatura, pode corresponder a $90 \%$ da energia total de deformação; $e_{m}$ trata-se da energia consumida pelas alterações da microestrutura 
associada à recristalização dinâmica e amorfização. $e_{\varepsilon i}$ é a parcela de energia dissipada no sistema pela deformação plástica (macla mecânica, discordâncias, bandas de escorregamento) e pela deformação elástica residual. Os tipos de defeitos no material e suas intensidades são relacionadas à metalurgia física do material. Neste contexto, destacam-se os efeitos da energia de defeito de empilhamento e solução sólida nas propriedades mecânicas, tais como, módulo de elasticidade $(E)$, coeficiente de encruamento $(n)$ e tensão de escoamento. $O$ último termo da Equação (5.2), $e_{S}$, trata-se da parcela de energia consumida para gerar superfície na forma de cavaco, partículas de desgaste e trincas, quando existirem.

Este balanço de energia mostra que a parte da energia não dissipada na forma de calor é consumida pela formação de defeitos cristalinos (deformação plástica) e pela recristalização dinâmica da subsuperfície, havendo o fenômeno de autoreparação. A Figura 5.49 mostra um diagrama de blocos que representa este modelo.

Figura 5.49. Diagrama de blocos do modelo de dissipação de energia para um evento abrasivo

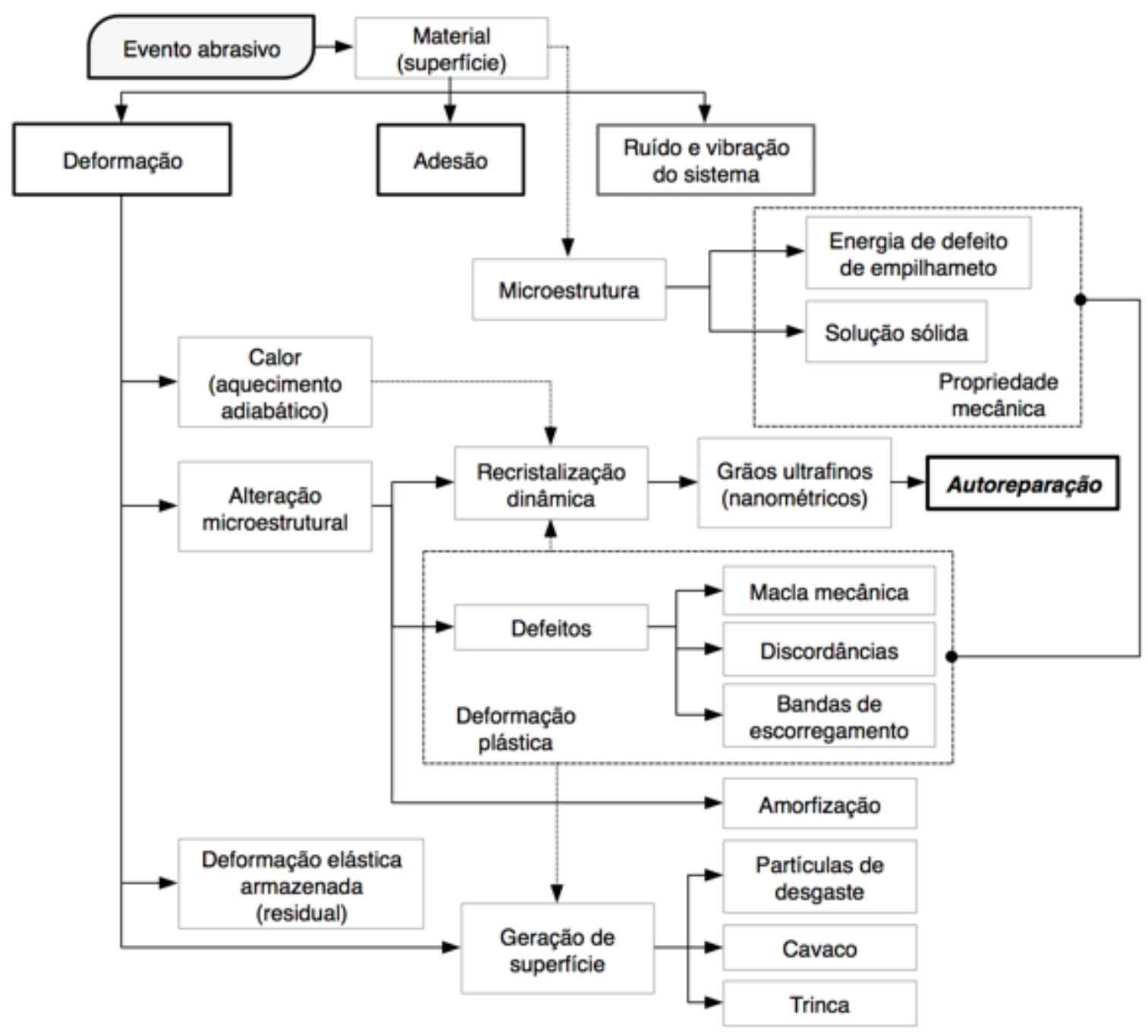




\subsection{Considerações Finais}

Em relação a análise da microestrutura do aço Hadfield deformado de acordo com a multiescala do fenômeno abrasivo é possível concluir que:

- A microestrutura do aço Hadfield deformado pela abrasão tem a maclação como principal mecanismo de deformação, a qual contribui para a permanência do formato poligonal do grão;

- O mecanismo de dano em revestimentos de britadores é constituído por nucleação superficial de trincas transgranulares ou intergranulares, propagação de trincas e destacamento de grão (macroescala);

- O fenômeno de recristalização dinâmica é o responsável pelo surgimento de grãos ultrafinos na subsuperfície do material em todas as escalas estudadas. Na macroescala observou-se crescimento de grão. Nesta escala de análise destacam-se dois pontos:

- A microestrutura do material deformado em forma de onda tem em sua extremidade semelhante à bruta de fundição do aço Hadfield, com grãos menores em uma ordem de grandeza que a microestrutura original, carbonetos em contorno de grão, carbonetos aciculares e maclas de recristalização;

- Formação de grãos pequenos na subsuperfície com duas ordens de grandeza inferior ao tamanho de grão da microestrutura original;

- Na subsuperfície deformada nas escalas meso e micro não foi identificado crescimento de grão. Portanto, o ensaio de laboratório de britador de mandíbula (mesoescala) não reproduz todos os fenômenos de alterações microestruturais existentes no desgaste de campo (macroescala);

- A microestrutura resultante da recristalização dinâmica e crescimento de grão na subsuperfície dos materiais desgastados foi relacionada ao fenômeno de autoreparação dos danos sofridos pela abrasão, tratando-se de um mecanismo de endurecimento secundário. 
Capitula 6. CONCLUUSOEES

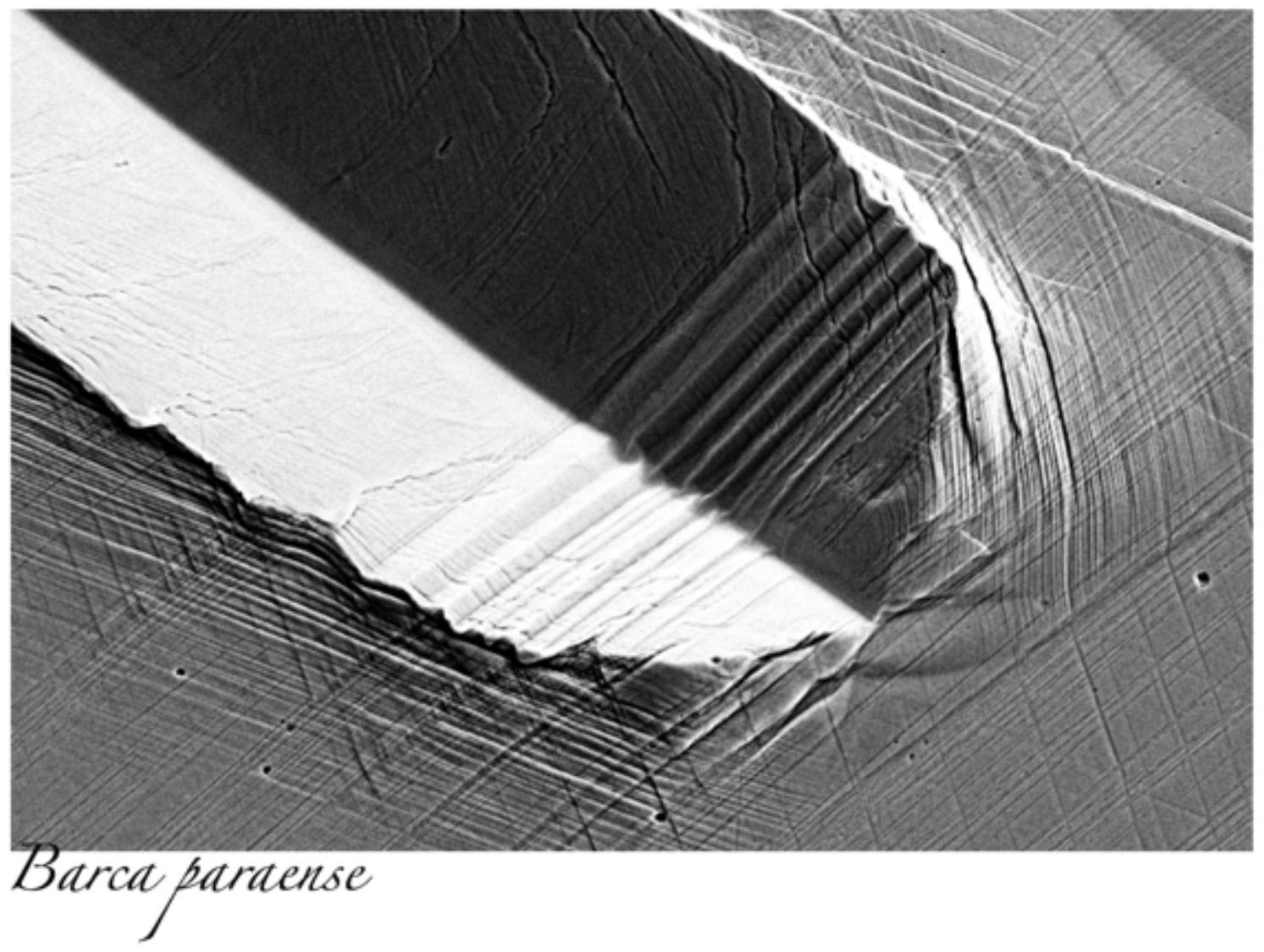


- A análise multiescala do fenômeno abrasivo mostrou as seguintes alterações microestruturais nas escalas estudadas: deformação plástica por maclação; grãos desgastados; formação de grãos ultrafinos por recristalização dinâmica. Na macroescala (desgaste em campo) foi identificado crescimento dos grãos recristalizados;

- O ensaio de britador de mandíbula (mesoescala) mostrou que o aço $20 \mathrm{Mn}$ tem uma tendência de menor perda de massa que o aço 12Mn (mandíbula fixa);

- O efeito da orientação cristalográfica no desgaste por riscamento (mesoescala) foi superior ao efeito da variação de dureza do perfil encruado;

- A anisotropia dos aços $12 \mathrm{Mn}$ e $20 \mathrm{Mn}$ teve significativo efeito no desgaste por riscamento. Os micromecanismos de desgaste para os planos (001), (111) e (101) dos aços foram semelhantes. No entanto, o aço $20 \mathrm{Mn}$ apresentou menor deformação lateral que o aço 12Mn e formação de proa, para o plano (001), tendo diferentes resultados de energia de riscamento;

- A formação da camada de grãos ultrafinos foi atribuída ao fenômeno de recristalização dinâmica de acordo com os modelos existentes para deformação plástica severa e o modelo proposto de dissipação de energia;

- A microestrutura resultante do desgaste e, consequentemente, da recristalização dinâmica foi associada ao fenômeno de autoreparação existente na superfície de materiais desgastados, o qual trata-se de um mecanismo de endurecimento secundário relacionado ao efeito HallPetch. 


\section{ATIVIDADES FUTURAS}

- Estudar o desgaste dos aços austeníticos 12Mn e 20Mn em condições operacionais de campo;

- Fabricar mandíbulas com diferentes texturas cristalográfica (direcionalizar o fluxo de calor na solidificação) para avaliar o desempenho de diferentes orientações no desgaste abrasivo via ensaio de britador de mandíbula e de roda de borracha;

- Estudar o desgaste (micromecanismos e taxa de desgaste) de revestimentos de britador cônico e giratório na condição fixo e móvel e comparar ao desgaste observado em britador de mandíbula;

- Análise de sinal dos resultados de profundidade e coeficiente de atrito obtidos via ensaio de microesclerometria nos planos (001), (111) e (101) para os aços $12 \mathrm{Mn}$ e $20 \mathrm{Mn}$;

- Avaliar os resultados de EBSD da região deformada da subsuperfície com ferramentas para análise de deformação disponíveis no software OIM, tais como, Fator de Taylor, Desorientação de Kernel e Fator de Schmid.

\section{REFERÊNCIAS BIBLIOGRÁFICAS}

ADLER, P. H.; OLSON, G. B.; OWEN, W. S. Strain hardening of hadfield manganese steel. Metallurgical and Materials Transactions A, v. 17, n. 10, p. 1725-1737, 1986.

ARANGO, C. C. V. Transição no regime de desgaste por deslizamento dos aços: uma abordagem termodinâmica. Universidade de São Paulo, Tese de doutorado, 2010.

ASM-HANDBOOK VOL. 18. Friction, lubrication, and wear technology - Volume 18, v. 2, p. 3470, 2003.

ASTM E112. Standard test methods for determining average grain size. ASTM International, v. West Consh, p. 1-27, 2014.

ASTM E384. Standard test method for knoop and vickers hardness of materials. ASTM Standards, p. 1-43, 2012. 
ASTM G1. Standard practice for preparing, cleaning, and evaluating corrosion test. ASTM Standards, v. 90, n. Reapproved 2011, p. 1-9, 1999.

ASTM A128. Standard specification for steel castings, austenitic manganese. ASTM International, v. 93, n. Reapproved 2012, 2012.

ASTM G171. Standard test method for scratch hardness of materials using a diamond stylus. ASTM international, v. G171-3, n. Reapproved 2009, p. 1-7, 2012. ASTM G40. Standard terminology relating to wear and erosion. ASTM Book of Standards, p. 1-9, 2014.

ASTM G81. Standard test method for jaw crusher gouging abrasion test. Annual Book of ASTM Standards, p. 1-7, 2007.

AVERY, H. S. Austenitic Manganese Steel. American Brake Shoe, p. 834-842, 1949.

AVERY, H. S. Work hardening in relation to abrasion resistance. Materials for the mining industry, p. $11-41,1974$

BAUSCHKE, H. M.; HORNBONGEN, E.; ZUM GAHR, K. Abrasiver VerschleiB austenitischer Stahle. Z. Metallkde, p. 1-12, 1981.

BAYRAKTAR, E.; KHALID, F. A.; LEVAILLANT, C. Deformation and fracture behaviour of high manganese austenitic steel. Journal of Materials Processing Technology, v. 147, n. 2, p. 145-154, 2004.

BAYRAKTAR, E.; LEVAILLANT, C.; ALTINTAŞ, S. Formability characterization of Hadfield steel. Journal of Materials Processing Technology, v. 47, n. 1-2, p. 1331, 1994.

BLICKENSDERFER, R.; MADSEN, B. W.; TYLCZAC, J. H. Comparison of several types of abrasive wear tests. Wear of materials, v. 122, p. $165-182,1985$.

BOWDEN, F. P.; TABOR, D.; MCFARLANE, J. S. Adhesion of solids and the effect of surface films, The Royal Society Stable. n. 1931, p. 224-243, 1950.

BRACKE, L.; KESTENS, L.; PENNING, J. Transformation mechanism of martensite in an austenitic Fe-Mn-C-N alloy. Scripta Materialia, v. 57, n. 5, p. 385-388, 2007.

BRADBY, J. E.; WILLIAMS, J. S.; WONG-LEUNG, J.; SWAIN, M. V.; MUNROE, P. Nanoindentation-induced deformation of Ge. Applied Physics Letters, v. 80, n. 15, p. 2651-2653, 2002.

BREWER, L.; CHANG, S.-G. Metallography, structures and phase diagrams. Metals Handbook, v. 8, 1973.

BUDINSKI, K. Wear News. World tribology congress, Vol. 9, n 5, 2013. 
BURTON, R. A. Thermal deformation in frictionally heated contact. Wear, v. 59, p. 1$20,1980$.

BUTTERY, T.C.; ARCHARD, J. F. Grinding and abrasive wear. Proceedings of the Institution of Mechanical Engineers. Part $\mathbf{H}$, Journal of engineering in medicine, v. 185, p. $43-71,1970$.

CAMPOS, M. P.; DAVIES, G. J. Solidificação e fundição de metais e suas ligas. Primeira edição, Editora: LTC, São Paulo, p. 246, 1978.

CHALLEN, J. M.; OXLEY, P. L. B.; DOYLE, E. D. The effect of strain hardening on the atomic nature of crystalline materials on friction. Wear, v. 88, p. 1-12, 1983.

CHOI, W. S.; SANDLÖBES, S.; MALYAR, N. V.; KIRCHLECHNER, C.; KORTEKERZEL, S.; DEHM, G.; DE COOMAN, B. C.; RAABE, D. Dislocation interaction and twinning-induced plasticity in face-centered cubic Fe-Mn-C micro-pillars. Acta Materialia, v. 132, p. 162 - 173, 2017.

COOMAN, B. DE; CHIN, K.; KIM, J. High Mn TWIP steels for automotive applications. New Trends and Developments in Automotive System Engineering, p. 1001-128, 2011.

CZICHOS, H. Tribology: a systems approach to the science and technology of friction, lubrication, and wear. $1^{\text {st }}$ edition. Elsevier. 1978

DASTUR, Y. N.; LESLIE, W. C. Mechanism of work hardening in Hadfield manganese steel. Metallurgical Transactions A, v. 12, n. 5, p. 749-759, 1981.

DERBY, B. Dynamic recrystallisation: the steady state grain size. Metalurgica et Materialia, v. 27, n. 1, p. 1581-1585, 1992.

DIESBURG, D. E.; BORIK, F. Optimizing Abrasion Resistance and Toughness in Steels and Irons for the Mining Industry. Materials for the mining industry, p. 1541, 1974

EMGE, A.; KARTHIKEYAN, S.; RIGNEY, D. A. The effects of sliding velocity and sliding time on nanocrystalline tribolayer development and properties in copper. Wear, v. 267, n. 1-4, p. 562-567, 2009.

EYRE, T. S. Wear characteristics of metals. Tribology International, v. 9, n. 5, p. 203-212, 1976.

FECHT, H. J. Defect-induced melting and solid-state amorphization. Nature, v. 356, n. 6365 , p. 133-135, 1992.

FECHT, H. J.; JOHNSON, W. L. Entropy and enthalpy catastrophe as a stability limit for crystalline material. Nature, v. 334, n. 6177, p. 50-51, 1988. 
FENG, X. Y.; ZHANG, F.; ZHENG, C.; LÜ, B. Micromechanics behavior of fatigue cracks in Hadfield steel railway crossing. Science China Technological Sciences, v. 56, n. 5, p. 1151-1154, 2013a.

FENG, X. Y.; ZHANG, F. C.; YANG, Z. N.; ZHANG, M. Wear behaviour of nanocrystallised Hadfield steel. Wear, v. 305, n. 1-2, p. 299-304, 2013b.

FRANCO, L. A. Abrasão de ferro fundido cinzento aplicação a motores automotivos. Tese de doutorado, Universidade de São Paulo, Departamento de Engenharia Mecânica, 2015.

FRANCO, L. A.; SINATORA, A. Material removal factor $\left(f_{a b}\right)$ : a critical assessment of its role in theoretical and practical approaches to abrasive wear of ductile materials. Wear, v. 382-383, n. April, p. 51-61, 2017.

FUOCO, R.; TODOROV, D.; CAVALCANTI, A. H.; SANTOS, N. L. Effect of chemical composition on the carbide reprecipitation kinetics of Hadfield austenitic manganese steel. Transactions of American Foundry Society, v. 120, n. 12-110, p. 507-522, 2012.

GATES, J. D. Two-body and three-body abrasion: A critical discussion. Wear, v. 214, p. 139-146, 1998.

GHOSH, S. K. Self-healing Materials - Fundamentals, Design Strategies, and Applications. Wiley-VCH, $1^{\text {st }}$ edition, p. 291, 2009.

GOUSSELAND, P. Mines, metals and materials. Materials for the mining industry. Colorado - EUA: 1974

GUO, S. L.; SUN, D. Y.; ZHANG, F. C.; FENG, X. Y.; QIAN, L. H. Damage of a Hadfield steel crossing due to wheel rolling impact passages. Wear, v. 305, n. 1-2, p. 267-273, 2013.

HAAKONSEN, F. Optimizing of Strømhard austenitic manganese steel. Norwegian University of Science and Technology, 2009.

HARATANI, T.; HUTCHINSON, W. B.; DILLAMORE, I. L.; BATE, P. Contribution of shear banding to origin of Goss texture in silicon iron. Metal Science, v. 38, n. 2, p. 57-66, 1998.

HÄRKISAARI, P. Wear and friction effects on energy consumption in the mining industry. Master thesis, Tampere University of Technology, p. 77, 2015.

HE, Z. M.; JIANG, Q. C.; FU, S. B.; XIE, J. P. Improved work-hardening ability and wear resistance of austenitic manganese steel under non-severe impact-loading conditions. Wear, v. 120, n. 3, p. 305-319, 1987. 
HERTZBERG, R. W. Deformation and fracture mechanics of engineering materials. John Wiley \& Sons Inc., p. 786, 1996.

HOKKIRIGAWA, K.; KATO, K. An experimental and theoretical investigation of ploughing, cutting and wedge formation during abrasive wear. Tribology International, v. 21, n. 1, p. 51-57, 1988.

HOKKIRIGAWA, K.; KATO, K.; LI, Z. Z. The effect of hardness on the transition of the abrasive wear mechanism of steels. Wear, v. 123, n. 2, p. 241-251, 1988.

HONEYCOMBE, R. W. The plastic deformation of metals. Publicher Edward Arnold, $2^{\text {nd }}$ edition, p. 496, 1984.

HORNBOGEN, E. Gefüge und Festigkeit von Metallen. Z. Metallkde, v. 68, p. 455469, 1977.

HUMPHEREYS, F. J.; HATHERLY, M. Recrystallization and related annealing phenomena. $2^{\text {nd }}$ edition, Pergamon ed. Oxford, p. 658, 1997.

HUMPHREYS, F. J. et al.

HUMPHREYS, F. J.; PRANGNELL, P. B.; BOWEN, J. R.; GHOLINIA, A.; HARRI, C. Developing stable fine-grain microstructures by large strain deformation. The royal society, p. 1663-1681, 1999.

HUTCHINGS, I. M. Tribology - friction and wear of engineering materials. Elsevier, $1^{\text {st }}$ edtion, p. 280, 1992.

HUTCHINSON, B.; RIDLEY, N. On dislocation accumulation and work hardening in Hadfield steel. Scripta Materialia, v. 55, n. 4, p. 299-302, 2006.

ISHIDA, K.; NISHIYAWA, T. No Title. Trans. Jpn. Inst. Met., v. 15, p. 225, 1974.

ISO 25178-2. Geometrical product specifications (GPS) - Surface texture: Areal

Part 2: Terms, definitions and surface texture parametersInternational Standard ISO, International Standard, 2012.

ISO 15577-1. Metallic materials - Instrumented indentation test for hardness and materials parameters - Part 1: Test method, International Standard, 2002.

JANKOWSKI, A. F.; NYAKITI, L. O.; AHMED, H. S. T.; HUMPHREY, R. T. High strain-rate scratch testing of nanoscale materials. v. 8, p. 710-717, 2011.

JOHNSON, K. L. Contact Mechanics. Cambridge University Press, $1^{\text {st }}$ edtion, p. 452, 1985.

JOST, H. P. Tribology - Origin and future. Wear, v. 136, n. 1, p. 1-17, 1990.

KARAMAN, I.; SEHITOGLU, H.; GALL, K.; CHUMLYAKOV, Y. I.; MAIER, H. J. Deformation of single crystal Hadfield steel by twinning and slip. Acta Materialia, 
v. 48, n. 6, p. 1345-1359, 2000a.

KARAMAN, I.; SEHITOGLU, H.; BEAUDOIN, A. J.; CHUMLYAKOV, Y. I.; MAIER, H. J.; TOME, C. N. Modeling the deformation behavior of Hadfield steel single and polycrystals due to twinning and slip. Acta Materialia, v. 48, n. 9, p. 2031-2047, 2000b.

KATO, K.; ADACHI, K. Wear mechanisms. Modern Tribology Handbook 1. p. 273300, 2001.

KHRUSCHOV, M. M. Resistance of metals to wear by abrasion as related to hardness. Proceedings of the conference on lubrication and wear, p. $655-659$, 1957.

KHRUSCHOV, M. M. Principles of abrasive wear. Wear, v. 28, n. 1, p. 69-88, 1974.

KOSTETSKY, B. I. The structural-energetic concept in the theory of friction and wear (synergism and self-organization). Wear, v. 159, n. 1, p. 1-15, 1992.

KUYUCAK, S.; ZAVADIL, R.; GERTSMAN, V. Heat-Treatment Processing of Austenitic Manganese Steels. Revista de Turnatorie, p. 1-16, 2004.

KUYUCAK, S.; ZAVADIL, R.; NEWCOMBE. P. Part 3: Heat Transfer Model, Macrosegregation and Phosphide Eutectic. AFS, p. 56 - 82, 2001a.

KUYUCAK, S.; ZAVADIL, R.; NEWCOMBE. P. Part 1: Step-down temperature and residuais. AFS, p. 1 - 19, $2001 b$.

KUYUCAK, S.; ZAVADIL, R.; NEWCOMBE. P. Part. 2 Metallographic studies. AFS, p. $21-55,2001 \mathrm{C}$.

LINDQVIST, M.; EVERTSSON, C. M. Linear wear in jaw crushers. Minerals Engineering, v. 16, n. 1, p. 1-12, 2003.

LINDROOS, M.; KUOKKALA, V.; LEHTOVAARA, A.; KIVIKYTÖ-REPONEN, P. Effects of strain and strain rate on the abrasive wear behavior of high manganese austenitic steel. Key Engineering Materials. v. 527, p. 211-216, 2013.

LINDROOS, M.; APOSTOL, M.; HEINO, V.; VALTONEN, K.; LAUKKANEN, A.; HOLMBERG, K.; KUOKKALA, V. The deformation, strain hardening, and wear behavior of chromium-alloyed Hadfield steel in abrasive and impact conditions. Tribology Letters, v. 57, n. 3, p. 1-11, 2015a.

LINDROOS, M.; VALTONEN, K.; KEMPPAINEN, A.; LAUKKANEN, A.; HOLMBERG, K.; KUOKKALA, V. Wear behavior and work hardening of high strength steels in high stress abrasion. Wear, v. 322-323, p. 32-40, 2015b.

LIU, G.; LU, J.; LU, K. Surface nanocrystallization of $316 \mathrm{~L}$ stainless steel induced by 
ultrasonic shot peening. Materials Science and Engineering: A, v. 286, n. 1, p. 9195, 2000.

LÜ, Y.; HUTCHINSON, B.; MOLODOV, A. D.; GOTTSTEIN, G. Effect of deformation and annealing on the formation and reversion of $\varepsilon$-martensite in an Fe-Mn-C alloy. Acta Materialia, v. 58, n. 8, p. 3079-3090, 2010.

LV, B.; ZHANG, M.; ZHANG, F. C.; ZHENG, C. L.; FENG, X. Y.; QIAN, L. H.; QIN, X. B. Micro-mechanism of rolling contact fatigue in Hadfield steel crossing. International Journal of Fatigue. v. 44, p. 273-278, 2012.

MINING ASSOCIATION OF CANADA. Benchmarking the energy consumption of canadian underground bulk mines. Ottawa, 2005.

MEYERS, M. A.; XU, Y. B.; XUE, Q.; PÉREZ-PRADO, M. T.; MCNELLEY, T. R. Microstructural evolution in adiabatic shear localization in stainless steel. Acta Materialia, v. 51, n. 5, p. 1307-1325, 2003.

MEYERS, M. A.; CHAWLA, K. K. Mechanical behavior of materials. Prentice-Hall, p. 680,1998 .

MEYERS, M.; PAK, H. No Title. Acta. Met., v. 34, p. 2493, 1986.

MOORE, M. A. A preliminary investigation of frictional heating during abrasive wear. Wear, v. 7, n. 1971, p. 51-58, 1970.

MOORE, M. A. Energy dissipation in abrasive wear. In wear of materails, ASME, 1979.

MOORE, M. A; RIGNEY, D. A. Abrasive wear. Fundamentals of friction and wear of materials. American Society for Metals, p. 73 - 118, 1981.

MOORE, M. A.; DOUTHWAITE, R. M. Plastic deformation below worn surfaces. Metallurgical Transactions A, v. 7, n. 11, p. 1833-1839, 1976.

NBR6953. Lastro-padrão - Determinação da resistência à compressão axial, ABNT (Assossiação Brasileira de Normas Tecnicas), 1990.

OKOLO, B.; PÉREZ-WILLARD, F.; HAWECKER, J.; GERTHSEN, D.; WANNER, A. Focused ion beam study of the effects of shot peening on the subsurface microstructure of normalized pearlitic steel. Journal of Materials Processing Technology, v. 183, n. 2-3, p. 160-164, 2007.

OLIVER, W. C.; PHARR, G. M. An improved technique for determining hardness and elastic modulus using load and displacement sensing indentation experiments.

J. Mater. Res., v. 7, n. 6, 1992.

PADILHA, A. F. Materiais de engenharia. n. Sem 5908, p. 349, 1997. 
PADILHA, A. F.; SICILIANO, F. Encruamento, recristalização, crescimento de grão e textura. 3 ed. São Paulo: ABM Livros, 2005.

PENAGOS, J. J. Efeito do refinamento da microestrutura e da adição de nióbio na resistência ao desgaste abrasivo de ferros fundidos de alto cromo. Tese de doutorado, Universidade de São Paulo, Departamento de Engenharia Mecânica, 2016.

PEREIRA, J. I.; MACHADO, P. C.; PENAGOS, J. J.; SINATORA, A. Wear characterization from field and laboratory tests of pearlitic steels used for SAG mill liners. Wear, v. 101, p. 99-101, 2017.

PEREIRA, J. I. Estudo do desgaste com abrasivo solto em ligas perlíticas utilizadas em revestimentos de moinhos semi-autógenos, Qualificação de Doutorado, Universidade de São Paulo, Departamento de Engenharia Mecânica, 2016.

PETROV, Y. N; GAVRILJUK, V. G.; BERNS, H.; SCHMALT, F. Surface structure of stainless and Hadfield steel after impact wear. Wear, v. 260, n. 6, p. 687-691, 2006. PIERCE, D. T.; NOWAG, K.; MONTAGNE, A.; JIMÉNEZ, J. A.; WITTIG, J. E.; GHISLENI, R. Single crystal elastic constants of high-manganese transformationand twinning-induced plasticity steels determined by a new method utilizing nanoindentation. Materials Science and Engineering A, v. 578, p. 134-139, 2013.

PINTAÚDE, G. Estudo do regime transiente em desgaste abrasivo - ensaios em britador de mandíbulas. Dissertação de mestrado, Universidade de São Paulo, Departamento de Engenharia Mecânica, 1998.

RABINOWICZ, E.; MUTIS, A. Effect of abrasive particle size on wear. Wear, v. 27, n. 3, p. 381-390, 1965.

RABINOWICZ, E. The least wear. Wear, v. 100, n. 1-3, p. 533-541, 1984.

RICHARDSON, R. C. D. The wear of metals by relatively soft abrasives. Wear, v. 11, n. 4, p. 245-275, 1968.

ROTONDARO, R. G. Mecanismos de desgaste abrasivo. Tese de doutorado, Departamento de Engenharia Metalúrgica, Universidade de São Paulo, 1989.

SAKAI, G.; HORITA, Z.; LANGDON, T. G. Grain refinement and superplasticity in an aluminum alloy processed by high-pressure torsion. Materials Science and Engineering A, v. 393, n. 1-2, p. 344-351, 2005.

SAKAI, T.; BELYAKOV, A.; KAIBYSHEV, R.; MIURA, H.; JONAS, J. J. Dynamic and post-dynamic recrystallization under hot, cold and severe plastic deformation 
conditions. Progress in Materials Science, v. 60, n. 1, p. 30-207, 2014.

SALDANA, C.; MURTHY, T. G.; SHANKAR, M. R.; STACH, E. A.; CHANDRASEKAR, S. Stabilizing nanostructured materials by coherent nanotwins and their grain boundary triple junction drag. Applied Physics Letters, v. 94, n. 2, p. 1-4, 2009.

SANDIM, H. R. Z. Heterogeneidade de deformação: uma visão microscópica. Textura e relações de orientações. $2^{\circ}$ Ed. São Paulo. p. 19-34, 2003.

SANT, S. B.; SMITH, R. W. A study in the work-hardening behaviour of austenitic manganese steels. Journal of Materials Science, v. 22, p. 1808-1814, 1987.

SANTOS, N. L. et al. Effect of carbide re-precipitation on the toughness of Hadfield austenitic manganese steel. American Foundry Society, p. 1-16, 2010.

SARE, I. R.; ARNOLD, B. K. Gouging abrasion of wear-resistance alloy white cast irons. Wear, v. 131, p. 15-37, 1989.

SARE, I. R.; CONSTANTINE, A. G. Development of methodologies for the evaluation of wear-resistant materials for the mineral industry. Wear, v. 203, p. 671-678, 1997.

SINATORA, A.; ALBERTIN, E. Abrasion resistant metallic alloys for the mining industry. International Syposium on Wear Resistant Alloys for the Mining and Processing Industry. Campinas, São Paulo - Brazil, 2015.

SIRIANE, F. A. Desgaste de mandíbulas de aço manganês em britadores. Tese de doutorado, Universidade de São Paulo, 1989.

STROUD, M. F.; WILMAN, H. The proportion of the groove volume removed as wear in abrasion of metals. British Journal of Applied Physics, v. 13, n. 4, p. 173 - 178, 1962.

SUBRAMANYAM, D. K.; SWANSIGER, A. E.; AVERY, H. S. Austenitic manganese steel. In: ASM Handbook Vol. 1, p. 1951-2004, 1990.

TANAKA, D. K. Exame de mandíbula de britador. Relatório técnico, Universidade de São Paulo, Departamento de Engenharia Mecânica, Laboratório de Fenômenos de Superfície - LFS, 2011.

THOMPSON, N. Proc Phys Soc 1953;66B:481. Proc Phys Soc, v. 66B:481, 1953.

TOLFREE, D. Investigation of the gouging abrasion resistance of materials in the mining industry. Thesis, Departement of Mine Engineering, The University of British Columbia, 2004.

TRESSIA, G. A. Efeito do tamanho do abrasivo e do pH do meio no desgaste de um aço austenítico e de um aço martensítico. Dissertação de mestrado, 
Universidade de São Paulo, Departamento de Engenharia Mecânica, 2015.

TSUJIMOTO, N. Casting practice of abrasion resistant austenitic manganese steel. AFS International Cast Metals Journal, p. 62 - 75, 1979.

UETZ, H.; FOHL, J. Gleitverschleibuntersuchungen an metallen und nichtmetallischen hartstoffen unter wirkung korniger stoffe. Braunkohle, Warme und Energie, p. 245-275, 1969.

VALIEV, R. Z.; IVANISENKO, YU. V.; RAUCH, E. F.; BAUDELET, B. Structure and deformaton behaviour of armco iron subjected to severe plastic deformation. Acta Mater., v. 44, n. 12, 1996.

VALIEV, R. Z.; ISLAMGALIEV, R. K.; ALEXANDROV, I. V. Bulk nanostructured materials from severe plastic deformation. Progress in Materials Science, v. 45, p. 103-189, 2000.

VATAVUK, J.; GOLDENSTEIN, H. Aços Hadfield contendo carbonetos de $\mathrm{Nb}$ e Ti. II encontro de tecnologia e utilização dos aços nacionais - ABM. Rio de Janeiro, 1986.

WAHL, H. VerschleiBprobleme im braunkohlenbergbau. Braunkohle, Warme und Energie, p. 75-87, 1951.

WANG, Y.; RAABE, D.; KLÜBER, C.; ROTERS, F. Orientation dependence of nanoindentation pile-up patterns and of nanoindentation microtexture in copper single crystals. Acta Materialia, v. 52, 2004.

WEIDNER, A.; KLIMANEK, P. Shear banding and texture development in cold-rolled alpha-brass. v. 38, n. 5, p. 851-856, 1998.

WELLINGER, K.; UETZ, H. Gleitverschleib, spulverschleib, strahlverschleib unter der wirkung von kornigen stoffenvdi-forschungsheft 449B, 1955.

WHITE, C.; HONEYCOMBE, R. W. . No Title. Iron Steel Inst., v. 200, p. 457, 1962. YAN, W. L.; FANG, L.; ZHENG, Z.; SUN, K.; XU, Y. Effect of surface nanocrystallization on abrasive wear properties in Hadfield steel. Tribology International, v. 42, n. 5, p. 634-641, 2009.

ZAVADIL, R.; KUYUCAK, S. Microstructure vs. impact toughness relationship in Hadfield's austenitic manganese steel. v. 8, p. 1290-1291, 2002.

ZHANG, H. W.; HEI, Z. K.; LIU, G.; LU, J.; LU, K. Formation of nanostructured surface layer on AISI 304 stainless steel by means of surface mechanical attrition treatment. Acta Materialia, v. 51, n. 7, p. 1871-1881, 2003.

ZHILYAEV, A. P.; GUBICZA, J.; NURISLAMOVA, G.; RÉVÉSZ, Á.; SURIÑACH, S.; 
BARÓ, M. D.; UNGÁR, T. Microstructural characterization of ultrafine-grained nickel. Physica Status Solidi (A) Applied Research, v. 198, n. 2, p. 263-271, 2003.

ZUIDEMA, B. K.; SUBRAMANYAM, D. K.; LESLIE, W. C. The effect of aluminum on the work hardening and wear resistance of Hadfield manganese steel. Metallurgical Transactions A, v. 18, n. 9, p. 1629-1639, 1987.

ZUM GAHR, K. FurchungsverchleiB duktiler Metalle. Z. Metallkde, p. 267-276, 1982.

ZUM GAHR, K. Microstructure and wear of materials. Elsevier, $1^{\text {st }}$ edition, p. 560, 1987. 


\section{Apêndice A - DESGASTE ABRASIVO DOS AÇOS AUSTENÍTICOS $12 \% \mathrm{Mn}$ E $20 \% M n$ VIA ENSAIO DE BRITADOR DE MANDÍBULA}

A Tabela A.1 mostra a composição química dos aços Hadfield B-4 e do aço austenítico com $23 \% \mathrm{Mn}$, nomeadas $14 \mathrm{Mn}$ e $23 \mathrm{Mn}$, respectivamente.

Tabela A.1. Composição química dos aços 14Mn e 23Mn

\begin{tabular}{ccccccc}
\multicolumn{7}{c}{$14 \mathrm{Mn}-[\%$ em peso $]$} \\
\hline $\mathrm{C}$ & $\mathrm{Mn}$ & $\mathrm{Si}$ & $\mathrm{P}$ & $\mathrm{S}$ & $\mathrm{Cr}$ & $\mathrm{Mo}$ \\
1,2 & 14,2 & 0,6 & 0,05 & 0,003 & 0,6 & 0,2 \\
\multicolumn{7}{c}{$\mathbf{2 4 M n}-[\%$ em peso $]$} \\
\hline $\mathrm{C}$ & $\mathrm{Mn}$ & $\mathrm{Si}$ & $\mathrm{P}$ & $\mathrm{S}$ & $\mathrm{Cr}$ & $\mathrm{Mo}$ \\
1,3 & 23,1 & 0,6 & 0,04 & 0,002 & 1,6 & 0,6
\end{tabular}

Os resultados de perda de massa dos aços $12 \mathrm{Mn}$ e $20 \mathrm{Mn}$ são novamente apresentados na Tabela A.2 com os resultados dos aços Hadfield 14Mn e 23Mn.

Tabela A.2. Desgaste relativo $\left(\mathrm{g} / \mathrm{m}^{2}\right)$ das mandíbulas fixa e móvel dos aços para $100 \mathrm{~kg}$ de abrasivo britado

\begin{tabular}{ccccccccc} 
& \multicolumn{7}{c}{ MF } & \multicolumn{5}{c}{ MM } \\
\cline { 2 - 9 } Aços & E.1 & E.2 & E.3 & Média & E.1 & E.2 & E.3 & Média \\
\hline $\mathbf{1 2 M n}$ & 137 & 158 & 147 & $147 \pm 6$ & 85 & 61 & 53 & $66 \pm 10$ \\
$\mathbf{1 4 M n}$ & 156 & 137 & 157 & $150 \pm 6$ & 94 & 96 & 71 & $87 \pm 8$ \\
$\mathbf{2 0 M n}$ & 107 & 142 & 124 & $124 \pm 10$ & 80 & 109 & 67 & $85 \pm 13$ \\
$\mathbf{2 3 M n}$ & 117 & 135 & 136 & $129 \pm 6$ & 90 & 74 & 60 & $75 \pm 9$
\end{tabular}

* perda de massa para $100 \mathrm{~kg}$ de abrasivo britado corrigido com o valor de área superficial da respectiva mandíbula, fixa ou móvel.

A Figura A.1 mostra os resultados de perda de massa das mandíbulas fixa e móvel dos quatro aços. A análise de variância (ANOVA) realizada nestes resultados, com intervalo de confiança de $90 \%$, mostrou que os resultados da MF são estatisticamente diferentes $\left(F=3,02>F_{\text {crit }}=2,92\right)$, enquanto que os resultados para MM são estatisticamente iguais $\left(F=0,97<F_{\text {crit }}=2,92\right)$. 
Figura A.1. Desgaste relativo $\left(\mathrm{g} / \mathrm{m}^{2}\right)$ das mandíbulas fixa e móvel dos aços para $100 \mathrm{~kg}$ de abrasivo britado

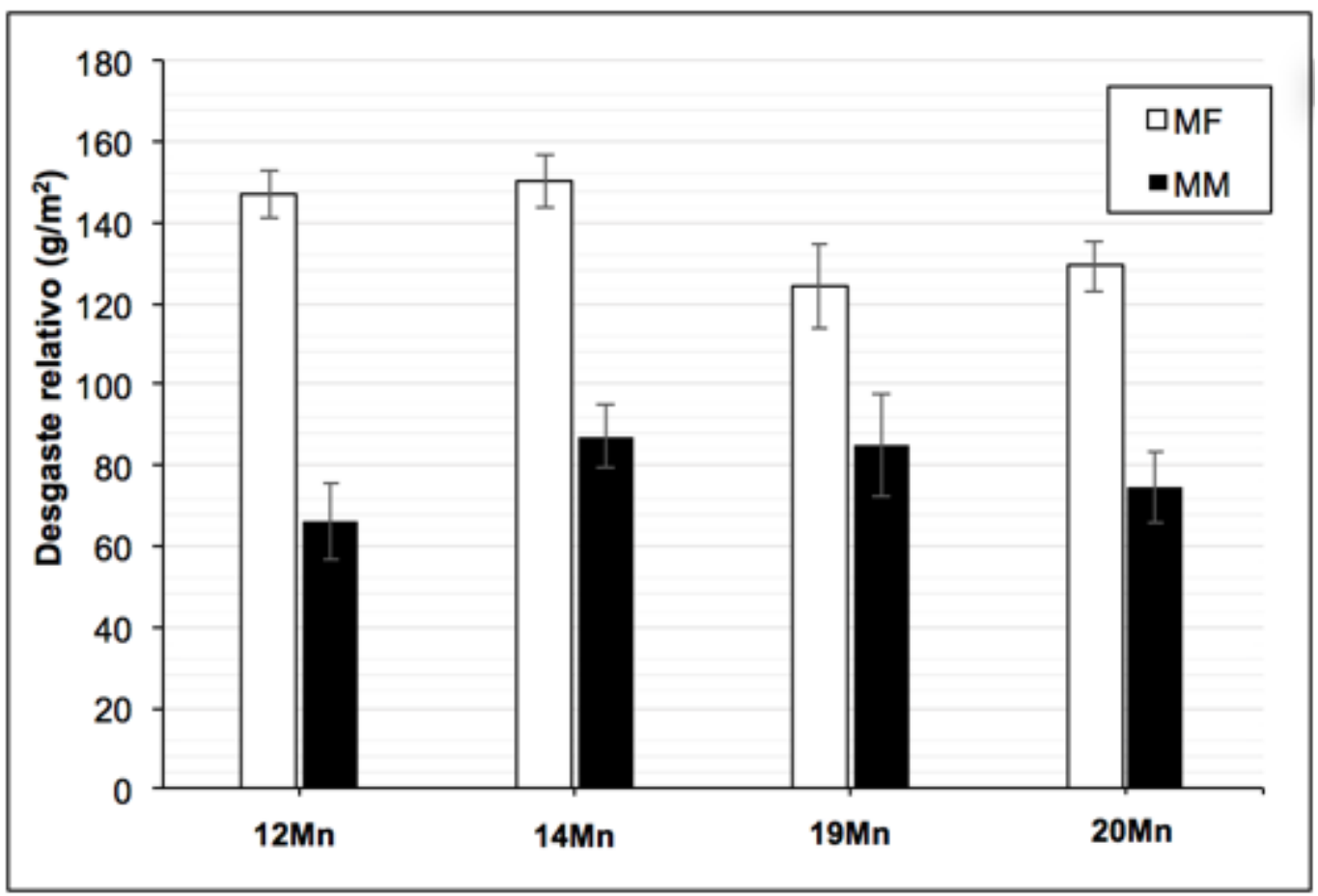

A Figura A.2 mostra o perfil de microdureza das mandíbulas fixa e móvel dos aços $14 \mathrm{Mn}$ e $23 \mathrm{Mn}$. O perfil de microdureza para estes materiais estabilizaram-se em $1,5 \mathrm{~mm}$ da superfície desgastada. 
Figura A.2. Perfil de dureza para mandíbula fixa e móvel dos materiais $14 \mathrm{Mn}$ (a) e $23 \mathrm{Mn}$ (b)
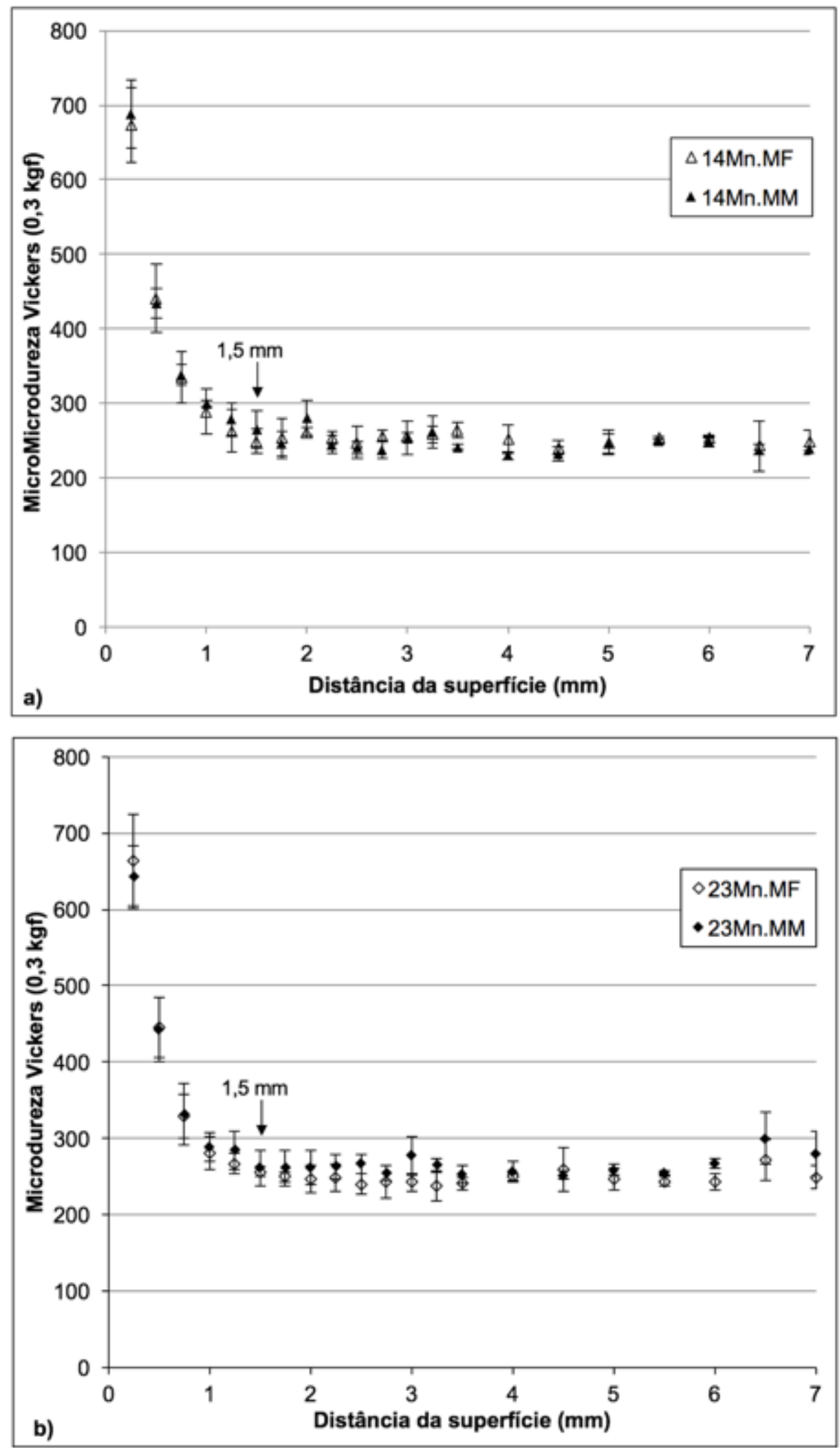
Apêndice B - EFEITO DO ENCRUAMENTO E DA ORIENTAÇÃO CRISTALOGRÁFICA NO DESGASTE POR RISCAMENTO DOS AÇOS AUSTENÍTICOS $12 \%$ Mn E $20 \%$ Mn

Figura B.1. Análise de correlação - Série i. (a) e (b) 50 mN. (c) e (d) 100 mN. (e) e (f) 200 mN
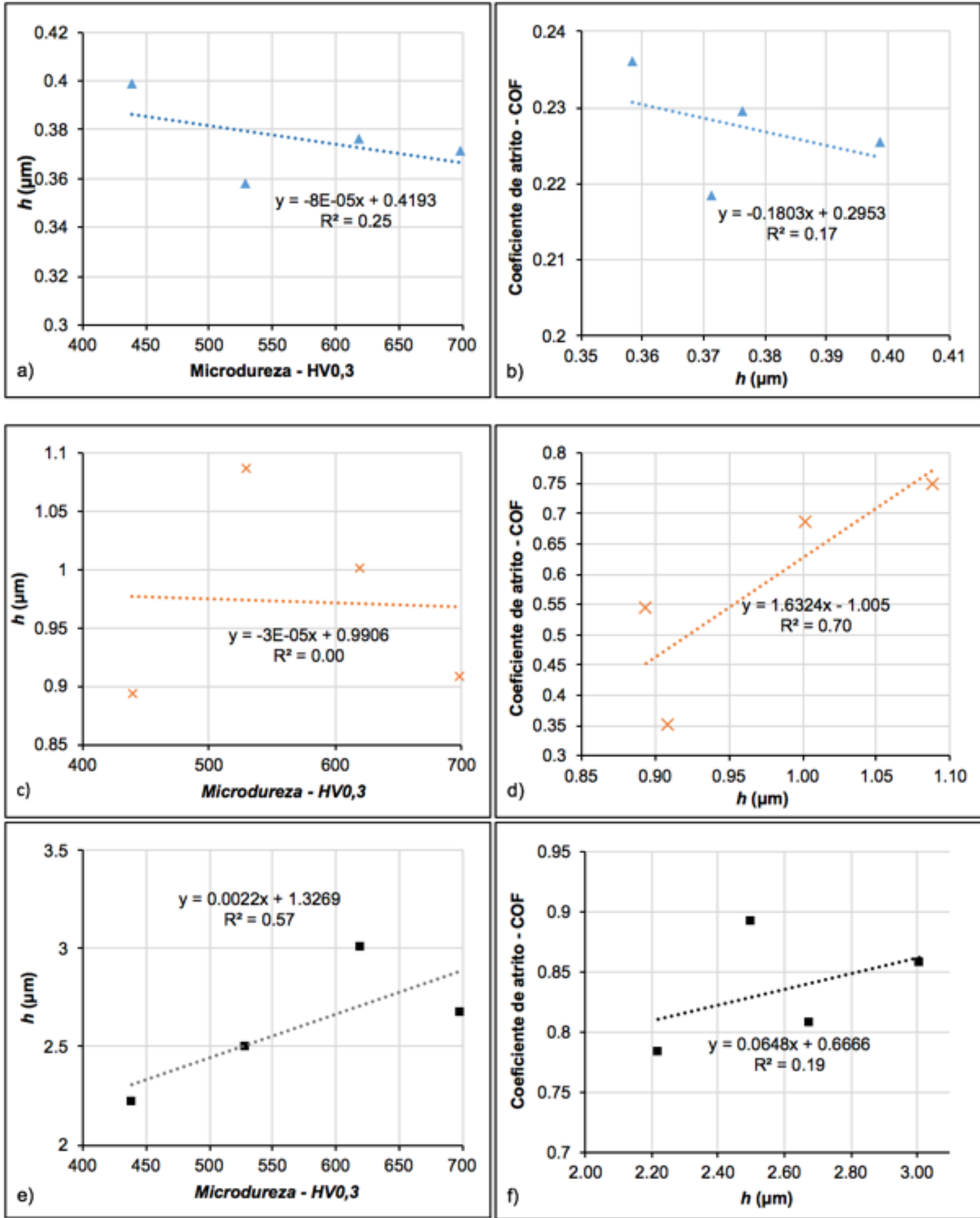
Figura B.2. Análise de correlação - Série ii. (a) e (b) 50 mN. (c) e (d) 100 mN. (e) e (f) 200 mN
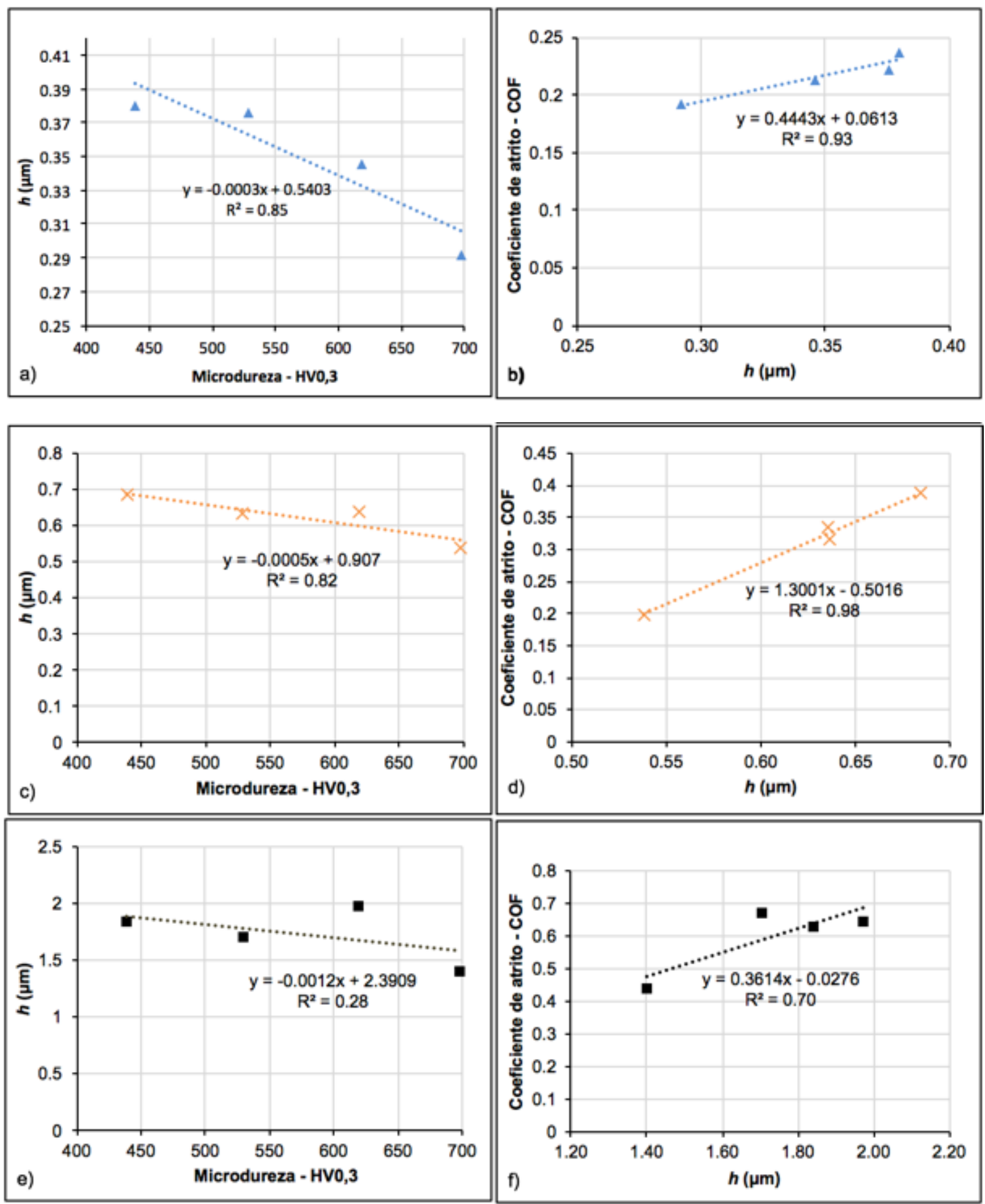

As Figuras B.3 e B.4 mostram os gráficos de coeficiente de atrito (ensaios 1, 2 e 3) nos planos (001), (111) e (101) para os aços $12 \mathrm{Mn}$ e $20 \mathrm{Mn}$, respectivamente. Notase a semelhança do comportamento do COF para as repetições do ensaio em cada plano. 
Figura B.3. Gráficos de coeficiente de atrito para os ensaios nos planos a) (001), b) (111) e c) (101) para o aço $12 \mathrm{Mn}$
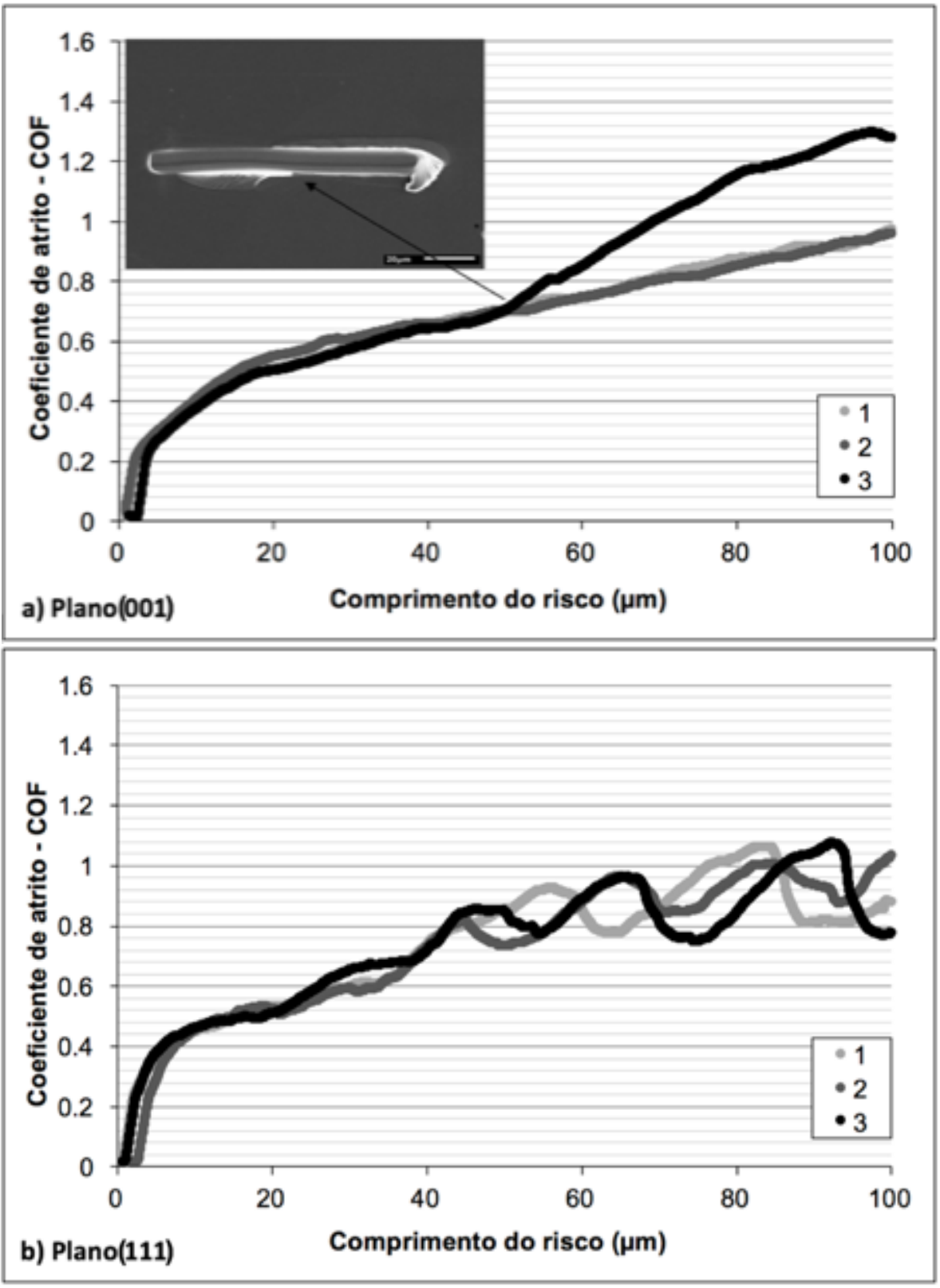


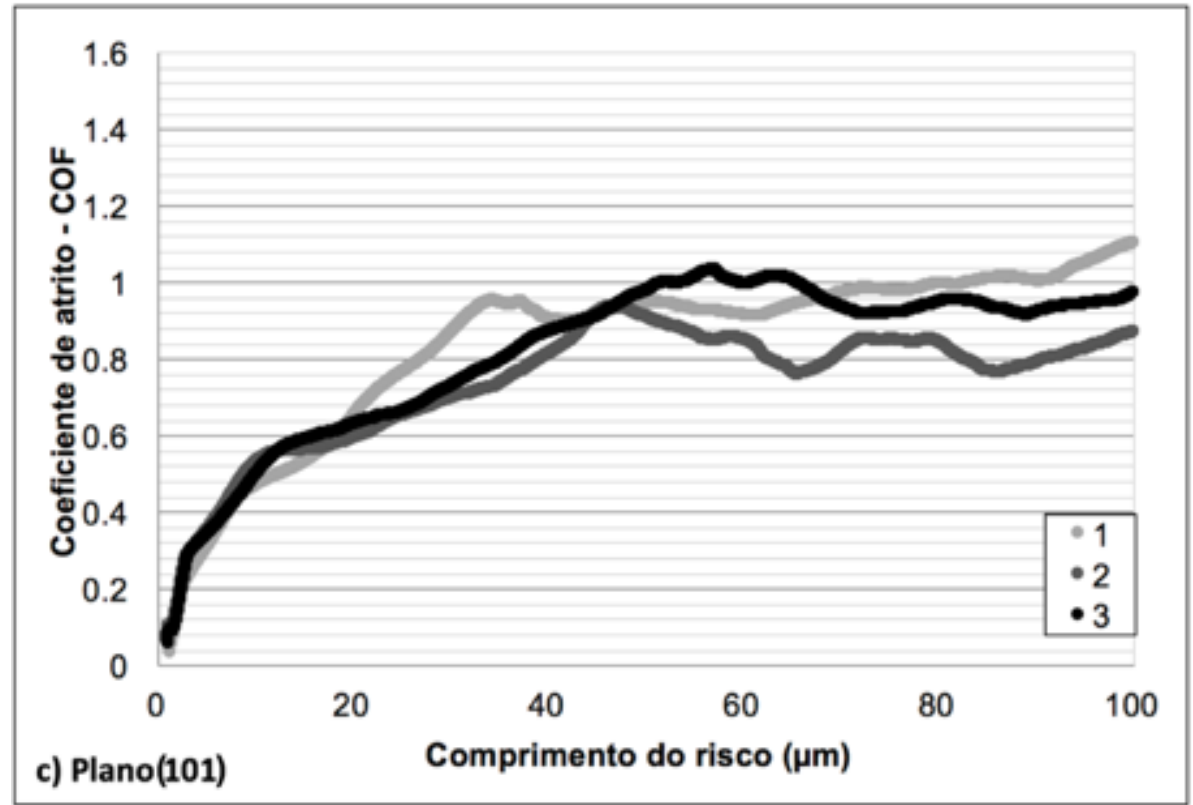

Figura B.4. Gráficos de coeficiente de atrito para os ensaios nos planos a) (001), b) (111) e c) (101) para o aço $20 \mathrm{Mn}$

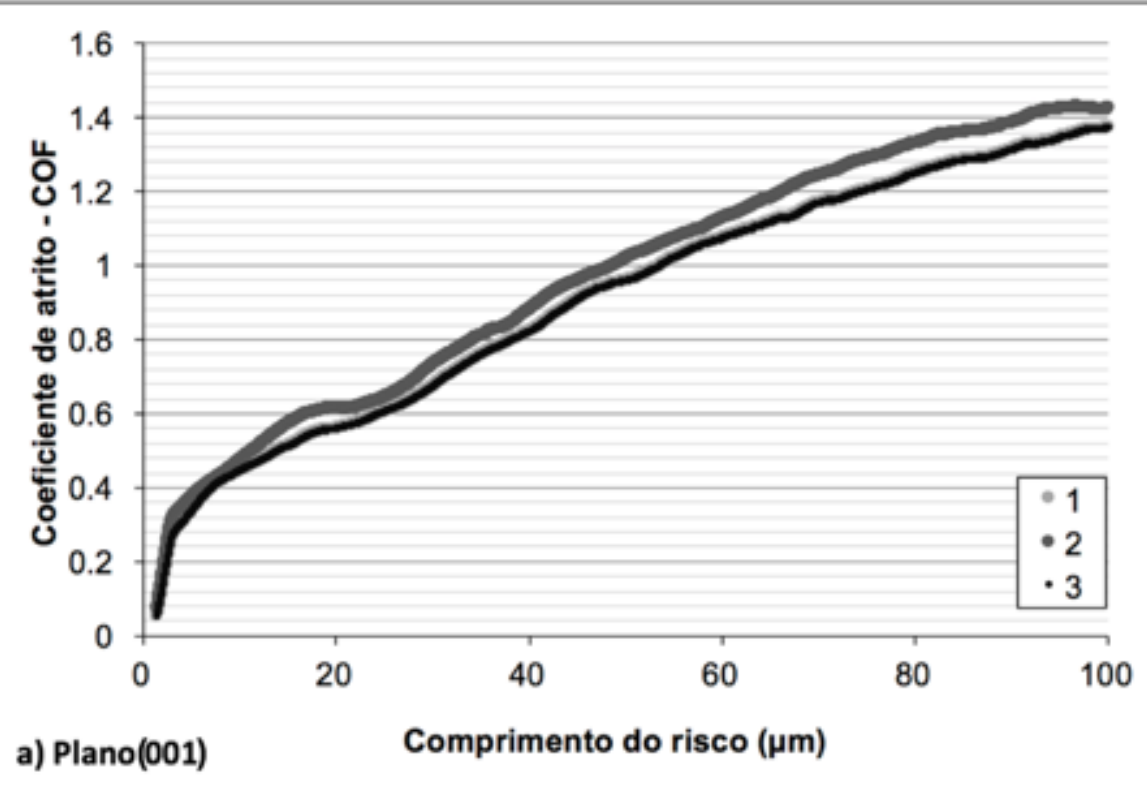



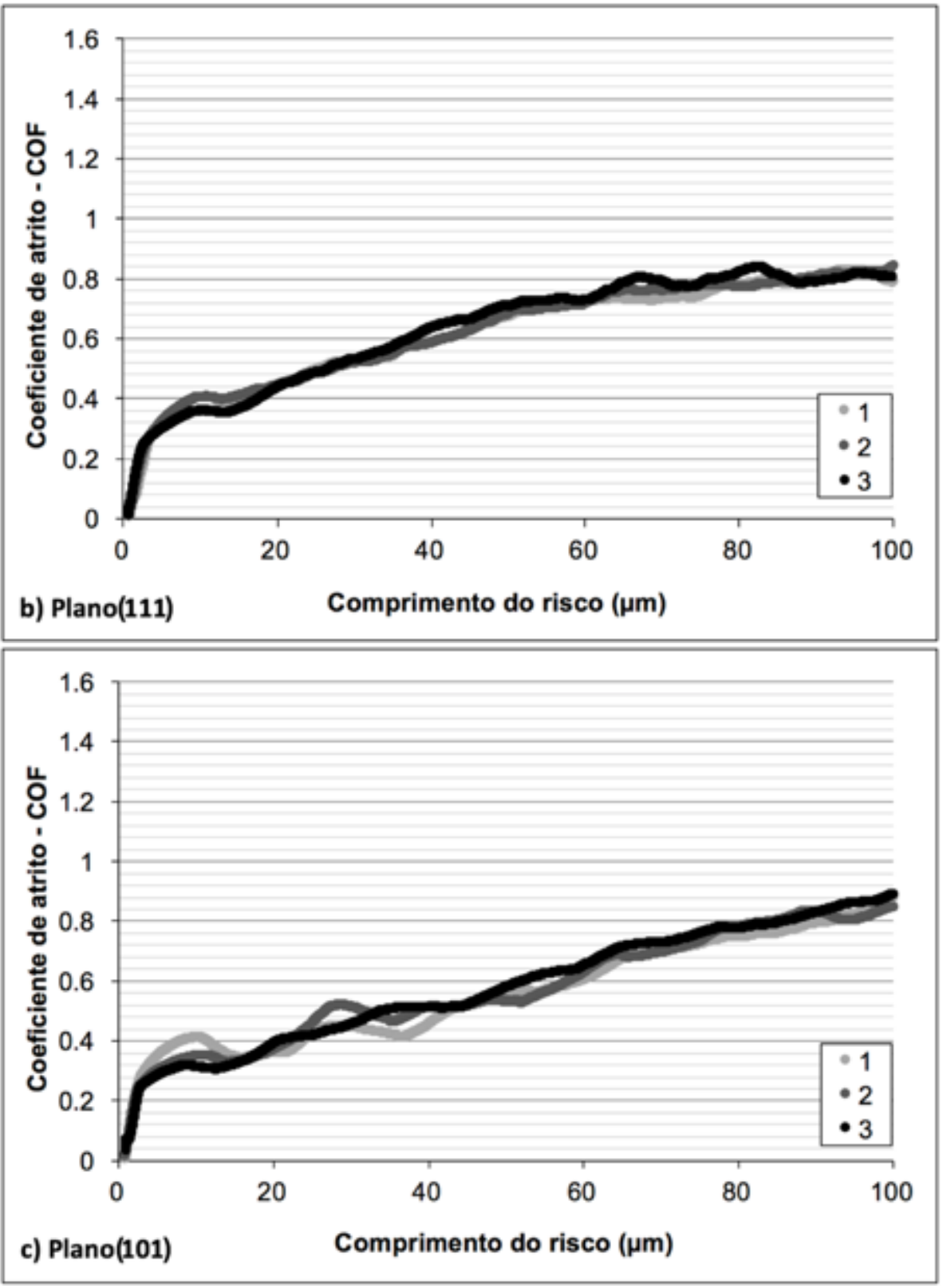

As Figuras B.5 e B.6 mostram os gráficos de coeficiente de atrito (ensaios 1, 2 e 3) nos planos (001), (111) e (101) para os aços 12Mn e 20Mn, respectivamente. 
Figura B.5. Gráficos de profundidade do risco $(h)$ para os ensaios nos planos a) (001), b) (111) e c) (101) para o aço $12 \mathrm{Mn}$
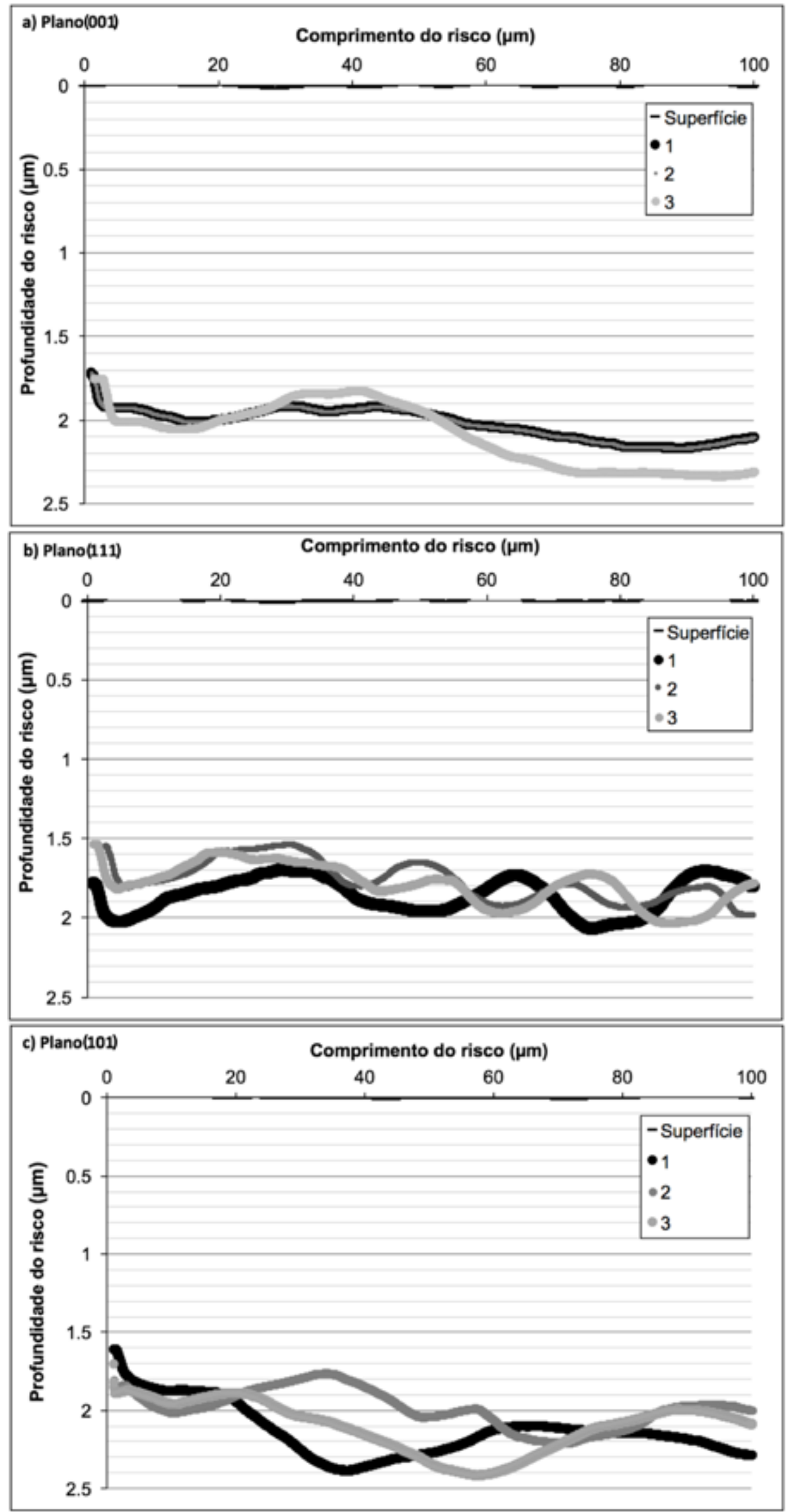
Figura B.6. Gráficos de profundidade do risco $(h)$ para os ensaios nos planos a) (001), b) (111) e c) (101) para o aço $20 \mathrm{Mn}$
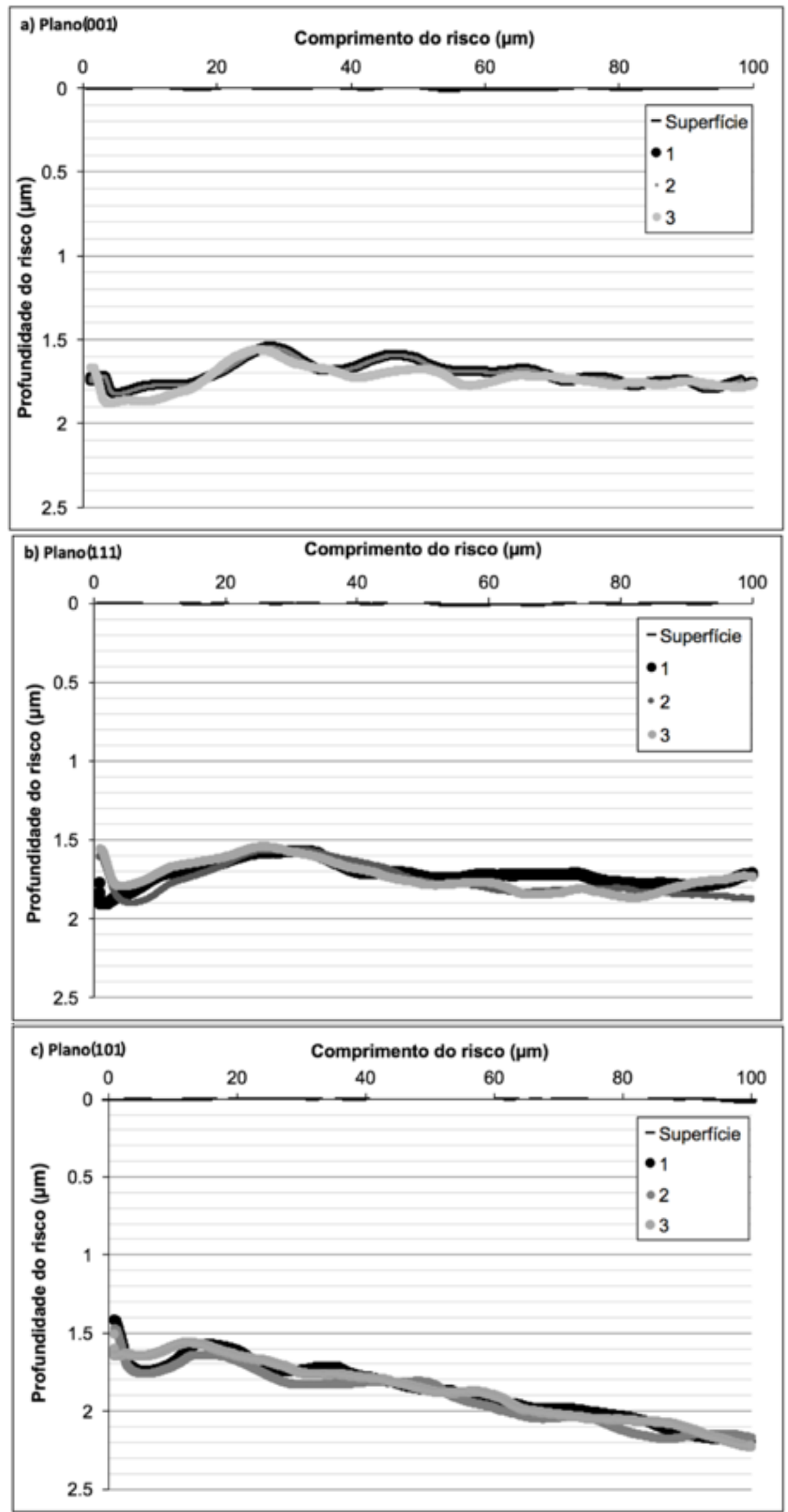
As Figuras a seguir mostram as micrografias dos riscos nos planos (001), (101) e (111) para os aços $12 \mathrm{Mn}$ e $20 \mathrm{Mn}$.

Figura B.7. Micrografia (MEV-SE) dos riscos no plano (001) para o aço 12Mn. 900X. a) Ensaio 1. b) Ensaio 2. c) Ensaio 3
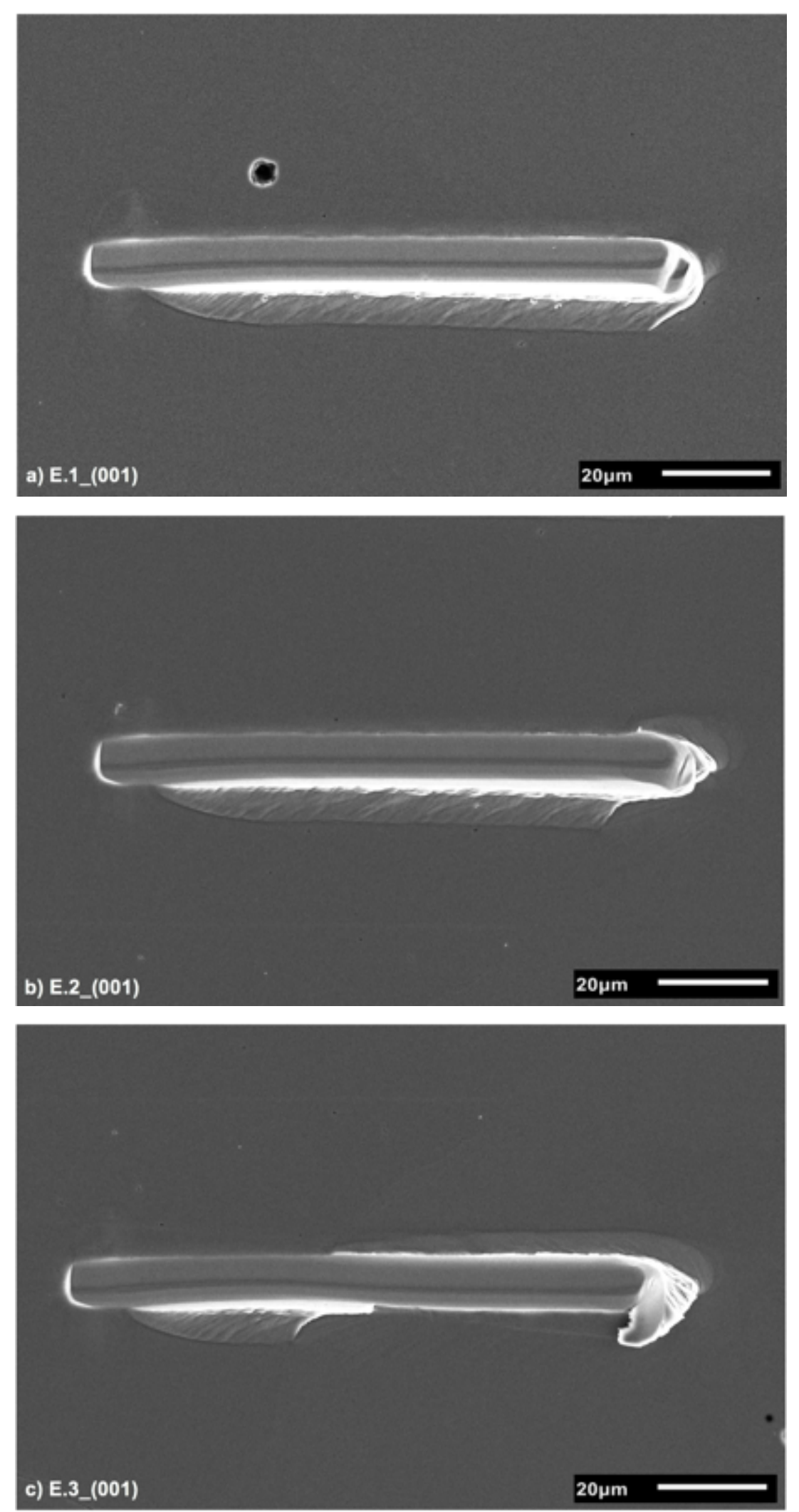
Figura B.8. Micrografia (MEV-SE) dos riscos no plano (111) para o aço 12Mn. 900X. a) Ensaio 1. b) Ensaio 2. c) Ensaio 3
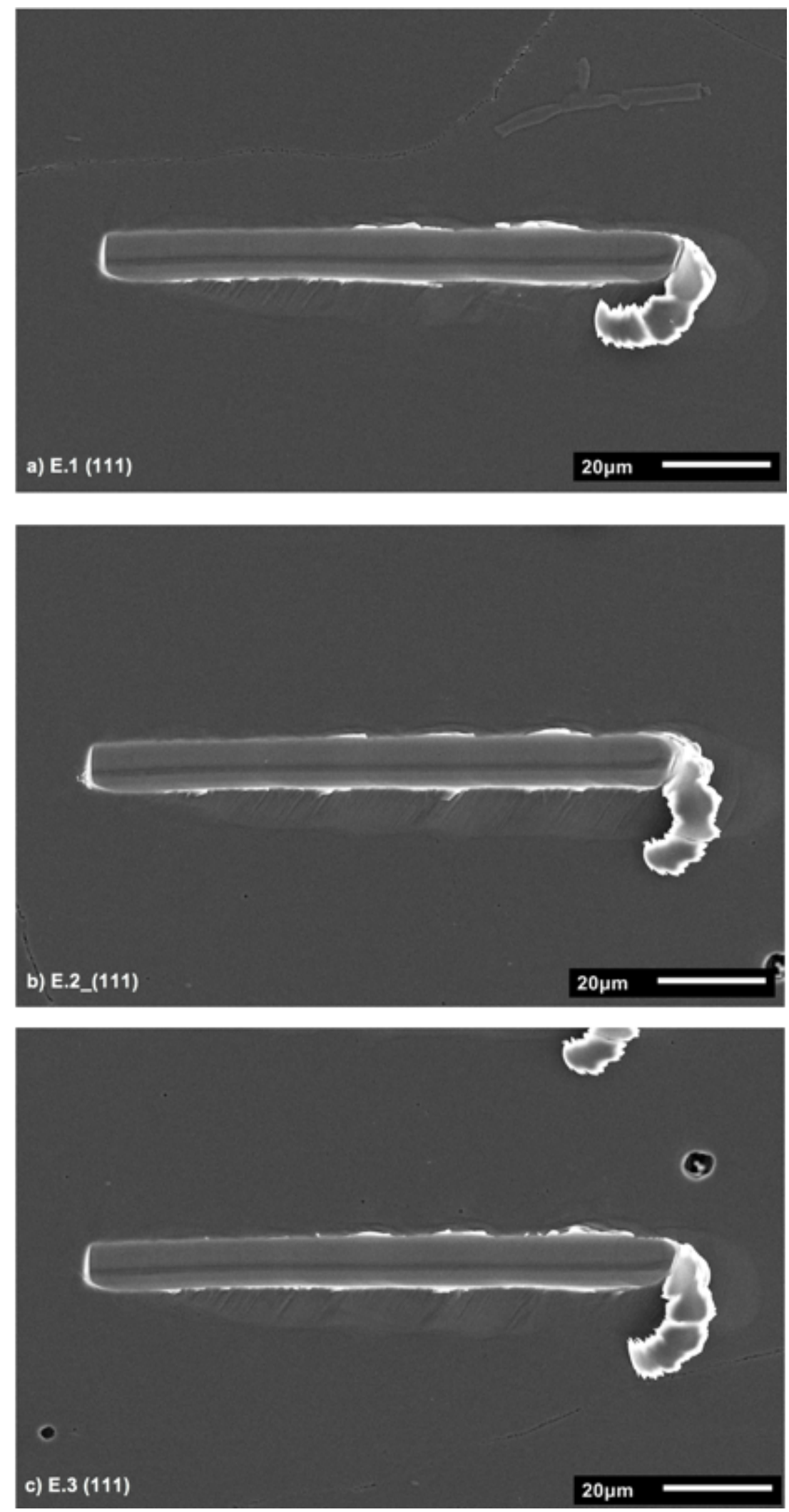
Figura B.9. Micrografia (MEV-SE) dos riscos no plano (101) para o aço 12Mn. 900X. a) Ensaio 1. b) Ensaio 2. c) Ensaio 3
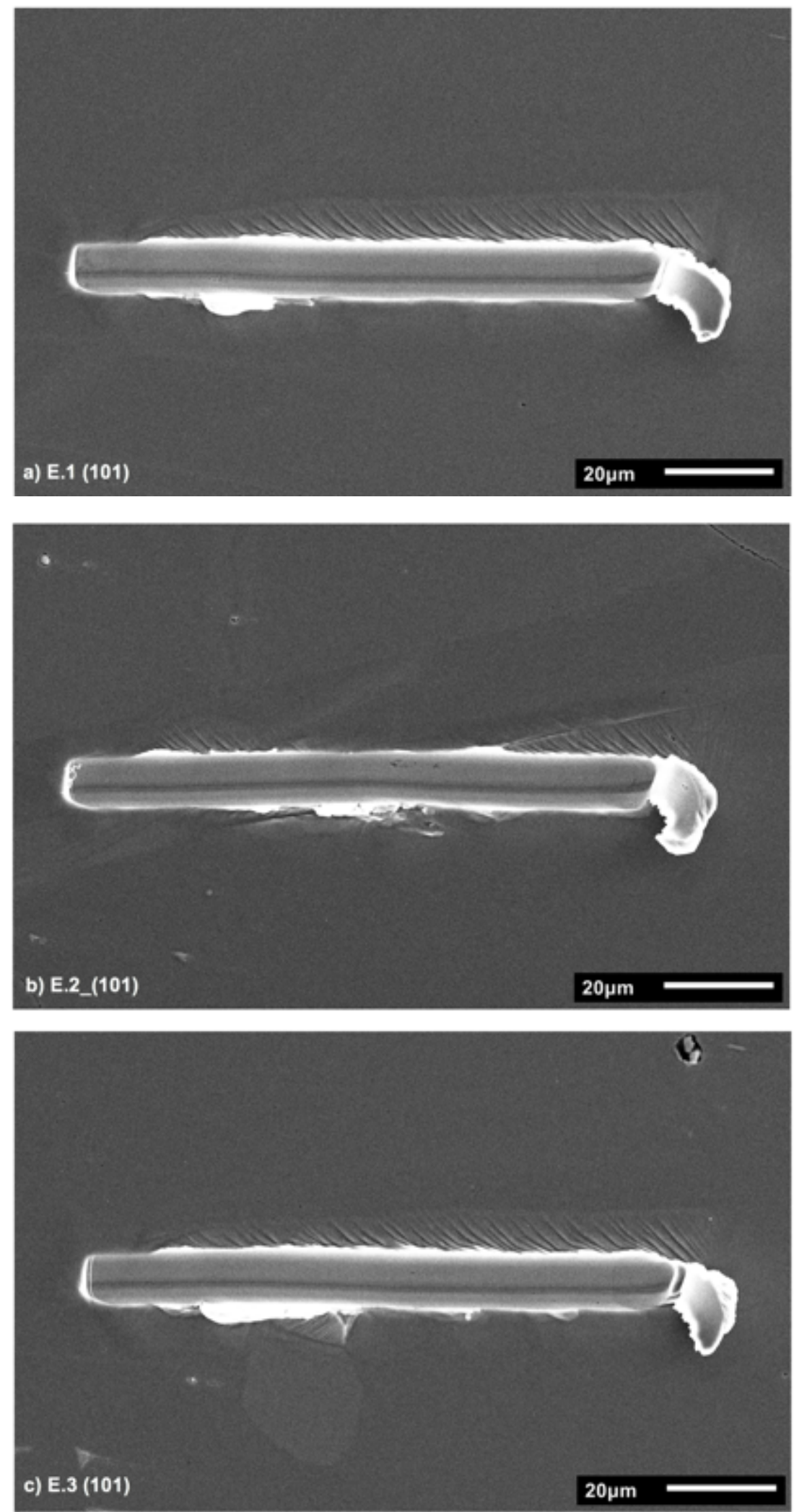
Figura B.10. Micrografia (MEV-SE) dos riscos no plano (001) para o aço 20Mn. 900X. a) Ensaio 1. b) Ensaio 2. c) Ensaio 3
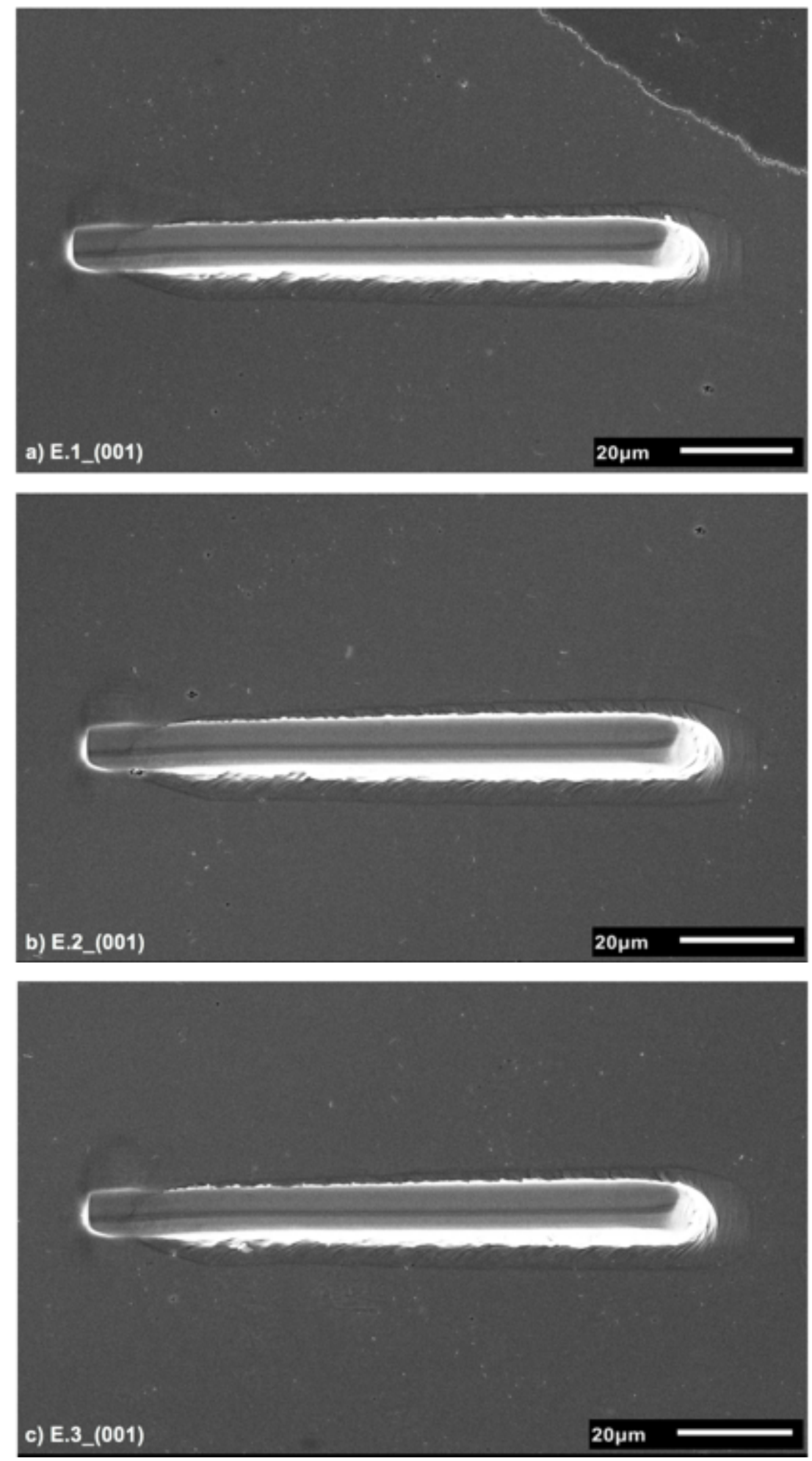
Figura B.11. Micrografia (MEV-SE) dos riscos no plano (111) para o aço 20Mn. 900X. a) Ensaio 1. b) Ensaio 2. c) Ensaio 3
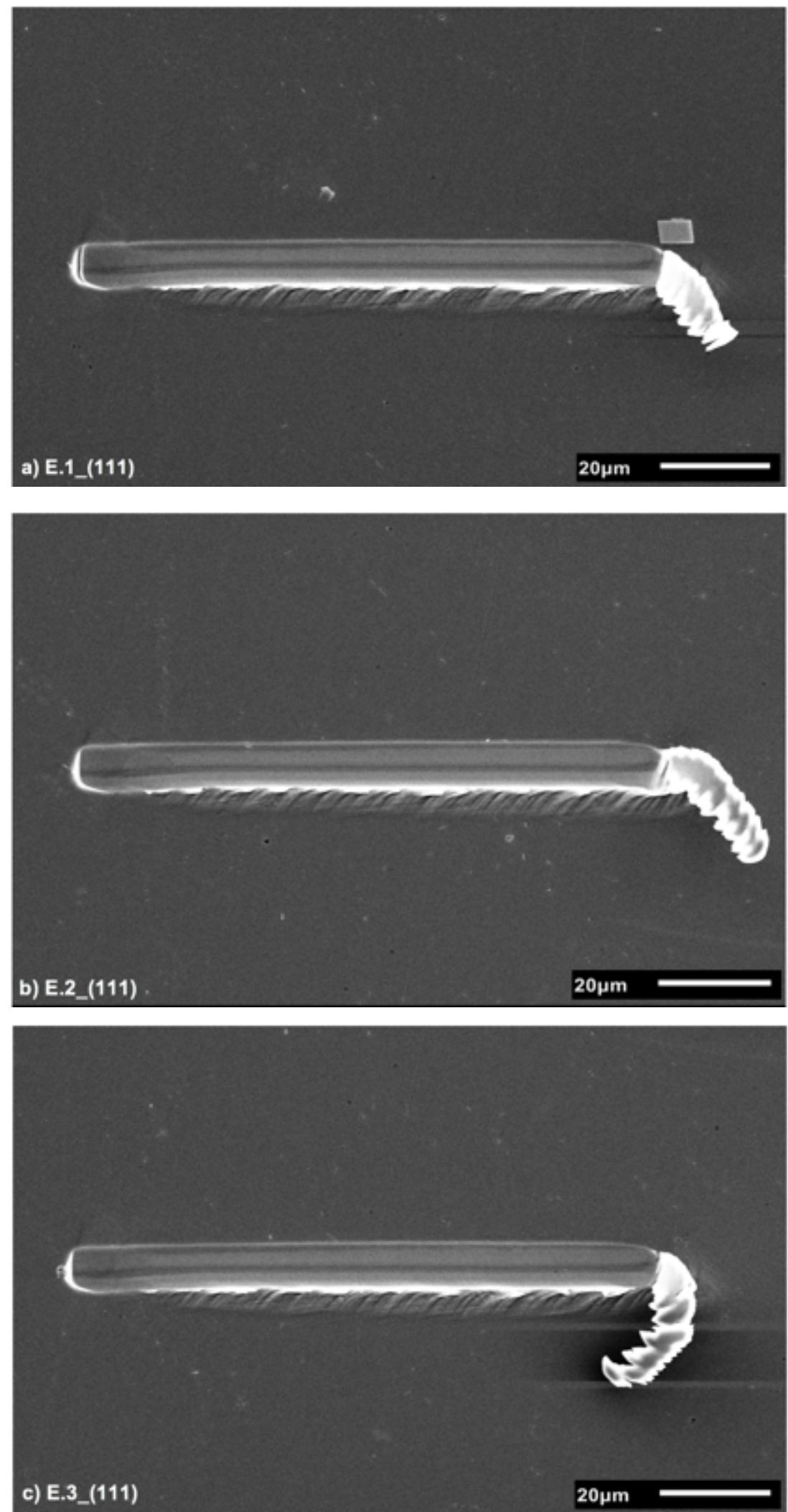
Figura B.12. Micrografia (MEV-SE) dos riscos no plano (101) para o aço 20Mn. 900X. a) Ensaio 1. b) Ensaio 2. c) Ensaio 3
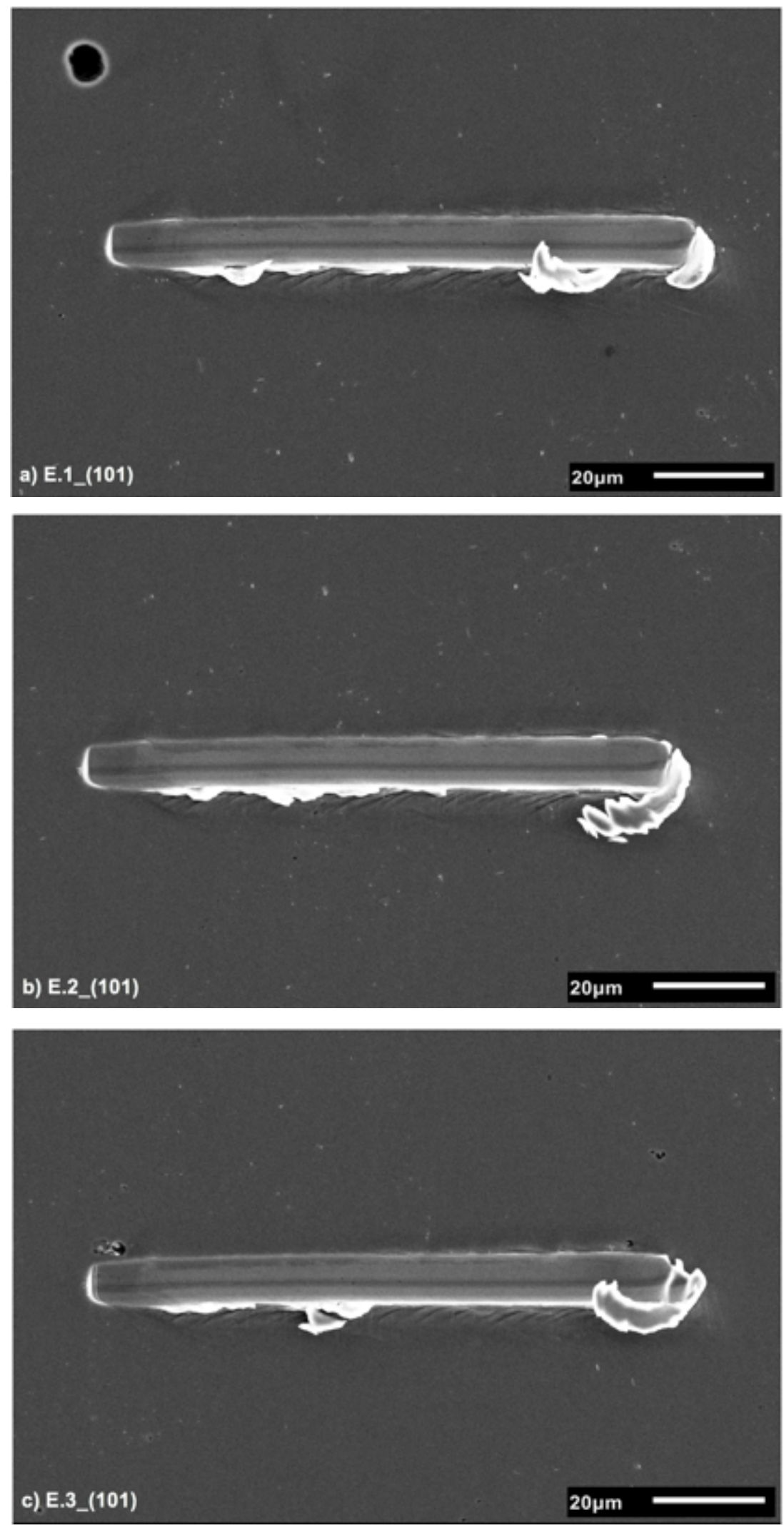


\section{Apêndice C: MICROESTRUTURA DA SUBSUPERFÍCIE DO AÇO AUSTENÍTICO COM 12\%Mn DEFORMADO POR DESGASTE ABRASIVO}

\section{AMOSTRA DE CAVACO}

Amostras de cavaco da superfície desgastada do revestimento do britador cônico foram obtidas com o processo de usinagem de aplainamento (oficina de máquinas operatrizes do Departamento de Engenharia Mecatrônica da Poli/USP). A Figura C.1 mostra a formação de cavaco durante o processo de aplainamento. Os cavacos gerados foram embutidos em baquelite condutora para realização dos procedimentos de metalografia descritos no tópico 5.2.3.

Figura C.1. Obtenção de cavacos via aplainamento do aço deformado

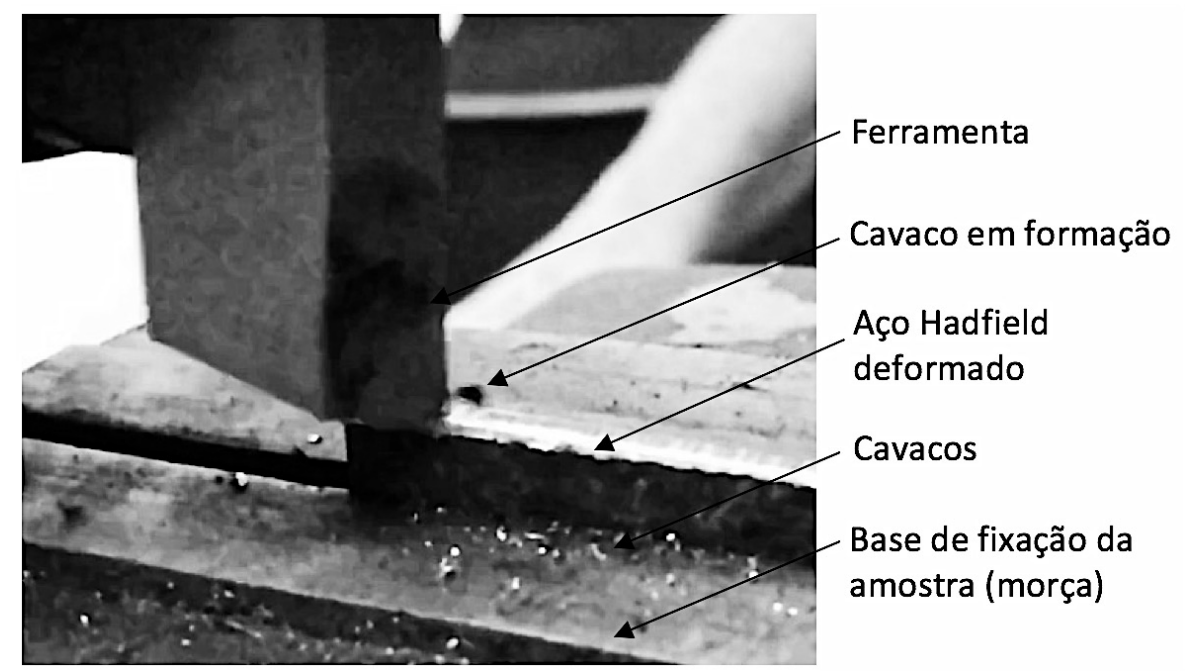

\section{MICROESTRUTURA DO CAVACO OBTIDA POR APLAINAMENTO}

A técnica de aplainamento utilizada para gerar cavacos da superfície deformada em campo se mostrou eficaz. A Figura C.2a mostra a micrografia de um cavaco obtida por microscopia eletrônica de varredura. Foram identificadas na micrografia trincas intergranular, microextrusão, maclas de deformação e bandas de escorregamento. As manchas em cinza são artefatos do processo de ataque químico. Na Figura C. $2 b$ é mostrada a área em destaque da Figura C.2a com 1.000X. 
Figura C.2. a) Micrografia via MEV de cavaco de aço Hadfield deformado, aumento de 300X. b) Aumento de $1.000 x$ da área em destaque na Figura a
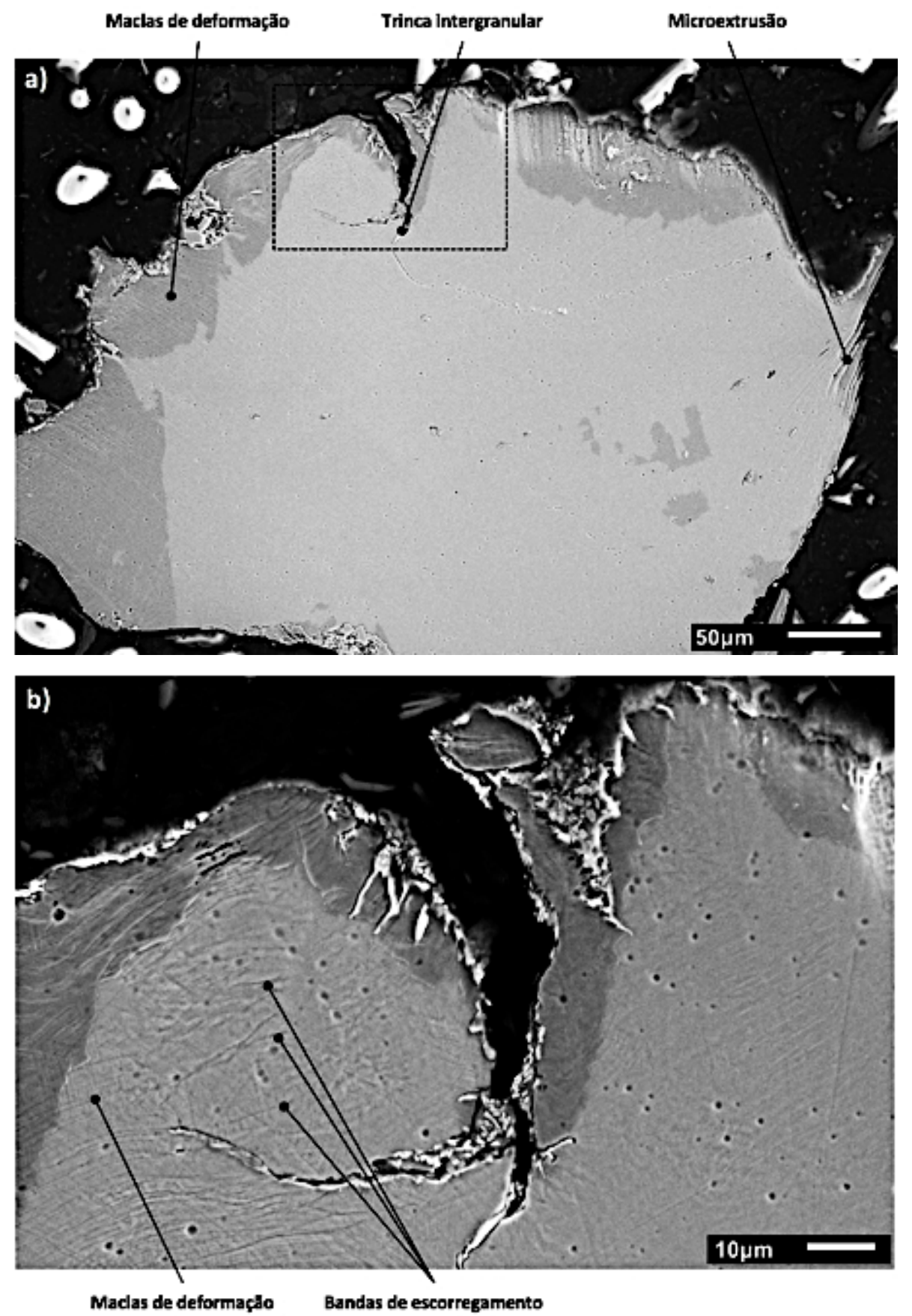

A Figura C.3 mostra a micrografia de outro cavaco obtida por microscopia óptica. Nota-se uma microestrutura com intensa deformação, no entanto sem evidencia de recristalização. Nesta imagem as manchas de ataque estão na cor branca. 
Figura C.3. Micrografia via MO de cavaco de aço Hadfield deformado. 1.000X

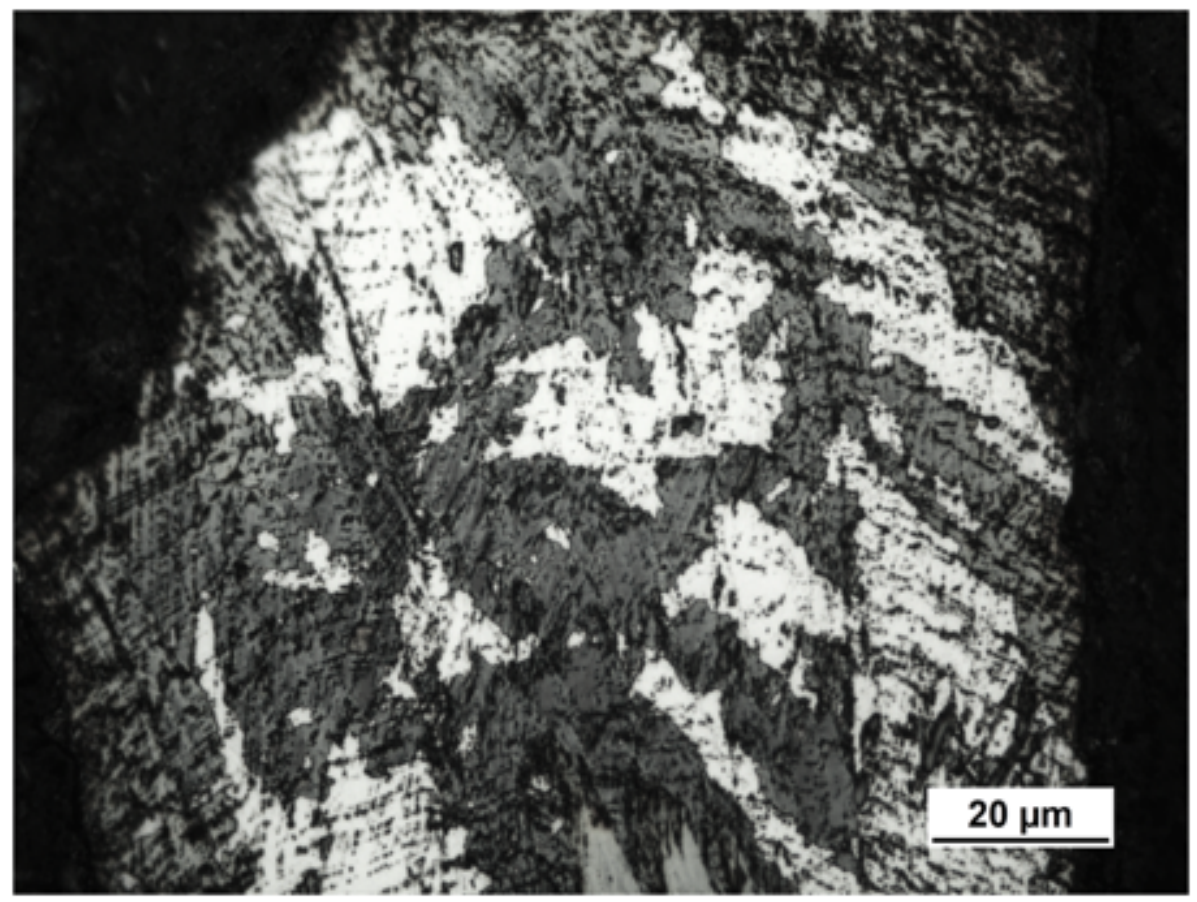

Após análise das micrografias dos cavacos conclui-se que o processo de gerar cavaco por aplainamento, realizado nesta pesquisa, não foi capaz de reproduzir a microestrutura observada na onda caracterizada pela existência de grãos pequenos equiaxiais, carbonetos em contorno de grão e maclas de recristalização. Contudo, o nível de energia necessária para atingir a morfologia microestrutural da onda é superior ao atingido pelo processo de formação de cavaco.

\section{COMPARAÇÃO ENTRE RESULTADO DE EBSD COM CLEAN UP E SEM CLEAN UP}

Os resultados de EBSD apresentados nesta pesquisa não foram tratados com a ferramenta clean up disponível no software Orientation Imaging Microscopy (OIM) Analysis 5.3. Segundo o manual do software esta ferramenta é utilizada para realizar uma "limpeza" dos dados errados, os quais são substituídos interpolação dos pontos vizinhos, alterando o resultado original, por isso, deve ser utilizado com atenção para evitar a introdução de tendências artificiais nos dados. Além disto, o manual indica que esta ferramenta tem bons resultados para tamanhos de grãos do material consideravelmente maiores que o tamanho de cada ponto de medida (step size). A Figura C.4 mostra um exemplo da aplicação do clean up. 
Figura C.4. Resultado de EBSD-IPF sem clean up (a) e com clean up (b) da subsuperfície deformada pelo desgaste laboratorial em britador de mandíbula
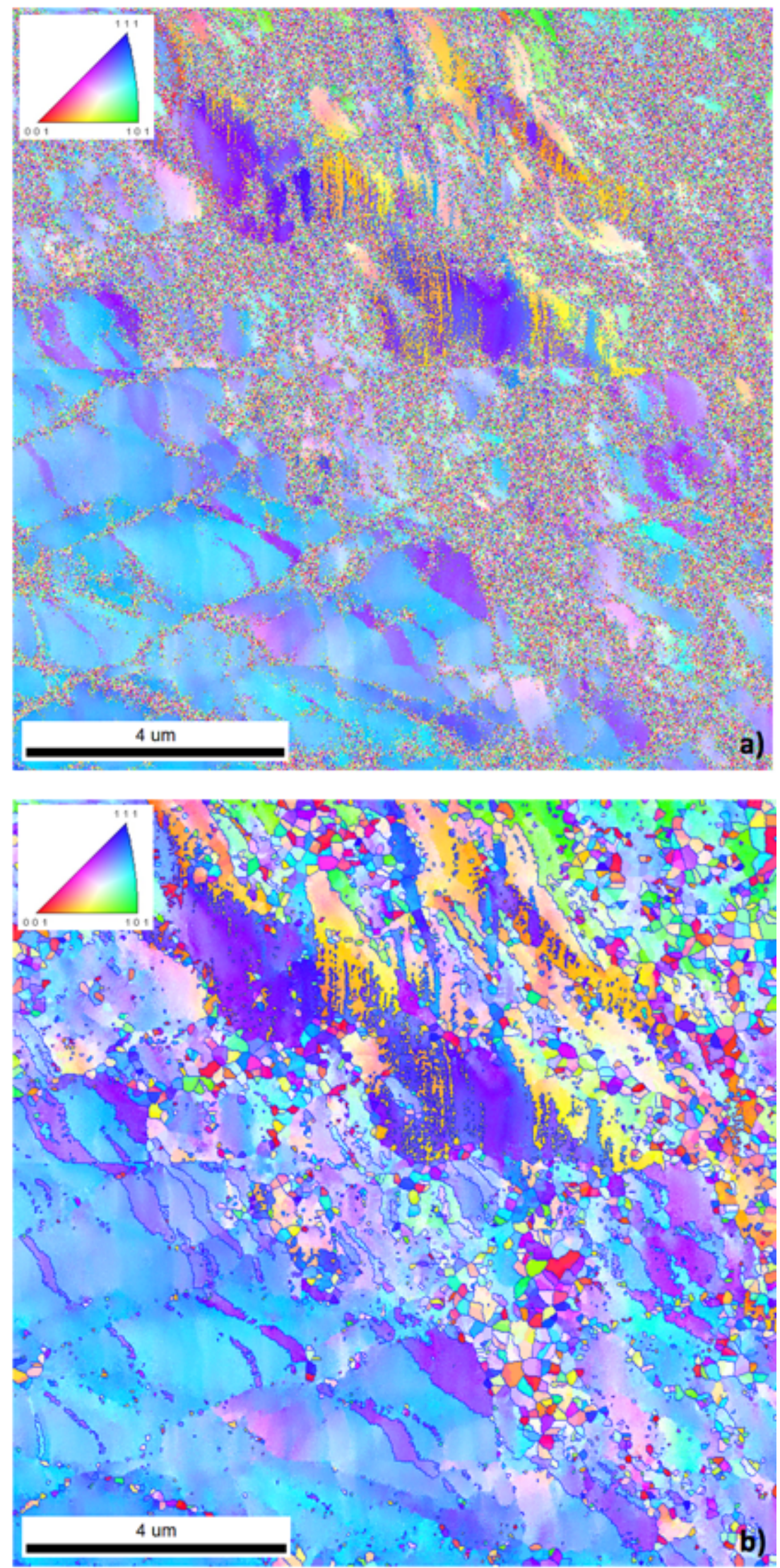
A camada deformada analisada nesta pesquisa mostrou, via técnicas de microscopia de alta resolução, que parte da microestrutura tem dimensões nanométricas. Desta forma, o resultado de EBSD sem a utilização do clean up na camada mais externa evidencia este fato, Figura C.4a. A aplicação do clean up, Figura C.4b, mostra um resultado diferente e não compatível com a nanoestrutura presente nesta região. 


\section{Apêndice D: A INCERTEZA DA MÉDIA}

Neste apêndice é apresentado um exemplo comparativo entre a análise de dois valores médios tendo como referência o desvio da amostra e a incerteza da média. Considerações: 18 medições de uma determinada grandeza em dois materiais apresentaram os seguintes resultados:

Média 1: $\bar{X}_{1}=174$;

Desvio 1: $S_{1}=5$;

Média 2: $\bar{X}_{2}=184$;

Desvio 2: $S_{2}=5$.

Uma comparação das duas médias (teste de hipóteses) feito sobre esses resultados forneceu o seguinte resultado:

$$
t_{n-1}=t_{17}=\frac{\left(\bar{X}_{2}-\bar{X}_{1}\right)}{S / \sqrt{n}}=\frac{184-174}{5 / \sqrt{18}}=8,48
$$

Como para o nível de significância de 5\% tem-se da tabela da distribuição de Student $t_{c r}=1,74$ para $n-1=17$ (número de graus de liberdade), conclui-se que há uma diferença significativa entre as duas medições e que a hipótese nula (de igualdade das médias) deve ser rejeitada.

A validade do teste de hipóteses foi questionada, sob alegação de que somando dois desvios à média mais baixa e subtraindo dois desvios à média mais alta teríamos 184 e 174, respectivamente, com uma razoável superposição das normais (distribuição assumida para os resultados), indicativa de que a probabilidade de que um valor pertencesse a qualquer das normais era elevada. A Figura D.1 expõe graficamente esse raciocínio. 
Figura D.1. Curvas de distribuição considerando os desvios das amostras

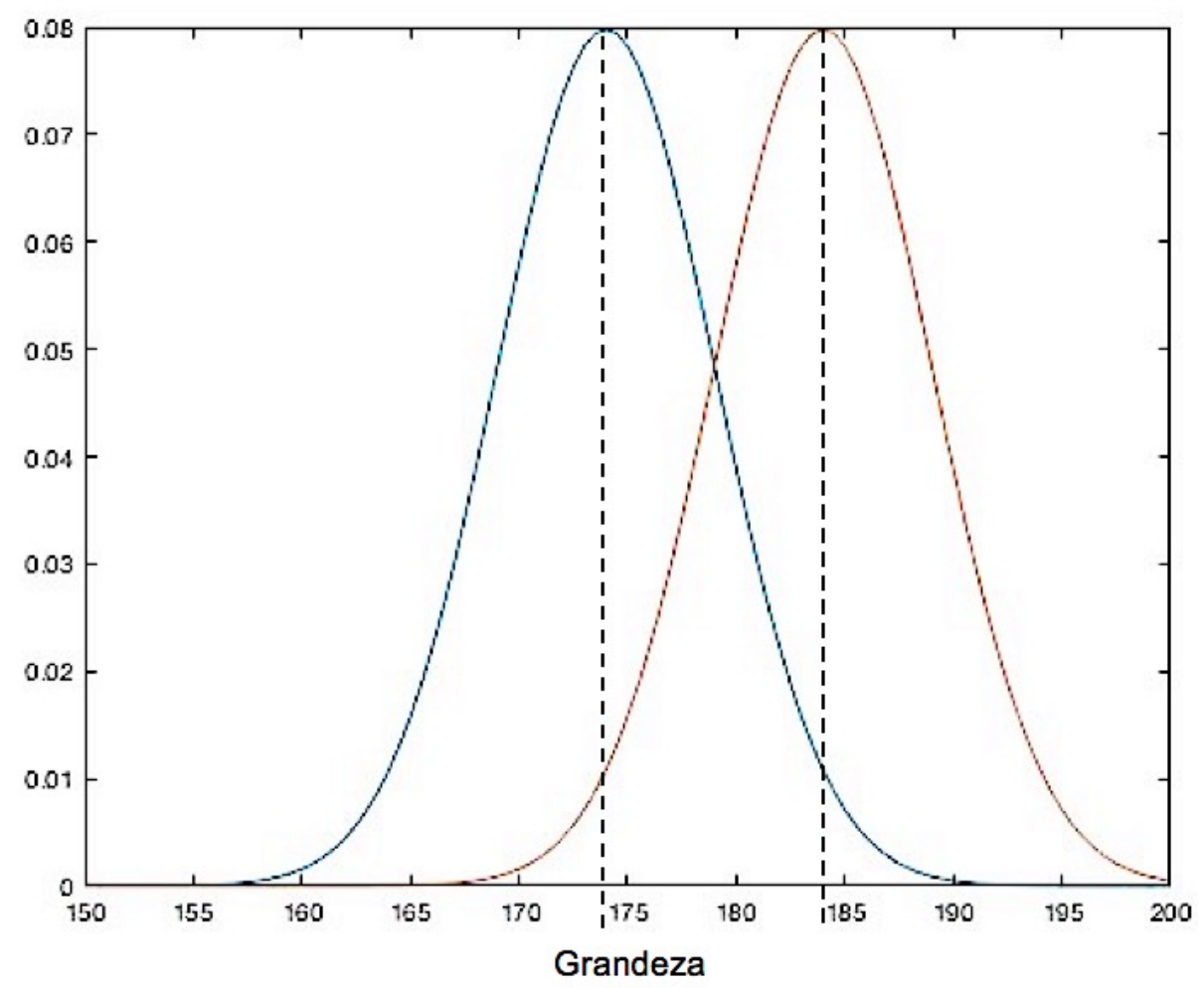

Este raciocínio não está correto pois ele se baseia na comparação das distribuições dos valores individuais. De fato, na Figura D.1 os picos das curvas correspondem aos valores médios encontrados de 174 e 184, mas o desvio é de 5, relativo aos valores individuais das medições. A comparação correta é a que considera as distribuições das médias, apresentada a seguir. Na Figura D.2 os picos não se alteram pois continuam nos pontos das médias obtidas nas medições. Entretanto, a dispersão está dividida por $\sqrt{n}=\sqrt{18}=4,24$, já que a dispersão da distribuição das médias é igual à dispersão da distribuição de valores individuais dividida pela raiz quadrada do número de elementos da amostra. 
Figura D.2. Curvas de distribuição considerando as incertezas das médias

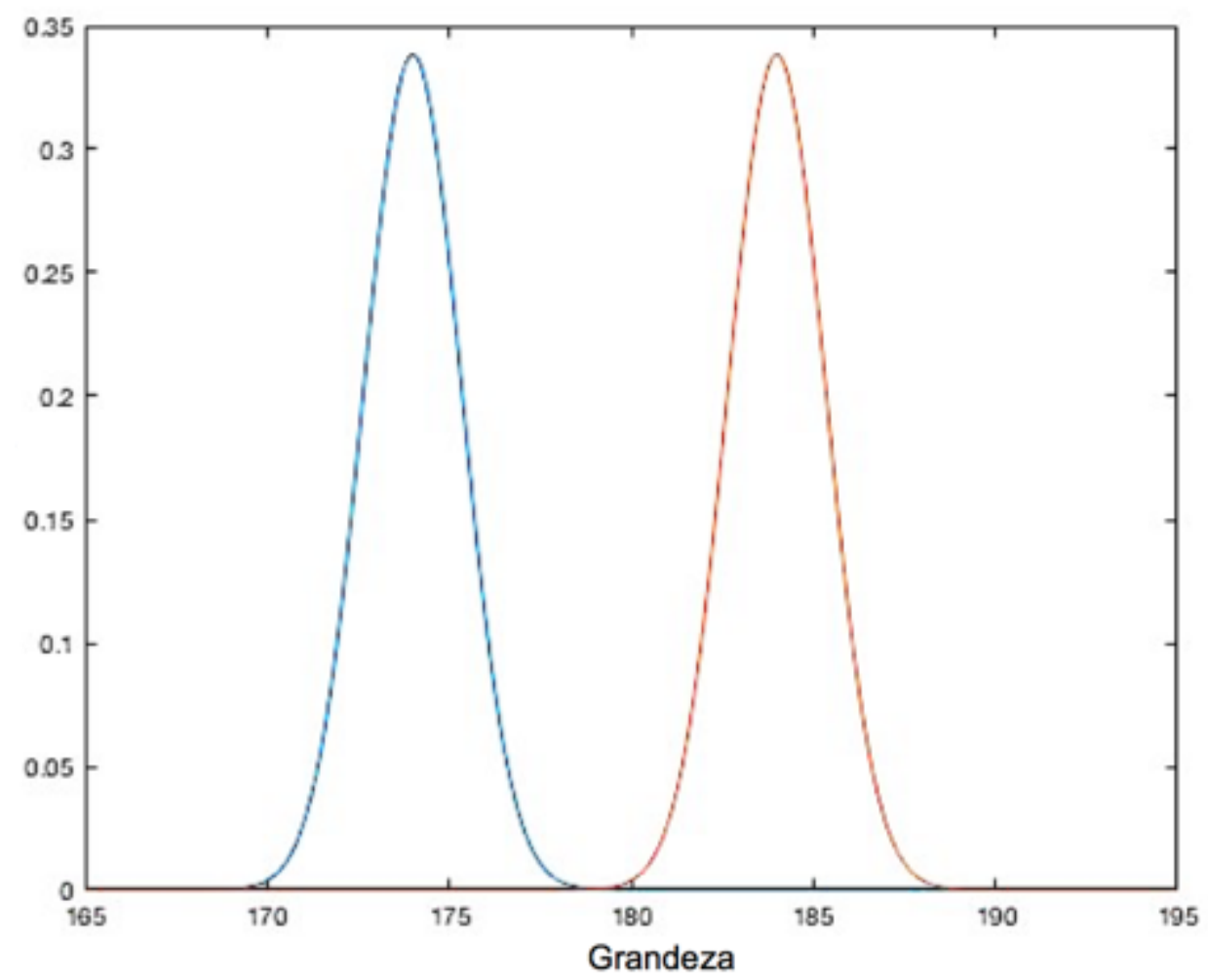

A Figura D.2 mostra claramente que não há superposição relevante das duas distribuições e que, portanto, é inteiramente válido o teste de hipóteses. O ponto importante da discussão é ressaltar que não se pode fazer raciocínios em cima dos valores de média mais ou menos dois (ou três) desvios da amostra quando o que está em jogo é uma comparação de médias; nesses casos é forçoso considerar o desvio da distribuição das médias (incerteza da média). 